\title{
Emerging Marine Biotoxins
} Ana Gago-Martínez and Arjen Gerssen Printed Edition of the Special Issue Published in Toxins 
Emerging Marine Biotoxins 



\section{Emerging Marine Biotoxins}

Special Issue Editors

Ana Gago-Martínez

Arjen Gerssen 
Special Issue Editors

Ana Gago-Martínez

Universidad de Vigo

Spain
Arjen Gerssen

Wageningen University and Research

The Netherlands

\section{Editorial Office}

MDPI

St. Alban-Anlage 66

4052 Basel, Switzerland

This is a reprint of articles from the Special Issue published online in the open access journal Toxins (ISSN 2072-6651) from 2018 to 2019 (available at: https://www.mdpi.com/journal/toxins/special_ issues/Emerging_marine_biotoxins)

For citation purposes, cite each article independently as indicated on the article page online and as indicated below:

LastName, A.A.; LastName, B.B.; LastName, C.C. Article Title. Journal Name Year, Article Number, Page Range.

ISBN 978-3-03921-349-8 (Pbk)

ISBN 978-3-03921-513-3 (PDF)

(C) 2019 by the authors. Articles in this book are Open Access and distributed under the Creative Commons Attribution (CC BY) license, which allows users to download, copy and build upon published articles, as long as the author and publisher are properly credited, which ensures maximum dissemination and a wider impact of our publications.

The book as a whole is distributed by MDPI under the terms and conditions of the Creative Commons license CC BY-NC-ND. 


\section{Contents}

About the Special Issue Editors $\ldots \ldots \ldots \ldots \ldots \ldots \ldots \ldots$

Arjen Gerssen and Ana Gago-Martínez

Emerging Marine Biotoxins

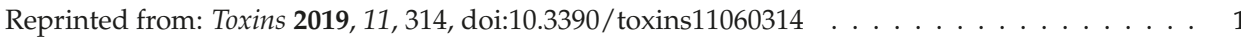

Pablo Estevez, David Castro, Ana Pequeño-Valtierra, José M. Leao, Oscar Vilariño, Jorge Diogène and Ana Gago-Martínez

An Attempt to Characterize the Ciguatoxin Profile in Seriola fasciata Causing Ciguatera Fish

Poisoning in Macaronesia

Reprinted from: Toxins 2019, 11, 221, doi:10.3390/toxins11040221 . . . . . . . . . . . . .

Pedro Reis Costa, Pablo Estevez, David Castro, Lucía Soliño, Neide Gouveia, Carolina Santos, Susana Margarida Rodrigues, José Manuel Leao and Ana Gago-Martínez

New Insights into the Occurrence and Toxin Profile of Ciguatoxins in Selvagens Islands (Madeira, Portugal)

Reprinted from: Toxins 2018, 10, 524, doi:10.3390/toxins10120524 _ . . . . . . . . . . . . 17

Bo Wang, Mimi Yao, Jin Zhou, Shangjin Tan, Hui Jin, Feng Zhang, Yim Ling Mak, Jiajun Wu, Leo Lai Chan and Zhonghua Cai

Growth and Toxin Production of Gambierdiscus spp. Can Be Regulated by Quorum-Sensing Bacteria

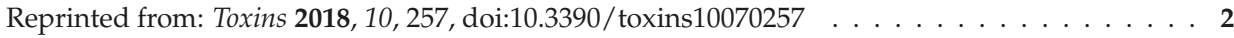

Inès Dom, Ronel Biré, Vincent Hort, Gwenaëlle Lavison-Bompard, Marina Nicolas and Thierry Guérin

Extended Targeted and Non-Targeted Strategies for the Analysis of Marine Toxins in Mussels and Oysters by (LC-HRMS)

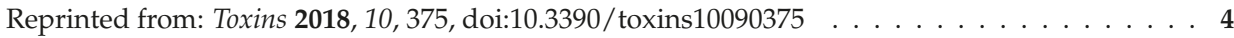

Mirjam D. Klijnstra and Arjen Gerssen

A Sensitive LC-MS/MS Method for Palytoxin Using Lithium Cationization

Reprinted from: Toxins 2018, 10, 537, doi:10.3390/toxins10120537 _ . . . . . . . . . . . . 64

Sarah C. Finch, Michael J. Boundy and D. Tim Harwood

The Acute Toxicity of Tetrodotoxin and Tetrodotoxin-Saxitoxin Mixtures to Mice by Various

Routes of Administration

Reprinted from: Toxins $\mathbf{2 0 1 8}, 10,423$, doi:10.3390/toxins10110423 . . . . . . . . . . . . 75

Arjen Gerssen, Toine H. F. Bovee, Mirjam D. Klijnstra, Marnix Poelman, Liza Portier and Ron L. A. P. Hoogenboom

First Report on the Occurrence of Tetrodotoxins in Bivalve Mollusks in The Netherlands

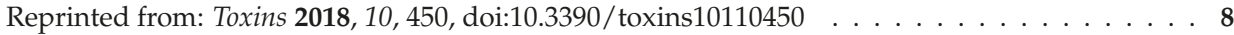

Benard Mucholwa Simiyu, Steve Omondi Oduor, Thomas Rohrlack, Lewis Sitoki and Rainer Kurmayer

Microcystin Content in Phytoplankton and in Small Fish from Eutrophic Nyanza Gulf, Lake Victoria, Kenya

Reprinted from: Toxins 2018, 10, 275, doi:10.3390/toxins10070275 . . . . . . . . . . . . . . . 100 
Megan Brooke-Jones, Martina Gáliková and Heinrich Dircksen

Cyanobacterial Neurotoxin Beta-Methyl-Amino-L-Alanine Affects Dopaminergic Neurons in Optic Ganglia and Brain of Daphnia magna

Reprinted from: Toxins 2018, 10, 527, doi:10.3390/toxins10120527

Valerio Zupo, Mirko Mutalipassi, Nadia Ruocco, Francesca Glaviano, Antonino Pollio, Antonio Luca Langellotti, Giovanna Romano and Maria Costantini

Distribution of Toxigenic Halomicronema spp. in Adjacent Environments on the Island of Ischia: Comparison of Strains from Thermal Waters and Free Living in Posidonia Oceanica Meadows Reprinted from: Toxins 2019, 11,99, doi:10.3390/toxins11020099 . . . . . . . . . . . . . 136

Qiwen Liao, Guiyi Gong, Shirley Weng In Siu, Clarence Tsun Ting Wong, Huidong Yu, Yu Chung Tse, Gandhi Rádis-Baptista and Simon Ming-Yuen Lee

A Novel ShK-Like Toxic Peptide from the Transcriptome of the Cnidarian Palythoa caribaeorum Displays Neuroprotection and Cardioprotection in Zebrafish

Reprinted from: Toxins 2018, 10, 238, doi:10.3390/toxins10060238

David Wilson and Norelle L. Daly

Nuclear Magnetic Resonance seq (NMRseq): A New Approach to Peptide Sequence Tags

Reprinted from: Toxins 2018, 10, 437, doi:10.3390/toxins10110437 . . . . . . . . . . . . . 17

Shiyong Zhang, Jia Li, Qin Qin, Wei Liu, Chao Bian, Yunhai Yi, Minghua Wang, Liqiang Zhong, Xinxin You, Shengkai Tang, Yanshan Liu, Yu Huang, Ruobo Gu, Junmin Xu, Wenji Bian, Qiong Shi and Xiaohui Chen

Whole-Genome Sequencing of Chinese Yellow Catfish Provides a Valuable Genetic Resource for High-Throughput Identification of Toxin Genes Reprinted from: Toxins 2018, 10, 488, doi:10.3390/toxins10120488 


\section{About the Special Issue Editors}

Ana Gago-Martínez with a Ph.D Degree in Analytical Chemistry from the University of Vigo (Spain, 1992), Dr. Ana Gago-Martínez leads a research team at the Department of Analytical and Food Chemistry at this same University. She graduated in Chemistry at the University of Santiago de Compostela (Spain, 1982), where she also obtained her Master's Degree in Analytical Chemistry. In 1993, she continued her Post Doctoral studies for two years at the Institute of Marine Biosciences (National Research Council) in Halifax (Canada) and obtained a fellowship from the Galician and Spanish Ministry of Education as a guest scientist in Health Canada, Ottawa (Canada, 2000). Since 2009, Ana Gago Martínez is the Director of the European Reference Laboratory for Marine Biotoxins.

Arjen Gerssen with a Ph.D. Degree in Toxicology/Analytical Chemistry from the Wageningen University (The Netherlands, 2010), Dr Arjen Gerssen is senior scientist and food contaminants program manager at Wageningen Food Safety Research. He graduated in analytical chemistry at the university of applied sciences in Alkmaar, the Netherlands (2001). In 2004, he obtained his Master's Degree in Analytical Chemistry at the Free University of Amsterdam. After obtaining his PhD degree in 2010, Arjen continued as a research scientist at Wageningen Food Safety Research and participated in various research projects on residues and contaminants in food. Since 2010, Arjen Gerssen is the scientist in charge of the national reference laboratory for Marine Biotoxins. 



\title{
Editorial
}

\section{Emerging Marine Biotoxins}

\author{
Arjen Gerssen ${ }^{1}$ and Ana Gago-Martínez ${ }^{2,3, *}$ \\ 1 Wageningen Food Safety Research (WFSR), Wageningen University \& Research, Akkermaalsbos 2, \\ 6708WB Wageningen, The Netherlands; arjen.gerssen@wur.nl \\ 2 Department of Analytical and Food Chemistry, University of Vigo, Campus Universitario de Vigo, \\ 36310 Vigo, Spain \\ 3 European Union Reference Laboratory for Marine Biotoxins, CITEXVI, Campus Universitario de Vigo, \\ 36310 Vigo, Spain \\ * Correspondence: anagago@uvigo.es
}

Received: 28 May 2019; Accepted: 30 May 2019; Published: 3 June 2019

The emergence of marine biotoxins in geographical areas where they have never been reported before is a concern of considerable impact on seafood contamination, and consequently, on public health. Several groups of marine biotoxins, in particular tetrodotoxins, ciguatoxins, and palytoxins, are included among the relevant marine biotoxins that have recently emerged in several coastal areas. A similar situation has been observed in freshwater, where cyanobacterial toxins such as microcystins might end up in unexpected areas such as the estuaries where shellfish are cultivated. Climate change and the increased availability of nutrients have been considered as the key factors in the expansion of all of these toxins into new areas; however, this could also be due to more intense biological invasions, more sensitive analytical methods, or perhaps even an increased scientific interest in these natural contaminations. The incidences of human intoxications due to the consumption of seafood contaminated with these toxins have made their study an important task to accomplish, in order to protect human health. This special issue has a focus on a wide variety of emerging biotoxin classes.

One of the most important classes of emerging toxins are ciguatoxins, which until recently were considered endemic to (sub)tropical regions in the Pacific and Indian Ocean as well as the Caribbean Sea, but are nowadays responsible for intoxications in other places worldwide. This is particularly so in Europe, not only through the consumption of imported ciguatoxin contaminated seafood from endemic areas, but also because of their occurrence in particular areas of Macaronesia such as Azores, Madeira Islands (Portugal) and the Canary Islands (Spain). Ciguatoxins are produced by the Gambierdiscus species. The effect of microbiological factors on both growth and toxin production is still poorly understood. Wang et al. investigated the effect of quorum sensing bacteria on both of these parameters [1]. It was found that quorum sensing bacteria have a major influence on the growth as well as the toxin production. This indicates the difficulty of predicting the growth and toxin production in environmental conditions as many factors have an influence on these algal toxins. Ciguatoxins accumulate in higher trophic fish; if these fish are consumed, this might lead to intoxication. To confirm the presence of these toxins in fish, confirmatory methods that use mass spectrometric detection can be used. However, these methods are challenging, mainly due to the lack of commercially available reference materials. A combination of toxicity screening with an in vitro cell test, i.e., the neuroblastoma cell viability test, is often used to screen the samples. This assay can also be used for effect directed analysis as that conducted by Estevez et al. [2]. Sample extracts from fish collected from Macaronesia were fractionated. The fractions were screened for toxicity and the active fractions were analyzed by liquid chromatography and tandem mass spectrometry (LC-MS/MS) to confirm the ciguatoxins involved in these contaminations. Caribbean ciguatoxin-1 (C-CTX-1) has been identified as being mainly responsible for the CTX contamination in these areas, although some other C-CTX1 analogues and metabolites have also been identified. Reis Costa et al. also reported on the presence of C-CTX1 in fish from the Portuguese area of Madeira and the Selvagem Islands [3]. It is difficult to conclude if 
ciguatoxins are really new to Macaronesia, or if their recent identification has been due to the increased research and knowledge on this particular issue. Alternative approaches can be also used for screening of a wide variety of toxins, based on non-targeted high resolution mass spectrometry. However, the confirmation of the suspected toxins by their accurate mass is still challenging, either due to the lack of certified standards or the lack of sensitivity of the high resolution mass spectrometer. Despite these limitations, significant improvements have been made [4]. In addition, the sensitivity of the MS detection of polytoxins has been considerably increased by using the so called cationization [5].

Comparable to the ciguatoxins is the occurrence of tetrodotoxin (TTX), which was recently associated with contaminations in bivalves, and not only to fish and gastropods as reported in the past. Furthermore, it was not expected to occur in temperate water conditions. However, researchers have demonstrated its presence in shellfish from the UK as well as seasonal occurrence in the Netherlands [6,7]. In the Dutch situation, an action limit was set at $44 \mu \mathrm{g}$ TTX/kg shellfish, which is based on the opinion by European Food Safety [8]. As TTX has the same mode of action as saxitoxin (STX), Finch et al. investigated the acute toxicity of TTX and STX/TTX mixtures in mice through various routes of administration [9]. They found additivity between STX and TTX, and therefore concluded that TTX could be treated as a member of the paralytic shellfish toxin group (i.e., STXs).

Furthermore, not truly marine biotoxins, cyanobacterial toxins such as microcystins are known to cause problems in drinking water and might not only end up in shellfish and fish produced in freshwater conditions, but also in estuaries [10]. The toxicological effects of non-proteinogenic amino acid beta-methyl-amino-L-alanine (BMAA), a neurotoxin produced by cyanobacteria, on the putative neurodegeneration of newly identified specific dopaminergic neurons in the optic ganglia/brain complex of $D$. magna have been evaluated by using quantitative tyrosine-hydroxylase immunohistochemistry and fluorescence cytometry [11]. Interesting information on the physiological properties of cyanobacteria phylogenetically related, but living in different environments, has been characterized by microscopy, molecular, and toxicity analyses. A variable pattern of toxicity was exhibited, in accordance with the constraints imposed by the host environments [12]. In general, based on more intensive agriculture, more nutrients from fertilizers might end up in surface waters, which improve the conditions for the growth of various cyanobacteria that might eventually threaten our food safety.

This special issue also contains original information on novel sequencing approaches to identify natural toxins. These include short sequence tags that can be used to elucidate full-length peptide sequences to identify natural toxins like conotoxins from the venom of the cone snail Conus geographus by NMR spectroscopy [13], or the use of novel sequencing approaches to identify a diversity of toxin-related peptide sequences by means of computational processing, comprising of structural phylogenetic analysis, model prediction, and the dynamics simulation of peptide-receptor interaction [14]. Sequencing approaches have been also used to characterize the whole-genome of Chinese Yellow Catfish, providing a valuable genetic resource for high-throughput identification of toxin genes [15].

To summarize, this special issue contains original contributions that allow for significant advance on the knowledge of a wide variety of emerging marine biotoxin classes as well as technological developments to screen and detect or even evaluate the toxicological effects of these toxins in various matrices and environments.

Acknowledgments: The editors are grateful to all of the authors who contributed to this special issue. They are also mindful that without the rigorous and selfless evaluation of the submitted manuscripts by expert peer reviewers, this special issue would not be possible. The valuable contributions, organization, and editorial support of the MDPI management team and staff are greatly appreciated.

Conflicts of Interest: The authors declare no conflict of interest. 


\section{References}

1. Wang, B.; Yao, M.; Zhou, J.; Tan, S.; Jin, H.; Zhang, F.; Mak, Y.L.; Wu, J.; Lai Chan, L.; Cai, Z. Growth and toxin production of gambierdiscus spp. Can be regulated by quorum-sensing bacteria. Toxins 2018, 10, 257. [CrossRef] [PubMed]

2. Estevez, P.; Castro, D.; Pequeno-Valtierra, A.; Leao, J.M.; Vilarino, O.; Diogene, J.; Gago-Martinez, A. An attempt to characterize the ciguatoxin profile in seriola fasciata causing ciguatera fish poisoning in macaronesia. Toxins 2019, 11, 221. [CrossRef] [PubMed]

3. Costa, P.R.; Estevez, P.; Castro, D.; Solino, L.; Gouveia, N.; Santos, C.; Rodrigues, S.M.; Leao, J.M.; Gago-Martinez, A. New insights into the occurrence and toxin profile of ciguatoxins in selvagens islands (madeira, portugal). Toxins 2018, 10, 524. [CrossRef] [PubMed]

4. Dom, I.; Bire, R.; Hort, V.; Lavison-Bompard, G.; Nicolas, M.; Guerin, T. Extended targeted and non-targeted strategies for the analysis of marine toxins in mussels and oysters by (lc-hrms). Toxins 2018, 10, 375. [CrossRef] [PubMed]

5. Klijnstra, M.D.; Gerssen, A. A sensitive lc-ms/ms method for palytoxin using lithium cationization. Toxins 2018, 10, 537. [CrossRef] [PubMed]

6. Turner, A.D.; Dhanji-Rapkova, M.; Coates, L.; Bickerstaff, L.; Milligan, S.; O'Neill, A.; Faulkner, D.; McEneny, H.; Baker-Austin, C.; Lees, D.N.; et al. Detection of tetrodotoxin shellfish poisoning (tsp) toxins and causative factors in bivalve molluscs from the UK. Mar. Drugs 2017, 15, 277. [CrossRef] [PubMed]

7. Gerssen, A.; Bovee, T.H.F.; Klijnstra, M.D.; Poelman, M.; Portier, L.; Hoogenboom, R. First report on the occurrence of tetrodotoxins in bivalve mollusks in the netherlands. Toxins 2018, 10, 450. [CrossRef] [PubMed]

8. Knutsen, H.K.; Alexander, J.; Barregard, L.; Bignami, M.; Bruschweiler, B.; Ceccatelli, S.; Cottrill, B.; Dinovi, M.; Edler, L.; Grasl-Kraupp, B.; et al. Risks for public health related to the presence of tetrodotoxin (ttx) and ttx analogues in marine bivalves and gastropods. EFSA J. 2017, 15, 4752. [CrossRef]

9. Finch, S.C.; Boundy, M.J.; Harwood, D.T. The acute toxicity of tetrodotoxin and tetrodotoxin(-)saxitoxin mixtures to mice by various routes of administration. Toxins 2018, 10, 423. [CrossRef] [PubMed]

10. Simiyu, B.M.; Oduor, S.O.; Rohrlack, T.; Sitoki, L.; Kurmayer, R. Microcystin content in phytoplankton and in small fish from eutrophic nyanza gulf, lake victoria, kenya. Toxins 2018, 10, 275. [CrossRef] [PubMed]

11. Brooke-Jones, M.; Galikova, M.; Dircksen, H. Cyanobacterial neurotoxin beta-methyl-amino-l-alanine affects dopaminergic neurons in optic ganglia and brain of daphnia magna. Toxins 2018, 10, 527. [CrossRef] [PubMed]

12. Zupo, V.; Mutalipassi, M.; Ruocco, N.; Glaviano, F.; Pollio, A.; Langellotti, A.L.; Romano, G.; Costantini, M. Distribution of toxigenic halomicronema spp. In adjacent environments on the island of ischia: Comparison of strains from thermal waters and free living in posidonia oceanica meadows. Toxins 2019, 11, 99. [CrossRef] [PubMed]

13. Wilson, D.; Daly, N.L. Nuclear magnetic resonance seq (nmrseq): A new approach to peptide sequence tags. Toxins 2018, 10, 437. [CrossRef] [PubMed]

14. Liao, Q.W.; Gong, G.Y.; Siu, S.W.I.; Wong, C.T.T.; Yu, H.D.; Tse, Y.C.; Radis-Baptista, G.; Lee, S.M.Y. A novel shk-like toxic peptide from the transcriptome of the cnidarian palythoa caribaeorum displays neuroprotection and cardioprotection in zebrafish. Toxins 2018, 10, 238. [CrossRef] [PubMed]

15. Zhang, S.Y.; Li, J.; Qin, Q.; Liu, W.; Bian, C.; Yi, Y.H.; Wang, M.H.; Zhong, L.Q.; You, X.X.; Tang, S.K.; et al. Whole-genome sequencing of chinese yellow catfish provides a valuable genetic resource for high-throughput identification of toxin genes. Toxins 2018, 10, 488. [CrossRef] [PubMed] 
Article

\title{
An Attempt to Characterize the Ciguatoxin Profile in Seriola fasciata Causing Ciguatera Fish Poisoning in Macaronesia
}

\author{
Pablo Estevez ${ }^{1}$, David Castro ${ }^{1}$, Ana Pequeño-Valtierra ${ }^{1}$, José M. Leao ${ }^{1,2}$, Oscar Vilariño ${ }^{1,2}$, \\ Jorge Diogène ${ }^{3}$ and Ana Gago-Martínez ${ }^{1,2, *}$ \\ 1 University of Vigo, Department of Analytical and Food Chemistry, Campus Universitario de Vigo, \\ 36310 Vigo, Spain; paestevez@uvigo.es (P.E.); dcastro@uvigo.es (D.C.); apequeno@uvigo.es (A.P.-V.); \\ leao@uvigo.es (J.M.L.); ovilarino@uvigo.es (O.V.) \\ 2 European Union Reference Laboratory for Marine Biotoxins, CITEXVI, Campus Universitario de Vigo, \\ 36310 Vigo, Spain \\ 3 IRTA, Marine and Continental Waters, Ctra. Poble Nou, km. 5.5, E-43540 Sant Carles de la Ràpita, Spain; \\ jorge.diogene@irta.cat \\ * Correspondence: anagago@uvigo.es; Tel.: +34-647-343-417
}

Received: 19 March 2019; Accepted: 10 April 2019; Published: 13 April 2019

\begin{abstract}
Ciguatera Fish Poisoning is a worldwide concern caused by the consumption of fish contaminated with ciguatoxins not only in endemic regions in the Pacific Ocean or the Caribbean Sea but also in emerging areas of Macaronesia on the eastern Atlantic. The recent emergence of these toxins in other coastal areas worldwide, prompted the need for the characterization of the risk in these areas. This Ciguatera Fish Poisoning risk has been recently identified as a potential threat in subtropical areas of the Atlantic coast and scientific efforts are being focused in the identification and confirmation of the toxins involved in this potential risk. Neuroblastoma cell assay has been widely used for the evaluation of the toxicity in several marine biotoxin groups, and found to be a very useful tool for toxicity screening. LC-MS/MS has been also used for confirmatory purposes although the main limitation of the advances on LC-MS/MS development is due to commercial unavailability of reference materials and hampers method implementation and validation or even confirmation of the ciguatoxins (CTXs) responsible for the toxic profiles. While neuroblastoma cell assay (N2a) is typically used for toxicity screening as mentioned above, being necessary to confirm this N2a toxicity by LC-MS/MS, this study is designed using N2a as a tool to confirm the toxicity of the fractions obtained corresponding to potential CTXs analogues according to the analysis by LC-MS/MS. With this aim, an amberjack sample (Seriola fasciata) from Selvagen Islads (Portugal) and implicated in Ciguatera Fish Poisoning was analyzed by LC-MS/MS and Caribbean Ciguatoxins were found to be mainly responsible for the toxicity. N2a was used in this work as a tool to help in the confirmation of the toxicity of fractions obtained by HPLC. Caribbean Ciguatoxin- 1 was found as the main analogue responsible for the N2a toxicity while three Caribbean Ciguatoxin-1 (C-CTX1) metabolites which contribute to the total toxicity were also identified.
\end{abstract}

Keywords: ciguatera fish poisoning; macaronesia; caribbean ciguatoxins; LC-MS/MS; N2a

Key Contribution: Caribbean Ciguatoxin- 1 and three toxic analogues previously detected in the Caribbean Sea, were identified for the first time in fish from Macaronesia in the Atlantic Ocean.

\section{Introduction}

Ciguatera Fish Poisoning (CFP) is known as a food intoxication with incidents typically known in certain tropical and subtropical areas. CFP is endemic in regions of the Pacific Ocean and Caribbean 
Sea and associated with the consumption of fish contaminated with ciguatoxins (CTXs). CTXs are lipophilic, ladder-like cyclic polyethers and stable to temperature [1,2]. They are oxidation products resulting from fish metabolization of its algal precursors, which are produced by benthic dinoflagellates (Gambierdiscus spp. and Fukuyoa spp.) [3,4]. The lack of reference materials commercially available is the main limitation to advance, not only in methods implementation, but also in the toxicological characterization of the different CTX analogues involved in this contamination. On the other hand, the low levels of CTXs typically found in the fish tissue makes their analysis very challenging, even when applying very sensitive techniques [5]. Among the three different groups of ciguatoxins currently known (Pacific, Caribbean and Indian), Pacific ciguatoxins (P-CTXs) have been better characterized since they are most widely distributed and evaluated [6-8]. More than 21 different analogues have been already identified as responsible for the CFP in the Pacific areas, and significant progress has been recently made on the identification of different P-CTXs profiles depending on the geographical regions where these toxins occur [9-11].

Studies carried out in contaminated fish from the area of the Caribbean Sea have shown that Caribbean Ciguatoxin-1 and -2 (C-CTX1 and C-CTX2) are the main analogues responsible for the CTX profile [12]. These CTXs were first isolated from a Horse-eye jack (Caranx latus) and structurally characterized by Nuclear Magnetic Resonance [13,14]. Due to the limitations above mentioned regarding the lack of reference materials, studies focused on this group of toxins are still limited. A limited number of publications refer to fish contaminations associated to Caribbean CTX profiles. Fewer investigations have been carried out on C-CTXs, and most of them are just concentrated in fish from the Caribbean Sea $[15,16]$. Important efforts have been made to identify the toxins responsible for fish contaminations in the Caribbean Sea (French West Indies) and at least 12 different C-CTXs analogues have been already detected in fish from these areas $[17,18]$ but no significant investigations have been carried out to characterize and confirm the presence of these C-CTXs analogues. The emergence of CTXs in European waters, in particular in eastern Atlantic areas, has been investigated and an opinion about these toxins has been also published by the European Food Safety Authority (EFSA) [19]. The risk evaluation has been mainly focused on Macaronesia, including the Canary Islands (Spain) and Madeira (Portugal). Some authors reported the presence of Pacific ciguatoxins (P-CTXs) [20] but the identification of Caribbean ciguatoxins in the Canary Islands has been also reported [21]. The characterization of the risk in these areas became a concern and investigations are currently in place to evaluate to which extent CFP represents a public health risk that needs to be controlled. The authors of this work are presently involved in a research project cofounded by the EFSA and coordinated by the Spanish Food Safety Agency (AESAN). The project is focused on the characterization of the risk of ciguatera fish poisoning in Europe, with particular emphasis in those EU areas from the eastern Atlantic where the problem had been already reported. The most recent results obtained on the characterization of the risk in the Canary Islands and Madeira, show that C-CTX1 seems to be the main analogue responsible of the contamination in this geographical region, although the presence of other C-CTX analogues is also suspected [22]. The main limitation to advance the characterization of CTXs is the lack of reference materials commercially available and in particular for C-CTXs. Despite this limitation, the support of collaborators working in this field, have made it possible to identify C-CTX1 as the main analogue responsible for the CFP contamination. However, the concentrations of this toxin in the samples analyzed so far are typically very low, which also limits the progress on the isolation of this toxin to be able to prepare pure standards, as well as the identification of possible analogues involved in CFP contamination. Based on these limitations and with the aim of achieving the main objectives of this project, a contingency plan has been established to prepare at least laboratory reference materials with known toxin profiles. The main objective of this work was to try to advance the characterization of the CTX profiles of samples from the areas above mentioned, and to achieve our goal we have used, not only our own materials, obtained through the EUROCIGUA project, which consisted of contaminated fish samples from Canary Islands and Madeira, but also trying to find materials that were used in the past from the areas described above. The analytical methods used for the screening 
and semi-quantitation of the toxicity were: a neuroblastoma cell assay (N2a) based on the action mode of CTXs on sodium channels; and for the further confirmation and full quantitation LC-MS/MS, which had been initially described by [23] and further optimized by [24]

A very interesting and valuable sample that was kept under appropriate conditions, to avoid decomposition $\left(-20^{\circ} \mathrm{C}\right)$ at the European Union Reference Laboratory for Marine Biotoxins (EURLMB), which had been analyzed by [25], was selected to continue with the objective of profile characterization. The sample consisted of a fish species of amberjack (Seriola fasciata) implicated in a CFP. The fish was captured in Selvagen Islands (Madeira, Portugal) and consumed in a restaurant in Tenerife (Canary Islands, Spain). The sample exhibited high cytotoxicity by N2a assay [25]. The sample was recently reanalyzed by N2a for the screening of the CTX-like toxicity and further confirmation by LC-MS/MS. Once the high CTX toxicity was confirmed, the sample was selected for further cigutatoxin profile characterization. The approach used to achieve our objective was to first develop a HPLC fractionation, combined with the N2a cytotoxicity evaluation of the fractions, and further confirmation of the toxicity by characterizing the possible analogues implicated in this toxicity by LC-MS/MS under the optimized method described by [24].

\section{Results}

\subsection{Cytotoxicity Assay}

The cytotoxicity of the purified extract of the contaminated fish was evaluated by N2a with the aim of evaluating the CTX-like response of this extract. A toxic response was observed in the treated oubaine-veratridine N2a cells whereas no positive response was detected in untreated cells confirming the presence of sodium channel specific activators (Figure 1). The semi-quantitation by N2a assay allows to determine a composite toxicity of $1.4 \mathrm{ng} \mathrm{C}$-CTX $1 \mathrm{eq} \cdot \mathrm{g}^{-1}$ which is 14 -fold above the guidance level proposed by the FDA, USA for C-CTX1 $\left(0.1 \mathrm{ng} \cdot \mathrm{g}^{-1}\right)$ [26].

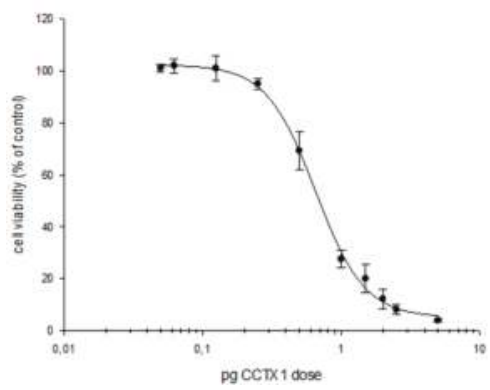

(A)

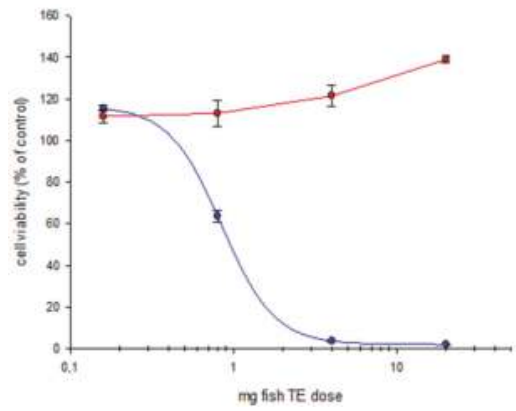

(B)

Figure 1. Neuroblastoma cell assay (N2a) cytotoxicity plots of (A) Caribbean Ciguatoxin-1 (C-CTX1) standard (B) amberjack (Seriola fasciata): blue line, sample treated with oubaine-veratridine; red line, sample without the oubaine-veratridine treatment.

\subsection{LC-MS/MS Analysis}

Previous studies carried out by this research group [24] showed an approach for the identification followed by confirmation of CTXs in the absence of reference materials, and is briefly described as follows. Identification is based on the high sensitivity detection of the sodium adducts and confirmation is by monitoring ions generated by several water losses and specific fragments. This approach has been used for C-CTXs, in particular C-CTX1, which have been recently identified as the main analogue responsible for the CFP in these areas [22,24]. The possible presence of Pacific ciguatoxins (P-CTXs) was also explored by using non-certified standards for 10 different P-CTXs analogues (kindly provided by Prof. Yasumoto). The results obtained showed that C-CTX1 was the only analogue clearly detected 
in this sample since the retention time and precursor/product ion transition, $\mathrm{m} / \mathrm{z} 1163.7->\mathrm{m} / \mathrm{z} 1163.7$, were consistent with those obtained for the C-CTX1 pure standard (kindly provided by Dr. R. Dickey and Dr. R. Manger) (Figure 2). Calibration curve was carried out with CTX1B standard due to the lack of enough C-CTX1 standard to obtain a proper quantitation $\left(0.6-22.2 \mathrm{ng} \cdot \mathrm{mL}^{-1}, R^{2}=0.999, n=5\right)$. C-CTX1 standard equivalents were obtained by interpolating in CTX1B calibration. C-CTX1 in sample was quantified as CTX1B and converted to C-CTX1 with the equivalents previously obtained. The concentration of C-CTX1 in the fish sample evaluated in this study was $0.84 \mathrm{ng}$ C-CTX1 $\cdot \mathrm{g}^{-1}$.
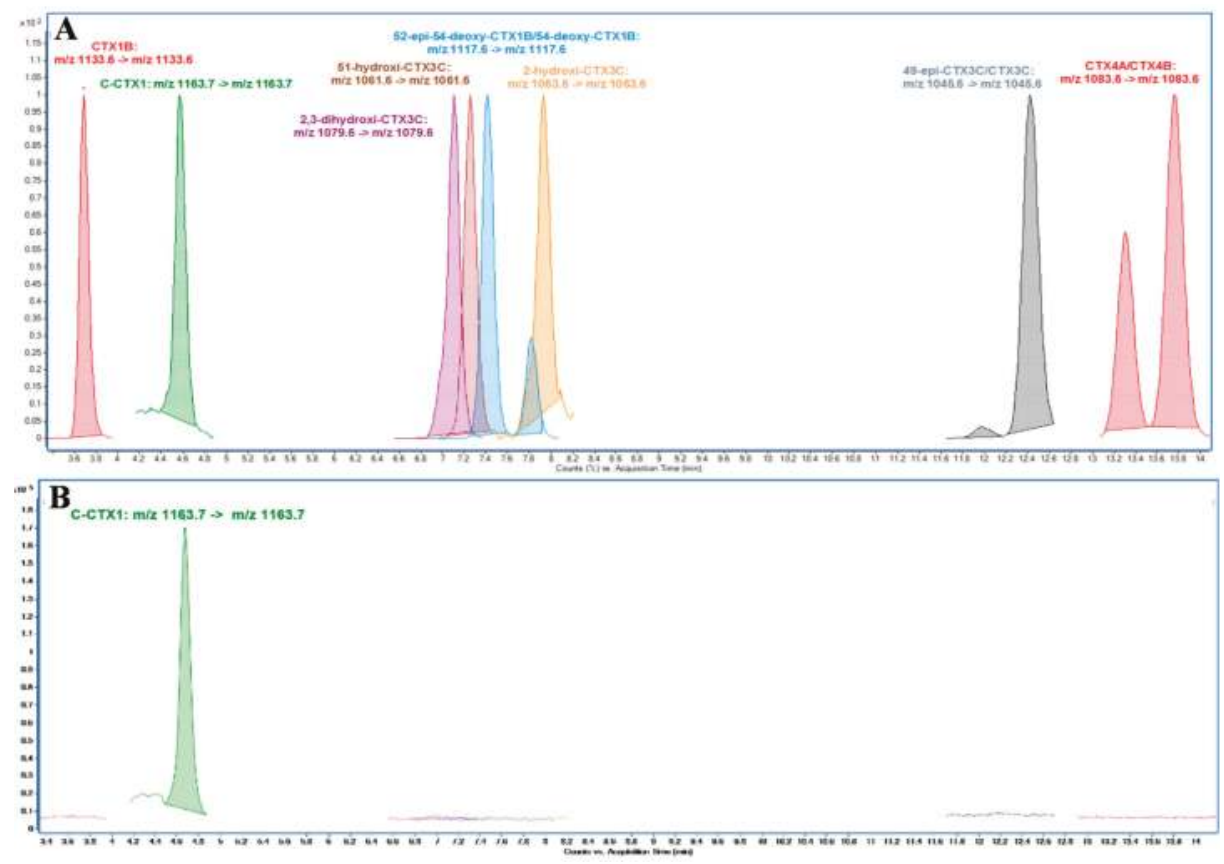

Figure 2. LC-MS/MS (MRM) analysis monitoring sodium adduct as precursor and product ion in (A) qualitative mixture of Pacific ciguatoxins (P-CTXs) and C-CTX1 standard (B) amberjack (S. fasciata) extract.

\subsection{Sample Fractionation for CTX Profile Identification}

The purified extract obtained after a double solid phase extraction (SPE) (Florisil + C18) according to [24] and equivalent to $100 \mathrm{~g}$ fish tissue was further fractionated by using HPLC. Fractions (49) collected were examined for cytotoxicity by N2a assay. The N2a cytotoxicity profile shows three prominent cytotoxic peaks (1,2 and 4) between the fraction 19 and 33 (Figure 3).

The fractions exhibiting cytotoxicity were analyzed by LC-MS/MS Multiple Reaction Monitoring (MRM) method monitoring several water losses $\left[\mathrm{M}+\mathrm{H}-\mathrm{nH}_{2} \mathrm{O}\right]^{+}$, sodium $[\mathrm{M}+\mathrm{Na}]^{+}$and a potassium $[\mathrm{M}+\mathrm{K}]^{+}$adducts and C-CTX1 specific fragments $m / z$ 191.1, $m / z$ 108.9. These two specific fragments were firstly described by [24] after the product ion analysis of C-CTX1 standard at high collision energy and were assigned to characteristic fragments of C-CTX1. The comparison of the ion ratios obtained with the C-CTX1 pure standard allows the confirmation of the possible C-CTXs analogues present in these toxic fractions (Tables 1 and 2). 


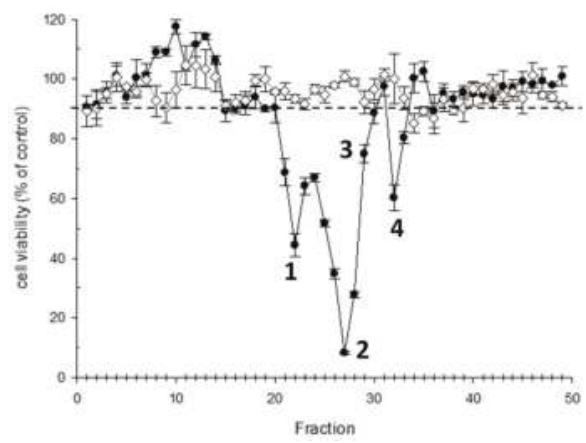

Figure 3. N2a cytotoxicity profile of HPLC fractionated amberjack sample: $4 \mathrm{mg}$ of fish tissue equivalent (TE)/well.

Table 1. Caribbean Ciguatoxins identified in N2a toxic fractions (n.d. not detected) *According to [17].

\begin{tabular}{ccccc}
\hline Peak & $\mathbf{1}$ & $\mathbf{2}$ & $\mathbf{3}$ & $\mathbf{4}$ \\
\hline Fractions & $19-22$ & $23-28$ & 29 & $32-33$ \\
Retention Time (min) & 7.6 & 9.4 & 10.6 & 10.8 \\
{$[\mathrm{M}+\mathrm{K}]^{+}$} & 1195.6 & 1179.6 & 1165.6 & n.d. \\
{$\left[\mathrm{M}+\mathrm{Na}^{+}\right.$} & 1179.6 & 1163.6 & 1149.6 & 1163.6 \\
{$\left[\mathrm{M}+\mathrm{NH}_{4}\right]^{+}$} & 1174.6 & 1158.6 & 1144.6 & n.d. \\
{$[\mathrm{M}+\mathrm{H}]^{+}$} & 1157.6 & 1141.6 & 1127.6 & n.d. \\
{$\left[\mathrm{M}+\mathrm{H}-\mathrm{nH} \mathrm{H}_{2} \mathrm{O}\right]^{+}$n range } & $1-3$ & $1-3$ & $1-4$ & $1-3$ \\
C-CTX identification * & C-CTX-1157 & C-CTX1 & C-CTX-1127 & Unknown \\
\hline
\end{tabular}

Table 2. MS/MS conditions for the confirmation of the different C-CTXs analogues identified in an amberjack (S. fasciata) sample.

\begin{tabular}{|c|c|c|c|}
\hline Compound & Precursor Ion (Q1) & Product Ion (Q3) & $\mathrm{CE}(\mathrm{eV})$ \\
\hline \multirow{6}{*}{ C-CTX-1157 } & {$[\mathrm{M}+\mathrm{Na}]^{+} m / z 1179.6$} & {$[\mathrm{M}+\mathrm{Na}]^{+} \mathrm{m} / \mathrm{z} 1179.6$} & 40 \\
\hline & {$\left[\mathrm{M}+\mathrm{H}-\mathrm{H}_{2} \mathrm{O}\right]^{+} m / z 1139.6$} & {$\left[\mathrm{M}+\mathrm{H}-2 \mathrm{H}_{2} \mathrm{O}\right]^{+} m / z 1121.6$} & 15 \\
\hline & {$\left[\mathrm{M}+\mathrm{H}-\mathrm{H}_{2} \mathrm{O}\right]^{+} m / z 1139.6$} & {$\left[\mathrm{M}+\mathrm{H}-3 \mathrm{H}_{2} \mathrm{O}\right]^{+} m / z 1103.6$} & 30 \\
\hline & {$\left[\mathrm{M}+\mathrm{H}-\mathrm{H}_{2} \mathrm{O}\right]^{+} m / z 1139.6$} & {$\left[\mathrm{M}+\mathrm{H}-4 \mathrm{H}_{2} \mathrm{O}\right]^{+} m / z 1085.6$} & 30 \\
\hline & {$\left[\mathrm{M}+\mathrm{H}-\mathrm{H}_{2} \mathrm{O}\right]^{+} m / z 1139.6$} & $m / z 191.1$ & 41 \\
\hline & {$\left[\mathrm{M}+\mathrm{H}-\mathrm{H}_{2} \mathrm{O}\right]^{+} m / z 1139.6$} & $m / z 108.9$ & 52 \\
\hline \multirow{5}{*}{ C-CTX1 and isomers } & {$\left[\mathrm{M}+\mathrm{H}-\mathrm{H}_{2} \mathrm{O}\right]^{+} m / z 1123.6$} & {$\left[\mathrm{M}+\mathrm{H}-2 \mathrm{H}_{2} \mathrm{O}\right]^{+} m / z 1105.6$} & 25 \\
\hline & {$\left[\mathrm{M}+\mathrm{H}-\mathrm{H}_{2} \mathrm{O}\right]^{+} m / z 1123.6$} & {$\left[\mathrm{M}+\mathrm{H}-3 \mathrm{H}_{2} \mathrm{O}\right]^{+} m / z 1087.6$} & 29 \\
\hline & {$\left[\mathrm{M}+\mathrm{H}-\mathrm{H}_{2} \mathrm{O}\right]^{+} m / z 1123.6$} & {$\left[\mathrm{M}+\mathrm{H}-4 \mathrm{H}_{2} \mathrm{O}\right]^{+} m / z 1069.6$} & 37 \\
\hline & {$\left[\mathrm{M}+\mathrm{H}-\mathrm{H}_{2} \mathrm{O}\right]^{+} m / z 1123.6$} & $m / z 191.1$ & 41 \\
\hline & {$\left[\mathrm{M}+\mathrm{H}-\mathrm{H}_{2} \mathrm{O}\right]^{+} m / z 1123.6$} & $m / z 108.9$ & 52 \\
\hline \multirow{5}{*}{ C-CTX-1127 } & {$[\mathrm{M}+\mathrm{Na}]^{+} m / z 1149.6$} & {$[\mathrm{M}+\mathrm{Na}]^{+} m / z 1149.6$} & 40 \\
\hline & {$[\mathrm{M}+\mathrm{H}]^{+} m / z 1127.6$} & {$\left[\mathrm{M}+\mathrm{H}-\mathrm{H}_{2} \mathrm{O}\right]^{+} m / z 1109.6$} & 30 \\
\hline & {$[\mathrm{M}+\mathrm{H}]^{+} m / z 1127.6$} & {$\left[\mathrm{M}+\mathrm{H}-2 \mathrm{H}_{2} \mathrm{O}\right]^{+} m / z 1091.6$} & 32 \\
\hline & {$[\mathrm{M}+\mathrm{H}]^{+} m / z 1127.6$} & {$\left[\mathrm{M}+\mathrm{H}-3 \mathrm{H}_{2} \mathrm{O}\right]^{+} m / z 1073.6$} & 37 \\
\hline & {$[\mathrm{M}+\mathrm{H}]^{+} m / z 1127.6$} & {$\left[\mathrm{M}+\mathrm{H}-4 \mathrm{H}_{2} \mathrm{O}\right]^{+} m / z 1055.6$} & 40 \\
\hline
\end{tabular}

The positive CTX-like response obtained by N2a for the Fraction 22 (Toxic peak 1) might be attributed to the presence of an ion $[\mathrm{M}+\mathrm{H}]^{+} \mathrm{m} / \mathrm{z} 1157.6$, which highest intensity corresponds to the first water loss $\left[\mathrm{M}+\mathrm{H}-\mathrm{H}_{2} \mathrm{O}\right]^{+} \mathrm{m} / z$ 1139.6. A cyclic polyether fragmentation was also observed detecting different water losses $\left[\mathrm{M}+\mathrm{H}-\mathrm{nH}_{2} \mathrm{O}\right]^{+}$and also adducts formation $[\mathrm{M}+\mathrm{Na}]^{+},[\mathrm{M}+\mathrm{K}]^{+}$. Further MRM analysis was carried out selecting the ion with the highest intensity $\left[\mathrm{M}+\mathrm{H}_{-} \mathrm{H}_{2} \mathrm{O}\right]^{+} \mathrm{m} / z 1139.6$ and monitoring three additional water losses. $[\mathrm{M}+\mathrm{Na}]^{+}$was monitored as precursor and product ion at high collision energy, and C-CTX1 specific fragments $(\mathrm{m} / \mathrm{z} 191.1 \mathrm{~m} / \mathrm{z} 108.9)$ were used for final 
confirmation which allowed to conclude that the toxicity of the fraction analyzed might correspond to a C-CTX analogue different than C-CTX1 but structurally similar (Figure 4).

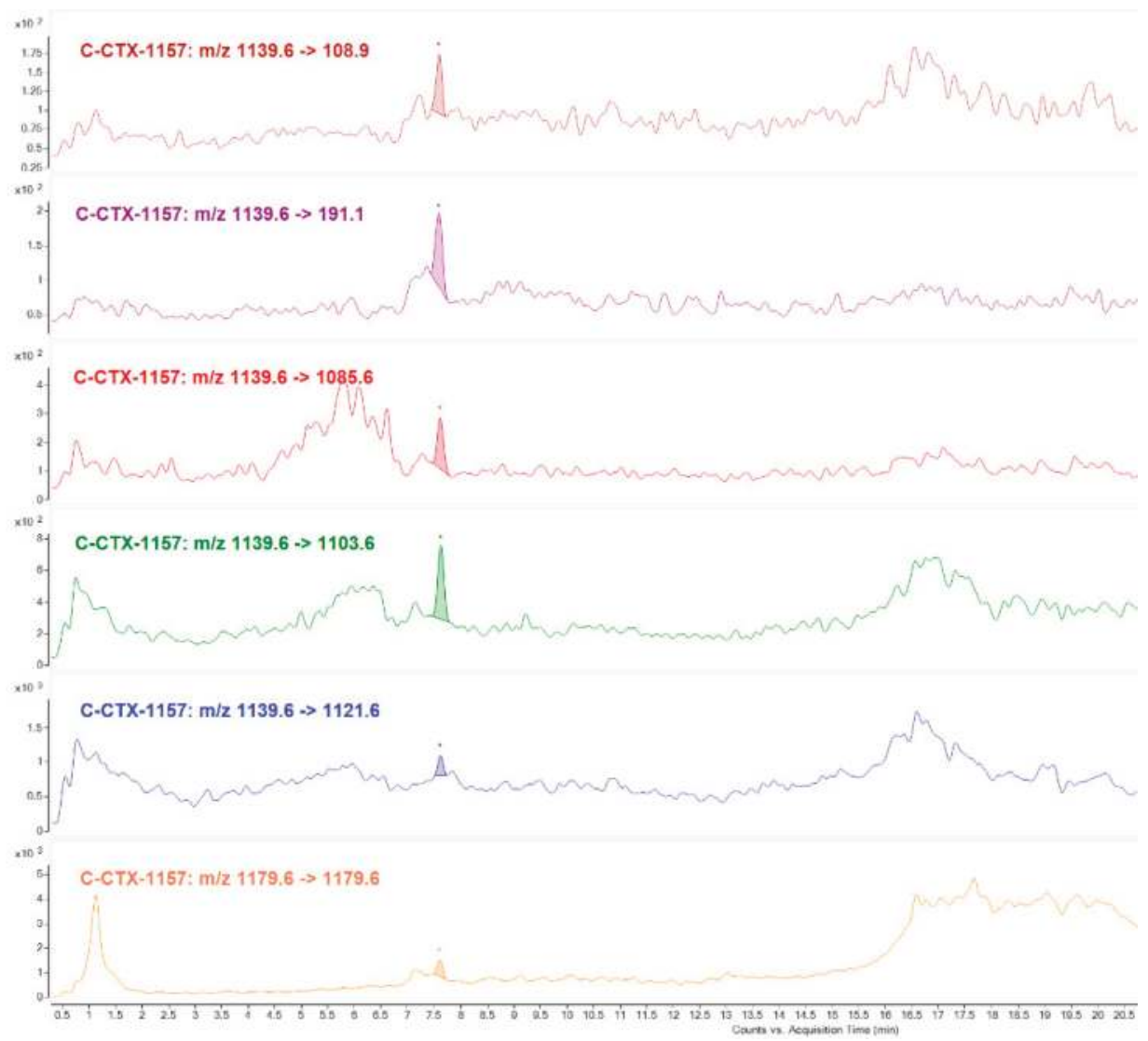

Figure 4. LC-MS/MS (MRM) analysis of Fraction 22 identifying putative C-CTX-1157 as responsible for the toxicity in N2a Toxic peak 1.

Fraction 27 (Toxic peak 2) was undoubtedly attributed to C-CTX1 since the availability of a pure standard for this particular compound allowed to establish its identity based, not only on the matching retention time, but also on the ion ratios for the different transitions used for confirmation (Figure 5).

In addition LC-MS/MS allows to identify in Fraction 29 a compound with $[\mathrm{M}+\mathrm{H}]^{+} \mathrm{m} / z 1127.6$ which has not been clearly identified in the fraction analyzed by N2a (Region 3 of Figure 3). A cyclic polyether fragmentation was also observed and the further MRM analysis allowed to monitor up to four water losses as well as the $[\mathrm{M}+\mathrm{Na}]^{+}$adduct as precursor and product ion at high collision energy. Specific C-CTX1 fragments were not detected and the ion ratios were not consistent with that obtained in the standard, suggesting structural differences comparing with C-CTX1 (Figure 6). 


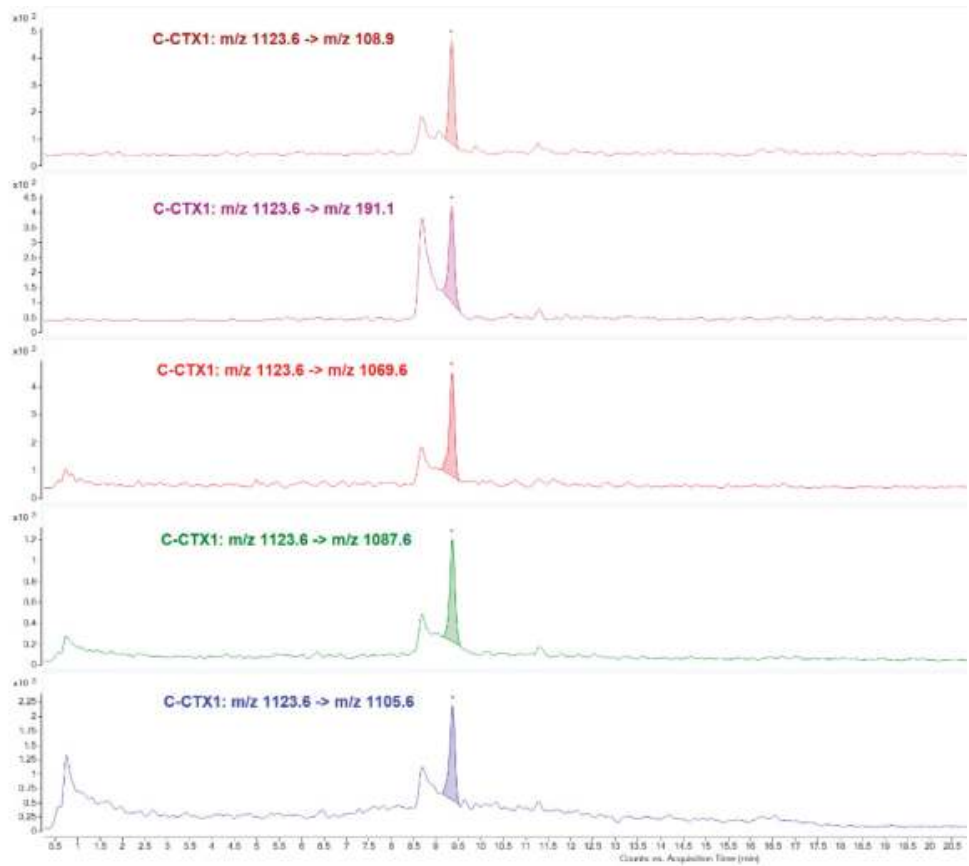

Figure 5. LC-MS/MS (MRM) analysis of Fraction 27 identifying C-CTX1 as responsible for the toxicity in N2a Toxic peak 2.

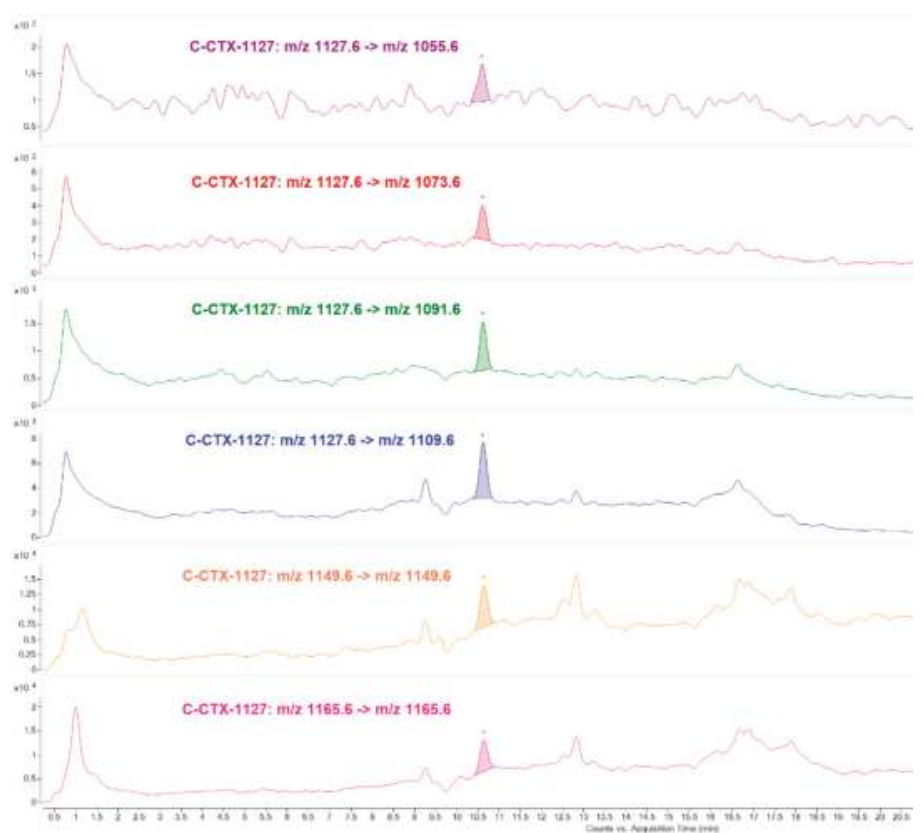

Figure 6. LC-MS/MS (MRM) analysis of Fraction 29 identifying putative C-CTX-1127 as responsible for the toxicity in N2a Toxic region 3. 
The last eluting toxic compound detected in Fraction 32 (peak 4) was attributed to a C-CTX1 isomer due to the detection of the same ion transitions as that obtained in C-CTX1 pure standard but with a different retention time (Figure 7).

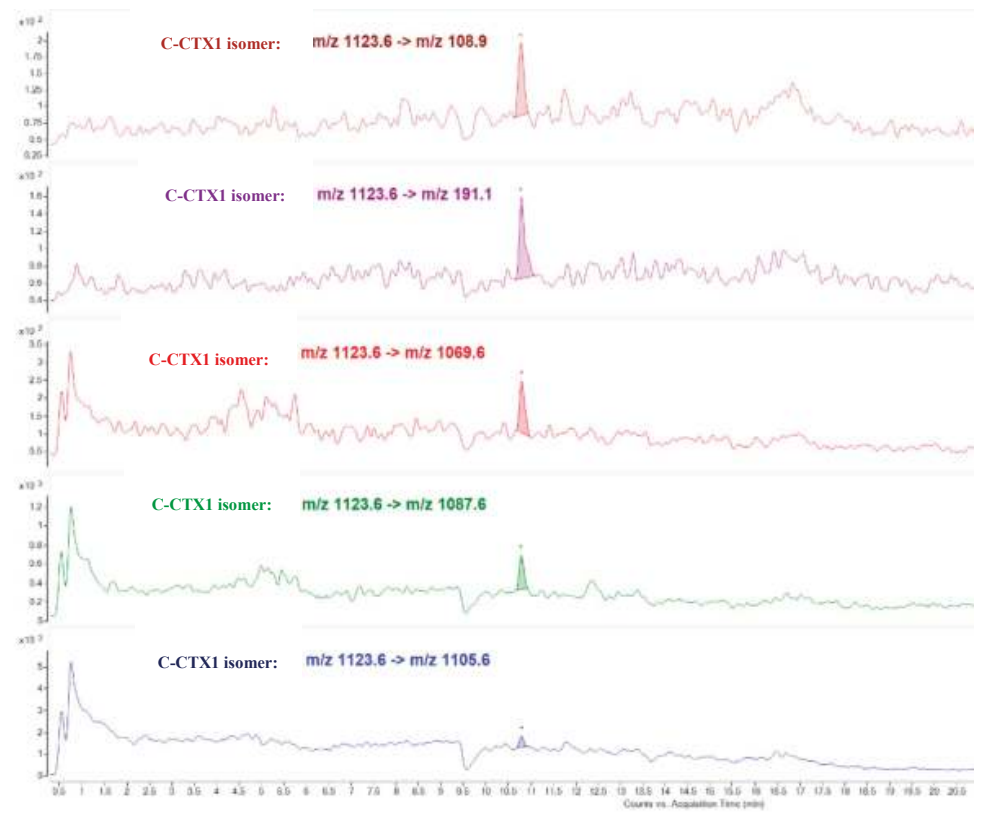

Figure 7. LC-MS/MS (MRM) analysis of Fraction 32 identifying putative C-CTX1 isomer as responsible for the toxicity in N2a Toxic peak 4.

\section{Discussion}

To our knowledge this is the first report of the CTX profile of a fish from Macaronesia that is implicated in CFP. The absence of samples with very high concentration of CTXs from the Atlantic areas limits the progress on the characterization of the CTXs involved in CFP contamination. Therefore, it was considered that this fish species previously characterized as $S$. fasciata by genetic analysis which toxicity had been also confirmed by N2a (Sample \#2 in the previous study) [25] showing a high CTX-like positive response, was considered to be a good candidate to be used for the characterization of the toxic profile.

The present study was conducted using the CFP implicated tissue stored at $-20{ }^{\circ} \mathrm{C}$ at the EURLMB. Sample was screened for cytotoxicity by N2a to ensure stability and the composite toxicity was determined as $1.4 \mathrm{ng}$ C-CTX1 eq.g ${ }^{-1}$. N2a cytotoxicity assay and LC-MS/MS confirmatory analysis were performed on SPE purified extracts prepared following the same protocols. The concentration of C-CTX1 was determined by LC-MS/MS using the protocol previously reported [24] and the level found was $0.84 \mathrm{ng} \cdot \mathrm{g}^{-1}$, which was lower than the composite sodium channel specific toxin level determined by N2a assay. LC-MS/MS analysis was focused on only C-CTX1 since it was reported as the major analogue responsible for the CTX toxicity in these areas [21,22,24].

The presence of P-CTXs was also evaluated using the P-CTXs standards available but none of these compounds were found in the sample analyzed, therefore the focus was on the Caribbean CTX profile, which supposed to be the one responsible for the toxicity of this sample, as previously mentioned. The approach of using the fractionation for evaluating the CTX-like toxicity by N2a on individual fractions is considered a very valuable tool to progress the characterization of the CTX profile, in the absence of standards for the CTX analogues. This approach also contributes to minimizing the possible 
misidentification due to the presence of interferences which could lead to a false conclusion about the CTX profile involved in the CFP contamination.

Full scan of the toxic fractions on the $m / z$ range 1000-1200 did not provide any specific information about possible presence of cyclic polyether analogues since the sensitivity of this mode is not enough to reach the trace levels at which these analogues could be present, also taking into account that the matrix effect could have an impact on this detection. Due to these limitations, the approach used was focused on monitoring, by MRM, the CTX analogues suspected to be present, allowing a higher specificity and sensitivity as well as minimizing the matrix effects.

The results on the CTX analogues found in the evaluated sample, as well as the reasons that justify their characterization, are summarized as follows:

C-CTX1 and three C-CTX congeners of $m / z$ 1157, $m / z 1127$ and $m / z 1123$ were detected in the HPLC purified fractions, with CTX-like activity by N2a. All these compounds produced characteristic ions associated with CTXs, including $[\mathrm{M}+\mathrm{H}]^{+},\left[\mathrm{M}+\mathrm{NH}_{4}\right]^{+},[\mathrm{M}+\mathrm{Na}]^{+},[\mathrm{M}+\mathrm{K}]^{+}$and $\left[\mathrm{M}+\mathrm{H}-\mathrm{nH}_{2} \mathrm{O}\right]^{+}$.

C-CTX1 was identified mainly in Fraction 27, in the highest toxicity peak (Toxic peak 2 ) and considered to be mainly responsible for the total toxicity being appropriately identified due to the availability of C-CTX1 pure standard.

C-CTX congener of $m / z 1157$ was identified mostly in Fraction 22 (Toxic peak 1 ). Not only were water losses detected, selecting its higher intensity ion $\left[\mathrm{M}+\mathrm{H}-\mathrm{H}_{2} \mathrm{O}\right]^{+} \mathrm{m} / \mathrm{z} 1139$ and sodium adduct $[\mathrm{M}+\mathrm{Na}]^{+} \mathrm{m} / z 1179$ as precursor and product ion, but also C-CTX1 specific fragments $(\mathrm{m} / \mathrm{z} 191.1$ and $m / z$ 108.9) with same ion ratios as C-CTX1 standard. This compound seems to be structurally similar to C-CTX1 in the ends of the molecule. C-CTX congener of $m / z 1157$ named as C-CTX-1157, was first identified by $[17,18]$ in a horse-eye jack (Caranx latus) and barracuda (Shyraena barracuda) from French West Indies (Caribbean Sea) and more recently in a barracuda from the same geographical region [15]. Differing in 16 Da from C-CTX1, and with a retention time indicative of having a higher polarity, could suggest that this compound could be an oxidized product.

C-CTX congener of $m / z 1127$ was detected in Fraction 29 (Unresolved cytotoxic peak 3). Despite detecting the typical CTXs fragmentation pattern, ion ratios were not consistent with that obtained in C-CTX1 standard. This indicates structural differences compared to C-CTX1 which are also observed in the formation of its highest intensity ion $[\mathrm{M}+\mathrm{H}]^{+} \mathrm{m} / \mathrm{z} 1127$ in contrast with other $\mathrm{C}-\mathrm{CTX}$ s congeners, e.g., putative C-CTX-1157 and C-CTX1 which its highest intensity ion is $\left[\mathrm{M}+\mathrm{H}-\mathrm{H}_{2} \mathrm{O}\right]^{+}$. Named as C-CTX-1127, this congener could be a demethylated product of C-CTX1 $[15,18]$.

The last CTX congener identified seems to be a C-CTX1 isomer and it was detected mostly in Fraction 32 (Toxic peak 4). The same transitions and ion ratios as C-CTX1 were observed in LC-MS/MS (MRM) analysis, but with a higher retention in the HPLC-C18 column. The literature suggests that this compound might be C-CTX2, but the lack of pure standard did not allow identifying this CTX congener. This conclusion has been also reached by other authors [15,17].

Product ions of the different analogues at different collision energies did not show the formation of any prominent peaks. The low concentration of these congeners as well as the well-known high stability of CTXs chemical structure hampers the fragmentation and consequently the structural characterization of the obtained fragments. The limited availability of this material and the trace levels of CTXs did not allow further structural characterization or a quantitative study.

\section{Conclusions}

The approach used in this work combining the HPLC fractionation, the CTX-like total toxicity evaluation by N2a and the final characterization by LC-MS/MS allowed the identification of the CTXs profile responsible for the toxicity of the fish sample evaluated, also allowing to confirm previous results about the presence of Caribbean ciguatoxin as responsible for the CFP contamination in fish samples from the East Atlantic coast related to CFP. The results obtained in this work also allow to conclude that the CTX profile in this geographical region seems to be similar to the one reported for endemic areas of the Caribbean Sea. 


\section{Materials and Methods}

\subsection{Standards and Reagents}

C-CTX1 pure standard solution $\left(5 \mathrm{ng} \cdot \mathrm{mL}^{-1}\right)$ was kindly provided by Dr. Robert Dickey (previously, U.S. Food and Drug Administration) via Dr. Ronald Manger (Fred Hutchinson Cancer Research Center, Seattle, USA). A qualitative mixture of P-CTXs standard solution containing: CTX1B, 2,3-dihydroxyCTX3C, 51-hydroxyCTX3C, 52-epi-54-deoxyCTX1B/54-deoxyCTX1B, 2-hydroxyCTX3C, 49-epiCTX3C, CTX3C, CTX4A and CTX4B, was kindly provided by Prof. Takeshi Yasumoto (Japan Food Research Laboratories, Japan)

Acetone, diethyl ether, methanol, water, hexane and ethyl acetate used for extraction and purification were of HPLC grade (Merck KGaA, Darmstadt, Germany). Methanol, Acetonitrile, formic acid, ammonium formiate (Merck KGaA, Darmstadt, Germany) and water (J. T. Baker, Center Valley, PA, USA) for LC-MS analysis were of LC-MS grade. Methanol, formic acid, ammonium formiate (Merck KGaA, Darmstadt, Germany) for HPLC fractionation were of HPLC grade. Water for fractionation was deionized and purified at $15 \mathrm{M} \Omega \cdot \mathrm{cm}^{-1}$ through a Milli-Q Gradient A10 system (Millipore, Molsheim, France)

\subsection{Samples}

The sample used for this study consisted of a raw portion of a CFP-implicated amberjack (Seriola fasciata) supplied by EURLMB. The sample was provided to EURLMB by the Health Directory of Canary Islands (Tenerife). Amberjack fish of $37 \mathrm{~kg}$ was captured in Selvagen Islands (Portugal) and it was associated to CFP in 2008 in Tenerife (Spain) [25].

\subsection{Sample Pretreatment}

Sample pretreatment was carried out according to [24] conditions with some modifications. Briefly, $115 \mathrm{~g}$ of fish tissue was extracted twice with acetone ( $3 \mathrm{~mL}$ acetone/g fish tissue) (Ultra Turrax ${ }^{\circledR} \mathrm{T} 25 \mathrm{basic}$ $\mathrm{IKA}^{\circledR}$ WERKE, Staufen, Germany) and centrifuged $10 \mathrm{~min}$ at $3000 \mathrm{rpm}$ and $4{ }^{\circ} \mathrm{C}$. The combined acetone layers were evaporated to an aqueous phase under reduced pressure (Syncore ${ }^{\circledR}$ Polyvap, Barcelona, Spain). The remaining aqueous phase was extracted twice with diethyl ether ( $1 \mathrm{~mL}$ diethyl ether/g fish tissue) and the combined organic layers were dried under nitrogen steam. The organic residue was partitioned between $90 \%$ methanol $(\mathrm{MeOH})$ and twice the volume of hexane $(0.3 \mathrm{~mL} 90 \% \mathrm{MeOH} / \mathrm{g}$ fish tissue). The hexane layer was discarded evaporating the $\mathrm{MeOH}$ layer to a solid residue.

Solid residue from extraction was further purified by Solid Phase Extaction (SPE) (15 g fish tissue eq./cartridge). Conditions for SPE are briefly described as follows: Florisil SPE (J. T. Baker, 500 mg, Center Valley, PA, USA) was used to remove polar interfering compound, $2 \mathrm{~mL}$ of sample extract in ethyl acetate (AcOEt) was loaded in a cartridge previously conditioned with $3 \mathrm{~mL}$ of AcOEt, and eluted in three consecutive steps with $3 \mathrm{~mL}$ of AcOEt, $5 \mathrm{~mL}$ AcOEt:MeOH (9:1) and $5 \mathrm{~mL}$ of AcOEt:MeOH (3:1). CTXs eluted in the second elution were evaporated and further purified in C18 SPE (SUPELCLEAN, Supelco, $500 \mathrm{mg}$, Bellefonte, PA, USA). C18 cartridge was conditioned with $3 \mathrm{~mL}$ of $60 \% \mathrm{MeOH}$, Florisil SPE purified extract was dissolved in $2 \mathrm{~mL}$ of $60 \% \mathrm{MeOH}$ and loaded in the cartridge, CTXs were retained and the cartridge was washed with $3 \mathrm{~mL}$ of $60 \% \mathrm{MeOH}$ eluting with $5 \mathrm{~mL}$ of $90 \% \mathrm{MeOH}$.

A C18 purified extract of $15 \mathrm{~g}$ fish tissue eq. was evaporated and reconstituted in $0.5 \mathrm{~mL}$ of $\mathrm{MeOH}$ LC-MS. The extract was filtered (Syringe Driver filter Unit, Millex ${ }^{\circledR}$-CV $0.22 \mathrm{um}, 13 \mathrm{~mm}$, Millipore, Billerica, MA, USA) prior to the analysis by both LC-MS/MS and N2a. The remaining C18 purified extracts equivalents to $100 \mathrm{~g}$ fish tissue were combined and evaporated to dryness to further fractionate in HPLC-C18.

\subsection{HPLC-C18 Sample Fractionation}

Sample fractionation was carried out on an Agilent 1100 G1312A binary pump coupled to an Agilent 1260 II fraction collector (Agilent Technologies, Waldbronn, Germany) with an Agilent 1260 II 
UV detector (Agilent Technologies, Waldbronn, Germany). Kinetex ${ }^{\circledR}$ LC-C18 $(4.6 \times 250 \mathrm{~mm}, 5 \mu \mathrm{m}$, $100 \mathrm{~A}$, Phenomenex) column was used for sample fractionation. The mobile phase for analysis consisted of: $5 \mathrm{mM}$ ammonium formate and $0.1 \%$ formic acid in water $\left(\mathrm{H}_{2} \mathrm{O}\right)(\mathrm{A})$ and $\mathrm{MeOH}(\mathrm{B})$. Chromatographic separation was performed by a slow linear gradient elution: Starting with $60 \% \mathrm{~B}$ to $100 \%$ B over $85 \mathrm{~min}$. The mobile phase flow rate was $1 \mathrm{~mL} \cdot \mathrm{min}^{-1}$ and the injection volume was $100 \mu \mathrm{L}$. Previous studies allowed to determine the chromatographic region where the CTX-like compounds elute optimizing the collection of the fractions in this region (data not shown). A total of 49 fractions were collected removing solvents under nitrogen. Cytotoxicity of each fraction was determined by N2a assay.

\subsection{N2a Assay}

Neuroblastoma 2-a cells (ATCC, CCL 131, Manassas, VA, USA) were cultured, maintained and used as described by $[27,28]$ with slight modifications: incubation time was reduced to $16 \mathrm{~h}$ and the concentration of Oubain/Veratridine (O/V) (O3125/ V5754, Sigma, St. Louis, MO, USA) was adjusted to improve sensitivity. Semiquantitation to obtain composite toxicity was expressed as ng C-CTX1 equivalents $\cdot \mathrm{g}^{-1}$ fish tissue. Samples and C-CTX1 standard were analyzed in triplicate and 96-well plate (Corning Incorporated, Corning, NY, USA) format was used for the assay.

\subsection{LC-MS/MS Analysis}

An Agilent 1290 Infinity Liquid Chromatography system coupled to an Agilent 6495 Triple Quadrupole LC-MS (Agilent Technologies, Waldbronn, Germany) with iFunnel ionization was used to perform the LC-MS/MS analysis following the conditions described by [24]. Two different approaches were used:

A first method was used for CTXs identification and quantitation purposes: Poroshell 120 EC-C18 $\left(3.0 \times 50 \mathrm{~mm}, 2.7 \mu \mathrm{m}\right.$, Agilent, Waldbronn, Germany) column was used for CTXs separation at $40{ }^{\circ} \mathrm{C}$. The mobile phase for analysis consisted of: $5 \mathrm{mM}$ ammonium formate and $0.1 \%$ formic acid (Merck KGaA, Darmstadt, Germany) in water $\left(\mathrm{H}_{2} \mathrm{O}\right)$ (J. T. Baker, Center Valley, PA, USA) (A) and Methanol (MeOH) (Merck KGaA, Darmstadt, Germany) (B). Chromatographic separation was performed by gradient elution: Starting with $78 \%$ B to $88 \%$ B in 10 min holding for $5 \mathrm{~min}$, increased to $100 \%$ B at $15.01 \mathrm{~min}$ for columns washing holding for $3 \mathrm{~min}$ reducing to initial conditions at $18 \mathrm{~min}$ equilibrating for $4 \mathrm{~min}$ before the next analysis. The mobile phase flow rate was $0.4 \mathrm{~mL} \cdot \mathrm{min}^{-1}$ and the injection volume was $1 \mu \mathrm{L}$. The MS method operated in positive ionization mode monitoring $[\mathrm{M}+\mathrm{Na}]^{+}$as precursor and product ions with collision energy of $40 \mathrm{eV}$. Drying gas was set at $15 \mathrm{~L} \cdot \mathrm{min}^{-1}$ of $\mathrm{N}_{2}$ at $290{ }^{\circ} \mathrm{C}$; sheath gas flow, $12 \mathrm{~L} \cdot \mathrm{min}^{-1}$ of $\mathrm{N}_{2}$ at $400{ }^{\circ} \mathrm{C}$; nebulizer gas, $\mathrm{N}_{2}$ at $50 \mathrm{psi}$; capillary voltage, $5000 \mathrm{~V}$; nozzle voltage: $300 \mathrm{~V}$; fragmentor potential $380 \mathrm{~V}$. All analyses were performed in Multiple Reaction Monitoring (MRM) mode. CTXs were monitored as follows: CTX1B $(\mathrm{m} / \mathrm{z}$ 1133.6), C-CTX1 ( $\mathrm{m} / \mathrm{z}$ 1163.7), 2,3-dihydroxyCTX3C ( $m / z$ 1079.6), 51-hydroxyCTX3C ( $m / z$ 1061.6), 52-epi-54-deoxyCTX1B/54-deoxyCTX1B $(\mathrm{m} / z$ 1117.6),

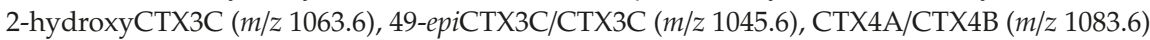

A second method was used for C-CTX1 confirmatory purposes and CTXs analogues identification: Poroshell 120 EC-C18 $(2.1 \times 100 \mathrm{~mm}, 2.7 \mu \mathrm{m}$, Agilent USA) column was used for CTXs separation at $40{ }^{\circ} \mathrm{C}$. The mobile phase for analysis consisted of: $5 \mathrm{mM}$ ammonium formate and $0.1 \%$ formic acid in $\mathrm{H}_{2} \mathrm{O}$ (A) and Acetonitrile (MeCN) (Merck KGaA, Darmstadt, Germany) (B). Chromatographic separation was performed by gradient elution: Starting with $35 \%$ B for 2 min, linear gradient to $80 \%$ B at $15 \mathrm{~min}$, increased to a $95 \% \mathrm{~B}$ at $16 \mathrm{~min}$, holding for $5 \mathrm{~min}$ and reducing afterward to $35 \% \mathrm{~B}$ at $24 \mathrm{~min}$ equilibrating for $4 \mathrm{~min}$ before the next analysis. The mobile phase flow rate was $0.4 \mathrm{~mL} \cdot \mathrm{min}^{-1}$ and the injection volume was $5 \mu \mathrm{L}$. The MS method operated in positive ionization mode monitoring water loss ions $\left(\left[\mathrm{M}+\mathrm{H}-\mathrm{nH}_{2} \mathrm{O}\right]^{+}\right)$and C-CTX1 fragments by MRM mode. MS/MS transitions, collision energy (CE) as well as Collision Acceleration Voltage (CAV) for each precursor/product ion are summarized in Table 2. Drying gas was set at $16 \mathrm{~L} \cdot \mathrm{min}^{-1}$ of $\mathrm{N}_{2}$ at $250{ }^{\circ} \mathrm{C}$; sheath gas flow, $12 \mathrm{~L} \cdot \mathrm{min}^{-1}$ of $\mathrm{N}_{2}$ at $400{ }^{\circ} \mathrm{C}$; 
nebulizer gas, $\mathrm{N}_{2}$ at 15 psi; capillary voltage, $5000 \mathrm{~V}$; nozzle voltage: $1000 \mathrm{~V}$; fragmentor potential $380 \mathrm{~V}$.

Author Contributions: A.G.-M. conceived the project. P.E., D.C. and A.P.-V. carried out the sample preparation. D.C. and A.P.-V. carried out the N2a cell assay. P.E. and J.M.L. performed the LC-MS/MS analysis. D.C., A.P.-V., O.V. and J.D. analyzed and revised the N2a cell assay data. P.E., J.M.L. and A.G.-M. analyzed the LC-MS/MS data. P.E. and A.G.-M. were involved in the preparation of the manuscript. A.G.-M. as corresponding author carried out the final revision of this manuscript.

Funding: This research was funded by the project EUROCIGUA: Risk characterization of ciguatera food poisoning in Europe, framework partnership agreement GP/EFSA/AFSCO/2015/03. P.E. acknowledges the financial support for the PhD studies, from Xunta de Galicia (Regional Government, Spain) under grant ED481A-2018/207. J.D. acknowledges the CERCA program from the Generalitat de Catalunya.

Acknowledgments: Takeshi Yasumoto (Japan Food Research Laboratories) for kindly providing standards of Pacific ciguatoxins. Robert Dickey (previously, U.S. Food and Drug Administration) via Ronald Manger (Fred Hutchinson Cancer Research Center, Seattle, USA) for kindly providing the standard of C-CTX1. The Health Directory of Canary Islands (Tenerife) for providing the fish sample.

Conflicts of Interest: The authors declare no conflict of interest.

\section{References}

1. Scheuer, P.J.; Takahashi, W.; Tsutsumi, J.; Yoshida, T. Ciguatoxin: Isolation and chemical nature. Science 1967, 155, 1267-1268. [CrossRef] [PubMed]

2. Yasumoto, T.; Murata, M. Marine toxins. Chem. Rev. 1993, 93, 1897-1909. [CrossRef]

3. Yasumoto, T.; Nakajima, I.; Bagnis, R.; Adachi, R. Finding of a Dinoflagellate as a Likely Culprit of Ciguatera. Nippon Suisan Gakkaishi 1977, 43, 1021-1026. [CrossRef]

4. Lewis, R.J.; Holmes, M.J. Origin and transfer of toxins involved in ciguatera. Comp. Biochem. Physiol. 1993, 106, 615-628. [CrossRef]

5. Suzuki, T.; Ha, D.V.; Uesugi, A.; Uchida, H. Analytical challenges to ciguatoxins. Curr. Opin. Food Sci. 2017, 18, 37-42. [CrossRef]

6. Murata, M.; Legrand, A.M.; Ishibashi, Y.; Yasumoto, T. Structures of ciguatoxin and its congener. J. Am. Chem. Soc. 1989, 111, 8929-8931. [CrossRef]

7. Yasumoto, T.; Igarashi, T.; Legrand, A.-M.; Cruchet, P.; Chinain, M.; Fujita, T.; Naoki, H. Structural elucidation of ciguatoxin congeners by fast-atom bombardment tandem mass spectroscopy. J. Am. Chem. Soc. 2000, 122, 4988-4989. [CrossRef]

8. Ikehara, T.; Kuniyoshi, K.; Oshiro, N.; Yasumoto, T. Biooxidation of Ciguatoxins Leads to Species-Specific Toxin Profiles. Toxins 2017, 9, 205. [CrossRef]

9. Oshiro, N.; Yogi, K.; Asato, S.; Sasaki, T.; Tamanaha, K.; Hirama, M.; Yasumoto, T.; Inafuku, Y. Ciguatera incidence and fish toxicity in Okinawa, Japan. Toxicon 2010, 56, 656-661. [CrossRef]

10. Yogi, K.; Oshiro, N.; Inafuku, Y.; Hirama, M.; Yasumoto, T. Detailed LC-MS/MS Analysis of Ciguatoxins Revealing Distinct Regional and Species Characteristics in Fish and Causative Alga from the Pacific. Anal. Chem. 2011, 83, 8886-8891. [CrossRef]

11. Sibat, M.; Herrenknecht, C.; Darius, H.T.; Roué, M.; Chinain, M.; Hess, P. Detection of pacific ciguatoxins using liquid chromatography coupled to either low or high resolution mass spectrometry (LC-MS/MS). J. Chromatogr. 2018, 1571, 16-28. [CrossRef] [PubMed]

12. Pottier, I.; Vernoux, J.-P.; Lewis, R.J. Ciguatera Fish Poisoning in the Caribbean Islands and Western Atlantic. In Reviews of Environmental Contamination and Toxicology: Continuation of Residue Reviews; Ware, G.W., Ed.; Springer: New York, NY, USA, 2001; pp. 99-141.

13. Vernoux, J.P.; Lewis, R.J. Isolation and characterisation of Caribbean ciguatoxins from the horse-eye jack (Caranx latus). Toxicon 1997, 35, 889-900. [CrossRef]

14. Lewis, R.J.; Vernoux, J.-P.; Brereton, I.M. Structure of Caribbean Ciguatoxin Isolated from Caranx latus. J. Am. Chem. Soc. 1998, 120, 5914-5920. [CrossRef]

15. Abraham, A.; Jester, E.L.E.; Granade, H.R.; Plakas, S.M.; Dickey, R.W. Caribbean ciguatoxin profile in raw and cooked fish implicated in ciguatera. Food Chem. 2012, 131, 192-198. [CrossRef] 
16. Loeffler, C.R.; Robertson, A.; Flores Quintana, H.A.; Silander, M.C.; Smith, T.B.; Olsen, D. Ciguatoxin prevalence in 4 commercial fish species along an oceanic exposure gradient in the US Virgin Islands. Environ. Toxicol. Chem. 2018, 37, 1852-1863. [CrossRef] [PubMed]

17. Pottier, I.; Vernoux, J.-P.; Jones, A.; Lewis, R.J. Characterisation of multiple Caribbean ciguatoxins and congeners in individual specimens of horse-eye jack (Caranx latus) by high-performance liquid chromatography/mass spectrometry. Toxicon 2002, 40, 929-939. [CrossRef]

18. Pottier, I.; Hamilton, B.; Jones, A.; Lewis, R.J.; Vernoux, J.P. Identification of slow and fast-acting toxins in a highly ciguatoxic barracuda (Sphyraena barracuda) by HPLC/MS and radiolabelled ligand binding. Toxicon 2003, 42, 663-672. [CrossRef]

19. Ciguatoxin Group. Pannel on Contaminants in the Food Chain Scientific Opinion on marine biotoxins in shellfish-Emerging toxins. EFSA J. 2010, 8, 1627.

20. Otero, P.; Pérez, S.; Alfonso, A.; Vale, C.; Rodríguez, P.; Gouveia, N.N.; Gouveia, N.; Delgado, J.; Vale, P.; Hirama, M.; et al. First Toxin Profile of Ciguateric Fish in Madeira Arquipelago (Europe). Anal. Chem. 2010, 82, 6032-6039. [CrossRef]

21. Boada, L.D.; Zumbado, M.; Luzardo, O.P.; Almeida-González, M.; Plakas, S.M.; Granade, H.R.; Abraham, A.; Jester, E.L.E.; Dickey, R.W. Ciguatera fish poisoning on the West Africa Coast: An emerging risk in the Canary Islands (Spain). Toxicon 2010, 56, 1516-1519. [CrossRef]

22. Costa, P.R.; Estevez, P.; Castro, D.; Soliño, L.; Gouveia, N.; Santos, C.; Rodrigues, S.M.; Leao, J.M.; Gago-Martínez, A. New Insights into the Occurrence and Toxin Profile of Ciguatoxins in Selvagens Islands (Madeira, Portugal). Toxins 2018, 10, 524. [CrossRef]

23. Moreiras, G.; Leão, J.M.; Gago-Martínez, A. Design of experiments for the optimization of electrospray ionization in the LC-MS/MS analysis of ciguatoxins. J. Mass. Spectrom. 2018, 53, 1059-1069. [CrossRef]

24. Estevez, P.; Castro, D.; Leao, J.M.; Yasumoto, T.; Dickey, R.; Gago-Martinez, A. Implementation of liquid chromatography tandem mass spectrometry for the analysis of ciguatera fish poisoning in contaminated fish samples from Atlantic coasts. Food Chem. 2019, 280, 8-14. [CrossRef] [PubMed]

25. Caillaud, A.; Eixarch, H.; de la Iglesia, P.; Rodriguez, M.; Dominguez, L.; Andree, K.B.; Diogène, J. Towards the standardisation of the neuroblastoma (neuro-2a) cell-based assay for ciguatoxin-like toxicity detection in fish: Application to fish caught in the Canary Islands. Food Addit. Contam. Part 2012, 29, 1000-1010. [CrossRef] [PubMed]

26. Dickey, R.W.; Plakas, S.M. Ciguatera: A public health perspective. Toxicon 2010, 56, 123-136. [CrossRef]

27. Manger, R.L.; Leja, L.S.; Lee, S.Y.; Hungerford, J.M.; Wekell, M.M. Tetrazolium-Based Cell Bioassay for Neurotoxins Active on Voltage-Sensitive Sodium Channels: Semiautomated Assay for Saxitoxins, Brevetoxins, and Ciguatoxins. Anal. Biochem. 1993, 214, 190-194. [CrossRef] [PubMed]

28. Manger, R.L.; Leja, L.S.; Lee, S.Y.; Hungerford, J.M.; Hokama, Y.; Dickey, R.W.; Granade, H.R.; Lewis, R.; Yasumoto, T.; Wekell, M.M. Detection of sodium channel toxins: Directed cytotoxicity assays of purified ciguatoxins, brevetoxins, saxitoxins, and seafood extracts. J. AOAC Int. 1995, 78, 521-527.

(C) 2019 by the authors. Licensee MDPI, Basel, Switzerland. This article is an open access article distributed under the terms and conditions of the Creative Commons Attribution (CC BY) license (http://creativecommons.org/licenses/by/4.0/). 
Article

\title{
New Insights into the Occurrence and Toxin Profile of Ciguatoxins in Selvagens Islands (Madeira, Portugal)
}

\author{
Pedro Reis Costa ${ }^{1}$, Pablo Estevez ${ }^{2}$, David Castro ${ }^{2}$, Lucía Soliño ${ }^{1}$, Neide Gouveia ${ }^{3}$, \\ Carolina Santos ${ }^{4}$, Susana Margarida Rodrigues ${ }^{1}$, José Manuel Leao ${ }^{2}$ and Ana Gago-Martínez ${ }^{2, *}$ \\ 1 IPMA-Portuguese Institute of the Sea and Atmosphere, Av. Brasília, 1449-006 Lisbon, Portugal; \\ prcosta@ipma.pt (P.R.C.); lucia.solino@ipma.pt (L.S.); srodrigues@ipma.pt (S.M.R.) \\ 2 Faculty of Chemistry, Department of Analytical and Food Chemistry, University of Vigo, Campus \\ Universitario de Vigo, 36310 Vigo, Spain; paestevez@uvigo.es (P.E.); dcastro@uvigo.es (D.C.); \\ leao@uvigo.es (J.M.L.) \\ 3 Regional Fisheries Management-Madeira Government, DSI-DRP, Estrada da Pontinha 9004-562 Funchal, \\ Madeira, Portugal; neide.gouveia@madeira.gov.pt \\ 4 Instituto das Florestas e Conservação da Natureza, IP-RAM, Secretaria Regional do Ambiente e Recursos \\ Naturais, Regional Government of Madeira, IFCN IP-RAM, Quinta Vila Passos-Rua Alferes \\ Veiga Pestana 15, 9054-505 Funchal, Madeira, Portugal; carolinasantos@gov-madeira.pt \\ * Correspondence: anagago@uvigo.es
}

Received: 5 November 2018; Accepted: 5 December 2018; Published: 7 December 2018

\begin{abstract}
Ciguatoxins (CTXs), endemic from tropical and subtropical regions of the Pacific and Indian Ocean and the Caribbean Sea, have caused several human poisonings during the last decade in Europe. Ciguatera fish poisonings (CFP) in Madeira and Canary Islands appear to be particularly related with consumption of fish caught close to Selvagens Islands, a Portuguese natural reserve composed of three small islands that harbor high fish biomass. In this study, fish specimens considered as potential vectors of CTXs were caught in Madeira and Selvagens archipelagos for toxins determination via sensitive liquid chromatography with tandem mass spectrometry detection (LC-MS/MS). CTXs were found in most of the fish samples from Selvagens and none from Madeira. Caribbean ciguatoxin-1 (C-CTX1) was the only toxin congener determined, reaching the highest value of $0.25 \mu \mathrm{g}$ C-CTX1 $\mathrm{kg}^{-1}$ in a $4.6 \mathrm{~kg}$ island grouper (Mycteroperca fusca). This study indicates that a diversity of fish from different trophic levels contains CTXs, Selvagens appear to be one of the most favorable locations for CTXs food web transfer and finally, this study highlights the need of further research based on intensive environmental and biological sampling on these remote islands.
\end{abstract}

Keywords: ciguatera fish poisoning; gambierdiscus; seafood safety; C-CTX-1

Key Contribution: Caribbean ciguatoxin- 1 can be frequently detected in fish from Selvagens Islands, Portugal.

\section{Introduction}

Ciguatera fish poisoning (CFP) is a human food-borne illness caused by consumption of tropical and subtropical fishes harboring ciguatoxins (CTXs). Coral reef fish are frequently reported to accumulate CTXs, which are products of fish metabolism resulting from biotransformation of precursor compounds produced by the benthic dinoflagellates, Gambierdiscus and Fukuyoa, and transferred through the marine food web [1-3].

CTXs have been classified according to their geographic distribution through tropical regions, as Pacific (P), Caribbean (C) and Indian Ocean (I) CTXs-group toxins. CTXs are lipophilic polyether compounds consisting of 13 or 14 ether rings forming a ladder-like structure, being known up to 40 
CTXs congeners [4]. CTXs are highly potent neurotoxins that act at voltage gated sodium channels (VGSC) increasing sodium ion permeability and cell disruption [5,6]. Humans affected by CTXs revealed a wide range of gastrointestinal (abdominal pain, nausea, vomiting, diarrhea), neurological (allodynia-burning pain caused by cold stimulus-, parestesia, dysesthesia) and cardiovascular symptoms (bradycardia, hypotension) [7,8]. The neurological symptoms may persist from weeks to months, or in cases without the appropriate treatment may become chronic [9]. In severe cases, CTXs can be fatal [10].

Possibly related to structural differences of CTXs congeners among regions, differences in human symptoms have been observed in outbreaks occurring in the Caribbean, Indian and Pacific Ocean. While neurological symptoms are highly dominant in the Pacific, gastrointestinal disorders are frequently reported in the initial phases of intoxications in the Caribbean, which may then be followed by neurological symptoms. In the Indian Ocean, neurological symptoms have also included hallucinations [11,12].

In Europe, CFP has been mainly seen as an issue of travellers to endemic regions, or resulting from consumption of toxic fish imported from tropical areas $[13,14]$. Therefore, legal framework in the EU is scarce, without regulatory limits imposed for CTXs-group toxins. In order to prevent the imports of toxic fish from endemic regions the EU legislation states that fishery products containing biotoxins, such as ciguatoxin or muscle-paralysing toxins must not be placed on the market $[15,16]$. Relatively recently, a paradigm shift had occurred after several human CFP outbreaks in the Spanish and Portuguese Atlantic islands of Canary, Madeira and Selvagens archipelagos. In 2004, five individuals suffered from gastrointestinal and neurological disorders, consistent with CFP, after consumption of amberjack Seriola rivoliana, weighing $26 \mathrm{~kg}$, captured by scuba divers along the coast of the Canary Islands [17]. The first outbreak in Portugal occurred in 2008, when 11 crew members of a fishing boat reported CFP symptoms after consumption of amberjack (30 kg) caught around Selvagens Islands $[18,19]$. In the same year, 20-30 people reported CFP symptoms after consuming amberjack purchased in the markets of the Canary Islands but caught close to Selvagens Islands [20].

Subsequent episodes led local and European authorities to take into consideration a new emerging risk of food poisoning. A monitoring program for detection of CTXs by cell based assays was implemented in the Canary Islands and restrictions to fisheries have been implemented in Madeira and Selvagens archipelagos. A panel of experts of the European Food Safety Authority (EFSA) stated a scientific opinion on the risk to human health related to the consumption of ciguatoxins in fish and emphasized the need for more data including data on the occurrence of CTXs in fish from European waters [21]. In addition, more recently a pan-European project was co-funded by EFSA to improve the risk characterization of CFP in Europe [22].

This study aims to (1) investigate the presence of CTXs in Portuguese waters by comparing CTXs occurrence in fish caught in Madeira and Selvagens Islands, and (2) to determine the CTXs profile in contaminated fish by sensitive liquid chromatography with tandem mass spectrometry detection (LC-MS/MS).

\section{Results}

Caribbean ciguatoxin-1 (C-CTX1) was detected by LC-MS/MS in eight out of 11 samples from Selvagens Islands while no CTXs were detected in any of the samples analyzed from Madeira Island. An example of the results obtained is shown in Figure 1. The retention time and transitions $m / z 1163.7 \rightarrow m / z 1163.7$ of C-CTX1 precursor $\rightarrow$ product ion in the evaluated samples were consistent with the ones found for the pure standard of C-CTX1. Some interfering peaks were also detected, which could be associated to Pacific ciguatoxins (P-CTXs) based on the similar $m / z$ and precursor/product ion transition, nevertheless, the retention times did not match with the ones found for the standard solutions of these P-CTXs analogues. 


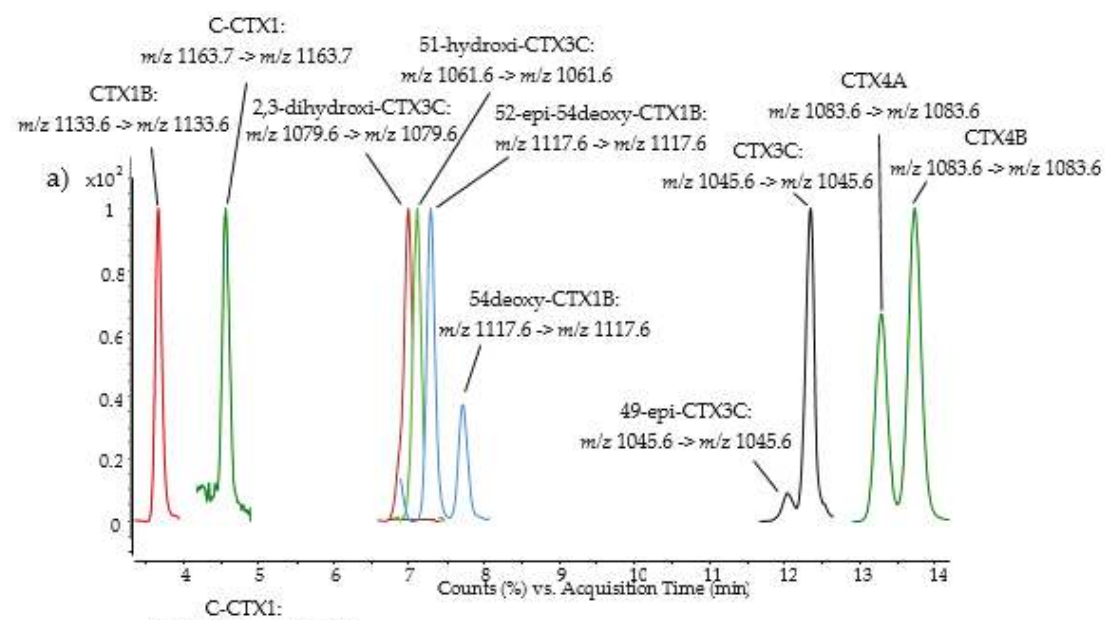

b)

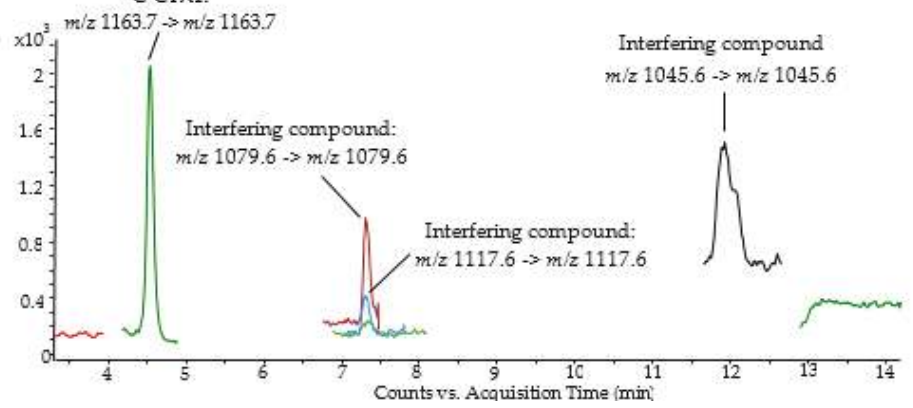

Figure 1. Sensitive liquid chromatography with tandem mass spectrometry detection (LC-MS/MS) chromatogram in Multiple Reaction Monitoring (MRM) mode of (a) a mixture of P-CTXs and C-CTX1 standard solution, and (b) CTXs profile in a sample of fish tissue (Island Grouper) from Selvagens Islands.

C-CTX1 was detected in fish of different size ranges and different trophic levels (Table 1). Due to the limited amount of C-CTX1 pure standard, C-CTX1 content was expressed in CTX1B equivalents and samples where C-CTX1 was detected were quantified as CTX1B and converted to C-CTX1 equivalents taking into account the conversion factor previously obtained for the pure standard of C-CTX1. Calibration was therefore carried out by using the pure standard of CTX1B in the concentration range of $0.28-27.88 \mathrm{ng} \mathrm{mL}^{-1}\left(n=5, R^{2}=0.999\right)$. Limits of detection $(\mathrm{S} / \mathrm{N}>3)$ and quantitation $(\mathrm{S} / \mathrm{N}>10)$ were of 0.0045 and $0.0150 \mathrm{ng} \mathrm{g}^{-1}$ in matrix matched samples spiked with CTX1B standard solution. The highest concentration level, reaching $0.25 \mu \mathrm{g} \mathrm{C-CTX1} \mathrm{kg}{ }^{-1}$, was determined in a $4.5 \mathrm{~kg}$ Island Grouper (sample 4), followed by a $1.6 \mathrm{~kg}$ Barred Hogfish (sample 6), which contained $0.11 \mu \mathrm{g}$ C-CTX1 $\mathrm{kg}^{-1}$. The toxin concentration determined in the $>19 \mathrm{~kg}$ top predator and known vector of CTX,

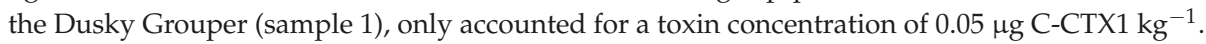


Table 1. Concentration of ciguatoxins (C-CTX1) determined in fish flesh from Selvagens Islands.

\begin{tabular}{cccc}
\hline Sample ID & Species & Common Name & C-CTX1 $\left(\boldsymbol{\mu g} \mathbf{~ k g}^{-\mathbf{1}}\right)$ \\
\hline S1 & Epinephelus marginatus & Dusky grouper & 0.05 \\
S2 & Bodianus scrofa & Barred hogfish & $<$ LOQ \\
S3 & Balistes capriscus & Grey triggerfish & $<$ LOQ \\
S4 & Mycteroperca fusca & Island grouper & 0.25 \\
S5 & Serranus atricauda & Blacktail comber & $<$ LOQ \\
S6 & B. scrofa & Barred hogfish & 0.11 \\
S7 & B. scrofa & Barred hogfish & 0.06 \\
S8 & B. capriscus & Grey triggerfish & 0.03 \\
S9 & Kyphosus sectatrix & Bermuda sea chub & $<$ LOD \\
S10 & K. sectatrix & Bermuda sea chub & $<$ LOD \\
S11 & Sphyraena viridensis & Yellowmouth barracuda & $<$ LOD \\
\hline LOQ & & &
\end{tabular}

\section{Discussion}

Several outbreaks reported in the Canary Islands since 2004 derived from consumption of fish caught close to the Selvagens Islands [20]. The cause of CFP in Portuguese waters has also been related to contaminated fish from Selvagens [18,19]. In the present study, CTXs was not detected in samples caught along the Madeira Island coast but were detected in most fish samples obtained from the further south Selvagens Islands. With the data available at the present day, reinforced with results of this study, one may argue that Selvagens islands are a hotspot of CTXs in Europe.

In this study, Caribbean CTXs was detected not only in top predators, as is the big size $>19 \mathrm{~kg}$ dusky grouper, Epinephelus marginatus, but also in smaller sized fish from intermediate levels of the trophic chain. The highest concentration was registered in a $4.5 \mathrm{~kg}$ Island grouper (Mycteroperca fusca). This species is a near rocky or sandy-rocky sea-beds inhabitant that preys on fish, crustaceans, and cephalopods. Its abundance has been positively correlated with upright seaweed cover, and individuals may reach a longevity of 30 to 40 years and up to $7.8 \mathrm{~kg}$ [23]. It is common to associate higher CFP risk with larger fish and indeed, fishing amberjacks in Madeira is restricted to specimens not exceeding $10 \mathrm{~kg}$. However, in addition to the fish size, longevity should also be considered. While island grouper may not reach a similar high size/weight as amberjacks, this species may live longer to accumulate high CTXs levels. In fact, after the first report of CFP in Portugal, due to consumption of $30 \mathrm{~kg}$ amberjack by crew members of a fishing boat, CFP was retrospectively identified in nature wardens of Selvagens Islands Nature Reserve that consumed parrotfish (Sparissoma cretense), blacktail comber (Serranus atricauda), barred hogfish (Bodianus scrofa), grey triggerfish (Balistes capriscus) and red porgy (Pagrus pagrus) and suffered from neurological disorders between 2 and 6 weeks [18]. However, LC-MS/MS analyses for the detection of CTXs had never been carried out in these fish species from Selvagens until the present study.

While several CTXs congeners have been indicated by [19] in fish caught from Selvagens after the 2008 incident, in the present study only C-CTX1 was detected, which is in agreement with the toxin profile described by [20] during outbreaks in Canary islands and it is typically observed in the Caribbean Sea [24]. Further studies need to be carried out to confirm the presence of other CTXs congeners, having in mind that LC-MS/MS analysis of CTXs is complex and interfering compounds leading to misidentification may occur. This fact was observed in some samples of pink dentex from Madeira (samples M3 to M5), which contained an interfering compound that was initially misidentified as a potential CTXs analogue.

According to EU directives, there are no limits for CTXs in fish, but the presence of CTXs as determined by any detection method is enough to ban the fishery products from the markets $[15,16]$. However, the toxic potential of C-CTX1 is assumed to be lower than most of other CTXs congeners, in particular to those from Pacific Ocean. EFSA stated that until better data is available, the following toxicity equivalency factors (TEFs) should be used to express fish toxicity as CTX1B equivalents: 
CTX1B $=1$ and C-CTX1 $=0.1$ [21]. EFSA estimates that fish containing $0.1-5 \mu \mathrm{g}$ CTX1B kg ${ }^{-1}$ has been related with cases of CFP and that a concentration of $0.01 \mu \mathrm{g} \mathrm{CTX} 1 \mathrm{~B} \mathrm{~kg}{ }^{-1}$ of fish is a level expected to not exert effects in sensitive consumers. In the present study, the highest concentrations reached in sample S4 and S6 are, according to EFSA, as well as according to the guidance levels established by the Food and Drug Administration (FDA) of the USA, low and around the safety levels respectively.

\section{Conclusions}

The evaluation of the risk of CFP in Europe is a very challenging task for scientists, seafood safety authorities and environmental managements. There are still unresolved issues related to the toxicology of the different CTXs analogues and metabolites, as well as with analytical methods, in particular due to the lack of reference materials, seasonal and spatial variability of toxin vectors and of the toxin precursor producers.

This study highlights Selvagens Islands as a key location to carry out studies on CFP incidence as an example of the emergence of this toxin in the EU coasts. Indeed, Selvagens may be used as a sentinel site for comparative CTXs occurrence in the Canary Islands and even Madeira. Selvagens Islands are a healthy ecosystem where fishing pressure is minimal, thereby fish may grow and reach high longevity and consequently harbor greater levels of CTXs. However, further studies involving intensive sampling in these remote Islands should be carried out to understand the Gambierdiscus dynamics, the toxin transfer in the food web and fish toxin metabolism.

\section{Materials and Methods}

\subsection{Madeira and Selvagens Islands}

Selvagens Islands are a very remote and isolated group of Portuguese oceanic islands, located in the Northeastern Atlantic, $293 \mathrm{~km}$ southeast from Madeira Island, Portugal, $180 \mathrm{~km}$ north from Tenerife Island, Spain and $600 \mathrm{~km}$ west from the African coast (Figure 2). They are comprised of three islands of volcanic origin: Selvagem Grande, Selvagem Pequena and Ilhéu de Fora, and several islets, shaped specially by marine abrasion. Classified as a nature reserve in 1971, with a total marine area of $92 \mathrm{~km}^{2}$ and included within the Natura 2000 Network, with a total marine area of $1242 \mathrm{~km}^{2}$, the biodiversity of the Selvagens Islands has greatly benefitted from this protection and the successive conservation action, being an example of a high coastal species diversity occurring even in very small areas of the northeastern Atlantic Ocean.

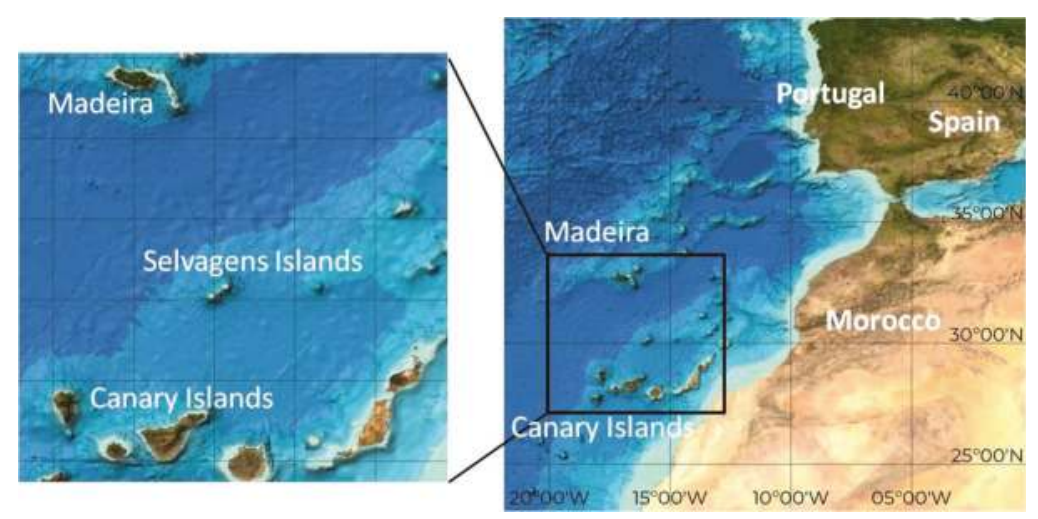

Figure 2. Location of Selvagens Islands (Madeira, Portugal).

Selvagens have been designated by National Geographic Society as one of the pristine sites in the oceans today [25]. Human pressure is very low in Selvagens, where limited number of visitors 
is allowed each year. In contrast, Madeira Island is heavily populated and a high popular tourism destination. As a result of the remote location of Selvagens Islands and the high anthropogenic pressures at Madeira, total fish biomass was estimated to be 3.2 times higher at Selvagens than at Madeira, and when considering only the fish top predators biomass it reach values 10 times higher at Selvagens [26]. Previous studies describing the marine fish diversity found that $34.1 \%$ of the ichthyofauna observed in Selvagens also occurs in the Canary Islands and 47.3\% in Madeira Island [27].

\subsection{Fish Samples}

Specimens of fish species previously identified as vectors or potentially vectors of CTXs and representative of different trophic levels from both Madeira and Selvagens Islands were opportunistically obtained for this study (Table 2). A portion of fish flesh (>100 g) were dissected from muscle close to fish head and stored at $-20^{\circ} \mathrm{C}$ until analysis.

Table 2. Biological and biometric parameters of the fish sample obtained from Selvagens and Madeira Islands for CTXs analysis.

\begin{tabular}{|c|c|c|c|c|c|c|c|c|}
\hline Sample ID & Species & $\begin{array}{l}\text { Common } \\
\text { Name }\end{array}$ & $\begin{array}{c}\text { Feeding Habits } \\
\qquad(\mathrm{H} / \mathrm{C}) \ddagger\end{array}$ & Weight (g) & $\begin{array}{l}\text { Total Length } \\
\quad(\mathrm{mm})\end{array}$ & $\begin{array}{l}\text { Fork Length } \\
\text { (mm) }\end{array}$ & $\begin{array}{c}\text { Gender } \\
\text { (Maturity Stage } \\
\S \text { ) }\end{array}$ & $\begin{array}{l}\text { Capture Date } \\
\text { (mm/dd/yy) }\end{array}$ \\
\hline & \multicolumn{8}{|c|}{ Selvagens Islands } \\
\hline $\mathrm{S} 1$ * & $\begin{array}{l}\text { Epinephelus } \\
\text { marginatus }\end{array}$ & $\begin{array}{l}\text { Dusky } \\
\text { grouper }\end{array}$ & C & 19,500 & 970 & - & - & $12 / 13 / 16$ \\
\hline $\mathrm{S} 2 *$ & $\begin{array}{l}\text { Bodianus } \\
\text { scrofa }\end{array}$ & $\begin{array}{l}\text { Barred } \\
\text { hogfish }\end{array}$ & $\mathrm{C}$ & 2362 & 510 & - & $F(-)$ & $12 / 13 / 16$ \\
\hline $\mathrm{S} 3$ * & $\begin{array}{c}\text { Balistes } \\
\text { capriscus }\end{array}$ & $\begin{array}{c}\text { Grey } \\
\text { triggerfish }\end{array}$ & C & 2208 & 500 & 462 & M (-) & $12 / 13 / 16$ \\
\hline $\mathrm{S} 4$ * & $\begin{array}{c}\text { Mycteroperca } \\
\text { fusca }\end{array}$ & $\begin{array}{l}\text { Island } \\
\text { grouper }\end{array}$ & $\mathrm{C}$ & 4533 & 690 & 657 & $\mathrm{M}(-)$ & $12 / 13 / 16$ \\
\hline $\mathrm{S}^{*}$ & $\begin{array}{l}\text { Serranus } \\
\text { atricauda }\end{array}$ & $\begin{array}{l}\text { Blacktail } \\
\text { comber }\end{array}$ & C & 810 & 380 & - & $F(-)$ & $12 / 13 / 16$ \\
\hline S6 & B. scrofa & $\begin{array}{l}\text { Barred } \\
\text { hogfish }\end{array}$ & $\mathrm{C}$ & 1652 & 440 & - & - & $11 / 28 / 17$ \\
\hline S7 & B. scrofa & $\begin{array}{l}\text { Barred } \\
\text { hogfish }\end{array}$ & $\mathrm{C}$ & 770 & 350 & - & $\mathrm{F}(2)$ & $11 / 28 / 17$ \\
\hline S8 & B. capriscus & $\begin{array}{c}\text { Grey } \\
\text { triggerfish }\end{array}$ & $\mathrm{C}$ & 1966 & 444 & 425 & $\mathrm{~F}(5)$ & $11 / 28 / 17$ \\
\hline S9 & $\begin{array}{l}\text { Kyphosus } \\
\text { sectatrix }\end{array}$ & $\begin{array}{c}\text { Bermuda sea } \\
\text { chub }\end{array}$ & $\mathrm{H}$ & 2286 & 531 & 477 & $\mathrm{~F}(5)$ & $11 / 28 / 17$ \\
\hline $\mathrm{S} 10$ & K. sectatrix & $\begin{array}{c}\text { Bermuda sea } \\
\text { chub }\end{array}$ & $\mathrm{H}$ & 492 & 315 & 277 & $\mathrm{~F}(2)$ & $11 / 28 / 17$ \\
\hline \multirow[t]{2}{*}{ S11 } & $\begin{array}{l}\text { Sphyraena } \\
\text { viridensis }\end{array}$ & Barracuda & $\mathrm{C}$ & 1564 & - & - & M (5) & $11 / 28 / 17$ \\
\hline & \multicolumn{8}{|c|}{ Madeira Island } \\
\hline M1 & $\begin{array}{c}\text { Seriola } \\
\text { rivoliana }\end{array}$ & $\begin{array}{l}\text { Longfin } \\
\text { yellowtail }\end{array}$ & C & 22,644 & 1234 & 1080 & M (5) & $01 / 19 / 17$ \\
\hline M2 * & $\begin{array}{c}\text { Makira } \\
\text { nigricans }\end{array}$ & Blue marlin & C & 298,000 & - & 3150 & - & $01 / 06 / 17$ \\
\hline M3 & $\begin{array}{l}\text { Dentex } \\
\text { gibbosus }\end{array}$ & Pink dentex & C & 7539 & 850 & 751 & M (5) & $10 / 12 / 17$ \\
\hline M4 & D. gibbosus & Pink dentex & C & 7841 & 859 & 768 & M (5) & $10 / 12 / 17$ \\
\hline M5 & D. gibbosus & Pink dentex & $\mathrm{C}$ & 8097 & 846 & 745 & $\mathrm{~F}(5)$ & $10 / 12 / 17$ \\
\hline M6 & $\begin{array}{c}\text { Seriola } \\
\text { dumerili }\end{array}$ & $\begin{array}{c}\text { Greater } \\
\text { amberjack }\end{array}$ & C & 20,117 & 1232 & 1090 & M (5) & $10 / 12 / 17$ \\
\hline M7 & S. dumerili & $\begin{array}{c}\text { Greater } \\
\text { amberjack }\end{array}$ & C & 31,480 & 1390 & 1221 & M (5) & $10 / 12 / 17$ \\
\hline M8 & $\begin{array}{l}\text { Sphyrna } \\
\text { zygaena }\end{array}$ & $\begin{array}{c}\text { Smooth } \\
\text { hammerhead }\end{array}$ & C & 10,297 & 1360 & - & $\mathrm{M}(-)$ & $10 / 12 / 16$ \\
\hline M9* & $\begin{array}{l}\text { Isurus } \\
\text { oxyrinchus }\end{array}$ & $\begin{array}{l}\text { Shortfin } \\
\text { mako }\end{array}$ & C & 67,000 & - & - & - & $06 / 10 / 16$ \\
\hline
\end{tabular}

* provided by the maritime authority, confiscated due to illegal fishing. $\ddagger \mathrm{H}$-herbivorous; C-carnivorous.

$\S$ Maturity scale adapted from [28].

\subsection{Reagents}

Acetone, diethyl ether, methanol, water, hexane and ethyl acetate used for ciguatoxins extraction and purification were of HPLC grade (Merck KGaA, Darmstadt, Germany). Methanol, formic acid, ammonium formiate (Merck KGaA, Darmstadt, Germany) and water (J. T. Baker, Center Valley, PA, USA) were of LC-MS grade.

Pure standard solution of CTX1B, a mixture of Pacific Ciguatoxins standard solution containing CTX1B， 2,3-dihydroxi-CTX3C， 51-hydroxi-CTX3C， 52-epi-54-deoxy-CTX1B/54-deoxy-CTX1B, 
49-epi-CTX3C/CTX3C, CTX4A/CTX4B were kindly supplied by Prof. Takeshi Yasumoto (Japan Food Research Laboratories). C-CTX1 pure standard solution was kindly provided by Dr. Robert Dickey (previously, U.S. Food and Drug Administration) via Dr. Ronald Manger (Fred Hutchinson Cancer Research Center, Seattle, USA).

\subsection{Ciguatoxins Extraction}

CTXs sample pretreatment was carried out following the conditions proposed by [29] with modifications [30,31], briefly: Fish flesh samples (15 g) were extracted twice by homogenizing $2 \mathrm{~min}$ at $9000 \mathrm{rpm}$ in $45 \mathrm{~mL}$ of acetone (Ultra Turrax ${ }^{\circledR} \mathrm{T} 25$ basic IKA ${ }^{\circledR}$ WERKE, Staufen, Germany). The combined extracts were concentrated to an aqueous residue and extracted twice with $15 \mathrm{~mL}$ of diethyl ether and further evaporated to dryness. The organic residue was dissolved in $4.5 \mathrm{~mL} 90 \%$ $\mathrm{MeOH}$ and defatted with $9 \mathrm{~mL}$ of hexane evaporating the aqueous layer using a multievaporator under reduced pressure (Syncore ${ }^{\circledR}$ Polyvap, Barcelona, Spain). The remaining solid residue was dissolved in $2 \mathrm{~mL}$ of ethyl acetate and further purified through a solid phase extraction (SPE) cleanup including two different SPE mechanisms. The first normal phase Florisil SPE was used to remove polar interferences whereas non-polar and semipolar interferences were removed by using C18 SPE reverse phase. Cleanup conditions are described as follows: The $2 \mathrm{~mL}$ of ethyl acetate extract from extraction were passed through a Florisil cartridge (J. T. Baker, $500 \mathrm{mg}$, Center Valley, PA, USA) conditioned with $3 \mathrm{~mL}$ of ethyl acetate, and washed consecutively, with $3 \mathrm{~mL}$ of ethyl acetate and $5 \mathrm{~mL}$ of ethyl acetate-methanol (9:1) and ethyl acetate-methanol (3:1) [32]. Previous work carried out by this group on the optimization on the sample pretreatment for the LC-MS/MS analysis of CTXs allowed to conclude that the toxin mainly elutes in the second fraction with a recovery around $80 \%$ [30]. The residue containing the toxin was further dried under nitrogen at $50{ }^{\circ} \mathrm{C}$ and then dissolved in $2 \mathrm{~mL}$ of $\mathrm{MeOH}$ $60 \%$ and applied to a C18 cartridge (SUPELCLEAN, Supelco, $500 \mathrm{mg}$, Bellefonte, PA, USA) conditioned with $3 \mathrm{~mL}$ of $\mathrm{MeOH} 60 \%$. The cartridge was washed with $3 \mathrm{~mL}$ of $\mathrm{MeOH} 60 \%$ and CTXs were eluted with $5 \mathrm{~mL}$ of $\mathrm{MeOH} 90 \%$. The final eluate was dried and dissolved in $0.5 \mathrm{~mL}$ of $\mathrm{MeOH}$ LC-MS grade filtering (Syringe Driver filter Unit, Millex ${ }^{\circledR}$-CV 0.22 um, 13 mm, Millipore, Billerica, MA, USA) prior to LC-MS analysis.

\subsection{LC-MS/MS Analysis}

LC-MS/MS analysis was carried out following [29] conditions with modifications introduced in the LC-MS instrument in order to improve sensitivity [30,31]. LC-MS/MS analyses were performed by using an Agilent 1290 Infinity LC system coupled to an Agilent 6495 Triple Quadrupole LC-MS (Agilent Technologies, Waldbronn, Germany) equipped with an Agilent Jet Stream electrospray ionization source (iFunnel).

Analytes were separated in a Poroshell 120 EC-C18 $(3.0 \times 50 \mathrm{~mm}, 2.7 \mu \mathrm{m}$, Agilent Technologies, Waldbronn, Germany) with column temperature set at $40{ }^{\circ} \mathrm{C}$. LC mobile phase was: $5 \mathrm{mM}$ ammonium formate and $0.1 \%$ formic acid in water (A) and $\mathrm{MeOH}(\mathrm{B})$. Gradient used was 78\% B to $88 \%$ B in $10 \mathrm{~min}$ and held for $5 \mathrm{~min}$, increased to $100 \% \mathrm{~B}$ at $15.01 \mathrm{~min}$ and held $3 \mathrm{~min}$ returning to $78 \% \mathrm{~B}$ at $18 \mathrm{~min}$, and $4 \mathrm{~min}$ of equilibration before the next injection. The injection volume was $1 \mu \mathrm{L}$ and the flow rate $0.4 \mathrm{~mL} / \mathrm{min}$. The mass spectrometer was operated in positive mode monitoring $[\mathrm{M}+\mathrm{Na}]^{+}$as precursor and product ions with collision energy of $40 \mathrm{eV}$. This approach allows a sensitive detection of the CTXs compared to other strategies that monitor CTXs water losses $[33,34]$. The selection of a single stable $[\mathrm{M}+\mathrm{Na}]^{+}$as precursor ion, with high collision energy and methanol as mobile phase, allows the removal of the background noise monitoring the same $[\mathrm{M}+\mathrm{Na}]^{+}$as product ion without any additional fragmentation due to the high stability of this adduct under the above mentioned conditions.

LC-MS/MS system settings were: Drying gas, $15 \mathrm{~L} \mathrm{~min}^{-1}$ of $\mathrm{N}_{2}$ at $290{ }^{\circ} \mathrm{C}$; sheath gas flow, $12 \mathrm{~L} \mathrm{~min}^{-1}$ of $\mathrm{N}_{2}$ at $400{ }^{\circ} \mathrm{C}$; nebulizer gas, $\mathrm{N}_{2}$ at $50 \mathrm{psi}$; capillary voltage, $5000 \mathrm{~V}$; nozzle voltage: $300 \mathrm{~V}$; fragmentor potential $380 \mathrm{~V}$. CTXs were monitored by MRM as follows: CTX1B $(\mathrm{m} / z$ z 1133.6 -> $m / z$ 1133.6), C-CTX1 ( $m / z 1163.7$-> m/z 1163.7), 2,3-dihydroxi-CTX3C $(m / z 1079.6$-> m/z 1079.6), 
51-Hydroxi-CTX3C ( $m / z$ 1061.6 -> m/z 1061.6), 52epi-54deoxy-CTX1B/54deoxy-CTX1B $(m / z 1117.6$ $\rightarrow m / z$ 1117.6), 49-epi-CTX3C/CTX3C (m/z 1045.6 -> m/z 1045.6), CTX4A/CTX4B $(m / z 1083.6$-> $m / z$ 1083.6).

Author Contributions: P.R.C. and A.G.-M. conceived the project. N.G. and C.S. designed the sampling plan. P.E., D.C., and L.S. carried out the sample preparation, P.E. and J.M.L. performed the LC-MS/MS analysis. P.R.C., S.M.R., J.M.L., A.G.-M. were involved in data analysis and interpretation, and all authors were involved in the manuscript preparation and writing. A.G.-M. as corresponding author carried out the final revision of this manuscript.

Funding: This research was funded by the project EUROCIGUA: Risk characterization of ciguatera food poisoning in Europe, framework partnership agreement GP/EFSA/AFSCO/2015/03. P.E. acknowledges the financial support for the PhD studies, from Xunta de Galicia (Regional Government, Spain) under grant ED481A-2018/207. D.C. acknowledges the financial support for the PhD studies, from the project EUROCIGUA: Risk characterization of ciguatera food poisoning in Europe, framework partnership agreement GP/EFSA/AFSCO/2015/03. L.S. was supported by SNMB-INOV, co-financed by the Operational Program Mar 2020, Portugal 2020. P.R.C. was supported by the FCT Investigator Program (IF/00271/2013).

Acknowledgments: Takeshi Yasumoto (Japan Food Research Laboratories) for kindly provided standards of Pacific ciguatoxins. Robert Dickey (previously, U.S. Food and Drug Administration) via Ronald Manger (Fred Hutchinson Cancer Research Center, Seattle, USA) for kindly provided the standard of C-CTX1. Authors also greatly appreciated the efforts of all technicians from Madeira DSI-DRP involved on fish samples collection.

Conflicts of Interest: The authors declare no conflict of interest.

\section{References}

1. Yasumoto, T.; Nakajima, I.; Bagnis, R.; Adachi, R. Finding of a dinoflagellate as a likely culprit of ciguatera. Bull. Japanese Soc. Sci. Fish. 1977, 43, 1021-1026. [CrossRef]

2. Lewis, R.J.; Holmes, M.J. Origin and transfer of toxins involved in ciguatera. Comp. Biochem. Physiol. C Pharmacol. Toxicol. Endocrinol. 1993, 106, 615-628. [CrossRef]

3. Ikehara, T.; Kuniyoshi, K.; Oshiro, N.; Yasumoto, T. Biooxidation of ciguatoxins leads to species-specific toxin profiles. Toxins 2017, 9, 205. [CrossRef] [PubMed]

4. Soliño, L.; Costa, P.R. Differential toxin profiles of ciguatoxins in marine organisms: Chemistry, fate and global distribution. Toxicon 2018, 150, 124-143. [CrossRef] [PubMed]

5. Bidard, J.N.; Vijverberg, H.P.; Frelin, C.; Chungue, E.; Legrand, A.M.; Bagnis, R.; Lazdunski, M. Ciguatoxin is a novel type of $\mathrm{Na}^{+}$channel toxin. J. Biol. Chem. 1984, 259, 8353-8357. [PubMed]

6. Lombet, A.; Bidard, J.-N.; Lazdunski, M. Ciguatoxin and brevetoxins share acommon receptor site on the neuronal voltage-dependent $\mathrm{Na}^{+}$channel. FEBS Lett. 1987, 219, 355-359. [CrossRef]

7. Wong, C.K.; Hung, P.; Lee, K.L.H.; Kam, K.-M. Study of an outbreak of ciguatera fish poisoning in Hong Kong. Toxicon 2005, 46, 563-571. [CrossRef]

8. Boucaud-Maitre, D.; Vernoux, J.P.; Pelczar, S.; Daudens-Vaysse, E.; Aubert, L.; Boa, S.; Ferracci, S.; Garnier, R. Incidence and clinical characteristics of ciguatera fish poisoning in Guadeloupe (French West Indies) between 2013 and 2016: A retrospective cases-series. Sci. Rep. 2018, 8, 3095. [CrossRef]

9. Baumann, F.; Bourrat, M.; Pauillac, S. Prevalence, symptoms and chronicity of ciguatera in New Caledonia: Results from an adult population survey conducted in Noumea during 2005. Toxicon 2010, 56, 662-667. [CrossRef]

10. Hamilton, B.; Whittle, N.; Shawc, G.; Eaglesham, G.; Moore, M.R.; Lewis, R.J. Human fatality associated with Pacific ciguatoxin contaminated fish. Toxicon 2010, 56, 668-673. [CrossRef]

11. Quod, J.P.; Turquet, J. Ciguatera in Reunion Island (SW Indian Ocean): Epidemiology and clinical patterns. Toxicon 1996, 34, 779-785. [CrossRef]

12. Pottier, I.; Vernoux, J.P.; Lewis, R. Ciguatera fish poisoning in the Caribbean Islands and Western Atlantic. Rev. Environ. Contam. Toxicol. 2001, 168, 99-141. [PubMed]

13. Sanner, B.M.; Rawert, B.; Henning, B.; Zidek, W. Ciguatera fish poisoning following travel to the tropics. Zeitschrift fur Gastroenterologie 1997, 35, 327-330. [PubMed]

14. Friedemann, M. Erster Ciguatera-Ausbruch in Deutschland 2012. Bundesgesundheitsblatt 2016, 59, 1556-1565. [CrossRef] [PubMed] 
15. Regulation (EC) No. 853/2004 of the European Parliament and of the Council of 29 April 2004 laying down specific hygiene rules for food of animal origin. Off. J. Eur. Union 2004, 135, 55.

16. Regulation (EC) No. 854/2004 of the European Parliament and of the Council of 29 April 2004 laying down specific rules for the organisation of official controls on products of animal origin intended for human consumption. Off. J. Eur. Union 2004, 226, 83.

17. Perez-Arellano, J.L.; Luzardo, O.P.; Brito, A.P.; Cabrera, M.H.; Zumbado, M.; Carranza, C.; Angel-Moreno, A.; Dickey, R.W.; Boada, L.D. Ciguatera fish poisoning, Canary Islands. Emerg. Infect. Dis. 2005, 11, 1981-1982. [CrossRef] [PubMed]

18. Gouveia, N.N.; Vale, P.; Gouveia, N.; Delgado, J. Primeiro registo da ocorrência de episódios do tipo ciguatérico no arquipélago da Madeira. In Algas tóxicas e biotoxinas nas águas da Península Ibérica-2009; Costa, P.R., Botelho, M.J., Rodrigues, S.M., Palma, A.S., Moita, M.T., Eds.; IPIMAR: Lisboa, Potugal, 2009; pp. 152-157.

19. Otero, P.; Pérez, S.; Alfonso, A.; Vale, C.; Rodríguez, P.; Gouveia, N.N.; Gouveia, N.; Delgado, J.; Vale, P.; Hirama, M.; et al. First toxin profile of ciguateric fish in Madeira Arquipelago (Europe). Anal. Chem. 2010, 82, 6032-6039. [CrossRef] [PubMed]

20. Boada, L.D.; Zumbado, M.; Luzardo, O.R.; Almeida-Gonzalez, M.; Plakas, S.M.; Granade, H.R.; Abraham, A.; Jester, E.L.E.; Dickey, R.W. Ciguatera fish poisoning on the West Africa Coast: An emerging risk in the Canary Islands (Spain). Toxicon 2010, 56, 1516-1519. [CrossRef] [PubMed]

21. EFSA. Panel on contaminants in the food chain; scientific opinion on marine biotoxins in shellfish—Emerging toxins: Ciguatoxin group. EFSA J. 2010, 1627, 1-38.

22. Canals, A.; Varela, C.; Diogène, J.; Gago-Martínez, A. EUROCIGUA, Risk Characterization of Ciguatera Food Poisoning in Europe. In Proceedings of the ECsafeSEAFOOD Project-Final Conference, Brussels, Belgium, 25-26 January 2017.

23. Salz, R.J. Island Grouper (Mycteroperca fusca) Draft Status Review Report. Report to National Marine Fisheries Service, Office of Protected Resources. 2015; p. 69. Available online: https://www.cio.noaa. gov/services_programs/prplans/pdfs/ID270_Island_Grouper_Status_Review_draft.pdf.pdf (accessed on 30 October 2018).

24. Soliño, L.; Widgy, S.; Pautonnier, A.; Turquet, J.; Loeffler, C.R.; Flores Quintana, H.A.; Diogène, J. Prevalence of ciguatoxins in lionfish (Pterois spp.) from Guadeloupe, Saint Martin, and Saint barthélmy islands (caribbean). Toxicon 2015, 102, 62-68.

25. Friedlander, A.M.; Ballesteros, E.; Clemente, S.; Estep, A.; Gonçalves, E.J.; Rose, P.; Shepard, M.; Thompson, C.; Meeuwig, J.J.; Sala, E. Marine Biodiversity and Ecosystem Health of Ilhas Selvagens, Portugal; Scientific Report to the Government of Portugal and the Regional Government of Madeira; National Geographic Pristine Seas: Washington, DC, USA, 2016; pp. 1-64.

26. Friedlander, A.M.; Ballesteros, E.; Clemente, S.; Gonçalves, E.J.; Estep, A.; Rose, P.; Sala, E. Contrasts in the marine ecosystem of two Macaronesian islands: A comparison between the remote Selvagens Reserve and Madeira Island. PLoS ONE 2017, 12, e0187935. [CrossRef]

27. Almada, F.; Abecasis, D.; Villegas-Ríos, D.; Henriques, S.; Pais, M.P.; Batista, M.; Horta e Costa, B.; Martins, J.; Tojeira, I.; Rodrigues, N.V.; et al. Ichthyofauna of the Selvagens Islands. Do small coastal areas show high species richness in the northeastern Atlantic? Mar. Biol. Res. 2015, 11, 49-61. [CrossRef]

28. Holden, M.J.; Raitt, D.F.S. Manual of Fisheries Science. Part 2. Methods of Resource Investigation and Their Application; FAO: Rome, Italy, 1974; p. 214.

29. Yogi, K.; Oshiro, N.; Inafuku, Y.; Hirama, M.; Yasumoto, T. Detailed LC-MS/MS Analysis of Ciguatoxins Revealing Distinct Regional and Species Characteristics in Fish and Causative Alga from the Pacific. Anal. Chem. 2011, 83, 8886-8891. [CrossRef]

30. Estevez, P.; Castro, D.; Leao, J.M.; Yasumoto, T.; Dickey, R.; Gago-Martínez, A. Implementation of Liquid Chromatography tandem Mass Spectrometry for the Analysis of ciguatera fish poisoning in contaminated fish samples from Atlantic coasts. Food Chem. 2018, in press.

31. Moreiras, G.; Leão, J.M.; Gago-Martínez, A. Design of experiments for the optimization of electrospray ionization in the LC-MS/MS analysis of ciguatoxins. J. Mass Spectrom. 2018, 53, 1059-1069. [CrossRef] [PubMed] 
32. Murata, M.; Legrand, A.M.; Ishibashi, Y.; Fukui, M.; Yasumoto, T. Structures and configurations of ciguatoxin from the moray eel Gymnothorax javanicus and its likely precursor from the dinoflagellate Gambierdiscus toxicus. J. Am. Chem. Soc. 1990, 112, 4380-4386. [CrossRef]

33. Abraham, A.; Jester, E.L.E.; Granade, H.R.; Plakas, S.M.; Dickey, R.W. Caribbean ciguatoxin profile in raw and cooked fish implicated in ciguatera. Food Chem. 2012, 131, 192-198. [CrossRef]

34. Lewis, R.J.; Yang, A.; Jones, A. Rapid extraction combined with LC-tandem mass spectrometry (CREM-LC/ MS/MS) for the determination of ciguatoxins in ciguateric fish flesh. Toxicon 2009, 54, 62-66. [CrossRef]

(C) 2018 by the authors. Licensee MDPI, Basel, Switzerland. This article is an open access article distributed under the terms and conditions of the Creative Commons Attribution (CC BY) license (http:/ / creativecommons.org/licenses/by/4.0/). 
Article

\title{
Growth and Toxin Production of Gambierdiscus spp. Can Be Regulated by Quorum-Sensing Bacteria
}

\author{
Bo Wang ${ }^{1}$, Mimi Yao ${ }^{2}$, Jin Zhou ${ }^{3}$, Shangjin Tan ${ }^{1}$, Hui Jin ${ }^{1}$, Feng Zhang ${ }^{4,5}$, Yim Ling Mak ${ }^{4,5}$, \\ Jiajun $\mathrm{Wu}^{4,5}$, Leo Lai Chan ${ }^{4,5}$ and Zhonghua Cai ${ }^{3, *}$ \\ 1 School of Life Science, Tsinghua University, Beijing 100084, China; cuhkbobwong@gmail.com (B.W.); \\ shangjin-tan@163.com (S.T.); jinhui0127@126.com (H.J.) \\ 2 Center for Microalgal Biotechnology and Biofuels, Institute of Hydrobiology, Chinese Academy of Sciences, \\ Wuhan 430070, China; mimiyao@ihb.ac.cn \\ 3 Shenzhen Public Platform of Screening \& Application of Marine Microbial Resources, Graduate School at \\ Shenzhen, Tsinghua University, Shenzhen 518055, China; zhou.jin@sz.tsinghua.edu.cn \\ 4 State Key Laboratory in Marine Pollution, City University of Hong Kong, Hong Kong 999077, China; \\ zhang_feng1220@163.com (F.Z.); maggieylmak@yahoo.com.hk (Y.L.M.); jiajun@hkc.edu.cn (J.W.); \\ Leochen@hkc.edu.cn (L.L.C.) \\ 5 Shenzhen Key Laboratory for the Sustainable Use of Marine Biodiversity, Research Centre for the Oceans \\ and Human Health, City University of Hong Kong Shenzhen Research Institute, Shenzhen 518057, China \\ * Correspondence: caizh@sz.tsinghua.edu.cn; Tel.: +86-0755-2603-6108
}

Received: 19 May 2018; Accepted: 20 June 2018; Published: 22 June 2018

\begin{abstract}
Gambierdiscus spp. are the major culprit responsible for global ciguatera fish poisoning (CFP). At present, the effects of microbiological factors on algal proliferation and toxin production are poorly understood. To evaluate the regulatory roles of quorum-sensing (QS) bacteria in the physiology of Gambierdiscus, co-culture experiments with screened QS strains were conducted in this study. Except for the growth-inhibiting effect from the strain Marinobacter hydrocarbonoclasticus, the algal host generally displayed much higher growth potential and toxin production ability with the existence of QS strains. In addition, Bacillus anthracis particularly exhibited a broad-spectrum growth enhancement effect on various Gambierdiscus types, as well as a remarkable influence on algal toxicity. The variations of algal physiological status, including growth rate, chlorophyll content, and responsive behaviors, are potential reasons for the observed positive or negative affection. This study suggests that QS bacteria regulate the algal growth and toxin production. Based on the evidence, we further speculate that QS bacteria may contribute to the site-specific distribution of CFP risk through regulating the algal host biomass and toxicity.
\end{abstract}

Keywords: Ciguatera fish poisoning; Gambierdiscus; quorum sensing; algal-bacterial relationship

Key Contribution: This study tells us that QS bacteria can regulate the algal toxin secretion and growth; it is also beneficial for expanding our knowledge of the algal-bacterial relationship.

\section{Introduction}

Public health around the world is threatened by the ciguatera fish poisoning (CFP), which is a serious syndrome that is caused by the ingestion of tropical and subtropical reef fish contaminated with lipophilic ciguatoxins (CTXs) [1]. Any toxicity that exceeding $0.31 \mathrm{ng} / \mathrm{g}$ P-CTX-3C equivalent of flesh would cause signs of intoxication including neurological, gastrointestinal, and cardiovascular dysfunctions [2,3]. Different groups of ciguatoxin analogues have been identified according to their geographic distribution, including the C-CTXs from the Caribbean Sea, P-CTXs from the Pacific Ocean, and I-CTXs from the Indian Ocean [4]. CTXs can accumulate in the liver to life-threatening levels 
and lead to death [5]. With the expanding of the international tropical fish trade, CFP has spread throughout the world, including places such as Hong Kong [6], Southeast Asia [7], Australia [8], and America [9]. By the end of the 20th century, more than 50,000 people each year suffered from CFP, and the global CFP incidences continue to increase [10]. In 2002, 464 CFP cases per 10,000 people were recorded in French Polynesian Raivavae Island [11]. Alongside the direct impact on human health, $\mathrm{CPF}$ also caused huge economic loss to the marine fishing industry. In America alone, the annual loss is estimated to $\$ 22$ million [12].

Several toxic benthic dinoflagellate belonging to the genus Gambierdiscus, which produce CTX intermediates (52-epi-54-deoxy-CTX-1B and 54-deoxy-CTX-1B) and gambiertoxins, are confirmed as the primary source of CTXs $[13,14]$. The Gambierdiscus could usually be found in microbial biofilms attached on the macroalgal surface [15]. The macroalgae are the food source of the herbivorous coral reef fishes, which could be further ingested by carnivorous fishes. In this process, toxin precursors and their intermediates are transferred into the food chain, and then biotransformed to the relatively oxidized CTXs, which are the more toxic final products [16]. Therefore, the toxin contamination in the fish and the resulting CFP risk are highly related to the total biomass and toxicity of the ingested Gambierdiscus. However, the CFP risk often exhibits site-specific spatial distribution characteristic [17]. As a typical example, the blue-spotted grouper (Cephalopholis argus), undulated moray (Gymnothorax undulatus) and yellow-edged moray (Gymnothorax flavimarginatus) collected near the western coast of Marakei Island, Republic of Kiribati, are at least 30 times more toxic than those collected from adjacent regions [18]. Interestingly, the food source composition of fish is different among regions with different CFP risks. According to an isotopic tracing study [19], the ingested biofilms account for a prominent proportion (16.4-29.9\%) in the food source of fishes from ciguatoxic sampling sites, while the fishes from the reference site have a more balanced diet. As the major components in the bacteria/algal biofilm [20], it is reasonable to infer that the bacterial community and Gambierdiscus correlate with the CFP risk.

Previously, the Gambierdiscus proliferation and toxicity have been reportedly influenced by nutrients, temperature, light, and salinity conditions [21-23]. However, the function of the microecological process has received little attention; limited studies have concerned the function of epiphytic microbial communities inhabiting on algal surfaces [24-26]. In fact, bacteria, in symbiotic relationships with algae, form the basic and active link in the phycosphere by extensively participating in substance cycling, oxidation-reduction activities, and the regulation of algal physiological behavior [27]. Many life processes including growth, defense, and toxin production, are mediated by physiochemical interactions at the individual, population, and community levels [28]. In addition, various community behaviors of heterotrophic bacteria have been identified in algal-bacterial symbionts through the abundant infochemicals in the phycosphere [28-30]. As a typical process involving infochemicals, quorum sensing (QS) controls community behaviors by the population density-dependent diffusible signaling molecules, typically the $\mathrm{N}$-acyl homoserine lactone (AHL) [31-33]. It has been reported that QS signals from algal-associated epiphytic or endophytic bacterial isolates could regulate a variety of bacterial behaviors such as biofilm formation, phenotype adaptation, exopolysaccharide production, zoospore settlement, carpospore liberation, virulence production, and motility, most of which are essential for the successful establishment of a symbiotic relationship with a eukaryotic host [34-38]. During the above processes, the bacteria and algae could interact in different ways, and the phycosphere environment could be significantly adjusted. Therefore, investigating the function of QS microbes in the Gambierdiscus phycosphere will help to better understand their roles in algal physiology and the potential influences on the distribution of CFP risks.

Inspired by previous reports, it is reasonable to speculate that through algal-microbial interactions, QS microbes play an important role in regulating the Gambierdiscus physiology, such as growth and toxin production. However, limited evidence is available to support this hypothesis at present. Therefore, in this study, we isolated and screened several AHL-producing strains from 
the Marakei Island of the Republic of Kiribati, and then investigated their effects on the growth and toxin production of several Gambierdiscus strains by co-culture experiments. The aim of this study is to investigate whether and how the signaling bacteria could influence the growth potential and toxicogenic behavior of Gambierdiscus, and have a better understanding of the reasons leading to the site-specific spatial distribution phenomenon of CFP.

\section{Results}

\subsection{QS Bacteria Screening}

In the 96-well microtiter-plate test (Figure S1a), more than 900 bacterial isolates from sampling sites were screened for AHL production, and 32 isolates were identified as potential AHL-producing candidates. After the removal of false positives, nine bacterial strains that showed positive signals and blue color zones with the bioreporter strain A136 remained (Figure S1b). The identities of these QS candidates were determined by $16 \mathrm{~S}$ rDNA gene sequencing and the Basic Local Alignment Search Tool (BLAST) alignment. The closest match of each corresponding bacterial species was selected and listed in Table 1. In addition, according to the taxonomic distribution (Genus level) of the four sampling sites (Figure S2), the corresponding Genus distribution of the screened QS bacteria was listed in Table S1. The $16 \mathrm{~S}$ rRNA phylogenetic tree of the screened bacteria was showed in Figure S3.

Table 1. Screened N-acyl homoserine lactone (AHL)-producing bacterial strains for co-culture experiments.

\begin{tabular}{|c|c|c|c|c|}
\hline No. * & Description & Bit Score & E Value & Ident \\
\hline 1 & Vibrio sp. WC141014 16S ribosomal RNA gene, partial sequence & 1836 & 0 & $99 \%$ \\
\hline 2 & $\begin{array}{l}\text { Alteromonas macleodii strain KS62 16S ribosomal RNA gene, } \\
\text { partial sequence }\end{array}$ & 2567 & 0 & $99 \%$ \\
\hline 3 & $\begin{array}{l}\text { Marinobacter hydrocarbonoclasticus strain NIOSSD020\#224 16S ribosomal } \\
\text { RNA gene, partial sequence }\end{array}$ & 2097 & 0 & $97 \%$ \\
\hline 4 & Thalassospira sp. KU27D2 gene for 16S rRNA, partial sequence & 1611 & 0 & $99 \%$ \\
\hline 5 & $\begin{array}{l}\text { Pseudomonas aeruginosa strain CFV } 16 \text { S ribosomal RNA gene, } \\
\text { partial sequence }\end{array}$ & 1094 & 0 & $100 \%$ \\
\hline 6 & Vibrio maritimus strain CR-IV-34 16S ribosomal RNA gene, partial sequence & 2084 & 0 & $97 \%$ \\
\hline 7 & $\begin{array}{l}\text { Providencia vermicola strain NBA-2365 16S ribosomal RNA gene, } \\
\text { partial sequence }\end{array}$ & 1131 & 0 & $99 \%$ \\
\hline 8 & Marinobacterium stanieri S30 contig00002, whole genome shotgun sequence & 2615 & 0 & $99 \%$ \\
\hline 9 & Bacillus anthracis strain C1E4 16S ribosomal RNA gene, partial sequence & 1962 & 0 & $99 \%$ \\
\hline
\end{tabular}

\subsection{Effects of QS Bacteria on Algal Growth}

In the log-phase co-culture experiment, the algal concentration and growth rate were monitored (supplementary material). In the control group, the 1022M2C12 (Gambierdiscus sp. type 5, Table S2) reached stationary phase on the 10th day; the concentration was about 2500 cells $/ \mathrm{mL}$ (Figure 1). The growth rate reached about 0.369 divisions day ${ }^{-1}$ (Table S4), which was consistent with a previous report regarding optimum culture conditions [3,39]. With the adding of AHL-producing bacteria, the algae in the experimental groups generally exhibited a higher cell yield in a bacterial concentration-dependent pattern. The algal concentration in the presence of low- and medium-concentration bacteria were moderately higher than that of the control, while it was significantly $(p<0.05)$ increased in high-dose bacterial co-cultures, reaching 4000 cells $/ \mathrm{mL}$ at the stationary phase. It is worth noting that algal proliferation was initially inhibited by the addition of high-concentration $\left(5 \times 10^{5}\right.$ cells $\left./ \mathrm{mL}\right)$ B. anthracis, and then increased dramatically (Figure 1i). The bloom-like behavior continued until the algal density peaked at approximately 12,000 cells $/ \mathrm{mL}$ on the 25 th day. On the contrary, the algal growth was significantly $(p<0.05)$ inhibited by a high concentration of $M$. hydrocarbonoclasticus (Figure 1c). The growth rate decreased to $0.056 \pm 0.006$ divisions per day ${ }^{-1}$ (Table S4), and no recovery of algal growth was observed. 


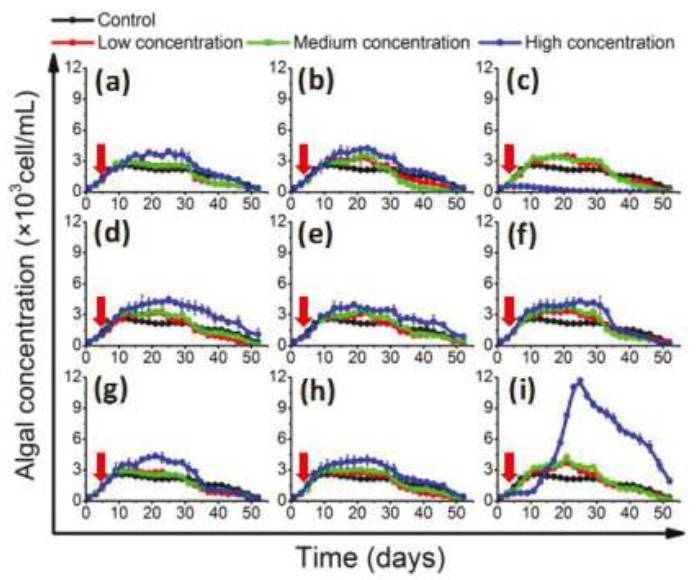

Figure 1. Growth of 1022M2C12 after co-culture with different concentration of (a) Vibrio sp.; (b) A. macleodii; (c) M. hydrocarbonoclasticus; (d) Thalassospira sp.; (e) P. aeruginosa; (f) V. maritimus; (g) P. vermicola; (h) M. stanieri; and (i) B. anthracis. Low concentration: $5 \times 10^{3}$ cells $/ \mathrm{mL}$. Medium concentration: $5 \times 10^{4}$ cells $/ \mathrm{mL}$. High concentration: $5 \times 10^{5}$ cells $/ \mathrm{mL}$. Red arrow: time point of bacteria addition.

The in vivo chlorophyll quantification results (Figure 2) showed that the cellular chlorophyll content generally accumulated slowly in the beginning, and then accelerated and culminated in the middle of the stationary phase. In the control group, the chlorophyll content peaked at $3.1 \times 10^{3} \mu \mathrm{g} / \mathrm{L} / \mathrm{cell}$ on the $22 \mathrm{nd}$ day. Most of the QS bacteria that significantly enhanced the growth of 1022M2C12 were also effective in increasing the cellular chlorophyll content. However, the in vivo chlorophyll content was significantly $(p<0.05)$ promoted by medium-concentration M. hydrocarbonoclasticus and reached $6.0 \times 10^{3} \mathrm{\mu g} / \mathrm{L} /$ cell, while the high concentration of the bacteria had decreased (Figure 2c). The high-concentration P. vermicola also stimulated the cellular chlorophyll content to $6.2 \times 10^{3} \mu \mathrm{g} / \mathrm{L} / \mathrm{cell}$, which was significantly higher than that of the other experimental groups.

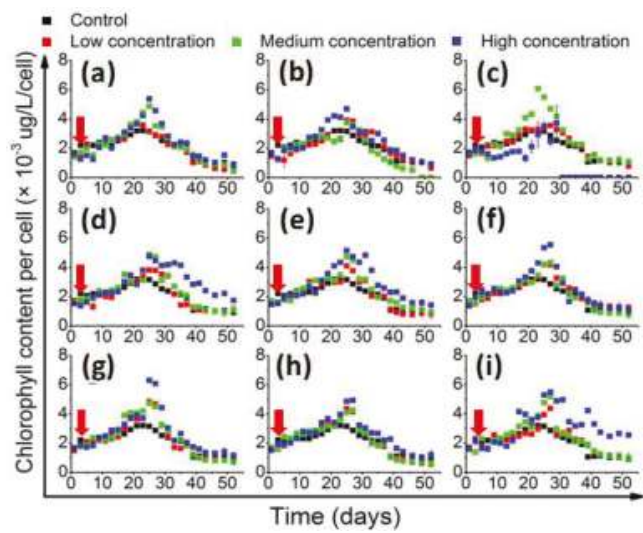

Figure 2. The change of in vivo chlorophyll content (chlorophyll content per cell) of 1022M2C12 co-cultured with (a) Vibrio sp.; (b) A. macleodii; (c) M. hydrocarbonoclasticus; (d) Thalassospira sp.; (e) P. aeruginosa; (f) V. maritimus; (g) P. vermicola; (h) M. stanieri; and (i) B. anthracis. Low concentration: $5 \times 10^{3}$ cells $/ \mathrm{mL}$. Medium concentration: $5 \times 10^{4}$ cells $/ \mathrm{mL}$. High concentration: $5 \times 10^{5}$ cells $/ \mathrm{mL}$. Red arrow: time point of bacteria addition. 


\subsection{The Growth Promotion Principle of QS Bacteria}

To dissect the principle of this growth promotion, B. anthracis was applied as a representative strain for further study, owing to its significant growth promoting potential. We assessed (1) the effective regulatory phase of adding the QS bacteria; (2) the existence of potential intracellular or extracellular bioactive substances; and (3) the species-specific growth enhancement effect of QS bacteria to the genus Gambierdiscus.

As shown in Figure 3a, at the beginning of the stationary phase, the algal growth was rapidly affected by the addition of bacterial suspensions. The added $5 \times 10^{5}$ cells/L B. anthracis exhibited a significant enhancement effect, leading to an additional $0.1496 \pm 0.0223$ divisions day $^{-1}$. The algal yield reached 7000 cells $/ \mathrm{mL}$. However, an inhibitory effect emerged after further increasing the concentration of added bacteria. The result indicated the existence of a threshold value of the added bacteria. The effect of QS bacteria in the decline phase was also evaluated; however, no enhancement in algal growth was observed (Figure 3b). For comparison, we assessed the effects of nutrient supplementation and secondary metabolite removal. Only a slight stimulation $\left(0.0186 \pm 0.0103\right.$ divisions day $\left.^{-1}\right)$ and extended lag phase in the secondary metabolite removal group were observed (Figure 3b).
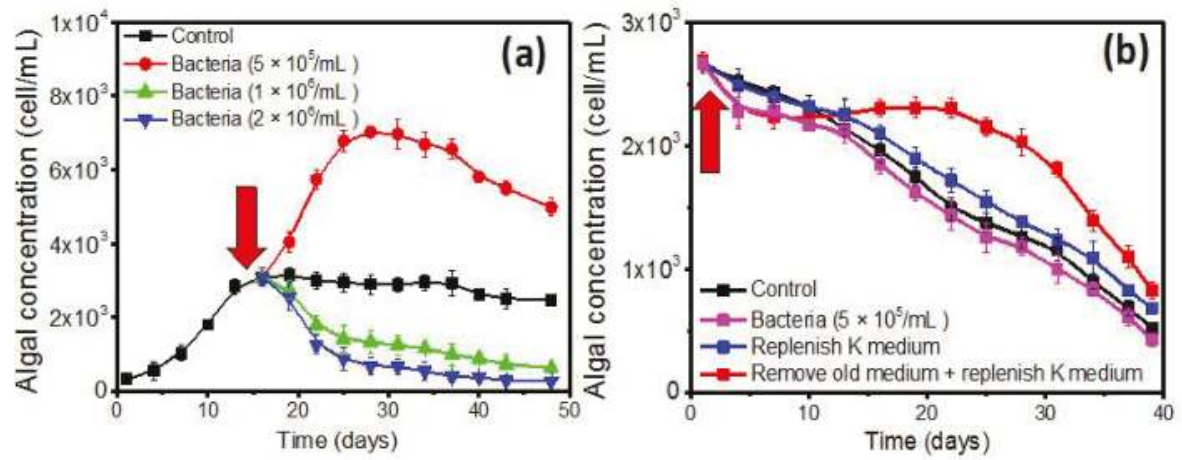

Figure 3. Growth of $1022 \mathrm{M} 2 \mathrm{C} 12$ in (a) the stationary phase; and (b) the decline phase after co-culture with $B$. anthracis, nutrient supplement, and removal of secondary metabolites, respectively. Red arrow: time point of addition.

Next, the existence of potential intracellular (in bacterial extracts) and extracellular (in supernatants) bioactive substances was investigated. Besides, the effect of nutrient supplementation was also investigated for comparison study. Consistent with the stationary phase co-culture experiment (Figure 3a), a rapid growth change of 1022M2C12 was observed after the addition of both bacterial extracts and supernatants (Figure 4 ). The extracts from $1 \times 10^{6}$ cells $/ \mathrm{mL}$ bacterial culture exhibited the strongest enhancement effect, leading to an additional $0.1811 \pm 0.0129$ divisions day $^{-1}$ to the algal growth rate. The yield was improved to approximately $1.0 \times 10^{4}$ cells $/ \mathrm{mL}$, which was four times that of the control group. The algal proliferation was also remarkably stimulated by the supernatants from $2 \times 10^{6}$ cells / mL bacterial culture (Figure 4), resulting in an additional $0.216 \pm 0.018$ divisions day $^{-1}$ growth rate. It is worth noting that although a prolonged log phase was observed after the addition of the fresh nutrients, the effect was not as pronounced as that of most of the other extract and supernatant groups. 


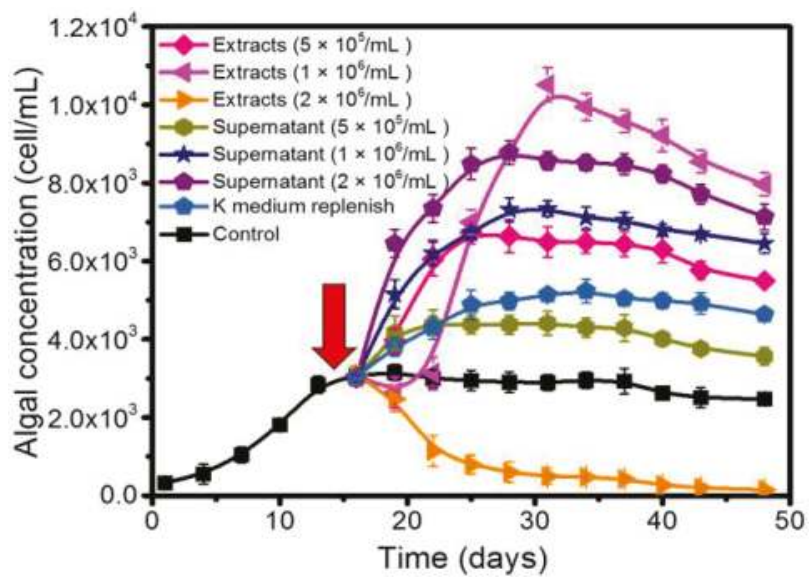

Figure 4. Effect of bacterial extracts, supernatants, and nutrient supplements on the growth of 1022M2C12 at an early stationary phase. Red arrow: time point of addition.

To investigate whether the growth enhancement effect of QS bacteria is species-specific to the genus Gambierdiscus, the growth of two additional Gambierdiscus strains (1112M1M03 and 1021M1DC4) in the presence of $B$. anthracis were also studied. Figure 5 revealed that the high-concentration bacteria $\left(5 \times 10^{5}\right.$ cells $\left./ \mathrm{mL}\right)$ could also promote the growth of the two strains, while the extent and pattern of this effect differs between species. The highest yield that 1112M1M03 (0.02 pg P-CTX-1/cell) and 1021M1DC4 (no toxicity) reached were $6.6 \times 10^{3}$ (Figure 5a) and $3.6 \times 10^{3}$ cells $/ \mathrm{mL}$ (Figure 5b), respectively.
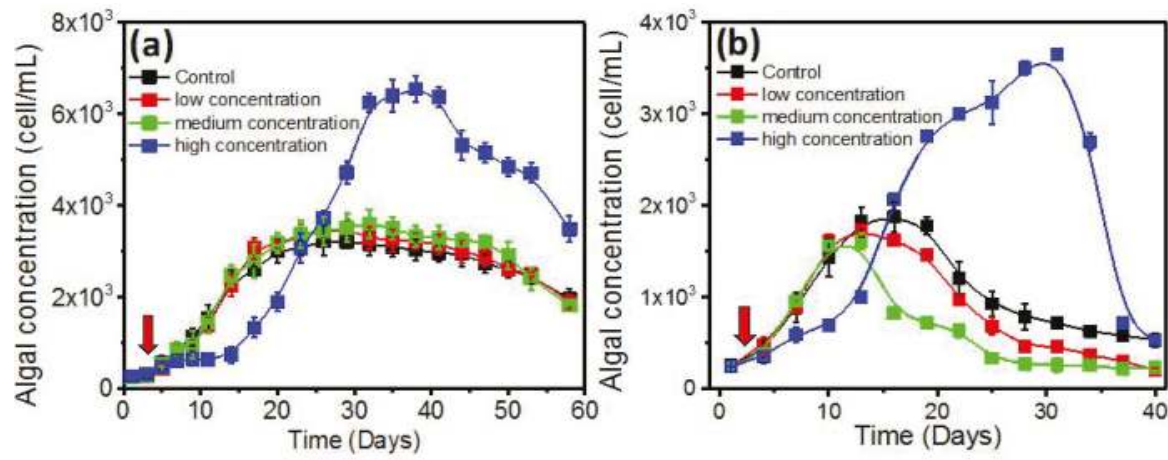

Figure 5. Effect of Bacillus anthracis on the growth of (a) 1112M1M03 (Gambierdiscus sp. type 6) and (b) 1021M1DC4 (Gambierdiscus sp. type 6). Red arrow: time point of bacteria addition. Low concentration: $5 \times 10^{3}$ cells $/ \mathrm{mL}$ bacteria. Medium concentration: $5 \times 10^{4}$ cells $/ \mathrm{mL}$ bacteria. High concentration: $5 \times 10^{5}$ cells $/ \mathrm{mL}$ bacteria. Red arrow: time point of bacteria addition.

\subsection{Influence of QS Bacteria on Algal Toxicity}

The influence of all the screened AHL-producing bacteria on the toxin production of 1022M2C12 was investigated. Generally, the toxicity of the control group periodically declined during the lag phase and improved in the decline phase (Figure 6). The algal toxicities in the control group from the lag phase to the final decline phase were 3.797, 1.553, 1.092 and $4.975 \times 10^{-3} \mathrm{pg}$ P-CTX-1 eq/cell, respectively. In the log and stationary phases, the algal toxicity was most strongly promoted by 
M. hydrocarbonoclasticus, reaching 5.804 and $2.103 \times 10^{-3}$ pg P-CTX-1 eq/cell, respectively. Meanwhile, M. stanieri significantly $(p<0.05)$ reduced the toxicity to $0.4 \times 10^{-3} \mathrm{pg}$ P-CTX-1 eq/cell at the log and stationary phases. In the decline phase, the low concentration of $B$. anthracis improved the algal toxicity to a remarkable $1.0 \times 10^{-2} \mathrm{pg}$ P-CTX-1 eq/cell, which was significantly $(p<0.05)$ higher than the control. In contrast, $V$. maritimus and P. vermicola decreased the algal toxicity to $2.0 \times 10^{-3} \mathrm{pg}$ P-CTX-1 eq/cell.

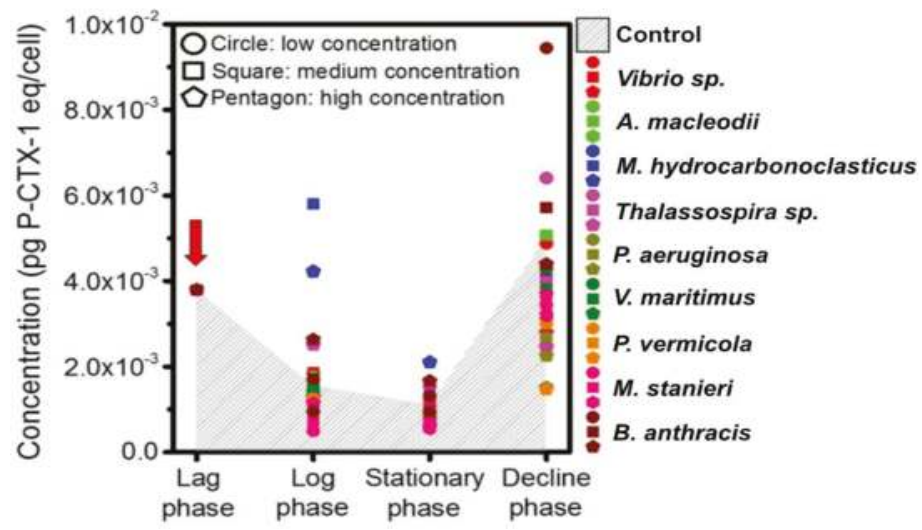

Figure 6. Toxicity of 1022M2C12 (Gambierdiscus sp. type 5) in different growth phases after co-culture with the screened quorum-sensing (QS) bacteria. Low concentration: $5 \times 10^{3}$ cells $/ \mathrm{mL}$ bacteria. Medium concentration: $5 \times 10^{4}$ cells $/ \mathrm{mL}$ bacteria. High concentration: $5 \times 10^{5}$ cells $/ \mathrm{mL}$ bacteria. Red arrow: time point of bacteria addition.

\section{Discussion}

Predicting the risk of CFP is difficult, because the abundance and toxicity of genus Gambierdiscus varies between different areas, and the digestion behaviors and metabolic pathways of fish may also affect the fate of CTX biotransformation [40]. However, it is plausible that the ingested biomass and toxicity of Gambierdiscus are the decisive factors that affect the CFP risk according to the food chain theory [14]. Diverse populations of microorganisms exist in phycosphere environments, and the algae-bacteria interactions mutually affect their physiology and alter the flux of matter and signaling compounds, shaping the diversity of the ecosystem [30]. Previous studies have shown that the algae could be greatly affected by the symbiotic bacteria, and those interactions were mediated through the production and exchange of infochemicals [30]. Therefore, understanding signaling strains may shed light on the effects of algae-associated microbial communities on the native host. Based on the ecological importance of signaling microbes, this study sought to interpret the modulatory functions of QS bacteria in algal growth and toxin production from a microbial-ecological perspective.

The co-culture experiments were prepared in xenic condition, because the benthic Gambierdiscus commonly live with associated bacterial flora [20], and the symbiotic relationship is potentially important for the life process of the algae. Besides, no differences have been previously found in the growth and toxicity of Gambierdiscus strains assayed in axenic versus xenic culture conditions [3,41]. Adding antibiotics may also bring an additional impact factor to the co-culture experiment. The results showed that the screened AHL-producing strains can affect the growth of 1022M2C12 (Gambierdiscus sp. type 5, Figure 1). The algal yield generally increased with the addition of signaling bacteria, and the effect is generally better than that of the reported optimum environmental conditions (i.e., temperature, salinity, and irradiance) on the growth of several Gambierdiscus spp. [23], suggesting that algae might acquire beneficial nutrients from the QS microbes or their metabolic products. In concordance with previous work, which showed that Alteromonas sp. could stimulate the growth of Gambierdiscus toxicus 
by providing "public goods" to its host [24], an Alteromonas strain (A. macleodii) in this study also exhibited the similar growth stimulatory effect. The generally increased in vivo chlorophyll contents (Figure 2) are also good evidence indicating the existence of sufficient energy sources for chlorophyll accumulation. The accumulated chlorophyll content could lead to stronger photosynthesis ability and higher biomass accumulation for cell division. The QS bacteria might directly mediate this process by acting as sources (Figure 7, part a) for siderophore production [42], trace elements adsorption, and vitamin supply $[43,44]$, or indirectly by re-mineralizing the dissolved organic matter (DOM) excreted from phytoplankton (Figure 7, part b). The process can facilitate the microbial recycling of fresh organic matter, and thus strengthen the role of the microbial loop in the phycosphere environment [45].

In addition to the enhancement effects, a clear algal growth-inhibitory role was observed from the high-concentration of M. hydrocarbonoclasticus (Figure 1c), exhibiting a distinct negative effect to the physiology of Gambierdiscus. A similar phenomenon could be observed from Gambierdiscus toxicus, which was significantly inhibited by Flavorbacterium sp. strain C1 [24]. This effect could be potentially due to bioactive substances released from the bacterial cells that are toxic to the algae (Figure 7, part c), resulting in a lethal effect when exceeding a threshold value. Alternatively, growth inhibition could be the result of nutrient competition between the bacteria and algae (Figure 7, part d) [46]. In addition to these potential scenarios, it is worth noting that the in vivo chlorophyll content of 1022M2C12 co-cultured with a high concentration of M. hydrocarbonoclasticus kept accumulating until the 30th day (Figure 2c), while not leading to cell growth (Figure 1c). Besides, the higher content of in vivo chlorophyll in the algae cultured with a medium concentration of $M$. hydrocarbonoclasticus did not led to additional algal accumulation compared with the low bacterial concentration group (Figure 1c). The result indicates that the photosynthesis process was inhibited. Therefore, a reasonable explanation for the growth inhibition is that a high concentration of M. hydrocarbonoclasticus might have affected the light adsorption and the photosynthesis process by direct or indirect interactions (e.g., inhibiting the function of photosystem), resulting in the inhibition of algal growth (Figure 7, part e). To confirm the speculation, further investigations are needed. From the current results, we proposed that M. hydrocarbonoclasticus might play a crucial role in the decline phase of Gambierdiscus.

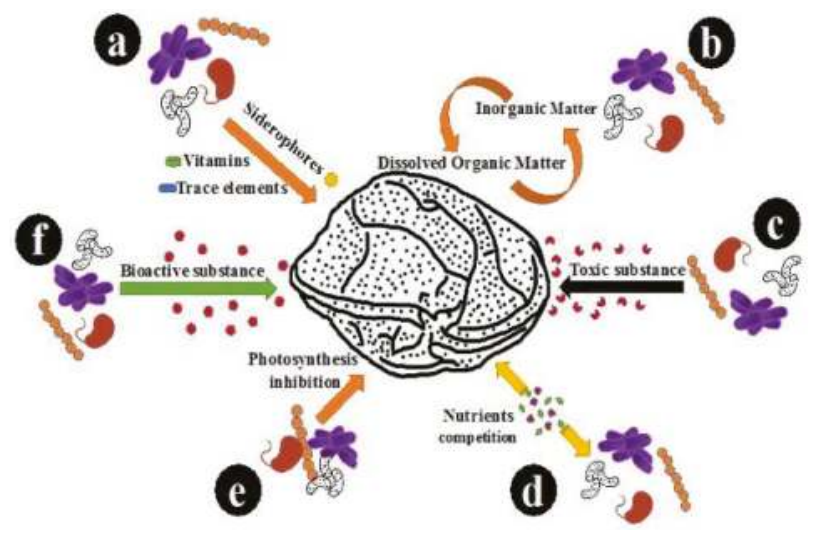

Figure 7. Scheme of the interactions between QS bacteria and Gambierdiscus.

Compared to the slow and absent algal responses in the log and decline phases (Figures 1 and $3 \mathrm{~b}$, respectively), the expansion of algal biomass in the early stationary phase was rapid and distinctive (Figure 3a). It reveals that the stimulatory role is most prominent during the stationary phase. Interestingly, the results indicate that similar to the density-dependent quorum sensing behavior of bacteria, the responsive ability of algae correlated with algal density. Generally, the physiology of 
algae will reach the optimum state and highest stability in the early stationary phase. It is reasonable that a high concentration of high-quality algae might allow for the prompt response to extraneous stimulation and better buffering of adverse conditions. In the co-culture experiment at the decline phase, the rebound in the secondary metabolite removal group demonstrated that the algal physiology was seriously affected by the deteriorated environment, leading to a lack of enhancement by QS bacteria in the decline phase (Figure 3b). The negative result illustrated that the effect of QS bacteria on Gambierdiscus is affected by the abiotic factors, biotic status, and physiological conditions of the algae.

The stimulatory effect of bacterial extracts and fermentation supernatants were also studied in order to identify and locate the potential bioactive substances. As illustrated in Figure 4, most of the experimental groups strongly promoted algal growth, and the performance was much higher than that of the nutrient supplementation. The result indicated that the extract and supernatant of the bacterial culture may have either provided higher nutrient concentration, or released growth-promoting bioactive substances to the algae (Figure 7, part f). The rapid response of algal growth revealed that the potential substance might act as a key growth factor that was used up at the end of the $\log$ phase. Therefore, it is suspected that either sufficient nutrients may exist in the bacterial extract and culture supernatant, or that bioactive substances that effectively stimulate algal growth were synthesized and released by the QS bacterial cells. However, the reason for the inhibitory effects of higher concentrations of living bacteria (Figure 3a) and extracts (Figure 4) is still unclear. Although the nutrient competition and growth inhibition by the bacterial endotoxins [47] could offer plausible explanations, enough evidence does not currently exist to support the hypothesis. Detailed information is essential for future study.

The growth stimulation effect on two additional Gambierdiscus strains with different toxicities illustrated that the QS bacteria B. anthracis possesses a broad-spectrum effect on the genus Gambierdiscus. Considering the remarkable bloom-like behavior of the three strains during co-culture experiments, this specific bacterium is likely to play an important role during the proliferation process of genus Gambierdiscus. More importantly, the different levels of growth stimulation among the three strains demonstrated that QS bacteria may specifically affect the concentration of Gambierdiscus with different toxicities. Thus, based on the evidence obtained from this study, we speculate that the QS bacteria act as a fundamental factor that regulates the site-specific spatial distribution of CFP risk.

The periodic variation of algal toxicity has been a topic for discussion for long time. It is widely believed that increasing toxicity is a self-protective strategy that empowers the algae with a higher competing ability in a deteriorative environment, which is the result of nutrient exhaustion and harmful metabolite accumulation in the late stationary phase. In an improved nutritional environment for algal survival, the acquired energy was preferentially utilized for cell division instead of toxin production. Therefore, the generally decreased toxicity in most groups supported the existence of a nutrient-transferring relationship between QS bacteria and Gambierdiscus (Figure 7, part b). However, the presence of multiple species-specific bacteria could also induce algal responses such as toxin production for self-protection [48]. Consistent with earlier speculations, the toxin production of algae was significantly enhanced by $M$. hydrocarbonoclasticus during the stationary phase (Figure 6), indicating that the algae were under intense pressure from the bacteria through altering the nutrient availability or interacting by harmful bioactive substances. In addition, distinct concentration-dependent behaviors were observed from $B$. anthracis, which promoted the algal toxicity at low concentrations (Figure 6) and enhanced the algal growth at high concentrations (Figure 1i). As a QS bacterium, when the community achieved certain density, the expression of specific genes could be activated and resulted in different microbial behaviors [31]. Therefore, the QS-regulated behavior is highly suspected to lead to different effects on Gambierdiscus. In future study, more efforts should be made to identify the substance and confirm the hypothesis. Additionally, it is worth noting that several Gambierdiscus species are non-toxic; the toxin-regulating effect of the QS strains used in this study should be further checked on those non-toxic species to investigate whether a universal toxicity regulation in QS bacteria exists toward Gambierdiscus. 


\section{Conclusions}

In this study, we identified several QS bacterial strains that could affect the growth and toxin production of Gambierdiscus. Both positive and negative regulatory effects were found to occur in algal-bacterial symbionts, and the bioactive effects were observed from bacterial extracts and supernatant fermentation. Among the screened QS bacteria, the bacteria B. anthracis exhibited the most potent broad-spectrum stimulatory effects, with various extents on different Gambierdiscus strains. On the contrary, the M. hydrocarbonoclasticus appears to play an important role in the decline of algae. Nutrient transferring, sources competition, toxic substance releasing, and photosynthesis inhibition are suspected to be involved in the algal-microbial interaction process. From a quorum-sensing perspective, the present work indicates that the algal-microbial relationship is highly complex and worthy of deep investigations. In addition, we found by affecting the growth and toxicity of the Gambierdiscus that the QS bacteria probably play an important role in the site-specific distribution of the CFP risk. Taken together, this study tells us that understanding the ecological roles of the QS phenomenon in the holobiont-associated community is beneficial for expanding our knowledge of the algal-bacterial relationship. However, a systematic investigation is still needed for determining the underlying mechanisms and finding an effectively way to predict and protect people from CFP risk.

\section{Materials and Methods}

\subsection{Sample Collection and Algal Culture}

The natural samples were scratched from the surface of red algae, dead coral, and seaweed from four sampling sites around Marakei Island, Republic of Kiribati, including M1 $\left(2^{\circ} 01.394^{\prime} \mathrm{N}, 173^{\circ} 15.383^{\prime} \mathrm{E}\right)$, M2 $\left(1^{\circ} 59.879^{\prime} \mathrm{N}, 173^{\circ} 15.032^{\prime} \mathrm{E}\right), \mathrm{M} 3\left(1^{\circ} 58.246^{\prime} \mathrm{N}, 173^{\circ} 16.268^{\prime} \mathrm{E}\right)$, and M4 $\left(2^{\circ} 00.150^{\prime} \mathrm{N}, 173^{\circ} 18.010^{\prime} \mathrm{E}\right)$. The fresh samples were immediately processed for algal isolation and QS bacteria screening. Three Pacific ribotype strains of Gambierdiscus were isolated, and the species information were identified through Gambierdiscus phylogenetic analyses [49], including 1022M2C12 (Gambierdiscus sp. type 5), 1112M1M03 (Gambierdiscus sp. type 6), and 1021M1DC4 (Gambierdiscus sp. type 6) (Table S2). The algal cultures were maintained in $225 \mathrm{~cm}^{2}$ angled neck cell culture flasks (Corning, NY, USA) in filtered seawater (salinity of 31.0 parts per thousand) supplemented with sterilized $100 \times$ stock solution of K medium [50]. To simulate the local environmental conditions of Marakei, all of the algal strains were cultured in a $26{ }^{\circ} \mathrm{C}$ incubator (LM-570RD, Yiheng, Shanghai, China) under 55- $\mu \mathrm{mol}$ photons $\mathrm{m}^{-2} \mathrm{~s}^{-1}$ cool-white fluorescent illumination with a 12 h:12 h light-dark cycle.

\subsection{Bacterial Isolation and AHL-Producer Identification}

The fresh samples were 100-fold diluted in sterilized seawater and spread on Zobell 2216E solid agar plates [51]. The plates were incubated at $25^{\circ} \mathrm{C}$ for $48 \mathrm{~h}$. The inoculation needles were used for picking bacterial colonies and transferring into $1 \mathrm{~mL}$ of autoclaved Zobell 2216E broth. After $12 \mathrm{~h}$ of incubation, all of the isolated samples were stored at $-80{ }^{\circ} \mathrm{C}$ in $15 \%$ glycerol. Then, the bacterial isolates were screened for AHL production by using the indicator strain Agrobacterium tumefaciens A136. A fast liquid screening method in 96-well microtiter plates (Figure S1a) was developed based on the traditional method conducted on agar plates [52]. The bioassay was conducted as follows. All of the isolated samples were cultured in $1 \mathrm{~mL}$ of liquid Zobell $2216 \mathrm{E}$ medium overnight at $25^{\circ} \mathrm{C}$, and the indicator strain A136 was pre-cultured in liquid LB medium at $30^{\circ} \mathrm{C}$ to stationary phase. Aliquots of $100-\mu \mathrm{L}$ A136 and 100- $\mu \mathrm{L}$ cultured isolated samples were mixed in the 96-well microtiter plates, and $5 \mu \mathrm{L}$ of X-Gal $(40 \mu \mathrm{g} / \mathrm{mL})$ were added into each well for colorimetric screening. The presence of a blue color after $24 \mathrm{~h}$ of incubation indicated candidate AHL-producing strains. The Pseudomonas aeruginosa PAO1, Escherichia coli DH5 $\alpha$, and ultrapure water were used as the positive control, negative control, and blank control, respectively. To conduct a more stringent second screen, $10 \mu \mathrm{L}$ of the potential AHL-positive bacterial strains were pipetted onto 5-mm diameter circle filter paper on solid 2216E plates, and then supplemented with $10 \mu \mathrm{L}$ of A136 and $5 \mu \mathrm{L}$ of X-Gal $(40 \mu \mathrm{g} / \mathrm{mL})$, and incubated 
overnight at $30{ }^{\circ} \mathrm{C}$. The visible blue pigmentation samples after incubation were retained (Figure S1b). To eliminate the false-positive results, the same method was conducted on the retained strains without the addition of A136, and the samples that still displayed a blue color were eliminated.

The genomic DNA of all of the screened AHL-producing bacterial strains were extracted using the StarPrep Bacterial DNA Kit (Gene Star, Beijing, China) and purified using the StarPrep PCR\&DNA Fragment Purification Kit (Gene Star, Beijing, China) following the manufacturer's instructions. The bacterial $16 \mathrm{~S}$ rRNA gene (position 27-1492) was amplified by polymerase chain reaction (PCR) using universal 16s 27F/1492R primers (27F: 5'-AGAGTTTGATCATGGCTCAG-3'; 1492R:5'-TACGGYTACCTTGTTACGACTT-3'). Then, the obtained $16 S$ rDNA were sent to the Beijing Genomics Institute (BGI, Shenzhen, China) for sequencing. The obtained sequences (Table S3) were aligned to the National Center for Biotechnology Information (NCBI) databases using the Microbial Nucleotide BLAST (basic local alignment search tool) to find the closest match of corresponding bacterial species. The MEGA 7 software was used for constructing the $16 \mathrm{~S}$ rRNA phylogenetic tree of screened bacteria (Figure S3). The sequences of all of the screened QS bacteria were uploaded to the GenBank; the accession numbers are KY777596-KY777604. In addition, 100-mL aliquots of seawater samples from the four sampling sites were used to extract the environmental microbial genomics using the DNA Isolation Kit (Power Water 14900-S, Mo Bio, Carlsbad, CA, USA). The 16s rDNA V6 area (967F/1046R) of the obtained DNA samples were further sequenced by the Beijing Genomics Institute (BGI, Shenzhen, China). The four sampling sites' taxonomic distribution at the genus level and the corresponding genus distribution of the screened QS bacteria were investigated.

\subsection{Co-Culture Experiment at Early Log Phase}

The 1022M2C12 (Gambierdiscus sp. type 5, 0.004 pg P-CTX-1/cell) was used to evaluate the growth effects of QS bacteria challenge in co-culture experiments. The algae in the early log phase (about $5 \times 10^{2}$ cells $/ \mathrm{mL}$ ) was used for the co-culture experiments. The screened AHL-producing bacterial strains were pre-cultured in Zobell $2216 \mathrm{E}$ broth at $25^{\circ} \mathrm{C}$ for $24 \mathrm{~h}$. Prior to the experiment, bacterial densities were determined by a flow cytometer (BD Accuri C6, BD Biosciences, Billerica, MA, USA) after Syto9 staining. Different concentrations of bacterial suspensions (pre-washed by ultrapure water) were added to $500 \mathrm{~mL}$ of algal culture without antibiotic treatment. The final concentration of added bacterial suspension was set to low $\left(5 \times 10^{3}\right.$ cells $\left./ \mathrm{mL}\right)$, medium $\left(5 \times 10^{4}\right.$ cells $\left./ \mathrm{mL}\right)$, and high $\left(5 \times 10^{5}\right.$ cells $\left./ \mathrm{mL}\right)$ concentration levels, respectively. Strict sterile manipulation was carried out to avoid contamination during the co-culture experiments. The algal concentration was monitored every three days in triplicate using a 100-grid algal counting plate under an optical microscope (E200, Nikon, Tokyo, Japan). Besides, the growth rates (divisions day ${ }^{-1}$ ) of all of the experimental groups were calculated (supplementary material). To monitor the in vivo chlorophyll content (chlorophyll content per cell), 5-mL aliquots of algal samples were collected every three days during the co-culture experiment, and then added into a $10 \times 10 \mathrm{~mm}$ quartz cuvette for measuring. The total chlorophyll content was determined using the total Chl function of a Phytoplankton Analyzer (PHYTO-PAM, Walz, Germany) in triplicate [53]. During the measuring, four LED with 470-nm, 520-nm, 645-nm, and 665-nm emission wavelengths were applied for the excitation of chlorophyll fluorescence. The measuring lights were modulated with alternating $10-\mu$ s pulses at a repetition rate of $1200 \mathrm{~Hz}$. The PhytoWin software was applied for analyzing the primary information in signals from the independent fluorescence. After that, the calculated total chlorophyll content was further divided by the algal concentration to obtain the chlorophyll content per cell $\left(\times 10^{3} \mu \mathrm{g} / \mathrm{L} /\right.$ cell $)$.

\subsection{Co-Culture Experiment at Stationary Phase and Decline Phase}

In addition to the study of bacterial challenge to algal growth in the log phase, the strain Bacillus anthracis was selected to evaluate the effects on algal growth at the stationary phase and the decline phase. The 1022M2C12 in the early stationary and decline phase was applied for the co-culture experiment, respectively. For the stationary phase co-culture experiment, $5 \times 10^{5}$ cells $/ \mathrm{mL}$ 
and additional higher final concentrations of $1 \times 10^{6}$ cells $/ \mathrm{mL}$ and $2 \times 10^{6}$ cells $/ \mathrm{mL}$ of bacteria were added. The concentration of 1022M2C12 was monitored every three days in triplicate by an optical microscope. For the decline phase of the co-culture experiment, $5 \times 10^{5}$ cells $/ \mathrm{mL}$ of bacteria suspension was added when the algae entered the decline phase. Besides, to simulate the effects of nutrient supplementation and secondary metabolite removal, additional reference experiments were performed by (1) supplementing $5 \mathrm{~mL}$ of $100 \times \mathrm{K}$ medium stock solution into $500 \mathrm{~mL}$ of algal culture or (2) removing $480 \mathrm{~mL}$ of old medium and supplementing an equal volume of fresh $\mathrm{K}$ medium. During the manipulation, all of the algal cells settled to the bottom, and were not removed with the old medium.

\subsection{Bioactive Substance Investigation}

To evaluate the presence of potential bioactive substances from $B$. anthracis, aliquots of living bacterial suspension were ultrasonic treated to obtain the bacterial extracts and centrifuged by $12,000 \times g$ to obtain the supernatants. The $1022 \mathrm{M} 2 \mathrm{C} 12$ in the early stationary phase (about 2500 cells $/ \mathrm{mL}$ ) was used for co-culture with the bacterial extracts and supernatants from different final concentrations of $5 \times 10^{5}$ cells $/ \mathrm{mL}, 1 \times 10^{6}$ cells $/ \mathrm{mL}$, and $2 \times 10^{6}$ cells $/ \mathrm{mL}$ living bacterial suspension. To simulate nutrient supplementation effects, additional reference experiments were conducted by supplementing $5 \mathrm{~mL}$ of $100 \times \mathrm{K}$ medium stock solution into the $500-\mathrm{mL}$ algal culture.

\subsection{Species-Specificity Survey}

To survey the species-specific activity of $B$. anthracis on the growth of different strains of Gambierdiscus, additional co-culture experiments were performed using 1112M1M03 (Gambierdiscus sp. type 6, $0.02 \mathrm{pg}$ P-CTX-1/cell) and 1021M1DC4 (Gambierdiscus sp. type 6, no toxicity). A final concentration of $5 \times 10^{5}$ cells $/ \mathrm{mL}$ of bacterial suspensions were co-cultured with the algal cultures. The algal concentration was monitored in triplicate using the same method as previously described.

\subsection{Algal Toxicity Study}

During the above described co-culture experiment of all of the AHL-producing bacteria with the 1022M2C12, the CTX toxins were also extracted from parallel experimental groups to evaluate the effects of QS bacteria on algal toxicity. The total algal cells in 500-mL culture medium were collected and extracted with $\mathrm{MeOH}$ under sonication. The extracts were evaporated in a rotary evaporator (N1200A, EYELA, Tokyo, Japan), and then reconstituted in MeOH and mixed with HPLC water and dichloromethane (DCM) in a separator funnel. After partitioning, the DCM extracts were evaporated and rinsed with $\mathrm{MeOH}$. The toxicity of extracts was quantified by the Mouse Neuroblastoma Assay (MNA) [54], which measures the proliferation of Neuroblastoma cells (Neuro-2a) dosed with toxic extracts by MTT [3-(4,5-dimethyl-thiazol-2-yl)2,5-diphenyltetrazolium bromide] assay. The results were standardized by P-CTX-1 standard curves and reported as mean P-CTX-1 equivalents.

\subsection{Statistical Analysis}

For all of the experimental results, the mean and standard deviations from triplicate experiments were calculated by Microsoft Excel 2013 and Origin Lab 8.5. The Student's $t$-test in SPSS 20.0 (IBM, New York, NY, USA, 2011) was used to detect significant differences in experiments. A $p$ value $<0.05$ was statistically significant.

Supplementary Materials: The following are available online at http:/ /www.mdpi.com/2072-6651/10/7/257/s1, Figure S1: (a) The fast liquid AHL producers screening method in a 96-well microtiter plate and (b) the traditional solid agar plate screening results, with indicator strain A136. Black arrow: negative control (E. coli DH $5 \alpha)$; white arrow: blank control (water); red arrow: positive control (P. aeruginosa PAO1); green arrow: potential AHL-producing bacteria; 1 to 9: the screened AHL-producing strains, Figure S2: Taxonomic distribution at the genus level of the four sampling sites, Figure S3: Phylogenetic tree generated using the 16s rRNA gene of the screened AHL-producing bacterial species/phylotypes. Statistical method: Neighbor-joining. Number of bootstrap replications: 500. Model: Maximum Composite Likelihood, Table S1: Distribution of the corresponding 
genus of the screened QS bacteria, Table S2: Gambierdiscus strains from Marakei, Republic of Kiribati, Table S3: The gene fragment for the phylogenetic analyses, Table S4: Growth rate (divisions day ${ }^{-1}$ ) of $1022 \mathrm{M} 2 \mathrm{C} 12$ in co-culture experiment.

Author Contributions: B.W. designed the experiments, carried out the research, analyzed the data, wrote and revised the manuscript. M.Y., J.Z., S.T., H.J., F.Z., Y.L.M., J.W. and L.L.C. gave important suggestions and assisted in data analysis. J.Z. and Z.C. revised the manuscript.

Funding: The author thanks to the funding support from Key Research and Development Plan of Ministry of Science and Technology of China (2017YFC1403600), Marine Fishery Science and Technology and Industry Development of Guangdong Province (A201603D05), and S\&T Projects of Shenzhen Science and Technology Innovation Committee (KQJSCX2016022619041970, JCYJ20150831192329178, and JCYJ20170412171959157).

Acknowledgments: The author thanks to the State Key Laboratory in Marine Pollution, City University of Hong Kong, for the great help in isolating algae, quantifying toxin and providing technical supports.

Conflicts of Interest: The authors declare no conflict of interest.

\section{References}

1. Grattan, L.M.; Holobaugh, S.; Morris, J.G. Harmful algal blooms and public health. Harmful Algae 2016, 70, 859-875. [CrossRef] [PubMed]

2. Chinain, M.; Darius, H.T.; Ung, A.; Fouc, M.T.; Revel, T.; Cruchet, P.; Pauillac, S.; Laurent, D. Ciguatera risk management in French Polynesia: The case study of Raivavae Island (Australes Archipelago). Toxicon 2010, 56, 674-690. [CrossRef] [PubMed]

3. Chinain, M.; Darius, H.T.; Ung, A.; Cruchet, P.; Wang, Z.; Ponton, D.; Laurent, D.; Pauillac, S. Growth and toxin production in the ciguatera-causing dinoflagellate Gambierdiscus polynesiensis (Dinophyceae) in culture. Toxicon 2010, 56, 739-750. [CrossRef] [PubMed]

4. Lewis, R.J. The changing face of ciguatera. Toxicon 2001, 39, 97-106. [CrossRef]

5. Hamilton, B.; Whittle, N.; Shaw, G.; Eaglesham, G.; Moore, M.R.; Lewis, R.J. Human fatality associated with Pacific ciguatoxin contaminated fish. Toxicon 2010, 56, 668-673. [CrossRef] [PubMed]

6. Wong, C.K.; Hung, P.; Lo, J.Y. Ciguatera fish poisoning in Hong Kong-a 10-year perspective on the class of ciguatoxins. Toxicon 2014, 86, 96-106. [CrossRef] [PubMed]

7. Holmes, M.J. Gambierdiscus yasumotoi sp. nov. (Dinophyceae), a toxic benthic dinoflagellate from southeastern Asia. J. Phycol. 1998, 34, 661-668. [CrossRef]

8. Lewis, R.J. Ciguatera: Australian perspectives on a global problem. Toxicon 2006, 48, 799-809. [CrossRef] [PubMed]

9. Barton, E.D.; Tanner, P.; Turchen, S.G.; Tunget, C.L.; Manoguerra, A.; Clark, R.F. Ciguatera fish poisoning. A southern California epidemic. West. J. Med. 1995, 163, 31. [PubMed]

10. Van Dolah, F.M. Marine algal toxins: Origins, health effects, and their increased occurrence. Environ. Health Perspect. 2000, 108 (Suppl. 1), 133. [CrossRef]

11. Caillaud, A.; De la Iglesia, P.; Darius, H.T.; Pauillac, S.; Aligizaki, K.; Fraga, S.; Chinain, M.; Diogène, J. Update on methodologies available for ciguatoxin determination: Perspectives to confront the onset of ciguatera fish poisoning in Europe. Mar. Drugs 2010, 8, 1838-1907. [CrossRef] [PubMed]

12. Rongo, T.; van Woesik, R. Socioeconomic consequences of ciguatera poisoning in Rarotonga, southern Cook Islands. Harmful Algae 2012, 20, 92-100. [CrossRef]

13. Yogi, K.; Oshiro, N.; Inafuku, Y.; Hirama, M.; Yasumoto, T. Detailed LC-MS/MS analysis of ciguatoxins revealing distinct regional and species characteristics in fish and causative alga from the Pacific. Anal. Chem. 2011, 83, 8886-8891. [CrossRef] [PubMed]

14. Yang, Z.; Luo, Q.; Liang, Y.; Mazumder, A. Processes and pathways of ciguatoxin in aquatic food webs and fish poisoning of seafood consumers. Environ. Rev. 2016, 24, 144-150. [CrossRef]

15. Cruz-Rivera, E.; Villareal, T.A. Macroalgal palatability and the flux of ciguatera toxins through marine food webs. Harmful Algae 2006, 5, 497-525. [CrossRef]

16. Yasumoto, T. The chemistry and biological function of natural marine toxins. Chem. Rec. 2001, 1, $228-242$. [CrossRef] [PubMed]

17. Chan, W.H.; Mak, Y.L.; Wu, J.J.; Jin, L.; Sit, W.H.; Lam, J.C.W.; Mitcheson, Y.S.; Chan, L.L.; Lam, P.K.S.; Murphy, M.B. Spatial distribution of ciguateric fish in the Republic of Kiribati. Chemosphere 2011, 84, 117-123. [CrossRef] [PubMed] 
18. Mak, Y.L.; Wai, T.C.; Murphy, M.B.; Chan, W.H.; Wu, J.J.; Lam, J.C.W.; Chan, L.L.; Lam, P.K.S. Pacific ciguatoxins in food web components of coral reef systems in the Republic of Kiribati. Environ. Sci. Technol. 2013, 47, 14070-14079. [CrossRef] [PubMed]

19. Mak, Y.L. Pacific-Ciguatoxins (P-CTXs) in Coral Reef Fishes: Toxin Purification, Analytical Method Validation and Trophodynamics in Marine Food Web. Ph.D. Thesis, City University of Hong Kong, Hong Kong, China, 2012.

20. Ashton, M.; Rosado, W.; Govind, N.S.; Tosteson, T.R. Culturable and nonculturable bacterial symbionts in the toxic benthic dinoflagellate Ostreopsis lenticularis. Toxicon 2003, 42, 419-424. [CrossRef]

21. Lartigue, J.; Jester, E.L.; Dickey, R.W.; Villareal, T.A. Nitrogen source effects on the growth and toxicity of two strains of the ciguatera-causing dinoflagellate Gambierdiscus toxicus. Harmful Algae 2009, 8, 781-791. [CrossRef]

22. Parsons, M.L.; Settlemier, C.J.; Bienfang, P.K. A simple model capable of simulating the population dynamics of Gambierdiscus, the benthic dinoflagellate responsible for ciguatera fish poisoning. Harmful Algae 2010, 10, 71-80. [CrossRef]

23. Kibler, S.R.; Litaker, R.W.; Holland, W.C.; Vandersea, M.W.; Tester, P.A. Growth of eight Gambierdiscus (Dinophyceae) species: Effects of temperature, salinity and irradiance. Harmful Algae 2012, 19, 1-14. [CrossRef]

24. Sakami, T.; Nakahara, H.; Chinain, M.; Ishida, Y. Effects of epiphytic bacteria on the growth of the toxic dinoflagellate Gambierdiscus toxicus (Dinophyceae). J. Exper. Mar. Biol. Ecol. 1999, 233, 231-246. [CrossRef]

25. Burke, C.; Thomas, T.; Lewis, M.; Steinberg, P.; Kjelleberg, S. Composition, uniqueness and variability of the epiphytic bacterial community of the green alga Ulva australis. ISME J. 2011, 5, 590. [CrossRef] [PubMed]

26. Rains, L.K.; Parsons, M.L. Gambierdiscus species exhibit different epiphytic behaviors toward a variety of macroalgal hosts. Harmful Algae 2015, 49, 29-39. [CrossRef]

27. Zhou, J.; Chen, G.; Zhu, X.; Chen, L.; Cai, Z. A review of the relationship between algae and bacteria in harmful algal blooms. Acta Ecol. Sin. 2014, 34, 269-281. [CrossRef]

28. Zhou, J.; Lyu, Y.; Richlen, M.L.; Anderson, D.M.; Cai, Z. Quorum sensing is a language of chemical signals and plays an ecological role in algal-bacterial interactions. Crit. Rev. Plant Sci. 2016, 35, 81-105. [CrossRef] [PubMed]

29. Ashen, J.B.; Goff, L.J. Molecular and ecological evidence for species specificity and coevolution in a group of marine algal-bacterial symbioses. Appl. Environ. Microbiol. 2000, 66, 3024-3030. [CrossRef] [PubMed]

30. Amin, S.A.; Parker, M.S.; Armbrust, E.V. Interactions between diatoms and bacteria. Microbiol. Mol. Biol. Rev. 2012, 76, 667-684. [CrossRef] [PubMed]

31. Waters, C.M.; Bassler, B.L. Quorum sensing: Cell-to-cell communication in bacteria. Annu. Rev. Cell Dev. Biol. 2005, 21, 319-346. [CrossRef] [PubMed]

32. Luc Rolland, J.; Stien, D.; Sanchez-Ferandin, S.; Lami, R. Quorum sensing and quorum quenching in the phycosphere of phytoplankton: A case of chemical interactions in ecology. J. Chem. Ecol. 2016, 42, 1201-1211. [CrossRef] [PubMed]

33. Fuqua, C.; Parsek, M.R.; Greenberg, E.P. Regulation of gene expression by cell-to-cell communication: Acyl-homoserine lactone quorum sensing. Annu. Rev. Genet. 2001, 35, 439-468. [CrossRef] [PubMed]

34. Joint, I.; Tait, K.; Callow, M.E.; Callow, J.A.; Milton, D.; Williams, P.; Cámara, M. Cell-to-cell communication across the prokaryote-eukaryote boundary. Science 2002, 298, 1207-1207. [CrossRef] [PubMed]

35. Tait, K.; Joint, I.; Daykin, M.; Milton, D.L.; Williams, P.; Camara, M. Disruption of quorum sensing in seawater abolishes attraction of zoospores of the green alga Ulva to bacterial biofilms. Environ. Microbiol. 2005, 7, 229-240. [CrossRef] [PubMed]

36. González, J.E.; Keshavan, N.D. Messing with bacterial quorum sensing. Microbiol. Mol. Biol. Rev. 2006, 70, 859-875. [CrossRef] [PubMed]

37. Singh, R.P.; Reddy, C.R.K. Seaweed-microbial interactions: Key functions of seaweed-associated bacteria. FEMS Microbiol. Ecol. 2014, 88, 213-230. [CrossRef] [PubMed]

38. Singh, R.P.; Baghel, R.S.; Reddy, C.R.K.; Jha, B. Effect of quorum sensing signals produced by seaweed-associated bacteria on carpospore liberation from Gracilaria dura. Front. Plant Sci. 2015, 6, 117. [CrossRef] [PubMed] 
39. Yoshimatsu, T.; Yamaguchi, H.; Iwamoto, H.; Nishimura, T.; Adachi, M. Effects of temperature, salinity and their interaction on growth of Japanese Gambierdiscus spp. (Dinophyceae). Harmful Algae 2014, 35, $29-37$. [CrossRef]

40. Lehane, L.; Lewis, R.J. Ciguatera: Recent advances but the risk remains. Int. J. Food Microbiol. 2000, 61, 91-125. [CrossRef]

41. Chinain, M.; Laurent, N.; Pauillac, S.; Legrand, A.M. Effects of an artificial medium and axenic culturing on toxicity of cultured Gambierdiscus toxicus. In Proceedings of the International Symposium on Ciguatera and Marine Natural Products; Hokama, Y., Scheuer, P.J., Yasumoto, T., Eds.; Asian Pacific Research Foundation: Hawaii, HI, USA, 1994; pp. 91-98.

42. Soria-Dengg, S.; Reissbrodt, R.A.H.U.; Horstmann, U. Siderophores in marine coastal waters and their relevance for iron uptake by phytoplankton: Experiments with the diatom Phaeodactylum tricornutum. Mar Ecol. Prog. Ser. 2001, 220, 73-82. [CrossRef]

43. Gutierrez, T.; Biller, D.V.; Shimmield, T.; Green, D.H. Metal binding properties of the EPS produced by Halomonas sp. TG39 and its potential in enhancing trace element bioavailability to eukaryotic phytoplankton. Biometals 2012, 25, 1185-1194. [CrossRef] [PubMed]

44. Fuentes, J.L.; Garbayo, I.; Cuaresma, M.; Montero, Z.; González-del-Valle, M.; Vílchez, C. Impact of microalgae-bacteria interactions on the production of algal biomass and associated compounds. Mar. Drugs 2016, 14, 100. [CrossRef] [PubMed]

45. Azam, F. Microbial control of oceanic carbon flux: The plot thickens. Science 1998, 280, 694-696. [CrossRef]

46. Russo, D.A.; Couto, N.; Beckerman, A.P.; Pandhal, J. A Metaproteomic analysis of the response of a freshwater microbial community under nutrient enrichment. Front. Microbiol. 2016, 7, 1172. [CrossRef] [PubMed]

47. Rietschel, E.T.; Kirikae, T.; Schade, F.U.; Mamat, U.; Schmidt, G.; Loppnow, H.; Di Padova, F. Bacterial endotoxin: Molecular relationships of structure to activity and function. FASEB J. 1994, 8, 217-225. [CrossRef] [PubMed]

48. Kaczmarska, I.; Ehrman, J.M.; Bates, S.S.; Green, D.H.; Léger, C.; Harris, J. Diversity and distribution of epibiotic bacteria on Pseudo-nitzschia multiseries (Bacillariophyceae) in culture, and comparison with those on diatoms in native seawater. Harmful Algae 2005, 4, 725-741. [CrossRef]

49. Xu, Y.; Richlen, M.L.; Morton, S.L.; Mak, Y.L.; Chan, L.L.; Tekiau, A.; Anderson, D.M. Distribution, abundance and diversity of Gambierdiscus spp. from a ciguatera-endemic area in Marakei, Republic of Kiribati. Harmful Algae 2014, 34, 56-68. [CrossRef]

50. Keller, M.D.; Selvin, R.C.; Claus, W.; Guillard, R.R. Media for the culture of oceanic ultraphytoplankton 1, 2. J. Phycol. 1987, 23, 633-638. [CrossRef]

51. Radjasa, O.K.; Urakawa, H.; Kita-Tsukamoto, K.; Ohwada, K. Characterization of psychrotrophic bacteria in the surface and deep-sea waters from the northwestern Pacific Ocean based on 16S ribosomal DNA analysis. Mar. Biotechnol. 2001, 3, 454-462. [CrossRef] [PubMed]

52. Zhu, J.; Chai, Y.; Zhong, Z.; Li, S.; Winans, S.C. Agrobacterium bioassay strain for ultrasensitive detection of $\mathrm{N}$-acylhomoserine lactone-type quorum-sensing molecules: Detection of autoinducers in Mesorhizobium huakuii. Appl. Environ. Microbiol. 2003, 69, 6949-6953. [CrossRef] [PubMed]

53. Jakob, T.; Schreiber, U.; Kirchesch, V.; Langner, U.; Wilhelm, C. Estimation of chlorophyll content and daily primary production of the major algal groups by means of multiwavelength-excitation PAM chlorophyll fluorometry: Performance and methodological limits. Photosynth. Res. 2005, 83, 343-361. [CrossRef] [PubMed]

54. Wu, J.J.; Mak, Y.L.; Murphy, M.B.; Lam, J.C.; Chan, W.H.; Wang, M.; Chan, L.L.; Lam, P.K.S. Validation of an accelerated solvent extraction liquid chromatography-tandem mass spectrometry method for Pacific ciguatoxin-1 in fish flesh and comparison with the mouse neuroblastoma assay. Anal. Bioanal. Chem. 2011, 400, 3165-3175. [CrossRef] [PubMed]

(C) 2018 by the authors. Licensee MDPI, Basel, Switzerland. This article is an open access article distributed under the terms and conditions of the Creative Commons Attribution (CC BY) license (http:/ / creativecommons.org/licenses/by/4.0/). 


\title{
Article \\ Extended Targeted and Non-Targeted Strategies for the Analysis of Marine Toxins in Mussels and Oysters by (LC-HRMS)
}

\author{
Inès Dom ${ }^{1,2}$, Ronel Biré ${ }^{1, *}$, Vincent Hort ${ }^{1}$, Gwenaëlle Lavison-Bompard ${ }^{1}$, Marina Nicolas ${ }^{1}$ and \\ Thierry Guérin ${ }^{1}$ \\ 1 Laboratory for Food Safety, ANSES, Université Paris-Est, F-94701 Maisons-Alfort, France; \\ ines.dom@anses.fr (I.D.); vincent.hort@anses.fr (V.H.); gwenaelle.lavison-bompard@anses.fr (G.L.-B.); \\ marina.nicolas@anses.fr (M.N.); thierry.guerin@anses.fr (T.G.) \\ 2 Agreenium, the French Agricultural, Veterinary and Forestry Institute, 75116 Paris, France \\ * Correspondence: ronel.bire@anses.fr; Tel.: +33-149-772-722
}

Received: 11 July 2018; Accepted: 11 September 2018; Published: 14 September 2018

\begin{abstract}
When considering the geographical expansion of marine toxins, the emergence of new toxins and the associated risk for human health, there is urgent need for versatile and efficient analytical methods that are able to detect a range, as wide as possible, of known or emerging toxins. Current detection methods for marine toxins rely on a priori defined target lists of toxins and are generally inappropriate for the detection and identification of emerging compounds. The authors describe the implementation of a recent approach for the non-targeted analysis of marine toxins in shellfish with a focus on a comprehensive workflow for the acquisition and treatment of the data generated after liquid chromatography coupled with high resolution mass spectrometry (LC-HRMS) analysis. First, the study was carried out in targeted mode to assess the performance of the method for known toxins with an extended range of polarities, including lipophilic toxins (okadaic acid, dinophysistoxins, azaspiracids, pectenotoxins, yessotoxins, cyclic imines, brevetoxins) and domoic acid. The targeted method, assessed for 14 toxins, shows good performance both in mussel and oyster extracts. The non-target potential of the method was then challenged via suspects and without a priori screening by blind analyzing mussel and oyster samples spiked with marine toxins. The data processing was optimized and successfully identified the toxins that were spiked in the blind samples.
\end{abstract}

Keywords: marine toxins; LC-HRMS; targeted analysis; suspects screening; non-targeted analysis; method characterization

Key Contribution: (1) Efficient liquid chromatography coupled with high resolution mass spectrometry (LC-HRMS) targeted quantitative method developed and characterized for the analysis of many marine toxins of different polarities, including lipophilic toxins and domoic acid. (2) Optimized strategy for non-targeted analysis of marine toxins, including suspect and without a priori screening. (3) Combination of targeted and non-targeted strategies allowing for good characterization of analyzed shellfish samples.

\section{Introduction}

Marine toxins are natural compounds produced by certain microalgae that can contaminate a wide variety of marine species, including fish, crabs, or filter feeding bivalves (shellfish), such as mussels, oysters, scallops, and clams [1]. Different groups of toxins have been identified: saxitoxins (STXs), domoic acid (DA) and its isomers, tetrodotoxins (TTXs), okadaic acid (OA) and dinophysistoxins (DTXs), pectenotoxins (PTXs), yessotoxins (YTXs), azaspiracids (AZAs), ciguatoxins 
(CTXs), palytoxins (PLTXs) and ovatoxins (OVTXs), brevetoxins (PbTxs) and cyclic imines (spirolides (SPXs), gymnodimines (GYMs), pinnatoxins (PnTXs), pteriatoxins, prorocentrolides, portimine) [2]. These toxins are responsible for various biological activities and can exert deleterious effects on human health $[3,4]$.

To protect human health from these toxigenic compounds and to avoid food poisoning, the presence of certain toxins in food destined for human consumption is regulated within the European Union (EU) [5,6] and is submitted to monitoring programs. These regulations clearly mention the toxins to monitor, the thresholds that should not be surpassed and the methods of analysis. Biological assays using mice and rats were prescribed as reference methods for certain toxins but are subject to controversy due to ethical issues and their lack of specificity [7]. To perform official monitoring of some toxins, such as saxitoxins and lipophilic toxins, chemical methods replace animal bioassays $[8,9]$. This is the case of liquid chromatography coupled with mass spectrometry (LC-MS). LC-MS methods are reported for the analysis of several toxin families in shellfish either individually or together [10-15]. Target monitoring approaches are fit for regulatory purposes as they achieve good sensitivity and specificity. These methods are based on a targeted screening that only seeks to find a short list of predetermined compounds, while missing all other toxins that could be present in the sample. To be fully integrative with respect to consumers' safety, monitoring programs should be able to detect the appearance of so called "emerging toxins". The latter include newly discovered toxins/toxin analogues, as well as the detection of known toxins in areas where they had not been previously described. Methods using high resolution mass spectrometry (HRMS) have been recently developed and used for the analysis of a larger panel of marine toxins in a single run [16-18]. The HRMS technology enables reliable analysis with excellent specificity and selectivity that are necessary to resolve the interference from complex matrices, such as mussels and oysters [19-21]. Besides, this technology offers new monitoring capabilities such as retrospective analysis and the possibility to move from targeted to non-targeted analysis allowing the identification of "unknowns". Yet, the non-targeted analysis is a very challenging task, as it requires extensive processing of the generated dataset. To render these data meaningful, multistep strategies using chemometric tools are required before the final identification of a specific signal among a forest of interfering signals.

While there are several studies in the literature regarding the characterization and validation of targeted methods for the analysis of marine toxins in different matrices, both in low and high resolution $[11,15,16,18,22-25]$, there are no studies presenting an appropriate characterized strategy for the non-targeted approach in the field of marine toxins. Only a few papers, inspired from the metabolomics approaches dealing with the analysis of environmental samples (wastewaters), addressed this challenge [26-31].

This paper describes the implementation and the characterization of an LC-HRMS method for the analysis of different toxins with an extended range of polarities, including lipophilic toxins and domoic acid, by the accurate measurement in MS and MS/MS modes in a single run while using a hybrid quadrupole time of flight mass spectrometer (QTOF). The expression "method characterization" should be understood throughout the manuscript as the assessment of some performances of the method but is different from a method validation, which is a more extensive and complete process. The method developed relies on a workflow (Figure 1) combining both targeted and non-targeted analysis composed of three approaches; (1) targeted screening similar to low resolution MS where reference standards are used to search for the compounds of interest; (2) suspect screening that consists of querying a database/library including an exhaustive list of suspect compounds for which reference standards might not be available; and, (3) non-targeted screening performed without a priori, thus, without reference standards or suspects to identify unexpected compounds [26,28]. First, suitable chromatographic conditions are chosen for the separation of the selected toxins with a broad range of polarities. The performance of the targeted quantitative analysis is assessed as a prerequisite for the non-targeted analysis. A multistep specific data filtering strategy from data acquisition to the final tentative identification of interesting ions is established and optimized by reducing the size of the 
search space. The general workflow for suspects and without a priori screening is tested and critically evaluated through the analysis in blinds of shellfish samples that are spiked with marine toxins.

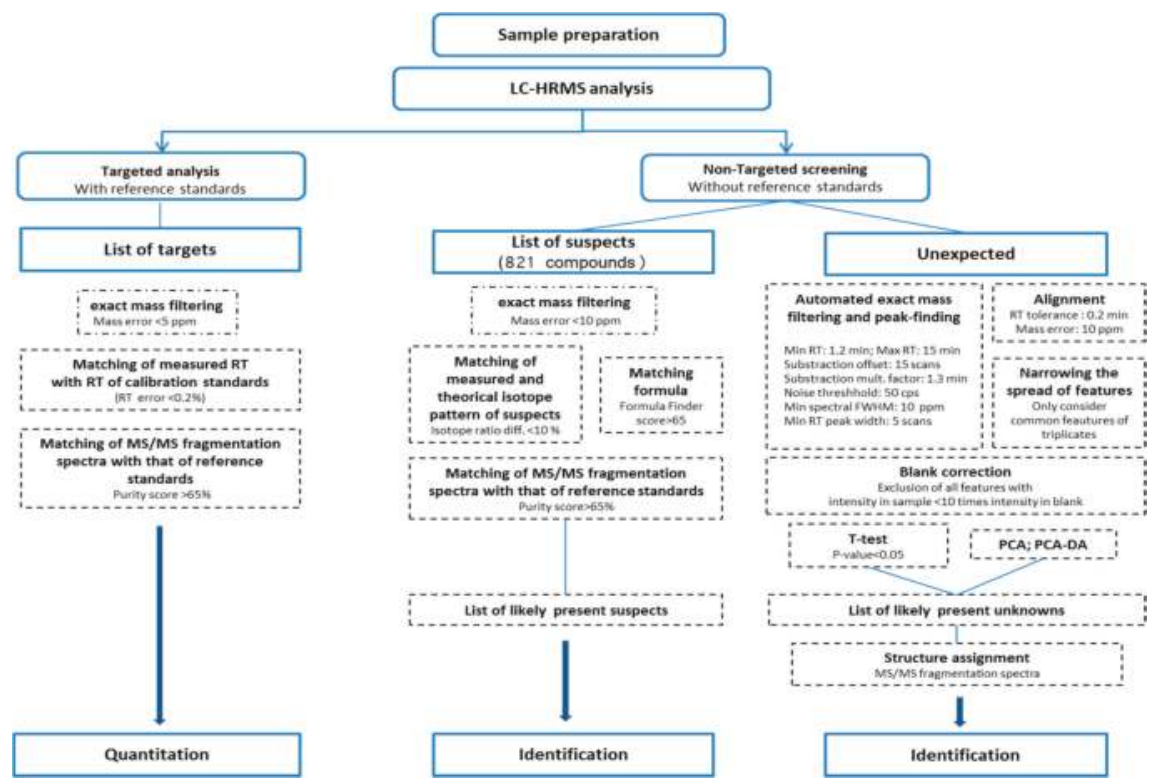

Figure 1. Processing workflow with optimized parameters for (1) quantitative targeted analysis, (2) suspect screening and (3) non-targeted screening of unknowns using liquid chromatography coupled with high resolution mass spectrometry (LC-HRMS) (adapted from Krauss et al. [26] and Nürenberg et al. [28]).

\section{Results}

\subsection{Targeted Analysis}

\subsubsection{Method Development}

The method was developed to analyze a large range of lipophilic and relatively polar toxins. A total of 18 toxins for which certified standard solutions were available were analyzed either in positive or negative ionization mode; azaspiracids 1, 2, and 3 (AZA1-3), pectenotoxin 2 (PTX2), okadaic acid (OA), dinophysistoxins 1 and 2 (DTX1 and 2), yessotoxin (YTX), homo-yessotoxin (hYTX), 13-desmethyl spirolide C (SPX1), pinnatoxin A and G (PnTX-A, PnTX-G), gymnodimine A (GYM), 13,19-didesmethyl Spirolide-C (13,19-didesMeC), 20-methyl spirolide-G (20-meG), domoic acid (DA), and brevetoxins 2 and 3 (PbTx-2 and PbTx-3).

Regarding all the toxins analyzed in $\mathrm{ESI}^{+}$(GYM, SPX1, 13,19-didesMeC, 20-meG, PnTX-A and $\mathrm{G}, \mathrm{AZA} 1$ to $-3, \mathrm{PTX} 2, \mathrm{PbTx}-2$, and -3 ), protonated molecules $[\mathrm{M}+\mathrm{H}]^{+}$were detected except for PTX2, for which the $\left[\mathrm{M}+\mathrm{NH}_{4}\right]^{+}$adduct was chosen as the characteristic ion. Concerning $\mathrm{ESI}^{-}$, the deprotonated form $[\mathrm{M}-\mathrm{H}]^{-}$was detected for OA, DTX1 and 2, YTX and hYTX. DA was detected in both ionization modes, but a better sensitivity was observed in $\mathrm{ESI}^{-}$. The deprotonated form $[\mathrm{M}-\mathrm{H}]^{-}$of DA $(\mathrm{m} / \mathrm{z}$ 310.12961) was used for identification and quantitation purposes.

Since working in high resolution, toxin identification was mainly based on the exact mass of each molecule. Thus, the mass accuracy (expressed in ppm) was determined while using the suspects list. The corresponding standard deviations (SDs) of the masses for the intra-day and inter-day precision 
ranged from 0.4 to $1.7 \mathrm{ppm}$ (Supplementary Material Figure S1). These results show good stability in mass measurements in the current analytical conditions.

Optimized LC conditions while using the C18 HSS T3 column allowed for a good separation of most of the toxins analyzed in both ionization modes (Figure 2). Chromatographic resolution was mostly important in the case of isobaric toxins (OA/DTX2), for which satisfactory separation was achieved. The inter-day and intra-day deviations in retention time (RT) did not exceed $0.2 \%$ over the course of the study, and were therefore negligible for all the targeted toxins.
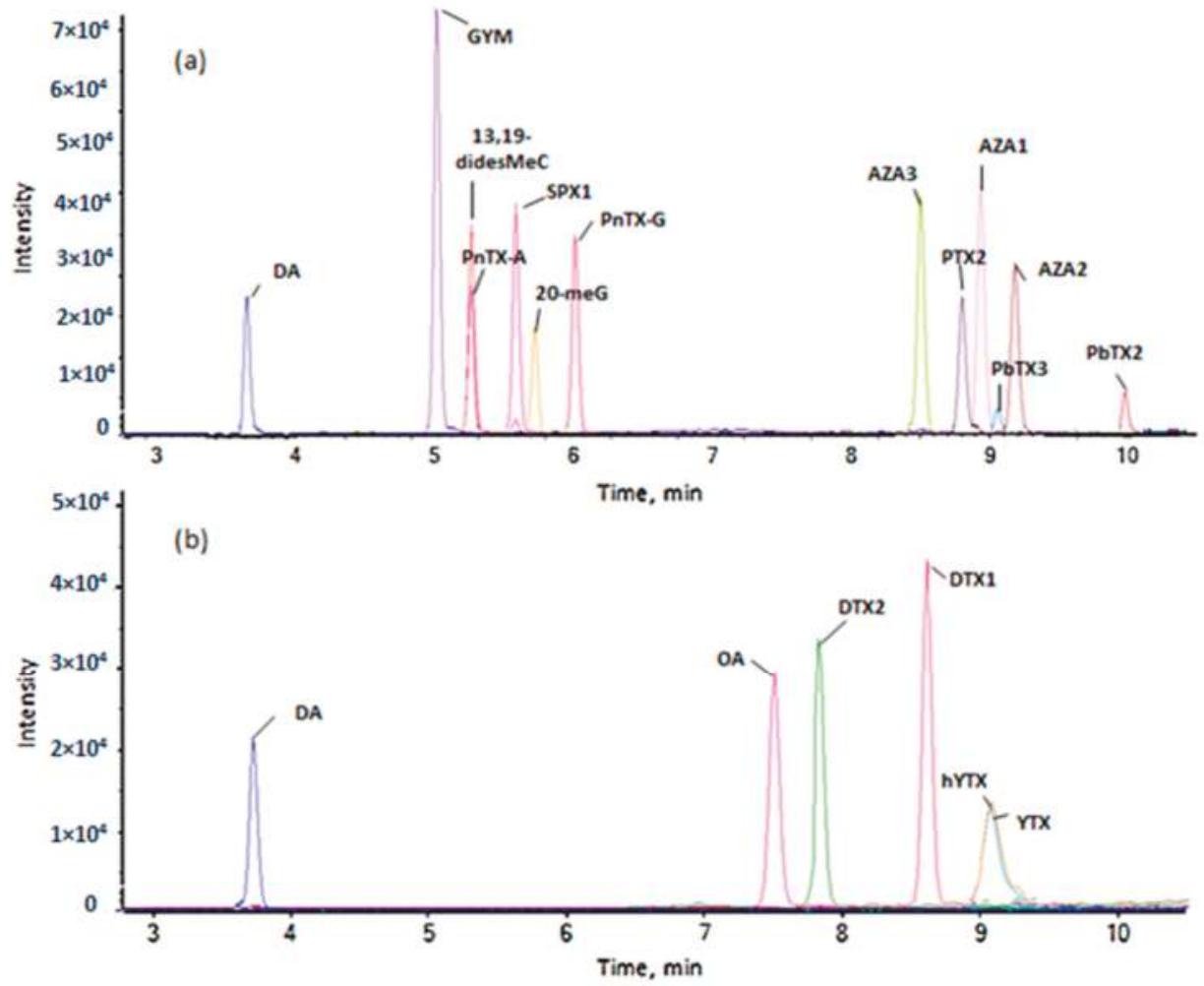

Figure 2. Separation of the different marine toxins in the optimized chromatographic conditions, analyzed on a 5600 quadrupole time of flight mass spectrometer (QTOF) (a) in positive ionization and (b) negative ionization mode.

A target compound list was created, including information, such as exact mass, adduct, and retention time, of all toxins analyzed to be used for quantitation (Supplementary Material Table S1). A library including the MS and MS/MS spectra of the available standards was also created for further confirmation purposes.

\subsubsection{Characterization Study of the Quantitative Method}

Several criteria were investigated to evaluate the suitability of the quantitative method. The linearity of the calibration curves was verified by a correlation study. All of the determination coefficients $\left(R^{2}\right)$ were above 0.99 for both solvent and matrix-matched calibration curves (Supplementary Materials Table S2). Specificity was assessed by analyzing and comparing non-spiked and spiked blank mussel and oyster samples. Results showed that all the toxins were only detected in the spiked samples at specific retention times. The high resolution in MS analysis also contributed to 
the specificity of the method and confirmed that toxins in real shellfish samples can be screened and clearly identified.

The sensitivity of the method was evaluated by the assessment of LODs and LOQs in MeOH and two different matrices, typically mussels and oysters (Table 1). Good sensitivity was achieved for the 14 toxins included in the characterization study. Using mussel extract, limits of quantification (LOQs) were comprised between $2.0 \mu \mathrm{g} / \mathrm{kg}(\mathrm{GYM})$ and $8.9 \mu \mathrm{g} / \mathrm{kg}(\mathrm{OA})$. DA had a higher LOQ (30 $\mu \mathrm{g} / \mathrm{kg})$. LOQs determined in the oyster extract were slightly lower for all toxins compared to the sensitivity in mussel extract, except for PnTX-G, DTX1, and DA. The lowest LOQs were achieved in $\mathrm{MeOH}$, in the absence of matrix, with values ranging from 1.1 to $26 \mu \mathrm{g} / \mathrm{kg}$ for GYM and DA respectively.

Regarding YTXs, LOQs were relatively higher than expected when compared to a triple quadrupole detector, but it can still be considered as acceptable. Brevetoxins were the least sensitive among the studied toxins in the presented conditions. A change in the mobile phase B from ACN to $\mathrm{MeOH}$ (keeping the rest of the composition the same as reported in the materials and methods section) allowed for a much better sensitivity for PbTx-2 and 3 (by a factor of 6-10). As most of the toxins analyzed responded well in the ACN mobile phase, the authors decided to keep this composition and evaluate the method for the 14 toxins with the lowest LOQs, excluding YTXs and PbTxs.

Table 1. Limits of quantification (LOQs) of the different toxins in methanol (MeOH) and matrix (mussel and oyster).

\begin{tabular}{cccc}
\hline & \multicolumn{3}{c}{ LOQ $(\mu \mathrm{g} / \mathbf{k g})$} \\
\cline { 2 - 4 } & MeOH & Mussel & Oyster \\
\hline AZA1 & 4.3 & 4.6 & 4.5 \\
AZA2 & 2.7 & 4.4 & 3.2 \\
AZA3 & 5.6 & 7.6 & 6.5 \\
PTX2 & 6.7 & 8.7 & 8.4 \\
GYM-A & 1.1 & 2.0 & 1.6 \\
SPX1 & 1.7 & 3.1 & 2.2 \\
PnTX-A & 4.4 & 5.1 & 4.6 \\
PnTX-G & 5.0 & 4.4 & 4.6 \\
13,19-didesMeC & 3.3 & 4.7 & 4.1 \\
20-meG & 3.5 & 5.0 & 4.0 \\
OA & 6.0 & 8.9 & 5.6 \\
DTX1 & 3.6 & 4.4 & 5.6 \\
DTX2 & 4.2 & 5.4 & 5.0 \\
DA & 26 & 30 & 31 \\
YTX * & 87 & 119 & 132 \\
hYTX * & 84 & 121 & 128 \\
PbTx-2 * & 280 & 312 & 324 \\
PbTx-3 * & 300 & 321 & 337 \\
\hline
\end{tabular}

* These toxins were not part of the characterization study for sensivity issues. Corresponding LOQs were estimated in a preliminary study, as equivalent to an $\mathrm{S} / \mathrm{N}$ of 10 , by analyzing in triplicate low level spiked extracts.

Matrix effects for mussel and oyster extracts were determined by a comparison of the mean slope of $\mathrm{MeOH}$ calibration curves $(n=3)$ to those of the matrix-matched calibration curves $(n=3)$. Observed effects can be described either as signal enhancement (responses $>100 \%$ ) or signal suppression (response $<100 \%$ ). Concerning the mussel extract, 11 of the toxins tested exhibited an ion suppression effect ranging from $-8 \%$ for AZA1 to $-27 \%$ for $20-\mathrm{meG}$ (Figure 3). No matrix effect was observed for PTX2, while DTX2 and DA were responsible for ion enhancement with a $+20 \%$ signal gain in mussel matrix. Concerning the oyster matrix, ion enhancement was observed for eight toxins (8 out of 14) with values generally $<+20 \%$, ranging from $+6 \%$ (AZA1) to $+15 \%$ (for SPX1 and $20-\mathrm{meG}$ ), except for DA $(+33 \%)$. The six remaining toxins showed ion suppression ranging from $-3 \%$ (PTX2) to $-13 \%$ (DTX1). Matrix effects are globally considered as satisfactory and no correction factors were applied for quantitation. 


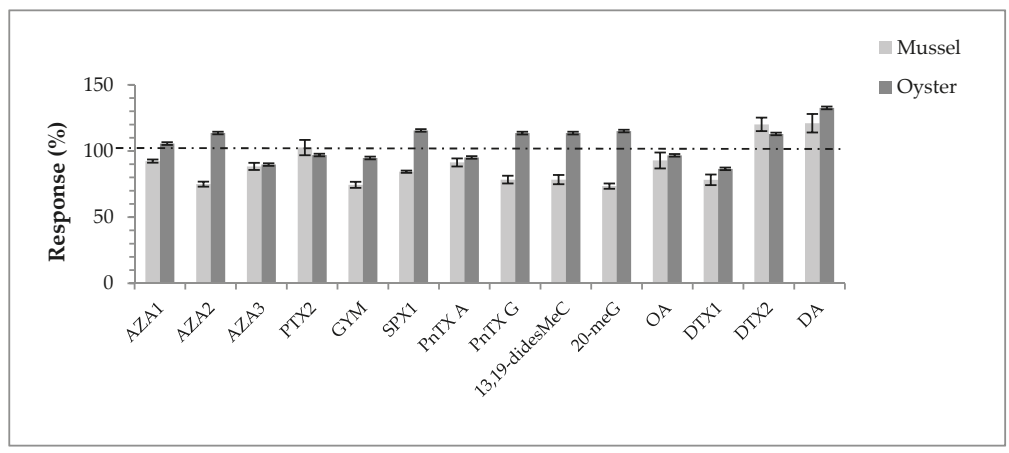

Figure 3. Matrix effects observed for the tested toxins in mussel and oyster extracts. The dashed line representing the $100 \%$ response corresponds to the results obtained in $\mathrm{MeOH}$, used as a reference.

The accuracy of the method was verified by measuring the recoveries from blank mussels spiked at two concentration levels, six replicates for each fortification level. Following the EU Commission decision 2002/657/EC as a guideline, the proposed method was found to be accurate with satisfactory recoveries ranging from $86 \%$ to $110 \%$ for the low spike level and from $95 \%$ to $106 \%$ for the high spike level (Table 2). These results confirm that the extraction method is well adapted for all of the toxins analyzed. This shows that discriminating purification steps, which might be a limitation for non-targeted analysis, can be avoided. The precision of the assay, reflected by the repeatability and within-laboratory reproducibility, was investigated by means of the relative standard deviation (\%RSD). The \%RSD values that were obtained for intra-day $\left(\mathrm{RSD}_{\mathrm{r}}\right)$ and inter-day variations $\left(\mathrm{RSD}_{\mathrm{R}}\right)$ ranged from $1.3 \%$ to $13.7 \%$ and from $1.7 \%$ to $19.8 \%$, respectively, depending on the toxins (Table 2). The precision was generally better for the high spike levels $(120,240$ or $720 \mu \mathrm{g} / \mathrm{kg})$. Results are within the acceptance criteria $(<20 \%)$ demonstrating that the proposed method is considered as precise and it could be adopted for quantitative analysis.

Table 2. Accuracy and precision $(n=6)$ for the quantitative procedure in mussel matrix.

\begin{tabular}{ccccc}
\hline Toxins & Spike Level $(\mu \mathrm{g} / \mathbf{k g})$ & Recovery $(\%)$ & RSDr $(\%)$ & RSD $_{\mathbf{R}}(\mathbf{\%})$ \\
\hline \multirow{2}{*}{ AZA1 } & 10 & 96 & 13.7 & 17.1 \\
& 120 & 105 & 3.4 & 5.8 \\
\hline \multirow{2}{*}{ AZA2 } & 10 & 86 & 8.2 & 11.3 \\
& 120 & 100 & 1.3 & 4.2 \\
\hline \multirow{2}{*}{ AZA3 } & 10 & 103 & 12.9 & 19.8 \\
& 120 & 104 & 2.9 & 6.9 \\
\hline \multirow{2}{*}{ PTX2 } & 20 & 110 & 9.4 & 11.0 \\
& 240 & 101 & 4.2 & 4.2 \\
\multirow{2}{*}{ GYM } & 10 & 97 & 6.1 & 6.1 \\
& 120 & 100 & 7.3 & 7.3 \\
\hline \multirow{2}{*}{ SPX1 } & 10 & 94 & 3.9 & 9.1 \\
& 120 & 103 & 1.6 & 1.7 \\
\hline \multirow{2}{*}{ PnTX-A } & 10 & 90 & 8.0 & 8.9 \\
& 120 & 97 & 4.8 & 6.2 \\
\hline \multirow{2}{*}{ PnTX-G } & 10 & 103 & 11.4 & 14.7 \\
& 120 & 95 & 11.4 & 14.7 \\
\hline \multirow{2}{*}{$13,19-$ didesMeC } & 10 & 91 & 8.7 & 12.1 \\
& 120 & 105 & 4.1 & 4.1 \\
\hline \multirow{2}{*}{$20-$ meG } & 10 & 88 & 9.1 & 14.1 \\
& 20 & 102 & 1.7 & 1.9 \\
\hline \multirow{2}{*}{} & & & &
\end{tabular}


Table 2. Cont.

\begin{tabular}{ccccc}
\hline Toxins & Spike Level $(\mu \mathrm{g} / \mathbf{k g})$ & Recovery $(\%)$ & RSDr $(\%)$ & RSD $_{\mathbf{R}}(\%)$ \\
\hline \multirow{2}{*}{ OA } & 20 & 106 & 5.9 & 8.7 \\
& 240 & 103 & 8.0 & 9.2 \\
\hline \multirow{2}{*}{ DTX1 } & 20 & 108 & 11.9 & 11.9 \\
& 240 & 106 & 3.0 & 3.2 \\
\hline \multirow{2}{*}{ DTX2 } & 20 & 106 & 6.9 & 7.1 \\
& 240 & 104 & 7.6 & 8.3 \\
\hline \multirow{2}{*}{ DA } & 60 & 99 & 12.2 & 12.2 \\
& 720 & 99 & 1.4 & 2.7 \\
\hline
\end{tabular}

\subsubsection{Application}

Homogenates of naturally contaminated mussel tissues (Mytilus spp.) containing lipophilic toxins or DA proposed by the European reference laboratory for marine biotoxins (EURLMB) as part of proficiency testing schemes were analyzed by LC-HRMS. The results highlighted a very good agreement with the assigned values (Figure 4). All the lipophilic toxins (OA, YTX, hYTX, 45-OH-YTX, AZA1 to 3) were correctly identified and quantified (Z-score values comprised between -2 and +2 ), except for total DTX2 in sample EURL/L/03 (Z-score value of -4.2), due to its concentration around the LOQ. Samples containing DA were quantified correctly and the results are within acceptable Z-score limits $(|z|<2)$. These results confirm that the method developed is suitable for the quantification of both lipophilic toxins and DA in naturally contaminated shellfish samples.

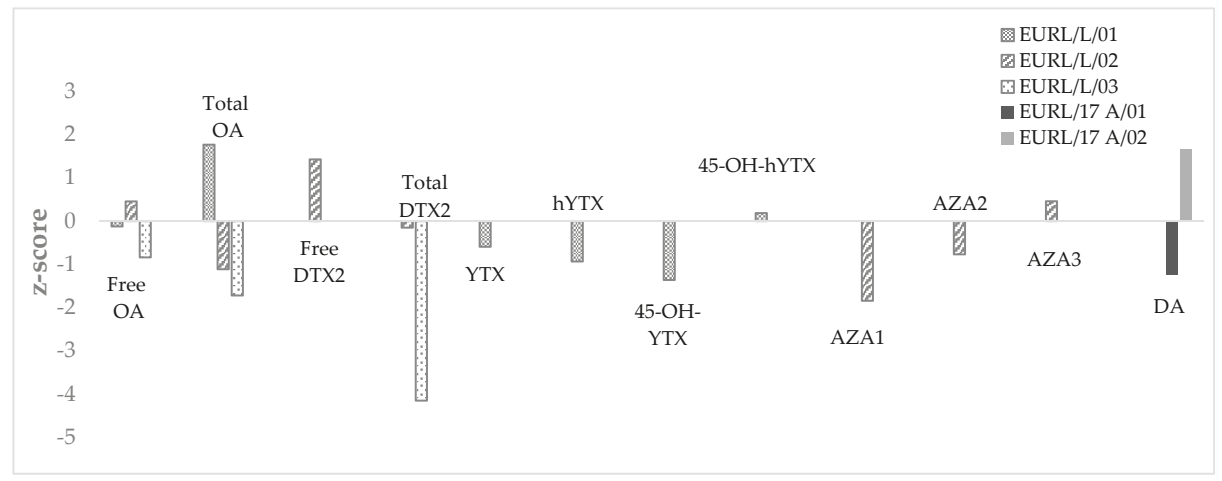

Figure 4. Z-scores obtained after analyzing, by LC-HRMS, the five samples provided by the EURLMB as part of a proficiency testing scheme for lipophilic toxins and DA.

The method developed has demonstrated good performances for the identification and quantification of many toxins belonging to different groups with a wide polarity range, proving that it is fit for targeted analysis. The method was fully characterized for the studied toxins, except for YTXs and PbTxs.

\subsection{Non-Targeted Analysis}

\subsubsection{Evaluation of the Suspect Screening Approach}

Criteria for the identification and confirmation of suspects needed to be carefully chosen to minimize the risks for both false-positive (features erroneously identified as peaks of interest) and false-negative results. Different parameters were selected and optimized for accurate mass matches through the suspects list. A minimal intensity of 1000 counts was required for a minimal area representative for an actual peak. An imposed minimum signal-to-noise ratio was set to 6:1 (comprised 
between the accepted criterion defining $\mathrm{LOD}(\mathrm{S} / \mathrm{N} 3)$ and $\mathrm{LOQ}(\mathrm{S} / \mathrm{N}$ 10)) as peak picking criterion to define the decision limit.

Identification criteria for suspect screening were determined from triplicate injections of reference standards. For each targeted compound, the software displays different parameters: mass error, formula finder score, isotope match, etc. The worst scores that were obtained in these experimental conditions were chosen and reported as confidence settings for the identification of compounds via the suspect list. Thus, it was empirically determined that selecting compounds with a formula finder score above 65 would reduce the number of potential false positives and reach the minimum number of false negatives. A $10 \mathrm{ppm}$ mass error and 10\% isotope ratio difference were selected as the best compromise for the suspect screening as it weeds out non-specific formula matches without losing too many matches for compounds that have peak distortions due to their large peak areas or detector saturation. Choosing appropriate values for different filtering criteria is the key step for suspect screening strategies.

The suspect screening strategy was tested on spiked mussel and oyster samples that were analyzed in $\mathrm{ESI}^{+}$. Comparable data were obtained for the different matrices, therefore only results relative to oyster samples are presented. After applying our final traffic light color-coding filtering step (retaining only 'green light' features) based on the chosen criteria mentioned above, 15 suspect compounds out of a list of 821 were first identified as toxins potentially present in the analyzed samples. For verification purposes, the presence of actual chromatographic peaks and coherence in retention times were checked for each compound in the replicate injections $(n=3)$. This second step led to the elimination of five candidates that were either not present in all three injections (and therefore considered as false positive features) or not fulfilling the criteria of an actual peak. This step led to a list of 10 candidates, including PnTX-A, PTX2, GYM, SPX1, and two of its isobaric analogues, AZA1 and three of its isobaric analogues. Since many molecular formulas can give the same accurate mass, it is only through the MS/MS fragmentation data that reliable identification of the peaks was achieved. A final confirmation step was then applied by means of the comparison of $\mathrm{MS}^{2}$ spectra acquired with theoretical fragment spectra derived from mol files that were obtained from ChemSpider or PubChem databases (Supplementary Materials Figure S2). All the experimental spectra showed good correlation with theoretical fragments (>70\%); SPX1 and AZA1 could be identified as the analogues present in the analyzed samples. An exception was observed for GYM, with only 20\% matching fragments. The software automatically attributed the most intense peak present in the extracted chromatogram (XIC) as corresponding to the exact mass of the selected compound in the suspect list. The XIC of GYM was then checked visually and a second less intense peak was present at a different retention time (5.1 $\mathrm{min}$ ) in the three different replicates. This peak was then manually selected and the correlation between the empirical and theoretical fragmentation spectra checked again, and this time the authors had a 100\% match. This shows the importance of keeping a critical mind when handling results automatically generated and not taking them for granted until they have been verified.

\subsubsection{Evaluation of the Non-Targeted Screening Approach}

Data that were generated from the blind test (Section 5.7) were processed while using two different options as part of the non-targeted screening; the first one consisted of comparing contaminated and non-contaminated samples pairwise while using a $t$-test to identify features only present in the contaminated samples. This option required that a non-contaminated sample with the same characteristics (elemental composition, species, location, et al.) as the contaminated one be available. The second option was to perform a multivariate analysis while using another statistical test, a principal component analysis (PCA).

Pairwise Comparison: $t$-Test Results

A $t$-test was carried out on the 5000 most intense features $(\mathrm{m} / \mathrm{z})$ and the data were then classified according to the increasing values of the $p$-value. Only ions with a $p$-value below 0.05 were investigated. 
Among all the data evaluated, only 100 to 150 ions (depending on the concentration level) out of the 5000 generated had a significant $p$-value below 0.05 .

Regarding this test, the aim was to check whether the $t$-test is an appropriate tool allowing for the identification of the molecules of interest among the 100-150 ions selected based on their $p$-value. Selected ions were manually reprocessed while using PeakView ${ }^{\circledR}$ to confirm that they were (1) corresponding to actual peaks (2) absent from the blank control samples and (3) present in the three replicates. Features not responding to these criteria were eliminated; this step allowed for reducing by half the list of ions of interest. Concerning both mussel and oyster matrices, the authors could identify clearly the supplemented toxins among the final list of features considered as responsible for the significant differences between contaminated and blank samples.

Table 3 shows the $p$-values obtained corresponding to each toxin for the six studied levels of contamination; SPX1 was the only toxin with a $p$-value below 0.05 for all six concentration levels in the mussel matrix, meaning that significant differences could be observed between the contaminated and non-contaminated samples for all six levels. Inversely, PTX2 had $p$-values below 0.05 only for the three most concentrated levels, typically L4-L6. Significant differences were observed between the blank mussel sample and the contaminated ones for AZA1 and PnTX-A from level 3 onward. Regarding the case of GYM, five out the six concentration levels had $p$-values below 0.05 ; the first concentration level was the only one that did not show a significant difference between the contaminated and non-contaminated samples. This illustrates the difference between the analytical determination limits inherent to the targeted method performances presented before and the discriminating power of the statistical tool. That proves that it is equally important to develop a sensitive method and to set up the adequate workflow able to pick up the signals of interest in a forest of features.

Table 3. $p$-values obtained in a $t$-test comparing pairwise a blank mussel sample with samples spiked at different concentration levels. Non-significant results ( $p$-values $>0.05$ ) are indicated in bold and italics.

\begin{tabular}{cccccc}
\hline Spike Levels & SPX1 & GYM & AZA1 & PnTX A & PTX2 \\
\hline L0/L1 & $<0.01$ & $>\mathbf{0 . 0 5}$ & $>\mathbf{0 . 0 5}$ & $>\mathbf{0 . 0 5}$ & $>\mathbf{0 . 0 5}$ \\
L0/L2 & $<0.01$ & $<0.01$ & $>\mathbf{0 . 0 5}$ & $>\mathbf{0 . 0 5}$ & $>\mathbf{0 . 0 5}$ \\
L0/L3 & $<0.01$ & $<0.05$ & $<0.01$ & $<0.01$ & $>\mathbf{0 . 0 5}$ \\
L0/L4 & $<0.01$ & $<0.01$ & $<0.01$ & $<0.01$ & $<0.05$ \\
L0/L5 & $<0.01$ & $<0.01$ & $<0.01$ & $<0.01$ & $<0.01$ \\
L0/L6 & $<0.01$ & $<0.01$ & $<0.01$ & $<0.01$ & $<0.01$ \\
\hline
\end{tabular}

Multivariate Analysis: PCA and PCA-DA Results

Initially, an unsupervised PCA test was carried out on the data that were generated after the analysis of the $\mathrm{MeOH}$ and matrix-matched samples. The representation obtained following this first PCA test and the PC1/PC2 scores plot showed the presence of three different clusters corresponding respectively to solvent, oyster and mussel extracts (Supplementary Materials Figure S3). This shows that components 1 and $\mathbf{2}$ reflect the variability related to matrix ions. This distribution is not surprising as matrix ions are predominant when compared to the ions representative of the compounds of interest. The study of the other components did not reveal any clusterization based on the presence or absence of toxins either.

To overcome or reduce the impact of the matrix variability that was preponderant during the first test, the authors carried out a supervised PCA-DA, which allowed for a definition of the samples of mussels and oysters as belonging to the same group.

Figure 5a shows all the "L0" corresponding to uncontaminated samples are well grouped at the top of the scores plot and separated from the remaining contaminated samples. The other samples are classified according to their concentration levels from the least concentrated to the most concentrated ones. Despite this stratification, the different toxin levels are not clearly separated after the PCA-DA data treatment. This could be explained by the fact that concentrations between levels were close. 
To identify the ions responsible for the clusterization presented in the loadings plot (Figure $5 b$ ), the authors selected those circled in blue as likely to be representative of the most contaminated levels; this included a total of 70 features reduced to 55 when removing the isotopes. The 55 selected features were further refined by excluding those not corresponding to actual peaks; this led to 38 and 36 features for the oyster and mussel matrices, respectively. Using each of the retained features, a tentative formula was generated in Peakview ${ }^{\circledR}$ while using Formula Finder. The number of suggested formulae was highly variable and ranged from 3 to 419 for the features in the oyster samples and from 3 to 426 in the mussels. The toxins were not necessarily among the first proposals in Formula Finder; as an example, PnTX-A was the fourth out of 169 proposed formulae in the mussel extracts, while AZA1 was 8 out of 357 . The next step of the general workflow was to upload each generated formula in the ChemSpider database to identify the corresponding compound(s), knowing that several potential compounds could be proposed for each formula. Once a compound was identified, its mol file was downloaded to compare the theoretical (in-silico) and the experimental spectra, provided that a spectrum had been acquired in TOF MS/MS. Following all of this workflow, the toxins (GYM, SPX1, AZA1, PnTX-A, and PTX2) marked with a star in Figure 5b were among the features that were identified as being responsible for the clusterization.

Scores for D1 $(22.9 \%)$ versus D2 (22.3\%), Pareto (DA)

(a)

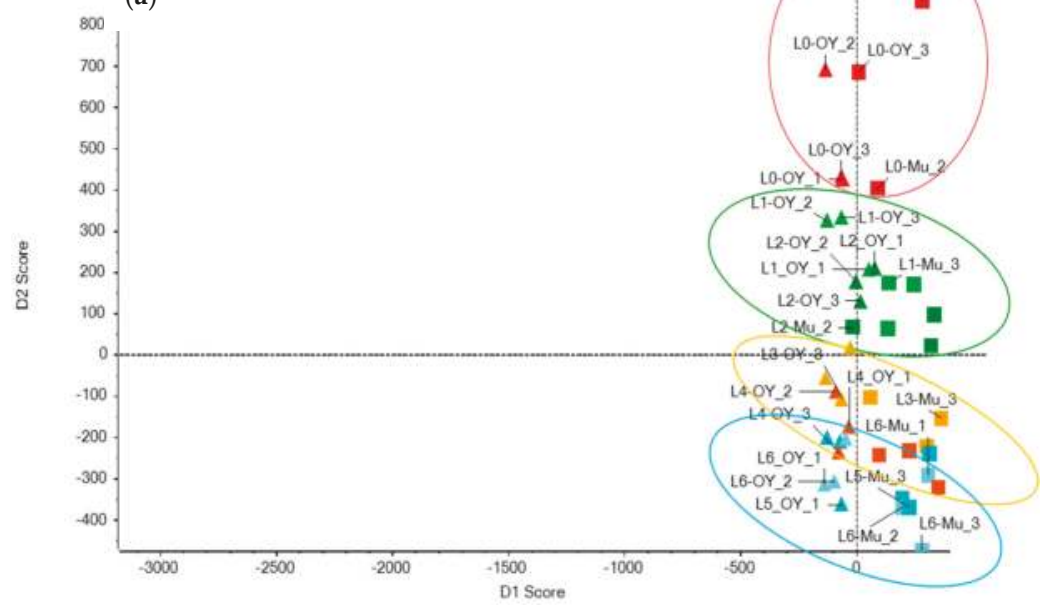

Figure 5. Cont. 


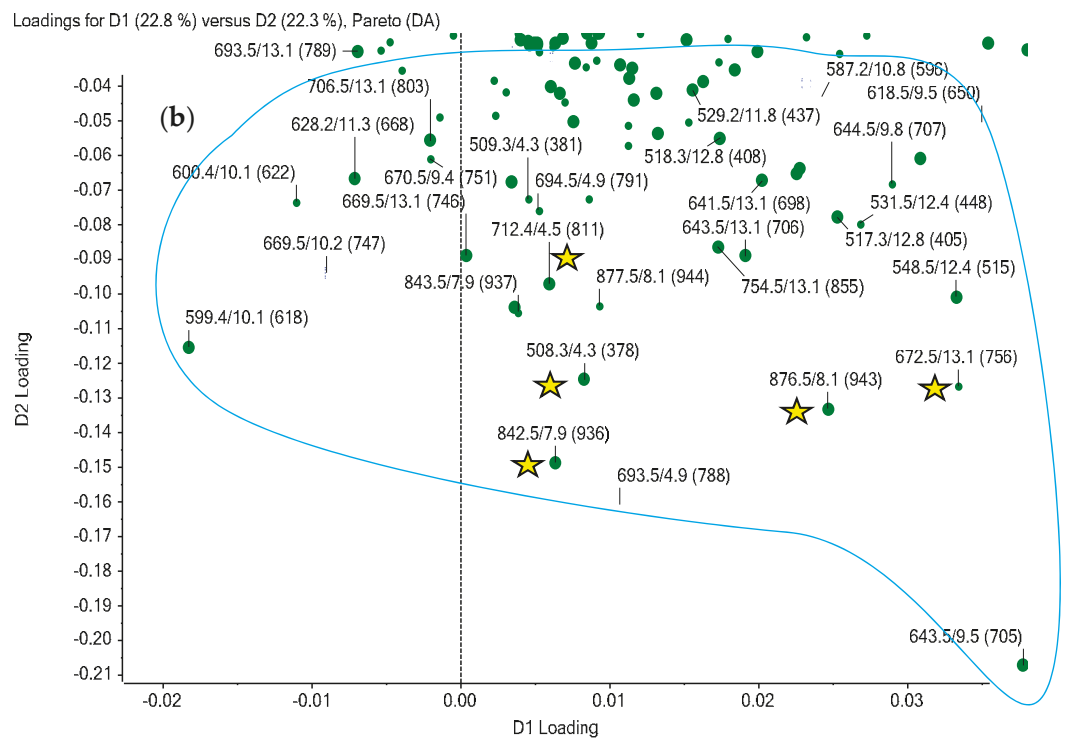

Figure 5. (a) Scores plot of a supervised PCA-DA analysis of the data generated after analyzing contaminated and non-contaminated extracts $\left(\mathrm{MeOH}\right.$, mussel, and oyster) by LC-HRMS in $\mathrm{ESI}^{+}$(in red: L0; green: L1 and L2; orange: L3 and L4; blue: L5 and L6); (b) Zoom at the corresponding loadings plot: ions circled in blue are the representative features (green dots) of the most contaminated level (L6). Ions corresponding to the toxins of interest are flagged with yellow stars. The three figures reported next to each green dot (such as 508.3/4.3 (378)) represent, respectively, the exact mass, the retention time, and the feature's area (in brackets).

\section{Discussion}

Several papers deal with the characterization/validation of methods for the analysis of targeted marine toxins in low $[11,23,32]$ and high resolution $[16,17,25,33-35]$, but there is no report in the literature of the proper characterization of the entire workflow for the non-targeted analysis of these compounds. More generally, there are no internationally recognized guidelines for the validation of non-targeted analysis [36], but tentative validation strategies were undertaken in the field of environmental pollutants $[28,31,37]$. The common feature between these studies lies in the fact that the validation procedure was carried out for known compounds or metabolites. The rationale behind this approach is that a validated targeted method is an essential step toward the production of a reliable and acceptable data set through the non-targeted approach. Furthermore, the compounds that are targeted should cover a range of polarity as wide as possible, from hydrophilic to lipophilic. This explains the choice of the 18 toxins that were used as part of this study.

\subsection{Targeted Analysis}

The LC-HRMS method developed enabled the separation and the analysis of the 18 marine toxins tested. The resolution of the mass spectrometer (QTOF) enables the unambiguous identification of the toxins. Initially, the HSS T3 column was selected, because it can withstand $100 \%$ water as mobile phase and it is indicated for the analysis of polar molecules, such as DA.

According to the criteria of the Commission Decision 2002/657/EC [38] and the associated cutoff values, the method developed gave satisfactory performances for the 14 marine toxins that were selected for the characterization study and spiked in the mussel and oyster matrices. Regarding the case of DA, positive ionization is mostly reported in the literature [39-43], but in this study's conditions, 
better sensitivity was observed in $\mathrm{ESI}^{-}$, as also reported by Ciminiello et al. [44]. The exact masses for the intra-day and inter-day precision, ranging from 0.4 to $1.7 \mathrm{ppm}$ for the different toxins, showed good stability in mass measurements in this study's analytical conditions and are consistent with previously published mass accuracy data in LC-HRMS $[16,18,45]$. The sensitivity of the method was overall satisfactory and estimated LOQs are comparable to previous studies [25,34,39,46]. Regarding YTXs, LODs were relatively higher than expected, as compared to the triple quadrupole detector, but still were considered as acceptable, since they are well below the regulatory threshold of $3.75 \mathrm{mg} / \mathrm{kg}$ [5]. Concerning PbTx-2 and 3, even if it has been shown that MeOH improves the sensitivity of the method (by a factor of 6-10) when compared to ACN, in agreement with previous studies, the LOQs obtained under the current conditions remained below the threshold concentration of $800 \mu \mathrm{g} \mathrm{PbTx}-2 \mathrm{eq} / \mathrm{kg}$ defined in both the American and Australian legislations [32,47].

Concerning the matrix effects, the toxins were affected to different extents with either ion enhancement or ion suppression of different magnitudes. DA was the compound that was the most affected with $+33 \%$ ion enhancement. To overcome such interferences, matrix-matched calibration curves might be a good solution, as reported elsewhere [11,48]. Sample treatments including purification steps such as solid phase extraction (SPE) or liquid-liquid extraction (LLE) could be effective in removing, or at least reducing the matrix effects but, in non-targeted analysis sample treatment should be kept as simple as possible to avoid losing potential compounds of interest. The matrix effects observed for the compounds spiked into the tested matrices and determined via targeted or suspect analysis can only define a degree of uncertainty for further evaluation [28]. Vergeynst et al. [31] developed a method, including a large volume injection (LVI) to avoid laborious sample enrichment and selective preconcentration of pharmaceuticals in surface waters. The use of a divert valve to eliminate highly polar organic and inorganic (salts) compounds at the beginning of the chromatographic run made the matrix effects comparable to those that were obtained with methods while using SPE as a sample treatment [31]. Dilution could also be advised to reduce the matrix effects, but, in the case of non-targeted analysis, there is a risk of reducing the intensity of the features of interest [28].

When dealing with a chemical method, such as LC-MS, there are several aspects, other than matrix effects, which are likely to impact the method performances. This has been largely reported in the literature [49-52] and it feeds the controversy upon the replacement of the mouse bioassay, used as a reference method for the analysis of certain toxins, with LC-MS. Although factors such as the availability and stability of standards and reference materials, as well as the difference in sensitivity of the MS analyzers, contribute to the gaps identified in food safety control for marine toxins by chemical methods, the non-targeted approach comes as an answer to one of the major criticisms of LC-MS methods: the analysis of pre-assigned masses, which hinders the detection of emerging and unknown toxins.

\subsection{Non-Targeted Analysis}

The suspect screening approach gives the ability to screen a large list of compounds and to do a retrospective analysis $[17,28]$. The list that was used as part of this study was composed of 821 compounds including both marine toxins and cyanotoxins with their exact masses. Using suspect screening no standard is required as the identification capability lies on different criteria, among which are the exact $m / z$ ratio, the isotopic profile, the MS/MS fragmentation pattern.

Different parameters were selected and optimized for accurate mass matches through the suspect list, based on the experience acquired when using the suspect screening approach. As an example, the imposed minimum signal-to-noise ratio was set to 6:1 as a peak picking criterion to determine the decision limit that defines a peak. Nürenberg et al. [28] reported the same value while Krauss et al. went for a value of 5:1 [26]. Overall, based on the chosen criteria the authors defined a traffic light color-coding filtering step (retaining only 'green light' features) that was successfully applied to test samples and enabled identifying the marine toxins that were spiked into the blind samples. Although 
this process was automated, it is important to keep a critical eye on the data generated and to check it to avoid errors.

To allow for confirmation purposes, the experimental fragmentation that was obtained for the toxin tentatively identified was compared to the built-in MS/MS spectrum in the library (when available) or to the in-silico fragmentation pattern that was obtained from a mol file (PubChem, ChemSpider). Regarding the case of in-silico fragmentation, it was necessary to be sure of the quality of the data available from the websites queried to avoid any misidentification.

Following the different optimized steps of the suspect strategy developed, tentative identification of emerging compounds was possible with a high confidence level. The interpretation of fragmentation patterns of HRMS/MS spectra was a successful way to elucidate the structure of a molecule, even in the case of isomeric structures provided that they had significant fragmentation patterns. To unequivocally identify the molecular structure of a compound, further analysis by nuclear magnetic resonance might be needed.

Using the non-targeted screening approach, two different options were tested for the data treatment. The first one consisted of performing a pairwise $t$-test between contaminated (spiked) and non-contaminated samples. This required that an appropriate reference sample be available. It should have the same elemental composition as the contaminated samples, except for the presence of toxins, to make sure that the significant difference that was picked by the statistical test was related to the contaminants and not to the difference in matrix composition. This condition is difficult to meet as there are many environmental factors that are likely to influence the matrix composition. Regarding the case of shellfish for instance, this could be the genus and species of the animal, its age, its geographical origin, the seasonality etc. To circumvent this difficulty in choosing the right reference, an approach consists of creating a library for each type of matrix that would apprehend the diversity in matrix composition mentioned previously. This approach was put in practice by the EURL for pesticides in fruit and vegetables to determine the matrix signature of different foodstuffs belonging to the eight groups that are defined by DG SANTE [53].

The key issue in the data treatment was to reduce the number of relevant features to screen. When using the $t$-test, this can be done with the $p$-value for which different cutoff values can be selected: $p$-value $<0.05$ or $p$-value $<0.01$. The cutoff value of 0.01 decreased the number of features from 5000 to a number ranging from 20 to 52 depending on the sample, in the current study. This value was too restrictive and some of the spiked toxins could not be found in the final list. A $p$-value of 0.05 was a better compromise, which reduced the final list of features that was composed of 100 to 150 ions without excluding compounds of interest. Mondeguer et al. [35] applied the same strategy and managed to drastically reduce the number of features for different sets of naturally contaminated mussel samples containing AZAs or unknown compounds from the Arcachon bay.

The $p$-values obtained in the pairwise comparison of the samples spiked with the different toxins at different concentrations and the blank sample illustrated the notion of the discriminating power of the statistical analysis. Therefore, depending on the toxins, the statistical test will be more or less efficient in picking the statistical differences between the sets of samples compared. This has nothing to do with the analytical sensitivity of the method. Using a non-targeted screening approach, it is necessary to have both a sensitive method and the appropriate statistical test with a good discriminating power.

Another data treatment option was tested: the multivariate analysis using a PCA or PCA and discriminant analysis (PCA-DA). The PCA was not appropriate as it discriminated the samples (spiked and blank) according to the nature of the matrix rather than according to the toxin composition (Figure S3). The PCA-DA gave a better clusterization of the samples based on the toxin composition by forcing the statistical test to not consider the matrix as a major discriminating factor (Figure 5). Even in PCA-DA, the identification of the features that were responsible for the clusterization of the samples, and likely to explain the differences in composition, is still time and labor intensive and requires a good methodology. Yet, the authors managed to identify the spiked marine toxins in the PCA-DA loadings plot as features potentially explaining the clusterization of the high toxin levels. 
Despite the automation of several tasks of the workflow, some of them must be manually done. This is the case, for instance, for the identification of false positive and false negative features that require a visual inspection of the chromatograms [28,37].

Whatever the statistical approach that was chosen, it is necessary to reduce the number of features to facilitate the data treatment and the identification of the compounds of interest. Several options can be adopted: (1) blank exclusion or blank reduction. Using the first case, all of the features present in the blank will be removed from the samples to be analyzed, whereas for blank reduction, the features with intensity in the sample less than ten times higher than in the blank will be excluded. Nürenberg et al. [28] tested blank exclusion and blank reduction and did not see any significant difference. Two types of blanks can be concomitantly used: a procedural blank (solvent) and a blank sample to reduce even further the number of features not related to the contamination event; (2) elimination of the adducts and isomers to reduce further the number of features; (3) limitation of the number of replicates to three as a compromise between a repeatability requirement and the fact that each injection generates its own false positives, thus reducing the proportion of common features between the different injections [28].

Depending on the identification confidence desired and identified by Schymansky et al. [54] as levels one to five, the time needed to perform both the analysis and the data processing could vary significantly. It could take from days for the level 5 (exact mass of interest) to months to reach the level 1 of identification confidence (confirmed structure by reference standard).

The chromatographic conditions in this paper cover a wide range of marine toxins, but they are not the most suitable for specific toxin groups such as palytoxins, ciguatoxins and maitotoxins. However, the same optimized workflow for data treatment can be applied to different extraction and separation methods. The best strategy to enhance hazard identification would be the combination of LC-HRMS with toxicity tests to reduce the size of the search space. Fractions from chromatographic separation containing potential candidates can be collected and screened while using cellular tests to identify the toxic ones. This step allows for focusing analytical efforts on relevant contaminants and ensures the identification of significantly toxic compounds. A similar methodology, while using both cellular tests and mass spectrometry, recently permitted the identification of a novel maitotoxin, MTX-4 [55].

\section{Conclusions}

To assess the potential of the LC-HRMS method to detect marine toxins as part of a non-targeted analysis, the authors performed a proof of concept study as a first essential step toward a reliable characterization of samples naturally contaminated with unknown marine toxins and the identification of the toxins. Since there are no guidelines for the validation of a non-targeted method, the LC-HRMS method that was developed for the analysis of marine biotoxins was characterized according to the approach used in the field of water micropollutants. The method performances were first evaluated in targeted mode for marine toxins with different polarities spiked in mussel and oyster samples and were found to be satisfactory for the criteria tested (LODs, LOQs, specificity, matrix effects, accuracy, and precision). The performances of the optimized non-targeted strategy were then evaluated, both for the suspect screening approach relying on the use of a library of 821 toxins and for the without a priori screening of unknowns. The essential steps for the non-targeted procedure have been detailed and discussed. The overall workflow was tested on spiked samples that were analyzed blindly and was shown to be highly efficient in narrowing down the number of potential false positive and false negative findings. Whatever the approach selected, the marine toxins spiked in the samples analyzed as blind for the proof of concept were picked among the features detected in LC-HRMS. It is important to report that, although many tasks could be automated in the data treatment, it is essential to critically and manually review the results that were obtained to avoid any misinterpretation

As the workflow is time and labor intensive, the number of features should be kept to a minimum by using blanks (procedural and sample) to exclude or reduce the corresponding features, according to 
the option chosen. The question of the reference sample must be addressed to help in identifying the compounds of interest in the contaminated sample among interfering features; an option could be to create matrix libraries apprehending the wide diversity of the features that are likely to be present in non-contaminated matrices.

It will be necessary to analyze naturally contaminated samples and to isolate a novel or unknown toxic compound to confirm the efficiency of this methodology. The present study should be completed by testing the non-targeted approach in the $\mathrm{ESI}^{-}$ionization mode while using blind samples spiked with the corresponding toxins. Further developments should be carried out by testing different techniques of extraction, separation, and so on to increase even further the range of the toxins falling into the scope (palytoxin-like, ciguatoxin-like). There is, therefore, a vast area of research on these non-targeted approaches to be investigated in the future to make non-targeted LC-HRMS more powerful for marine toxin monitoring and to guarantee consumer safety.

\section{Materials and Methods}

\subsection{Standards and Reagents}

All the solutions were prepared with analytical reagent-grade chemicals and ultrapure water $(18.2 \mathrm{M} \Omega \mathrm{cm})$ produced by purifying deionized water with a Milli-Q Academic water purification system (Millipore S.A., Saint-Quentin-en-Yvelines, France).

Hydrochloric acid $(\mathrm{HCl} ; 37 \%)$ and sodium hydroxide $(\mathrm{NaOH} ; 99 \%)$ were purchased from Merck (Fontenay-sous-Bois, France). Ammonium formate (>97\%) was purchased from Sigma-Aldrich, Saint-Quentin-Fallavier, France. Formic acid (98-100\%), acetonitrile (ACN; HPLC grade), and methanol (MeOH; HPLC grade) were purchased from Fisher Scientific SAS (Illkirch, France). Ammonium hydroxide (25\%) was purchased from VWR (Fontenay-sous-Bois, France). Atmospheric pressure chemical ionization (APCI) calibration solutions were purchased from Sciex (Nieuwerkerk aan den Ijssel, The Netherlands).

Certified reference materials (CRMs) were purchased from the National Research Council of Canada (NRCC, Halifax, NS, Canada). These included certified calibration solutions of the following toxins: DA, AZA1-3, PTX2, OA, DTX1 and 2, YTX, hYTX, SPX1, PnTX-G, and GYM. Standards of PnTX-A, 13,19-didesMeC, and 20-meG were purchased from Cifga (Lugo, Spain). PbTx-2 and 3 were purchased from Abcam (Cambridge, UK).

\subsection{Sample Preparation}

Blank mussels samples $(n=3)$ and oysters samples $(n=3)$ were prepared according to the standard operating procedure of the EURLMB by extracting $2 \mathrm{~g}$ of homogenized tissue with $2 \times 9 \mathrm{~mL}$ of $100 \%$ $\mathrm{MeOH}$ [56]. Following centrifugation, the supernatants were combined into a volumetric flask and the volume adjusted to $20 \mathrm{~mL}$ while using $\mathrm{MeOH}$.

To detect and quantify the total amount of OA group toxins present, including the esterified forms, an alkaline hydrolysis was performed before LC-MS/MS analysis [57]. Regarding the hydrolysis step, $500 \mu \mathrm{L}$ of aqueous $\mathrm{NaOH} 2.5 \mathrm{M}$ solution was added to $4 \mathrm{~mL}$ of methanolic extract, homogenised by vortex mixing for $0.5 \mathrm{~min}$ and heated at $76^{\circ} \mathrm{C}$ for $40 \mathrm{~min}$. Once cooled to room temperature, the extract was neutralised with $500 \mu \mathrm{L}$ of aqueous $\mathrm{HCl} 2.5 \mathrm{M}$ solution. Samples were filtered $(0.45 \mu \mathrm{m})$ prior to analysis.

\subsection{Preparation of Standards and Matrix-Matched Calibration Solutions}

A toxin mixture stock solution was prepared in $\mathrm{MeOH}$ from the certified calibration solutions and contained PTX2, AZA1 to 3, OA, DTX1 and 2, PnTX-A, PnTX-G, YTX, h-YTX, SPX1, 13,19-didesMeC, 20-meG, GYM-A, and DA at concentrations ranging from 120 to $240 \mathrm{ng} / \mathrm{mL}$ depending on the toxins. This stock solution was serially diluted in $\mathrm{MeOH}$ to prepare six working solutions (L1-L6), each containing the studied toxins at different concentrations. Brevetoxins (PbTx-2 and 3) working 
solutions were prepared separately while using a $250 \mathrm{ng} / \mathrm{mL}$ stock solution. These working solutions were then used to prepare matrix-matched standards with previously prepared blank mussel and oyster extracts to reach the appropriate concentration levels: $450 \mu \mathrm{L}$ aliquots of shellfish extracts were dispensed into HPLC vials, and $50 \mu \mathrm{L}$ of working solution was added, resulting in six different concentration levels per matrix. This operating procedure resulted in a consistent matrix concentration of $0.09 \mathrm{~g} / \mathrm{mL}$ at each concentration level. Matrix-free standards were prepared similarly, while using pure $\mathrm{MeOH}$ instead of shellfish extracts.

The calibration curves for matrix effect assessments ranged from 1 to $12 \mathrm{ng} / \mathrm{mL}$ for AZAs and cyclic imines; 2-24 ng/mL for YTXs, OA, DTXs and PTX2; 6-72 ng/mL for DA.

$\mathrm{MeOH}$ and matrix-matched calibration curves, mean slopes, intercept and determination coefficients $\left(R^{2}\right)$ were calculated based on triplicate injections of seven concentration levels (including the blank, L0).

\subsection{LC-HRMS Analysis}

Measurements were carried out by LC-HRMS. A Dionex Ultimate 3000 HPLC system (Thermo Fisher Scientific, San Jose, CA, USA) was coupled to a QTOF (Sciex 5600 Triple TOF, Darmstadt, Germany). The QTOF system was equipped with a DuoSpray ion source and a TurboIonSpray ${ }^{\mathrm{TM}}$ probe. The chromatographic separation was achieved on a Waters (Saint-Quentin-en-Yvelines, France) Xselect ${ }^{\circledR}$ HSS T3 column $(100 \times 2.1 \mathrm{~mm}, 2.5 \mu \mathrm{m})$ with a binary mobile phase of $(\mathrm{A})$ water and (B) ACN-water $(95 / 5, v / v)$, each containing $50 \mathrm{mM}$ formic acid and $2 \mathrm{mM}$ ammonium formate. The gradient of the LC method was composed by the following steps within a total run time of $20 \mathrm{~min}$. Subsequent to an isocratic step for $1 \mathrm{~min}$, a linear gradient was applied from $2 \%$ to $100 \%$ B within $9 \mathrm{~min}$, and held at $100 \%$ of B for $5 \mathrm{~min}$. The initial conditions were reached again and were kept constant for $5 \mathrm{~min}$ to re-equilibrate the column. The flow rate was $0.45 \mathrm{~mL} / \mathrm{min}$ and the column temperature was $30^{\circ} \mathrm{C}$. The injection volume was set to $5 \mu \mathrm{L}$.

Concerning the MS detection, electrospray ionization (ESI) was used in positive and negative modes in separate runs. The parameters for positive and negative ionization were as follows (deviating values for negative ion mode are indicated in parentheses): ion source gas (GS) 1 and 2, 35 and 45 psi; curtain gas (CUR), $30 \mathrm{psi}$; source temperature (TEM), $500{ }^{\circ} \mathrm{C}$; ion spray voltage floating (ISVF), 5.5 $(-4.5) \mathrm{kV}$; declustering potential (DP), $60 \mathrm{~V}(-100 \mathrm{~V})$; ion release delay (IRD), $67 \mathrm{~ms}$; ion release width (IRW), $25 \mathrm{~ms}$.

The MS was operated in full scan TOF MS and MS/MS modes with information dependent acquisition (IDA) in a single run analysis for targeted and non-targeted screening. The full scan experiment (100-1250 Da) was performed with an accumulation time of $0.2 \mathrm{~s}$ while using the high sensitivity mode. An additional eight MS2 spectra experiments (accumulation time: $0.05 \mathrm{~s}$ ) were programmed. A collision energy spread $(\mathrm{CES} \pm 20 \mathrm{eV})$ was applied in conjunction with the $\mathrm{CE}(40 \mathrm{eV})$ for IDA mode to perform both low and high collision-energy, simultaneously resulting in valuable fragmentation information for identification purposes. The mass spectrometer was recalibrated automatically after five measurements while using an automated calibrant delivery system (CDS) via the atmospheric pressure chemical ionization (APCI) probe of the DuoSpray ion source.

Each sample/standard solution was injected in triplicate to generate enough data to perform the chemometric processing (e.g., $t$-test), as descibed in the next section.

\subsection{Post-Acquisition Data Processing}

The data acquisition was carried out by Analyst ${ }^{\circledR}$ TF 1.7.1 software (Sciex, Toronto, ON, Canada). Data were then processed following three different approaches: (1) quantitative target analysis with reference standards; (2) suspect screening without reference standards; and, (3) non-target screening of unknowns. A diagram of the processing data strategy is shown in Figure 1.

The MasterView ${ }^{\mathrm{TM}}$ application of the PeakView ${ }^{\circledR} 2.2$ software (Sciex, Toronto, ON, Canada) was used to create target and suspect compound lists and display identification criteria while using 
"traffic lights" on the basis of confidence settings for the following parameters: molecular formula, accurate mass (mass error), isotopic pattern, and MS/MS library (purity score), as well as further peak information, such as retention time, S/N (signal-to-noise ratio), or FWHM (full width at half maximum) (Supplementary Materials Figure S4). The traffic light turns green when the confidence settings of the above-mentioned parameters are met; this indicates a good confidence level in the identification of the compounds in the suspects list.

The quantitation of target toxins was achieved by MultiQuant ${ }^{\mathrm{TM}}$ 2.1.1 (Sciex, Toronto, ON, Canada). The decision of whether a feature was counted as a peak was done manually by visual control while using the integrated MultiQuant ${ }^{\mathrm{TM}}$ data sets of each XIC (extracted ion chromatogram). Decision criteria for a peak to be recognized as such were the peak shape (approximatively Gaussian), an $\mathrm{S} / \mathrm{N}$ above 6 , and a peak width at the base below $0.6 \mathrm{~min}$.

Concerning the non-target screening purpose, the extraction and the alignment of the features from the full scan experiment were processed by MarkerView ${ }^{\mathrm{TM}}$ software 1.2.1 (Sciex, Toronto, ON, Canada). Statistical data analyses ( $t$-test, principal components analysis (PCA)) were also performed while using this software. ChemSpider and PubChem databases were used for searching for possible structure identities and MS/MS fragment ion prediction to identify compounds and to characterize chemical structures.

\subsection{Method Performance Characteristics for Target Quantitation}

To assess the method performances and matrix effects, each concentration level of calibration curves was injected in triplicate, alternating between standards in methanol, standards in oyster matrix and standards in mussel matrix. Detection and quantification limits (LOD and LOQ) were first estimated as equivalent to an $\mathrm{S} / \mathrm{N}$ of 3 and 10, respectively, by analyzing low level spiked extracts in triplicate. Regarding the characterization study, LODs and LOQs were determined with the ordinary least-squares regression data method $[58,59]$ while using solvent and matrix-matched calibration curves. LODs and LOQs were calculated, respectively, as 3 and 10 times the standard deviation of the $y$-intercepts, over the slope of the calibration curve.

The suitability of the quantitation method for the studied toxins was evaluated following the EU Commission Decision 2002/657/EC as a guideline.

To determine the repeatability and the intermediate precision of the method, mussel samples that were spiked with marine toxins were extracted and injected twice daily, at three different days over the course of two weeks.

The relative standard deviation (RSD) was determined in repeatability $\left(\mathrm{RSD}_{\mathrm{r}}\right)$ and within-laboratory reproducibility $\left(\mathrm{RSD}_{\mathrm{R}}\right)$ conditions.

Samples provided by the EURLMB as part of proficiency testing schemes for lipophilic toxins and DA were analyzed by LC-HRMS after being extracted as described in Section 5.2., Z-scores [60] were determined for each toxin in the different samples, while using the following equation:

$$
\mathrm{Z} \text { score }=\frac{x-X}{\sigma}
$$

with

$x=$ analytical result

$X=$ assigned value as determined by the EURLMB

$\sigma=$ standard deviation

$|z|<2$ : results are satisfactory

$2<|z|<3$ : results are questionable

$|z|>3$ : results are unsatisfactory 


\subsection{Non-Targeted Screening of Marine Toxins}

The workflow was tested by treating a selected set of target compounds (from different toxin families; GYM, SPX1, AZA 1, PnTX A, and PTX2) spiked in MeOH and shellfish extracts (mussel and oyster) at 6 different concentration levels L1-L6 $(2,4,8,12,16,24 \mathrm{ng} / \mathrm{mL})$ as unknowns to check the performance of the procedure. Blind samples were analyzed in triplicate in $\mathrm{ESI}^{+}$. Suspect screening data were treated using PeakView ${ }^{\circledR}$ and MasterView ${ }^{\mathrm{TM}}$ softwares, via an XIC list of 821 molecules, including marine toxins and cyanotoxins kindly provided by Dr. A. Gerssen (Rikilt Institute of food safety, Wageningen, The Netherlands). The only a priori information was the exact mass of the protonated ions $[\mathrm{M}+\mathrm{H}]^{+}$or $\left[\mathrm{M}+\mathrm{NH}_{4}\right]^{+}$of the toxins that were included in that list. The authors chose to test the workflow in positive mode only.

To contrast suspect screening, the unknown screening strategy was run without any a priori information. Data were processed using MarkerView ${ }^{\mathrm{TM}}$ and the workflow included alignment, peak detection, deconvolution, component intensity comparison, and statistics. Two statistical approaches were applied; (1) $t$-test to determine if statistically significant differences between contaminated and non-contaminated samples could be associated to the presence of toxins; and, (2) multivariate statistical analysis (PCA) either supervised or not.

Supplementary Materials: The following are available online at http:/ /www.mdpi.com/2072-6651/10/9/375/s1, Figure S1: Mass variations (mass-to-charge-ratio) for the toxins (positive and negative ion mode), Figure S2: Example of tentative identification of non-target compound, Figure S3: Scores plot of a PCA analysis of the data generated after analyzing contaminated and on-contaminated extracts ( $\mathrm{MeOH}$, mussel, and oyster) by LC-HRMS in $\mathrm{ESI}^{+}$, Figure S4: Example of result display of the MasterView software using "traffic lights" and selected confidence setting for target compounds identification, Table S1: Chemical formula, detected ion, measured mass, $m / z(n=15)$ and retention time for each toxin in mussel extracts obtained on 5600 Q-TOF, Table S2: Determination coefficients $\left(r^{2}\right)$ for both solvent and matrix-matched calibration curves.

Author Contributions: Conceptualization, R.B.; Data curation, I.D. and R.B.; Formal analysis, I.D. and V.H.; Methodology, I.D. and R.B.; Project administration, R.B., G.L.-B., M.N. and T.G.; Software, I.D. and R.B.; Supervision, R.B. and T.G.; Writing—original draft, I.D. and R.B.; Writing—review \& editing, I.D., R.B., V.H., G.L.-B., M.N. and T.G.

Funding: This research was funded by the French Agency for Food, Environmental and Occupational Health \& Safety (ANSES) and ABIES Doctoral School from Agreenium Institute.

Acknowledgments: The authors acknowledge A. Gerssen (Rikilt Institute for food safety, Wageningen, The Netherlands) for providing a list of 821 marine toxins and cyanotoxins for suspect screening. Christophe ROGER is acknowledged for his contribution in sample preparation and analysis and Loïc BEYET from Sciex (France) for his technical support with the softwares.

Conflicts of Interest: The authors declare no conflict of interest. The founding sponsors had no role in the design of the study; in the collection, analyses, or interpretation of data; in the writing of the manuscript, and in the decision to publish the results.

\section{References}

1. Frémy, J.-M.; Lassus, P. Toxines d'Algues dans l'Alimentation; Ifremer: Issy-les-Moulineaux, France, 2001.

2. UNESCO. Report of the Joint FAO/IOC/WHO ad hoc Expert Consultation on Biotoxins in Bivalve Molluscs; Technical Report for UNESCO; UNESCO: Oslo, Norway, 2005.

3. Asakawa, M. Marine Biotoxins: Occurrence, Toxicity, and Detection Methods. Mater. Sci. Eng. 2017. [CrossRef]

4. Morabito, S.; Silvestro, S.; Faggio, C. How the marine biotoxins affect human health. Nat. Prod. Res. 2018, 32, 621-631. [CrossRef] [PubMed]

5. European Commission. Commission Regulation No 786/2013 of 16th August 2013 amending Annex III to Regulation (EC) No 853/2004 of the European Parliament and of the Council as regards the permitted limits of yessotoxins in live bivalve molluscs Text with EEA relevance. Off. J. Eur. Union 2013, 220, 14.

6. European Commission. Regulation (EC) No 853/2004 of the European Parliament and of the Council of 29 April 2004 laying down specific hygiene rules for on the hygiene of foodstuffs. Off. J. Eur. Union 2004, $139,151$. 
7. Hess, P.; Grune, B.; Anderson, D.B.; Aune, T.; Botana, L.; Caricato, P.; Egmond, H.; Halder, M.; Hall, S.; Lawrence, J.F.; et al. Three Rs Approaches in Marine Biotoxin Testing. The Report and Recommendations of a joint ECVAM/DG SANCO Workshop (ECVAM Workshop 54). Altern. Lab. Anim. 2006, 34, 193-224. [PubMed]

8. European Commission. Commission regulation (EU) No 15/2011 of 10 January 2011 amending Regulation (EC) No 2074/2005 as regards recognised testing methods for detecting marine biotoxins in live bivalve molluscs. Off. J. Eur. Union 2011, 6, 4.

9. European Commission. Commission regulation (EC) No 1664/2006 of 6 November 2006 amending Regulation (EC) No 2074/2005 as regards implementing measures for certain products of animal origin intended for human consumption and repealing certain implementing measures. Off. J. Eur. Union 2006, $320,33$.

10. Fux, E.; McMillan, D.; Bire, R.; Hess, P. Development of an ultra-performance liquid chromatography-mass spectrometry method for the detection of lipophilic marine toxins. J. Chromatogr. A 2007, 1157, 273-280. [CrossRef] [PubMed]

11. Gerssen, A.; van Olst, E.H.W.; Mulder, P.P.J.; de Boer, J. In-house validation of a liquid chromatography tandem mass spectrometry method for the analysis of lipophilic marine toxins in shellfish using matrix-matched calibration. Anal. Bioanal. Chem. 2010, 397, 3079-3088. [CrossRef] [PubMed]

12. MacKenzie, L.; Holland, P.; McNabb, P.; Beuzenberg, V.; Selwood, A.; Suzuki, T. Complex toxin profiles in phytoplankton and Greenshell mussels (Perna canaliculus), revealed by LC-MS/MS analysis. Toxicon 2002, 40, 1321-1330. [CrossRef]

13. Quilliam, M.A. Analysis of diarrhetic shellfish poisoning toxins in shellfish tissue by liquid chromatography with fluorometric and mass spectrometric detection. J. AOAC Int. 1995, 78, 555-570. [PubMed]

14. Yogi, K.; Oshiro, N.; Inafuku, Y.; Hirama, M.; Yasumoto, T. Detailed LC-MS/MS Analysis of Ciguatoxins Revealing Distinct Regional and Species Characteristics in Fish and Causative Alga from the Pacific. Anal. Chem. 2011, 83, 8886-8891. [CrossRef] [PubMed]

15. Ciminiello, P.; Dell'Aversano, C.; Iacovo, E.D.; Fattorusso, E.; Forino, M.; Tartaglione, L. LC-MS of palytoxin and its analogues: State of the art and future perspectives. Toxicon 2011, 57, 376-389. [CrossRef] [PubMed]

16. Domènech, A.; Cortés-Francisco, N.; Palacios, O.; Franco, J.M.; Riobó, P.; Llerena, J.J.; Vichi, S.; Caixach, J. Determination of lipophilic marine toxins in mussels. Quantification and confirmation criteria using high resolution mass spectrometry. J. Chromatogr. A 2014, 1328, 16-25. [CrossRef] [PubMed]

17. Gerssen, A.; Mulder, P.P.J.; de Boer, J. Screening of lipophilic marine toxins in shellfish and algae: Development of a library using liquid chromatography coupled to orbitrap mass spectrometry. Anal. Chim. Acta 2011, 685, 176-185. [CrossRef] [PubMed]

18. Blay, P.; Hui, J.P.M.; Chang, J.M.; Melanson, J.E. Screening for multiple classes of marine biotoxins by liquid chromatography-high-resolution mass spectrometry. Anal. Bioanal. Chem. 2011, 400, 577-585. [CrossRef] [PubMed]

19. Dzuman, Z.; Zachariasova, M.; Veprikova, Z.; Godula, M.; Hajslova, J. Multi-analyte high performance liquid chromatography coupled to high resolution tandem mass spectrometry method for control of pesticide residues, mycotoxins, and pyrrolizidine alkaloids. Anal. Chim. Acta 2015, 863, 29-40. [CrossRef] [PubMed]

20. Gago-Martinez, A.; Hungerford, J.M. Comment on "the effect of uncontrolled factors in a validated liquid chromatography-tandem mass spectrometry method question its use as reference method for marine toxins: Major causes for concern". Anal. Chem. 2012, 84, 475. [CrossRef] [PubMed]

21. Gerssen, A.; Van Den Top, H.J.; Van Egmond, H.P. Comment on "effect of uncontrolled factors in a validated liquid chromatography-tandem mass spectrometry method question its use as a reference method for marine toxins: Major causes for concern". Anal. Chem. 2012, 84, 476-477. [CrossRef] [PubMed]

22. Boundy, M.J.; Selwood, A.I.; Harwood, D.T.; McNabb, P.S.; Turner, A.D. Development of a sensitive and selective liquid chromatography-mass spectrometry method for high throughput analysis of paralytic shellfish toxins using graphitised carbon solid phase extraction. J. Chromatogr. A 2015, 1387, 1-12. [CrossRef] [PubMed]

23. Turner, A.D.; McNabb, P.S.; Harwood, D.T.; Selwood, A.I.; Boundy, M.J. Single-laboratory validation of a multitoxin ultra-performance LC-hydrophilic interaction LC-MS/MS method for quantitation of paralytic shellfish toxins in bivalve shellfish. J. AOAC Int. 2015, 98, 609-621. [CrossRef] [PubMed] 
24. Wu, H.; Guo, M.; Tan, Z.; Cheng, H.; Li, Z.; Zhai, Y. Liquid chromatography quadrupole linear ion trap mass spectrometry for multiclass screening and identification of lipophilic marine biotoxins in bivalve mollusks. J. Chromatogr. A 2014, 1358, 172-180. [CrossRef] [PubMed]

25. Orellana, G.; Vanden Bussche, J.; Van Meulebroek, L.; Vandegehuchte, M.; Janssen, C.; Vanhaecke, L. Validation of a confirmatory method for lipophilic marine toxins in shellfish using UHPLC-HR-Orbitrap MS. Anal. Bioanal. Chem. 2014, 406, 5303-5312. [CrossRef] [PubMed]

26. Krauss, M.; Singer, H.; Hollender, J. LC-high resolution MS in environmental analysis: from target screening to the identification of unknowns. Anal. Bioanal. Chem. 2010, 397, 943-951. [CrossRef] [PubMed]

27. Martínez Bueno, M.J.; Ulaszewska, M.M.; Gomez, M.J.; Hernando, M.D.; Fernández-Alba, A.R. Simultaneous measurement in mass and mass/mass mode for accurate qualitative and quantitative screening analysis of pharmaceuticals in river water. J. Chromatogr. A 2012, 1256, 80-88. [CrossRef] [PubMed]

28. Nürenberg, G.; Schulz, M.; Kunkel, U.; Ternes, T.A. Development and validation of a generic nontarget method based on liquid chromatography-High resolution mass spectrometry analysis for the evaluation of different wastewater treatment options. J. Chromatogr. A 2015, 1426, 77-90. [CrossRef] [PubMed]

29. Schymanski, E.L.; Singer, H.P.; Slobodnik, J.; Ipolyi, I.M.; Oswald, P.; Krauss, M.; Schulze, T.; Haglund, P.; Letzel, T.; Grosse, S.; et al. Non-target screening with high-resolution mass spectrometry: critical review using a collaborative trial on water analysis. Anal. Bioanal. Chem. 2015, 407, 6237-6255. [CrossRef] [PubMed]

30. Vergeynst, L.; Van Langenhove, H.; Joos, P.; Demeestere, K. High-resolution time-of-flight mass spectrometry for suspect screening and target quantification of pharmaceuticals in river water. Commun. Agric. Appl. Biol. Sci. 2013, 78, 9-14. [PubMed]

31. Vergeynst, L.; Van Langenhove, H.; Joos, P.; Demeestere, K. Suspect screening and target quantification of multi-class pharmaceuticals in surface water based on large-volume injection liquid chromatography and time-of-flight mass spectrometry. Anal. Bioanal. Chem. 2014, 406, 2533-2547. [CrossRef] [PubMed]

32. McNabb, P.S.; Selwood, A.I.; Van Ginkel, R.; Boundy, M.; Holland, P.T. Determination of brevetoxins in shellfish by LC/MS/MS: Single-laboratory validation. J. AOAC Int. 2012, 95, 1097-1105. [CrossRef] [PubMed]

33. Zendong, Z.; Bertrand, S.; Herrenknecht, C.; Abadie, E.; Jauzein, C.; Lemée, R.; Gouriou, J.; Amzil, Z.; Hess, P. Passive Sampling and High Resolution Mass Spectrometry for Chemical Profiling of French Coastal Areas with a Focus on Marine Biotoxins. Environ. Sci. Technol. 2016, 50, 8522-8529. [CrossRef] [PubMed]

34. Zendong, Z.; McCarron, P.; Herrenknecht, C.; Sibat, M.; Amzil, Z.; Cole, R.B.; Hess, P. High resolution mass spectrometry for quantitative analysis and untargeted screening of algal toxins in mussels and passive samplers. J. Chromatogr. A 2015, 1416, 10-21. [CrossRef] [PubMed]

35. Mondeguer, F.; Antignac, J.-P.; Guitton, Y.; Monteau, F.; Le Borgne, S.; Hess, P. Nouvelle stratégie de caractérisation non ciblée de type métabolomique au service de l'identification de composés bioactifs accumulés dans les mollusques bivalves: Couplage chromatographie liquide-spectrométrie de masse haute résolution (LC-HRMS). Spectra Anal. 2012, 284, 10.

36. Naz, S.; Vallejo, M.; Garcia, A.; Barbas, C. Method validation strategies involved in non-targeted metabolomics. J. Chromatogr. A 2014, 1353, 99-105. [CrossRef] [PubMed]

37. Heffernan, A.L.; Gomez-Ramos, M.M.; Gaus, C.; Vijayasarathy, S.; Bell, I.; Hof, C.; Mueller, J.F.; Gomez-Ramos, M.J. Non-targeted, high resolution mass spectrometry strategy for simultaneous monitoring of xenobiotics and endogenous compounds in green sea turtles on the Great Barrier Reef. Sci. Total Environ. 2017, 599-600, 1251-1262. [CrossRef] [PubMed]

38. European Commission. Commission Decision of 12 August 2002 implementing Council Directive 96/23/EC concerning the performance of analytical methods and the interpretation of results. Off. J. Eur. Commun. 2002, 221, 29.

39. McCarron, P.; Wright, E.; Quilliam, M.A. Liquid chromatography/mass spectrometry of domoic acid and lipophilic shellfish toxins with selected reaction monitoring and optional confirmation by library searching of product ion spectra. J. AOAC Int. 2014, 97, 316-324. [CrossRef] [PubMed]

40. Beach, D.G.; Walsh, C.M.; McCarron, P. High-throughput quantitative analysis of domoic acid directly from mussel tissue using Laser Ablation Electrospray Ionization-Tandem mass spectrometry. Toxicon 2014, 92, 75-80. [CrossRef] [PubMed] 
41. James, K.J.; Gillman, M.; Amandi, M.F.; López-Rivera, A.; Puente, P.F.; Lehane, M.; Mitrovic, S.; Furey, A. Amnesic shellfish poisoning toxins in bivalve molluscs in Ireland. Toxicon 2005, 46, 852-858. [CrossRef] [PubMed]

42. Wang, Z.; Maucher-Fuquay, J.; Fire, S.E.; Mikulski, C.M.; Haynes, B.; Doucette, G.J.; Ramsdell, J.S. Optimization of solid-phase extraction and liquid chromatography-tandem mass spectrometry for the determination of domoic acid in seawater, phytoplankton, and mammalian fluids and tissues. Anal. Chim. Acta 2012, 715, 71-79. [CrossRef] [PubMed]

43. Zhang, Y.; Chen, D.; Hong, Z. A rapid LC-HRMS method for the determination of domoic acid in urine using a self-assembly pipette tip solid-phase extraction. Toxins 2015, 8, 10. [CrossRef] [PubMed]

44. Ciminiello, P.; Dell'Aversano, C.; Fattorusso, E.; Forino, M.; Magno, G.S.; Tartaglione, L.; Quilliam, M.A.; Tubaro, A.; Poletti, R. Hydrophilic interaction liquid chromatography/mass spectrometry for determination of domoic acid in Adriatic shellfish. Rapid Commun. Mass Spectrom. 2005, 19, 2030-2038. [CrossRef] [PubMed]

45. Zendong, S.Z. Développement de Méthodes de Spectrométrie de Masse Haute Résolution (SMHR) Pour le Criblage des Phycotoxines dans les Echantillons Biologiques et Environnementaux. Ph.D. Thesis, Nantes University, Nantes, France, 2015.

46. Zhuo, L.; Fu, W.; Yang, Y.; Qiu, B.; Lin, Z.; Shan, L.; Zheng, L.; Li, J.; Chen, G. Simultaneous determination of biotoxins DSP and AZAs in bivalve molluscs and fish by liquid chromatography/tandem mass spectrometry. Rapid Commun. Mass Spectrom. 2014, 28, 1479-1488. [CrossRef] [PubMed]

47. Ishida, H.; Nozawa, A.; Nukaya, H.; Tsuji, K. Comparative concentrations of brevetoxins PbTx-2, PbTx-3, BTX-B1 and BTX-B5 in cockle, Austrovenus stutchburyi, greenshell mussel, Perna canaliculus, and Pacific oyster, Crassostrea gigas, involved neurotoxic shellfish poisoning in New Zealand. Toxicon 2004, 43, 779-789. [CrossRef] [PubMed]

48. Kilcoyne, J.; Fux, E. Strategies for the elimination of matrix effects in the liquid chromatography tandem mass spectrometry analysis of the lipophilic toxins okadaic acid and azaspiracid-1 in molluscan shellfish. J. Chromatogr. A. 2010, 1217, 7123-7130. [CrossRef] [PubMed]

49. Botana, L.M.; Alfonso, A.; Rodríguez, I.; Botana, A.M.; Louzao, M.C.; Vieytes, M.R. How safe is safe for marine toxins monitoring? Toxins 2016, 8, 208. [CrossRef] [PubMed]

50. Campbell, K.; Vilariño, N.; Botana, L.M.; Elliott, C.T. A European perspective on progress in moving away from the mouse bioassay for marine-toxin analysis. TrAC Trends Anal. Chem. 2011, 30, 239-253. [CrossRef]

51. Otero, P.; Alfonso, A.; Alfonso, C.; Rodríguez, P.; Vieytes, M.R.; Botana, L.M. Effect of uncontrolled factors in a validated liquid chromatography-tandem mass spectrometry method question its use as a reference method for marine toxins: Major causes for concern. Anal. Chem. 2011, 83, 5903-5911. [CrossRef] [PubMed]

52. Otero, P.; Alfonso, C. Analysis of marine toxins: gaps on food safety control for marine toxins by chemical methods. In Phycotoxins: Chemistry and Biochemistry, 2nd ed.; Botana, L.M., Alfonso, A., Eds.; John Wiley and Sons: Hoboken, NJ, USA, 2015; p. 22.

53. Molecular Components Map of Representative Matrices of Commodity Groups in document SANTE/11813/2017. Available online: http://www.eurl-pesticides.eu/userfiles/file//EURL-FV(2018 -M23)\%20Molecular\%20component\%20map.pdf (accessed on the 12 September 2018).

54. Schymanski, E.L.; Jeon, J.; Gulde, R.; Fenner, K.; Ruff, M.; Singer, H.P.; Hollender, J. Identifying small molecules via high resolution mass spectrometry: communicating confidence. Environ. Sci. Technol. 2014, 48, 2097-2098. [CrossRef] [PubMed]

55. Pisapia, F.; Sibat, M.; Herrenknecht, C.; Lhaute, K.; Gaiani, G.; Ferron, P.J.; Fessard, V.; Fraga, S.; Nascimento, S.M.; Litaker, R.W.; et al. Maitotoxin-4, a Novel MTX Analog Produced by Gambierdiscus excentricus. Mar. Drugs 2017, 15, 220. [CrossRef] [PubMed]

56. EU-Harmonised Standard Operating Procedure for Determination of Lipophilic Marine Biotoxins in Molluscs by LC-MS/MS. Available online: www.aecosan.msssi.gob.es/AECOSAN/docs/documentos /laboratorios/LNRBM/ARCHIVO2EU-Harmonised-SOP-LIPO-LCMSMS_Version5.pdf (accessed on the 12 September 2018).

57. Mountfort, D.O.; Suzuki, T.; Truman, P. Protein phosphatase inhibition assay adapted for determination of total DSP in contaminated mussels. Toxicon 2001, 39, 383-390. [CrossRef] 
58. Sanagi, M.M.; Ling, S.L.; Nasir, Z.; Hermawan, D.; Ibrahim, W.A.; Abu Naim, A. Comparison of signal-to-noise, blank determination, and linear regression methods for the estimation of detection and quantification limits for volatile organic compounds by gas chromatography. J. AOAC Int. 2009, 92, 1833-1838. [PubMed]

59. Vial, J.; Jardy, A. Experimental comparison of the different approaches to estimate LOD and LOQ of an HPLC method. Anal. Chem. 1999, 71, 2672-2677. [CrossRef]

60. ISO 13528:2015. Statistical Methods for Use in Proficiency Testing by Interlaboratory Comparison. Available online: https://www.iso.org/obp/ui/\#iso:std:iso:13528:ed-2:v2:en (accessed on the 12 September 2018).

(C) 2018 by the authors. Licensee MDPI, Basel, Switzerland. This article is an open access article distributed under the terms and conditions of the Creative Commons Attribution (CC BY) license (http:/ / creativecommons.org/licenses/by/4.0/). 
Article

\title{
A Sensitive LC-MS/MS Method for Palytoxin Using Lithium Cationization
}

\author{
Mirjam D. Klijnstra * and Arjen Gerssen * \\ RIKILT, Wageningen University and Research Center, Akkermaalsbos 2, 6708 WB Wageningen, The Netherlands \\ * Correspondence: mirjam.klijnstra@wur.nl (M.D.K.); arjen.gerssen@wur.nl (A.G.)
}

Received: 30 October 2018; Accepted: 11 December 2018; Published: 14 December 2018

\begin{abstract}
Palytoxin (PITX) and analogues are produced by certain dinoflagellates, sea anemones, corals and cyanobacteria. PITX can accumulate in the food chain and when consumed it may cause intoxication with symptoms like myalgia, weakness, fever, nausea, and vomiting. The analysis of PITXs is challenging, and because of the large molecular structure, it is difficult to develop a sensitive and selective liquid chromatography-mass spectrometry (LC-MS/MS) method. In this work, an LC-MS/MS method was developed to analyse PITXs with use of lithium iodine and formic acid as additives in the mobile phase. For method development, initially, LC-hrMS was used to accurately determine the elemental composition of the precursor and product ions. The main adduct formed was $[\mathrm{M}+\mathrm{H}+2 \mathrm{Li}]^{3+}$. Fragments were identified with LC-hrMS and these were incorporated in the LC-MS/MS method. A method of $10 \mathrm{~min}$ was developed and a solid phase extraction clean-up procedure was optimised for shellfish matrix. The determined limits of detection were respectively 8 and $22 \mu \mathrm{g}$ PITX $\mathrm{kg}^{-1}$ for mussel and oyster matrix. Oysters gave a low recovery of approximately $50 \%$ for PITX during extraction. The method was successfully in-house validated, repeatability had a relative standard deviation less than $20 \%(n=5)$ at $30 \mu \mathrm{g}$ PITX kg ${ }^{-1}$ in mussel, cockle, and ensis, and at $60 \mu \mathrm{g}$ PITX kg-1 in oyster.
\end{abstract}

Keywords: palytoxin; ovatoxins; mass spectrometry; cationization

Key Contribution: A highly sensitive LC-MS/MS method for palytoxin detection in shellfish using cationization was developed. Using lithium; we were able to improve the ionization and detect intact palytoxins at low levels of 8 and $22 \mu \mathrm{g} \mathrm{kg}^{-1}$ for respectively mussel and oyster matrices.

\section{Introduction}

Palytoxin (PITX), ovatoxin (OVTX), ostreocin, and other analogues are produced by the dinoflagellates Ostreopsis ovata and Ostreopsis siamensis [1-4] as well as by certain sea anemones, and corals of the Palythoa species and cyanobacteria of the genus Trichodesmium $[5,6]$. The Ostreopsis species is widely spread throughout the world [7]. From these producers, PITXs can accumulate in the food chain in organisms like mussels, crabs, and fish [8]. PITXs are one of the largest non-protein compounds within the class of marine biotoxins. These polyhydroxylated compounds with both lipophilic and hydrophilic parts consist out of a long, partially unsaturated, aliphatic backbone containing cyclic ethers, hydroxyl, and amide groups. Currently, more than 25 different PITX analogues have been described such as the OVTX a-e, ostreocins and mascarenotoxins $[9,10]$. Since the discovery of PITX in the 1960's, a number of exposures and poisonings related to PITX have been reported from several parts of the world [11,12]. Exposure to PITXs was mostly related to inhalation exposure. The most well know intoxication event was in Italy in 2005 where over 200 people showed respiratory problems [13]. However, smaller incidents are also reported such as in the Netherlands where four people suffered from high fever and overall malaise after cleaning an aquarium, where stones were cooked in order to 
remove a colony of zoanthids [14]. PITX binds to the extracellular part of the $\mathrm{Na}^{+} / \mathrm{K}^{+}$-ATPase, opening the cation channel, which inhibits the transport of $\mathrm{Na}^{+}$and $\mathrm{K}^{+}$across the cell membrane. This results in mitochondrial damage and cell death [15]. Furthermore, an increase in the cytosolic $\mathrm{Ca}^{2+}$, caused by the action of $\mathrm{Na}^{+} / \mathrm{Ca}^{2+}$ exchange pump, is observed, which also eventually causes cell death [16]. Symptoms of PITX intoxication are myalgia, weakness, fever, nausea, and vomiting. The toxicity of PITX is strongly dependent on the route of administration; in animal experiments, the toxicity of PITX is much lower after oral administration compared to intraperitoneal (i.p.) administration. Animal studies revealed an $\mathrm{LD}_{50}$ of $<1 \mu \mathrm{g} \mathrm{kg}^{-1}$ via intravenous administration, however, it is approximately 1000-fold less toxic after oral administration ( $\left.\mathrm{LD}_{50} 767 \mu \mathrm{g} \mathrm{kg}{ }^{-1}\right)$ [17,18]. Currently, no international legislation has been established mentioning safe PITX levels in shellfish. The European Food Safety Authority (EFSA) has reviewed the available toxicological data in 2009. They concluded based on the available data an acute reference dose (ARfD) of $0.2 \mu \mathrm{g} \mathrm{kg}^{-1}$ bodyweight. This ARfD can be translated to a limit of $30 \mu \mathrm{g}$ PITX-eq $\mathrm{kg}^{-1}$ in shellfish meat with the assumption of a person of $60 \mathrm{~kg}$ consuming $400 \mathrm{~g}$ of shellfish meat [19].

To detect PITXs in shellfish, several methods have been described: In vivo methods, in vitro methods, immunological methods, and analytical chemical methods. The in vivo mousse bioassay (MBA) [20] is based on the i.p. injection of a shellfish extract. The observed effect is stretching of hind limbs and lower back, weakening of forelimbs, ataxia, decreased locomotion, convulsions, gasping for breath, and eventually death. In vitro assays are based on the toxicological effect on either a cell line or on receptor binding. The latter is based on the effect on the $\mathrm{Na}+/ \mathrm{K}+$ ATPase pump which is labelled with a fluorescent label. This can be measured using fluorescence polarisation [21]. Other in vitro assays developed are for example based on a neuro2a cell line and the detection of cell viability based on 3-(4,5-dimethylthiazol-2-yl)-2,5-diphenyltetrazolium bromide (MTT) [22] or on haemolytic activity of palytoxin against erythrocytes [23]. Immunological methods are based on the recognition of a certain part of the PITX molecule by an antibody, as for example described by Fraga et al. [24]. Each type of method has its advantages and disadvantages. The in vivo test has a direct response (mouse death) and proponents believe unknown toxins will be detected by this system. The drawback of this test, beside that the method is unethical, is the route of administration, which is i.p. instead of oral. This will result in discrepancies as adsorption and metabolism are not taken into account. Furthermore, the methodology has a poor selectivity towards which compound is responsible for the observed effect. The in vitro tests are a good alternative. A pro of the in vitro test is that no expensive standards solutions and animal facilities are required. However, an observed response will still need verification by a confirmatory method. Immunological methods are fast and sensitive. However, as only a part of the molecule is recognized by the antibody, cross reactivity towards PITX analogues might be poor, causing an underestimation or an overestimation of the true PITX concentration, and still confirmation of the toxin should be performed. For confirmatory purposes, analytical chemistry based on liquid chromatography coupled to mass spectrometry (MS) can be used. The drawback of analytical chemical methods is the need for individual toxin standards for each analogue [20]. Unfortunately, for PITXs the developed chemical methods are not always sensitive enough to detect PITXs at the EFSA recommended safe levels. Ciminiello et al. published a method based on liquid chromatography coupled to high resolution mass spectrometry (LC-hrMS) to obtain accurate masses in full scan mode. In the hrMS complex spectra were obtained consisting out of multiple adducts with various charge states and in source fragmentation of multiple losses of water. The sensitivity of this method is sufficient (limit of quantitation (LOQ) of $44 \mathrm{ng} \mathrm{mL}^{-1}$ in shellfish extract) but can be improved $[25,26]$.

Selwood et al. developed a more sensitive method based on a micro oxidation of PITX to low molecular weight oxidation products [27]. These oxidation products are then analysed by LC-MS/MS. The drawback of this method is that various PITX analogues will give the same oxidation products which hamper selectivity. This selectivity is important as not all PITX analogues will have the same toxicological potency [28]. Therefore, in this paper a sensitive method based on the ionization of intact 
PITX is presented. The principle is based on cationization, this can be accomplished by the addition of alkali-metal ions such as lithium to the mobile phase. The alkali-metal ions will form a chelate or complex with the oxygen groups in the molecule. This approach has been described for somewhat larger molecules in various application fields such as the analysis of polysaccharides, polymers, and oils [29-31].

\section{Results}

\subsection{Infusion Experiments with High Resolution Mass Spectrometry}

In order to obtain the optimal conditions for the cationization, infusion experiments were carried out with different mobile phase compositions. The LC flow of $0.1 \mathrm{~mL} \mathrm{~min}^{-1}$ and a concentration of $1 \mu \mathrm{g}$ $\mathrm{mL}^{-1}$ PITX were kept constant during all infusion experiments. The initial infusion experiments with hrMS were performed with a mobile phase containing formic acid and ammonium formate. Spectra in positive and negative ionisation mode contained, respectively, $[\mathrm{M}+\mathrm{H}+\mathrm{Na}]^{2+}$ and $[\mathrm{M}-2 \mathrm{H}]^{2-}$ ions with relatively low abundance (spectra in Supplementary Material Figures S1 and S2). For cationization, $\mathrm{LiI}$ or $\mathrm{LiCl}$ were added to the mobile phase. Ionization efficiency under different $\mathrm{pH}$ conditions were investigated by adding various additives to the mobile phase. For acidic conditions formic acid was added, for alkaline conditions ammonia was added and also the mobile phase without additive was tested. The concentration of the cationizing agent varied from 0.1 to $2 \mathrm{mM}$, and the concentration of the additive varied from $0.0005 \%$ to $0.01 \%$. During the initial experiment, a full MS scan of $\mathrm{m} / \mathrm{z}$ 700 to 2800 was acquired in both positive and negative electrospray ionisation (ESI) mode. With ESI negative mode no PITX ions were formed when the mobile phase contained Li. With positive ESI mode, PITX ions were formed without additives, and under both acidic and alkaline conditions. However, no single charged ion species was obtained (Figures S3-S8). Therefore, in all further full scan MS experiments, spectra were acquired with an $\mathrm{m} / \mathrm{z} 500$ to 1400 in positive ESI mode. Figure 1 shows all major ions formed with formic acid or ammonia as an additive. The ions formed without additives in the mobile phase were similar to the ions under acidic conditions, only lower in abundance. Despite the fact that due to the high number of carbon elements, $\mathrm{C}_{129} \mathrm{H}_{223} \mathrm{~N}_{3} \mathrm{O}_{54}$, the ${ }^{13} \mathrm{C}$ isotopic mass of PITX is higher in abundance compared to the monoisotopic mass, all $\mathrm{m} / \mathrm{z}$ values mentioned in the article and in the figures are based on the monoisotopic masses in order to avoid confusion about elemental compositions.

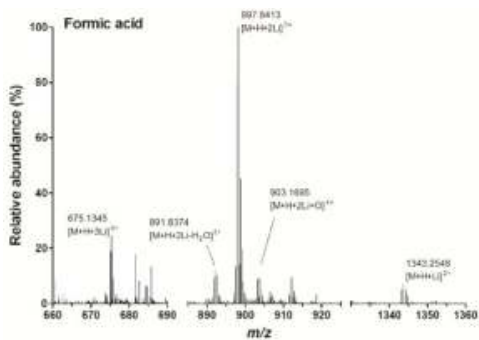

(a)

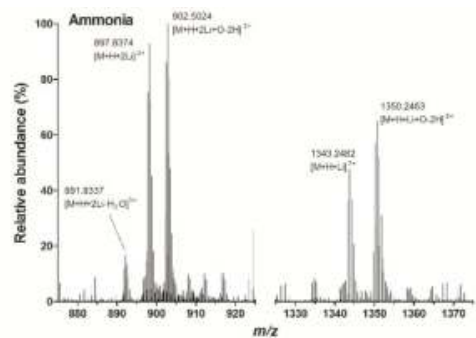

(b)

Figure 1. Ionisation of PITX with LiI under (a) acidic and (b) alkaline conditions, masses shown are the monoisotopic $m / z$ values.

Under acidic conditions one major ion was formed: $m / z$ 897.8413, which corresponds to the $[\mathrm{M}+\mathrm{H}+2 \mathrm{Li}]^{3+}$ ion. Furthermore, $m / z 903.1695\left([\mathrm{M}+\mathrm{H}+2 \mathrm{Li}+\mathrm{O}]^{3+}\right), m / z 891.8374([\mathrm{M}+\mathrm{H}+2 \mathrm{Li}$ $\left.\left.-\mathrm{H}_{2} \mathrm{O}\right]^{3+}\right), m / z 675.1345\left([\mathrm{M}+\mathrm{H}+3 \mathrm{Li}]^{4+}\right)$, and $m / z 1343.2548\left([\mathrm{M}+\mathrm{H}+\mathrm{Li}]^{2+}\right)$ were observed. Under alkaline conditions two major ions were formed: $m / z$ 897.8374 $\left([\mathrm{M}+\mathrm{H}+2 \mathrm{Li}]^{3+}\right)$ and $m / z$ $902.5024\left([\mathrm{M}+\mathrm{H}+2 \mathrm{Li}-2 \mathrm{H}+\mathrm{O}]^{3+}\right)$. Furthermore, low abundant ions with $m / z 1343.2482([\mathrm{M}+\mathrm{H}+$ $\left.\mathrm{Li}]^{2+}\right)$ and $m / z 1350.2463\left(\left[\mathrm{M}+\mathrm{H}+\mathrm{Li}-2 \mathrm{H}+\mathrm{O}^{2+}\right)\right.$ as well as some in-source fragmentation resulting 
in multiple losses of water were detected. No quadruple charged ions were formed under alkaline conditions. The average $\Delta$ ppm error of the measured masses compared to the theoretical masses was $2.5 \mathrm{ppm}$ with a maximum of $4.1 \mathrm{ppm}$ for the $[\mathrm{M}+\mathrm{H}+\mathrm{Li}-2 \mathrm{H}+\mathrm{O}]^{2+}$ ion and a minimum of $1.6 \mathrm{ppm}$ for the $[\mathrm{M}+\mathrm{H}+2 \mathrm{Li}+\mathrm{O}]^{3+}$ ion. Under both the acidic and alkaline conditions, an in-source oxidation product was observed, the $[\mathrm{M}+\mathrm{H}+2 \mathrm{Li}+\mathrm{O}]^{2+}$ and $[\mathrm{M}+\mathrm{H}+\mathrm{Li}-2 \mathrm{H}+\mathrm{O}]^{2+}$ ion under respectively acidic and alkaline conditions. This in-source oxidation which occurred is not very often described, however, there is some literature available on the oxidation of large molecules. A possible cause might be the condition of the ESI capillary, which is described by Chen et al. who showed that corroded capillaries can cause in-source oxidation of peptides [32]. The effect of the counter ion was studied by applying two different Li salts, $\mathrm{LiI}$ and $\mathrm{LiCl}$. Both salts gave the same PlTX ions in the spectra. However, when LiI was used in the mobile phase there was a higher abundance in the PITX ions of interest. Finally, the formic acid concentration in the mobile phase was optimized. The highest abundance of the $[\mathrm{M}+\mathrm{H}+2 \mathrm{Li}]^{3+}$ ion was found with $0.25 \mathrm{mM} \mathrm{LiI}$ in combination with $0.00125 \%$ formic acid.

\subsection{Fragmentation PITX with High Resolution Mass Spectrometry}

When selecting $\mathrm{m} / \mathrm{z} 898$ as the precursor ion, the fragmentation spectrum as shown in Figure 2 was obtained. A series of water losses were observed with $m / z 891.8354\left(-\mathrm{H}_{2} \mathrm{O}\right), m / z 885.8322\left(-2 \mathrm{H}_{2} \mathrm{O}\right), m / z$ $879.8289\left(-3 \mathrm{H}_{2} \mathrm{O}\right)$, and $m / z 873.8255\left(-4 \mathrm{H}_{2} \mathrm{O}\right)$. Furthermore, more structural specific product ions with $\mathrm{m} / \mathrm{z} 1215.7195, \mathrm{~m} / \mathrm{z}$ 711.8843, and $\mathrm{m} / \mathrm{z} 327.1916$ were obtained. Elemental compositions of these ions are respectively $\left[\mathrm{C}_{58} \mathrm{H}_{106} \mathrm{O}_{24} \mathrm{~N}_{2}+\mathrm{H}\right]^{1+},\left[\mathrm{C}_{70} \mathrm{H}_{113} \mathrm{O}_{28} \mathrm{~N}+\mathrm{H}+\mathrm{Li}\right]^{2+}$ and $\left[\mathrm{C}_{16} \mathrm{H}_{26} \mathrm{O}_{5} \mathrm{~N}_{2}+\mathrm{H}\right]^{1+}$. The proposed structures of the fragments are shown in Figure 3.

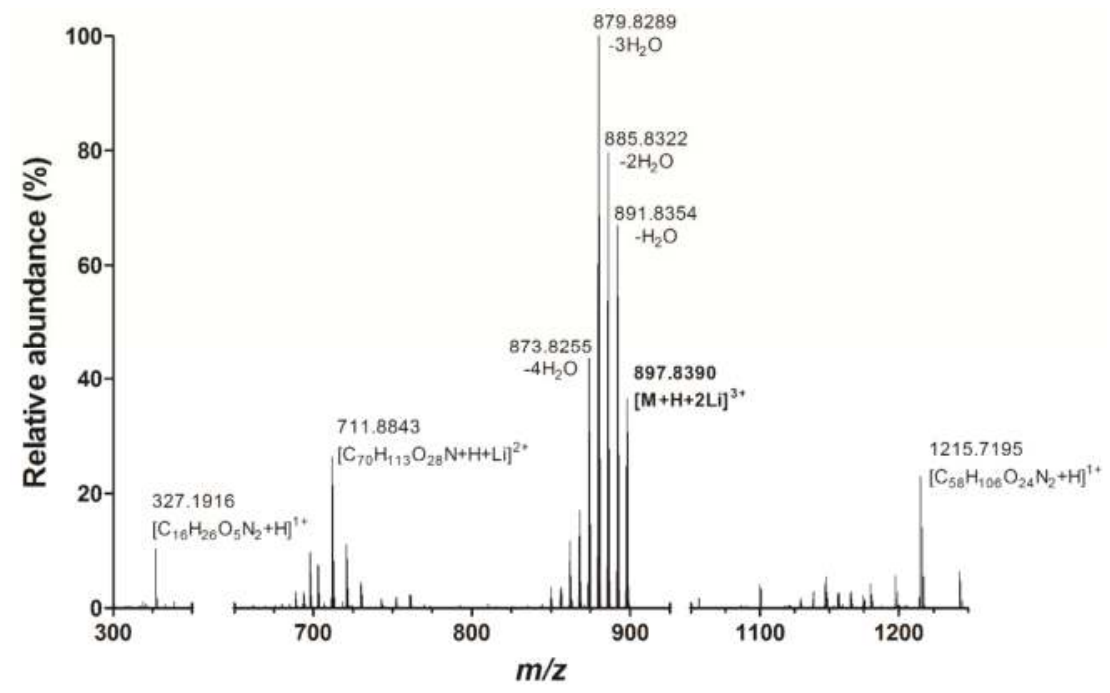

Figure 2. Fragmentation spectrum of PITX under acidic conditions with LiI in electrospray ionisation (ESI) positive mode. 


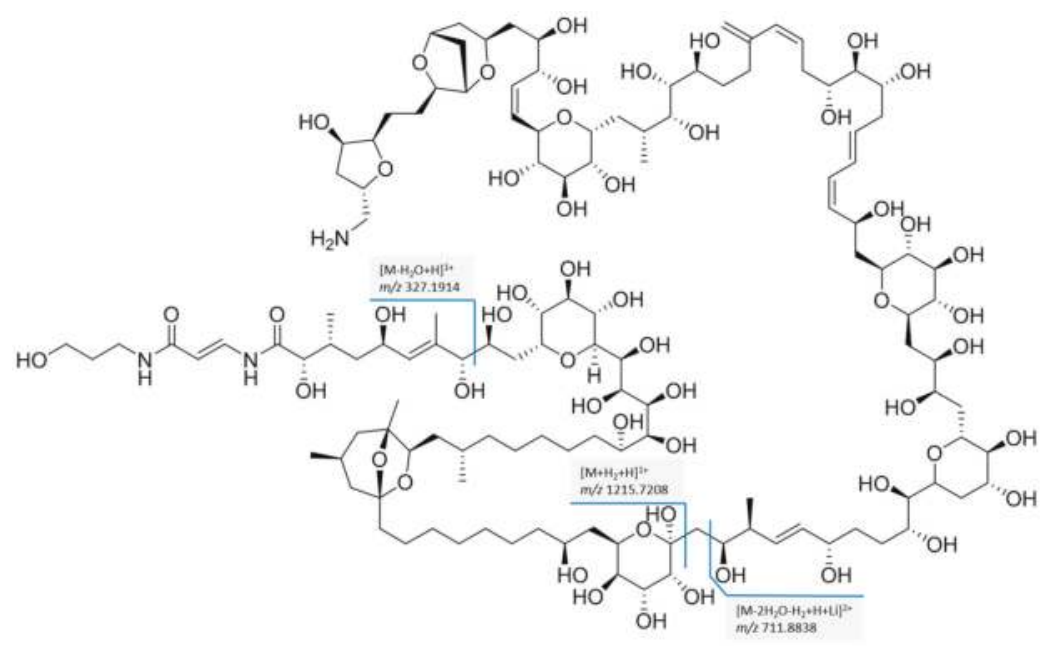

Figure 3. Proposed fragmentation of PITX under acidic conditions with LiI.

\subsection{Chromatography}

To rapidly screen for PITXs a 10 min LC method was developed, as shown in Figure 4, where the total ion current (TIC) is shown. Although most PITXs are separated by time or $m / z$, some of the OVTXs have the same $\mathrm{m} / \mathrm{z}$ and are structurally similar and are therefore not separated with the fast 10 min LC gradient. To obtain an improved chromatographic separation a slightly longer LC-method with a gradient with a slower increase over time in organic strength was developed. The longer LC method is capable of separating the OVTXs a to e and putative PITX (pPITX) as demonstrated for an algae extract (Figure 5).

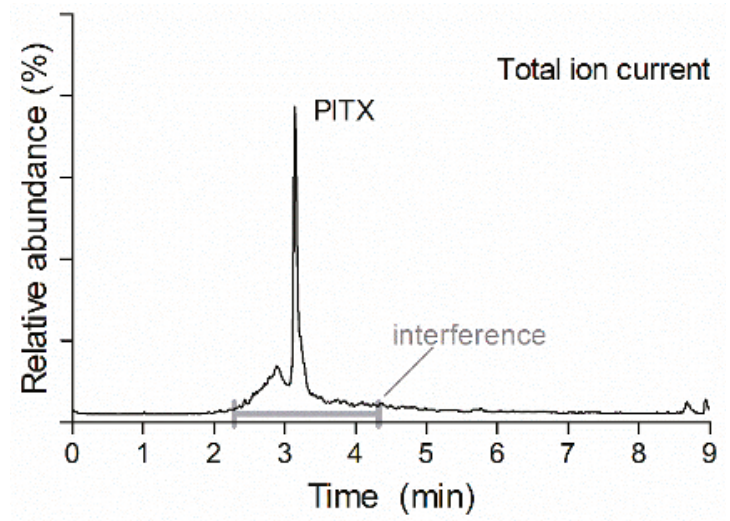

Figure 4. Chromatography PITX $100 \mu \mathrm{g} \mathrm{kg}^{-1}$ in mussel with $10 \mathrm{~min}$ screening method. 


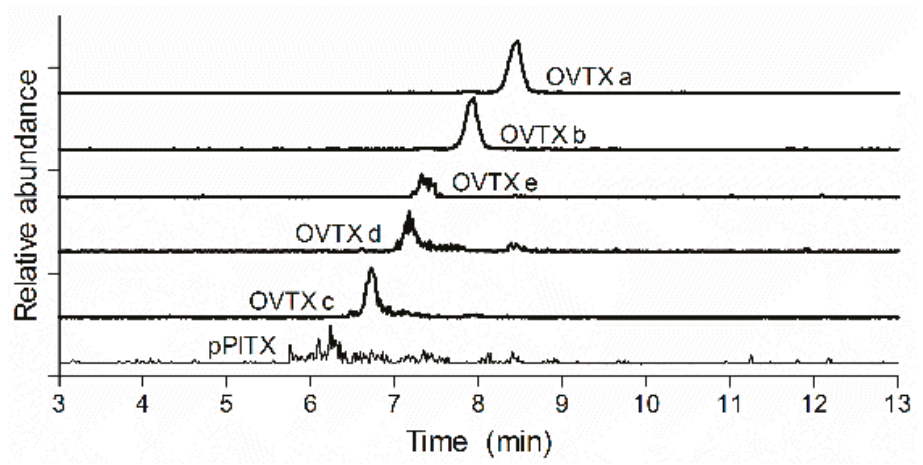

Figure 5. Separation of ovatoxins (OVTXs) a, b, c, d, e and putative PITX (pPITX) in algae extract.

\subsection{Sample Clean-Up}

For method development of the extraction and clean-up procedure, blank mussel and oyster homogenates were fortified with $60 \mu \mathrm{g}$ PITX $\mathrm{kg}^{-1}$. During method development, oyster gave a low recovery varying between approximately 5 and $50 \%$. By performing spike experiments at different stages in the procedure it could be concluded that the low recovery of PITX in oyster occurred during the extraction and not during the solid phase extraction (SPE) clean-up procedure. Besides the methanol/water $(50: 50 \mathrm{v} / \mathrm{v})$ extraction, a variety of extraction solvents was tried like $100 \%$ methanol or methanol/water (50:50 v/v) with additives at various pHs. Furthermore, the addition of ethylenediaminetetraacetic acid (EDTA) was explored to improve extraction efficiency. EDTA was added to create metal complexes and reduce the amount of free metals like zinc in the extract which might also form complexes with PITX. This might be the case as it is well known that oysters are rich in zinc content compared to other shellfish species [33]. Unfortunately, recoveries did not improve with the tested procedures, therefore it was decided to continue with the methanol/water $(50: 50 \mathrm{v} / \mathrm{v})$ extraction solvent. The low observed recoveries of PITX in oyster were also obtained during the validation study (Figure 6). When extracting with methanol/water (50:50 $v / v$ ) and performing SPE clean-up the limit of detection (LOD) for PITX in mussel and oyster are respectively 8 and $22 \mu \mathrm{g} \mathrm{kg}^{-1}$.

\subsection{Method Validation}

In order to validate the developed quantitative LC-MS/MS method twenty-one samples were used to determine selectivity, linearity, recovery, and repeatability. Validation was performed according to the SANTE/2015/11945 guidance document [34]. Solely PITX was validated as no other commercial standards for the analogues and OVTXs are available.

The selectivity of the method was determined by the analysis of 20 blank shellfish samples (five mussels, five oysters, five ensis and five cockles). According to the SANTE document, the interferences present should be less than $30 \%$ of the PITX peak area. During the validation, the water loss multiple reaction monitoring (MRM) transitions used, $898.2>880.2$ and $898.2>874.2$, showed background interference in both mussel and oyster (Figure 4). The area of the background in the samples spiked with $10 \mu \mathrm{g}$ PITX kg ${ }^{-1}$ exceeded the $30 \%$, at higher concentrations, $>30 \mu \mathrm{g}$ PITX kg ${ }^{-1}$, this improved. With the other MRM transition used, $897.8>711.9$, less background interference was obtained. However, LODs with the water loss MRMs were much lower compared to the other MRM transitions and therefore the water loss MRMs were used for quantification. Furthermore, it can be argued that these water losses were not specific. From a triply charged ion, a single loss of water is a loss of $m / z 6$, which is not possible to observe from single and doubly charged molecules. Although, the loss of $3 \mathrm{H}_{2} \mathrm{O}$, MRM transition $898.2>880.2$, is the loss of $m / z 18$, which is the same as the loss of one $\mathrm{H}_{2} \mathrm{O}$ in a single charged molecule. This might explain the relatively high interference background for this transition. However, the loss of $4 \mathrm{H}_{2} \mathrm{O}$ corresponds to a $m / z 24$ loss which is not 
a commonly obtained neutral loss. For additional confirmation, a third transition $(897.8>711.9)$ was used, however, this transition was not used for quantitation. Both ensis and cockle showed the same kind of background signal as mussel and oyster. However, it was less in abundance and therefore when spiked with $10 \mu \mathrm{g}$ PITX kg-1 the area of the interference was less than $30 \%$ of the PITX area.

Linearity was determined by constructing a calibration curve with five matrix matched standards ranging from 5 to $100 \mu \mathrm{g}$ PITX kg ${ }^{-1}$ in mussel homogenate. The requirement for the correlation coefficient was $>0.990$. During the validation, the correlation coefficient was $\geq 0.997$ and therefore it met the requirements. Furthermore, as a requirement, the residuals from the regression line should be below $20 \%$. Only the $5 \mu \mathrm{g}$ PITX kg ${ }^{-1}$ standard did not meet this criterion as a residual of $-27 \%$ was observed. This is also in line with the LOQ of $8 \mu \mathrm{g}$ PITX $\mathrm{kg}^{-1}$ in mussel caused by the relatively high background signal.

To calculate the recovery, all various shellfish matrices were quantified using the calibration curve constructed using mussel matrix matched standards. The recovery of mussels, cockles and ensis were within the requirements of $>70 \%$ and $<120 \%$ (Figure 6 ). The recovery of PITX in oysters was on average $50 \%$. For the repeatability error, the relative standard deviation (RSD) should be below 20\%. The RSD of the repeatability exceeded the $20 \%$ in mussel fortified at $10 \mu \mathrm{g}$ PITX kg ${ }^{-1}$ and in oysters at 10 and $30 \mu \mathrm{g}$ PITX $\mathrm{kg}^{-1}$ due to the background signal and relative low recovery in oysters.

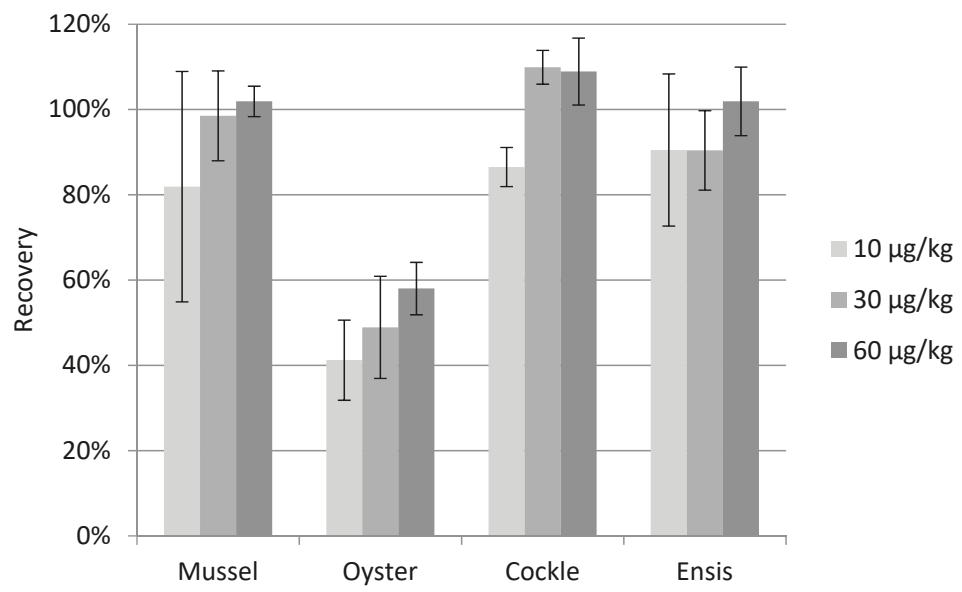

Figure 6. Recovery and relative standard deviation (RSD) of PITX in shellfish matrix $(n=5)$.

\section{Discussion}

The analysis of PITXs is challenging, because of the large molecular structure it is difficult to develop a sensitive and selective LC-MS method. A method was successfully developed to analyse PITXs in shellfish with LC-MS/MS. Improved sensitivity was obtained using cationization with lithium.

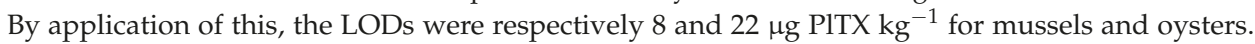
The method was successfully in-house validated at levels of 30 and $60 \mu \mathrm{g}$ PITX kg ${ }^{-1}$. Currently, no legislation is established for PITXs, however, based on the EFSA opinion, safe consumption levels should be below $30 \mu \mathrm{g}$ PITX-eq $\mathrm{kg}^{-1}$ of edible shellfish. Therefore, the developed method can be used for the analysis on the levels as mentioned in the EFSA opinion.

Compared to previous described LC-MS methods, i.e., Ciminiello et al. and Selwood et al., sensitivity is slightly improved or comparable [25,27]. The hrMS method by Ciminiello et al. provided more complex spectra compared to our more simplified spectra which resulted in improved LODs. Although the method of Selwood et al. is comparable in sensitivity with an LOQ of $10 \mu \mathrm{g}$ PlTX kg-1 in seafood, the selectivity is greatly improved. With the developed method intact, PITX molecules and analogues can be analysed compared to the generic oxidation products as done by Selwood et al. 
Our method will give more insight into the toxin profile, which might be important as not all analogues pose the same toxicological potency.

Furthermore, another marine biotoxin class was also tested with the same method. These are the ciguatoxins (CTXs). Current LC-MS/MS methodologies for CTXs would benefit from a gain in sensitivity, as the main challenge with the analysis of CTXs is the low LOQs required. This is because the recommended safe concentrations by the US food and drug administration as well as the EFSA are $0.01 \mu \mathrm{g}$ equivalents of Pacific-CTX- $1 \mathrm{~kg}^{-1}$ of fish. CTXs analysed with straightforward LC-MS/MS methods gave relatively poor ionization and fragmentation due to the structure of CTXs. Although recently Moreiras et al. [35] published a systematic approach to optimize ionisation for CTXs, which already slightly improved sensitivity, an attempt was made with the formation of possible lithium adducts. Unfortunately, no detectable lithium ions were formed when CTX standards were analysed with this method, most likely due to the limited availability of hydroxyl groups in the CTX structure.

\section{Materials and Methods}

\subsection{Chemicals and Materials}

Formic acid (98-100\%), acetic acid (96\%), and ammonia (25\%) were purchased from VWR, Amsterdam, the Netherlands. Acetonitrile (Ultra LC-MS), methanol (Ultra LC-MS), and water (Ultra LC-MS) were purchased from Actu-All, Oss, the Netherlands. Lithium iodide hydrate (98\%) and lithium chloride $(>99 \%)$ were purchased from Sigma-Aldrich, Zwijndrecht, the Netherlands. PITX $(>90 \%)$ was purchased from Wako, Osaka, Japan.

Blank shellfish samples used for method validation were collected in 2017 from several shellfish production areas in the Netherlands. Contaminated sample extracts containing PPITX and OVTXs were a gift from Carmela Dell'aversano, University of Naples Federico II, Napoli, Italy.

\subsection{Preparation of Standards}

The PITX standard was dissolved to a concentration of $20 \mu \mathrm{g} \mathrm{mL} \mathrm{m}^{-1}$ in methanol/water $(50: 50 \mathrm{v} / \mathrm{v})$. Before the spiking experiments, the stock solution was further diluted to $1 \mu \mathrm{g} \mathrm{mL} \mathrm{m}^{-1}$ with methanol/water $(50: 50 v / v)$.

\subsection{Liquid Chromatography Coupled with Mass Spectrometry}

\subsubsection{Sample Clean-up}

$1.0 \pm 0.05 \mathrm{~g}$ shellfish tissue homogenate was weighed and extracted with $3 \mathrm{~mL}$ methanol/water $(50: 50 \mathrm{v} / \mathrm{v})$. The sample was vortex mixed for one minute using a multi-pulse vortex. The sample was centrifuged at 2,000 $\times g$ for $5 \mathrm{~min}$ and the supernatant was decanted from the pellet to a new tube. The extraction procedure was repeated twice and supernatants were combined.

A Strata-X polymeric reversed phase cartridge of $60 \mathrm{mg}$ (Phenomenex, Utrecht, the Netherlands) was conditioned and equilibrated with $3 \mathrm{~mL}$ methanol followed by $3 \mathrm{~mL}$ water. The sample extract of $9 \mathrm{~mL}$ was applied to the cartridge and subsequently washed with $3 \mathrm{~mL}$ water. PITXs were eluted with $3 \mathrm{~mL}$ methanol containing $0.1 \%$ acetic acid. The eluent was transferred into a glass vial and used for analysis with LC-MS.

\subsubsection{Liquid Chromatography Methods}

Chromatographic separation of PITXs was achieved on a Kinetex $C_{18} 1.7 \mu \mathrm{m}, 2.1 \times 100 \mathrm{~mm}$ column (Phenomenex, Utrecht, the Netherlands). Mobile phase A consisted of water, and mobile phase B consisted of acetonitrile/water $(9: 1 \mathrm{v} / \mathrm{v})$, both containing $0.25 \mathrm{mM}$ lithium iodide and $0.00125 \%$ formic acid. The injection volume was set at $10 \mu \mathrm{L}$. The column temperature was set at $40{ }^{\circ} \mathrm{C}$ and the total run time was $10 \mathrm{~min}$. The gradient elution with a flow of $0.4 \mathrm{~mL} \mathrm{~min}^{-1}$ was as follows: $0.5 \mathrm{~min}$ at $10 \%$ 
mobile phase B, then linearly increased to 100\% mobile phase B in 5.5 min and kept at $100 \%$ mobile phase B for $1.9 \mathrm{~min}$. Subsequently, the gradient went back to $10 \%$ mobile phase B in $0.1 \mathrm{~min}$ and kept at $10 \%$ mobile phase B for 2 min to equilibrate the column for the next run.

An additional 15 min LC-gradient was developed with the same column, mobile phases, and settings to separate OVTXs when necessary. The flow was kept for $0.5 \mathrm{~min}$ at $100 \%$ mobile phase A, then mobile phase B was linearly increased to $28 \%$ in $0.5 \mathrm{~min}$. In the next $12 \mathrm{~min}$, mobile phase B was linearly increased to $32 \%$. Subsequently, mobile phase B was linearly increased to $100 \%$ in $0.5 \mathrm{~min}$ and was kept at $100 \%$ mobile phase B for 0.5 min. The gradient went back to $100 \%$ mobile phase A in $0.1 \mathrm{~min}$ and kept at $100 \%$ mobile phase A for $0.9 \mathrm{~min}$ to equilibrate the column for the next run.

\subsubsection{High Resolution Mass Spectrometry}

For method development, a Thermo Scientific UltiMate 3000 LC-system coupled to a Thermo Scientific Q Exactive focus hybrid quadrupole-orbitrap mass spectrometer (Thermo Fisher Scientific, Waltham, MA, USA) was used. In order to detect the PITXs, electrospray ionisation in positive was used. The spray voltage in positive ionisation mode was set at $3.5 \mathrm{kV}$. The capillary temperature was set at $260^{\circ} \mathrm{C}$. For infusion experiments, PITX was infused directly into the Mass spectrometer together with a flow of $0.1 \mathrm{~mL} \mathrm{~min}^{-1}$ mobile phase containing $50 \%$ acetonitrile and additives. A full MS scan event of 500 to $1400 \mathrm{~m} / \mathrm{z}$ with a resolution of 70,000 full width at half maximum (FWHM) was acquired. In order to obtain fragmentation spectra of PITX, fragmentation spectra were also acquired. The so called MS ${ }^{2}$ scans were obtained by selecting mass $898\left([\mathrm{M}+\mathrm{H}+2 \mathrm{Li}]^{3+}\right)$ with an isolation window of $4 \mathrm{Da}$. As collision gas nitrogen was used. The normalized collision energy (NCE) was set at 20 during fragmentation. Then after fragmentation, the ions were scanned from 187 to $1850 \mathrm{~m} / \mathrm{z}$ with a resolution set at 70,000 FWHM. The automatic gain control representing the maximum capacity of the C-trap was set at a maximum of $10^{6}$ ions or a maximum injection time of $200 \mathrm{~ms}$ for the full scan and a maximum of $2 \times 10^{5}$ ions or a maximum injection time of $200 \mathrm{~ms}$ for the $\mathrm{MS}^{2}$ scans were allowed.

\subsubsection{Triple Quad Mass Spectrometry}

For measurements of shellfish extracts and the validation study, a Waters Acquity UPLC coupled to a Waters Xevo TQ-S tandem mass spectrometer (Waters, Milford, MA, USA) was used. The triple quad MS system was operated in positive electrospray mode and data were recorded in MRM mode using three transitions per toxin. PITX: 898.2 > 880.2 collision energy (CE) $25 \mathrm{eV}, 898.2>874.2 \mathrm{CE} 25 \mathrm{eV}$, 897.8 > 711.9 CE 30 eV; OVTX a: 887.6 > 869.6 CE 25 eV, 887.6 > 863.6 CE 25 eV, 887.2 > 327.2 CE 30 eV; OVTX b: 902.2 > 884.2 CE 25 eV, $902.2>878.2$ CE 25 eV, $901.9>371.2$ CE 30 eV; OVTX c: $907.6>889.6$ CE $25 \mathrm{eV}, 907.6>883.6 \mathrm{CE} 25 \mathrm{eV}, 907.2>703.9 \mathrm{CE} 30 \mathrm{eV}$; OVTX d and e: $892.8>874.8 \mathrm{CE} 25 \mathrm{eV}, 892.8$ $>868.8 \mathrm{CE} 25 \mathrm{eV}, 892.5>327.2 \mathrm{CE} 30 \mathrm{eV}$ (specific for OVTX d) and 892.5 > $343.2 \mathrm{CE} 30 \mathrm{eV}$ (specific for OVTX e). Furthermore, a cone voltage of $30 \mathrm{~V}$, a capillary voltage of $3 \mathrm{kV}$, source temperature of $150{ }^{\circ} \mathrm{C}$, desolvation temperature of $600{ }^{\circ} \mathrm{C}$ and desolvation gas flow of $800 \mathrm{~L} \mathrm{~h}^{-1}$ was set.

\subsection{Method Validation}

Validation of the LC-MS/MS method for quantification of PITX in shellfish was done according to the SANTE/2015/11945 guidance document [34]. There were twenty samples including mussel (Mytilus edulis), five oysters (Castostrea gigas now Magallana gigas), five ensis (Ensis sp.) and five cockles

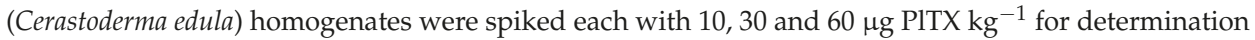
of recovery and repeatability. The same 20 blank samples were used to determine selectivity. Matrix matched standards in mussel homogenate at 0, 5, 10, 30, 60 and $100 \mu \mathrm{g}$ PITX $\mathrm{kg}^{-1}$ were used for quantification and linearity.

Supplementary Materials: The following are available online at http:/ /www.mdpi.com/2072-6651/10/12/537/ s1. Figure S1. Spectrum palytoxin (PITX), electrospray ionisation (ESI) positive, mobile phase: Acetonitrile, $\mathrm{H}_{2} \mathrm{O}$, formic acid, ammonium formate. Figure S2. Spectrum PITX, ESI negative, mobile phase: Acetonitrile, $\mathrm{H}_{2} \mathrm{O}$, formic acid, ammonium formate. Figure S3. Spectrum PITX, ESI positive, mobile phase: Acetonitrile, $\mathrm{H}_{2} \mathrm{O}$, LiI, 
formic acid. Figure S4. Spectrum PITX, ESI negative, mobile phase: Acetonitrile, $\mathrm{H}_{2} \mathrm{O}$, LiI, formic acid. Figure S5. Spectrum PITX, ESI positive, mobile phase: Acetonitrile, $\mathrm{H}_{2} \mathrm{O}$, LiI. Figure S6. Spectrum PITX, ESI negative, mobile phase: Acetonitrile, $\mathrm{H}_{2} \mathrm{O}$, LiI. Figure S7. Spectrum PITX, ESI positive, mobile phase: Acetonitrile, $\mathrm{H}_{2} \mathrm{O}$, LiI, ammonia. Figure S8. Spectrum PITX, ESI negative, mobile phase: Acetonitrile, $\mathrm{H}_{2} \mathrm{O}$, LiI, ammonia.

Author Contributions: Conceptualization, A.G.; methodology, A.G. and M.D.K.; validation, M.D.K.; formal analysis, M.D.K.; investigation, M.D.K.; writing—original draft preparation, M.D.K.; writing—review and editing, A.G.; visualization, M.D.K.; supervision, A.G.; project administration, A.G. and M.D.K.; funding acquisition, A.G.

Funding: This research was funded by the Dutch ministry of Agriculture, Nature and Food Quality [KB-23-002-21].

Conflicts of Interest: The authors declare no conflict of interest.

\section{References}

1. Usami, M.; Satake, M.; Ishida, S.; Inoue, A.; Kan, Y.; Yasumoto, T. Palytoxin analogs from the dinoflagellate ostreopsis siamensis. J. Am. Chem. Soc. 1995, 117, 5389-5390. [CrossRef]

2. Ciminiello, P.; Dell'Aversano, C.; Dello Iacovo, E.; Fattorusso, E.; Forino, M.; Grauso, L.; Tartaglione, L.; Guerrini, F.; Pezzolesi, L.; Pistocchi, R.; et al. Isolation and structure elucidation of ovatoxin-a, the major toxin produced by ostreopsis ovata. J. Am. Chem. Soc. 2012, 134, 1869-1875. [CrossRef] [PubMed]

3. Rhodes, L.; Towers, N.; Briggs, L.; Munday, R.; Adamson, J. Uptake of palytoxin-like compounds by shellfish fed ostreopsis siamensis (dinophyceae). N. Z. J. Mar. Freshw. Res. 2002, 36, 631-636. [CrossRef]

4. Lenoir, S.; Ten-Hage, L.; Turquet, J.; Quod, J.-P.; Bernard, C.; Hennion, M.-C. First evidence of palytoxin analogues from an ostreopsis mascarenensis (dinophyceae) benthic bloom in southwestern indian ocean1. J. Phycol. 2004, 40, 1042-1051. [CrossRef]

5. Fraga, M.; Vilariño, N.; Louzao, M.C.; Molina, L.; López, Y.; Poli, M.; Botana, L.M. First identification of palytoxin-like molecules in the atlantic coral species palythoa canariensis. Anal. Chem. 2017, 89, 7438-7446. [CrossRef]

6. Kerbrat, A.S.; Amzil, Z.; Pawlowiez, R.; Golubic, S.; Sibat, M.; Darius, H.T.; Chinain, M.; Laurent, D. First evidence of palytoxin and 42-hydroxy-palytoxin in the marine cyanobacterium trichodesmium. Mar. Drugs 2011, 9, 543. [CrossRef]

7. Rhodes, L. World-wide occurrence of the toxic dinoflagellate genus ostreopsis schmidt. Toxicon 2011, 57, 400-407. [CrossRef]

8. Aligizaki, K.; Katikou, P.; Milandri, A.; Diogène, J. Occurrence of palytoxin-group toxins in seafood and future strategies to complement the present state of the art. Toxicon 2011, 57, 390-399. [CrossRef]

9. Ciminiello, P.; Dell'Aversano, C.; Forino, M. Chemistry of palytoxin and its analogues. In Phycotoxins: Chemistry and Biochemistry, 2nd ed.; Wiley-Blackwell: Hoboken, NJ, USA, 2015; pp. 85-111.

10. Tartaglione, L.; Dello Iacovo, E.; Mazzeo, A.; Casabianca, S.; Ciminiello, P.; Penna, A.; Dell'Aversano, C. Variability in toxin profiles of the mediterranean ostreopsis cf. Ovata and in structural features of the produced ovatoxins. Environ. Sci. Technol. 2017, 51, 13920-13928. [CrossRef]

11. Deeds, J.R.; Schwartz, M.D. Human risk associated with palytoxin exposure. Toxicon 2010, 56, $150-162$. [CrossRef]

12. Murphy, L.T.; Charlton, N.P. Prevalence and characteristics of inhalational and dermal palytoxin exposures reported to the national poison data system in the U.S. Environ. Toxicol. Pharmacol. 2017, 55, 107-109. [CrossRef]

13. Durando, P.; Ansaldi, F.; Oreste, P.; Moscatelli, P.; Marensi, L.; Grillo, C.; Gasparini, R.; Icardi, G. Ostreopsis ovata and human health: Epidemiological and clinical features of respiratory syndrome outbreaks from a two-year syndromic surveillance, 2005-06, in North-West Italy. Wkly. Releases (1997-2007) 2007, 12, 3212.

14. Snoeks, L.; Veenstra, J. Family with fever after cleaning a sea aquarium. Ned. Tijdschr. Geneeskd. 2012, 156, A4200.

15. Patocka, J.; Nepovimova, E.; Wu, Q.; Kuca, K. Palytoxin congeners. Arch. Toxicol. 2017, 92, 143-156. [CrossRef]

16. Satoh, E.; Ishii, T.; Nishimura, M. Palytoxin-induced increase in cytosolic-free $\mathrm{Ca}^{2+}$ in mouse spleen cells. Eur. J. Pharmacol. 2003, 465, 9-13. [CrossRef]

17. Wiles, J.S.; Vick, J.A.; Christensen, M.K. Toxicological evaluation of palytoxin in several animal species. Toxicon 1974, 12, 427-433. [CrossRef] 
18. Sosa, S.; Del Favero, G.; De Bortoli, M.; Vita, F.; Soranzo, M.R.; Beltramo, D.; Ardizzone, M.; Tubaro, A. Palytoxin toxicity after acute oral administration in mice. Toxicol. Lett. 2009, 191, 253-259. [CrossRef]

19. EFSA. Scientific opinion on marine biotoxins in shellfish-palytoxin group. EFSA J. 2009, 1393, 1-40.

20. Riobó, P.; Franco, J.M. Palytoxins: Biological and chemical determination. Toxicon 2011, 57, 368-375. [CrossRef]

21. Alfonso, A.; Fernández-Araujo, A.; Alfonso, C.; Caramés, B.; Tobio, A.; Louzao, M.C.; Vieytes, M.R.; Botana, L.M. Palytoxin detection and quantification using the fluorescence polarization technique. Anal. Biochem. 2012, 424, 64-70. [CrossRef] [PubMed]

22. Nicolas, J.; Bovee, T.F.H.; Kamelia, L.; Rietjens, I.M.C.M.; Hendriksen, P.J.M. Exploration of new functional endpoints in neuro-2a cells for the detection of the marine biotoxins saxitoxin, palytoxin and tetrodotoxin. Toxicol. in Vitro 2015, 30, 341-347. [CrossRef]

23. Brovedani, V.; Sosa, S.; Poli, M.; Forino, M.; Varello, K.; Tubaro, A.; Pelin, M. A revisited hemolytic assay for palytoxin detection: Limitations for its quantitation in mussels. Toxicon 2016, 119, 225-233. [CrossRef] [PubMed]

24. Fraga, M.; Vilariño, N.; Louzao, M.C.; Fernández, D.A.; Poli, M.; Botana, L.M. Detection of palytoxin-like compounds by a flow cytometry-based immunoassay supported by functional and analytical methods. Ana. Chim. Acta 2016, 903, 1-12. [CrossRef] [PubMed]

25. Ciminiello, P.; Dell'Aversano, C.; Dello Iacovo, E.; Forino, M.; Tartaglione, L. Liquid chromatography-high-resolution mass spectrometry for palytoxins in mussels. Anal. Bioanal. Chem. 2015, 407, 1463-1473. [CrossRef] [PubMed]

26. García-Altares, M.; Tartaglione, L.; Dell'Aversano, C.; Carnicer, O.; de la Iglesia, P.; Forino, M.; Diogène, J.; Ciminiello, P. The novel ovatoxin-g and isobaric palytoxin (so far referred to as putative palytoxin) from ostreopsis cf. Ovata (nw mediterranean sea): Structural insights by lc-high resolution msn. Anal. Bioanal. Chem. 2015, 407, 1191-1204. [CrossRef] [PubMed]

27. Selwood, A.I.; van Ginkel, R.; Harwood, D.T.; McNabb, P.S.; Rhodes, L.R.; Holland, P.T. A sensitive assay for palytoxins, ovatoxins and ostreocins using lc-ms/ms analysis of cleavage fragments from micro-scale oxidation. Toxicon 2012, 60, 810-820. [CrossRef] [PubMed]

28. Pelin, M.; Forino, M.; Brovedani, V.; Tartaglione, L.; Dell'Aversano, C.; Pistocchi, R.; Poli, M.; Sosa, S.; Florio, C.; Ciminiello, P.; et al. Ovatoxin-a, a palytoxin analogue isolated from ostreopsis cf. Ovata fukuyo: Cytotoxic activity and elisa detection. Environ. Sci. Technol. 2016, 50, 1544-1551. [CrossRef] [PubMed]

29. Asam, M.R.; Glish, G.L. Tandem mass spectrometry of alkali cationized polysaccharides in a quadrupole ion trap. J. Am. Soc. Mass Spectrom. 1997, 8, 987-995. [CrossRef]

30. Ramaley, L.; Herrera, L.C.; Melanson, J.E. Quantitative analysis of tag in oils using lithium cationization and direct-infusion esi tandem mass spectrometry. J. Am. Oil Chem. Soc. 2015, 92, 323-334. [CrossRef]

31. Wei, J.; Bristow, A.W.T.; O'Connor, P.B. The competitive influence of $\mathrm{Li}^{+}, \mathrm{Na}^{+}, \mathrm{K}^{+}, \mathrm{Ag}^{+}$, and $\mathrm{H}^{+}$on the fragmentation of a pegylated polymeric excipient. J. Am. Soc. Mass Spectrom. 2015, 26, 166-173. [CrossRef]

32. Chen, M.; Cook, K.D. Oxidation artifacts in the electrospray mass spectrometry of a $\beta$ peptide. Anal. Chem. 2007, 79, 2031-2036. [CrossRef] [PubMed]

33. Turner, A.D.; Dhanji-Rapkova, M.; Algoet, M.; Suarez-Isla, B.A.; Cordova, M.; Caceres, C.; Murphy, C.J.; Casey, M.; Lees, D.N. Investigations into matrix components affecting the performance of the official bioassay reference method for quantitation of paralytic shellfish poisoning toxins in oysters. Toxicon 2012, 59, 215-230. [CrossRef]

34. EU Reference Laboratories for Residues of Pesticides. Sante/11945/2015-Guidance Document on Analytical Quality Control and Method Validation Procedures for Pesticides Residues Analysis in Food and Feed. Available online: https:/ / www.accredia.it/en/documento/guidance-sante-119452015-guidance-documenton-analytical-quality-control-and-method-validation-procedures-for-pesticides-residues-analysis-infood-and-feed/ (accessed on 14 December 2018).

35. Moreiras, G.; Leão, J.M.; Gago-Martínez, A. Design of experiments for the optimization of electrospray ionization in the lc-ms/ms analysis of ciguatoxins. J. Mass Spectrom. 2018, 53, 1059-1069. [CrossRef]

(C) 2018 by the authors. Licensee MDPI, Basel, Switzerland. This article is an open access article distributed under the terms and conditions of the Creative Commons Attribution (CC BY) license (http:/ / creativecommons.org/licenses/by/4.0/). 
Article

\title{
The Acute Toxicity of Tetrodotoxin and Tetrodotoxin-Saxitoxin Mixtures to Mice by Various Routes of Administration
}

\author{
Sarah C. Finch ${ }^{1, *}$, Michael J. Boundy ${ }^{2}$ and D. Tim Harwood ${ }^{2}$ \\ 1 AgResearch Limited, Ruakura Research Centre, Private Bag 3123, Hamilton 3240, New Zealand \\ 2 Cawthron Institute, Private Bag 2, Nelson 7042, New Zealand; michael.boundy@cawthron.org.nz (M.J.B.); \\ tim.harwood@cawthron.org.nz (D.T.H.) \\ * Correspondence: sarah.finch@agresearch.co.nz
}

Received: 8 October 2018; Accepted: 19 October 2018; Published: 23 October 2018

\begin{abstract}
Tetrodotoxin (TTX) is a potent neurotoxin associated with human poisonings through the consumption of pufferfish. More recently, TTX has been identified in bivalve molluscs from diverse geographical environments, including Europe, and is therefore recognised as an emerging threat to food safety. A recent scientific opinion of the EFSA Panel on Contaminants in the Food Chain recognised the need for further data on the acute oral toxicity of TTX and suggested that, since saxitoxin (STX) and TTX had similar modes of action, it was possible that their toxicities were additive so could perhaps be combined to yield one health-based guideline value. The present study determined the toxicity of TTX by various routes of administration. The testing of three different mixtures of STX and TTX and comparing the experimentally determined values to those predicted on the basis of additive toxicity demonstrated that the toxicities of STX and TTX are additive. This illustrates that it is appropriate to treat TTX as a member of the paralytic shellfish group of toxins. Since the toxicity of TTX was found to be the same as STX by feeding, a molar toxicity equivalence factor of 1.0 for TTX can be applied.
\end{abstract}

Keywords: paralytic shellfish toxins; acute toxicity; oral toxicity; tetrodotoxin; saxitoxin; toxicity equivalence factor

Key Contribution: The determination of the oral toxicity of tetrodotoxin by feeding represents the most robust toxicity assessment to date. The toxicities of saxitoxin and tetrodotoxin were demonstrated to be additive, which allows tetrodotoxin to be included with the paralytic shellfish group of toxins.

\section{Introduction}

Tetrodotoxin (TTX) is a potent neurotoxin, which is well-known for its presence in pufferfish (Fugu), a revered delicacy in Japan [1]. Its name comes from Tetraodontidae, which is the family of pufferfish associated with its presence and currently 22 species of pufferfish of this family are known to contain TTX [2]. Human intoxications and deaths due to TTX in pufferfish are well recognised throughout history, occurring mainly in Japan, China, and Taiwan [3]. Although initially thought to be present solely in pufferfish it was later discovered that TTX was present in a wide range of marine and terrestrial animals including gastropods [4], crabs [5], marine flatworms [6], ribbon worms [7], arrow worms [8], annelid worms [9], starfish [10], grey side-gilled sea slug [11], blue ringed octopus [12], newts [13], frogs [14], and terrestrial flatworms [15]. In addition to intoxication from pufferfish, human poisonings have also been observed due to the ingestion of toxic gastropods and crabs in many countries throughout the world [3]. In more recent times the distribution of pufferfish has become 
more widespread. This is thought to be due to the opening of the Suez canal and toxic pufferfish have been found in the waters of Turkey, the Israeli coast, Greece and Rhodes Island [16]. Of more concern, TTX has also been identified in bivalve molluscs in diverse geographical environments. In Japan, in 1993, TTX was reported in scallop (Patinopecten yessoensis) digestive glands at concentrations of up to $8 \mathrm{mg} / \mathrm{kg}$ [17]. In New Zealand, in 2011, TTX was reported in a clam species (pipi; Paphies australis) at $0.8 \mathrm{mg} / \mathrm{kg}$ [18]. In the UK, in 2014, it was observed in samples of mussels (Mytilus edulis) and Pacific oysters (Crassostrea gigas) at low concentrations of $0.003-0.12 \mathrm{mg} / \mathrm{kg}$ [19]. In Greece, an unexplained positive mouse bioassay screen led to the retrospective analysis of mussels (Mytilus galloprovincialis) and clams (Venus verrucusa) collected between 2006 and 2012, which were found to contain TTX at concentrations of $0.061-0.194 \mathrm{mg} / \mathrm{kg}$ [20]. In China, in 2015, manila clams (Ruditapes philippinarum) were found to contain trace levels of TTX [21], and in the Netherlands it was identified in bivalve mollusc samples collected in 2015 and 2016 [22]. This body of evidence clearly demonstrates that TTX is a contaminant of bivalve molluscs and has the potential to pose a food safety risk to consumers. For this reason TTX is recognised as an emerging risk by international regulators.

The question of the origin of TTX remains a controversial one with the two most common hypotheses being that it is being produced by symbiotic bacteria or that it is accumulated through the diet. Although there has been a large amount of work conducted in this area a clear consensus does not yet exist $[9,23,24]$.

The clinical signs of intoxication by TTX (neuromuscular, gastrointestinal, cardiovascular, and dermatologic symptoms and respiratory distress) are the same as those observed with paralytic shellfish poisoning (PSP), and indeed saxitoxin (STX) and its analogues are found in bivalves [17], pufferfish, crabs, and gastropods along with TTX [25]. Although the chemical structures of TTX and STX are considerably different (Figure 1), both toxins exert their effects through an interaction with voltage-gated sodium channels $\left(\mathrm{Na}_{\mathrm{v}}\right)$ [26]. This interaction blocks conductance resulting in inhibition of neuromuscular transmission. Both toxins are active on the $\alpha$-subunit of the $\mathrm{Na}_{\mathrm{V}}$ channel although there are some differences in the affinities of TTX and STX for different $\mathrm{Na}_{\mathrm{V}}$ isoforms [27].

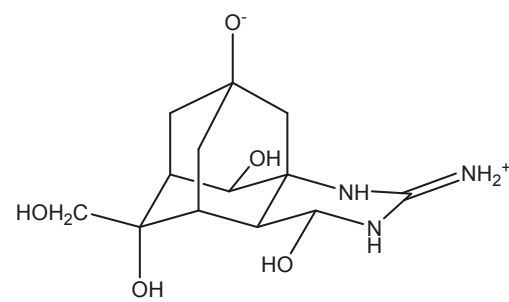

Tetrodotoxin

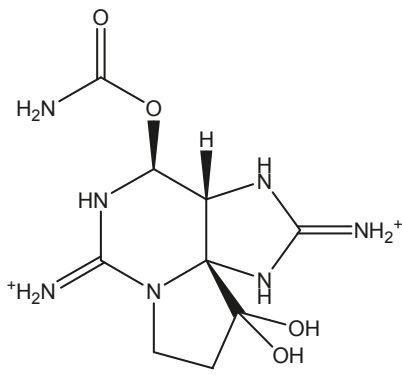

Saxitoxin

Figure 1. Structures of tetrodotoxin and saxitoxin.

The acute toxicities of STX and its analogues are well-defined [28,29] and a regulatory limit of $\leq 0.8 \mathrm{mg}$ of STX $(2 \mathrm{HCl})$ equivalents $/ \mathrm{kg}$ of mollusc flesh has been set for this class of marine toxin [30]. This limit has been demonstrated to be appropriate for protecting human health and facilitating international trade. The concentrations of STX and its analogues can be quantified by analytical methods but to translate this into an estimate of toxicity the relative toxicities of the individual components must be applied. These relative toxicities are termed toxicity equivalence factors (TEFs) and are defined as the "toxicity ratio of a compound from a chemical group that shares the same mode of action of a reference compound in the same group." For the PSP group of toxins, STX is used as the reference compound and is assigned a TEF of 1.0. The acute toxicity of each analogue, on a molar basis, can then be expressed as a fraction of the toxicity of STX to yield TEFs. To determine TEFs, toxicity data is considered with the following order of importance; data from human cases 
(outbreaks), oral $\mathrm{LD}_{50}$ in animals, intraperitoneal (i.p.) $\mathrm{LD}_{50}$ in animals, mouse bioassay, and in vitro data [31,32]. Since outbreak data is rarely available, oral toxicity data determined using rodents is usually the best achievable option. This can be determined by dosing purified toxin either by gavage or by feeding. It is well-recognised that feeding is the superior choice as administration by gavage in experiments with rodents gives an overestimation of toxicity. This is because, unlike a human, the stomach contents of rodents is semi-solid such that, when a dose is administered by gavage, it can flow around the semi-solid mass to be rapidly absorbed by the duodenum. In contrast, if the test compound is incorporated with a solid matrix when this is consumed by a rodent, it mixes with the existing stomach contents as occurs with the liquid stomach contents of humans [32,33]. Once the TEFs are available, the overall toxicity of a sample can be calculated by adding the concentration of each compound multiplied by the individual TEF values. There is very little data available on the acute toxicity of TTX and much of what exists lacks adequate experimental detail. Toxicity by i.p. injection was found to be 10.7 [34] and $10 \mu \mathrm{g} / \mathrm{kg}$ [35], which is very similar to that published for STX. The toxicity of TTX by gavage was found to be 532 [34] and $232 \mu \mathrm{g} / \mathrm{kg}$ [36]. A No Observable Adverse Effect Level (NOAEL) of $75 \mu \mathrm{g} / \mathrm{kg}$ was also determined in the latter study.

Some Asian countries have policies to manage the risk of TTX poisoning by pufferfish which is based on a mouse bioassay (MBA). Similarly, a MBA for the PSP toxins has traditionally been used, but neither the PSP MBA nor the TTX MBA can distinguish between STX and TTX since both toxin types induce the same symptomology. The two MBAs follow the same principle, although the TTX MBA uses acetic acid as the extraction and dosing solution [37], whereas the PSP MBA uses a solution of hydrochloric acid [38]. Because TEFs of saxitoxin analogues have previously been determined using $3 \mathrm{mM}$ hydrochloric acid as the solvent vehicle $[28,29]$, this protocol was followed in the current study. However, to ensure that the toxicity of TTX was not influenced by the dosing solvent employed, the $\mathrm{LD}_{50}$ of TTX was determined by i.p. injection using both acetic acid as the solvent vehicle, as used in the TTX MBA, and using hydrochloric acid as the solvent vehicle, as used in the PSP MBA and in the toxicological studies of STX analogues. Many countries, including those in Europe and Australasia, have stopped using the MBA for regulatory monitoring and instead use instrumental techniques such as liquid chromatography coupled with fluorescence detection or functional assays such as receptor binding assays. TTX is not currently included on the list of marine biotoxins to be tested either at the $\mathrm{EU}$ or international level [30]. The risk posed by toxic pufferfish is managed by the European Union (EU) by banning the sale of fish belonging to the families Tetraodonidae, Molidae, Diodontidae, and Canthigasteridae, including products derived from these fish species [39]. While the STX group of toxins is monitored and regulated within the EU, the presence of TTX will not be routinely detected in shellfish. In New Zealand, LC-MS is used for the quantitative screening of paralytic shellfish toxins, a method that also detects TTX. Due to the recent discovery of TTX-contaminated shellfish in European waters, TTX is considered an emerging threat to food safety. The EFSA Panel on Contaminants in the Food Chain (CONTAM Panel) was asked to deliver a scientific opinion on the risk related to the presence of tetrodotoxin (TTX) and TTX analogues in marine bivalves and gastropods. The panel reviewed all of the available literature and proposed an acute reference dose (ARfD) of $0.25 \mu \mathrm{g} / \mathrm{kg}$ for TTX and its analogues based on the NOAEL determined by Abal et al. [36]. This is lower than the ARfD of STX $(0.5 \mu \mathrm{g} / \mathrm{kg})$ [40]. Using a large portion size of $400 \mathrm{~g}$ of bivalves, they then determined that a concentration below $0.044 \mathrm{mg} / \mathrm{kg}$ TTX equivalents $/ \mathrm{kg}$ of shellfish meat was considered not to result in adverse effects in humans [22]. Concentrations in bivalves have been reported that exceed this level, which implies that there is a potential health risk if a large portion size is consumed. The CONTAM Panel recognised the need for further information on the acute oral toxicity of TTX and noted that, "as saxitoxin and tetrodotoxin exert similar toxic effects via a similar mode of action, the possibility to combine saxitoxin and its analogues together with tetrodotoxin and its analogues in one health-based guidance factor (HBGV) should be explored."

We have addressed these two recommendations by determining the toxicity of TTX by a number of different routes of exposure including feeding and investigating whether the toxicities of STX and 
TTX are additive. In addition, we have determined NOAELs for TTX and STX by feeding to allow for a better estimation of the ARfD. Results showed that the oral toxicity of TTX by feeding was the same as that of STX and that the toxicities of the two toxin types are additive. This demonstrates that including TTX in the estimation of PSP toxicity is valid. The inclusion of TTX in the estimation of PSP toxicity (as expressed in STX.2HCl equivalents) will ensure that samples of shellfish containing STX and/or TTX above acceptable levels will not be sold to consumers, thereby eliminating the risk to food safety posed by these compounds.

\section{Results}

\subsection{Purity of TTX and STX}

The concentration of the TTX test material was determined using reference materials from NRC and Cifga, which were found to give identical results and showed a high level of purity. The only TTX analogues detected in the TTX test material were 4epi-TTX and 4,9anhydro-TTX. These impurities were quantified using the TTX certified reference material (CRM) (Cifga) (Table 1). The concentration and purity of the TTX material was unchanged over the course of the study.

Table 1. Relative molar contribution of detected analogues in the tetrodotoxin (TTX) test material.

\begin{tabular}{cc}
\hline Compound Name & \% Contribution \\
\hline TTX & $99.54 \%$ \\
4epi-TTX & $0.19 \% 1$ \\
4,9-anhydro-TTX & $0.27 \%$ \\
\hline
\end{tabular}

${ }^{1} 4$ epi-TTX concentration was determined on the basis of the Cifga TTX CRM although this analyte is not certified.

The STX was shown to be of very high purity with only minor traces of the STX analogues neosaxitoxin (neoSTX) and decarbamoyl saxitoxin (dcSTX) (Table 2).

Table 2. Relative molar contribution of detected analogues in the saxitoxin (STX) test material.

\begin{tabular}{cc}
\hline Compound Name & \% Contribution \\
\hline STX & $99.79 \%$ \\
neoSTX & $0.05 \%$ \\
dcSTX & $0.16 \%$ \\
\hline
\end{tabular}

\subsection{Determination of the Specific Activities of STX and TTX by the PSP MBA}

The specific activity of STX was determined in this study to be $2085 \mathrm{MU} / \mu \mathrm{mol}$, which is very close to the figure of $2090 \mathrm{MU} / \mu \mathrm{mol}$, which has previously been reported by Munday et al. [28]. The specific activity of TTX was determined to be $1120 \mathrm{MU} / \mu \mathrm{mol}$.

\subsection{Determination of the Correlation between Dose Rate and Death Time for TTX}

The relationship between the dose of TTX administered i.p. and the death time (mean \pm standard deviation) is presented in Figure 2. Death was observed for all of the mice in the groups dosed 80, $75,70,65$, and $60 \mathrm{nmol} / \mathrm{kg}$, while $86 \%, 80 \%, 83 \%, 80 \%, 40 \%, 40 \%$, and $0 \%$ of the mice died in the groups dosed 55, 50, 45, 40, 35, 30, and $25 \mathrm{nmol} / \mathrm{kg}$, respectively (Table S1). For comparison, a dose rate versus death time graph was constructed for STX based on that predicted from Sommer's table in the AOAC Official Test Method 959.08 [38]. This was calculated from the specific activity determined in this study (2085 MU/ $\mu$ mole) for STX.2 HCl $(372.21 \mathrm{~g} / \mathrm{mol})$. The dose-death time curve derived for TTX showed a similar linearity as that predicted by Sommer's table at high dose rates of TTX $(\geq 40 \mathrm{nmol} / \mathrm{kg}$ ). However, at lower dose rates, in contrast to the STX curve, that of TTX did not level out, indicating that the toxicity of TTX would be underestimated if based on the MBA figure. 


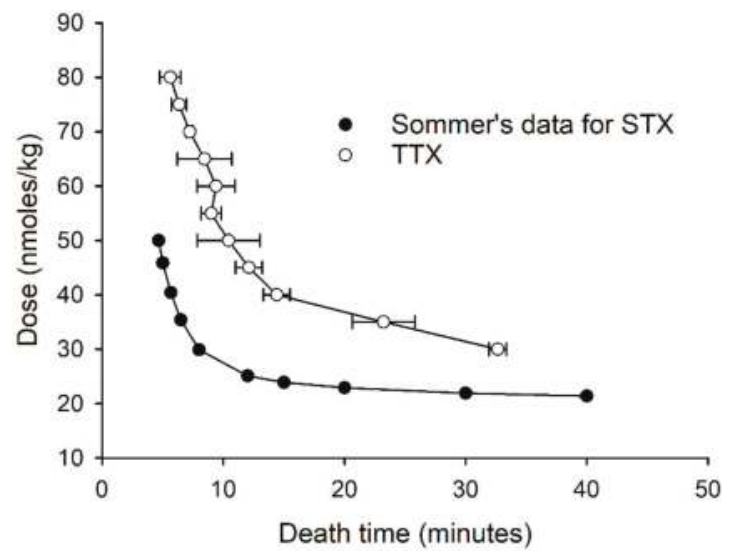

Figure 2. Dose-death time curve of mice injected i.p. with TTX, and the dose-death curve for STX calculated from the data of Sommer.

\subsection{Determination of Median Lethal Doses by i.p. Injection}

The median lethal doses ( $\mathrm{LD}_{50}$ values) of STX, TTX, and three mixtures containing different ratios of the two toxin types dosed in $\mathrm{HCl}(3 \mathrm{mM})$ solutions are presented in Table 3 . The clinical signs induced by STX and TTX were indistinguishable. At lethal doses, mice very rapidly became lethargic with abdominal breathing. Within $10 \mathrm{~min}$, the animals became immobile and respiration rates slowed until breathing ceased. Death was observed within $45 \mathrm{~min}$ (Table S2). At sub-lethal doses, mice initially showed the same clinical signs of lethargy, immobility, and abdominal breathing. However, mice started to become more alert 30-90 min post-dosing and appeared normal by $4 \mathrm{~h}$. Over the following 14-day observation period, mice exhibited a normal appearance and behaviour, and all treated mice gained weight. No abnormalities were observed at necropsy. If the toxicities of STX and TTX are additive, then the toxicity of a mixture of the two compounds can be predicted using Equation (1).

$$
\mathrm{LD}_{50} \text { mixture }=100 /\left(\frac{\% \mathrm{STX}}{\mathrm{LD}_{50} \mathrm{STX}}+\frac{\% \text { TTX }}{\mathrm{LD}_{50} \mathrm{TTX}}\right)
$$

where $\mathrm{LD}_{50}$ mixture $=$ the predicted $\mathrm{LD}_{50}$ of the mixture; $\mathrm{LD}_{50} \mathrm{STX}=$ the experimentally determined $\mathrm{LD}_{50}$ of STX; $\mathrm{LD}_{50} \mathrm{TTX}=$ the experimentally determined $\mathrm{LD}_{50}$ of TTX; $\% \mathrm{STX}=$ the molar contribution of STX to the mixture represented as a percentage of the total; \% TTX = the molar contribution of TTX to the mixture represented as a percentage of the total.

The predicted toxicity of the three STX/TTX mixtures was calculated using this equation and then compared to the toxicities that had been experimentally determined (Table 3 ). These two values showed a good correlation, which demonstrated that the toxicities of STX and TTX were additive when injected i.p.

Table 3. Predicted and experimentally determined acute toxicities of test compounds by i.p. injection.

\begin{tabular}{ccc}
\hline Compound & Predicted LD $_{\mathbf{5 0}}$ & LD $_{\mathbf{5 0}}(\mathbf{n m o l} / \mathbf{k g})^{\mathbf{1}}$ \\
\hline STX & & $24.0(22.1-24.8)$ \\
TTX & 28.4 & $31.2(27.6-35.0)$ \\
STX/TTX (1:2) & 27.1 & $27.8(23.3-32.0)$ \\
STX/TTX $(1: 1)$ & 26.0 & $24.0(22.1-24.8)$ \\
STX/TTX (2:1) & $24.8(21.6-29.6)$ \\
\hline \multicolumn{2}{c}{${ }^{1}$ Figures in brackets indicate 95\% confidence limits. }
\end{tabular}

${ }^{1}$ Figures in brackets indicate $95 \%$ confidence limits. 
The $\mathrm{LD}_{50}$ of TTX by i.p. injection determined using $0.1 \%$ acetic acid as the solvent vehicle was $31.2 \mathrm{nmol} / \mathrm{kg}$ with $95 \%$ confidence limits of 29.1 and $36.1 \mathrm{nmol} / \mathrm{kg}$. This is in agreement with that determined using $3 \mathrm{mM} \mathrm{HCl}$ as the solvent vehicle $(31.2(27.6-35.0) \mathrm{nmol} / \mathrm{kg})$, showing that the toxicity of TTX is not influenced by the type of acidic solution utilised.

\subsection{Determination of Median Lethal Doses and NOAELs by Oral Administration}

The median lethal doses ( $\mathrm{LD}_{50}$ values) of STX and TTX by gavage and by feeding are presented in Table 4. In addition, the median lethal doses of three mixtures containing different ratios of the two toxin types and the NOAELs of STX and TTX were determined by feeding (Table 4). Oral administration of the mixtures by feeding rather than by gavage was chosen due to the greater accuracy and relevance of this route of exposure. The clinical signs of toxicity induced by STX and TTX when administered orally were indistinguishable. For both toxin types and for the mixtures, mice initially became hunched and lethargic. This symptom was generally present in all of the dosed mice at all of the dose rates tested. Although not always present at the lower dose rates, the movement of more severely affected mice was characterised by the hind legs being splayed. All mice that died and some of the severely affected survivors showed some paralysis as well as whole-body tremors. Respiration rates were slowed as observed with i.p. administration. Death was often associated with jerky, running movements of the back legs. Compared to i.p. administration, the time of onset, death times and recovery times observed with administration by gavage and feeding were extended. Onset of symptoms were observed up to $21 / 2 \mathrm{~h}$ post-dosing, death times were observed $1-5 \mathrm{~h}$ post-dosing (Tables S3 and S4), and recovery from sub-lethal doses could take up to $7 \mathrm{~h}$. Over the following 14-day observation period, mice exhibited normal appearance and behaviour, and all mice gained weight. No abnormalities were observed at necropsy. The predicted toxicities of the STX/TTX mixtures by feeding were calculated using Equation (1) and were compared to those experimentally determined (Table 4). These values showed a close correlation with the exception of the $\mathrm{LD}_{50}$ value determined for the 1:2 STX/TTX mixture, which was higher than that predicted. This outlier result was put down to a greater variation in animal response for this dosing group compared to the others. This hypothesis is consistent with the large $95 \%$ confidence limits observed for this particular $\mathrm{LD}_{50}$ determination. These results demonstrate that the toxicities of STX and TTX are additive when fed to mice.

For the determination of NOAEL, mice were observed continuously for $3 \mathrm{~h}$, and any change in behaviour, posture, respiration rate, and movement was noted. The NOAELs determined by feeding were very similar for STX and TTX (Table 4). At a dose rate of $1430 \mathrm{nmol} / \mathrm{kg}, 2 / 2$ mice dosed STX and $2 / 3$ mice dosed TTX showed a change in posture (lying flat rather than in their natural position), were lethargic, and exhibited abdominal breathing. These symptoms occurred $30 \mathrm{~min}-1 \frac{1}{2} \mathrm{~h}$ post-dosing and lasted for 10-45 min. At a dose rate of $1270 \mathrm{nmol} / \mathrm{kg}, 2 / 3$ mice dosed TTX and 1/3 mice dosed STX showed adverse effects but at a dose rate of $1140 \mathrm{nmol} / \mathrm{kgno}$ adverse effects were seen in any mice dosed either STX or TTX. Over the following 14-day observation period, mice exhibited normal appearance and behaviour, and all mice gained weight. No abnormalities were observed at necropsy.

Table 4. Predicted and experimentally determined acute toxicities and NOAELs of the test compounds by gavage and by feeding.

\begin{tabular}{|c|c|c|c|c|}
\hline Compound & $\begin{array}{l}\text { LD }_{50} \text { by Gavage } \\
\left(\text { nmol/kg) }{ }^{1}\right.\end{array}$ & $\begin{array}{l}\text { Predicted } L^{2} D_{50} \\
\text { by Feeding }\end{array}$ & $\begin{array}{l}\mathrm{LD}_{50} \text { by Feeding } \\
(\mathrm{nmol} / \mathrm{kg})^{1}\end{array}$ & $\begin{array}{l}\text { NOAEL by Feeding } \\
(\mathrm{nmol} / \mathrm{kg})^{1}\end{array}$ \\
\hline STX & $1237(1056-1630)$ & & $2850(2468-3390)$ & $1270(1189-1470)$ \\
\hline TTX & $1890(1669-2120)$ & & $2850(2475-3410)$ & $1294(888-1480)$ \\
\hline STX/TTX (1:2) & ND & 2850 & 3532 (3016-7830) & ND \\
\hline STX/TTX (1:1) & ND & 2850 & $2850(2382-3280)$ & ND \\
\hline STX/TTX (2:1) & ND & 2850 & $2850(2475-3410)$ & ND \\
\hline
\end{tabular}

${ }^{1}$ Figures in brackets indicate $95 \%$ confidence limits; ND, Not determined. 


\section{Discussion}

A comparison of the dose-death time curve determined for TTX with that of STX derived from Sommer's table showed the dose-death time curve shapes to be considerably different. This would result in the toxicity of TTX being underestimated if based on the MBA. The MBA is a bioassay rather than a toxicological evaluation, and its assumption that the relationship between the dose and death time is the same for STX and related compounds is clearly not valid for TTX. This is consistent with the observation that the MBA is not appropriate for estimating the toxicity of other STX analogues [28]. A comparison of the dose-death time curve of TTX with those previously reported in the literature showed it to be very similar to those of decarbamoyl saxitoxin and the equilibrated epimer mixture of gonyautoxins $2 \& 3$ (70:30 ratio) [28].

As expected, the median lethal dose of TTX was found to be lowest by i.p. injection which is due to rapid and extensive absorption from the peritoneal cavity. Toxicity was found to be greater by gavage in comparison to feeding. This is also a well-recognised phenomenon and has been observed previously for seafood toxins [29]. This is due to the stomach contents of rodents being of a semi-solid consistency, meaning that the gavage dose can bypass this mass to be rapidly absorbed by the duodenum, giving an over-estimation of toxicity. It is interesting to note that the toxicity of TTX relative to STX is dependent on the route of administration (Table 5). This difference is due to the impact of toxicokinetics. By i.p. injection, absorption of the toxin is not required, whereas by oral administration the toxicity is influenced by absorption, by distribution rates throughout the body, and by metabolism. A comparison between the $\mathrm{LD}_{50}$ values of other shellfish toxins by i.p. injection and by oral administration shows a wide range of ratios [29]. These results clearly show that the oral toxicity of seafood toxins cannot be predicted on the basis of i.p. toxicity.

Table 5. Relative molar $\mathrm{LD}_{50}$ values of STX and TTX by different routes of exposure.

\begin{tabular}{cccc}
\hline Compound & Relative $\mathbf{L D}_{\mathbf{5 0}}$ by i.p. & Relative $\mathbf{L D}_{\mathbf{5 0}}$ by Gavage & Relative $\mathbf{L D}_{\mathbf{5 0}}$ by Feeding \\
\hline Saxitoxin & 1.0 & 1.0 & 1.0 \\
Tetrodotoxin & 0.77 & 0.65 & 1.0 \\
\hline
\end{tabular}

The $\mathrm{LD}_{50}$ values determined for STX as part of this study $(24.0,1237$, and $2850 \mathrm{nmol} / \mathrm{kg}$ by i.p., gavage, and feeding, respectively) are consistent with those previously published by Munday et al. $(28.8,1190$, and $3200 \mathrm{nmol} / \mathrm{kg}$ ) [28]. Little reliable toxicity data for TTX is available in the literature. However, although the source and hence the purity of the TTX used was not identified, studies by Xu et al. [34] and Kao and Fuhrman [35] quote LD $_{50}$ values by i.p. injection of 10.7 and $10.0 \mu \mathrm{g} / \mathrm{kg}$, respectively. When converted to toxicity on a molar basis ( 33.5 and $31.3 \mathrm{nmol} / \mathrm{kg})$, this shows a close correlation to the result obtained for TTX in this study $(31.2 \mathrm{nmol} / \mathrm{kg})$. By gavage, we determined an $\mathrm{LD}_{50}$ of $1890 \mathrm{nmol} / \mathrm{kg}$, which is consistent with that of Xu et al. (532 $\mu \mathrm{g} / \mathrm{kg} ; 1667 \mathrm{nmol} / \mathrm{kg}$ ) but not that of Abal et al. $(232 \mu \mathrm{g} / \mathrm{kg} ; 727 \mathrm{nmol} / \mathrm{kg})$ [36]. There are a number of possible explanations for this difference. Firstly, the protocol employed by Abal et al. used mice, which had been fasted for $12 \mathrm{~h}$, much longer than the 3-4 h specified in the OECD guideline [41]. Whether to fast animals or not prior to testing is long debated, but we chose to use fed mice, as this better represents reality, as seafood is unlikely to be consumed on an empty stomach. Furthermore, the dosing of animals early in the morning, which is possible without fasting, allows close observation for $10 \mathrm{~h}$ enabling an ethical decision to be made over whether an animal is likely to endure prolonged distress. Another significant difference between the two protocols is the duration of the experiments. In the Abal et al. study, the experiment was only $2 \mathrm{~h}$ in duration and any animals surviving this period were killed, which negated the possibility of deaths at later time points, a concern noted by the EFSA CONTAM Panel [22]. In our study, we observed mice for the full 14-day period as specified in the OECD guideline, and we observed deaths in mice up to $7 \mathrm{~h}$ post-dosing. This observation is consistent with the prolonged deaths observed by Vlamis et al. [20], with extracts of TTX-containing shellfish. The death times 
quoted in the Abal et al. study were surprisingly short, occurring in a matter of minutes in a number of instances. In contrast, we did not see onset of symptoms before $15 \mathrm{~min}$ post-dosing in any of our mice dosed by gavage or by feeding, even at high dose rates. Many researchers have highlighted the difficulty of dosing by gavage and how different operators can influence the result [42]. The $\mathrm{LD}_{50}$ and NOAEL determined for TTX in this study by feeding rather than by gavage therefore represent the most accurate data available for use in the assessment of risk posed by TTX-contaminated seafood.

The ARfD determined for TTX by the EFSA CONTAM Panel was calculated on the basis of the NOAEL of $75 \mu \mathrm{g} / \mathrm{kg}(235 \mathrm{nmol} / \mathrm{kg})$ published by Abal et al. [36], which was generated by gavage. As already discussed, gavage administration to mice is fraught with uncertainty, and we consider the NOAEL of $1294 \mathrm{nmol} / \mathrm{kg}$ determined in this study by feeding to be more robust. If we apply the same logic as that used by the EFSA CONTAM Panel, we can calculate an updated ARfD. This is achieved by using the dose rate one step lower in the dose progression sequence $(1010 \mathrm{nmol} / \mathrm{kg})$ used in our study as the reference point and applying an uncertainty factor of 100. This results in an ARfD for TTX of $10.1 \mathrm{nmol} / \mathrm{kg}(3.2 \mu \mathrm{g} / \mathrm{kg})$. This figure is almost 13 times higher than that proposed by the EFSA CONTAM Panel [22]. Again, following the logic of the panel, based on a large portion size (400 g) and an adult body weight of $70 \mathrm{~kg}$, the $3.2 \mu \mathrm{g} / \mathrm{kg}$ ARfD yields a figure of $560 \mu \mathrm{g}$ TTX $/ \mathrm{kg}$ of shellfish meat, which would not be expected to lead to adverse effects in humans. For STX, an ARfD of $0.5 \mu \mathrm{g} / \mathrm{kg}(1.34 \mathrm{nmol} / \mathrm{kg})$, which is based on human poisoning data, has been proposed [40]. In our study we found that the NOAELs of STX and TTX are the same (1279 and $1294 \mathrm{nmol} / \mathrm{kg}$, respectively) so alternatively the ARfD of TTX could be set at the same level as that of STX $(1.34 \mathrm{nmol} / \mathrm{kg})$, which equates to $0.43 \mu \mathrm{g} / \mathrm{kg}$ for TTX.

However, rather than treating STX and TTX separately, it would be much simpler and accurate to combine them together since it is the total risk posed by shellfish products, which is of importance. The results presented demonstrate that the toxicities of TTX and STX are additive. This means that STX and its analogues and TTX and its analogues can be combined to yield one HBGV. To determine the overall toxicity of seafood samples containing STX and/or TTX, the concentrations of each individual analogue can be measured by analytical methods, such as those developed using LC-MS [43,44]. To yield toxicity information, the relative toxicity of each compound must then be applied, which requires the determination of TEFs. The best data for determining TEFs is oral toxicity by feeding. The $\mathrm{LD}_{50}$ determined for TTX by feeding in the present study is therefore the most relevant data for establishing the TEF and gives a value of 1.0 on a molar basis for TTX.

The threat of TTX-contaminated seafood to consumers is becoming of increased importance due to the observation of TTX in a greater number of seafood types over wider geographical areas. The incorporation of TTX into the toxicity assessment of shellfish for the PSP group of toxins will mean that it will be built into the maximum level of $\leq 0.8 \mathrm{mg}$ of STX ( $2 \mathrm{HCl})$ equivalents $/ \mathrm{kg}$ of mollusc flesh, which will ensure that shellfish is safe for human consumption. Further work is required to determine TEFs by feeding for TTX analogues observed in bivalve species.

\section{Materials and Methods}

\subsection{Purity and Quantity Assessment of TTX and STX}

TTX citrate free (10 mg; Cayman Chemicals, purchased from Sapphire Bioscience, Redfern, NSW, Australia) was dissolved in $10 \mathrm{~mL}$ of $10 \mathrm{mM}$ acetic acid. This solution was calibrated against certified reference material from the National Research Council of Canada (NRC) and from Cifga (Lugo, Spain) using high performance liquid chromatography with ultra-violet detection (HPLC-UV) and liquid chromatography with tandem quadrupole mass spectrometry (LC-MS/MS). HPLC-UV was performed using an Agilent Zorbax Bonus-RP $3.5 \mu \mathrm{m}, 4.6 \times 150 \mathrm{~mm}$ column (Agilent, Santa Clara, CA, USA) at $20^{\circ} \mathrm{C}$, which was eluted with a mobile phase of $11 \mathrm{mmol}$ heptanesulfonate with $2.7 \mathrm{mmol}$ phosphoric acid ( $\mathrm{pH} 7.1$ ) and a flow rate of $1 \mathrm{~mL} / \mathrm{min}$. Eluting compounds were detected at $210 \mathrm{~nm}$ using a photodiode array detector. The impurities were determined and quantified by LC-MS/MS. LC-MS/MS 
was performed using a Waters Xevo TQ-S (Waters, Milford, MA, USA) with Waters Acquity i-Class UPLC (Waters, Milford, MA, USA) in accord with the method of Boundy et al. [43]. MRM transitions for TTX analogues monitored in positive electrospray ionisation mode used are shown in Table 6.

Table 6. MRM transitions used for monitoring TTX analogue impurities.

\begin{tabular}{|c|c|c|c|}
\hline Analogue(s) & Precursor Mass $(\mathrm{m} / \mathrm{z})$ & Product Mass $(\mathrm{m} / \mathrm{z})$ & Collision Energy \\
\hline \multirow{2}{*}{ 11-oxo-TTX (hydrated aldehyde) } & 336.1 & 318.1 & 25 \\
\hline & 336.1 & 162.1 & 35 \\
\hline \multirow{2}{*}{ (4/6-epi)-TTX } & 320.1 & 302.1 & 26 \\
\hline & 320.1 & 162.1 & 38 \\
\hline \multirow{2}{*}{ 11-oxo-TTX (aldehyde) } & 318.1 & 300.1 & 20 \\
\hline & 318.1 & 162.0 & 30 \\
\hline \multirow{2}{*}{ 11-norTTX-6,6-diol } & 306.1 & 288.1 & 25 \\
\hline & 306.1 & 60.0 & 35 \\
\hline \multirow{3}{*}{ (5/11)-deoxy-TTX } & 304.1 & 286.1 & 35 \\
\hline & 304.1 & 240.1 & 35 \\
\hline & 304.1 & 176.1 & 35 \\
\hline \multirow{2}{*}{ 4,9-anhydro-TTX } & 302.1 & 256.1 & 35 \\
\hline & 302.1 & 162.1 & 35 \\
\hline \multirow{3}{*}{$\begin{array}{l}\text { (4-epi)-11-nor TTX-6S-ol } \\
\text { (4-epi)-11-nor TTX-6R-ol }\end{array}$} & 290.1 & 272.1 & 26 \\
\hline & 290.1 & 226.0 & 30 \\
\hline & 290.1 & 60.1 & 35 \\
\hline 5,11-dideoxyTTX & 288.1 & 270.1 & 25 \\
\hline 6,11 dideoxyTTX & 288.1 & 162.1 & 35 \\
\hline 4,9-anhydro-11-norTTX-6,6-diol & 288.1 & 60.1 & 35 \\
\hline \multirow{2}{*}{$\begin{array}{c}\text { 4,9-anhydro-5-deoxy-TTX } \\
\text { iso-anhydro-deoxy-TTX } \\
\text { 4,9-anhydro-11-deoxy-TTX }\end{array}$} & 286.1 & 135.1 & 30 \\
\hline & 286.1 & 60.1 & 25 \\
\hline \multirow{3}{*}{$\begin{array}{c}\text { (4-epi)-5,6,11-trideoxyTTX } \\
\text { 4,9-anhydro-11-norTTX-6(S/R)-ol }\end{array}$} & 272.1 & 254.1 & 20 \\
\hline & 272.1 & 95.0 & 35 \\
\hline & 272.1 & 60.0 & 35 \\
\hline 4,9-anhydro-5,11-dideoxyTTX & 270.1 & 176.1 & 25 \\
\hline 4,9-anhydro-6,11-dideoxyTTX & 270.1 & 166.1 & 25 \\
\hline Iso-anhydro-dideoxy-TTX & 270.1 & 60.1 & 25 \\
\hline \multirow{2}{*}{ 4,9-anhydro-5,6,11-trideoxy-TTX } & 254.1 & 208.1 & 26 \\
\hline & 254.1 & 60.1 & 35 \\
\hline
\end{tabular}

STX was supplied by Cawthron Natural Compounds (CNC, NZ), and calibrated against paralytic shellfish toxin certified reference materials from NRC. Purity of the STX test material was determined using HPLC-UV. Liquid chromatography was performed using an Agilent Zorbax Bonus-RP $3.5 \mu \mathrm{m}$, $4.6 \times 150 \mathrm{~mm}$ column (Agilent, Santa Clara, CA, USA) at $20^{\circ} \mathrm{C}$, which was eluted with a mobile phase of $11.5 \%$ acetonitrile with $11 \mathrm{mmol}$ heptanesulfonate and $16.5 \mathrm{mmol}$ phosphoric acid (pH 7.1) and a flow rate of $1 \mathrm{~mL} / \mathrm{min}$. Eluting compounds were detected at $210 \mathrm{~nm}$ using a photodiode array detector. Concentration and purity were determined by LC-MS/MS monitoring of MRM transitions on a Shimadzu LCMS-8050 (Shimadzu, Kyoto, Japan) coupled with Shimadzu Nexera X2 (Shimadzu, Kyoto, Japan) (Table 7). Positive and negative electrospray ionisation modes were used (ESI+, ESI-). Ionisation voltage: $0.5 \mathrm{kV},-0.5 \mathrm{kV}$. Nebulisation gas flow $2 \mathrm{~L} / \mathrm{min}$, heating gas: $10 \mathrm{~L} / \mathrm{min}$, drying gas: $10 \mathrm{~L} / \mathrm{min}$, interface temperature: $300{ }^{\circ} \mathrm{C}$, desolvation line temperature: $250{ }^{\circ} \mathrm{C}$, heat block temperature: $400{ }^{\circ} \mathrm{C}$, Mobile Phase A: $0.1 \%$ acetic acid in water, Mobile Phase B: $0.1 \%$ acetic acid in acetonitrile. Flow rate was $0.6 \mathrm{~mL} / \mathrm{min}$ with a Waters Acquity BEH Amide $1.7 \mu \mathrm{m} 2.1 \times 100 \mathrm{~mm}$ column (Milford, MA, USA) at $60{ }^{\circ} \mathrm{C}$. Initial conditions were $80 \% \mathrm{~B}$, held for $6 \mathrm{~min}$, followed by a linear gradient from $80 \% \mathrm{~B}$ to $55 \%$ B over $5 \mathrm{~min}$, then returned to $80 \%$ B over $0.5 \mathrm{~min}$, and held and re-equilibrated for $3.5 \mathrm{~min}$. 
Table 7. MRM transitions used for monitoring saxitoxin analogue impurities.

\begin{tabular}{ccccccc}
\hline Analogue(s) & $\begin{array}{c}\text { Ionisation } \\
\text { Mode }\end{array}$ & $\begin{array}{c}\text { Precursor } \\
(\mathbf{m} / \mathbf{z})\end{array}$ & $\begin{array}{c}\text { Product } \\
(\mathbf{m} / \mathbf{z})\end{array}$ & $\begin{array}{c}\text { Q1 Prebias } \\
(\mathbf{V})\end{array}$ & $\begin{array}{c}\text { Collision } \\
\text { Energy }\end{array}$ & $\begin{array}{c}\text { Q3 Prebias } \\
(\mathbf{V})\end{array}$ \\
\hline C3,4 & ESI- & 490.1 & 122.0 & 11 & 33 & 12 \\
C1,2 & ESI- & 474.1 & 122.0 & 11 & 29 & 21 \\
GTX1,4 & ESI- & 410.1 & 367.1 & 12 & 15 & 27 \\
GTX2,3 & ESI- & 394.1 & 351.1 & 12 & 16 & 27 \\
GTX6 & ESI- & 394.1 & 122.0 & 19 & 22 & 13 \\
GTX5 & ESI- & 378.1 & 122.0 & 14 & 23 & 24 \\
dcGTX1,4 & ESI- & 367.1 & 349.1 & 13 & 18 & 15 \\
dcGTX2,3 & ESI- & 351.1 & 333.1 & 13 & 18 & -24 \\
NEO & ESI+ & 316.1 & 126.0 & -22 & -24 & -14 \\
STX & ESI+ & 300.1 & 204.1 & -15 & -24 & -15 \\
dcNEO & ESI+ & 273.1 & 225.1 & -13 & -22 & -23 \\
dcSTX & ESI+ & 257.1 & 126.0 & -13 & -21 & \\
\hline
\end{tabular}

Working solutions of the toxins were prepared gravimetrically by taking weighed aliquots of the stock solutions and diluting with $3 \mathrm{mM} \mathrm{HCl}$ in accord with previous studies [29].

\subsection{Animals}

Female Swiss albino mice (18-22 g) were bred at AgResearch, Ruakura, New Zealand. The mice were housed individually during the experiments and were allowed unrestricted access to food (Rat and Mouse Cubes, Speciality Feeds Ltd., Glen Forrest, Western Australia) and water. All experiments were approved by the Ruakura Animal Ethics Committee established under the Animal Protection (code of ethical conduct) Regulations Act, 1987 (New Zealand), Project Number 14320, approval date 2 November 2017.

\subsection{Determination of the Specific Activities of STX and TTX by the PSP MBA}

The specific activities of TTX and STX were determined by taking aliquots of the standard solutions and diluting to $1 \mathrm{~mL}$ with $3 \mathrm{mM} \mathrm{HCl}$. These solutions were then injected i.p. into mice according to the protocol of AOAC Official Test Method 959.08 [38]. In brief, dose rates were used to yield death times of 5-7 min and the median death times calculated. Using Sommer's table in the AOAC method, the death time could then be converted to mouse units and the specific activities (MU/ $\mu \mathrm{mol})$ calculated.

\subsection{Determination of the Correlation between Dose Rate and Death Time for TTX}

A dose versus death time graph was constructed by i.p. injecting groups of mice (5-7 animals) with TTX solutions (aliquots of standard solutions diluted to $1 \mathrm{~mL}$ with $3 \mathrm{mM} \mathrm{HCl}$ ) at dose rates of between $25 \mathrm{nmol} / \mathrm{kg}$ and $80 \mathrm{nmol} / \mathrm{kg}$ with $5 \mathrm{nmol} / \mathrm{kg}$ increments. These dose rates spanned a concentration range that induced death within $6 \mathrm{~min}$ and that which resulted in no deaths in any mice of the dosing group.

\subsection{Determination of Median Lethal Doses}

Acute toxicities were determined according to the principles of OECD guideline 425 [41]. This guideline keeps the number of animals used to a minimum while still yielding a robust determination of the median lethal dose and an estimate of confidence intervals. It employs an up-and-down procedure whereby one animal is given a dose of the test compound at one step below the estimated $\mathrm{LD}_{50}$. If this animal survives, the dose for the next animal is increased by a factor determined by the computer program associated with the guideline [45]. This factor is determined from an estimate of the slope steepness of the dose-response curve. If the initial animal dies, the dose 
for the next animal is decreased by the same factor. Dosing is continued until 4 live-death reversals have been achieved.

Mice were weighed immediately prior to dosing and the appropriate quantities of test compounds calculated to yield the required doses on a $\mu \mathrm{mol} / \mathrm{kg}$ basis. Aliquots of the test compounds were diluted with $3 \mathrm{mM} \mathrm{HCl}$. A dosing volume of $1 \mathrm{~mL}$ was used for i.p. injection and a dosing volume of $200 \mu \mathrm{L}$ was used for administration by gavage. The acute toxicity of TTX by i.p. injection was also determined using $0.1 \%$ acetic acid as the solvent vehicle and a dosing volume of $1 \mathrm{~mL}$. For oral dosing, mice were trained to eat small quantities of cream cheese [33]. This was done by first feeding groups of weanling mice twice a day with cream cheese $(\sim 1 \mathrm{~g})$. When mice were happy to eat this matrix, they were split into individual cages where the twice-daily feeding continued ( $200 \mathrm{mg})$. At the time of dosing, aliquots of the test compound were mixed with cream cheese (150 mg) on a watch glass. Mice consumed the laced cream cheese within $30 \mathrm{~s}$. To avoid any diurnal variations in response, all dosing was conducted between 8:00 and 9:30 a.m. All mice were monitored intensively during the day of dosing. Mice that survived were monitored for a 14-day period which included a measurement of body weight. After 14 days, the animals were killed by carbon dioxide inhalation and necropsied.

\subsection{Determination of NOAEL}

Mice were dosed by feeding according to the methods described above. However, rather than using death as the parameter, "toxic effect" was instead used. Toxic effect was determined by observing mice continuously for $3 \mathrm{~h}$ and noting any change in posture, respiratory rate, or movement.

Supplementary Materials: The following are available online at http://www.mdpi.com/2072-6651/10/11/ 423/s1. Table S1: Dose and death times for mice dosed tetrodotoxin by intraperitoneal injection; Table S2: Mortalities and death times of mice dosed with tetrodotoxin (TTX), saxitoxin (STX), or mixtures of the two toxins by intraperitoneal injection. Table S3: Mortalities and death times of mice dosed with tetrodotoxin (TTX) or saxitoxin (STX) by gavage. Table S4: Mortalities and death times of mice dosed with tetrodotoxin (TTX), saxitoxin (STX), or mixtures of the two toxins by feeding.

Author Contributions: Conceptualisation, S.C.F., M.J.B., and D.T.H.; data curation, S.C.F. and M.J.B.; Formal analysis, S.C.F. and M.J.B.; funding acquisition, D.T.H.; investigation, S.C.F. and M.J.B.; methodology, S.C.F., M.J.B., and D.T.H.; project administration, D.T.H.; writing—original draft, S.C.F., M.J.B., and D.T.H.; writing-review \& editing, S.C.F., M.J.B., and D.T.H.

Funding: This work was funded by the New Zealand Ministry for Business Innovation and Employment (Contract CAWX1317).

Acknowledgments: This study was planned before the sad and unexpected death of Rex Munday. He is greatly missed.

Conflicts of Interest: The authors declare no conflict of interest.

\section{References}

1. Goto, T.; Kishi, Y.; Takahashi, S.; Hirata, Y. Tetrodotoxin. Tetrahedron 1965, 21, 2059-2088. [CrossRef]

2. Noguchi, T.; Arakawa, O. Tetrodotoxin-Distribution and Accumulation in Aquatic Organisms, and Cases of Human Intoxication. Mar. Drugs 2008, 6, 220-242. [CrossRef] [PubMed]

3. Hwang, D.F.; Noguchi, T. Tetrodotoxin Poisoning. In Advances in Food and Nutrition Research; Academic Press: Cambridge, MA, USA, 2007; Volume 52, pp. 141-236.

4. Hwang, P.-A.; Tsai, Y.-H.; Lin, S.-J.; Hwang, D.-F. The Gastropods Possessing TTX and/or PSP. Food Rev. Int. 2007, 23, 321-340. [CrossRef]

5. Hwang, D.F.; Tsai, Y.H. Toxins in toxic Taiwanese crabs. Food Rev. Int. 1999, 15, 145-162. [CrossRef]

6. Miyazawa, K.; Jeon, J.K.; Noguchi, T.; Ito, K.; Hashimoto, K. Distribution of tetrodotoxin in the tissues of the flatworm Planocera multitentaculata (Platyhelminthes). Toxicon 1987, 25, 975-980. [CrossRef]

7. Ali, A.E.; Arakawa, O.; Noguchi, T.; Miyazawa, K.; Shida, Y.; Hashimoto, K. Tetrodotoxin and related substances in a ribbon worm Cephalothrix linearis (Nemertean). Toxicon 1990, 28, 1083-1093. [CrossRef]

8. Thuesen, E.V.; Kogure, K.; Hashimoto, K.; Nemoto, T. Poison arrowworms: A tetrodotoxin venom in the marine phylum Chaetognatha. J. Exp. Mar. Biol. Ecol. 1988, 116, 249-256. [CrossRef] 
9. Miyazawa, K.; Noguchi, T. Distribution and origin of Tetrodotoxin. J. Toxicol. Toxin Rev. 2001, 20, 11-33. [CrossRef]

10. Noguchi, T.; Narita, H.; Maruyama, J.; Hashimoto, K. Tetrodotoxin in the Starfish Astropecten polyacanthus, in Association with Toxification of a Trumpet Shell, "Boshubora" Charonia sauliae. Nippon Suisan Gakkaishi 1982, 48, 1173-1177. [CrossRef]

11. McNabb, P.; Selwood, A.I.; Munday, R.; Wood, S.A.; Taylor, D.I.; MacKenzie, L.A.; van Ginkel, R.; Rhodes, L.L.; Cornelisen, C.; Heasman, K.; et al. Detection of tetrodotoxin from the grey side-gilled sea slug-Pleurobranchaea maculata, and associated dog neurotoxicosis on beaches adjacent to the Hauraki Gulf, Auckland, New Zealand. Toxicon 2010, 56, 466-473. [CrossRef] [PubMed]

12. Freeman, S.E.; Turner, R.J. Maculotoxin, a potent toxin secreted by Octopus maculosus Hoyle. Toxicol. Appl. Pharmacol. 1970, 16, 681-690. [CrossRef]

13. Brown, M.S.; Mosher, H.S. Tarichatoxin: Isolation and Purification. Science 1963, 140, 295-296. [CrossRef] [PubMed]

14. Kim, Y.H.; Brown, G.B.; Mosher, H.S.; Fuhrman, F.A. Tetrodotoxin: Occurrence in Atelopid Frogs of Costa Rica. Science 1975, 189, 151-152. [CrossRef] [PubMed]

15. Stokes, A.N.; Ducey, P.K.; Neuman-Lee, L.; Hanifin, C.T.; French, S.S.; Pfrender, M.E.; Brodie, E.D., III; Brodie, E.D., Jr. Confirmation and Distribution of Tetrodotoxin for the First Time in Terrestrial Invertebrates: Two Terrestrial Flatworm Species (Bipalium adventitium and Bipalium kewense). PLoS ONE 2014, 9, e100718. [CrossRef] [PubMed]

16. Rodríguez, P.; Alfonso, A.; Otero, P.; Katikou, P.; Georgantelis, D.; Botana, L.M. Liquid chromatography-mass spectrometry method to detect Tetrodotoxin and its analogues in the puffer fish Lagocephalus sceleratus (Gmelin, 1789) from European waters. Food Chem. 2012, 132, 1103-1111. [CrossRef]

17. Kodama, M.; Sato, S.; Ogata, T. Alexandrium tamarense as a source of tetrodotoxin in the scallop Patinopectin yessoensis. In Toxic Phytoplankton Blooms in the Sea; Smayda, T.J., Shimizu, Y., Eds.; Elsevier: New York, NY, USA, 1993; pp. 401-406.

18. McNabb, P.S.; Taylor, D.I.; Ogilvie, S.C.; Wilkinson, L.; Anderson, A.; Hamon, D.; Wood, S.A.; Peake, B.M. First Detection of Tetrodotoxin in the Bivalve Paphies australis by Liquid Chromatography Coupled to Triple Quadrupole Mass Spectrometry with and without Precolumn Reaction. J. AOAC Int. 2014, 97, 325-333. [CrossRef] [PubMed]

19. Turner, A.D.; Powell, A.; Schofield, A.; Lees, D.N.; Baker-Austin, C. Detection of the pufferfish toxin tetrodotoxin in European bivalves, England, 2013 to 2014. Eurosurveillance 2015, 20, 21009. [CrossRef] [PubMed]

20. Vlamis, A.; Katikou, P.; Rodriguez, I.; Rey, V.; Alfonso, A.; Papazachariou, A.; Zacharaki, T.; Botana, A.; Botana, L. First Detection of Tetrodotoxin in Greek Shellfish by UPLC-MS/MS Potentially Linked to the Presence of the Dinoflagellate Prorocentrum minimum. Toxins 2015, 7, 1779-1807. [CrossRef] [PubMed]

21. Zhang, X.; Yan, Z.; Wang, Y.; Jiang, T.; Wang, J.; Sun, X.; Guo, Y. Immunoaffinity Chromatography Purification and Ultrahigh Performance Liquid Chromatography Tandem Mass Spectrometry Determination of Tetrodotoxin in Marine Organisms. J. Agric. Food Chem. 2015, 63, 3129-3134. [CrossRef] [PubMed]

22. EFSA CONTAM Panel (EFSA Panel on Contaminants in the Food Chain); Knutsen, H.K.; Alexander, J.; Barregård, L.; Bignami, M.; Brüschweiler, B.; Ceccatelli, S.; Cottrill, B.; Dinovi, M.; Edler, L.; et al. Scientific opinion on the risks for public health related to the presence of tetrodotoxin (TTX) and TTX analogues in marine bivalves and gastropods. EFSA J. 2017, 15, 4752.

23. Lago, J.; Rodríguez, P.L.; Blanco, L.; Vieites, M.J.; Cabado, G.A. Tetrodotoxin, an Extremely Potent Marine Neurotoxin: Distribution, Toxicity, Origin and Therapeutical Uses. Mar. Drugs 2015, 13, 6384-6406. [CrossRef] [PubMed]

24. Moczydlowski, E.G. The molecular mystique of tetrodotoxin. Toxicon 2013, 63, 165-183. [CrossRef] [PubMed]

25. Bane, V.; Lehane, M.; Dikshit, M.; O’Riordan, A.; Furey, A. Tetrodotoxin: Chemistry, Toxicity, Source, Distribution and Detection. Toxins 2014, 6, 693-755. [CrossRef] [PubMed]

26. Narahashi, T. Mechanism of Tetrodotoxin and Saxitoxin Action. In Handbook of Natural Toxins; Tu, A.T., Ed.; Marcel Dekker, Inc.: New York, NY, USA; Basel, Switzerland, 1988; Volume 3.

27. Walker, J.R.; Novick, P.A.; Parsons, W.H.; McGregor, M.; Zablocki, J.; Pande, V.S.; Du Bois, J. Marked difference in saxitoxin and tetrodotoxin affinity for the human nociceptive voltage-gated sodium channel (Nav 1.7). Proc. Natl. Acad. Sci. USA 2012, 109, 18102-18107. [CrossRef] [PubMed] 
28. Munday, R.; Thomas, K.; Gibbs, R.; Murphy, C.; Quilliam, M.A. Acute toxicities of saxitoxin, neosaxitoxin, decarbamoyl saxitoxin and gonyautoxins $1 \& 4$ and $2 \& 3$ to mice by various routes of administration. Toxicon 2013, 76, 77-83. [PubMed]

29. Selwood, A.I.; Waugh, C.; Harwood, D.T.; Rhodes, L.L.; Reeve, J.; Sim, J.; Munday, R. Acute Toxicities of the Saxitoxin Congeners Gonyautoxin 5, Gonyautoxin 6, Decarbamoyl Gonyautoxin 2\&3, Decarbamoyl Neosaxitoxin, C-1\&2 and C-3\&4 to Mice by Various Routes of Administration. Toxins 2017, 9, 73.

30. Standard for Live and Raw Bivalve Molluscs Codex Stan 292-2008. Available online: http://www.fao. org/fao-who-codexalimentarius/sh-proxy/es / ?lnk=1\&url=https \%253A\%252F\%252Fworkspace.fao.org\% 252Fsites\%252Fcodex\%252FStandards\%252FCODEX\%2BSTAN\%2B292-2008\%252FCXS_292e_2015.pdf (accessed on 23 October 2018).

31. Botana, L.M.; Hess, P.; Munday, R.; Nathalie, A.; DeGrasse, S.L.; Feeley, M.; Suzuki, T.; van den Berg, M.; Fattori, V.; Garrido Gamarro, E.; et al. Derivation of toxicity equivalency factors for marine biotoxins associated with Bivalve Molluscs. Trends Food Sci. Technol. 2017, 59, 15-24. [CrossRef]

32. FAO/WHO. Technical Paper on Toxicity Equivalency Factors for Marine Biotoxins Associated with Bivalve Molluscs; FAO: Rome, Italy, 2016.

33. Munday, R.; Reeve, J. Risk Assessment of Shellfish Toxins. Toxins 2013, 5, 2109-2137. [CrossRef] [PubMed]

34. Xu, Q.; Kai, H.; Gao, L.; Zhang, H. Toxicity of tetrodotoxin towards mice and rabbits. J. Hyg. Res. 2003, 32, 371-374.

35. Kao, C.Y.; Fuhrman, F.A. Pharmacological studies on Tarichatoxin, a potent neurotoxin. J. Pharmacol. Exp. Ther. 1963, 140, 31. [PubMed]

36. Abal, P.; Louzao, M.; Antelo, A.; Alvarez, M.; Cagide, E.; Vilariño, N.; Vieytes, M.; Botana, L. Acute Oral Toxicity of Tetrodotoxin in Mice: Determination of Lethal Dose 50 (LD50) and No Observed Adverse Effect Level (NOAEL). Toxins 2017, 9, 75. [CrossRef] [PubMed]

37. Hungerford, J.M. General Referee Reports, Committee on Natural Toxins and Food Allergens: Marine and Freshwater Toxins. J. AOAC Int. 2006, 89, 248-269. [PubMed]

38. AOAC Official Method 959.08. Paralytic shellfish poisoning. Biological method. In Official Methods of Analysis of AOAC International, 18th ed.; Horwitz, W.; Latimer, G.W., Eds.; AOAC International: Gaithersburg, MD, USA, 2005; pp. 79-82.

39. Regulation (EC) No 853/2004 of the European Parliament and of the Council of 29 April 2004; Laying down Specific Hygiene Rules for Food of Animal Origin. Available online: www.fsai.ie/uploadedFiles/Reg853 2004(1).pdf (accessed on 23 October 2018).

40. EFSA. Scientific Opinion of the Panel on Contaminants in the Food Chain on a request from the European Commission on Marine Biotoxins in Shellfish-Saxitoxin group. EFSA J. 2009, 1019, 1-76.

41. OECD Guidelines for the Testing of Chemicals; Acute Oral Toxicity-Up-and-Down Procedure (UDP). Available online: http://www.oecd.org/env/test-no-425-acute-oral-toxicity-up-and-down-procedure9789264071049-en.htm (accessed on 23 October 2018).

42. Munday, R. Toxicology of Seafood Toxins: A Critical Review. In Seafood and Freshwater Toxins: Pharmacology, Physiology, and Detection, 3rd ed.; Botana, L.M., Ed.; CRC Press: Boca Raton, FL, USA, 2014; pp. 197-290.

43. Boundy, M.J.; Selwood, A.I.; Harwood, D.T.; McNabb, P.S.; Turner, A.D. Development of a sensitive and selective liquid chromatography-mass spectrometry method for high throughput analysis of paralytic shellfish toxins using graphitised carbon solid phase extraction. J. Chromatogr. A 2015, 1387, 1-12. [CrossRef] [PubMed]

44. Turner, A.D.; McNabb, P.S.; Harwood, D.T.; Selwood, A.I.; Boundy, M.J. Single-Laboratory Validation of a Multitoxin Ultra-Performance LC-Hydrophilic Interaction LC-MS/MS Method for Quantitation of Paralytic Shellfish Toxins in Bivalve Shellfish. J. AOAC Int. 2015, 98, 609-621. [CrossRef] [PubMed]

45. USEPA User Documentation for the AOT425StatPgm Program. 2002. Available online: http://www.oecd. org/dataoecd/19/57/1839830.pdf (accessed on 24 May 2001).

(c) 2018 by the authors. Licensee MDPI, Basel, Switzerland. This article is an open access article distributed under the terms and conditions of the Creative Commons Attribution (CC BY) license (http:/ / creativecommons.org/licenses/by/4.0/). 
Article

\title{
First Report on the Occurrence of Tetrodotoxins in Bivalve Mollusks in The Netherlands
}

\author{
Arjen Gerssen ${ }^{1, *}$, Toine H. F. Bovee ${ }^{1}$, Mirjam D. Klijnstra ${ }^{1}$, Marnix Poelman ${ }^{2}$, Liza Portier ${ }^{1}$ and \\ Ron L. A. P. Hoogenboom ${ }^{1}$ \\ 1 RIKILT, Wageningen University and Research, Akkermaalsbos 2, 6708WB Wageningen, The Netherlands; \\ Toine.Bovee@wur.nl (T.H.F.B.); Mirjam.Klijnstra@wur.nl (M.D.K.); Liza.Portier@wur.nl (L.P.); \\ Ron.Hoogenboom@wur.nl (R.L.A.P.H.) \\ 2 Wageningen Marine Research, Korringaweg 7, 4401NT Yerseke, The Netherlands; Marnix.Poelman@wur.nl \\ * Correspondence: Arjen.Gerssen@wur.nl
}

Received: 30 August 2018; Accepted: 30 October 2018; Published: 1 November 2018

\begin{abstract}
Tetrodotoxin (TTX) is traditionally associated with seafood from tropical regions, but recently TTX was detected in bivalve mollusks in more temperate European waters. In The Netherlands it was therefore decided to monitor TTX in shellfish harvested from Dutch production areas. All shellfish production areas were monitored in 2015, 2016 and 2017. Samples were analyzed using liquid chromatography coupled to tandem mass spectrometry (LC-MS/MS). In total 1063 samples were investigated, and the highest concentrations were observed in 2016, i.e., $253 \mu \mathrm{g}$ TTX/ $\mathrm{kg}$ in oysters and $101 \mu \mathrm{g}$ TTX/kg in mussels. No TTX analogues, with the exception of 4-epi-TTX in one single sample, were found and contaminated samples also showed positive results in the neuro-2a bioassay. The occurrence of TTX seems to be consistent over the last three years with the highest concentrations observed annually in late June. The causative organism and the reasons why specific Dutch production areas are affected while others are not, are still unclear. Initially in The Netherlands an action limit of $20 \mu \mathrm{g}$ TTX/ $\mathrm{kg}$ was used to ensure the safety of consumers (2016), but recently The European Food Safety Authority (EFSA) established an acute reference dose, and based on a high portion size of consuming $400 \mathrm{~g}$ mussels, this dose was translated into a safe concentration of $44 \mu \mathrm{g}$ TTX per $\mathrm{kg}$ for shellfish. This concentration is now used as an action limit and TTX is formally included in the Dutch shellfish monitoring program.
\end{abstract}

Keywords: tetrodotoxins; bivalve mollusks; marine biotoxins; LC-MS/MS; neuroblastoma bioassay

Key Contribution: First finding and identification of tetrodotoxins with liquid chromatography tandem mass spectrometry in Dutch shellfish production areas. Presence of a neurotoxin confirmed with the neuro-2a bioassay (effect) and by high-resolution mass spectrometry for identification (structural confirmation of the responsible toxin).

\section{Introduction}

Consumption of bivalve mollusks such as oysters, mussels and clams contaminated with marine biotoxins may lead to severe intoxications [1]. Well-known intoxication syndromes are amnesic shellfish poisoning (ASP), diarrheic shellfish poisoning (DSP) and paralytic shellfish poisoning (PSP). Intoxications can also be caused by consumption of fish contaminated with marine biotoxins. Examples are ciguatera fish poisoning and pufferfish poisoning [2-4]. Marine biotoxins are produced by specific algal and/or bacterial strains and accumulate in shellfish through filter feeding and in fish through the food web. Toxins responsible for PSP and pufferfish poisoning are saxitoxins (STXs) and tetrodotoxins (TTXs) respectively. Both STXs and TTXs act as blockers of voltage gated sodium channels (VGSC) as present in e.g., excitable neuronal cells [5]. In mild cases intoxications by these two toxin groups will 
lead to nausea, vomiting, numbing in the lips and mouth. More severe cases lead to paralysis of the motoric muscles leading to respiratory problems. In these cases, patients need to be hospitalized and placed under respiratory assistance [6]. In extreme cases or where respiratory assistance is too late, consumers die [7]. Strict legislation is established in order to avoid such intoxications. For PSP toxins, shellfish production sites are regularly monitored and shellfish areas are closed when concentrations of these toxins exceed the regulatory limit, which in the EU legislation is established at $800 \mu \mathrm{g}$ STX-2HCl-eq $/ \mathrm{kg}$ edible shellfish [8]. For puffer fish, EU legislation is clear: fish from the families Tetraodontidae, Molidae, Diodontidae, and Canthigasteridae (which are the main species containing TTXs) are not allowed to be placed on the market [8]. Official control for the presence of PSP toxins in shellfish is based either on a mouse bioassay (MBA) or on high performance liquid chromatography with fluorescence detection (HPLC-FLD) [9]. The MBA is currently the EU reference method, but this will change in the coming year [10]. For TTXs, as the expected TTX containing species are forbidden, no official control programs and methods for toxin analysis are established in the EU. Till recently, TTXs were solely associated with specific fish species, snails, and newts [11]. Since 2015, studies have shown that TTXs might end up in shellfish such as oysters and mussels in Europe too.

Within the EU there is a strong tendency to move away from the MBA as the reference method for various classes of marine biotoxins. LC-MS/MS became the reference method for lipophilic marine biotoxins and this will be followed by the possible change towards the HPLC-FLD as the reference method for PSP toxins in shellfish. However, moving from the MBA, which is based on the effect of toxins, towards an HPLC-FLD method, which is based on physiochemical properties, will result in discrepancies. It is well known that the MBA results in false positives, for example due to the presence of high concentrations of zinc in shellfish, specifically oysters [12]. On the other hand, the MBA is probably able to protect consumers for emerging risks, such as recently for TTXs in shellfish in Europe. The first reports of TTXs in shellfish in Europe were from Greece [13]. Unexplained MBA results were further investigated. The initial follow-up method based on the HPLC-FLD for the detection of PSP toxins did not reveal the presence of any STXs. Therefore, a more sophisticated analytical method based on liquid chromatography coupled to tandem mass spectrometry (LC-MS/MS) was applied. This method showed the presence of TTX in shellfish at concentrations ranging between 61 and 195 $\mu \mathrm{g} / \mathrm{kg}$. The presence of TTXs in the Aegean Sea was not a complete surprise, as TTX containing fish were already observed in the Mediterranean sea, most likely migrated through the Suez channel [14]. However, that could not explain the presence of TTX in shellfish. The occurrence of TTX in more temperate waters such as in the United Kingdom was even more surprising, as these toxins were thought only to be present in warmer climates. A survey held in the UK with LC-MS/MS, published early 2015, showed the presence of TTX in shellfish at concentrations as high as $137 \mu \mathrm{g}$ TTX/ $\mathrm{kg}$ [15]. A follow-up study showed a maximum concentration of $253 \mu \mathrm{g} \mathrm{TTX} / \mathrm{kg}$ in oysters [16]. Moreover, bacterial strains suspected to be responsible for the production of TTXs were successfully identified and positive for TTXs when analyzed [15]. These findings in temperate waters initiated a survey in The Netherlands in 2015 to analyze all shellfish samples harvested for the official control for lipophilic marine toxins also for the presence of TTXs. In this paper, the findings of TTX in Dutch production areas in 2015 as well as the seasonal occurrence in 2016 and 2017 are presented.

\section{Results}

\subsection{Sanitary Survey Results}

After the publication by Turner et al. in 2015, a survey on the occurrence of TTX in shellfish produced and harvested in Dutch production areas was organized. The samples for these TTX analysis were already collected in the framework of the official control of the regulated marine biotoxins (i.e., lipophilic toxins including DSP toxins, azaspiracids, PSP toxins and ASP toxin). None of the samples collected exceeded the regulatory limits for these regulated toxins. In fact, no detectable concentrations of PSP toxins were found and only two shellfish samples were found to contain detectable concentrations 
of DSP toxins, at respectively 12 and $11 \mu \mathrm{g}$ okadaic acid (OA)-eq $/ \mathrm{kg}$. These concentrations are far below the regulated concentration of $160 \mu \mathrm{g}$ OA-eq $/ \mathrm{kg}$. From all collected samples a sub-portion, stored at $-20^{\circ} \mathrm{C}$, was investigated for the presence of TTX. The applied LC-MS/MS method was based on the method published by Boundy et al. [17]. In total 257 samples were analyzed from 14 different production sites (Figure 1A shows the mussel and oyster production sites). Four different species were investigated, 183 mussel (Mytilus edulis), 41 oyster (Castostrea gigas now Magallana gigas), 20 razor clam (Ensis sp.) and 13 cockle samples (Cerastoderma edula). TTX was detected above the limit of detection (LOD) in 15 samples, 7 mussel and 8 oyster samples harvested in the Eastern Scheldt east and north (Figure 1B), and in 5 of these cases above the limit of quantitation (LOQ) of $20 \mu \mathrm{g} T \mathrm{TX} / \mathrm{kg}$. The highest concentration of TTX was found in an oyster sample collected in the Eastern Scheldt east (124 $\mu \mathrm{g}$ TTX/kg). In the absence of any international health-based guidance values, the findings of TTX in shellfish led to a first risk assessment by the National Institute for public health and the environment (RIVM) and RIKILT Wageningen Research Front office. It was concluded that in the absence of suitable data on toxic concentrations in humans, there should be a zero tolerance for TTX. In practice, this meant that the LOQ of the analytical method, i.e., $20 \mu \mathrm{g}$ TTX/ kg was applied as a temporary decision limit. At the same time, The Netherlands presented the data to the European Commission and asked them to request a risk assessment from European Food Safety Authority (EFSA).
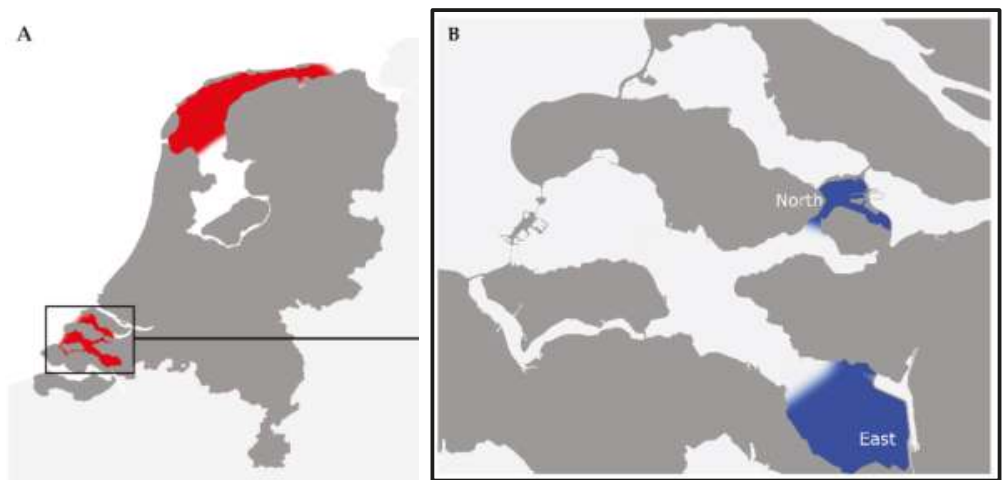

Figure 1. Various shellfish production areas in The Netherlands for mussels and oysters: (A) in red an overview of the production locations for mussels and oysters in The Netherlands; (B) in blue the areas with a higher prevalence of TTX in the Eastern Scheldt in the South-West of The Netherlands. Based on samples of the official national shellfish food safety program.

In 2016 all production areas as pointed out in Figure 1A were investigated. In total 403 samples were analyzed in the sanitary survey program, 280 mussel, 60 oyster, 38 razor clam and 25 cockle samples. Sampling was done on a regular basis and was weekly from June till October. When levels were above the LOQ, measures by the official authorities were taken. TTX was found and again solely in the Eastern Scheldt east and north (Figure 1B) and in the same period as in 2015 (June). TTX was detected in 36 samples, 17 mussel and 19 oyster samples, and 20 of these samples contained concentrations above the LOQ of $20 \mu \mathrm{g}$ TTX $/ \mathrm{kg}$. The highest concentration of TTX was found in an oyster sample at $253 \mu \mathrm{g}$ TTX/kg. TTX concentrations in mussels were much lower, with a maximum of $42 \mu \mathrm{g}$ TTX $/ \mathrm{kg}$. It should be noted that the mussels were not harvested from adjacent plots with oysters but were harvested from the northern part of the Eastern Scheldt while the oysters were harvested from the eastern part of the Eastern Scheldt (Figure 1B). After the first positive finding, the sampling scheme for the Eastern Scheldt was intensified, i.e., more samples were collected in order to follow the TTX concentrations during the toxic episode. The results showed that the concentrations tended to decline rapidly, and the toxic episode lasted for only 4 weeks. For the other regulated toxins, no samples were 
above the regulated limit. Only a low concentration of $5.3 \mathrm{mg} / \mathrm{kg}$ was detected with LC-MS/MS for the ASP toxin domoic acid, i.e., well below the regulatory limit of $20 \mathrm{mg}$ domoic acid $/ \mathrm{kg}$.

In 2017 the monitoring was continued in all production areas. Again, a total of 403 samples was analyzed, 281 mussel, 61 oyster, 36 razor clam and 25 cockle samples. The Eastern Scheldt east and north were not affected as much as in 2016. TTX was detected above the LOD of $3 \mu \mathrm{g}$ TTX/kg in 18 samples, 8 mussel and 10 oyster samples, and in 6 cases ( 3 mussel and 3 oyster) concentrations were above the LOQ of $20 \mu \mathrm{g}$ TTX/kg. Again, the highest concentration was found in an oyster sample collected in June $(51 \mu \mathrm{g} / \mathrm{kg})$.

Figure 2 summarizes the results for the occurrence of TTX in 2015, 2016 and 2017. In the figure also values below the LOQ are showed as indicative values, to get some information about background occurrence of TTX. As already mentioned, only two sampling areas in the Eastern Scheldt were affected, i.e., east and north (Figure 1B). The species sampled in Eastern Scheldt north were rope cultured mussel and in the Eastern Scheldt east oysters. For the rope cultured mussels, samples taken for the official control program were pooled samples with equal numbers of shellfish from top, middle and bottom of the rope. However, in several occasions top, middle and bottom were analyzed individually to determine if there are variations between sampling heights. No significant difference was observed between samples taken from the three different positions. For example, on the 14 July 2016, the sample from the top, middle and bottom contained, respectively, 26, 26 and $20 \mu \mathrm{g} T \mathrm{TX} / \mathrm{kg}$. As from all the data collected it seemed that oysters were more susceptible for TTX than mussels, additional mussel samples were taken from the Eastern Scheldt east as close as possible (based on occurrence) to the oyster production plots. Analysis confirmed that oysters contain indeed higher concentrations of TTX than mussels, as for example on the 29-30th of June 2016 both mussel and oyster samples harvested from adjacent shellfish plots showed concentrations of, respectively, 101 and $218 \mu \mathrm{g}$ TTX/kg. This difference between mussels and oysters was observed over the course of 2015 to 2017, Figure 2.

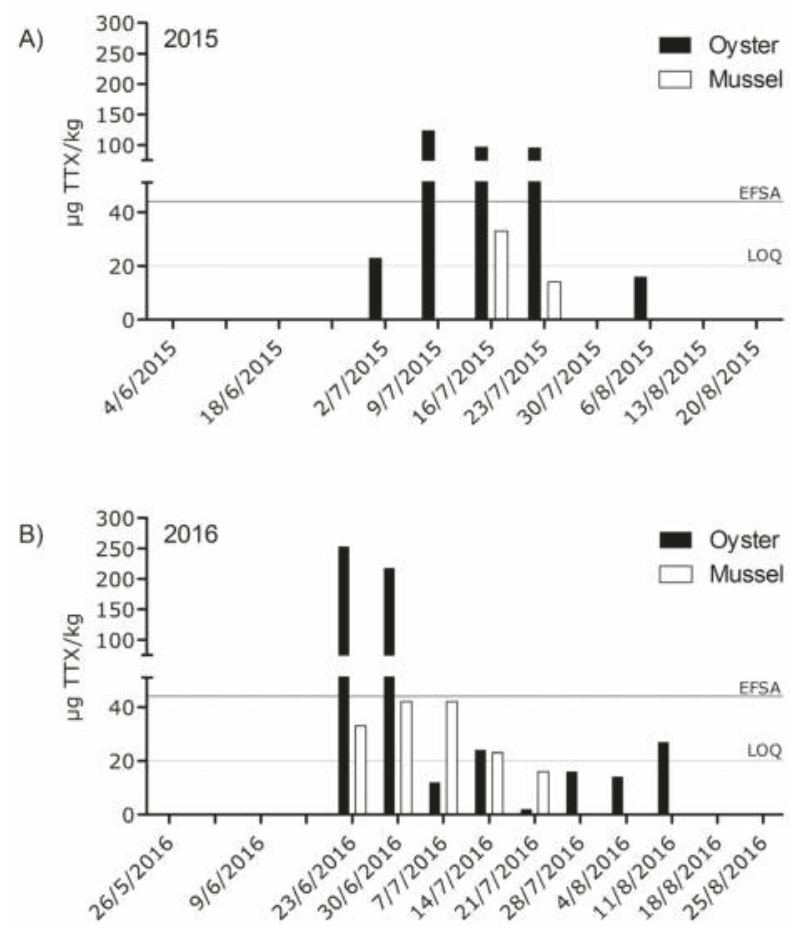

Figure 2. Cont. 


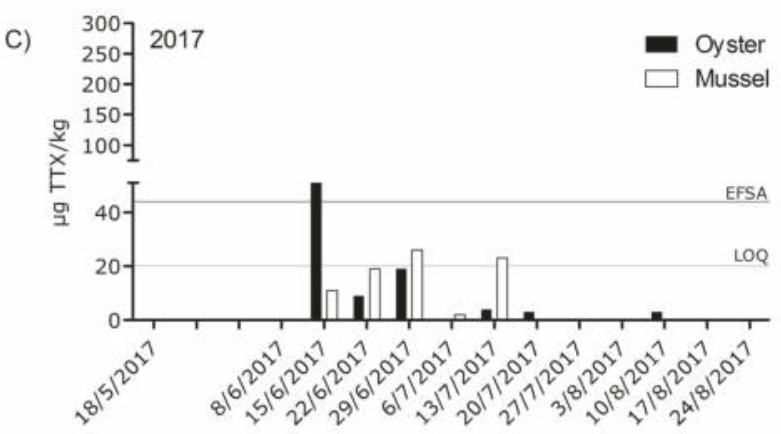

Figure 2. TTX concentrations found in oyster and mussels harvested from the sanitary survey plots in the Eastern Scheldt in respectively (A) 2015, (B) 2016 and (C) 2017. Oysters are harvested in Eastern Scheldt east and mussels were rope cultured mussels in the Eastern Scheldt north. Dates on the x-axis indicate the sampling date of the sanitary survey monitoring program. The EFSA line represents $44 \mu \mathrm{g}$ TTX-eq/kg and the LOQ $20 \mu \mathrm{g}$ TTX-eq/kg. Furthermore, the bars displayed below the LOQ (above the LOD) are indicative concentrations more uncertainty will be present in these concentrations.

\subsection{Verfication of the Results Obtained}

To verify our first positive LC-MS/MS findings and as well to test the applicability of an alternative method for the mouse bioassay, a subset of samples was also analyzed with the neuroblastoma (neuro-2a) bioassay. This assay was shown to be sensitive for this toxin [18,19], but thus far no reports on the testing of fish or shellfish have been published. The principle of this bioassay is based on the cell's MTT (3-[4,5-dimethylthiazol-2-yl]-2,5 diphenyl tetrazolium bromide) activity assay following exposure to the samples. Neuroblastoma cells were therefore treated simultaneously with sample extracts and with ouabain and veratridine $(\mathrm{o} / \mathrm{v})$, the latter leading to an increased sodium influx in cells and resulting in reduced MTT activity. The presence of voltage gated sodium channel blockers such as TTX will reduce the sodium influx as induced by o/v, resulting in more viable cells and thus less reduction of MTT activity. Based on the LC-MS/MS results, two contaminated oyster samples, one contaminated mussel sample and three blank shellfish samples were selected. The contaminated oysters contained 253 and $113 \mu \mathrm{g}$ TTX/kg and the mussel sample contained $171 \mu \mathrm{g}$ TTX/kg. The assay was developed as such that a concentration of $20 \mu \mathrm{g}$ TTX $/ \mathrm{kg}$ shellfish could be detected. Extracts were prepared, and cells were exposed to these extracts. Results of the neuroblastoma bioassay as shown in Figure 3 clearly indicated that the three contaminated samples are classified as suspect by the bioassay, i.e., showing an increased MTT activity as measured by the absorbance of the formed purple colored formazan. The blank shellfish samples and chemical blank and dimethyl sulfoxide (DMSO) $(0 \mathrm{~nm}$ TTX) controls all resulted in similar low MTT activities, while the positive control (100 nM TTX) resulted in a clear increase of the MTT activity. These results confirmed that using this specific protocol, the neuroblastoma bioassay could be used for the qualitative screening of large numbers of shellfish samples for the potential presence of voltage gated sodium blocker toxins such as TTXs and PSP toxins in shellfish. These initial findings are promising and therefore the assay is currently being validated for the application towards detecting TTX at regulated levels in shellfish. The presence of relative low levels of PSP toxins (STXs) is expected to cause false positive results as the sensitivity of the bioassay is comparable for STX and TTX and the regulated level of STXs is much higher than that of TTXs, i.e., $800 \mu \mathrm{g}$ STX $2 \mathrm{HCl}-\mathrm{eq} / \mathrm{kg}$. However, Dutch shellfish production areas were not affected by PSP toxins over the last 20 years. 


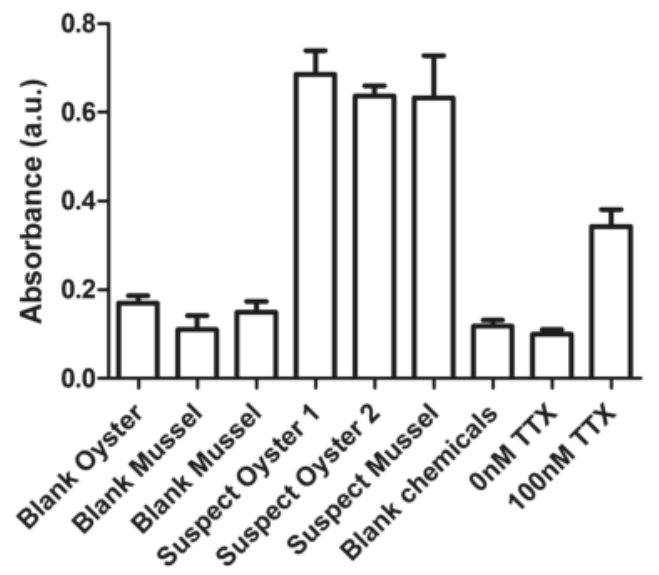

Figure 3. MTT activity of neuroblastoma cells exposed to a pure TTX standard (100 nM), a DMSO control $(0 \mathrm{nM})$, a chemical blank (control) and a subset of contaminated and blank shellfish samples. According to LC-MS/MS analysis, oyster 1 contained $253 \mu \mathrm{g}$ TTX/kg, oyster $2113 \mu \mathrm{g}$ TTX/kg and the mussel sample $171 \mu \mathrm{g}$ TTX $/ \mathrm{kg}$. The MTT activity is measured by the absorbance of the purple colored formazan formed by the neuro-2a cells. Results are mean absorbance with the standard deviation $(n=3)$. Cells are co-exposed to o/v which reduces the MTT activity, which is than counteracted by TTX.

Additionally, a subset of contaminated samples, the same as used for the neuro-blastoma assay, was analyzed by high-resolution mass spectrometry in order to screen for the presence of a broad range of TTXs and other marine biotoxins. The search included 31 different TTX analogues as well as approximately 800 other marine and freshwater toxins. It is well known that for species such as puffer fish and snails, a wide variety of TTX analogues such as deoxy analogues and epimers can be present due to the metabolism in the contaminated organism. The search with high-resolution mass spectrometry did not reveal other analogues than the ones already detected in the targeted LC-MS/MS method. For confirmation, also, high-resolution MS/MS spectra were recorded from both a standard as well as from the contaminated oyster sample (Figure 4). Both precursor $m / z$ as well as the fragments showed mass deviation errors well below $5 \mathrm{ppm}$. The contaminated shellfish contained TTX predominantly and only in a single case 4 epi-TTX was detected. The concentration, determined with the LC-MS/MS, of 4 epi-TTX was estimated at $14.5 \mu \mathrm{g}$ TTX-eq $/ \mathrm{kg}$ using the TTX calibration curve. While TTX itself was present at $96 \mu \mathrm{g} / \mathrm{kg}$. The lack of TTX metabolites in shellfish is in line with the findings in Greece and the UK [13,15].

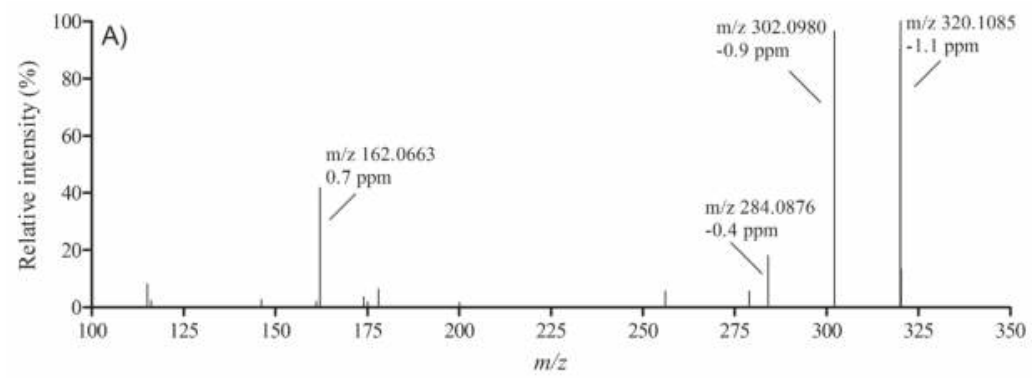

Figure 4. Cont. 


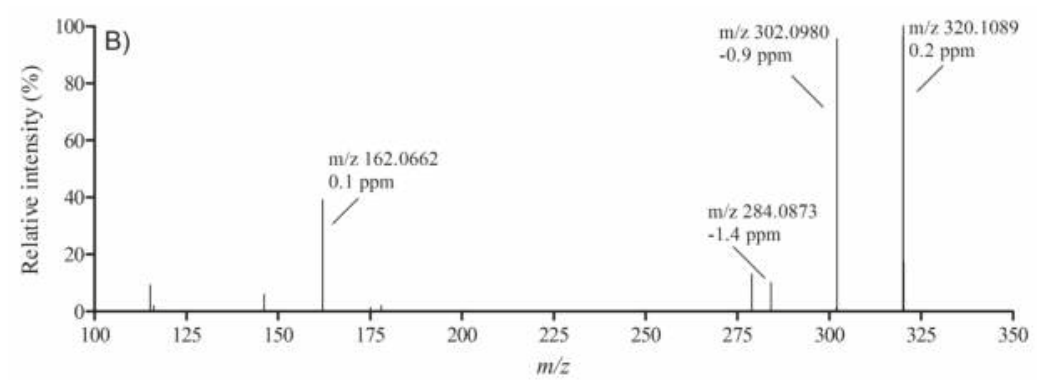

Figure 4. High-resolution MS/MS spectra recorded on a Q-Exactive orbitrap at a resolution of 140,000 full width half maximum (FWHM) of (A) standard solution of TTX and (B) of TTX in a naturally contaminated oyster sample.

\section{Discussion}

No action or legislative limit was established for shellfish on both a national or international level at the time of the first positive samples in 2015. After our findings, confirming those of Greece and the UK, discussions on an international level started on safe concentrations for TTX in shellfish. As TTX is a toxin associated with serious intoxications, it was decided in The Netherlands to apply the precautionary principle for the course of 2016. Therefore, the LOQ of the method, which is $20 \mu \mathrm{g} / \mathrm{kg}$, was used by the competent authority as decision limit for shellfish food safety management to open and close Dutch shellfish production areas. In 2017, the EFSA performed a risk assessment on TTX in shellfish [20]. An acute reference dose (ARfD) for TTX of $0.25 \mu \mathrm{g} / \mathrm{kg}$ body weight was derived, based on effects in mice. This implied that the TTX concentration in a large portion of $400 \mathrm{~g}$ shellfish, consumed by a $70 \mathrm{~kg}$ person, should not exceed $44 \mu \mathrm{g}$ TTX $/ \mathrm{kg}$ shellfish. This safe concentration was adopted in The Netherlands by the risk managers and thus used in 2017 as the decision limit in the shellfish food safety program to open and close Dutch production areas. Looking back at the results since 2015 only 6 samples taken in the sanitary survey program exceeded the limit of $44 \mu \mathrm{g}$ TTX $/ \mathrm{kg}$. Respectively, 3 times in 2015, 2 times in 2016 and only once in 2017. Furthermore, within the sanitary survey samples only oysters exceeded this limit. If these Dutch episodes are placed in perspective with other toxin classes in other countries, the number of closures can be regarded as relatively low and short. However, the closures were problematic, as one of the affected locations was close to the shellfish packaging facilities that are used as a shellfish warehouse. This means that even a short closure has a major financial impact on the shellfish industry.

The toxic episodes seem to be consistent over the last three years with an increase in TTX concentration during late June followed by a rapid decline in July and absence of TTX during the rest of the year. The organism responsible for producing TTX in these areas is not known yet and still under investigation. In other areas such as the UK and Spain, vibrio was positively identified as one of the producers of TTX $[15,21]$. In literature a relationship is suggested between the occurrence of TTX and phytoplankton, which should thus be kept in mind as a possible factor for TTX transport to shellfish too. Other important factors that play a role in TTX production are most likely the climatic and hydrodynamic conditions as suggested by Turner et al. [16]. For example, currents, refreshment rate, water depth, nutrients, bacteria and phytoplankton compositions and numbers, rain fall, water temperature, etc. might be of influence. The relationships of these factors with the TTX concentration in shellfish are unclear and still under investigation. Water temperatures, phytoplankton composition and numbers as well as rainfall conditions were completely different in the three years [22]. Unfortunately, only from 2017 and onwards data are continuously collected on the various climatic and hydrodynamic parameters. Therefore, it will be difficult to retrospectively explain why the maximum TTX concentrations in shellfish in 2015 and 2016 were higher than those observed in 2017. However, when looking at the conditions in the affected areas, there are some factors that seem to be 
of importance, as the affected areas are relatively shallow with a low refreshment rate of the water. Additionally, the water depth is also low compared to other production areas. Positive relationships between TTX concentrations and low refreshment rates and low depths are in line with findings of Turner et al. [16]. However, more data should be collected in a harmonized way in the coming years to study and identify the parameters involved in TTX production and the organism responsible for producing it.

Regarding toxin analysis, mass spectrometric analysis revealed almost solely TTX and no analogues with the exception of a low concentration of 4-epi-TTX in one sample. This indicates that there is a limited degree of metabolism of TTX in the shellfish itself. It is known that bacterial strains produce mainly TTX however also 4-epi-TTX and anhydro-TTX can be formed [23]. Other metabolites are most likely produced within the liver of for example puffer fish; however TTX and 4,9-anhydro-TTX are often the most predominant metabolites [24]. This simplifies the analytical procedure for mussels, as the TTX certified reference standard also contains low levels of 4-epi and 4,9 anhydro-TTX, while standards for other low abundant metabolites as detected in fish are not available. As already mentioned in the introduction, the use of the MBA in the past might have protected consumers for being exposed to TTX via contaminated shellfish products. The use of alternative methods based on a different principle such as analytical techniques (physiochemical processes) instead of animals (toxicological effect) might overlook these toxins. Therefore, the use of alternative animal-free effect-based bioassays such as the neuro-2a cell viability assay can be useful to detect potential new risks/toxins present in shellfish, as shown in the present study.

\section{Conclusions}

During the course of 2015, 2016 and 2017, TTX was detected in shellfish harvested in Dutch production waters. Oysters seem to be more susceptible than mussels, as the highest concentrations annually found are in oysters, with a maximum concentration of $253 \mu \mathrm{g}$ TTX/ $\mathrm{kg}$ shellfish in 2016. Solely TTX was found and no analogues of TTX. In the past the MBA might have protected consumers to high TTX exposure but nowadays TTX can be detected at sufficiently low concentrations by LC-MS/MS. However, when relying solely on analytical techniques, new risks might be missed. To detect known marine biotoxins including TTX and its analogues but also new risks/toxins, the use of effect-based in vitro assays such as the neuro-2a cell viability assay might be of interest. At the Dutch national level, the concentration of $44 \mu \mathrm{g}$ TTX/kg derived by EFSA was adapted as the action limit. At the European level, no decision is taken yet. From 2016 and onwards TTX is included in the Dutch sanitary survey program and monitored by LC-MS/MS most likely till the neuroblastoma assay is validated and accredited.

\section{Materials and Methods}

\subsection{Reagents and Standards}

Water was deionized and passed through a Milli-Q water purification system from Merkmillipore, Darmstadt, Germany. Acetonitrile (ULC-MS) and methanol (ULC-MS) were purchased from Biosolve, Valkenswaard, The Netherlands. Ammonium hydroxide (25\%), formic acid (98-100\%), acetic acid $(100 \%)$, dimethylsulfoxide (DMSO), $n$-hexane, ouabain and veratridine were purchased from Merck, Darmstadt, Germany. Certified Tetrodotoxin (TTX) material $(25.8 \pm 2.1 \mu \mathrm{g} / \mathrm{g})$ was purchased from Cifga, Lugo, Spain. Non-certified TTX material was purchased from Latoxan, Portes lès Valence, France.

\subsection{Preperation of Extracts}

Homogenates of shellfish (mussels, oysters, cockles and ensis) were prepared by homogenizing at least $100 \mathrm{~g}$ of whole flesh tissue with a T25 Ultra Turrax mixer at 24,000 rpm (IKA Works, Wilmington, NC, USA). For LC-MS/MS analysis, one gram of homogenate was extracted by vortex mixing during one minute with $1.5 \mathrm{~mL}$ 50:50 $(\mathrm{v} / \mathrm{v})$ water/methanol containing 0.015 M acetic acid. Subsequently the 
extract was centrifuged at $3600 \mathrm{rpm}$ during $5 \mathrm{~min}$. The supernatant was transferred to a volumetric

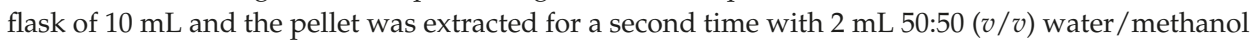
containing $0.015 \mathrm{M}$ acetic acid. After centrifugation for $5 \mathrm{~min}$ at $3600 \mathrm{rpm}$, the supernatant was transferred to the same volumetric flask already containing previous obtained extract. The volume was adjusted to $10 \mathrm{~mL}$ with acetonitrile, and the solution was mixed. After $2 \mathrm{~min}$, this time was allowed for precipitation of proteins, an aliquot of $2 \mathrm{~mL}$ was transferred to an ultra-centrifuge filter tube (Amicon Ultra-4 30kD, Merck, Darmstadt, Germany), centrifuged for $30 \mathrm{~min}$ at 3,600 rpm. An aliquot of the filtrate was transferred to a LC-MS/MS vial for analysis.

For initial quantitation, a calibration curve was constructed using blank mussel fortified with TTX at respectively $0,20,40,60$ and $80 \mu \mathrm{g}$ TTX/kg shellfish. For a more accurate quantitation, a single concentration standard addition was performed at $60 \mu \mathrm{g}$ TTX/kg for the samples from the affected areas. If concentrations were much higher, above $100 \mu \mathrm{g} / \mathrm{kg}$, a second experiment was performed with a higher standard addition concentration.

For the neuroblastoma bioassay, two grams of homogenate was extracted by vortex mixing for one minute with $0.6 \mathrm{~mL} 2 \%(v / v)$ acetic acid. Afterwards the samples were placed in a $100{ }^{\circ} \mathrm{C}$ water bath for $5 \mathrm{~min}$. After cooling to room temperature, the sample was centrifuged at $3600 \mathrm{rpm}$ for $5 \mathrm{~min}$. The supernatant was transferred to a conical calibrated tube and the pellet was extracted a second time with $0.6 \mathrm{~mL} 2 \%(v / v)$ acetic acid. After vortex mixing, the extract was centrifuged at $3600 \mathrm{rpm}$ and the supernatant was combined with the previous obtained supernatant. The total volume was adjusted to $2 \mathrm{~mL}$ with water. To remove matrix effects, a solid phase extraction (SPE) using a Strata-X cartridge (200 mg/6 mL) (Phenomenex, Torrance, CA, USA) was applied. The cartridge was conditioned with $6 \mathrm{~mL}$ methanol followed by $6 \mathrm{~mL}$ water. Then $1 \mathrm{~mL}$ of the crude extract was applied to the cartridge and the eluate was collected in a conical graduated tube. Subsequently, the cartridge was additionally eluted with $2 \mathrm{~mL}$ water, the eluate was collected in the same conical graduated tube. Vacuum was applied to retrieve all eluent, thereafter the eluent volume was adjusted to $4 \mathrm{~mL}$ with water. Subsequently the obtained eluent was further cleaned using liquid-liquid partitioning by adding $4 \mathrm{~mL}$ of hexane. After vigorously mixing the mixture was centrifuged at $3000 \mathrm{rpm}$ for $7 \mathrm{~min}$. The hexane layer was discarded, and $3 \mathrm{~mL}$ of the water layer was evaporated in a water bath at $60{ }^{\circ} \mathrm{C}$ under a continuous stream of nitrogen. The residue was reconstituted in $300 \mu \mathrm{L}$ DMSO and filtered using an $0.45 \mu \mathrm{m}$ mini-membrane filter (Whatman uniprep, Merck, Darmstadt, Germany) prior to the application of the neuroblastoma bioassay.

\subsection{TTX LC-MS/MS Analysis}

The chromatographic method was adapted from Boundy et al. [17]. Briefly, chromatographic separation was achieved using a Waters Acquity I-Class UPLC system (Waters, Milford, MA, USA). The system consisted of a binary solvent manager, sample manager and a column manager. The column temperature was kept set at $60{ }^{\circ} \mathrm{C}$ and the temperature of the sample manager was kept at $10{ }^{\circ} \mathrm{C}$. The analytical column used was a Waters BEH Amide $(150 \times 2.1 \mathrm{~mm}, 1.7 \mu \mathrm{m})$ column, the analytical column was protected by a Waters BEH Amide VanGuard pre-column $(5 \times 2.1 \mathrm{~mm}, 1.7 \mu \mathrm{m})$. See Boundy et al. for a detailed description of the conditioning and rinsing procedures [17]. Mobile phase A was water containing $0.015 \%(v / v)$ ammonia and $0.015 \%(v / v)$ formic acid and mobile phase $\mathrm{B}$ was acetonitrile/water $(70: 30 \mathrm{v} / \mathrm{v})$ containing $0.01 \%(v / v)$ formic acid. A gradient started at $2 \%$ $\mathrm{A}$ at a constant flow rate of $0.4 \mathrm{~mL} /$ minute and after $5 \mathrm{~min}$ this was linearly increased to $50 \% \mathrm{~A}$ in $2.5 \mathrm{~min}$. This composition was kept for $1.5 \mathrm{~min}$, but the flowrate was linearly increased to $0.5 \mathrm{~mL} / \mathrm{min}$. Within $0.5 \mathrm{~min}$ the mobile phase composition was returned to $2 \% \mathrm{~A}$. Subsequently the flow increased to $0.8 \mathrm{~mL} / \mathrm{minute}$ and was kept for $0.6 \mathrm{~min}$. The flow was linearly decreased to $0.4 \mathrm{~mL} / \mathrm{minute}$ in $0.4 \mathrm{~min}$ prior the next injection. A $2 \mu \mathrm{L}$ injection volume was used. The effluent was directly interfaced in the electrospray ionization (ESI) source of the Waters TQ-S. The ESI was operated in the positive modus. A capillary voltage of $0.5 \mathrm{kV}$, a source temperature of $150{ }^{\circ} \mathrm{C}$ and a desolvation temperature of $600{ }^{\circ} \mathrm{C}$ at a $\mathrm{N}_{2}$ flow of $1000 \mathrm{~L} / \mathrm{h}$ were used. Argon was used as collision induced dissociation gas at 
a flow rate of $0.25 \mathrm{~mL} / \mathrm{min}$. The LC-MS/MS was operated in multiple-reaction-monitoring (MRM) mode, the cone voltage was kept at 40V for all MRM transitions. For TTX (and the 4-epi-TTX) two transitions were monitored $m / z 320.1>302.1$ (CE 20eV) and $m / z 320.1>162.1$ (CE 38 eV). Furthermore, the following TTX metabolites were included in the method, 5,6,11 trideoxy TTX $m / z 272.1>254.1$ $(\mathrm{CE} 20 \mathrm{eV})$ and $m / z 272.1>162.1(\mathrm{CE} 38 \mathrm{eV}), 11$ nor TTX-6-ol $m / z 290.1>272.1$ (CE 20eV) and $m / z$ $290.1>162.1$ (CE $38 \mathrm{eV}$ ), 4,9-anhydro-TTX $m / z$ 302.1 > 256.1 (CE 20eV) and $m / z 302.1>162.1$ (CE 38 $\mathrm{eV}), 5$ - and 11- deoxy TTX $m / z 304.1>286.1$ (CE 20eV) and $m / z 304.1>176.1$ (CE $38 \mathrm{eV})$. Acceptance criteria for the data were as follows: (1) the constructed calibration curve for TTX should have a correlation above 0.990 ; (2) sensitivity based on the slope of the calibration curve measured before and after the samples should not deviate more than 25\%; (3) the retention times should not deviate more than $0.2 \mathrm{~min}$ with the average retention time obtained with the samples used to construct the calibration curves and (4) the calculated ion ratio should not deviate more than $30 \%$ with the obtained ion ratios from the samples used to construct the calibration curves. The LOD and LOQ were determined in fortified shellfish extracts. The LOD was determined at a signal to noise of 3 for the transition with the highest intensity $(m / z 320.1>302.1)$ and the LOQ was determined by a signal of noise of 3 for the transition with the lowest intensity $(m / z 320.1>162.1)$. This will mean that at the LOQ two transitions are available and confirmation based on ion ratio can be performed.

\subsection{LC-Q-Exactive Orbitrap Screening TTX Analogues}

The chromatographic method used is a method developed for the broad screening of marine and freshwater toxins in various matrices such as fish, shellfish, and food supplements. In this case, the method was solely used for screening of TTX and analogues. Chromatographic separation was achieved using a Thermo scientific Ultimate 3000 (San Jose, CA, USA). The column temperature was set at $35^{\circ} \mathrm{C}$ and the temperature of the sample manager was kept at $10^{\circ} \mathrm{C}$. The analytical column used was a TSK-Amide-80 $(150 \times 3 \mathrm{~mm}, 2 \mu \mathrm{m})$ column (Merck, Darmstadt, Germany). Mobile phase A was water and mobile phase B was acetonitrile/water (90:10 v/v) both containing $0.5 \mathrm{mM}$ formic acid and $2 \mathrm{mM}$ ammonium formate. A gradient started at $10 \% \mathrm{~A}$ at a constant flow rate of $0.5 \mathrm{~mL} / \mathrm{minute}$ and after $0.1 \mathrm{~min}$ this was linearly increased to $55 \% \mathrm{~A}$ in $13.9 \mathrm{~min}$. Then within $0.1 \mathrm{~min}$ the composition was changed to $80 \% \mathrm{~A}$. This composition was kept for $1.9 \mathrm{~min}$. Within $0.1 \mathrm{~min}$ the mobile phase composition was returned to $10 \% \mathrm{~A}$. This composition was kept for $3.9 \mathrm{~min}$ prior the next injection. A $10 \mu \mathrm{L}$ injection volume was used. The effluent was directly interfaced in the heated electrospray ionization (HESI) source of the Thermo Scientific Q-Exactive focus hybrid quadrupole-orbitrap mass spectrometer (San Jose, CA, USA). The ESI was operated in the positive modus. A spray voltage of $3.5 \mathrm{kV}$, a capillary temperature of $256.25^{\circ} \mathrm{C}$, a probe heather of $412.5^{\circ} \mathrm{C}$ and S-Lens of $50 \mathrm{~V}$ was set. The data was acquired in full scan (FS) and data independent acquisition (DIA) mode. In FS the scan mass range was set at $m / z$ 100-1500 with a mass resolution of 70,000 at full width half maximum (FWHM), the automatic gain control (AGC) was set at $1.0 \mathrm{e} 6$ and the maximum injection time (IT) $200 \mathrm{~ms}$. For DIA the mass resolution was set at 17,500 at FWHM, AGC at $1.0 \times 10^{6}$ and IT $200 \mathrm{~ms}$ and a variable isolation window. The inclusion list contained three DIA windows $m / z 300$ with an isolation window of $400 \mathrm{Da}, m / z 750$ with an isolation window of $500 \mathrm{Da}$ and $\mathrm{m} / z 1250$ with an isolation window of 500 Da in every DIA window a normalized collision energy of $40 \%$ was applied. Data analysis was performed with Thermo TraceFinder using a library for marine and freshwater toxins, the specific part on tetrodotoxins could be found in the supplementary material (Table S1). To have a suspect hit the precursor ion $m / z$ should be present with a mass deviation below 5 ppm and at least one fragment ion with a mass deviation of less than 5 ppm should be visible. To test the system a mixture of various hydrophilic toxins is used including TTX for which retention time and mass deviations for the precursor and fragments should full fill the mentioned mass criteria. The mixture also contained a variety of PSP toxins such as saxitoxin, neo-saxitoxin, gonyautoxins, $-1,-2,-3,-4$ and their decarbomoyl forms but also freshwater toxins such as anatoxins and cylindrospermopsin and also $\beta$-methylamino-L-alanine was included. For identification purpose, also, high-resolution 
MS/MS spectra were recorded from both a standard solution as well as from a high contaminated oyster sample. The $m / z 320.1$ was used as precursor mass and spectra were recorded with a resolution of 140,000 FWHM.

\subsection{Neuroblastoma Assay}

Neuroblastoma neuro-2a cells were purchased from the American Type Culture Collection (ATCC; CCL-131) and cultured in $75 \mathrm{~cm}^{2}$ culture flasks containing $15 \mathrm{~mL}$ RPMI-1640 medium (R0883, Merck, Darmstadt, Germany) supplemented with 10\% ( $v / v)$ Fetal Bovine Serum (FBS), 1\% ( $v / v)$ of a 100 $\mathrm{mM}$ sodium pyruvate solution and $1 \%(v / v)$ of a $200 \mathrm{mM}$ L-glutamine solution. The cell line was maintained in a humidified incubator at $37{ }^{\circ} \mathrm{C}$ under $5 \% \mathrm{CO}_{2}$ and sub-cultured three times per week (dilution 1/14) up to approximately $90 \%$ confluence.

Neuro-2a cells were seeded into 96-well plates with an initial density of $2.5 \times 10^{4}$ cells / well. After growing the cells for $24 \mathrm{~h}$, exposure to a $100 \mathrm{nM}$ TTX standard solution and $20 \mu \mathrm{L}$ of the previous obtained sample extracts was performed in quadruplicate in $200 \mu \mathrm{L}$ medium for $24 \mathrm{~h}$. For screening neurotoxic effects, ouabain and veratridine at concentrations that produce an $80 \%$ decrease in MTT activity $(0.3 \mathrm{mM}$ and $0.03 \mathrm{mM}$ respectively) were added to each well in combination with the test compound or sample extract in fresh serum free medium. The final DMSO concentration in the medium was kept at $0.25 \%(v / v)$ for all standards and extracts. At the end of the exposure, cell viability was measured using the MTT assay. Briefly, $60 \mu \mathrm{L}$ of MTT (final concentration of $0.8 \mathrm{mg} / \mathrm{mL}$ ), dissolved in medium were added to each well. After $30 \mathrm{~min}$ incubation at $37^{\circ} \mathrm{C}$, the medium was removed, and the formed formazan crystals were dissolved in $100 \mu \mathrm{L}$ DMSO. The absorbance was measured at $540 \mathrm{~nm}$ and corrected for background absorption at $650 \mathrm{~nm}$.

Supplementary Materials: The following are available online at http:/ /www.mdpi.com/2072-6651/10/11/450/s1, Table S1: TTX HRMS library used.

Author Contributions: Conceptualization, A.G.; Methodology, A.G. and T.H.F.B.; Validation, M.D.K. and L.P.; Formal Analysis, M.D.K. and L.P.; Investigation, M.D.K. and L.P.; Resources, M.P.; Writing-Original Draft Preparation, A.G.; Writing-Review and Editing, T.H.F.B., R.L.A.P.H.; Visualization, A.G.; Supervision, A.G. and T.F.H.B.; Project Administration, A.G., M.D.K., M.P. and R.L.A.P.H.; Funding Acquisition, A.G., M.P. and R.L.A.P.H.

Funding: This research was funded by the Dutch ministry of Agriculture, Nature and Food Quality [WOT-02-001-016 and WOT-02-001-020], by the Dutch ministry of Health, Welfare and Sport [9.2.8 A sanitary shellfish research] and through a public private partnership, topsector Agrifood [AF-16054].

Conflicts of Interest: The founding sponsors had no role in the design of the study; in the collection, analyses, or interpretation of data; in the writing of the manuscript, and in the decision to publish the results.

\section{References}

1. Nicolas, J.; Hoogenboom, R.L.A.P.; Hendriksen, P.J.M.; Bodero, M.; Bovee, T.F.H.; Rietjens, I.M.C.M.; Gerssen, A. Marine biotoxins and associated outbreaks following seafood consumption: Prevention and surveillance in the 21st century. Glob. Food Secur.-Agric. 2017, 15, 11-21. [CrossRef]

2. Cole, J.B.; Heegaard, W.G.; Deeds, J.R.; McGrath, S.C.; Handy, S.M. Tetrodotoxin poisoning outbreak from imported dried puffer-fish Minneapolis, Minnesota, 2014. MMWR-Morbid. Mortal. Wkly. Rep. 2015, 63, 1222-1225.

3. Yogi, K.; Sakugawa, S.; Oshiro, N.; Ikehara, T.; Sugiyama, K.; Yasumoto, T. Determination of toxins involved in ciguatera fish poisoning in the pacific by lc/ms. J. AOAC Int. 2014, 97, 398-402. [CrossRef] [PubMed]

4. Mattei, C.; Vetter, I.; Eisenblatter, A.; Krock, B.; Ebbecke, M.; Desel, H.; Zimmermann, K. Ciguatera fish poisoning: A first epidemic in germany highlights an increasing risk for European countries. Toxicon 2014, 91, 76-83. [CrossRef] [PubMed]

5. Cusick, K.D.; Sayler, G.S. An overview on the marine neurotoxin, saxitoxin: Genetics, molecular targets, methods of detection and ecological functions. Mar. Drugs 2013, 11, 991-1018. [CrossRef] [PubMed]

6. Bane, V.; Lehane, M.; Dikshit, M.; O’Riordan, A.; Furey, A. Tetrodotoxin: Chemistry, toxicity, source, distribution and detection. Toxins 2014, 6, 693-755. [CrossRef] [PubMed] 
7. How, C.K.; Chern, C.H.; Huang, Y.C.; Wang, L.M.; Lee, C.H. Tetrodotoxin poisoning. Am. J. Emerg. Med. 2003, 21, 51-54. [CrossRef] [PubMed]

8. Anon. Corrigendum to regulation (ec) no 853/2004 of the european parliament and of the council of 29 April 2004 laying down specific hygiene rules for food of animal origin. Off. J. Eur. Commun. 2004, 47, $22-82$.

9. Lawrence, J.F.; Niedzwiadek, B.; Menard, C. Quantitative determination of paralytic shellfish poisoning toxins in shellfish using prechromatographic oxidation and liquid chromatography with fluorescence detection: Collaborative study. J. AOAC Int. 2005, 88, 1714-1732. [PubMed]

10. Anon. Commision regulation (eu) 2017/1980 of 31 October 2017 amending annex iii to regulation (ec) no 2074/2005 as regards paralytic shellfish poison (psp) detection method. Off. J. Eur. Commun. 2017, 60, 8-9.

11. Fernandez-Ortega, J.F.; Morales-de los Santos, J.M.; Herrera-Gutierrez, M.E.; Fernandez-Sanchez, V.; Loureo, P.R.; Rancano, A.A.; Tellez-Andrade, A. Seafood intoxication by tetrodotoxin: First case in Europe. J. Emerg. Med. 2010, 39, 612-617. [CrossRef] [PubMed]

12. Aune, T.; Ramstad, H.; Heidenreich, B.; Landsverk, T.; Waaler, T.; Egaas, E.; Julshamn, K. Zinc accumulation in oysters giving mouse deaths in paralytic shellfish poisoning bioassay. J. Shellfish Res. 1998, 17, 1243-1246.

13. Vlamis, A.; Katikou, P.; Rodriguez, I.; Rey, V.; Alfonso, A.; Papazachariou, A.; Zacharaki, T.; Botana, A.M.; Botana, L.M. First detection of tetrodotoxin in Greek shellfish by uplc-ms/ms potentially linked to the presence of the dinoflagellate prorocentrum minimum. Toxins 2015, 7, 1779-1807. [CrossRef] [PubMed]

14. Bentur, Y.; Ashkar, J.; Lurie, Y.; Levy, Y.; Azzam, Z.S.; Litmanovich, M.; Golik, M.; Gurevych, B.; Golani, D.; Eisenman, A. Lessepsian migration and tetrodotoxin poisoning due to Lagocephalus sceleratus in the eastern Mediterranean. Toxicon 2008, 52, 964-968. [CrossRef] [PubMed]

15. Turner, A.D.; Powell, A.; Schofield, A.; Lees, D.N.; Baker-Austin, C. Detection of the pufferfish toxin tetrodotoxin in European Bivalves, England, 2013 to 2014. Eurosurveillance 2015, 20, 2-8. [CrossRef]

16. Turner, A.D.; Dhanji-Rapkova, M.; Coates, L.; Bickerstaff, L.; Milligan, S.; O’Neill, A.; Faulkner, D.; McEneny, H.; Baker-Austin, C.; Lees, D.N.; et al. Detection of tetrodotoxin shellfish poisoning (tsp) toxins and causative factors in bivalve molluscs from the UK. Mar. Drugs 2017, 15, 277. [CrossRef] [PubMed]

17. Boundy, M.J.; Selwood, A.I.; Harwood, D.T.; McNabb, P.S.; Turner, A.D. Development of a sensitive and selective liquid chromatography-mass spectrometry method for high throughput analysis of paralytic shellfish toxins using graphitised carbon solid phase extraction. J. Chromatogr. A 2015, 1387, 1-12. [CrossRef] [PubMed]

18. Kogure, K.; Tamplin, M.L.; Simidu, U.; Colwell, R.R. A tissue culture assay for tetrodotoxin, saxitoxin and related toxins. Toxicon 1988, 26, 191-197. [CrossRef]

19. Hamasaki, K.; Kogure, K.; Ohwada, K. A biological method for the quantitative measurement of tetrodotoxin (ttx): Tissue culture bioassay in combination with a water-soluble tetrazolium salt. Toxicon 1996, 34, 490-495. [CrossRef]

20. Knutsen, H.K.; Alexander, J.; Barregård, L.; Bignami, M.; Brüschweiler, B.; Ceccatelli, S.; Cottrill, B.; Dinovi, M.; Edler, L.; Grasl-Kraupp, B.; et al. Risks for public health related to the presence of tetrodotoxin (ttx) and ttx analogues in marine bivalves and gastropods. EFSA J. 2017, 15. [CrossRef]

21. Leao, J.M.; Lozano-Leon, A.; Giraldez, J.; Vilarino, O.; Gago-Martinez, A. Preliminary results on the evaluation of the occurrence of tetrodotoxin associated to marine Vibrio spp. In bivalves from the galician rias (northwest of Spain). Mar. Drugs 2018, 16, 81. [CrossRef] [PubMed]

22. Poelman, M.; Wageningen Marine Research, Yerseke, The Netherlands. Presentations on National Ttx Meetings. Personal communication, 2017.

23. Yotsu, M.; Yamazaki, T.; Meguro, Y.; Endo, A.; Murata, M.; Naoki, H.; Yasumoto, T. Production of tetrodotoxin and its derivatives by Pseudomonas sp. Isolated from the skin of a pufferfish. Toxicon 1987, 25, 225-228. [CrossRef]

24. Kono, M.; Matsui, T.; Furukawa, K.; Takase, T.; Yamamori, K.; Kaneda, H.; Aoki, D.; Jang, J.H.; Yotsu-Yamashita, M. Examination of transformation among tetrodotoxin and its analogs in the living cultured juvenile puffer fish, kusafugu, fugu niphobles by intramuscular administration. Toxicon 2008, 52, 714-720. [CrossRef] [PubMed]

(C) 2018 by the authors. Licensee MDPI, Basel, Switzerland. This article is an open access article distributed under the terms and conditions of the Creative Commons Attribution (CC BY) license (http:/ / creativecommons.org/licenses/by/4.0/). 
Article

\title{
Microcystin Content in Phytoplankton and in Small Fish from Eutrophic Nyanza Gulf, Lake Victoria, Kenya
}

\author{
Benard Mucholwa Simiyu ${ }^{1,2}$, Steve Omondi Oduor ${ }^{2}$, Thomas Rohrlack ${ }^{3}$, Lewis Sitoki ${ }^{4}$ \\ and Rainer Kurmayer ${ }^{1, *}$ \\ 1 Research Department for Limnology, University of Innsbruck, Mondseestrasse 9, 5310 Mondsee, Austria; \\ bmucholwa@gmail.com \\ 2 Department of Biological Sciences, Egerton University, P.O. Box 536, Egerton 20115, Kenya; \\ soduor@egerton.ac.ke \\ 3 Environmental Sciences, Norwegian University of Life Sciences (NMBU), 1430 As, Norway; \\ thomas.rohrlack@nmbu.no \\ 4 Department of Geosciences and the Environment, The Technical University of Kenya, P.O. Box 52428, \\ Nairobi 00200, Kenya; sitoki@hotmail.com \\ * Correspondence: rainer.kurmayer@uibk.ac.at; Tel.: +43-512-507-50242
}

Received: 23 April 2018; Accepted: 2 July 2018; Published: 3 July 2018

\begin{abstract}
The human health risks posed by exposure to cyanobacterial toxins such as microcystin (MC) through water and fish consumption remain poorly described. During the last two decades, coastal regions of Lake Victoria such as Nyanza Gulf (Kisumu Bay) have shown severe signs of eutrophication with blooms formed by Microcystis producing MC. In this study, the spatial variability in MC concentration in Kisumu Bay was investigated which was mostly caused by Microcystis buoyancy and wind drifting. Small fish $(<6 \mathrm{~cm})$ mainly composed of Rastrineobola argentea were examined for MC content by means of biological methods such as ELISA and protein phosphatase inhibition assay (PPIA) and partly by chemical-analytical methods such as LC-MS/MS. Overall, the MC content in small fish was related to the MC content observed in the seston. When comparing the MC content in the seston in relation to dry weight with the MC content in small fish the latter was found three orders of magnitude decreased. On average, the ELISA-determined MC contents exceeded the PPIA-determined MC contents by a factor of $8.2 \pm 0.5$ (SE) while the MC contents as determined by LC-MS/MS were close to the detection limit. Using PPIA, the MC content varied from 25-109 (mean $62 \pm 7$ ) ng/g fish dry weight in Kisumu Bay vs. $14 \pm 0.8 \mathrm{ng} \mathrm{MC} / \mathrm{g}$ in the more open water of L. Victoria at Rusinga channel. Drying the fish under the sun showed little effect on MC content, although increased humidity might indirectly favor photocatalyzed MC degradation.
\end{abstract}

Keywords: eutrophication; Microcystis; spatial variability; cyanotoxins; ELISA; PPIA; food chain; Rastrineobola argentea

Key Contribution: MC contents were determined in phytoplankton and in small fish consumed as a whole using two independent methods ELISA and PPIA in parallel and were found biodiluted by three orders of magnitude.

\section{Introduction}

Lake Victoria has experienced major deterioration in its water quality mainly due to pollution and the introduction of exotic species [1]. The increased eutrophication is associated with urbanization, agricultural malpractices and deforestation [2]. Nutrients enter the lake from both point sources [1] 
and diffuse sources, including atmospheric deposition [3], which has exerted a considerable impact on the near shore areas $[2,4]$.

Nyanza Gulf is one of the bays of Lake Victoria that is most affected by nutrient enrichment [5] which is coming from the highly populated catchment with mostly subsistence agriculture $[2,6]$. This has led to regular occurrence of bloom-forming cyanobacteria [7]. Some cyanobacterial species have the potential to produce cyanotoxins that pose a health risk to livestock and humans who rely on such water for drinking, sanitation, or as a food source [8]. The regular occurrence of cyanobacterial blooms in the Nyanza Gulf has been associated with fish kills and temporary shutdown of drinking water supply, i.e., from January to March 2004 [9].

The harmful cyanobacteria form surface scums due to a combination of buoyancy in the cells and wind action [10]. The buoyancy is caused by intracellular gas vesicles that decrease the specific density of the cells and is enhanced by cells forming large aggregates known as colonies. The diameter of the colonies can be several millimeters resulting in a rising of the cells up to the calm water surface within minutes [11]. These scums are also accumulated by wind action at the water surface which may result in the accumulation of cyanotoxins several orders of magnitude higher compared with the depth-integrated average concentrations [10]. The most common cyanotoxins are the hepatotoxic microcystins (MC) produced by cyanobacteria such as Microcystis, Dolichospermum (Anabaena), Planktothrix (Oscillatoria) and Nostoc [8]. The toxicity of MC is based on the potent inhibition of the protein phosphatases, PP1 and PP2a, disturbing cytoskeleton formation in eukaryotic cells. The oral $\mathrm{LD}_{50}$ for MC-LR in rats is $5 \mathrm{mg}$ per $\mathrm{kg}$ of body weight that is comparable to the toxicity of cyanide [12]. Chronic MC exposure may promote tumor formation and has been linked to cancer development [13]. The colony-forming cyanobacteria such as Microcystis and Dolichospermum are most frequent in the Lake Victoria region and Microcystis is most frequently occurring in turbid and eutrophic water bodies [14]. It was shown that in Ugandan freshwater systems, the genus Microcystis rather than Dolichospermum or other genera produce MC [15].

$\mathrm{MC}$ is transferred through feeding from the cyanobacteria to zooplankton, fish and other aquatic biota and even to higher trophic levels [16-18]. Phytoplanktivouros fish such as filter-feeding Oreochromis niloticus are exposed to MC by unselective ingestion of toxic cyanobacterial cells [19]. In contrast, zooplanktivorous and carnivorous fish show a more direct feeding mode and could be exposed to cyanotoxins via trophic transfer [20]. On the other hand, even juvenile Oreochromis niloticus and smaller fish feeding more selectively on zooplankton in Murchison Bay, Lake Victoria, were observed to ingest toxic cyanobacteria along with detritus [21]. The occurrence of MC in fish tissue sampled from East African Lakes (including Lake Mburo, Napoleon Gulf and Murchison Bay of L. Victoria) has been demonstrated previously $[19,22,23]$. In order to assess human exposure risk, Poste et al. [23] pointed out the need to consider potential exposure to MC through fish consumption. These authors tested a variety of different fish species differing in feeding modes, including filter feeders, carnivorous feeders and small (juvenile) zooplanktivorous fish species. In contrast to large fish species where dorso-lateral fish muscle tissue was analyzed, the small fish $(<10 \mathrm{~cm})$ were analyzed in total. In this study, [23] the total MC concentrations were estimated by ELISA sometimes exceeding the Total Daily Intake (TDI) guideline $(0.04 \mu \mathrm{g} / \mathrm{kg}$ body weight assuming a consumption of $100 \mathrm{~g}$ of fish daily) several fold [24]. The highest MC concentrations were determined in small (juvenile) zooplanktivorous fish such as Haplochromis spp. and the silver cyprinid Rastrineobola argentea, which could have resulted from the inclusion of toxic cyanobacteria in the gut. Commercial fishing for $R$. argentea started in the 1980s and today is considered the most important fishery by mass in the Lake Victoria region [25]. Small fish such as R. argentea are popular food around Lake Victoria and are marketed locally by women providing a cheap source of animal protein for the undernourished population [26,27]. These small fish are caught during the night using light traps and dried in the sun between 6 and $8 \mathrm{~h}$ the following day. Since the small fish are eaten as a whole, a transfer of MC to humans seems more likely when compared with fish muscle tissue consumption. It is known that MC cannot be degraded by sunlight alone. Indeed, the rate of MC degradation in 
the light depends on several factors such as wavelength (UV), $\mathrm{pH}$ and the presence of pigments or photocatalysts [12]. Because the small fish are dried in the sun for several hours, the exposure to sunlight might enable a breakdown of MC because ingested and lysing cyanobacterial cells in the gut would release photopigments as well. This study aimed to (i) quantify MC content in the locally consumed small fish in relation to the MC concentration in phytoplankton, and (ii) establish whether the processing of fish through drying in the sunlight has an effect on the final MC content in the fish. Fish sampled from inside the eutrophic Nyanza Gulf (ST1) near Kisumu were compared with fish sampled from Rusinga Channel located close to the main basin (ST2), that is less affected by eutrophication and MC contamination [9].

\section{Results}

\subsection{Spatial Variation of Physical-Chemical Parameters}

Over the entire study period, at ST1 (near Kisumu) the lake water was found to be rather turbid with low transparency $(<26 \mathrm{~cm}$ ). In contrast, at ST2 (close to the main basin) higher water transparency was recorded $(85 \mathrm{~cm})$. At ST1 higher conductivity was recorded while temperature and $\mathrm{pH}$ showed no variation between ST1 and ST2 (Table 1). For chlorophyll $a$, relatively low concentrations were recorded from the depth-integrated water samples both at ST1 (10-30 $\mu \mathrm{g} / \mathrm{L})$ and at ST2 in the main basin. Higher concentrations occurred at ST1 at the surface $(19-50 \mu \mathrm{g} / \mathrm{L})$, while maximum concentrations were recorded from the patches $(274-4382 \mu \mathrm{g} / \mathrm{L})$ forming bands possibly formed by Langmuir movements (Supplementary Figure S1). High chlorophyll $a$ concentrations were also observed at the shore $(18-1737 \mu \mathrm{g} / \mathrm{L})$. 


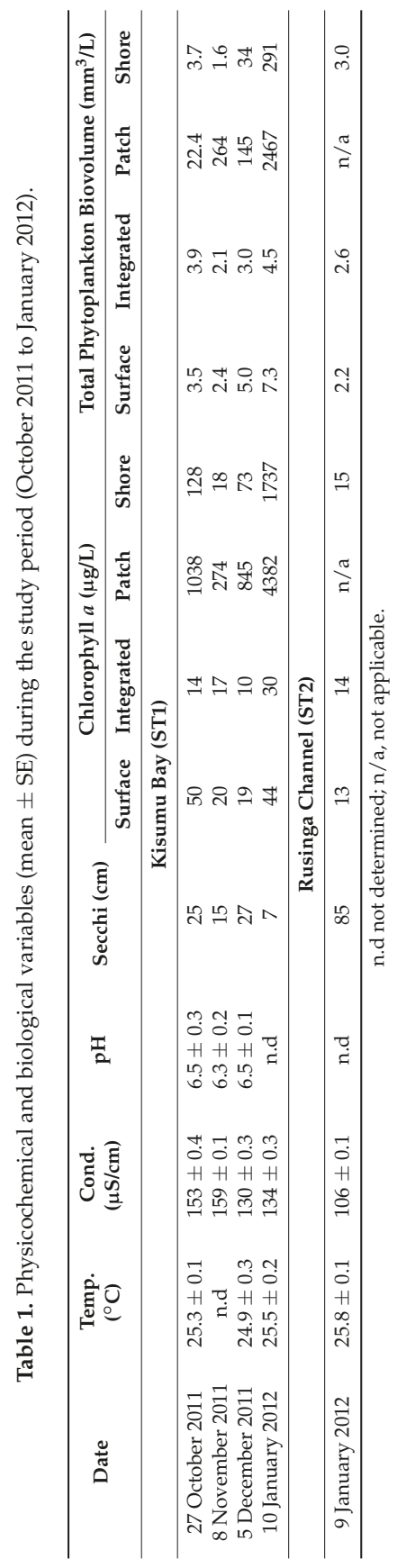




\subsection{Phytoplankton Composition}

Phytoplankton composition was dominated by Cyanobacteria, Bacillariophyceae, Cryptophyceae, and Chlorophyceae; however, all groups occurred with relatively few taxa only. Cyanobacteria were composed mainly of the genera Microcystis, Planktolyngbya and Dolichospermum (Anabaena) at both ST1 and ST2. The Bacillariophyceae, Cryptophytes and Chlorophytes were dominated by Nitzschia, Cryptomonas and Chlamydomonas, respectively (Supplementary Table S1).

The cyanobacteria dominated in all depth-integrated samples at ST1 and ST2. Typically, this dominance was due to the abundance of Microcystis (54 \pm (SE) 10\%) and Planktolyngbya $(20 \pm 8 \%)$. When compared with depth-integrated samples, the proportion of Microcystis increased significantly in patch $(98 \pm 2 \%)$ and shore $(80 \pm 7 \%)$ samples (Repeated Measures ANOVA on Ranks, $p<0.001$, Tukey test for post-hoc pairwise multiple comparison, $p<0.05)$. In contrast, a decrease in proportion of Planktolyngbya in patch $(1 \pm 1 \%)$ and shore $(5 \pm 3 \%)$ samples was found (Repeated Measures ANOVA on Ranks, $p \leq 0.001$, Tukey test $p<0.05$ ). The patch and shore samples also showed maximum phytoplankton biovolume that differed from depth-integrated samples on average by an order of magnitude (Figure 1). In contrast, the changes in phytoplankton composition at the surface of the water column were less visible. The Bacillariophyceae contributed the second most abundant algal class, most importantly by the genus Nitzschia. The proportion of Nitzschia decreased when comparing depth-integrated $(13 \pm 6 \%)$ samples with patch $(1 \pm 1 \%)$ and shore $(2 \pm 1 \%)$ samples (Repeated Measures ANOVA on Ranks, $p=0.002$, Tukey test $p<0.05$ ). In summary, the general dominance of Microcystis in phytoplankton became even more pronounced among patch and shore samples. There was a positive correlation between the two phytoplankton biomass estimates, phytoplankton biovolume and chlorophyll $a$ concentrations $\left(\mathrm{R}^{2}=0.81, p<0.001\right)$, (Supplementary Figure $\mathrm{S} 2$ ).

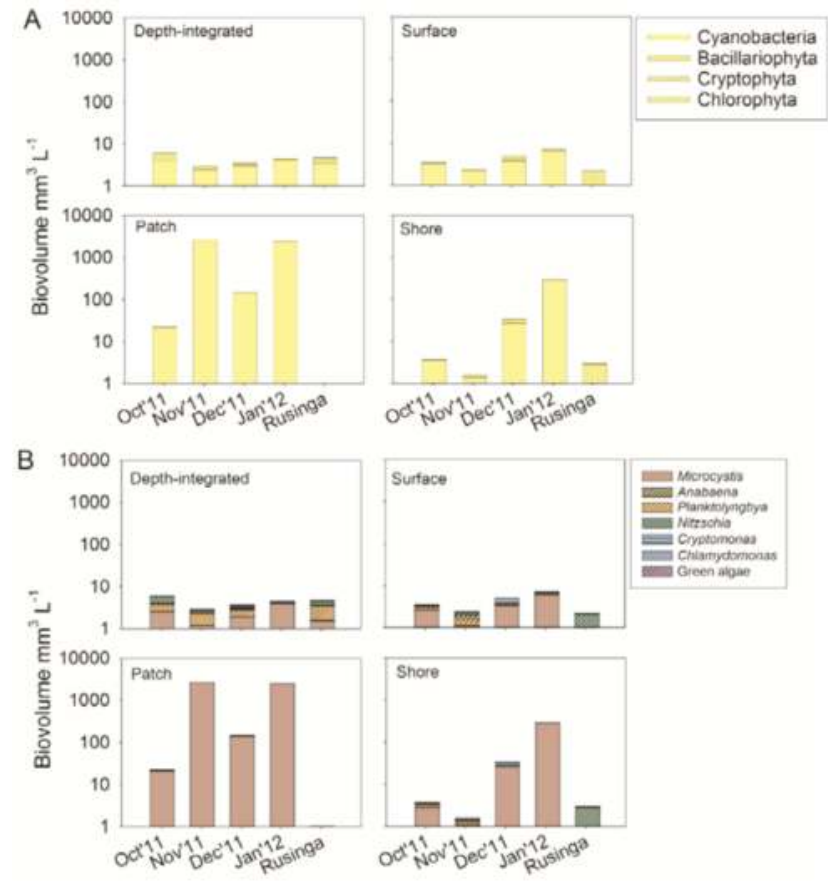

Figure 1. Phytoplankton biovolume composition from different sample types (depth-integrated, surface, patch and shore) in Nyanza Gulf and Rusinga Channel during October 2011 to January 2012. (A) phytoplankton groups (relative proportion $>5 \%$ ), (B) phytoplankton genera (relative proportion $>5 \%$ ). 


\subsection{Microcystin Concentrations in Water}

MC was detected in all water sample types collected from Kisumu Bay $(n=20)$ but not in any samples from Rusinga channel. Four MC structural variants occurred: MC-YR $(\mathrm{m} / z=1045$ with retention time of $17 \mathrm{~min}), \mathrm{MC}-\mathrm{LR}(\mathrm{m} / \mathrm{z}=995,18 \mathrm{~min})$ and two unknown MC variants eluting at $24 \mathrm{~min}(\mathrm{~m} / z=1052)$ and $25 \mathrm{~min}(\mathrm{~m} / z=1002)$, respectively. On average, MC-YR and MC-LR and MC m/z 1052 accounted for the major part of the total MC (Table 2). The proportion of MC-YR was significantly higher and that of MC m/z 1052 was lower in patch samples when compared with depth-integrated samples.

Table 2. Average ( $\pm \mathrm{SE}$ ) proportion of microcystin structural variants and microcystin concentrations (in MC-LR equiv.) recorded at Kisumu Bay from various sample types $(n=4)$.

\begin{tabular}{|c|c|c|c|c|c|c|}
\hline Structural Variant & Retention (min) & Surface & Integrated & Patch & Shore & $p$-Value ${ }^{1}$ \\
\hline \multicolumn{7}{|c|}{ Proportion } \\
\hline MC-YR & $17.06-17.26$ & $40 \pm 5^{a, b}$ & $26 \pm 6^{b}$ & $45 \pm 2^{a}$ & $33 \pm 4^{\mathrm{a}, \mathrm{b}}$ & 0.015 \\
\hline MC-LR & $18.34-18.52$ & $28 \pm 4$ & $18 \pm 4$ & $29 \pm 2$ & $26 \pm 4$ & 0.136 \\
\hline MC m/z 1052 & $23.95-24.16$ & $25 \pm 9$ & $51 \pm 12$ & $16 \pm 1$ & $31 \pm 9$ & 0.05 \\
\hline $\mathrm{MC} m / z 1002$ & $25.0-25.07$ & $7 \pm 3$ & $6 \pm 2$ & $11 \pm 2$ & $9 \pm 2$ & 0.463 \\
\hline \multicolumn{7}{|c|}{ Concentration $(\mu \mathrm{g} / \mathrm{L})$} \\
\hline MC-YR & $17.06-17.26$ & $0.6 \pm 0.4^{\mathrm{a}, \mathrm{b}}$ & $0.5 \pm 0.1^{\mathrm{b}}$ & $343 \pm 186^{\mathrm{a}}$ & $29 \pm 17^{a, b}$ & $<0.001$ \\
\hline MC-LR & $18.34-18.52$ & $1.3 \pm 0.3^{b}$ & $0.4 \pm 0.1^{\mathrm{b}}$ & $210 \pm 102^{a}$ & $22 \pm 12^{a, b}$ & $<0.001$ \\
\hline MC $m / z 1052$ & $23.95-24.16$ & $1.4 \pm 0.6^{b}$ & $1.2 \pm 0.3^{b}$ & $160 \pm 94^{a}$ & $17 \pm 9^{a, b}$ & $<0.001$ \\
\hline MC $m / z 1002$ & $25.0-25.07$ & $0.6 \pm 0.5^{b}$ & $0.2 \pm 0.04^{b}$ & $111 \pm 60^{a}$ & $9 \pm 5^{a, b}$ & $<0.001$ \\
\hline
\end{tabular}

\footnotetext{
${ }^{1}$ Friedman Repeated Measures ANOVA on Ranks (Superscripts indicate homogeneous subsets not significantly
} different at $p=0.05$ according to Tukey-test post-hoc pairwise comparison).

The highest total MC concentrations were recorded in patch samples with maximum concentrations exceeding $2 \mathrm{mg} / \mathrm{L}$ of MC-LR equiv. (Figure 2) as recorded in November 2011. MC concentrations also increased in shore water samples exceeding $100 \mu \mathrm{g} / \mathrm{L}$ in January 2012. In contrast, total MC concentrations from depth-integrated and surface samples were below $10 \mu \mathrm{g} / \mathrm{L}$. In general, the dissolved MC showed low concentrations only $(<3.3 \mu \mathrm{g} / \mathrm{L})$. On average, the patch samples had five times higher MC concentration than the depth-integrated sample, while the shore samples had MC concentrations twice that of the depth-integrated sample. For the cell-bound fractions, the MC concentrations were 387, 28 and 2 times higher in the patch, shore and surface water samples respectively when compared with the depth-integrated sample. The total MC concentrations were significantly related to Microcystis cell numbers $\left(n=19, \mathrm{R}^{2}=0.71, p<0.0001\right)$ but not to any other abundant cyanobacteria (i.e., Planktolyngbya, Anabaena) (Supplementary Figure S3). This suggests that other genera than Microcystis potentially producing MC were not important during the study period. Average cellular MC contents varied from 2-250 fg (mean \pm SE, $49 \pm 9$ ) MC per Microcystis cell, and did not differ between sample types (Repeated Measures ANOVA on Ranks, $p=0.139$ ). On a dry weight (DW) basis the average cellular MC content varied from 247 and $261 \mu \mathrm{g}$ MC/g DW in depth-integrated and surface samples to $495 \mu \mathrm{g} \mathrm{MC} / \mathrm{g}$ DW in patch and shore samples but did not differ between sample types (Repeated Measures ANOVA on Ranks, $p=0.65$ ). Surprisingly, intracellular MC and dissolved $\mathrm{MC}$ concentrations were not related. For example, the highest intracellular MC concentrations in patch samples had only $0.4-3 \mu \mathrm{g} / \mathrm{L}$ of dissolved MC. This discrepancy might be explained by high turbulence induced by wind action leading to a constant dilution of dissolved MC that, however, was overcome by the buoyant Microcystis colonies forming the patches. 

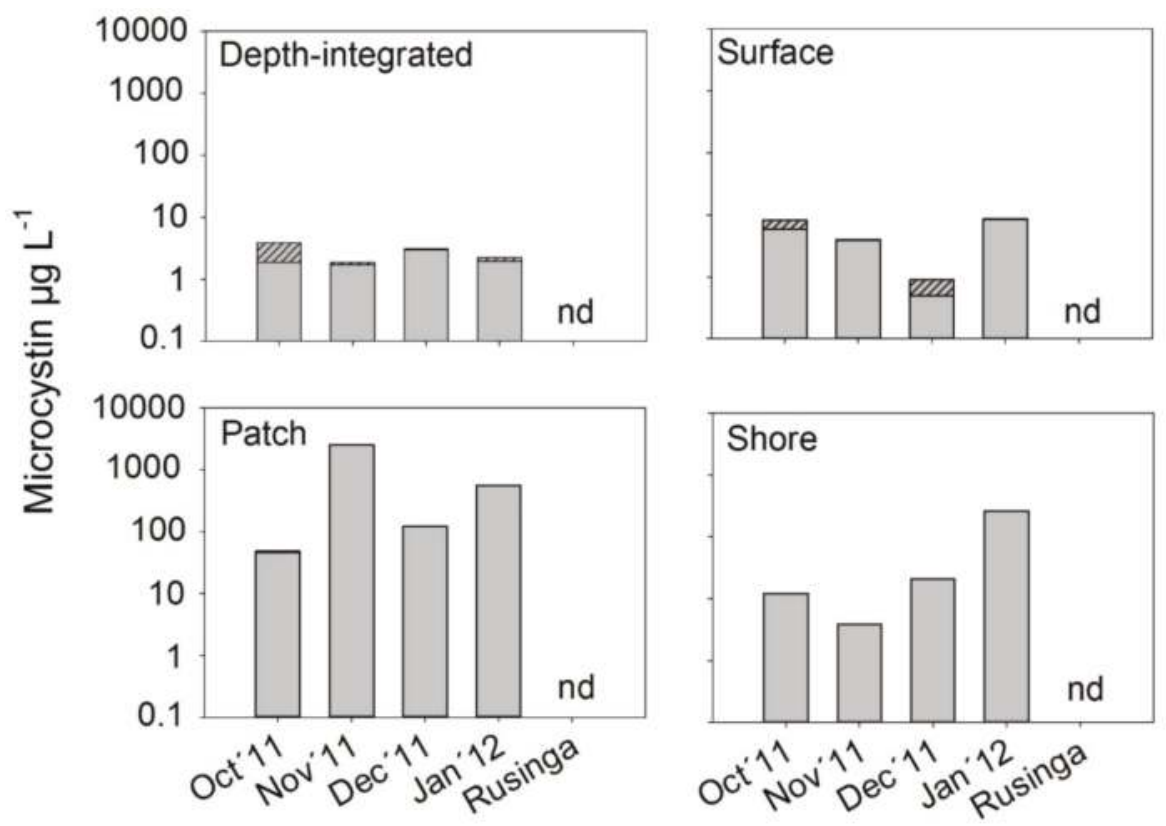

Figure 2. Intracellular microcystin concentrations (in MC-LR equivalents) as determined by HPLC-DAD and dissolved MC concentrations as determined by ELISA from different sample types in Nyanza Gulf and Rusinga Channel during October 2011 to January 2012. (n.d, not detected).

\subsection{Small Fish Species Composition}

The following small fish species were identified in Kisumu Bay (ST1): Barbus sp., Haplochromis sp., Lates niloticus and R. argentea. All samples were dominated by R. argentea both in terms of individual numbers (>55\%) and in terms of fresh weight ( $>51 \%)$, (Table 3). In Rusinga channel (ST2) only three fish species were identified (R. argentea, L. niloticus and Barbus sp.) and R. argentea showed the maximum proportion (95\%).

During the study period, the average fresh weight of individual Barbus sp. was highest (mean $\pm \mathrm{SE}, 1.0 \mathrm{~g} \pm 0.07$ ), while it was $0.6 \mathrm{~g} \pm 0.02$ for $R$. argentea, $0.6 \mathrm{~g} \pm 0.07$ for L. niloticus and $0.6 \mathrm{~g} \pm 0.2$ for Haplochromis sp. In the Rusinga channel, ST2 individuals of L. niloticus were heavier $(1.8 \mathrm{~g} \pm 0.2)$, while $R$. argentea was on average lighter $(0.5 \mathrm{~g} \pm 0.02)$.

In Kisumu Bay, Barbus sp. had the highest total length $(47 \pm 1.3 \mathrm{~mm})$ while $R$. argentea $(39 \pm 0.6 \mathrm{~mm})$, L. niloticus $(35 \pm 1 \mathrm{~mm})$ and Haplochromis sp. $(32 \pm 3 \mathrm{~mm})$ were on average smaller. In Rusinga, L. niloticus was longer $(58 \pm 2 \mathrm{~mm})$, while R. argentea $(40 \pm 0.5 \mathrm{~mm})$ did not show a difference in length. As prey size selection depends to a significant extent on fish size, it is concluded from the observed length distribution that the sampled fish were mostly feeding on plankton.

\subsection{Microcystin Content in Small Fish as Determined by Biological and Chemical-Analytical Methods}

MC occurred in fish samples obtained from Kisumu Bay (ST1) and Rusinga channel (ST2), as revealed by both biological methods, ELISA and PPIA. The MC contents ranged from 0-990 
and 11-109 ng MC/g DW for ELISA and PPIA, respectively. Altogether the MC contents as determined in fish by ELISA were linearly related to the MC contents as determined by PPIA: $y=82.2+5.2 x$, where $\mathrm{y}$ is $\mathrm{MC}$ in $\mathrm{ng} / \mathrm{g}$ DW as determined by ELISA and $\mathrm{x}$ is MC in $\mathrm{ng} / \mathrm{g}$ DW as determined by PPIA $\left(\mathrm{R}^{2}=0.29, p<0.0001\right)$. On average, the ELISA-determined MC contents showed a higher variability and exceeded the PPIA-determined MC contents by a factor of $8.2 \pm 0.5$ (Figure 3 ).

All samples obtained from December 2011 were additionally tested for MC content using chemical-analytical methods such as LC-MS/MS $(n=16)$. In four samples, MC-YR was detected ranging from 8-20 ng MC/g DW while the other MC variants were not observed. It is concluded that MC-YR indeed specifically occurred in small fish. However, compared with water samples (i.e., $\mu \mathrm{g}$ of MC per $\mathrm{g}$ DW of plankton biomass as determined by HPLC) the concentration of MC-YR in small fish tissue was found to be very low (i.e., ng of MC per g DW of fish biomass as determined by LC-MS/MS).

Table 3. Number (proportion) of individuals assigned to small fish species sampled in Nyanza Gulf (ST1) during October 2011-January 2012 and in Rusinga channel (ST2) in January 2012, as well as average \pm SE (min-max) fresh weight and total length.

\begin{tabular}{ccccc}
\hline & Barbus sp. & Haplochromis sp. & L. niloticus & R. argentea \\
\hline \multicolumn{5}{c}{ Number (Proportion) } \\
\hline ST1, October 2011 & $26(33)$ & $2(2.6)$ & $6(7.8)$ & $43(55.5)$ \\
ST1, November 2011 & $17(10)$ & $2(2.2)$ & $51(30.5)$ & $97(58)$ \\
ST1, December 2011 & $3(2.5)$ & 0 & $44(37.3)$ & $71(60.2)$ \\
ST1, January 2012 & $19(13)$ & 0 & $18(12.6)$ & $106(74.1)$ \\
ST2, January 2012 & $1(0.1)$ & 0 & $6(4.2)$ & $137(95.1)$ \\
\hline & \multicolumn{5}{c}{ Fresh weight (g) } & $0.5 \pm 0.1(0.3-1.7)$ \\
ST1, October 2011 & $1.2 \pm 0.1(0.1-2.6)$ & $(0.3-0.4)$ & $0.7 \pm 0.3(0.2-1.9)$ & $0.6 \pm 0.1(0.1-1.6)$ \\
ST1, November 2011 & $1 \pm 0.1(0.4-2.4)$ & $(0.5-1.2)$ & $0.8 \pm 0.1(0.2-4.2)$ & $0.6 \pm 0(0.1-1.2)$ \\
ST1, December 2011 & $1.4 \pm 0.3(1.1-2)$ & - & $0.6 \pm 0.1(0.1-4.6)$ & $0.5 \pm 0(0.1-1.3)$ \\
ST1, January 2012 & $0.7 \pm 0.1(0.3-1.9)$ & - & $0.3 \pm 0.0(0.1-0.7)$ & $0.5 \pm 0(0.1-1.5)$ \\
ST2, January 2012 & 1.2 & - & $1.8 \pm 0.2(1.3-2.3)$ & \\
\hline & & & $35 \pm 5(21-53)$ & $44 \pm 1(30-56)$ \\
ST1, October 2011 & $47 \pm 3(19-64)$ & $(26-30)$ & $37 \pm 2(12-70)$ & $36 \pm 2(10-58)$ \\
ST1, November 2011 & $48 \pm 2(38-65)$ & $(31-40)$ & $34 \pm 2(17-70)$ & $44 \pm 1(20-56)$ \\
ST1, December 2011 & $56 \pm 4(51-63)$ & - & $30 \pm 3(17-62)$ & $36 \pm 1(4-60)$ \\
ST1, January 2012 & $40 \pm 2(29-60)$ & - & $58 \pm 2(50-61)$ & $40 \pm 1(27-56)$ \\
ST2, January 2012 & 56 & - &
\end{tabular}

\subsection{Microcystin Content in Small Fish in Relation to MC in Phytoplankton}

Over the study period, fish samples originating from Kisumu Bay (ST1) had a higher MC content when compared with fish samples obtained from Rusinga channel (ST2), i.e., MC contents ranged from $190 \pm 51$ to $543 \pm 26 \mathrm{ng} \mathrm{MC/g} \mathrm{DW} \mathrm{in} \mathrm{Kisumu} \mathrm{Bay} \mathrm{vs.} 56 \pm 56 \mathrm{ng} \mathrm{MC} / \mathrm{g}$ DW in Rusinga channel as determined by ELISA (Repeated Measures ANOVA on Ranks, $p=0.034$, Tukey test $p<0.05)$. Analogously, MC content varied from $43 \pm 10$ to $95 \pm 14 \mathrm{ng} \mathrm{MC} / \mathrm{g}$ DW in Kisumu Bay vs. $14 \pm 0.8 \mathrm{ng} \mathrm{MC} / \mathrm{g}$ DW in Rusinga channel as determined by PPIA (Repeated Measures ANOVA on Ranks, $p=0.107$ ), (Figure 4). Thus the MC content in fish was related to the MC content in the seston, i.e., higher MC contents in fish from Kisumu Bay vs. lower MC contents in fish sampled from more open water at Rusinga channel. Using both biological methods the MC content in fish was found decreased by a factor of $10^{3}$ implying significant biodilution rather than biomagnification through the food chain. 


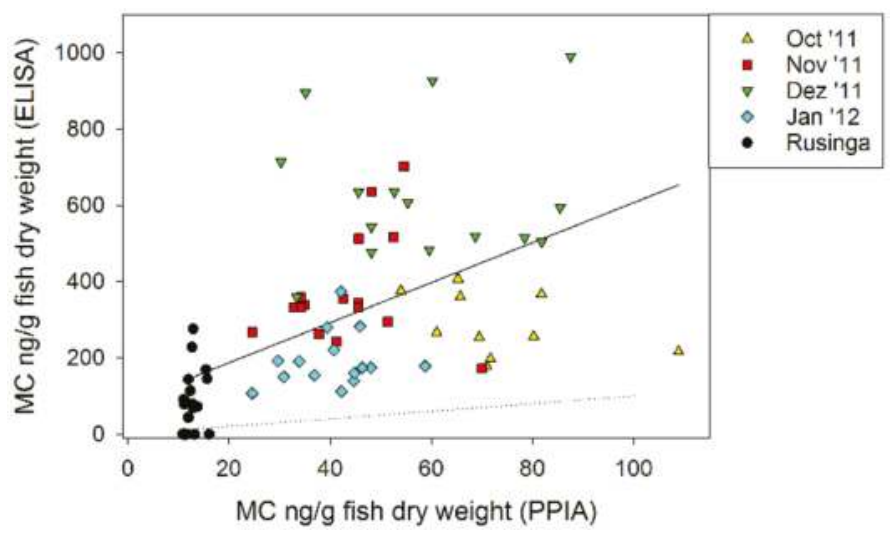

Figure 3. Correlation of microcystin contents in small fish (ng/g in dry weight) as determined by ELISA vs. microcystin contents as determined by the PPIA $\left(\mathrm{R}^{2}=0.29, p<0.0001\right)$. The PPIA results were on average 8.2 $( \pm 0.5)$-fold lower than those obtained by ELISA. The one-to-one relationship is indicated by the dotted line.

In order to find out whether the air-drying time influenced the MC content in small fish, the proportion of $\mathrm{MC}$ content in relation to $\mathrm{t}_{0}$ was calculated. There was no clear trend in $\mathrm{MC}$ content in relation to $\mathrm{MC}$ content at $\mathrm{t}_{0}$ for all sampling dates as inferred from the ELISA. However, there was a decrease in MC content as determined from PPIA in relation to $t_{0}$ with an increase in exposure time (2-8 h) in October and December samples (Figure 5). During the December experiment, the average MC content $77 \pm 5 \mathrm{ng} \mathrm{MC} / \mathrm{g}$ DW significantly decreased down to $36 \pm 5 \mathrm{ng} \mathrm{MC} / \mathrm{g}$ DW (Repeated Measures ANOVA on Ranks, $p<0.027$ ). During October, the average MC content $95 \pm 14 \mathrm{ng} \mathrm{MC} / \mathrm{g}$ DW also decreased down to $69 \pm 6 \mathrm{ng}$ MC/g DW (Repeated Measures ANOVA on Ranks, $p=0.147$ ). The recording of meteorological data at Kisumu Airport showed relatively low variability in daily temperature $\left(22.7-25^{\circ} \mathrm{C}\right)$ and irradiance $\left(866-1387 \mu \mathrm{mol}\right.$ photons. $\mathrm{m}^{-2} \cdot \mathrm{s}^{-1}$, Supplementary Table S2). In contrast, the relative humidity varied and showed maxima of $80 \%$ in October and December while it was lower in November (35\%) and in January 2012 (62-66\%), (Supplementary Table S2). In summary, the MC content in small fish showed a relatively high stability during the drying process and the overall relation to MC content in seston was not changed.

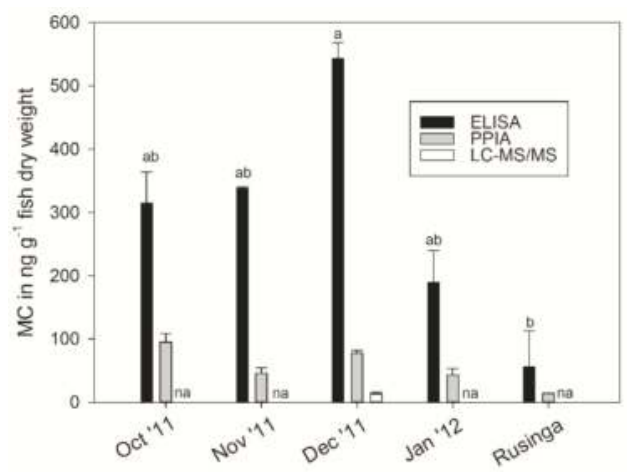

Figure 4. Mean ( \pm SE) microcystin contents in small fish (in ng/g dry weight) as determined by ELISA and PPIA and LC-MS/MS originating from Kisumu Bay in Nyanza Gulf and Rusinga Channel during October 2011 to January 2012 (n.a, not analyzed). Letters indicate subgroups not significantly different at $p<0.05$ if an overall difference was found (Friedman Repeated Measures ANOVA on Ranks). 


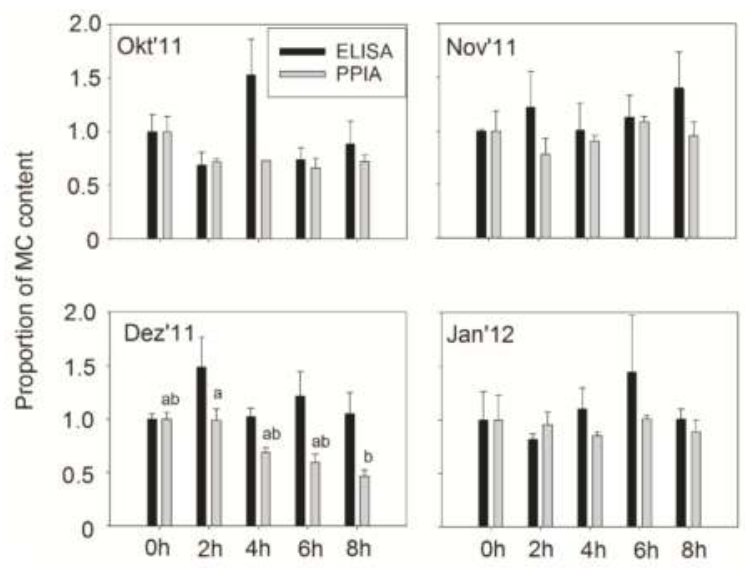

Figure 5. Mean $( \pm \mathrm{SE})$ proportion of microcystin contents in small fish after $0-8 \mathrm{~h}$ of sun drying. Letters indicate subgroups not significantly different at $p<0.05$ if an overall difference was found (Friedman Repeated Measures ANOVA on Ranks).

\section{Discussion}

\subsection{Eutrophication and Spatial Variability of Phytoplankton Composition}

The Nyanza Gulf is a semi-closed bay, therefore, it has a limited exchange of water with the main basin which is related to increased turbidity due to high algal biomass [28,29]. In other bays of Lake Victoria and open waters such as the Rusinga channel, there is dilution because of water exchange with the main basin, which can explain the lower phytoplankton biovolume [4]. Besides algal growth, the suspended solids from three river inflows in this area (Sondu, Kisat and Nyamasaria) also further increase the turbidity, i.e., satellite images show sediment-laden inflow waters during the rainy seasons [29]. The high turbidity reduces light availability and selectively favors specialized algal species such as Microcystis capable of remaining near the water surface through the presence of gas vesicles [30]. Particularly in shallow aquatic ecosystems, buoyant cyanobacteria of the genus Microcystis are favored by both eutrophication and turbidity and have been found to be dominant in freshwater ecosystems which are naturally eutrophic (such as Lake George in Uganda) [14]. The larger size of the buoyant colonies not only enables pronounced vertical migration but also accumulation within Langmuir circulation where positively buoyant particles will accumulate above the downwelling region [31]. In contrast, nonbuoyant phytoplankton such as cyanobacteria Planktolyngbya and diatoms of the genus Nitzschia were unaffected when compared with depth-integrated samples and thus reduced in proportion. For another large lake, Lake Biwa in Japan, Ishikawa et al. [31] further described large circular horizontal currents that accumulate Microcystis in the center transporting Microcystis from inshore to offshore areas. Indeed, for the eastern part of the Nyanza Gulf a large circular current has been described which contributes to the strong horizontal gradient in salinity from the eastern part to the western part towards the main basin [29]. The larger scale hydrodynamic forces may help in supporting the more stable formation of Langmuir circulations which depend on moderate wind speed and the presence of wind waves [31]. In general, the pronounced physico-chemical gradient from the eastern part to the western part of Nyanza Gulf has been increased by reducing the hydrological connectivity to the main basin [31]. Most importantly, a causeway was constructed to link Rusinga island with the main land in 1983, which reduced the water exchange with the main basin [32]. However, in May 2017, the Mbita channel was re-opened to reconnect Nyanza Gulf with the main Lake Victoria besides Rusinga channel. This opening (now called Mbita channel) with a width 
of $150 \mathrm{~m}$ is supposed to increase ecological and hydrological connectivity and might also reduce the internal physical stability of the eastern part of Nyanza Gulf.

\subsection{Spatial Variability of Microcystin Concentration in Water}

Spatial and temporal variability in MC concentration has been described along the shoreline of wind-exposed systems worldwide and has been considered as an important variable in estimating health risks through exposure to toxic algal blooms. While maximum MC concentrations are typically observed along the shore [10], in this study, maximum MC concentrations occurred within the patches drifting at the surface in Kisumu Bay (Supplementary Figure S1). The positive correlation between MC concentration and Microcystis cell numbers showed that Microcystis sp. was the major MC producer while the contribution of other cyanobacteria species was of minor importance. This is in agreement with earlier results from Uganda and Nyanza Gulf, respectively $[9,15]$. Thus the lack of detectable MC in all sample types obtained from Rusinga channel can be best explained by the general lowest numbers of Microcystis ( $<100$ cells $/ \mathrm{mL}$ ). In contrast, in the eutrophic Nyanza Gulf, the selective entrainment of Microcystis in the Langmuir circuits as described above increased the horizontal patchiness in MC concentration considerably. When compared with depth-integrated samples, the proportions of the more abundant MC structural variants changed, i.e., the proportion of MC-YR increased and the unknown MC m/z 1052 variant decreased (Table 2). This change in MC-variant proportion might imply a change in genotype composition of Microcystis sp., for example, through favoring the large sized colonies such as M. aeruginosa vs. other morphospecies that occur as smaller sized colonies [33]. The genus Microcystis shows impressive variability of cell numbers per colony ranging from a few cells to $>10^{5}$ cells, which can be explained in part by the variable cationic chemical composition of the mucilage embedding the cells [34]. Notably, the large sized Microcystis colonies frequently show maximum MC contents while smaller sized Microcystis colonies typically show the lowest MC contents, i.e., as reported from Wannsee in northern Germany [33], from northern Missouri and Iowa in North America [35] and Lake Taihu in China [36]. Thus, the rather high MC concentrations observed in this study within the patches may be further increased by selective enrichment of large sized buoyant Microcystis colonies.

\subsection{Microcystin Content in Small Fish as Determined by Biological and Chemical-Analytical Methods}

The extraction and detection of MC from complex matrices such as fish tissue is an important question and both free and covalently-bound MC need to be distinguished [37]. Methods measuring free MC may underestimate the total MC content because of covalent binding of the Methyl-dehydro-alanine (Mdha) residue in pos. 7 of the MC molecule to the active site of PP or other cysteine-containing peptides such as glutathione. These covalently bound MC can be released by oxidation through the so-called Lemieux technique resulting in an oxidative derivative of the Adda side chain as 2-methyl-3-methoxy-4-phenylbutyric acid (MMPB) which is measured by LC-MS/MS [38]. It is under question whether the covalently bound $\mathrm{MC}$ is toxicologically active, i.e., through slow release by digestive enzymes during gut passage [39]. The proportion of covalently-bound $\mathrm{MC}$ in fish tissue can be substantial [20] (and references therein) and ELISA has been shown to be able to detect the cysteine-MC and the glutathione conjugates. Thus, it is not surprising that MC concentrations as estimated by ELISA were highest also in this study because of its crossreactivity with both detoxification and PP conjugates.

In contrast to ELISA, the PPIA measures the effect of inhibitors such as MC on the activity of PP monitored through enzymatic release of a chromogenic substrate. Thus the PPIA quantifies the toxicity of a sample and yields toxicity equivalents. ELISA is based on structural recognition of MC molecules and is designed to yield toxin concentrations in MC-LR equivalents. As other natural products of cyanobacteria (e.g., anabaenopeptins, okadaic acid) also inhibit PP and MC structural variants differ in activity, the results obtained by the two biological methods cannot be directly compared. However, in general, PPIA is expected to target the free MC.

On the other hand, chemical-analytical techniques such as LC-MS/MS are known to be highly specific with high resolution and are able to detect known MC molecule parent and fragment ions 
even in complex sample matrices [8]. However, because of the high target molecule specificity, covalently-bound MC also is likely overlooked. This target molecule specificity is less relevant in LC-DAD (UV based) methods, however, the latter are generally less sensitive and suffering from sample matrix effects [8]. In summary, it is rather the combination of biological and chemical-analytical methods that is used to evaluate the exposure risk through small fish consumption. In this study the occurrence of MC-YR in fish sample extracts was unambiguously identified while the MC contents estimated by ELISA might imply a significant share of bound MC through various catabolic processes. Since the actual toxicity is most directly addressed by the PPIA, in this study the PPIA-derived estimates have been used to estimate the exposure risk.

\subsection{Microcystin Content in Small Fish}

The MC contents, as determined by ELISA in this study (190 \pm 51 to $543 \pm 26 \mathrm{ng} \mathrm{MC} / \mathrm{g} \mathrm{DW}$ ), were in the range of MC contents reported previously by Poste et al. [23,40]. For example, $R$. argentea and Haplochromis sp. species sampled from Murchison Bay and Napoleon Gulf contained 36-41 and 39-129 $\mu \mathrm{g} / \mathrm{kg}$ wet weight that would translate into 360-1290 $\mathrm{\mu g} / \mathrm{kg}$ DW (assuming dry weight to be $10 \%$ of wet weight). The MC contents derived by ELISA were quantitatively supported by PPIA, i.e., small fish sampled from Rusinga channel contained significantly less MC as observed by both methods (Figures 3 and 4). The general experience is that active MC have a proportion which is one order of magnitude lower when compared with the total extractable MC [20]. Indeed, in this study MC contents in small fish, as estimated by PPIA, were on average eight-fold lower when compared with ELISA-derived estimates. The World Health Organization (WHO) recommended the tolerable daily intake (TDI) for MC over the lifetime of a human being to be $0.04 \mu \mathrm{g}$ MC-LR equivalents per $\mathrm{kg}$ of body weight per day [24]. Using this guideline, the tolerable dose of MC-LR is calculated assuming a consumption of $100 \mathrm{~g}$ (wet weight) of fish per day. In this study, the PPIA-derived estimate would translate to 246-519 \pm 24-1089 ng of MC-LR equiv. (min-mean \pm SE-max) consumed from small fish in Kisumu bay per day, which would be below the theoretical tolerable intake for an adult ( $2.4 \mu \mathrm{g}$ for a $60 \mathrm{~kg}$ adult).

When compared with muscle tissue, the higher MC contents can be explained by the inclusion of the viscera containing Microcystis colonies in the analyzed sample [20]. As small fish have been found to contain a significant amount of Microcystis in their diet (e.g., 80\% of phytoplankton), this diet-based vector is considered a relevant one [21]. The surprisingly high proportion of phytoplankton (Microcystis sp.) in the diet of zooplanktivorous fish may be linked to the general high turbidity in the Gulf system but also has been reported from other systems (e.g., in Rwanda [41]). Currently, the diet composition and the possible relation to MC content in small fish along the eutrophication gradient in Nyanza Gulf is not known but should be explored further. The feeding behavior of small fish and a possible avoidance of the observed patches with Microcystis dominance and maximum MC concentrations would also be a research route. On the other hand, the lysed cyanobacteria in the gut actually release not only the MC but also photopigments such as phycobilins known to act as photo sensitizers accelerating the photolysis of MC [42]. Thus, exposure of the small fish containing phytoplankton in the diet in the sunlight actually might result in reduced MC contents. In this study, such significant reduction in MC content was only observed at relatively high humidity conditions (Figure 5, Supplementary Table S2). This result would imply that an accelerated drying process actually would reduce the photolysis potential because photocatalyzed degradation is occurring in the aquatic solution [43]. Nevertheless, the photolysis-induced MC degradation would be a relatively simple measure to reduce the $\mathrm{MC}$ content in the small fish, for example, by maintaining the humidity of the fish biomass during a certain time of sun exposure.

\section{Conclusions}

The eutrophication of the eastern part of Nyanza Gulf has led to high concentrations of MCs, which is mainly caused by the dominance of the bloom-forming cyanobacterium of the 
genus Microcystis. The buoyant Microcystis colonies accumulated in the patches through advective currents possibly formed by Langmuir circulations linked to maximum MC concentrations in the patches. In consequence, MC contents have been observed in small planktivorous fish species such as $R$. argentea. Although active MC in small fish was detected regularly, the theoretical lifetime tolerable daily intake for adults was not exceeded. The fish drying process in the sun did not consistently reduce the $\mathrm{MC}$ content in the fish which might be explained by the variable relative humidity. However, since photocatalyzed degradation of MC in the sunlight is a fast process, exposing the fish in wet conditions to the sun for a short time period might be a possibility to reduce MC content in food.

\section{Materials and Methods}

\subsection{Study Area and Sampling}

Nyanza Gulf is located in the North-Eastern part of L. Victoria and is connected to the main basin via the Rusinga channel. Besides Mwanza Gulf (Tanzania) and Napoleon Gulf (Uganda), Nyanza Gulf is one of the largest bays of Lake Victoria with an area of $1400 \mathrm{~km}^{2}$. With an average depth of $5 \mathrm{~m}$, it is relatively shallow in comparison with the main basin [28]. Samples were collected monthly (from October 2011 to January 2012) at one sampling station in

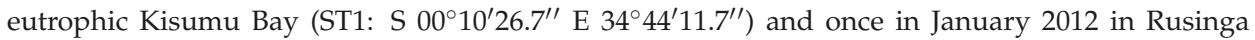
Channel (ST2: S $00^{\circ} 22^{\prime} 46.2^{\prime \prime}$ E $34^{\circ} 11^{\prime} 15.0^{\prime \prime}$ ), (Figure 6). Water temperature, dissolved oxygen, $\mathrm{pH}$ and conductivity were determined at 1-m depth using a multiprobe (Hach-Lange, Düsseldorf, Germany).

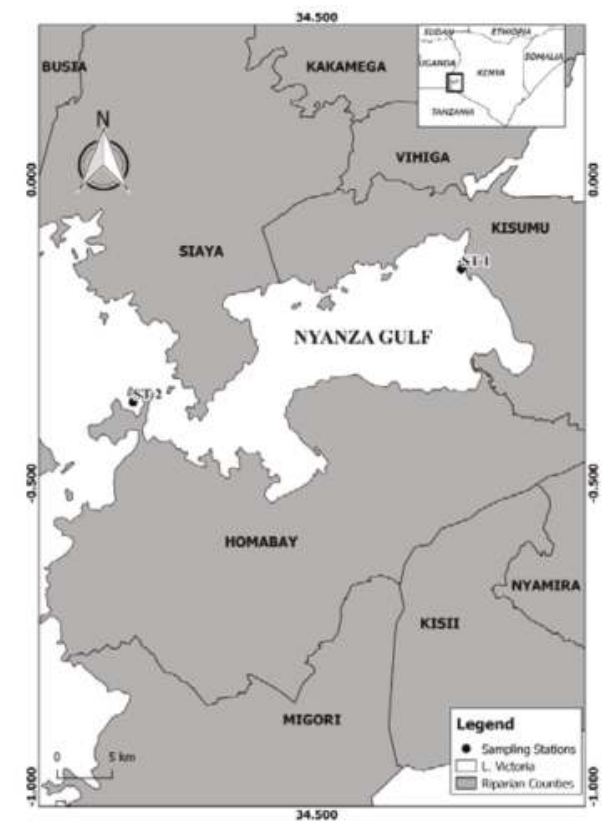

Figure 6. Map of Lake Victoria, Kenyan side, showing Nyanza Gulf and the two sampling stations (ST1, Kisumu Bay and ST2, Rusinga Channel).

Depth-integrated water samples were obtained by mixing 1 liter collected from every meter through the water column down to $3 \mathrm{~m}$ depth using a Van Dorn sampler. Surface samples were taken from scums visible as patches possibly formed by Langmuir spirals ("patch" samples) or at the 
shore ("shore" samples). Water samples were filtered using Whatman GF/C filters. For chlorophyll $a$ analysis, the filters were stored frozen and processed the following day. For cell bound MC analysis, filters were dried overnight $\left(50{ }^{\circ} \mathrm{C}\right)$ and stored frozen. The filtrate was used for determination of dissolved MC in water using ELISA.

\subsection{Phytoplankton Composition and Abundance}

Chlorophyll $a$ was extracted using hot ethanol [44]. Phytoplankton composition was determined from $2 \mathrm{~mL}$ of Lugol-fixed samples using an inverted microscope at $400 \times$ magnification [45]. Phytoplankton taxa were identified from morphological characteristics according to Talling, Komàrek and Kling, Cronberg and Anadotter [46-48]. In general, phytoplankton specimen were counted as distinct cells (Microcystis sp., Anabaena (Dolichospermum) sp., Merismopedia sp.; or the pennate diatom Nitzschia sp.). Filamentous cyanobacteria were counted as filaments (Planktolyngbya sp.). In order to determine phytoplankton biovolume of individual taxa the biovolume was determined by geometric approximation [45]. To quantify Microcystis cells the colonies were disintegrated into single cells using sonication for $10 \mathrm{~s}$ (output 40 watt) by a sonicator (Heat Systems-Ultrasonics, Inc., Plainview, NY, USA, 11,803) [49]. Pilot experiments revealed that maximum Microcystis cell numbers were obtained after 10 sonication treatments (in $10 \mathrm{~mL}$ volume).

\subsection{Microcystin Determination in Water}

The dissolved $\mathrm{MC}$ in water was determined directly in the filtrate using indirect competitive ELISA (Abraxis LLC, Warminster, PA, USA, Microcystins-ADDA ELISA kit, PN 520011) according to the manufacturer's instructions and reading absorbance was calibrated though the provided MC-LR standards at $450 \mathrm{~nm}$ wavelength. The ELISA has a limit of detection of $0.1 \mathrm{ng} / \mathrm{mL}(0.1 \mu \mathrm{g} / \mathrm{L})$. For the cell-bound fraction of $\mathrm{MC}$, cells were collected on filters and biomass was extracted in aqueous methanol $(75 \%, w / v)$ according to Fastner et al. [50]. MC structural variants were chromatographically separated using High performance liquid chromatography with diode array detection (HPLC-DAD) as described [33]. MC variants were identified by their characteristic absorption spectra and retention times [15] and quantified at $240 \mathrm{~nm}$ wavelength. Using MC-LR as the external standard, the concentration of MC-LR equivalents was calculated from the regression curve $y=1885.3 x-6.8775$, $\left(\mathrm{R}^{2}=0.99\right)$, where $(\mathrm{y})$ was the absorption (mAU) recorded at $240 \mathrm{~nm}$ and $\mathrm{x}$ represented the injected concentration (ng) of MC-LR standard (CyanoBiotech GmbH, Berlin, Germany). Under the specified conditions, $50 \mathrm{ng}$ of MC-LR equivalents injected could be resolved resulting in a theoretical limit of detection of $300 \mathrm{ng}$ of MC-LR (=0.6 $\mu \mathrm{g} / \mathrm{L}$ assuming a typical filtration volume of $500 \mathrm{~mL}$ ).

\subsection{Fish Sampling}

Fishing for small fish (mostly $R$. argentea) was performed using light attraction by means of kerosene pressure lamps floating on the water surface during moonless nights. Samples were obtained monthly from fishermen early in the morning from Kisumu Bay (ST1) during October 2011-January 2012 as well as Rusinga channel (ST2) in January 2012. Fish samples were packed immediately on ice and were transported to the laboratory for further processing within $12 \mathrm{~h}$. Fish samples were subsampled, taking aliquots of approximately $80 \mathrm{~g}$ wet weight at random. The species composition, fresh weight $(\mathrm{g})$ and total length $(\mathrm{mm})$ for each specimen from one aliquot subsample were determined. Fish samples were dried either directly $\left(50^{\circ} \mathrm{C}\right)$ or dried under the sun for 2, 4, 6 and 8 hours respectively, and subsequently dried at $50{ }^{\circ} \mathrm{C}$ (Figure 7, Supplementary Figure S4). Individual fish sample aliquots had a dry weight of $18.3 \pm 0.6$ (mean \pm SE), $16.8 \pm 0.2,16.6 \pm 0.3$, $16.9 \pm 0.2,17.1 \pm 0.2 \mathrm{~g}$ in October, November, December, and January at ST1 and in January at ST2, respectively. 


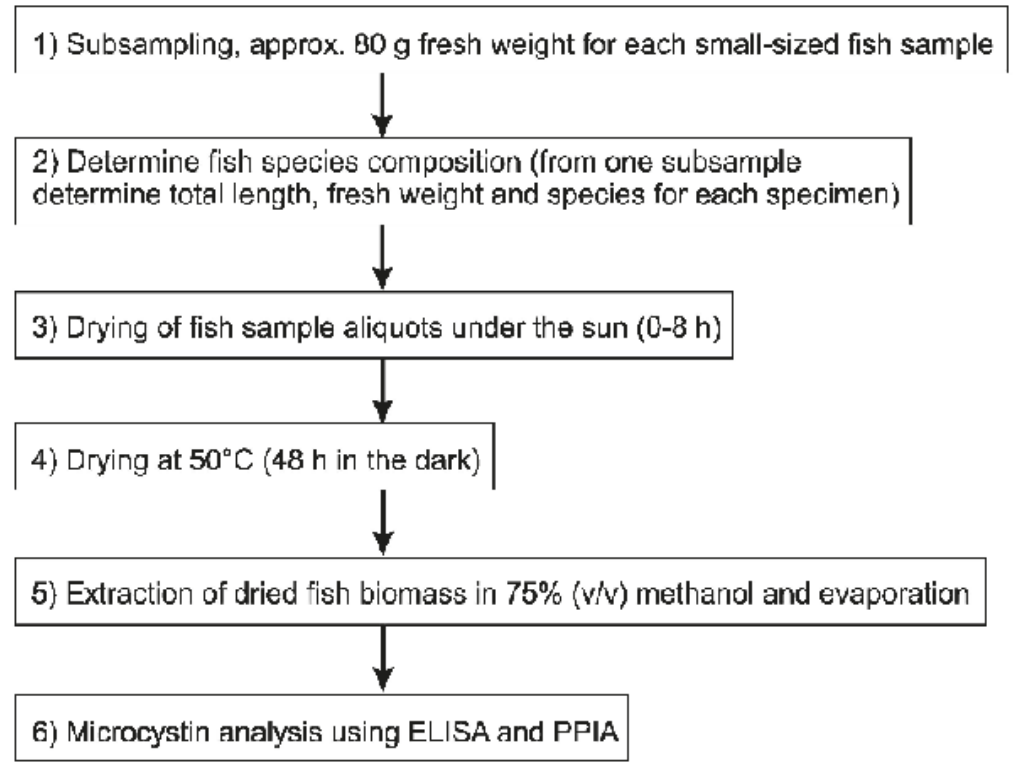

Figure 7. The workflow for fish sample processing including sampling, drying, extraction and MC analysis.

\subsection{Microcystin Analysis in Small Fish}

MC extraction from dried fish samples was done by aqueous methanol as described [51]. The extraction process was repeated three times. In the first two extraction steps, the dried and weighed fishes were ground as a whole in a mortar and extracted in $75 \%(v / v)$ methanol $(2 \mathrm{~h}$, $\left.4{ }^{\circ} \mathrm{C}\right)$. After centrifugation the pellet was resuspended in $30 \mathrm{~mL}$ of $75 \%(\mathrm{v} / \mathrm{v})$ methanol containing $0.002 \%(v / v)$ glacial acetic acid $\left(24 \mathrm{~h}, 4{ }^{\circ} \mathrm{C}\right)$. The next day the pooled supernatant was centrifuged to remove particles and the cleared extract was evaporated to dryness (BUCHI Rota vapor R-205) and stored at $-20{ }^{\circ} \mathrm{C}$. The residues from the evaporation were resuspended in $2 \mathrm{~mL}$ of methanol and transferred to glass bottles kept open under the fumehood overnight to evaporate the methanol (as methanol is known to interfere with ELISA, [52]). To enhance the evaporation of methanol the extract was incubated at $60^{\circ} \mathrm{C}$ for another $2 \mathrm{~h}$. The extract was then diluted with distilled water (1:1000) in glass vials and MCYST concentration was determined by the same indirect competitive ELISA (Microcystins-ADDA ELISA kit, PN 520011) as described above. Using the same MC-LR standard, the concentrations were expressed as MC-LR equivalents in nanograms per gram of fish dry weight. In order to identify the proportion of active MC in the fish tissues the standard protein phosphatase inhibition assay (PPIA) technique [53] was used for aliquots of the fish extract samples dissolved in methanol and stored at $-20^{\circ} \mathrm{C}$. A commercially available microplate test kit (Microcystest) from Zeulab (Zaragoza, Spain) has been used and 250-fold dilutions of fish sample extracts were analyzed according to the manufacturer's instructions. The inhibition of the PP2A activity was monitored using the conversion of chromogenic substrate and reading absorbance at $405 \mathrm{~nm}$ wavelength. Finally, using all fish samples from December 2011 the MC was quantified using chemical-analytical methods by LC-MS/MS [19]. The tandem mass-spectrometry instrumental setup included a water ACQUITY UPLC system directly connected to a Quattro Premier XE MS/MS detector. MC structural variants were quantified in positive ESI mode using multiple reaction monitoring according to the retention time and the precursor ion. The daughter ion monitored for all MCs was the typical $135 \mathrm{Da}$ Adda fragment. All MS settings were optimized with commercial standards (purchased from 
Sigma, Oslo, Norway) which were also used to calibrate the system: MC-RR $m / z=519.8[\mathrm{M}+2 \mathrm{H}]^{2+}$, MC-YR $m / z=1045.5[\mathrm{M}+\mathrm{H}], \mathrm{MC}-\mathrm{LR} \mathrm{m} / z=995.5[\mathrm{M}+\mathrm{H}]$. The detection limit was $40 \mathrm{ng} / \mathrm{mL}$ for MC-YR and MC-LR (10 $\mu \mathrm{L}$ injection volume).

\subsection{Statistical Analysis}

Phytoplankton composition and MC contents were compared between samples using the Friedman repeated measures analysis of variance (ANOVA) on ranks $(p<0.05)$ followed by pairwise multiple comparison (Tukey test, $p<0.05$ ) using SigmaPlot (Version 13.0, Systat Software Inc, San Jose, CA, USA).

Supplementary Materials: The following are available online at http:/ /www.mdpi.com/2072-6651/10/7/275/s1, Figure S1: Sampling sites in Nyanza Gulf, L. Victoria showing cyanobacteria mass accumulation, Figure S2: Relationship between total phytoplankton biovolume $\left(\mathrm{mm}^{3} \mathrm{~L}^{-1}\right)$ and Chlorophyll $a\left(\mu \mathrm{g} \mathrm{L}{ }^{-1}\right)$ for all water samples from different sample types in Kisumu Bay, Nyanza Gulf, and Rusinga Channel, Lake Victoria, Figure S3: Relationship between Microcystis cell numbers and total (intracellular and dissolved) MC concentration for all water samples from different sample types in Kisumu Bay, Nyanza Gulf, and Rusinga channel, Lake Victoria, Figure S4: Drying of fish samples for the experiment on microcystin stability $(0-8 \mathrm{~h})$ and for the market, Table S1: Phytoplankton taxa which were discriminated for biovolume estimation, Table S2: Meteorological characteristics for dates of fish drying to study the stability of microcystin in fish samples.

Author Contributions: R.K. and B.M.S. conceived and designed the experiments; B.M.S. performed the experiments; R.K. and B.M.S. analyzed the data; S.O.O., L.S. and T.R. contributed reagents/materials/analysis tools; B.M.S. and R.K. wrote the paper.

Funding: This research was funded by [Austrian Science Fund (FWF)] grant number [P24070] to R.K., and [OEAD GmbH] Appear Ph.D. fellowship (2017-2020) to B.M.S., and [International Postgraduate Course of Limnology] MSc fellowship to B.M.S.

Acknowledgments: We are grateful to Gerold Winkler and Regina Brandstaetter for their support and funding of the practical work through the International Postgraduate Training Course in Limnology (IPGL). We thank James Outa and Brenda Apiyo for assistance during field sampling. Jared Ochieng and Harman Otieno (University of Egerton, Department of Chemistry) assisted in sample processing and analysis. The Meteorological Station at the Kisumu International Airport kindly provided weather data during the fish drying experiments. The authors are grateful for the critical suggestions of two anonymous reviewers which helped to improve this manuscript.

Conflicts of Interest: The authors declare no conflict of interest. The founding sponsors had no role in the design of the study; in the collection, analyses, or interpretation of data; in the writing of the manuscript, and in the decision to publish the results.

\section{References}

1. Verschuren, D.; Johnson, T.C.; Kling, H.J.; Edgington, D.N.; Leavitt, P.R.; Brown, E.T.; Talbot, M.R.; Hecky, R.E. History and timing of human impact on Lake Victoria, East Africa. Proc. R. Soc. B 2001, 269, 289-294. [CrossRef] [PubMed]

2. Hecky, R.E.; Muggide, R.; Ramlal, P.S.; Talbot, M.R.; Kling, G.W. Multiple stressors cause rapid ecosystem change in Lake Victoria. Freshw. Biol. 2010, 55, 19-42. [CrossRef]

3. Tamatamah, R.A.; Hecky, R.E.; Duthie, H. The atmospheric deposition of phosphorus in Lake Victoria (East Africa). Biogeochemistry 2005, 73, 325-344. [CrossRef]

4. Mbonde, A.S.; Sitoki, L.; Kurmayer, R. Phytoplankton composition and microcystin concentrations in open and closed bays of Lake Victoria, Tanzania. Aquat. Ecosyst. Health Manag. 2015, 18, 212-220. [CrossRef] [PubMed]

5. Gikuma-Njuru, P.; Hecky, R.E.; Guildford, S.J.; MacIntyre, S. Spatial variability of nutrient concentrations, fluxes, and ecosystem metabolism in Nyanza Gulf and Rusinga Channel, Lake Victoria (East Africa). Limnol. Oceanogr. 2013, 58, 774-789. [CrossRef]

6. Calamari, D.; Akech, M.O.; Ochumba, P.B.O. Pollution of Winam Gulf, Lake Victoria, Kenya: A case study for preliminary risk assessment. Lakes Reserv. Res. Manag. 1995, 1, 89-106. [CrossRef] 
7. Kling, H.J.; Mugidde, R.; Hecky, R.E. Recent changes in the phytoplankton community of Lake Victoria in response to eutrophication. In The Great Lakes of the World (GLOW): Food Web, Health and Integrity; Munawar, M., Hecky, R.E., Eds.; Ecovision World Monograph Series; Backhuys Publishers: Leiden, The Netherlands, 2001; pp. 47-65. ISBN 978-0-9921007-8-0.

8. Meriluoto, J.; Spoof, L.; Codd, G.A. Handbook of Cyanobacterial Monitoring and Cyanotoxin Analysis; John Wiley \& Sons, Ltd.: Chichester, UK, 2017; p. 576. ISBN 9781119068747.

9. Sitoki, L.; Kurmayer, R.; Rott, E. Spatial variation of phytoplankton composition, biovolume, and resulting microcystin concentrations in the Nyanza Gulf (Lake Victoria, Kenya). Hydrobiologia 2012, 691, 109-122. [CrossRef] [PubMed]

10. Humbert, J.-F; Fastner, J. Ecology of cyanobacteria. In Handbook of Cyanobacterial Monitoring and Cyanotoxin Analysis; Meriluoto, J., Spoof, L., Codd, G.A., Eds.; John Wiley \& Sons, Ltd.: Chichester, UK, 2017; pp. 9-18. ISBN 9781119068747.

11. Reynolds, C.S.; Oliver, R.L.; Walsby, A.E. Cyanobacterial dominance: The role of buoyancy regulation in dynamic lake environments. N. Z. J. Mar. Freshw. Res. 1987, 21, 379-390. [CrossRef]

12. Schmidt, J.R.; Wilhelm, S.W.; Boyer, G.L. The fate of microcystins in the environment and challenges for monitoring. Toxins 2014, 6, 3354-3387. [CrossRef] [PubMed]

13. Svircev, Z.; Drobac, D.; Tokodi, N.; Mijovic, B.; Codd, G.A.; Meriluoto, J. Toxicology of microcystins with reference to cases of human intoxications and epidemiological investigations of exposures to cyanobacteria and cyanotoxins. Arch. Toxicol. 2017, 91, 621-650. [CrossRef] [PubMed]

14. Okello, W.; Kurmayer, R. Seasonal development of cyanobacteria and microcystin production in Ugandan freshwater lakes. Lakes Reserv. Res. Manag. 2011, 16, 123-135. [CrossRef]

15. Okello, W.; Portmann, C.; Erhard, M.; Gademann, K.; Kurmayer, R. Occurrence of microcystin-producing cyanobacteria in Ugandan freshwater habitats. Environ. Toxicol. 2010, 25, 367-380. [CrossRef] [PubMed]

16. Zhang, D.; Xie, P.; Liu, Y.; Qiu, T. Transfer, distribution and bioaccumulation of microcystins in the aquatic food web in Lake Taihu, China, with potential risks to human health. Sci. Total Environ. 2009, 407, 2191-2199. [CrossRef] [PubMed]

17. Sotton, B.; Guillard, J.; Anneville, O.; Maréchal, M.; Savichtcheva, O.; Domaizon, I. Trophic transfer of microcystins through the lake pelagic food web: Evidence for the role of zooplankton as a vector in fish contamination. Sci. Total Environ. 2014, 466, 152-163. [CrossRef] [PubMed]

18. Wood, J.D.; Franklin, R.B.; Garman, G.; McIninch, S.; Porter, A.J.; Bukaveckas, P.A. Exposure to the cyanotoxin microcystin arising from interspecific differences in feeding habits among fish and shellfish in the James River Estuary, Virginia. Environ. Sci. Technol. 2014, 48, 5194-5202. [CrossRef] [PubMed]

19. Semyalo, R.; Rohrlack, T.; Naggawa, C.; Nyakairu, G.W. Microcystin concentrations in Nile Tilapia (Oreochromis niloticus) caught from Murchison Bay, Lake Victoria and Lake Mburo: Uganda. Hydrobiologia 2010, 638, 235-244. [CrossRef]

20. Ibelings, B.W.; Chorus, I. Accumulation of cyanobacterial toxins in freshwater "seafood" and its consequences for public health: A review. Environ. Pollut. 2007, 150, 177-192. [CrossRef] [PubMed]

21. Semyalo, R.; Rohrlack, T.; Kayiira, D.; Kizito, Y.S.; Byarujali, S.; Nyakairu, G.; Larsson, P. On the diet of Nile tilapia in two eutrophic tropical lakes containing toxin producing cyanobacteria. Limnologica 2011, 41, 30-36. [CrossRef]

22. Nyakairu, G.W.; Nagawa, C.B.; Mbabazi, J. Assessment of cyanobacteria toxins in freshwater fish: A case study of Murchison Bay (Lake Victoria) and Lake Mburo, Uganda. Toxicon 2010, 55, 939-946. [CrossRef] [PubMed]

23. Poste, A.E.; Hecky, R.E.; Guildford, S.J. Evaluating microcystin exposure risk through fish consumption. Environ. Sci. Technol. 2011, 45, 5806-5811. [CrossRef] [PubMed]

24. World Health Organization. Guidelines for Drinking-Water Quality. Fourth Edition Incorporating the First Addendum; WHO: Geneva, Switzerland, 2017; p. 541. ISBN 978-92-4-154995-0.

25. Sharpe, D.M.; Wandera, S.B.; Chapman, L.J. Life history change in response to fishing and an introduced predator in the East African cyprinid Rastrineobola argentea. Evol. Appl. 2012, 5, 677-693. [CrossRef] [PubMed]

26. Abila, R.O. Assessment of fisheries products values along Kenya's export marketing chain. In FAO Fisheries Technical Report; No. 819; Food and Agriculture Organization of the United Nations: Rome, Italy, 2007; p. 262.

27. Wangechi, K.S.; Muigai, A.W.T.; Ouma, S.O. The Impact of evolution and socio-economics of commercially exploited fish stock: A Review on Rastrineobola argentea in Lake Victoria. J. Food Secur. 2015, 3, 82-86. 
28. Alexander, R.; Imberger, J. Phytoplankton patchiness in Winam Gulf, Lake Victoria: A study using principal component analysis of in situ fluorescent excitation spectra. Freshw. Biol. 2013, 58, 275-291. [CrossRef]

29. Okely, P.; Imberger, J.; Antenucci, P.J. Processes affecting horizontal mixing and dispersion in Winam Gulf, Lake Victoria. Limnol. Oceanogr. 2010, 55, 1865-1880. [CrossRef]

30. Gikuma-Njuru, P.; Hecky, R.E. Nutrient concentrations in Nyanza Gulf, Lake Victoria, Kenya: Light limits algal demand and abundance. Hydrobiologia 2005, 534, 131-140. [CrossRef]

31. Ishikawa, K.; Kumagai, M.; Vincent, W.F.; Tsujimura, S.; Nakahara, H. Transport and accumulation of bloom-forming cyanobacteria in a large, mid-latitude lake: The gyre-Microcystis hypothesis. Limnology 2002, 3, 87-96. [CrossRef]

32. Khisa, P.; Romero, J.R.; Imberger, J.; Ewing, T.; Antenucci, J.; Njuguna, H.; Okungu, J. The effect of the Mbita Causeway on water currents in the region of Rusinga Channel, Winam Gulf, Lake Victoria: A 3D modelling study with ELCOM. In Proceedings of the 11th World Lakes Conference, Nairobi, Kenya, 31 October-4 November 2005; Odada, E.O., Olago, D.O., Ochola, W., Ntiba, M., Wandiga, S., Gichuki, N., Oyieke, H., Eds.; Ministry of Water and Irrigation: Nairobi, Kenya, 2005; pp. 74-78.

33. Kurmayer, R.; Christiansen, G.; Chorus, I. The abundance of microcystin-producing genotypes correlates positively with colony size in Microcystis and determines its microcystin net production in Lake Wannsee. Appl. Environ. Microbiol. 2003, 69, 787-795. [CrossRef] [PubMed]

34. Kurmayer, R.; Dittmann, E.; Fastner, J.; Chorus, I. Diversity of microcystin genes within a population of the toxic cyanobacterium Microcystis. In Lake Wannsee (Berlin, Germany). Microb. Ecol. 2002, 43, 107-118. [CrossRef] [PubMed]

35. Graham, J.L.; Jones, J.R. Microcystin distribution in physical size class separations of natural plankton communities. Lake Reserv. Manag. 2007, 23, 161-168. [CrossRef]

36. Wang, X.; Sun, M.; Xie, M.; Liu, M.; Luo, L.; Li, P.; Kong, F. Differences in microcystin production and genotype composition among Microcystis colonies of different sizes in Lake Taihu. Water Res. 2013, 47, 5659-5669. [CrossRef] [PubMed]

37. Testai, E.; Buratti, F.M.; Funari, E.; Manganelli, M.; Vichi, S.; Arnich, N.; Biré, R.; Fessard, V.; Sialehaamoa, A. Review and analysis of occurrence, exposure and toxicity of cyanobacteria toxins in food. EFSA Support. Publ. 2016, 13, 998E. [CrossRef]

38. Cadel-Six, S.; Moyenga, D.; Magny, S.; Trotereau, S.; Edery, M.; Krys, S. Detection of free and covalently bound microcystins in different tissues (liver, intestines, gills, and muscles) of rainbow trout (Oncorhynchus mykiss) by liquid chromatography-tandem mass spectrometry: Method Characterization. Environ. Pollut. 2014, 185, 333-339. [CrossRef] [PubMed]

39. Smith, J.L.; Schulz, K.L.; Zimba, P.V.; Boyer, G.L. Possible mechanism for the foodweb transfer of covalently bound microcystins. Ecotoxicol. Environ. Saf. 2010, 73, 757-761. [CrossRef] [PubMed]

40. Schmidt, J.R.; Shaskus, M.; Estenik, J.F.; Oesch, C.; Khidekel, R.; Boyer, G.L. Variations in the microcystin content of different fish species collected from a eutrophic lake. Toxins 2013, 5, 992-1009. [CrossRef] [PubMed]

41. Isumbisho, M.; Petit, P.; Gashagaza, J.B.; Moreau, J. The feeding habit of the Cyprinidae Rastrineobola argentea in its new habitat, Lakes Bulera and Ruhondo, two Rwandan lakes (Eastern Africa). Knowl. Manag. Aquat. Ecosyst. 2011. [CrossRef]

42. Lawton, L.A.; Robertson, P.K.J. Physico-chemical treatment methods for the removal of microcystins (cyanobacterial hepatotoxins) from potable waters. Chem. Soc. Rev. 1999, 28, 217-224. [CrossRef]

43. Jacobs, L.C.V.; Peralta-Zamora, P.; Campos, F.R.; Pontarolo, R. Photocatalytic degradation of microcystin-LR in aqueous solutions. Chemosphere 2013, 90, 1552-1557. [CrossRef] [PubMed]

44. International Organization for Standardization. Water Quality-Measurement of Biochemical Parameters_Spectrometric Determination of the Chlorophyll-A Concentration; ISO 10260; ISO: Geneve, Switzerland, 1992.

45. Wetzel, R.G.; Likens, G.E. Limnological Analyses, 3rd ed.; Springer: New York, NY, USA, 2000; p. 429. ISBN 978-1-4757-3250-4.

46. Talling, J.F. The phytoplankton of Lake Victoria (East Africa). Arch. Hydrobiol. Beih. Ergeb. Limnol. 1987, 25, 229-56.

47. Komárek, J.; Kling, H. Variation in six planktonic cyanophyte genera in Lake Victoria (East Africa). Algol. Stud. 1991, 61, 21-45. 
48. Cronberg, G.; Annadotter, H. Manual on Aquatic Cyanobacteria; A Photo Guide and Synopsis of Their Toxicology; International Society for the Study of Harmful Algae (ISSHA) and United Nations Educational, Scientific and Cultural Organisation (UNESCO): Copenhagen, Denmark, 2006; p. 106. ISBN 8799082705.

49. Lawton, L.; Marsalek, B.; Padisak, J.; Chorus, I. Determination of cyanobacteria in the laboratory. In Toxic Cyanobacteria in Water; A Guide to Their Public Health Consequences, Monitoring and Management; Chorus, I., Bartram, J., Eds.; WHO: London, UK, 1999; pp. 347-368. ISBN 0-419-23930-8.

50. Fastner, J.; Flieger, I.; Neumann, U. Optimised extraction of microcystins from field samples-A comparison of different solvents and procedures. Water Res. 1998, 32, 3177-3181. [CrossRef]

51. Wilson, A.E.; Gossiaux, D.C.; Höök, T.O.; Berry, J.P.; Landrum, P.F.; Dyble, J.; Guildford, S.J. Evaluation of the human health threat associated with the hepatotoxin microcystin in the muscle and liver tissues of yellow perch (Perca flavescens). Can. J. Fish. Aquat. Sci. 2008, 65, 1487-1497. [CrossRef]

52. Metcalf, J.S.; Hyenstrand, P.; Beattie, K.A.; Codd, G.A. Effects of physicochemical variables and cyanobacterial extracts on the immunoassay of microcystin-LR by two ELISA kits. J. Appl. Microbiol. 2000, 89, 532-538. [CrossRef] [PubMed]

53. An, J.; Carmichael, W.W. Use of a colorimetric protein phosphatase inhibition assay and enzyme linked immunosorbent assay for the study of microcystins and nodularins. Toxicon 1994, 32, 1495-1507. [CrossRef]

(C) 2018 by the authors. Licensee MDPI, Basel, Switzerland. This article is an open access article distributed under the terms and conditions of the Creative Commons Attribution (CC BY) license (http:/ / creativecommons.org/licenses/by/4.0/). 
Article

\title{
Cyanobacterial Neurotoxin Beta-Methyl-Amino-L-Alanine Affects Dopaminergic Neurons in Optic Ganglia and Brain of Daphnia magna
}

\author{
Megan Brooke-Jones, Martina Gáliková and Heinrich Dircksen * \\ Department of Zoology, Functional Morphology, Stockholm University, Svante Arrhenius väg 18B, \\ S-10691 Stockholm, Sweden; megbrookejones27@gmail.com (M.B.-J.); martina.galikova@zoologi.su.se (M.G.) \\ * Correspondence: dircksen@zoologi.su.se; Tel.: +46-8-164076
}

Received: 18 November 2018; Accepted: 6 December 2018; Published: 8 December 2018

\begin{abstract}
The non-proteinogenic amino acid beta-methyl-amino-L-alanine (BMAA) is a neurotoxin produced by cyanobacteria. BMAA accumulation in the brain of animals via biomagnification along the food web can contribute to the development of neurodegenerative diseases such as Amyotrophic lateral sclerosis/Parkinsonism dementia complex (ALS/PDC), the latter being associated with a loss of dopaminergic neurons. Daphnia magna is an important microcrustacean zooplankton species that plays a key role in aquatic food webs, and BMAA-producing cyanobacteria often form part of their diet. Here, we tested the effects of BMAA on putative neurodegeneration of newly identified specific dopaminergic neurons in the optic ganglia/brain complex of D. magna using quantitative tyrosine-hydroxylase immunohistochemistry and fluorescence cytometry. The dopaminergic system was analysed in fed and starved isogenic D. magna adults incubated under different BMAA concentrations over 4 days. Increased BMAA concentration showed significant decrease in the stainability of dopaminergic neurons of D. magna, with fed animals showing a more extreme loss. Furthermore, higher BMAA concentrations tended to increase offspring mortality during incubation. These results are indicative of ingested BMAA causing neurodegeneration of dopaminergic neurons in D. magna and adversely affecting reproduction. This may imply similar effects of BMAA on known human neurodegenerative diseases involving dopaminergic neurons.
\end{abstract}

Keywords: water flea; Daphnia magna; dopaminergic neurons; cyanobacterial toxin; BMAA; beta-methyl-amino-L-alanine; neurodegeneration

Key Contribution: Application of neurotoxic BMAA already for 4 days affects the dopaminergic system of the Daphnia optic ganglia and the brain newly described here by immunohistochemistry. Significant decreases of dopamine-specific fluorescence under increased BMAA concentration are indicative of toxic neurodegeneration similar to what is proposed as a cause for human ALS/PDC disease.

\section{Introduction}

The non-proteinogenic amino acid $\beta$-methyl-amino-L-alanine (BMAA), was first identified from the seeds of Cycas trees on the island of Guam in the Pacific Ocean linked as a causative agent to the high incidence of amyotrophic lateral sclerosis/parkinsonism-dementia complex (ALS-PDC) among many of the indigenous Chamorro people of this island [1-3]. The cyanobacterium Nostoc living symbiotically with cycad trees was identified as the source for BMAA [2]. Another extensive source for BMAA was discovered in the skin of flying foxes, which devour large amounts of Cycas seeds and are 
regularly consumed as a food delicacy by the same indigenous people suffering from the neurological disease $[4,5]$.

Several potential mechanisms by which environmental exposure to BMAA can lead to such neurological disorders have been proposed [6-8] and which are caused by neurodegeneration [9-11]. BMAA, however, is not only produced by many cyanobacteria but also by diatoms and dinoflagellates which occur almost ubiquitously in terrestrial, freshwater, brackish, and marine habitats [12-15]. BMAA has been detected in many freshwater lakes and brackish water bodies in Britain [16], in South African freshwater impoundments [17], and in urban waters bodies in the Netherlands [18]. BMAA even occurred in the desert sand of the Persian Gulf as a cause of neurological disorders in soldiers [19,20], in springs from a Gobi Desert oasis [21], as well as probably globally in freshwater and marine ecosystems [22,23]. Thus, there is mounting evidence for sporadic ALS or ALS/PDC being linked to environmental impact factors among which certainly cyanobacterial BMAA seems to be an important one as it is derived from knowledge about high incidences of ALS and dementia in Guam and the Kii peninsula of Japan [24-27]. These factors might even affect non-motor neurons in the disease pathology of ALS/PDC in susceptible individuals alongside the more familial genetic disease causes $[28,29]$.

In particular, in freshwater environments in Sweden and in large swathes all around the Baltic Sea during summer months, algal blooms are a common phenomenon, and cyanobacteria and diatoms that also produce BMAA attain the highest concentrations [14,15,30,31]. Zooplankton organisms which naturally feed on different cyanobacteria usually contain higher levels of BMAA than the BMAA producers themselves [31]. In addition, recent studies have shown that fish and shellfish tissues from local markets in Sweden also contain higher concentrations of BMAA than the cyanobacteria [32,33]. Thus, these results clearly show that BMAA is biotransferred in aquatic ecosystems all around the world and accumulated in several aquatic organisms [34].

Bioaccumulation of BMAA has also been proven for Daphnia magna, one of the keystone organisms in the food web of freshwater ecosystems and likely the most common ecotoxicological test organism in the world [35-38]. Daphnia feeds on phytoplankton such as green algae but also on cyanobacteria, thereby being exposed to several cyanotoxins [36]. One of these cyanotoxins, BMAA, was later shown to adversely affect swimming behavior, reproductive output and survival especially upon exposure of the supposedly most sensitive neonate stages of D. magna, effects that were clearly dose-dependent [39]. However, nothing is known about the possible nature of these adverse effects on the physiology of Daphnia. In the present study, we set out to test the hypothesis of whether BMAA affects female fitness, locomotion, or causes neurological impairments. Because of the known links of BMAA and ALS/PDC syndromes as described above, we analyzed first whether dopaminergic neurons long known to be responsible for ALS/PDC syndromes in humans $[40,41]$ may also be affected in $D$. magna.

The existence of dopamine as a transmitter in the Daphnia nervous system was evidenced long ago by the relatively unspecific Falck-Hillarp histofluorescence method [42] and later in Daphnia central nervous system (CNS) extracts [43]. More recently, dopamine and its rate-limiting enzyme tyrosine hydroxylase have been shown to have a role in modulating the motor behavior of D. magna, specifically their swimming movement [44]. Furthermore, other authors have proposed dopamine as a possible compound in some peripheral supposedly sensory cells and even found evidence for dopamine being involved in the expression of predator-induced defense in Daphnia [45]. We provide here the first description of identified dopamine neurons in Daphnia by the use of antibodies against tyrosine-hydroxylase, the rate limiting enzyme in dopamine biosynthesis. In fact, we found profound dose-dependent effects of BMAA on reduced dopamine activity in nearly all dopaminergic neurons of D. magna during short acute toxicity exposures. 


\section{Results}

\subsection{Identified Dopaminergic Neurons}

In total, a system of 25-27 paired dopaminergic neurons have been mapped in the optic ganglia/brain complex of D. magna (Figure 1). These comprise single neurons, some in groups of two or three and some in larger groups comprising up to 10 neurons. Neuron types have been attributed to five different cell clusters (cc) and are found to innervate several distinct neuroanatomical landmarks as defined earlier [46]. In the Lamina (La), 10 paired cells lie horizontally and make up the bipolar Lamina Ventral neurons $(\mathrm{LaV})$ and bipolar Laminal Dorsal neurons (LaD) that lie in cc2 (Figure 1B-D). The axons of these cells innervate single cartridges in the La and anterior areas of the Visual Tectum (VT). In the anterior brain, two unipolar Ventral Anterior Lateral neurons (VAL) lie in cc6 which partly innervate the anterior ventral Central Body (CB) (Figure 1A), and three Dorsal Anterior Lateral neurons (DAL) innervate the Lateral Neuropiles (LN) (Figure 1B,D). Also, in the anterior brain, two types of Dorsal Anterior Median neurons (DAM1 and DAM2) which lie in cc5 innervate the LN. Axons from the DAM1 neurons project through the Funnel Tract (FT) from dorsal to ventral, finally innervating several layers of the CB (Figure 1A-C). Furthermore, in the deutocerebrum of the ventral brain, a single bipolar Ventral Lateral Deutocerebral (VLD) neuron lies posterior to the LN in cc8 and innervates the ipsi- and contralateral anterior parts of the Olfactory Lobe Neuropiles (OLNs) (Figure 1A). Also in cc8 and posterior to the VLD neuron in the tritocerebrum lies the single bipolar Ventral Median Tritocerebral neuron (VMT) and the single bipolar Ventral Lateral Tritocerebral neuron (VLT) (Figure 1A,B). Both cells have an ipsi- and contralateral projection with their respective axons into the tritocerebrum [46]. A cluster of 8-10 Dorsal Posterior Median neurons (DPM) lies in cc9, and the cells innervate the Dorsal Neuropile (DN) and Posterior LN (Figure 1C,D).
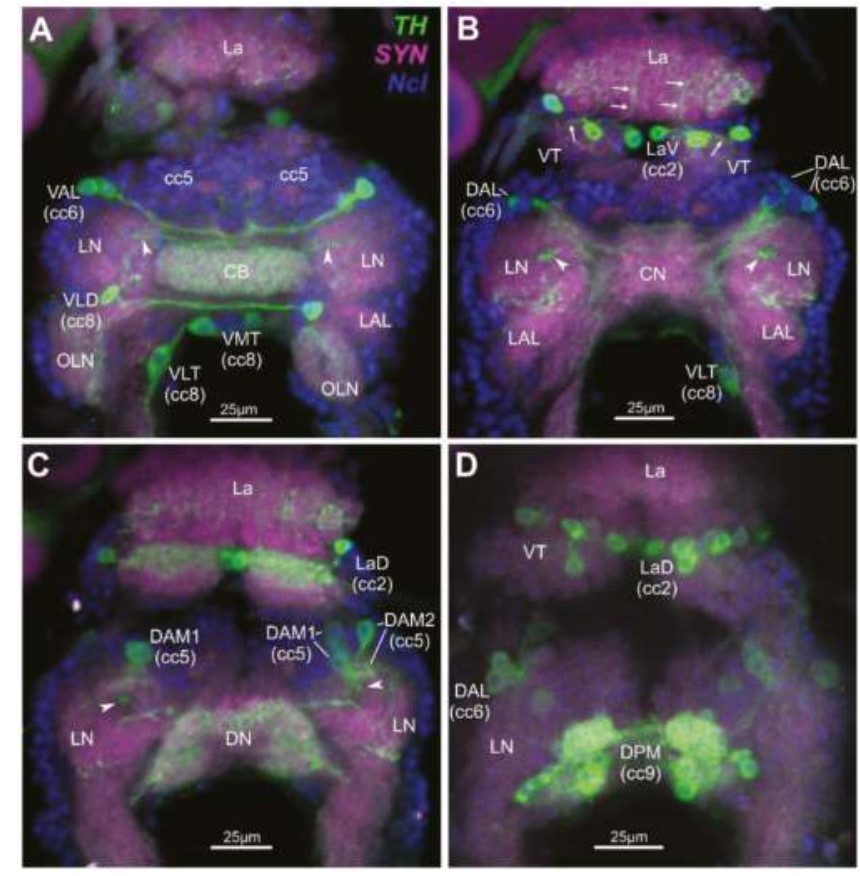

Figure 1. Dopaminergic neurons in the optic ganglia and central brain of Daphnia magna as revealed by tyrosine-hydroxylase $(\mathrm{TH})$-immunohistochemistry; ventral view; triple staining using fluoresceine-isothiocyanate-(FITC)-labelling for TH, green, AlexaFluor546-labelling for synapsin (SYN), 
magenta, 4' ,6-Diamidine-2' -phenylindole (DAPI) nuclear stain ( $\mathrm{Ncl}$ ), blue. (A) Unipolar ventral anterior lateral (VAL), bipolar ventral lateral deutocerebral (VLD), bipolar ventral median tritocerebral (VMT) and bipolar ventral lateral tritocerebral (VLT) neurons; VAL partly innervate the anterior ventral central body (CB) and VLD innervate the ipsi- and contralateral anterior parts of the olfactory lobe neuropiles (OLN); 7 virtual $1 \mu \mathrm{m}$-sections combined. (B) Bipolar lamina neurons in ventral median to lateral positions $(\mathrm{LaV})$, arrows indicate axons innervating single lamina cartridges and anterior areas of the visual tectum (VT); dorsal anterior lateral (DAL) neurons innervating the lateral neuropiles (LN); seven combined $1 \mu \mathrm{m}$-sections. (C) Dorsal anterior median (DAM1 and DAM2) innervating the LN, and DAM1 axons entering the funnel tract (arrowheads); eight combined $1 \mu \mathrm{m}$-sections. (D) Dorsal lamina (LaD) bipolar and dorsal anterior lateral (DAL) neurons, and the cluster of 8-10 dorsal posterior median (DPM) neurons, the latter innervating the dorsal neuropile (DN) and the posterior lateral neuropile (LN) (more details in C); three combined $1 \mu \mathrm{m}$-sections. Arrowheads in $(\mathbf{A}, \mathbf{C})$ indicate axons from DAM1-neurons in the funnel tract innervating several layers of the $\mathrm{CB}$. Abbreviations: $\mathrm{cc}$, cell cluster; $\mathrm{CB}$, central body; $\mathrm{CN}$, central neuropile; $\mathrm{DN}$, dorsal neuropile; La, lamina; LAL, lateral accessory lobe; LN, lateral neuropile; OLN, olfactory lobe neuropile; VT, visual tectum; nomenclature according to [46].

\subsection{Effects of BMAA on Reproduction, Development and Behavior}

In order to analyze the potential effect of the BMAA toxin on the fitness of Daphnia, we investigated the development and reproduction of females exposed to three different concentrations of BMAA (200, 500 and $1000 \mu \mathrm{g}$ BMAA per L of medium). The toxin did not visibly affect the molting cycle of D. magna. Each adult animal successfully molted and shed a complete carapace between every release of young and before the next development of eggs in the brood chamber. However, the exposure to the high BMAA concentrations caused a tendency towards reduction of female fertility (Figure 2). Fertility was considered reduced if the female produced predominantly non-viable progeny. However, exposure to BMAA did not affect the length of development inside the brood chamber (Figure 3). Next, we analyzed whether BMAA affects female fecundity, i.e., the number of eggs inside the brood pouch. To analyze potential interactions between the toxin exposure and the nutritional status of the females, we tested females that were starved during the toxin exposure, as well as females that were fed ad libitum during the treatment. During the exposure time (4 days), females laid two clutches of eggs. We therefore analyzed the effect of feeding, BMAA treatment, and their interaction on both the first and the second clutch of eggs. Neither BMAA treatment nor feeding status affected the number of eggs in the first clutch (Figure 4A). Nevertheless, BMAA significantly affected the number of eggs in the second clutch in females that were fed during the treatment (Figure 4B), increasing fecundity of females exposed to the $200 \mu \mathrm{g} \mathrm{L}^{-1}$ BMAA. Interestingly, BMAA treatment increased the proportion of eggs in the second clutch upon all tested concentrations under feeding conditions (Figure 4C).

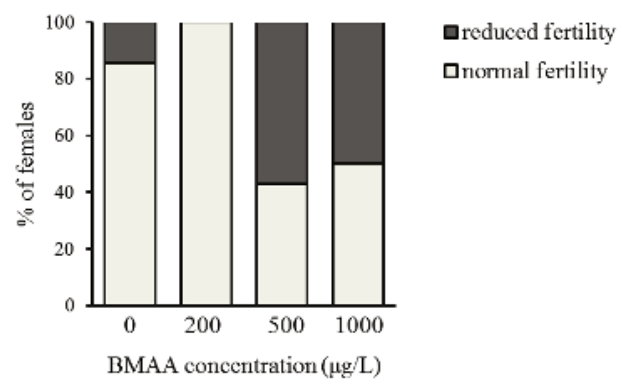

Figure 2. Exposure to beta-methyl-amino-L-alanine (BMAA) tends to decrease fertility of D. magna females. Fertility was defined as reduced if more than $50 \%$ of progeny was non-viable. Nonetheless, data do not reach statistical significance (pairwise comparisons with the $0 \mu \mathrm{g} \mathrm{L}{ }^{-1}$ BMAA using Fischer's exact test: $p>0.05$ for each comparison). Sample size: $0 \mu \mathrm{g} \mathrm{L}^{-1}$ BMAA $n=7 ; 200 \mu \mathrm{g} \mathrm{L}^{-1}$ BMAA $n=6$; $500 \mu \mathrm{g} \mathrm{L}{ }^{-1}$ BMAA $n=7 ; 1000 \mu \mathrm{g} \mathrm{L}^{-1}$ BMAA $n=8$. 


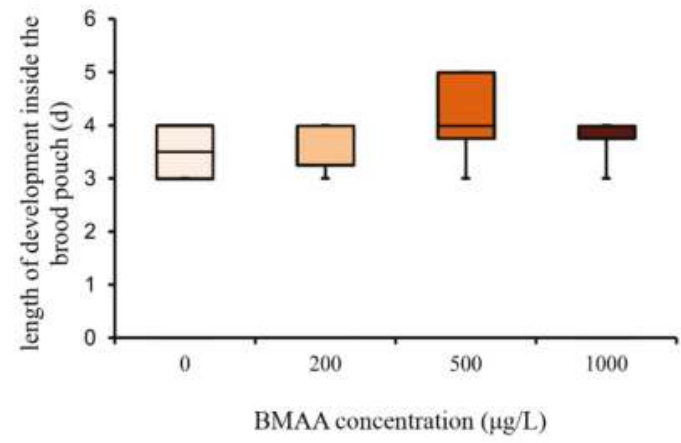

Figure 3. Beta-methyl-amino-L-alanine (BMAA) does not affect the length of development inside the brood chamber (one-way ANOVA, $p>0.05$ ). Sample size: $0 \mu \mathrm{g} \mathrm{L}^{-1}$ BMAA $n=6 ; 200 \mu \mathrm{g} \mathrm{L}^{-1}$ BMAA $n=6 ; 500 \mu \mathrm{g} \mathrm{L}^{-1}$ BMAA $n=8 ; 1000 \mu \mathrm{g} \mathrm{L}^{-1}$ BMAA $n=4$.

A

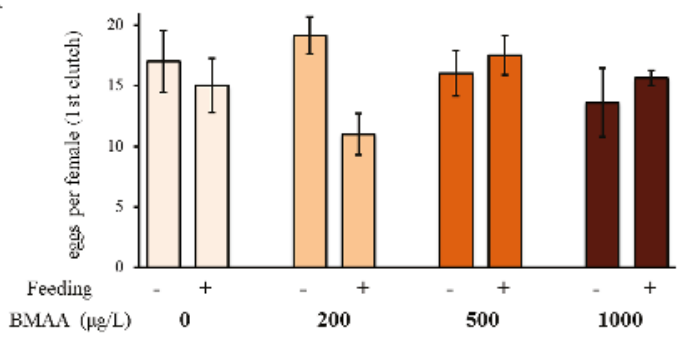

B

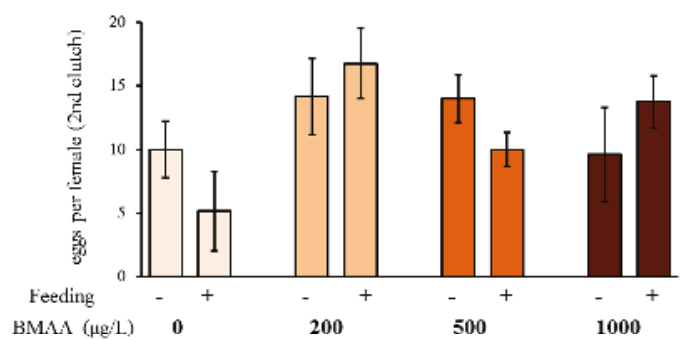

C
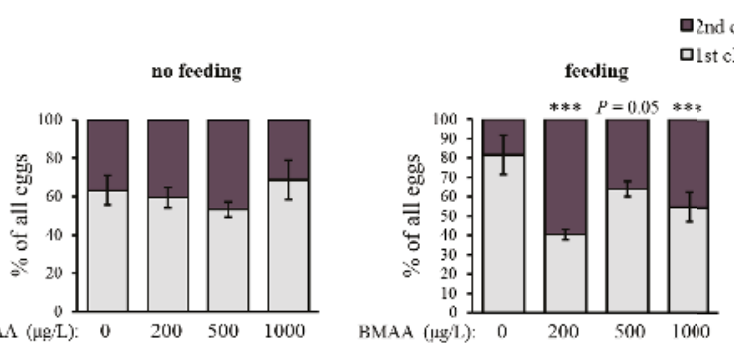

Figure 4. Beta-methyl-amino-L-alanine (BMAA) increases the number of eggs in the second clutch after the exposure to the toxin. (A) BMAA does not have any pronounced effect on the number of eggs in the first clutch after the exposure to the toxin (two-way ANOVA, feeding state: $p>0.05$, BMAA: $p>0.05$, 
feeding state $\times$ BMAA: $p<0.05$ ). The toxin does not have any significant effect under the non-feeding stage (one-way ANOVA, $p>0.05$ ), and under feeding conditions, the only detected difference was between the effects of the 200 and $500 \mu \mathrm{g} \mathrm{L}^{-1}$ BMAA (one-way ANOVA, $p<0.05$; Tukey's HSD, $p<0.05$ ). Pairwise comparisons (two-tailed Student's $t$-test, comparison to $0 \mu \mathrm{g} \mathrm{L}^{-1} \mathrm{BMAA}$ ) also did not reveal any significant decrease in egg production under exposure to BMAA $(p>0.05$ for each comparison). (B) BMAA has an effect on the number of eggs in the second clutch after the exposure (two-way ANOVA, BMAA: $p=0.02$, feeding: $p>0.05$, BMAA $\times$ feeding: $p>0.05$ ). BMAA does not affect the number of eggs in the second clutch under non-feeding condition (one-way ANOVA, $p>0.05$ ), but significantly affects the number of eggs under feeding conditions (one-way ANOVA, $p<0.05$ ) by increasing the number of eggs under exposure to $200 \mu \mathrm{g} \mathrm{L}^{-1}$ BMAA (Tukey's HSD, $p<0.01$ ). (C) BMAA does not affect the ratio between the eggs in the first and the second clutch after the exposure to the toxin in non-feeding animals (Fischer's exact test, pairwise comparisons with the $0 \mu \mathrm{g} \mathrm{L}{ }^{-1}$ BMAA, $p>0.05$ for each comparison). BMAA increases the proportion of eggs in the second clutch in feeding animals (Fischer's exact test, pairwise comparisons with the $0 \mu \mathrm{g} \mathrm{L}{ }^{-1}$ BMAA: $200 \mu \mathrm{g} \mathrm{L}{ }^{-1}$ BMAA: $p<0.001 ; 500 \mu \mathrm{g} \mathrm{L}^{-1}$ BMAA: $p=0.05 ; 1000 \mu \mathrm{g} \mathrm{L}^{-1}$ BMAA: $p<0.001$ ). (A-C) Sample size for the non-feeding females: $0 \mu \mathrm{g} \mathrm{L}{ }^{-1}$ BMAA $n=5 ; 200 \mu \mathrm{g} \mathrm{L}^{-1}$ BMAA $n=6 ; 500 \mu \mathrm{g} \mathrm{L}^{-1}$ BMAA $n=5$; $1000 \mu \mathrm{g} \mathrm{L}{ }^{-1}$ BMAA $n=5$. Sample size for feeding females: $0 \mu \mathrm{g} \mathrm{L}^{-1}$ BMAA $n=6 ; 200 \mu \mathrm{g} \mathrm{L}^{-1}$ BMAA $n=8 ; 500 \mu \mathrm{g} \mathrm{L}^{-1}$ BMAA $n=8 ; 1000 \mu \mathrm{g} \mathrm{L}^{-1}$ BMAA $n=8$. Error bars represent standard error of the mean (SEM).

Altogether, BMAA affects female reproduction. Next, we tested whether BMAA changes motility, which we analyzed as spontaneous swimming. Depending on their swimming capability, animals were categorized into three classes-immobile water fleas, weak swimmers and strong swimmers. Exposure to BMAA did not change the proportion of the categories, neither under starvation, nor under feeding conditions (Figure 5).

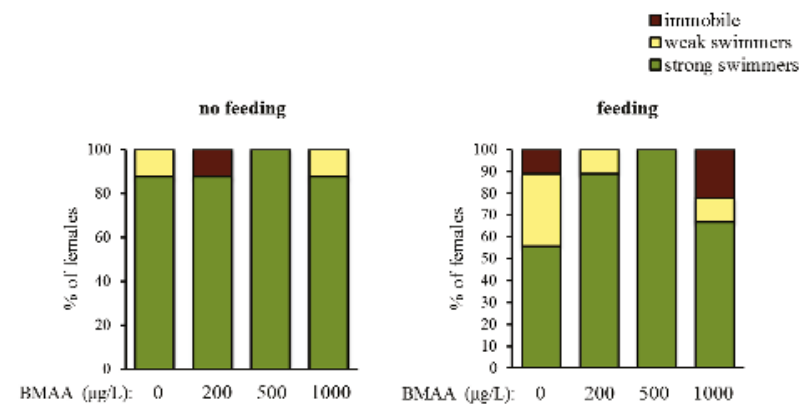

Figure 5. Beta-methyl-amino-L-alanine (BMAA) does not have a significant effect on the swimming ability, analyzed as differences in the \% of females that are immobile, weakly and strongly swimming after 4 days of exposure to the toxin ( $\chi^{2}$ test, $p>0.05$ both under non-feeding and feeding conditions). Sample size for the non-feeding females: $n=8$ for each concentration, sample size for the feeding females: $n=9$ for each concentration.

\subsection{Effects of BMAA on Dopaminergic Neurons}

Since we did not detect any impairment of mobility upon exposure to BMAA (Figure 5), we analyzed the potential effects of the toxin on the dopaminergic neurons directly, by analyzing their anatomy and dopamine levels by immunostainings, using an antibody against tyrosine-hydroxylase, the rate-limiting enzyme in dopamine biosynthesis. Exposure to the toxin led to a progressive decrease of immunofluorescence of the entirety of dopaminergic neurons in water fleas that were not fed during the exposure to the toxin (Figure 6), as well as in animals that were fed ad libitum during the treatment (Figure 7). Quantification of the immunofluorescence confirmed this negative effect of the BMAA (Figure 8). Increased concentrations of BMAA dramatically decreased the fluorescence 
intensity of dopaminergic neurons in D. magna. Since measurements of the entire sets of dopaminergic neurons were performed on flattened Zeta-stacks, the behavior of individual neuron types was no longer discernable. Nevertheless, at $500 \mu \mathrm{g} \mathrm{L}^{-1}$, a tendency was seen for dopaminergic lamina and some ventral neuron groups to apparently withstand BMAA treatment better than the dorsal groups (Figures 6 and 7).
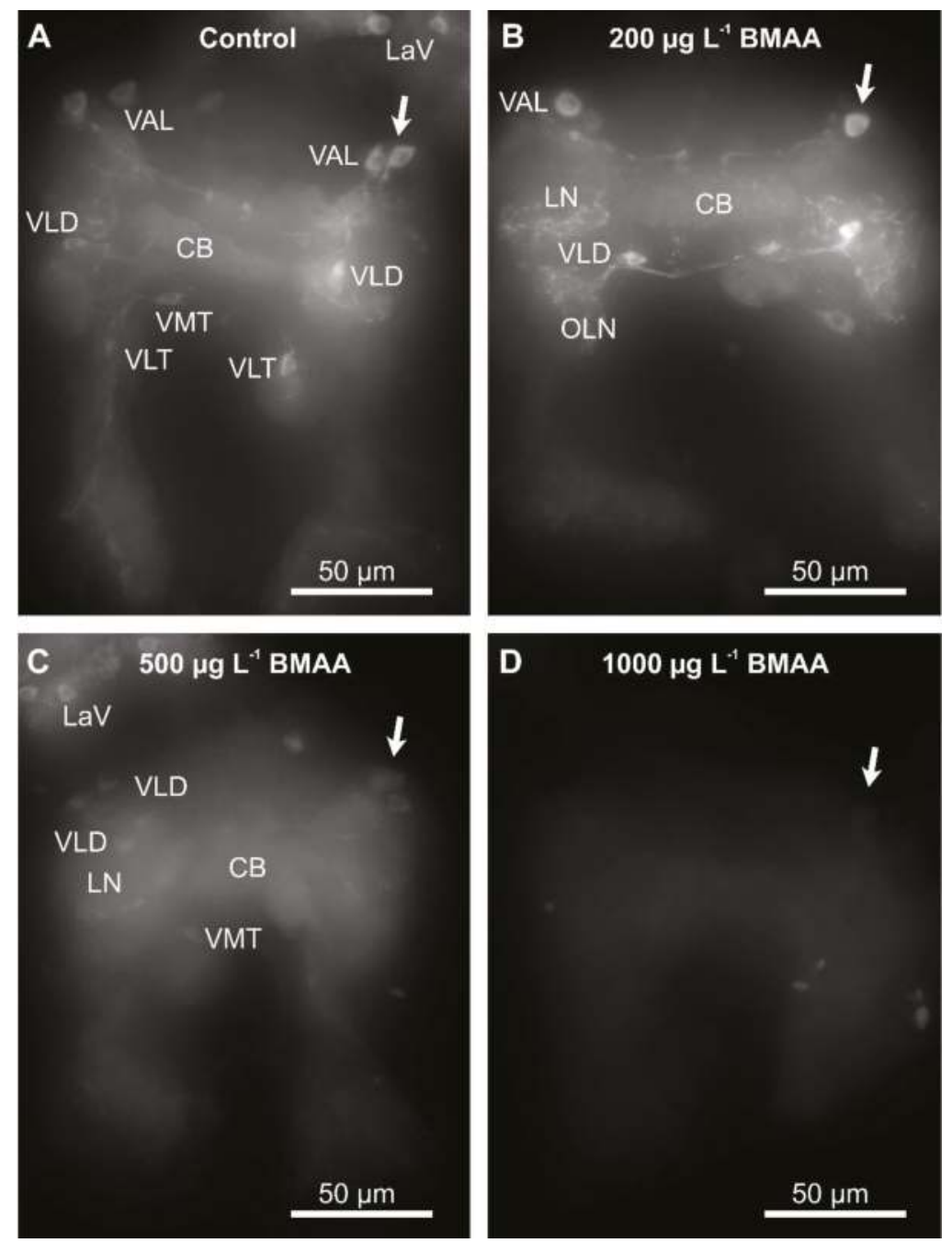

Figure 6. Beta-methyl-amino-L-alanine (BMAA) affects identified dopaminergic neurons in the brain cells of starved D. magna after 4 days of exposure to different concentrations of BMAA toxin. Identifiable neuron groups are labelled; arrows show identical unipolar ventral anterior lateral (VAL) neuron group as an example, cp. Figure 1A for abbreviations). (A) Control group, no BMAA added. (B) $200 \mu \mathrm{g} \mathrm{L}^{-1}$ BMAA exposure. (C) $500 \mu \mathrm{g} \mathrm{L}{ }^{-1}$ BMAA exposure. (D) $1000 \mu \mathrm{g} \mathrm{L}^{-1}$ BMAA exposure. Note that the cell bodies of lamina neurons (e.g., LaV) and ventral neuron groups appear least affected by increased BMAA concentration, but neuropile fibers are also affected. Immunofluorescence demonstrated by the Zeiss Axioscope-2 microscope using the AxioCam HR camera with exposure time of $900 \mathrm{ms,}$ $40 \times$ objective, $1.6 \times$ further magnification (via optovar) and $1 \mu \mathrm{m}$ optical thickness in zeta-stacks. 

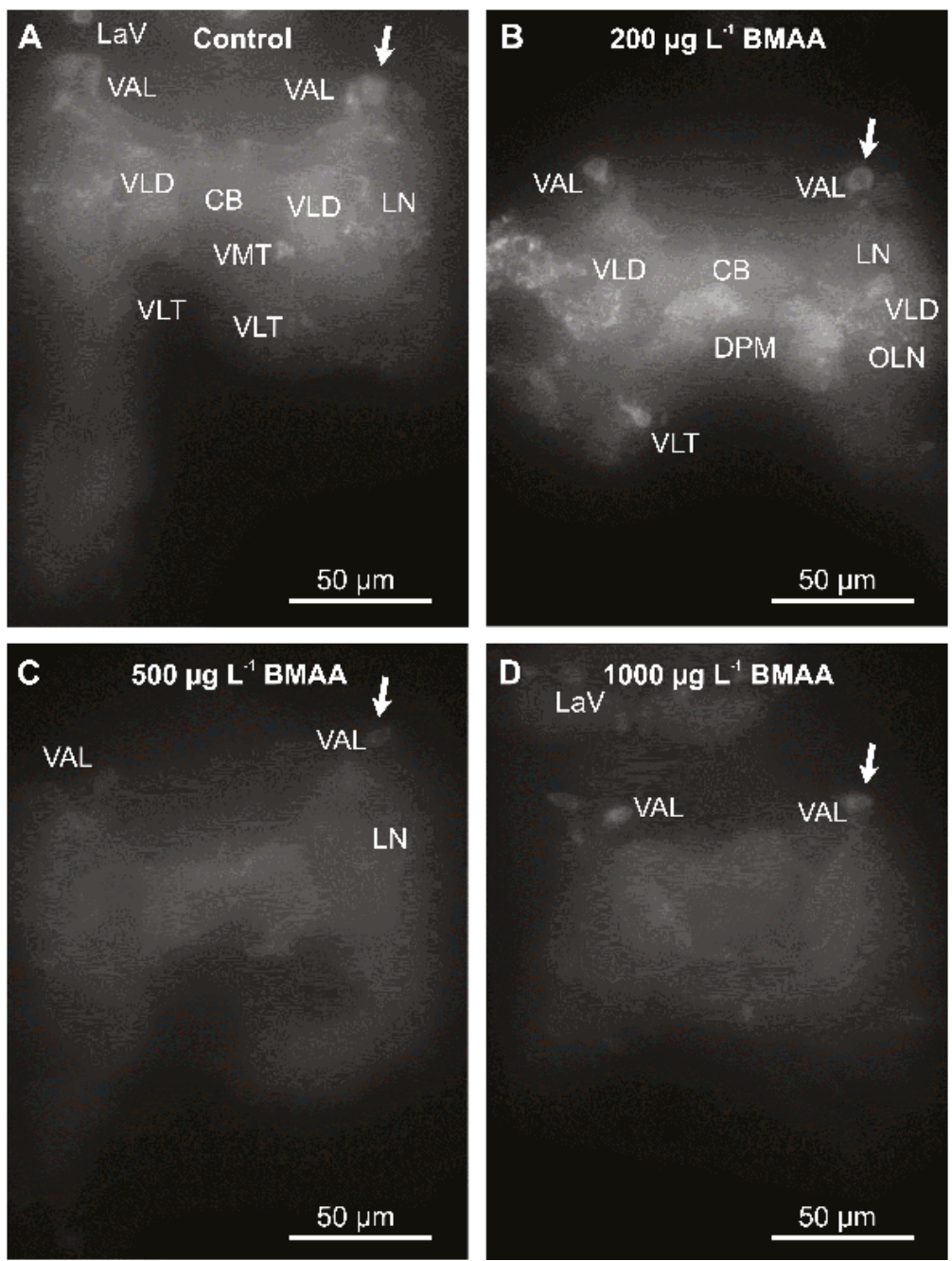

Figure 7. Beta-methyl-amino-L-alanine (BMAA) affects identified dopaminergic neurons in the brain cells of fed D. magna after 4 days of exposure to different concentrations of the BMAA toxin. Identifiable neuron groups are labelled; arrows show identical unipolar ventral anterior lateral (VAL) neuron group as an example, cp. Figure 1A for abbreviations. (A) Control group, no BMAA added. (B) $200 \mu \mathrm{g} \mathrm{L} \mathrm{g}^{-1}$ BMAA exposure. (C) $500 \mu \mathrm{g} \mathrm{L}-1$ BMAA exposure. (D) $1000 \mu \mathrm{g} \mathrm{L}^{-1}$ BMAA exposure. Immunofluorescence as demonstrated by the Zeiss Axioscope-2 microscope and AxioCam HR camera using the same settings as in the legend to Figure 6. 


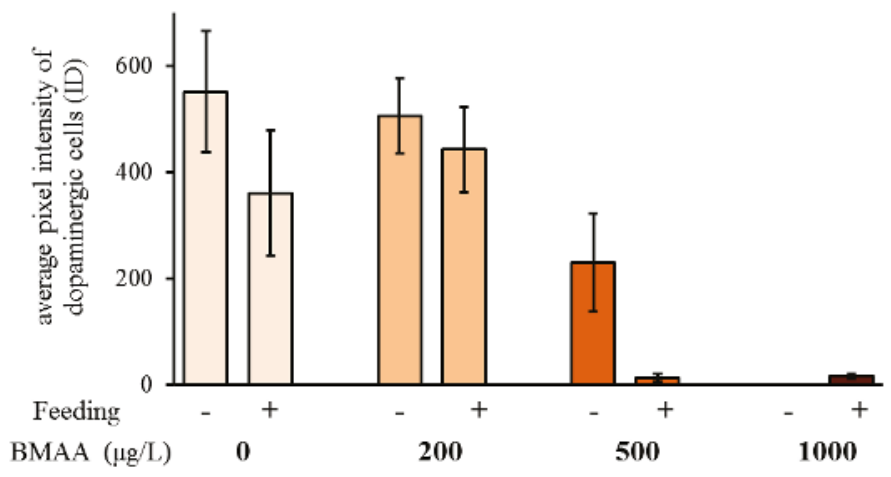

Figure 8. Beta-methyl-amino-L-alanine (BMAA) decreases immunofluorescence of the dopaminergic neurons, measured as integrated density (ID $=$ fluorescent area of the dopaminergic neurons $\times$ their average pixel intensity). Both feeding state and BMAA treatment have a significant effect on the immunofluorescence of the dopaminergic neurons (two-way ANOVA, feeding state: $p<0.05$, BMAA: $p<0.0001$, feeding state $\times$ BMAA: $p>0.05$ ). Sample size for the non-feeding females: $0 \mu \mathrm{g} \mathrm{L}{ }^{-1}$ BMAA $n=16 ; 200 \mu \mathrm{g} \mathrm{L}^{-1}$ BMAA $n=10 ; 500 \mu \mathrm{g} \mathrm{L}^{-1}$ BMAA $n=13 ; 1000 \mu \mathrm{g} \mathrm{L}{ }^{-1}$ BMAA $n=14$. Sample size for the feeding females: $0 \mu \mathrm{g} \mathrm{L}{ }^{-1}$ BMAA $n=14 ; 200 \mu \mathrm{g} \mathrm{L}^{-1}$ BMAA $n=11 ; 500 \mu \mathrm{g} \mathrm{L}^{-1}$ BMAA $n=17$; $1000 \mu \mathrm{g} \mathrm{L}^{-1}$ BMAA $n=16$. Error bars represent SEM.

\section{Discussion}

A putative localization of dopamine in D. magna brain tissue has only been briefly described in the previous literature. The first evidence for dopaminergic neurons in D. magna brain and optic ganglia neurons was provided by the use of the Falck-Hillarp fluorescence technique [42]; it found reactivity in similar neuropiles and some cell groups as in the present study. The present study, however, has used a specific immunohistochemical technique to identify the entire dopaminergic system of D. magna for the first time, by use of an antibody against tyrosine-hydroxylase, the rate-limiting enzyme in the dopamine-synthesis pathway. The number and distribution pattern of dopaminergic neurons does not correlate to any other set of hitherto described neurons incl. neurosecretory neurons detected up to the present date in D. magna. Known neurosecretory and other systems include neurons producing crustacean hyperglycemic hormone [47], pigment dispersing hormone [48], allatostatin A-type, FMRFamide-related, tachykinin neuropeptides, and the neurotransmitters histamine [46] and serotonin [49].

The tendency towards lower fertility of D. magna in the acute toxicity test conducted in the present study correlates with increased mortality seen in other aquatic organisms when incubated in BMAA, like fish larvae Danio rerio, brine shrimps Artemia salina and the ciliate Nassula sorex [50]. These results also show substantial similarities with previous findings in D. magna neonates incubated for $48 \mathrm{~h}$ in BMAA [39]. This period is shorter compared with the 4-day incubation used in the present study, but their study found that immobility and mortality of D. magna neonates increased with increasing concentrations of BMAA. The present study used 4-day instead of 2-day exposures in order to cover the entire molting and reproductive cycle during adulthood (usually three days) and the possible influences. The present study did not find any significant effect of BMAA on the survival of the neonates, although a negative effect of BMAA on D. magna neonatal survival has been described previously [39]. Lürling et al. (2011) used the concentration from $100 \mu \mathrm{g} \mathrm{L}^{-1} \mathrm{BMAA}$ to $1000 \mu \mathrm{g} \mathrm{L}^{-1}$ BMAA, but only at $1000 \mu \mathrm{g} \mathrm{L} \mathrm{L}^{-1}$ BMAA did the D. magna neonates show significantly increased mortality [39]. The differential outcome of this study vs. the work by Lürling et al. (2011) may have been caused by a different strategy of exposure of neonates to the toxin. Whereas Lürling et al. incubated D. magna neonates directly in BMAA [39], the present study looked at offspring neonatal survival produced from D. magna mothers incubated in BMAA. D. magna adults molt before each 
development of eggs in the brood chamber which is usually every 3-4 days [49]. Hence, 4 days of incubation in BMAA in the present study allowed time for each D. magna adult to molt at least once. The molting cycle of D. magna was not significantly affected by BMAA. Interestingly, in the females that have been fed during the toxin exposure, BMAA affected egg production. A mild exposure to the toxin increased the number of eggs in the second clutch. In addition, BMAA affected the ratio between the number of eggs in the first and second clutch. Under all tested concentrations, the number of eggs in the second clutch increased, in comparison to the first clutch. The analysis of the identified dopaminergic system of D. magna adults has clearly detected a significant decrease of dopaminergic neuron activity with increased exposure to BMAA. In both the fed and starved animals, a significant decrease of activity was seen in dopaminergic neurons of animals incubated in $500 \mu \mathrm{g} \mathrm{L}^{-1}$ and $1000 \mu \mathrm{g} \mathrm{L}^{-1}$ BMAA concentrations compared to the controls. The results showed that fed D. magna had very low dopaminergic neuron activity in both $500 \mu \mathrm{g} \mathrm{L}^{-1}$ and $1000 \mu \mathrm{g} \mathrm{L}^{-1}$ BMAA incubation whereas starved $D$. magna had very low dopaminergic activity only in the highest BMAA concentration of $1000 \mu \mathrm{g} \mathrm{L}^{-1}$. This suggests that feeding aids BMAA uptake because the fed D. magna are more affected by the toxins even at lower concentrations and hence may have taken up more BMAA. However, to obtain more distinctive results for individual dopaminergic neuron types or groups, their full reconstruction would be necessary to apply similar analysis methods.

Loss of activity of dopaminergic neurons in D. magna can be linked to neurodegenerative diseases in humans, as these diseases are associated with a loss of dopaminergic neurons [51,52]. Studying the effects of BMAA on dopaminergic neurons in D. magna in the present study has thus been an effective way to test the role of BMAA in neurodegenerative diseases, especially since this animal cannot avoid being affected in its aquatic environment. The BMAA hypothesis, first put forward from the investigations on Guam, states that BMAA could be a cause of neurodegeneration [53]. The results from this study on D. magna appear to support this BMAA hypothesis. In D. magna, dopaminergic neurons apparently have an integrated role in modulating motor behavior, specifically swimming movements [44]. Neurodegeneration of dopaminergic neurons could therefore explain the swimming deficits seen in D. magna neonates [39] during BMAA exposure. In humans, dopamine release in distinct brain neurons is important for motor control and decreased release of dopamine, especially when during neurodegenerative disease dopaminergic neurons are lost, can severely affect movement including reduced gait speed, shorter step length and prolonged standing phase [54,55]. The similarities of the role of dopamine in D. magna and humans, and the consequential behaviors that are observed when dopamine is decreased in both species demonstrates that $D$. magna is an adequate model organism to test toxicity effects leading to neurodegeneration closely similar to that known in humans. D. magna would even be capable of passing BMAA along the food chain from cyanobacteria (or from BMAA-containing green algae) via fish or shellfish predators to the human diet leading to BMAA biomagnifications as seen in the analyses of Swedish seafood [32,33].

In conclusion, the present study has proven D. magna to be an adequate model organism for toxicity testing of BMAA at the level of identified neurons. These results extend our knowledge of the crucial link between human neurodegenerative diseases and their being influenced by the environment, and they raise the ecotoxicological aspects of possible disease acquisition pathways. With the incidence of cyanobacterial blooms prone to increase worldwide due to global warming [56], it is now more important than ever that further investigations into the neurotoxic effects of BMAA are completed.

\section{Materials and Methods}

\subsection{Experimental Animals}

All animals used in the present study were cladoceran Daphnia magna (Strauss 1820), the test strain for environmental pollution, "Klon 5" from the State office for Nature, Environment and Customer Protection (North-Rhine Westphalia, Bonn, Germany) originating from the Federal Environmental Agency (Berlin, Germany). They have since been cultured in the laboratory at the Department 
of Zoology of Stockholm university (Sweden) in tap water in $1 \mathrm{~L}$ vials in a climate chamber with photoperiod set to a $16 \mathrm{~h}$ light: $8 \mathrm{~h}$ dark cycle and temperature at $20 \pm 2{ }^{\circ} \mathrm{C}$ under ca. $1200 \mathrm{Lux}$ artificial light. These animals were fed ad libitum the green algae Scenedesmus subspicatus (Chodat 1926) and Chlorella vulgaris (Beijerinck 1890) that were axenically reared under normal daylight in a defined culture medium (DIN 38412-9.1).

Prior to the experiments, a new isogenic female lineage of $D$. magna was set up. Six parthenogenetic females from one mother were incubated in 1 L glass vials, with one animal in each, containing $750 \mathrm{~mL}$ reconstituted artificial lake water medium $\left(8 \mathrm{mg} \mathrm{L}^{-1} \mathrm{KCL}, 192 \mathrm{mg} \mathrm{L}^{-1}\right.$ $\mathrm{NaHCO}_{3}, 245.95 \mathrm{mg} \mathrm{L}^{-1} \mathrm{MgSO}_{4} \times 6 \mathrm{H}_{2} \mathrm{O}, 120 \mathrm{mg} \mathrm{L}^{-1} \mathrm{CaSO}_{4}$, MilliQ-filtered $\mathrm{H}_{2} \mathrm{O}$ ), as standardized by the American Society for Testing and Materials (ASTM) with $4 \mathrm{~mL} \mathrm{~L}^{-1}$ of added Scottish marine algae extract (Scotland) (at optical densities between 0.56-0.60 as measured photometrically at $400 \mathrm{~nm}$ wave length) [57]. The medium was exchanged every 3 to 4 days and the animals were fed $\sim 8.5 \times 10^{7} \mathrm{~mL}^{-1}$ S. subspicatus and $\sim 9.6 \times 10^{7} \mathrm{~mL}^{-1} \mathrm{C}$. vulgaris daily. The neonates of the first synchronized brood were isolated and separated into different vials; these were allowed to grow in the medium until they themselves produced a synchronised brood, the neonates of which were then isolated and separated again into $1 \mathrm{~L}$ vials. This third generation of parthenogenetic females (all of the same age $\pm 12 \mathrm{~h}$ ) was grown for 10 days until adulthood to be used in the experiments.

\subsection{BMAA Toxicity Test}

Previous work had shown that at lower toxin concentrations, D. magna are better at taking up dissolved BMAA rather than BMAA in cyanobacteria [35]. Accordingly, the present study used only dissolved BMAA instead of cyanobacteria as a food source. For the toxicity test, 68 adult parthenogenetic females of D. magna were separated individually into $100 \mathrm{~mL}$ glass vials containing $50 \mathrm{~mL}$ of ASTM medium and $20 \mu \mathrm{L}$ Scottish marine algae extract. The animals in vials 1 to 17 were kept as controls with no BMAA toxin added. Previous work had shown that after being exposed to $100 \mu \mathrm{g} \mathrm{L}^{-1}$ BMAA over $48 \mathrm{~h}, 50 \%$ of $\mathrm{D}$. magna neonates became immobile (showing heartbeat but no swimming) [39]. Following these results, the present study incubated animals in concentrations of 200, 500 and $1000 \mu \mathrm{g} \mathrm{L}^{-1}$ BMAA for 4 days. An incubation time of 4 days was chosen in order to allow each animal to molt once to see if BMAA has effects on or during molting.

In addition, the effects of feeding on BMAA uptake were investigated. Therefore, half of the animals from each independent group were fed and half were starved (last fed $24 \mathrm{~h}$ prior to incubation start). Animals that were fed were given high food levels $\left(5 \times 10^{5} \mathrm{~mL}^{-1}\right)$ of S. subspicatus and $\left(5 \times 10^{5} \mathrm{~mL}^{-1}\right)$ C. vulgaris daily. The concentration of both $S$. subspicatus and C. vulgaris was calculated as follows: $4 \mu \mathrm{L}$ of each alga was placed onto glass slides under $20 \times 20 \mathrm{~mm}^{2}$ cover slips, to cover the whole cover slip. Ten photographs were taken at random with the $20 \times$ objective and at $1.0 \times$ magnification of each alga with a Leitz DMRBE microscope using a Leica DFC290 camera computer-controlled by Leica Q with Standard v. 3.5.0 software (Leica Microsystems, Wetzlar, Germany). A photograph of the same size was taken of a graticule to measure the photographic magnification. To calculate the number of green algae in each photo, every image was opened in ImageJ software (version 1.51j8, National Institute of Health, Bethesda, MD, USA, https://imagej.nih.gov/ij/) and converted to 8-bit grey-scales. The photos were then inverted and threshold defined in order to select the individual algae. The algae were counted by analyzing the particles of each image using the particle analysis tool. The mean number of algae from the 10 images was then calculated, and using the measurements from the graticule, the mean number of algae on the whole cover slip could be calculated as the number of algae in $4 \mu \mathrm{L}$. This was then used to finally work out the number of algae per $\mathrm{mL}$.

ASTM medium and Scottish marine algae in each vial were exchanged half way through the 4-day incubation for fresh medium. Neonates were removed within $24 \mathrm{~h}$, and animals that had died before the end of the experiment were dissected as soon as was possible. The swimming strength (as estimated by looking at swimming speed by eye), number of eggs in the brood chamber, egg development time, 
number of neonates released, and number of completely molted carapaces shed was recorded daily by examining each individual experimental animal.

\subsection{Dissection of Optic Ganglia and Brains}

After the experiment, the animals were transferred to Sylgard ${ }^{\circledR}$-coated Falcon ${ }^{\circledR}$ Petri dishes (Silicone elastomer 184: Dow Corning Co, Midland, MI, USA; dishes: no. 351008, Becton Dickinson Co, Franklin Lakes, NJ, USA) containing Daphnia saline (3.565 g L ${ }^{-1} \mathrm{NaCl}, 0.224 \mathrm{~g} \mathrm{~L}^{-1} \mathrm{KCL}, 0.203 \mathrm{~g} \mathrm{~L}^{-1}$ $\mathrm{MgCl}_{2} \times 6 \mathrm{H}_{2} \mathrm{O}, 1.668 \mathrm{~g} \mathrm{~L}^{-1}$ HEPES, Waters MilliQ ${ }^{\circledR}$-filtered $\mathrm{H}_{2} \mathrm{O}, \mathrm{pH}$ adjusted to 7.3 with $0.1 \mathrm{M}$ $\mathrm{NaOH}$ ) [58]. With the use of microdissection scissors and fine forceps, both second antennae were removed at the base close to the carapace, and the headshield was opened by cutting the dorsal carapace from the anterior end of the heart to the anterior side of the hepatic caeca. The foregut and hepatic caeca were carefully removed creating a flow-through area for the later applied fixative. A dorso-ventral cut posterior to the mandibles was made, allowing the head to be removed from the rest of the body. These heads were then bathed in Zamboni fixative consisting of $4 \%$ paraformaldehyde and $15 \%$ picric acid in 0.1 M sodium phosphate buffer at pH 7.3 [59] (Chemicals from Sigma-Aldrich/Merck KG, Darmstadt, Germany) for $1 \mathrm{~h}$ at room temperature. After this time, the dissected heads were put back into the Daphnia saline. The mandibles were removed and the cuticle was carefully torn apart, breaking the connection between the eye and cuticle. The complex of the optic ganglia and the central brain together with the compound eye were then further fixed in Zamboni fixative once more and left overnight at $4{ }^{\circ} \mathrm{C}$ for tissue stabilization.

\subsection{Immunohistochemistry and Confocal Microscopy}

For immunohistochemical labelling, preparations were first washed for $4 \times 15$ min with $0.1 \mathrm{M}$ phosphate buffered saline (PBS) on a Gyrotory ${ }^{\circledR}$ shaker (New Brunswick Scientific G2, Edison, NJ, USA) to remove the fixative. Preparations were then incubated at room temperature in humid conditions for $24 \mathrm{~h}$ in rabbit anti-tyrosine hydroxylase (TH) primary antibody (Sino Biological Inc., Beijing, China; no. 50997) diluted 1:2000 in Tris-hydroxyl-amino methane-buffer at $\mathrm{pH} 7.4$ containing $0.3 \mathrm{M} \mathrm{NaCl}$ and $0.5 \%$ Triton-X-100 detergent (TBTX0.5) with $0.02 \%$ sodium azide. This was followed by $4 \times 15 \mathrm{~min}$ washes in Tris-hydroxyl-amino methane-buffer containing $0.3 \mathrm{M} \mathrm{NaCl}$ and $0.1 \%$ Triton-X-100 detergent (TBTX0.1) and then the preparations were incubated at room temperature for $1 \mathrm{~h} 45 \mathrm{~min}$ in darkness in goat-anti-rabbit-IgG-FITC conjugate secondary antibody (F0382, Sigma-Aldrich/Merck KG, Darmstadt, Germany) diluted 1:100 in TBTX0.5 with $0.02 \%$ sodium azide. After $3 \times 15$ min washes in TXTB0.1 and $1 \times 15 \mathrm{~min}$ wash in PBS, preparations were mounted in $80 \%$ aqueous glycerol containing $50 \mathrm{mg} \mathrm{mL}^{-1}$ 1,4-diazabicyclo (2.2.2) octane (Fluka, Sigma-Aldrich/Merck KG, Darmstadt, Germany) as anti-fading agent.

To obtain a more detailed overview of the dopaminergic system of D. magna, preparations for confocal microscopy were triple-labelled by in addition using antibodies revealing entire ganglionic neuropile areas via labelling synapsin, a protein found in all synaptic contacts [60,61]. Together with the TH antibody, a mouse monoclonal anti-synapsin primary antibody (DSHB, Developmental Studies Hybridoma Bank, University of Iowa, Iowa, IA, USA, code 3C11 = anti SYNORF1, [60]) diluted 1:100 in TBTX0.5 with $0.02 \%$ sodium azide was applied. After several washes in TBTX0.1, a goat anti-rabbit-IgG-FITC conjugate secondary antibody (Sigma F0382) diluted 1:100 in TBTX0.5 with $0.02 \%$ sodium azide was added as well as a goat anti-mouse-IgG $(\mathrm{H}+\mathrm{L})$-Alexa Fluor 546 conjugated secondary antibody (Life Technologies 11003, Thermo Fisher Scientific, Waltham, MA. USA) diluted 1:500 in TBTX0.5 with $0.02 \%$ sodium azide for $1 \mathrm{~h}$ at room temperature to reveal both TH and synapsin. Here, finally a DAPI stain (4',6-Diamidine-2' - phenylindole dihydrochloride, Sigma-Aldrich/Merck KG, Darmstadt, Germany) diluted to $1 \mu \mathrm{g} \mathrm{mL}^{-1}$ in TBTX0.5 with $0.02 \%$ sodium azide was added to stain the DNA in cell nuclei. This triple staining was used to provide background staining (for neuropiles and cell nuclei) to show where the dopaminergic neurons are in relation to the whole optic ganglia and brain. The preparations were analyzed and imaged using a Zeiss LSM 780 confocal laser-scanning microscope 
(Carl Zeiss, Oberkochen, Germany) operating with lasers at $405 \mathrm{~nm}$ (for DAPI), $488 \mathrm{~nm}$ (for FITC), $561 \mathrm{~nm}$ (for Alexa Fluor 546) wavelengths and Zeiss Zen 2012 LSM Confocal software (Carl Zeiss, Oberkochen, Germany). Final pictures were edited and slightly adjusted for contrast and brightness using Corel Photopaint v. X7 and assembled in CorelDraw v. X7 (Corel Co, Ottawa, ON, Canada).

\subsection{Imaging and Morphometry for Toxicity Test Evaluation}

Immunofluorescence imaging and quantification were performed as previously described [49]. Preparations were imaged with a Zeiss Axioscope-2 microscope (Carl Zeiss, Oberkochen, Germany) with a Lambda 10-c filter wheel, a motorized focus, equipped with epifluorescence (FITC filter system-excitation filter band pass $485 \pm 20 \mathrm{~nm}$, emission filter band pass 515-565 nm) computer-controlled by Zeiss Axiovision v. 4.8.2.0 software (Carl Zeiss, Oberkochen, Germany) allowing for merging and smoothing of several Z-series focus planes (extended focus module). A valid comparability of measurements of the different preparations was ensured by taking all photographs at a fixed exposure time of $900 \mathrm{~ms}$ and by using identical microscope settings of a $40 \times$ objective and $1.6 \times$ secondary Zeiss Optovar magnification [48] with an optical thickness of $1 \mu \mathrm{m}$ by an AxioCam HR camera (Carl Zeiss, Oberkochen, Germany) set to $1388 \times 1040$ pixels standard mono using Z-stacking. All Z-stack images were merged into an extended focus high projection single image.

\subsection{Data Analysis}

Fluorescence intensity for the toxicity test was quantified using ImageJ software by analyzing Average Pixel Intensity (API) [62], which was calculated manually. Therefore, each of the images were introduced into ImageJ two times; these were then converted to 8-bit grey-scale images of 8 bit. One of the images was then inverted and threshold defined for the selection of the relative fluorescent neurons. To have comparable measurements of each preparation, the same optimum threshold level was used for each image. The threshold-defined selection from the first image was then transferred to the second image. For the calculation of background API, we chose the part outside of the selection and measured its average pixel intensity. This background pixel intensity was thereafter subtracted from every pixel in the image to remove it. The selected fluorescent neuronal areas were again superimposed to the image from which the background had been subtracted. In order to measure only specific fluorescence, every image was background-subtracted so that from every threshold-defined region its API and fluorescent area could be calculated. Instead of API, the Integrated Density ((ID), which equals fluorescent area $\times$ average pixel intensity) was, however, used as a valid representation of the fluorescence of the neurons. This is because ID considers the labelled area as well as API [63]. Thereby, ID is a good representation of dopamine immunoreactivity in individual optic ganglia/brain-complexes (OGBC) of the experimental animals; pictures of optic ganglia and brains were usually analyzed separately but derived values were later combined. All statistical tests were performed with PAST (http://palaeo-electronica.org/2001_1/past/issue1_01.htm) [64].

Author Contributions: Research and writing for this article was shared among both authors with emphasis on conceptualization, H.D.; methodology, M.B.-J. and H.D.; software, M.G., H.D.; validation, M.B.-J., M.G., and H.D.; formal analysis, M.B.-J. and M.G.; investigation, M.B.-J. and H.D.; resources, H.D.; data curation, M.B.-J., M.G., and H.D.; writing-original draft preparation, M.B.-J.; writing—review and editing, M.B.-J., M.G., and H.D.; visualization, M.B.-J., M.G., and H.D.; supervision, H.D.; project administration, H.D.; funding acquisition, H.D.

Funding: M.B.-J. was funded by a University of Manchester, U.K., School of Biological Sciences undergraduate placement program. H.D. is grateful to the Faculty of Natural Sciences, Stockholm University, Sweden, and the Carl Tryggers Stiftelse för Vetenskaplig Forskning, Stockholm, Schweden, for support.

Acknowledgments: The authors are grateful to Bruno Campos, Unilever, Milton Keynes, U.K. for introduction into the fluorescence microscopical quantification of immunolabellings.

Conflicts of Interest: The authors declare no conflict of interest. The funders had no role in the design of the study; in the collection, analyses, or interpretation of data; in the writing of the manuscript, or in the decision to publish the results. 


\section{References}

1. Kurland, L.T.; Mulder, D.W. Epidemiologic investigations of amyotrophic lateral sclerosis. I. Preliminary report on geographic distribution, with special reference to the Mariana Islands, including clinical and pathologic observations. Neurology 1954, 4, 355-378. [CrossRef]

2. Cox, P.A.; Banack, S.A.; Murch, S.J. Biomagnification of cyanobacterial neurotoxins and neurodegenerative disease among the Chamorro people of Guam. Proc. Natl. Acad. Sci. USA 2003, 100, 13380-13383. [CrossRef]

3. Holtcamp, W. The emerging science of BMAA: Do cyanobacteria contribute to neurodegenerative disease? Environ. Health Perspect. 2012, 120, A110. [CrossRef] [PubMed]

4. Cox, P.A.; Sacks, O.W. Cycad neurotoxins, consumption of flying foxes, and ALS-PDC disease in Guam. Neurology 2002, 58, 956-959. [CrossRef] [PubMed]

5. Banack, S.A.; Cox, P.A. Biomagnification of cycad neurotoxins in flying foxes: Implications for ALS-PDC in Guam. Neurology 2003, 61, 387-389. [CrossRef] [PubMed]

6. Rao, S.D.; Banack, S.A.; Cox, P.A.; Weiss, J.H. BMAA selectively injures motor neurons via AMPA/kainate receptor activation. Exp. Neurol. 2006, 201, 244-252. [CrossRef] [PubMed]

7. Lobner, D.; Piana, P.M.T.; Salous, A.K.; Peoples, R.W. $\beta$-N-methylamino-L-alanine enhances neurotoxicity through multiple mechanisms. Neurobiol. Dis. 2007, 25, 360-366. [CrossRef] [PubMed]

8. Liu, X.; Rush, T.; Zapata, J.; Lobner, D. $\beta-N$-methylamino-L-alanine induces oxidative stress and glutamate release through action on system $X_{\mathrm{C}}(-)$. Exp. Neurol. 2009, 217, 429-433. [CrossRef]

9. Murch, S.J.; Cox, P.A.; Banack, S.A.; Steele, J.C.; Sacks, O.W. Occurrence of $\beta$-methylamino-L-alanine (BMAA) in ALS/PDC patients from Guam. Acta Neurol. Scand. 2004, 110, 267-269. [CrossRef]

10. Pablo, J.; Banack, S.A.; Cox, P.A.; Johnson, T.E.; Papapetropoulos, S.; Bradley, W.G.; Buck, A.; Mash, D.C. Cyanobacterial neurotoxin BMAA in ALS and Alzheimer's disease. Acta Neurol. Scand. 2009, 120, $216-225$. [CrossRef]

11. Mello, F.D.; Braidy, N.; Marcal, H.; Guillemin, G.; Nabavi, S.M.; Neilan, B.A. Mechanisms and effects posed by neurotoxic products of cyanobacteria/microbial eukaryotes/dinoflagellates in algae blooms: A review. Neurotox. Res. 2018, 33, 153-167. [CrossRef] [PubMed]

12. Bienfang, P.K.; Defelice, S.V.; Laws, E.A.; Brand, L.E.; Bidigare, R.R.; Christensen, S.; Trapido-Rosenthal, H.; Hemscheidt, T.K.; McGillicuddy, D.J.; Anderson, D.M.; et al. Prominent human health impacts from several marine microbes: History, ecology, and public health implications. Int. J. Microbiol. 2011, 2011, 152815. [CrossRef]

13. Cox, P.A.; Banack, S.A.; Murch, S.J.; Rasmussen, U.; Tien, G.; Bidigare, R.R.; Metcalf, J.S.; Morrison, L.F.; Codd, G.A.; Bergman, B. Diverse taxa of cyanobacteria produce $\beta-N$-methylamino-L-alanine, a neurotoxic amino acid. Proc. Natl. Acad. Sci. USA 2005, 102, 5074-5078. [CrossRef] [PubMed]

14. Jiang, L.; Eriksson, J.; Lage, S.; Jonasson, S.; Shams, S.; Mehine, M.; Ilag, L.L.; Rasmussen, U. Diatoms: A novel source for the neurotoxin BMAA in aquatic environments. PLoS ONE 2014, 9, e84578. [CrossRef] [PubMed]

15. Lage, S.; Costa, P.R.; Moita, T.; Eriksson, J.; Rasmussen, U.; Rydberg, S.J. BMAA in shellfish from two Portuguese transitional water bodies suggests the marine dinoflagellate Gymnodinium catenatum as a potential BMAA source. Aquat.Toxicol. 2014, 152, 131-138. [CrossRef] [PubMed]

16. Metcalf, J.S.; Banack, S.A.; Lindsay, J.; Morrison, L.F.; Cox, P.A.; Codd, G.A. Co-occurrence of $\beta-N$-methylamino-L-alanine, a neurotoxic amino acid with other cyanobacterial toxins in British waterbodies, 1990-2004. Environ. Microbiol. 2008, 10, 702-708. [CrossRef]

17. Esterhuizen, M.; Downing, T.G. $\beta-N$-methylamino-L-alanine (BMAA) in novel South African cyanobacterial isolates. Ecotoxicol. Environ. Saf. 2008, 71, 309-313. [CrossRef]

18. Faassen, E.J.; Gillissen, F.; Zweers, H.A.; Lurling, M. Determination of the neurotoxins BMAA ( $\beta$-N-methylamino-L-alanine) and DAB (alpha-,gamma-diaminobutyric acid) by LC-MSMS in Dutch urban waters with cyanobacterial blooms. Amyotroph. Lateral Scler. 2009, 10 (Suppl. 2), 79-84. [CrossRef]

19. Horner, R.D.; Kamins, K.G.; Feussner, J.R.; Grambow, S.C.; Hoff-Lindquist, J.; Harati, Y.; Mitsumoto, H.; Pascuzzi, R.; Spencer, P.S.; Tim, R.; et al. Occurrence of amyotrophic lateral sclerosis among Gulf War veterans. Neurology 2003, 61, 742-749. [CrossRef] 
20. Cox, P.A.; Richer, R.; Metcalf, J.S.; Banack, S.A.; Codd, G.A.; Bradley, W.G. Cyanobacteria and BMAA exposure from desert dust: A possible link to sporadic ALS among Gulf War veterans. Amyotroph. Lateral Scler. 2009, 10, 109-117. [CrossRef]

21. Craighead, D.; Metcalf, J.S.; Banack, S.A.; Amgalan, L.; Reynolds, H.V.; Batmunkh, M. Presence of the neurotoxic amino acids $\beta$ - $N$-methylamino-L-alanine (BMAA) and 2,4-diamino-butyric acid (DAB) in shallow springs from the Gobi Desert. Amyotroph. Lateral Scler. 2009, 10 (Suppl. 2), 96-100. [CrossRef] [PubMed]

22. Li, A.; Tian, Z.; Li, J.; Yu, R.; Banack, S.A.; Wang, Z. Detection of the neurotoxin BMAA within cyanobacteria isolated from freshwater in China. Toxicon 2010, 55, 947-953. [CrossRef] [PubMed]

23. Hilborn, E.D.; Beasley, V.R. One health and cyanobacteria in freshwater systems: Animal illnesses and deaths are sentinel events for human health risks. Toxins 2015, 7, 1374-1395. [CrossRef]

24. Spencer, P.; Ohta, M.; Palmer, V. Cycad use and motor neurone disease in Kii peninsula of Japan. Lancet 1987, 330, 1462-1463. [CrossRef]

25. Cox, P.A.; Davis, D.A.; Mash, D.C.; Metcalf, J.S.; Banack, S.A. Dietary exposure to an environmental toxin triggers neurofibrillary tangles and amyloid deposits in the brain. Proc. R. Soc. B: Biol. Sci. 2016, 283. [CrossRef] [PubMed]

26. Caller, T.; Henegan, P.; Stommel, E. The Potential Role of BMAA in Neurodegeneration. Neurotox. Res. 2018, 33, 222-226. [CrossRef] [PubMed]

27. Mimuro, M.; Yoshida, M.; Kuzuhara, S.; Kokubo, Y. Amyotrophic lateral sclerosis and parkinsonism-dementia complex of the Hohara focus of the Kii Peninsula: A multiple proteinopathy? Neuropathology 2018, 38, 98-107. [CrossRef]

28. Al-Chalabi, A.; Hardiman, O. The epidemiology of ALS: A conspiracy of genes, environment and time. Nat. Rev. Neurol. 2013, 9, 617-628. [CrossRef]

29. Al-Chalabi, A.; Calvo, A.; Chio, A.; Colville, S.; Ellis, C.M.; Hardiman, O.; Heverin, M.; Howard, R.S.; Huisman, M.H.B.; Keren, N.; et al. Analysis of amyotrophic lateral sclerosis as a multistep process: A population-based modelling study. Lancet Neurol. 2014, 13, 1108-1113. [CrossRef]

30. Degerholm, J.; Gundersen, K.; Bergman, B.; Soderback, E. Phosphorus-limited growth dynamics in two Baltic Sea cyanobacteria, Nodularia sp. and Aphanizomenon sp. FEMS Microbiol. Ecol. 2006, 58, 323-332. [CrossRef]

31. Jonasson, S.; Eriksson, J.; Berntzon, L.; Spacil, Z.; Ilag, L.L.; Ronnevi, L.O.; Rasmussen, U.; Bergman, B. Transfer of a cyanobacterial neurotoxin within a temperate aquatic ecosystem suggests pathways for human exposure. Proc. Natl. Acad. Sci. USA 2010, 107, 9252-9257. [CrossRef] [PubMed]

32. Jiang, L.; Kiselova, N.; Rosén, J.; Ilag, L.L. Quantification of neurotoxin BMAA ( $\beta-N$-methylamino-L-alanine) in seafood from Swedish markets. Sci. Rep. 2014, 4, srep06931. [CrossRef] [PubMed]

33. Salomonsson, M.L.; Fredriksson, E.; Alfjorden, A.; Hedeland, M.; Bondesson, U. Seafood sold in Sweden contains BMAA: A study of free and total concentrations with UHPLC-MS/MS and dansyl chloride derivatization. Toxicol. Rep. 2015, 2, 1473-1481. [CrossRef] [PubMed]

34. Lage, S.; Annadotter, H.; Rasmussen, U.; Rydberg, S. Biotransfer of $\beta$ - $N$-methylamino-L-alanine (BMAA) in a eutrophicated freshwater lake. Mar. Drugs 2015, 13, 1185-1201. [CrossRef] [PubMed]

35. Esterhuizen-Londt, M.; Wiegand, C.; Downing, T.G. $\beta-N$-methylamino-L-alanine (BMAA) uptake by the animal model, Daphnia magna and subsequent oxidative stress. Toxicon 2015, 100, 20-26. [CrossRef]

36. Lürling, M. Effects of microcystin-free and microcystin-containing strains of the cyanobacterium Microcystis aeruginosa on growth of the grazer Daphnia magna. Environ. Toxicol. 2003, 18, 202-210. [CrossRef]

37. McQueen, D.J.; Post, J.R.; Mills, E.L. Trophic Relationships in Freshwater Pelagic Ecosystems. Can. J. Fish. Aquat. Sci. 1986, 43, 1571-1581. [CrossRef]

38. Martins, J.; Oliva Teles, L.; Vasconcelos, V. Assays with Daphnia magna and Danio rerio as alert systems in aquatic toxicology. Environ. Int. 2007, 33, 414-425. [CrossRef]

39. Lürling, M.; Faassen, E.J.; Van Eenennaam, J.S. Effects of the cyanobacterial neurotoxin $\beta-N$-methylamino-L-alanine (BMAA) on the survival, mobility and reproduction of Daphnia magna. J. Plankton Res. 2011, 33, 333-342. [CrossRef]

40. Kokubo, Y.; Ishii, K.; Morimoto, S.; Mimuro, M.; Sasak, R.; Murayama, S.; Kuzuhara, S. Dopaminergic positron emission tomography study on Amyotrophic lateral sclerosis/Parkinsonism-Dementia complex in Kii, Japan. J. Alzheimers Dis. Parkinsonism 2017, 7, 311. [CrossRef] 
41. Takahashi, H.; Snow, B.; Bhatt, M.H.; Peppard, R.; Eisen, A.; Calne, D.B. Evidence for a dopaminergic deficit in sporadic amyotrophic lateral sclerosis on positron emission scanning. Lancet 1993, 342, 1016-1018. [CrossRef]

42. Aramant, R.; Elofsson, R. Distribution of monoaminergic neurons in the nervous system of non-malacostracan crustaceans. Cell Tissue Res. 1976, 166, 1-24. [CrossRef] [PubMed]

43. Ehrenström, F.; Berglind, R. Determination of biogenic amines in the water flea, Daphnia magna (Cladocera, Crustacea) and their diurnal variations using ion-pair reversed phase HPLC with electrochemical detection. Comp. Biochem. Physiol. C Comp. Pharmacol. Toxicol. 1988, 90, 123-132. [CrossRef]

44. Barrozo, E.R.; Fowler, D.A.; Beckman, M.L. Exposure to D2-like dopamine receptor agonists inhibits swimming in Daphnia magna. Pharmacol. Biochem. Behav. 2015, 137, 101-109. [CrossRef] [PubMed]

45. Weiss, L.C.; Leese, F.; Laforsch, C.; Tollrian, R. Dopamine is a key regulator in the signalling pathway underlying predator-induced defences in Daphnia. Proc. R. Soc. B Biol. Sci. 2015, 282. [CrossRef] [PubMed]

46. Kress, T.; Harzsch, S.; Dircksen, H. Neuroanatomy of the optic ganglia and central brain of the water flea Daphnia magna (Crustacea, Cladocera). Cell Tissue Res. 2016, 363, 649-677. [CrossRef] [PubMed]

47. Zhang, Q.; Keller, R.; Dircksen, H. Crustacean hyperglycaemic hormone in the nervous system of the primitive crustacean species Daphnia magna and Artemia salina (Crustacea: Branchiopoda). Cell Tissue Res. 1997, 287, 565-576. [CrossRef]

48. Strauß, J.; Zhang, Q.; Verleyen, P.; Huybrechts, J.; Neupert, S.; Predel, R.; Pauwels, K.; Dircksen, H. Pigment-dispersing hormone in Daphnia interneurons, one type homologous to insect clock neurons displaying circadian rhythmicity. Cell. Mol. Life Sci. 2011, 68, 3403-3423. [CrossRef]

49. Campos, B.; Rivetti, C.; Kress, T.; Barata, C.; Dircksen, H. Depressing antidepressant: Fluoxetine affects serotonin neurons causing adverse reproductive responses in Daphnia magna. Environ. Sci. Technol. 2016, 50, 6000-6007. [CrossRef]

50. Purdie, E.L.; Metcalf, J.S.; Kashmiri, S.; Codd, G.A. Toxicity of the cyanobacterial neurotoxin $\beta-N$-methylamino-L-alanine to three aquatic animal species. Amyotroph. Lateral Scler. 2009, 10 (Suppl. 2), 67-70. [CrossRef]

51. Bernheimer, H.; Birkmayer, W.; Hornykiewicz, O.; Jellinger, K.; Seitelberger, F. Brain dopamine and the syndromes of Parkinson and Huntington. Clinical, morphological and neurochemical correlations. J. Neurol. Sci. 1973, 20, 415-455. [CrossRef]

52. Jana, S.; Sinha, M.; Chanda, D.; Roy, T.; Banerjee, K.; Munshi, S.; Patro, B.S.; Chakrabarti, S. Mitochondrial dysfunction mediated by quinone oxidation products of dopamine: Implications in dopamine cytotoxicity and pathogenesis of Parkinson's disease. Biochim. Biophys. Acta 2011, 1812, 663-673. [CrossRef] [PubMed]

53. Spencer, P.S. Guam ALS/parkinsonism-dementia: A long-latency neurotoxic disorder caused by "slow toxin(s)" in food? Can. J. Neurol. Sci. 1987, 14, 347-357. [CrossRef] [PubMed]

54. Crocker, A.D. The regulation of motor control: An evaluation of the role of dopamine receptors in the substantia nigra. Rev. Neurosci. 1997, 8, 55-76. [CrossRef] [PubMed]

55. Pistacchi, M.; Gioulis, M.; Sanson, F.; De Giovannini, E.; Filippi, G.; Rossetto, F.; Zambito Marsala, S. Gait analysis and clinical correlations in early Parkinson's disease. Funct. Neurol. 2017, 32, 28-34. [CrossRef] [PubMed]

56. Paerl, H.W.; Huisman, J. Climate. Blooms like it hot. Science 2008, 320, 57-58. [CrossRef] [PubMed]

57. Baird, D.J.; Soares, A.M.V.M.; Girling, A.E.; Barber, I.; Bradley, M.C.; Calow, P. The long-term maintenance of Daphnia magna for use in ecotoxicity tests: Problems and prospects. In Proceedings of the First European Conference on Ecotoxicology; Lokke, H., Tyle, H., Bro-Rasmussen, F., Eds.; Technical University: Lyngby, Denmark, 1989; pp. 144-148.

58. Van Harreveld, A. A physiological solution for freshwater crustaceans. Proc. Soc. Exp. Biol. Med. 1936, 34, 428-432. [CrossRef]

59. Stefanini, M.; De Martino, C.; Zamboni, L. Fixation of ejaculated spermatozoa for electron microscopy. Nature 1967, 216, 173-174. [CrossRef]

60. Klagges, B.R.E.; Heimbeck, G.; Godenschwege, T.A.; Hofbauer, A.; Pflugfelder, G.O.; Reifegerste, R.; Reisch, D.; Schaupp, M.; Buchner, S.; Buchner, E. Invertebrate synapsins: A single gene codes for several isoforms in Drosophila. J. Neurosci. 1996, 16, 3154-3165. [CrossRef] 
61. Harzsch, S.; Glötzner, J. An immunohistochemical study of structure and development of the nervous system in the brine shrimp Artemia salina Linnaeus, 1758 (Branchiopoda, Anostraca) with remarks on the evolution of the arthropod brain. Arthropod Struct. Dev. 2002, 30, 251-270. [CrossRef]

62. Raldúa, D.; Babin, P.J. Simple, rapid zebrafish larva bioassay for assessing the potential of chemical pollutants and drugs to disrupt thyroid gland function. Environ. Sci. Technol. 2009, 43, 6844-6850. [CrossRef] [PubMed]

63. Thienpont, B.; Tingaud-Sequeira, A.; Prats, E.; Barata, C.; Babin, P.J.; Raldúa, D. Zebrafish eleutheroembryos provide a suitable vertebrate model for screening chemicals that impair thyroid hormone synthesis. Environ. Sci. Technol. 2011, 45, 7525-7532. [CrossRef] [PubMed]

64. Hammer, Ø.; Harper, D.A.T.; Ryan, P.D. PAST: Paleontological statistics software package for education and data analysis. Palaeontol. Electron. 2001, 4. Available online: http://palaeo-electronica.org/2001_1/past/ past.pdf (accessed on 2 December 2018).

(C) 2018 by the authors. Licensee MDPI, Basel, Switzerland. This article is an open access article distributed under the terms and conditions of the Creative Commons Attribution (CC BY) license (http:/ / creativecommons.org/licenses/by/4.0/). 
Article

\title{
Distribution of Toxigenic Halomicronema spp. in Adjacent Environments on the Island of Ischia: Comparison of Strains from Thermal Waters and Free Living in Posidonia Oceanica Meadows
}

\author{
Valerio Zupo ${ }^{1, *}$, Mirko Mutalipassi ${ }^{1}$, Nadia Ruocco ${ }^{1}$, Francesca Glaviano ${ }^{1}$, Antonino Pollio ${ }^{2}$, \\ Antonio Luca Langellotti ${ }^{3}$, Giovanna Romano ${ }^{1}$ and Maria Costantini ${ }^{1}$ \\ 1 Department of Marine Biotechnology, Stazione Zoologica Anton Dohrn, 80121 Naples, Italy; \\ mirko.mutalipassi@szn.it (M.M.); nadia.ruocco@szn.it (N.R.); francesca.glaviano@szn.it (F.G.); \\ romano@szn.it (G.R.); mcosta@szn.it (M.C.) \\ 2 Department of Biology, University of Naples Federico II, Complesso Universitario di Monte Sant'Angelo, \\ Via Cinthia, 80126 Naples, Italy; anpollio@unina.it \\ 3 CAISIAL, Aquaculture Division, University of Naples Federico II. Via Università, 80055 Portici (NA), Italy; \\ langello@unina.it \\ * Correspondence: vzupo@szn.it; Tel.: +39-081-583-3503
}

Received: 19 December 2018; Accepted: 1 February 2019; Published: 8 February 2019

\begin{abstract}
Organisms adaptable to extreme conditions share the ability to establish protective biofilms or secrete defence toxins. The extracellular substances that are secreted may contain monosaccharides and other toxic compounds, but environmental conditions influence biofilm characteristics. Microorganisms that are present in the same environment achieve similar compositions, regardless of their phylogenetic relationships. Alternatively, cyanobacteria phylogenetically related may live in different environments, but we ignore if their physiological answers may be similar. To test this hypothesis, two strains of cyanobacteria that were both ascribed to the genus Halomicronema were isolated. H. metazoicum was isolated in marine waters off the island of Ischia (Bay of Naples, Italy), free living on leaves of Posidonia oceanica. Halomicronema sp. was isolated in adjacent thermal waters. Thus, two congeneric species adapted to different environments but diffused in the same area were polyphasically characterized by microscopy, molecular, and toxicity analyses. A variable pattern of toxicity was exhibited, in accordance with the constraints imposed by the host environments. Cyanobacteria adapted to extreme environments of thermal waters face a few competitors and exhibit a low toxicity; in contrast, congeneric strains that have adapted to stable and complex environments as seagrass meadows compete with several organisms for space and resources, and they produce toxic compounds that are constitutively secreted in the surrounding waters.
\end{abstract}

Keywords: toxicology; thermal water; marine; adaptation; evolution; spent medium

Key Contribution: The evolutionary success of cyanobacteria is due to variable proportions of toxigenic power and adaptability to extreme conditions, according to environmental constraints.

\section{Introduction}

Filamentous cyanobacteria are ubiquitous and widely distributed across many environments, including freshwater, seawater, and terrestrial habitats [1]; they are present in the benthos, in the water column, and even in the body of specific hosts [2]. Proliferations of benthic mat-forming cyanobacteria belonging to LPPgroups have been reported in various sites in the world, and they commonly produce a range of neurotoxins that are collectively known as anatoxins, which pose risks 
to human and animal health. Due to their overall similarity, they are frequently indistinguishable from a morphological point of view, and recently, Komarek et al. [3] suggested that when possible, it should be preferable to circumscribe smaller monophyletic genera, avoiding polyphyletic genera including not related species [4]. Often, they dominate extreme environments, as they are protected by a film of extracellular polymeric substances (EPS) that makes them adapted to the lowest (Antarctic [5]) or highest (thermal environments [6]) temperatures and salinities, as well as low irradiances [7]. Many cyanobacteria produce toxins that, according to their effects, can be pooled into five groups: cytotoxins, dermatotoxins, hepatotoxins, neurotoxins, and irritant toxins [8]. Cyanobacteria can shape the dynamics of aquatic microbial communities [9] due to the production of cyanotoxins (a diverse group of compounds, both from the chemical and the toxicological points of view) as depsipeptides, portoamides, and halogenated organic compounds $[10,11]$ that exhibit clear toxigenic effects toward other bacteria, eukaryotic algae, protozoans, and various invertebrates [12], dramatically impacting the diversity of aquatic communities [13]. Furthermore, cyanobacteria-dominated blooms, which are characterized by marked seasonal patterns, have been observed in several freshwater basins [14]. In addition, cyanobacteria are known to produce homoanatoxin-a, microcystins, and saxitoxins [15-18]. Saxitoxins trigger the blockage of sodium ion channels and the inhibition of impulse generation in peripheral nerves and skeletal muscles. Anatoxins (acetylcholinesterase inhibitors) may mimic acetylcholine functions, since they bind to muscle acetylcholine receptors, inducing contraction. These toxins continuously stimulate the muscles until paralysis occurs [19]. Hepatotoxins, in their turn, may be divided in three groups (microcystins, nodularins, and cylindrospermopsins), according to their chemical nature. Microcystins are probably the prevalent cyanotoxins in the environment, and they are the most studied group among cyanobacteria bioactive compounds [20]. They form a family of monocyclic heptapeptides containing the unusual $\beta$-amino acid Adda (3-amino-9-methoxy-2,6,8-trimethyl-10-phenyldeca- $4 \mathrm{E}$, $6 \mathrm{E}$-dienoic acid) and represent possible hazards for human beings when dissolved in drinking water [21]. On the whole, they may produce sub-chronic and chronic toxicity along with tumor promotion. Nodularins have a structure similar to that of microcystins except for the number of amino acids, while cylindrospermopsins are alkaloids produced by Cylindrospermopsis spp., Umezakia spp., and Aphanizomenon spp. [12], producing pathological changes in the liver, kidneys, spleen, thymus, and heart of mammals, birds, and fish [22,23]. However, other compounds that are responsible for these effects belong to various classes of chemicals, ranging from alkaloids to aromatic compounds, cyclophanes, fatty acids, macrolides, nucleoside, peptides, polyketides, and terpenoids [24]. Since their presence may produce acute toxicity for animals and humans [17], and their natural blooms correspond to deadly conditions for various organisms that are present in the same communities [25], there is rising awareness of the risk that thin filamentous cyanobacteria proliferations pose to human and animal health [26,27]. The list of cyanobacteria secondary metabolites elongates continuously, and they embody important, still underexplored organisms for the discovery of new drugs, cosmeceuticals, and anti-inflammatory drugs [28]. Cyanobacteria also produce volatile compounds such as geosmin, whose toxicity was demonstrated [29]. In parallel, bloom-associated cyanobacteria produce toxins impacting their ecosystems and the surroundings, bringing the associated communities to hypoxia.

The ecological role of toxin produced by cyanobacteria is still debated: apart from being produced to discourage predation, they probably play multiple functions in cellular metabolism, in particular counteracting oxidative stresses, and facilitating the uptake of nutrients, particularly iron [30]. However, the microbial community itself may mitigate their effects under some ecological conditions, since the allelopathic behavior and the production of secondary metabolites may be influenced by the nutrient availability and other interactions with the resident microbiota, as well as by abiotic factors such as salinity and irradiance [31]. Several uncertainties persist regarding the environmental triggers that facilitate the formation of cyanobacteria blooms and their persistence [32], but it has been demonstrated that various abiotic factors, including nutrient loads, salinity, and temperature, influence the production of toxins and their release in the surrounding environments [33]. From this perspective, 
it is likely that the increased frequency of toxic blooms [32] that has been observed in the last decades may be an indirect result of global warming [34,35]. The consequences of global climate changes (elevated temperature, increased atmospheric concentrations of carbon dioxide, elevated ultraviolet (UV) fluxes) also depend on cyanobacterial ecology and growth [36]. Eutrophication and higher temperatures trigger a higher release of cyanotoxins in waters, increasing the ecological risk [37,38]. Trends emerging from previous research [28] indicate that the functions of these microbes within a given environment may be highly conserved, going beyond their phylogenetic relationships and taxonomic identities [39]. Thus, it is worth investigating the relationships among taxonomically-related strains of cyanobacteria and their specific toxicity, especially when their populations are established in extreme environments [40,41].

We have recently isolated two strains of cyanobacteria, which are both ascribed to the genus Halomicronema, and have both been established as new species in the last decades [42,43], but are linked to very different environments. The first strain belongs to Halomicronema metazoicum (Caroppo, Pagliara, Albertano, 2012). It was previously known to be an endobiont of marine metazoans [42], and it has only recently [44] been found to be also associated with the epiphytic community of a Posidonia oceanica (L.) Delile meadow [45] off the island of Ischia. The second strain was attributed to Halomicronema sp. It is considered to be "a benthic, moderately halophilic and thermophilic genus of cyanobacteria with very thin trichomes" [43], and it has been isolated in thermal waters on the island of Ischia. Thus, both species were present in the same area: the first in a typically stable seawater environment, and the second in thermal waters. Their morphology is quite similar, since they both appear to be non-heterocystous, thin filamentous oxygenic prototroph cyanobacteria exhibiting trichomes that have a diameter of less than two $\mu \mathrm{m}$ [46]. In addition, the first was previously known only as an endobiont of metazoans (and it was found, in contrast, free living as an epiphyte), while the second was considered "moderately thermotolerant", but it was isolated in thermal waters at a higher temperature. In addition, the latter was considered to be "benthic", since it was initially isolated from benthic microbial mats [43], but it has been demonstrated to produce blooms in the water column when high concentrations of nutrients are available. The availability of two related species of cyanobacteria living in such different environments permits investigating the factors influencing the interactions between microalgae and bacteria, and those determining the wide ecological success of the latter [47]. In fact, interactions within these organisms are still poorly understood and are affected by various environmental features as limiting resources and competition issues. For example, some cyanobacteria were reported to use toxins as a response to nutrient depletion and related allelopathic interactions, and these can contribute to their expansion, even when nutrient loading is limited [48]. The presence of two taxonomically related species in the same area will possibly explain the evolution and dispersion of cyanobacteria in different environments [4]. For these reasons, we present here a polyphasic analysis of two novel strains that have been recently isolated from very different environments in the same geographical area; the analysis includes their morphological description along with their ultrastructural, physiological, and molecular characterisation. Our aim is to test the hypothesis that the ability of cyanobacteria to produce toxic weapons has evolved according to environmental constraints, and that a stronger presence of possible competitors promotes the evolution of a higher toxigenic activity.

\section{Results}

\subsection{Halomicronema Metazoicum}

The strain collected on Posidonia oceanica leaves in Lacco Ameno d'Ischia (Italy) and grown in $f / 2$ medium, according to our micromorphology analyses, exhibited filaments grouped into emerald-green macroscopic aggregates, which are generally not adherent to the culture vessel (Figure 1). Their sheath was colorless, generally thin, amorphous, and somewhat diffused around the trichome, but rarely extending over the trichome apex. Cells had a diameter of 0.8 to $1.0 \mu \mathrm{m}$, and they were cylindrical, elongated, and usually two to five $\mu \mathrm{m}$ long. Terminal cells were rounded, exhibiting constrictions at 
the cross wall. Reproduction was observed to occur by fragmentation in a few-celled hormogonia. The strains exhibited 99\% pairwise sequence identity with Halomicronema metazoicum ITAC101 (isolated for the first time by Caroppo et al. [42]) according to the molecular characterization. The strain of cyanobacteria that was isolated from leaves of Posidonia, named Cyano_Pos, was phylogenetically well-separated from $H$. excentricum, with a $93.5 \%$ pairwise sequence identity.

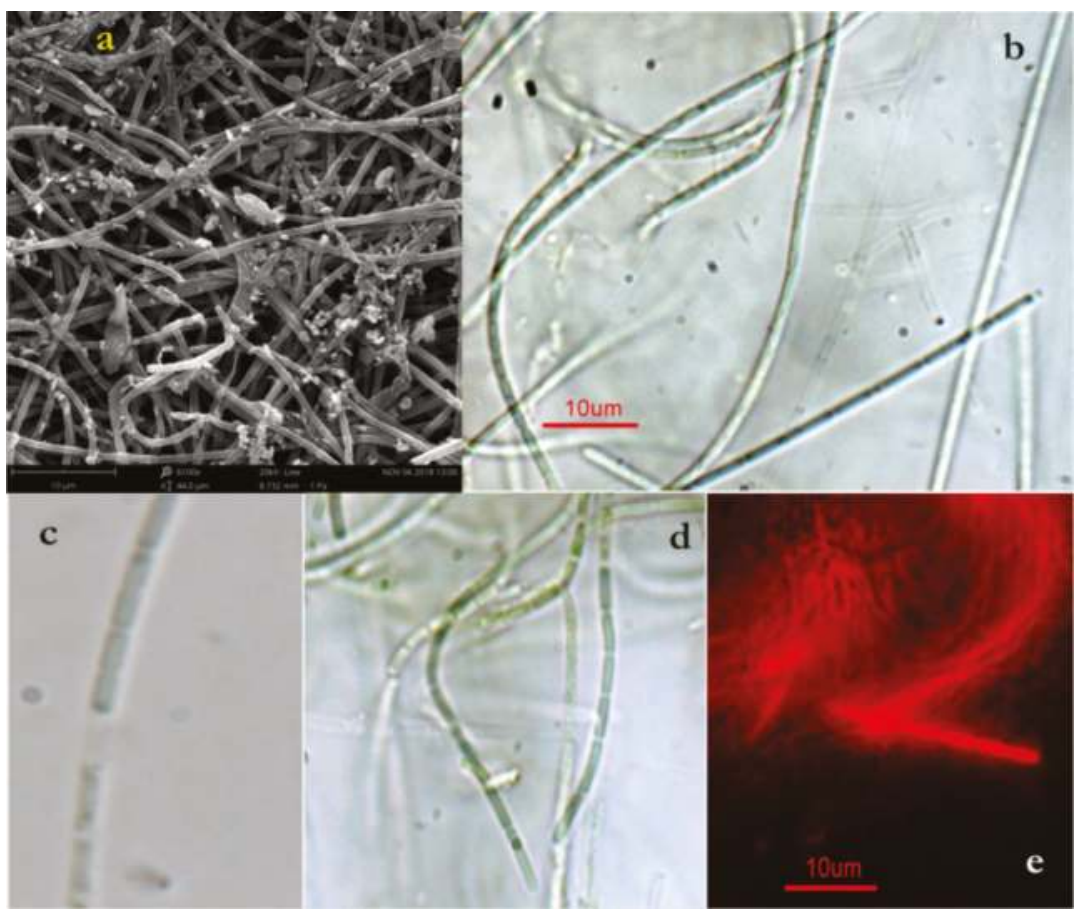

Figure 1. Photomicrographs of $H$. metazoicum mats grown in $f / 2$ medium. (a) Structure of the surface of a benthic mat observed at the high performance desktop SEM Phantom ProX (gentle concession of Alfatest, ThermoFisher Scientific, Rome, Italy), showing thin filaments and mucous secretions at $6100 \times$; (b) occurrence of a papilla at the apex of a trichome at $100 \times$; (c) necridic cell between two neighboring cells at $100 \times$; (d) cells of each trichome are cylindrical, with constrictions at the cross walls at $100 \times$; (e) light fluorescence micrograph of filaments surrounded by an amorphous colorless sheath at $100 \times$.

\subsection{Halomicronema sp.}

The strain collected in thermal waters and grown on agarized BBM medium formed a brownish-green mat, with thin filaments grouped in layered fascicles (Figure 2a). In liquid cultures, filaments were pale-blue green, with a very thin colorless sheath, and straight or slightly bent, without false ramifications. Trichomes consisted of elongated cells with a length/diameter ratio higher than one; the apical cell appeared rounded, with a papilla (Figure $2 b$ ). Cell wall constrictions were not clearly visible under optical microscopy. Trichomes are divided in non-motile segments, without necridic cells. Transmission electron microscopy (TEM) revealed the presence of moderate constrictions at the cross walls (Figure 2c). Thylakoids are arranged concentrically to from three to five rows that run parallel to the longitudinal axis of the cell (Figure 2d). The multiplication of filaments takes place by fragmentation. The apical ends of hormogonia are long-pointed after trichome breakage, and had no calyptra. Gas vesicles are present (Figure 2e). 


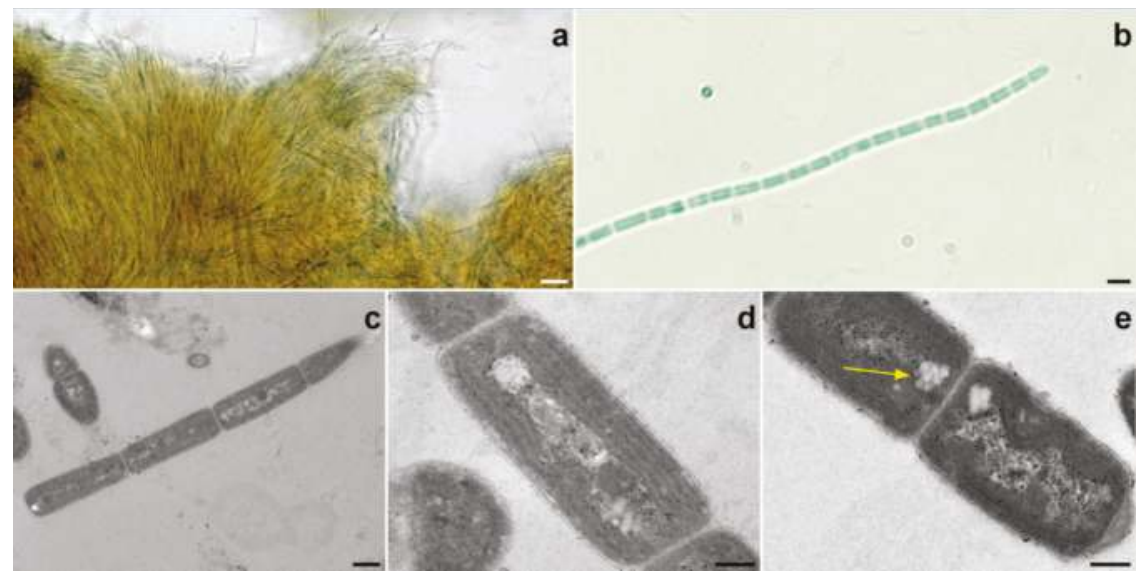

Figure 2. (a) Photomicrographs of Halomicronema sp. mats grown on agarized BBM medium at $20 \times$. Bar scale $=20 \mu \mathrm{m} ;(\mathbf{b})$ photomicrograph of a Halomicronema sp. filament at $100 \times$. Bar scale $=2 \mu \mathrm{m}$. Ultrastructure (TEM) of Halomicronema sp. (c) four-celled hormogonium, with a tapered apical cell at $8000 \times$. Bar scale $=0.5 \mu \mathrm{m}$; (d) disposition of the thylakoids, arranged in four rows, parallel to the longitudinal axis of the cell at 20,000 $\times$. Bar scale $=0.2 \mu \mathrm{m}$; (e) gas vacuoles (arrow) apically placed at $20,000 \times$. Bar scale $=0.2 \mu \mathrm{m}$.

$16 \mathrm{~S}$ rRNA gene analysis showed, as sequence-producing significant alignments, "uncultured Oscillatoriales cyanobacterium". Phylogenetic analysis of this strain along with another 13 cyanobacteria (phylogenetically related [44]) revealed that it was well-separated from Cyano Pos with $89 \%$ sequence identity (Figure 3). Furthermore, this thermal water cyanobacterium exhibited about $90 \%$ pairwise sequence identity with Halomicronema metazoicum, Halomicronema excentricum, Halomicronema sp. SCyano39, Halomicronema sp. PCyano40, Halomicronema sp. Goniastrea-1, Nodosolinea nodulosa UTEX 2910, Oscillatoria neglecta IAM_M-82, Pseudanabaena constantiae, and Plectonema sp. F3., whereas it exhibited about $85 \%$ pairwise sequence identity with Gloeobacter violaceus PCC7421 and Pseudanabaena PCC7403, Synechococcus sp. According to morphological and molecular characterizations, we ascribed this undetermined cyanobacterium strain to the Halomicronema genus, indicating it as Halomicronema sp., and assuming that it needed further analyses in order to be fully characterized.

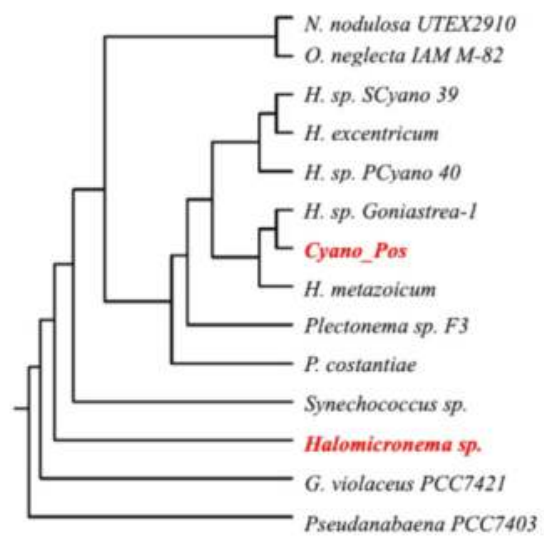

Figure 3. Phylogenetic tree based on $16 \mathrm{~S}$ rRNA gene sequences. Strains analysed in this work, Cyan_Pos, and Halomicronema sp., are indicated in red. 


\subsection{Comparisons of Toxicity Tests}

The results of toxicity tests one hour after the fertilization of sea urchin embryos showed clear effects of H. metazoicum even at low concentrations of the spent medium, up to 1/10,000 (Figure 4), both in terms of the block of the first division (Figure $4 \mathrm{a}$ ) and the production of larvae (Figure $4 \mathrm{~b}$ ), after normalization over controls. The spent medium of Halomicronema sp. that was collected in thermal waters exhibited quite a lower toxicity, reducing the percentage of first divided embryos only at concentration of 1:10 (Figure 4a). At the same concentration, consistently, normal plutei were not produced (Figure $4 \mathrm{~b}$ ), but negligible effects were observed at higher dilutions. Statistical comparisons confirmed that one hour after fertilization the effects induced by the spent medium of H. metazoicum and those of the fresh medium were significantly different, up to a dilution of 1:10,000 (Figure 5a). At higher dilutions, no significant effects were recorded. In contrast, Halomicronema sp. triggered a clear increase of apoptotic embryos (i.e., embryos presenting clear blebbing formation) at the highest concentration (dilution 1:10), and very low effects at further dilutions (Figure 5b). As well, when the percentage of divided embryos in test replicates and their controls was statistically compared, we demonstrated that the spent medium of $H$. metazoicum triggers a significant effect with respect to controls, up to the highest dilutions (Figure 6a), while the effect of the spent medium of Halomicronema sp. is negligible at any concentration (Figure 6b). An effect of the control medium was recorded, because the BG11 medium is quite dense, and it impacts the physiology of embryos at the highest concentrations (Figure 6b). These results are mirrored by the records obtained $48 \mathrm{~h}$ after fertilization. In fact, $H$. metazoicum triggered the production of apoptotic embryos at all concentrations, with a clear threshold above a dilution of 1:10,000 (Figure 7a), while Halomicronema sp. had an effect only at the highest concentration, with respect to controls (Figure $7 \mathrm{~b}$ ). No effect of the control medium was recorded on apoptotic processes, even at the highest concentrations. The effect of spent medium on the production of abnormal plutei was less evident. However, the remaining percentage of viable embryos (that were still present at dilutions higher than 1:1000, because they were not impacted by the apoptotic processes reported in Figure 7a) exhibited malformations in the replicates treated with H. metazoicum spent medium (Figure 8a); in contrast, a clear effect was produced by the BG11 medium that was used to culture Halomicronema sp. at the highest concentration (Figure 8b), but no effects of the spent medium were detected at any concentration. 


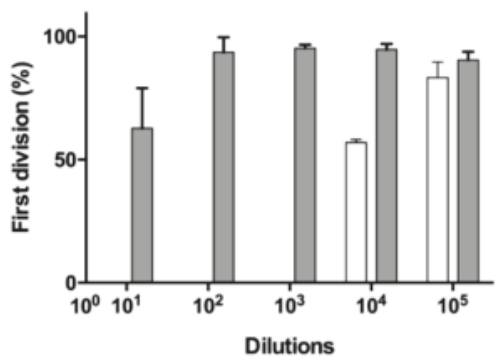

a)

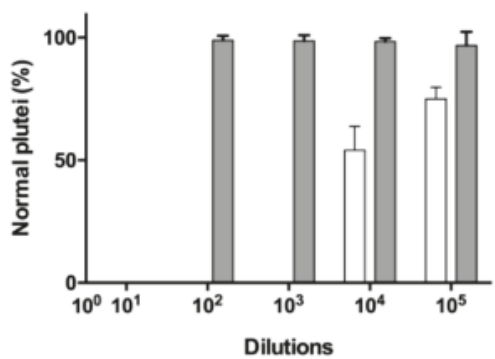

b)

\section{H. metazoicum}

Halomicronema sp.

Figure 4. Toxicity of Halomicronema sp. and H. metazoicum spent media measured on sea urchin embryos at the first division (a); and as a percentage of normal plutei produced (b) at various dilutions of spent medium, from 1:10 to 1:100,000. The results of toxicity tests at one hour (rates of first division and percentage of normal plutei produced) were normalized over the effects on controls, to facilitate comparisons, according to the relationship (1) reported in methods. At the lowest dilutions, H. metazoicum triggered the block of divisions (a), and, consequently, a lack of normal plutei (b).

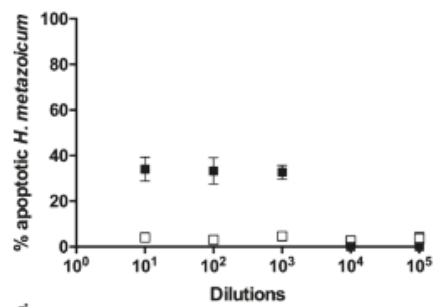

a)

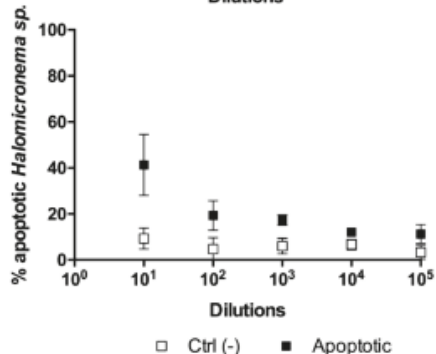

b)

Figure 5. Toxicity of Halomicronema metazoicum (a) and Halomicronema sp. (b) spent medium measured on sea urchin embryos one hour after fertilization by recording the percentage of apoptotic embryos in controls and in treated samples at various dilutions of the media, from 1:10 to 1:100,000. Ctrl (-) indicates the negative control. 


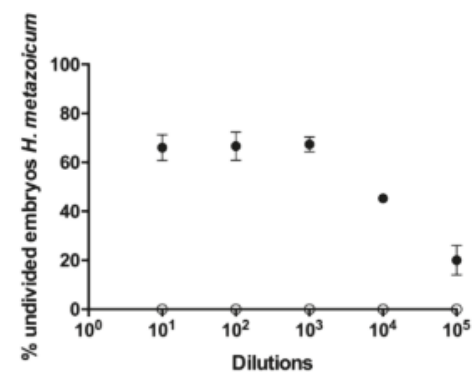

a)

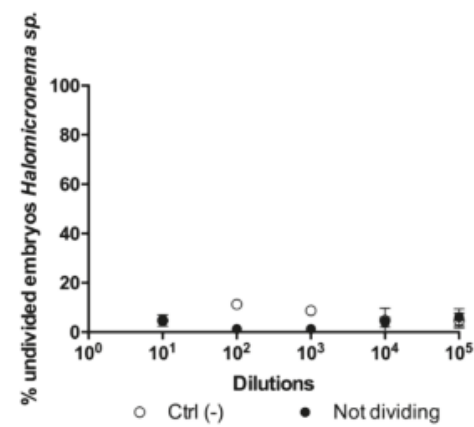

b)

Figure 6. Toxicity of Halomicronema metazoicum (a) and Halomicronema sp. (b) spent medium measured on sea urchin embryos one hour after fertilization by recording the percentage of undivided embryos in controls and in treated samples at various dilutions of the media, from 1:10 to 1:100,000. Ctrl (-) indicates the negative control.

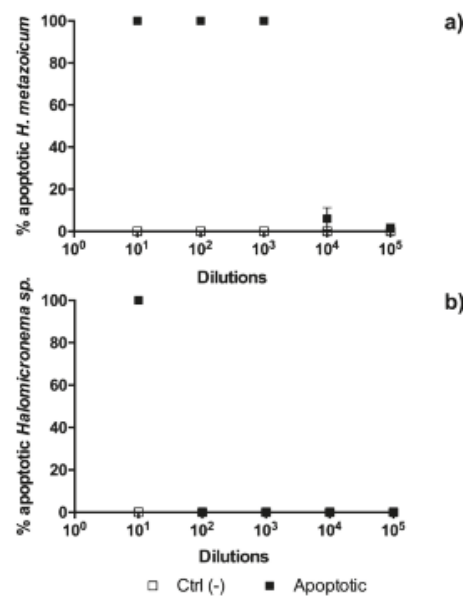

a)

b)

Figure 7. Toxicity of Halomicronema metazoicum (a) and Halomicronema sp. (b) spent medium measured on sea urchin embryos $48 \mathrm{~h}$ after fertilization by recording the percentage of apoptotic embryos in controls and in treated samples at various dilutions of the media, from 1:10 to 1:100,000. Ctrl (-) indicates the negative control. 

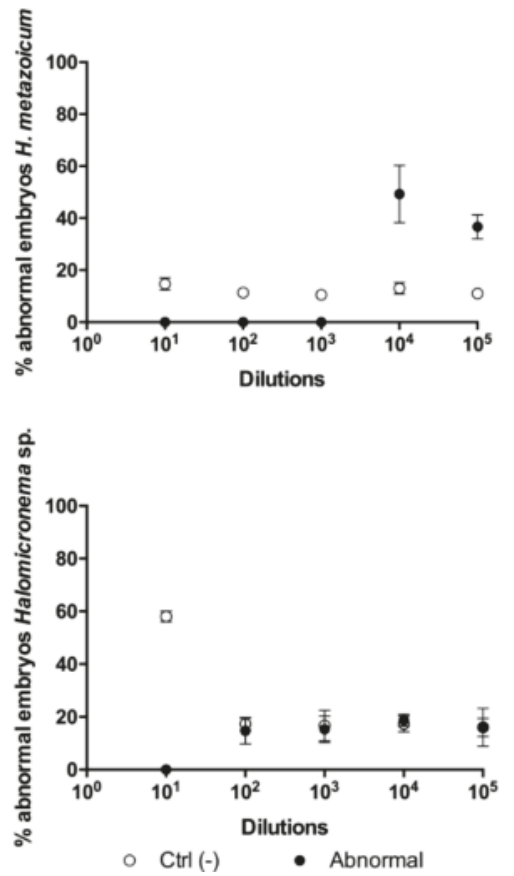

a)

b)

Figure 8. Toxicity of Halomicronema metazoicum (a) and Halomicronema sp. (b) spent medium measured on sea urchin embryos $48 \mathrm{~h}$ after fertilization by recording the percentage of abnormal larvae in controls and in treated samples at various dilutions of the media, from 1:10 to 1:100,000. Ctrl (-) indicates the negative control.

These effects are due to compounds constitutionally produced and excreted in the spent medium, but the cells of bacteria are characterized by clear differences in composition (Figure 9) detected by the high-performance scanning electron microscope (SEM). In fact, X-ray analyses detected similar contents of constitutive elements such as oxygen, carbon, and nitrogen, but H. metazoicum actively stored larger amounts of bromine and sulfur, while Halomicronema sp. was characterized by higher concentrations of calcium, sodium, and chlorine. As well, potassium and phosphorus were detected exclusively and in large amounts in the species collected in thermal waters.

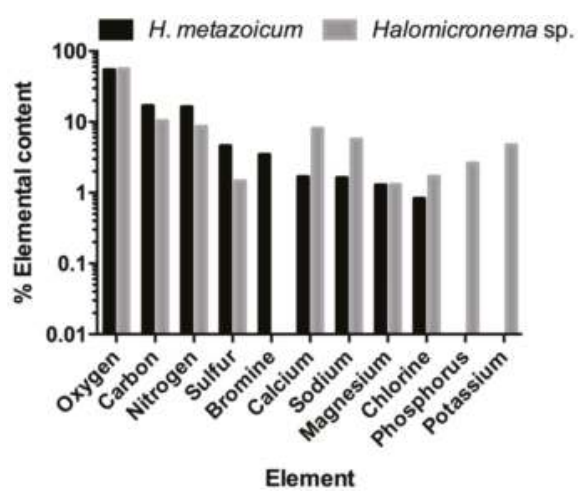

Figure 9. Elemental composition of Halomicronema sp. and H. metazoicum measured by means of X-ray diffraction using a high-performance SEM Phenom ProX. 
The toxicity tests that were performed on homogenates of bacterial cells confirmed a low toxicity of H. metazoicum, which was exhibited at the highest concentrations (1:5-1:10), while lower concentrations were innocuous for sea urchin embryos at the first division, and triggered a moderate effect on plutei development after 48 hours (Figure 10). In contrast, Halomicronema sp. cells exhibited an absence of toxigenic activities both at the first division and during the development of plutei. A very low activity was exhibited only at the highest concentrations after 48 hours, which is comparable to the one produced by their culture medium (Figure 10b). ANOVA tests indicated that all of the described differences are significant at $p<0.001$.

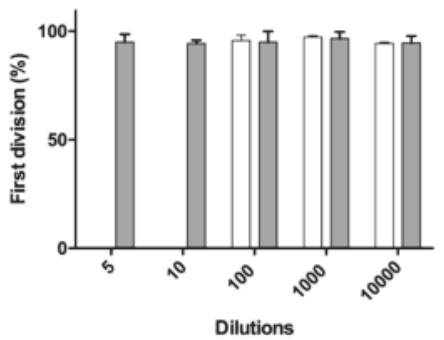

a)

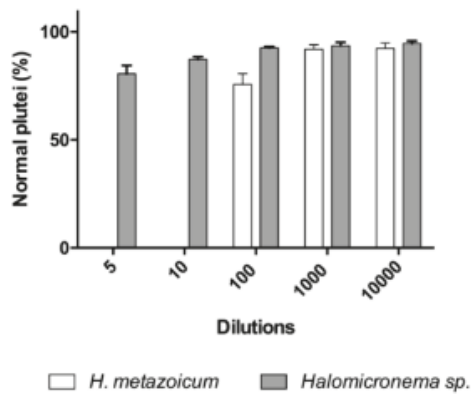

b)

Figure 10. Toxicity of Halomicronema sp. and H. metazoicum cell homogenates measured on sea urchin embryos at the first division (a), and as a percentage of normal plutei produced (b) at various dilutions of spent medium, from 1:5 to 1:10,000. The results of toxicity tests at one hour (rates of first division and percentage of normal plutei produced) were normalized over the effects on controls, to facilitate comparisons, according to the relationship (1) reported in methods. At the lowest dilutions, H. metazoicum triggered an absence of divisions (a), and consequently, a lack of normal plutei (b).

\section{Discussion}

The two species of cyanobacteria recently isolated are characterized by distinct morphological, ultramorphological, and chemical properties. They are both thin filamentous cyanobacteria, but TEM analyses indicate peculiar cellular features and different trends in the mat aggregations. Halomicronema sp. needed a richer culture medium and tended to remain in the water column, while H. metazoicum demonstrated maximum vitality in $f / 2$ and a tendency to settle to produce growing mats. This is in line with the environmental conditions of the collection sites, since the latter was found epiphytic on seagrass leaves, and the first was collected dispersed in the thermal waters. The thin filamentous genera of cyanobacteria such as Oscillatoria spp, Phormidium spp, and Plectonema spp. are known to be polyphyletic $[4,11,43]$; this probably increases their large physiologic plasticity and genetic diversity, favoring the possibility of colonizing extreme environments. Our polyphasic investigation indicates that the two species herein considered are different, and the undetermined one will need accurate analyses to be characterized, since the $16 \mathrm{~S}$ rRNA molecular signatures failed at finding a clear determination based on comparisons with known taxa. In fact, as forecasted by previous 
authors [35,49], "this genus should be further extended in the future, to include more isolates from hypersaline environments", which are known to be elective habitats for thin filamentous non-heterocystous cyanobacterial populations.

Toxicological analyses added some important details, since the species living in thermal waters, which were characterized by low competition levels with other organisms and adapted to extreme conditions of salinity and temperature [49], exhibited the lowest toxicity, as constitutionally expressed both in their culture medium and in the cell homogenates. In contrast, H. metazoicum living as an epiphyte of seagrass leaves is subjected to a strong competition for space and nutrients prompted by a complex association of algae and animals, and it elicited, indeed, the biosynthesis of an effective set of chemical weapons. There are remarkable effects detected by standard toxicity tests on sea urchin embryos [50] that demonstrate that this species is able to keep its area of proliferation clear of competing species of epiphytes. As well, the toxicity contained in their homogenates may represent an efficient defence against possible consumers as various grazers living in the seagrass leaf stratum. It is also interesting to consider that the same species was firstly set as an endobiont of marine metazoans [42], and it will be worth investigating whether any difference in the production of toxic metabolites exists between the two strains of H. metazoicum, since such a toxigenic power could be in contrast to a physiologic cooperation with hosts. Previous investigation [48] indicated that specific alkaloids, such as cylindrospermopsins (CYN), are synthesized by selected cyanobacteria, and they are involved in allelopathic responses, providing an advantage over sympatric species in habitats characterized by complex antagonistic relationships. In addition, the levels of production of allelopathic compounds may be modulated by Microcystis aeruginosa according to the needs imposed by the presence of competing species and their actual density in the medium. These relationships produce a dense network of chemical communications that is yet to be fully understood, but it is evident that two specific features (namely, the ability to colonize extreme environments and the secretion of several chemical weapons) explain the evolutionary potential of cyanobacteria in various geographical regions.

In our case, the toxigenic power of H. metazoicum was demonstrated at various levels, inducing fertilization failure (personal observation), antimitotic power, apoptogenic power, and mutagenic influence. Thus, various compounds might be contemporaneously produced and liberated in the culture medium, to control the presence of assorted categories of competitors. Alternatively, the same compound could have different modes of action depending on its initial levels of production, as demonstrated in other species [48]. This complex set of chemical weapons will be further investigated, since extracellular compounds could be used for biotechnological purposes (e.g., for medical and anti-parasitic purposes), given the marked biological activity here demonstrated. In contrast, Halomicronema sp. spent medium exhibited a very low antimitotic power, only at the highest concentrations, even after longer exposure times. This apparent lack of allelochemical power fits with the features of the extreme environment where it was isolated, because target competitors and possible consumers are virtually absent. However, the induction of apoptosis has been demonstrated, and this could lead in the future to therapeutic applications, since it is associated with low generic toxicity levels. These features indicate the different possible applications for the compounds constitutively secreted by the two species: strong toxigenic activity against metazoans for H. metazoicum, even at low concentrations, and specific apoptogenic activity that is potentially useful for medical applications in the case of Halomicronema sp. Further tests and chemical characterizations will explore these hypotheses.

The elemental composition of the two species that were obtained by taking advantage of the high-performance SEM analyses confirmed these differences [51]. The larger amounts of phosphorus and potassium in Halomicronema sp. could be a consequence of the different culture media needed for the two species, since some compounds that were abundant in the medium were certainly stored in the cells. More interesting is the difference among the sulfur, bromine, and chlorine concentrations. In fact, brominated organic compounds are known to be produced during cyanobacteria blooms [52], and the substitution of $\mathrm{Cl}^{-}$with $\mathrm{Br}^{-}$is a typical process occurring during the biosynthesis of these 
compounds [53]. For example, dibromoacetic acid produced by freshwater cyanobacteria is known to be toxic for nematodes, and even for mammalians [54]. Since the difference in the contents of these elements is specular in the two species, we could hypothesize a different efficiency in the pathways of biosynthesis, leading to dissimilarities in their toxigenic power, and fitting their adaptations to distinct environments.

\section{Conclusions}

Evidently, the chemical defences of Halomicronema spp. are tuned according to local needs, and the data herein collected indicate that even their alternative presence in benthic or planktonic environments could be characterized by differences in the chemical ecology of their populations. Thin cyanobacteria are definitely demonstrated to be quite strong organisms, controlling the populations of their competitors and possible consumers priming antimitotic, apoptogenic, and teratogenic effects, but their constitutive production and secretion in the surroundings is evolved according to environmental constraints. For example, colonial cyanobacterial blooms are responsible for the deterioration of freshwater systems with increasing frequency and intensity, also due to global warming [31,55], and this hardly impacts the possible uses of those water masses for humans. In addition, a conserved phylogenetic structure was observed in the cyanobacterial populations for several lake samples [28], confirming our assumption that phylogenetic traits are paired with the ability of cyanobacteria to settle in given environmental conditions. Thus, phylogenetic and evolutionary constraints are paired with physiologic traits and toxigenic properties of cyanobacteria, directing their adaptability to a wide range of environments, including extreme physical conditions. This evidence may on one side help the comprehension of their patterns of geographical distribution and expansion; on the other side, it may direct our attention toward strains characterized by peculiar biological activities, in the search of active compounds for interesting biotechnological applications.

\section{Materials and Methods}

\subsection{Collections of Cyanobacteria in Seawater}

Leaves of Posidonia oceanica were collected in April 2017 by scuba divers, at five meters depth, in a meadow off Lacco Ameno d'Ischia (Bay of Napoli, Italy: $40^{\circ} 44^{\prime} 56^{\prime \prime} \mathrm{N}, 13^{\circ} 53^{\prime} 13^{\prime \prime} \mathrm{E}$ ). At the collection site, the temperature was about $19^{\circ} \mathrm{C}, \mathrm{pH} 8.12$, salinity $38 \mathrm{psu}$, at an irradiance of about $400 \mu \mathrm{E} \mathrm{m}{ }^{-2}$. After their arrival in the laboratory, they were reared in aerated closed-cycle tanks containing sterilized water. An inspection under a stereomicroscope permitted the detection of small portions of various epiphytes, which were promptly collected by forceps and moved into multi-well plates with Guillard's $f / 2$ medium (Sigma Aldrich, Milan, Italy). Their development was recorded while they were kept in a thermostatic chamber at $18{ }^{\circ} \mathrm{C}$, with an irradiance of $200 \mu \mathrm{E} \mathrm{m}^{-2}$, and a 12:12 hour dark/light cycle. When axenic thalli were obtained, they were further transferred every two to three days in multi-wells containing fresh $f / 2$ medium, up to a complete isolation. The first identification of the strains was performed under a light microscope, and was based on the filament and cell shape and size, the shape of the terminal cell, the presence of calyptra, sheaths, and the type of reproduction.

\subsection{Collection of Cyanobacteria in Thermal Waters}

A surface water sample rich in algal mats was collected in sterile bottles in June 2012 from a thermal pond near Citara beach, Ischia Island, Italy $\left(13^{\circ} 51^{\prime} 45^{\prime \prime}, 40^{\circ} 43^{\prime} 12^{\prime \prime}\right)$ and transported in the microalgae lab of the CAISIAL Centre (Portici, Napoli) at about $15^{\circ} \mathrm{C}$ in dark. The temperature of water, which is classified as sulfate-chloride-alkaline, during sampling was $36.8^{\circ} \mathrm{C}$ with a $\mathrm{pH}$ of 8.5 and salinity of $39.6 \mathrm{psu}$. The cyanobaterial strain was isolated from other microorganisms by the repeated transfer of isolated trichomes on agar plates of BG11 medium [46] in artificial seawater (salinity $38 \mathrm{psu}, \mathrm{pH}$ 8.5). After isolation, a culture was established in a thermostastic chamber at $25 \pm 1{ }^{\circ} \mathrm{C}$, with a light intensity of $200 \mu \mathrm{E} \mathrm{m}^{-2}$ and a 12:12 h dark/light cycle. A living culture of the 
cyanobacteria strain has been deposited at the Algal Collection (ACUF) at the Biology Department of Naples University Federico II (Italy).

\subsection{Light and Electron Microscopy}

The identification and morphological characterization of cyanobacteria were performed by light microscopy (Nikon Eclipse E-800). Samples for TEM were fixed with 1\% glutaraldehyde in sodium cacodylate buffer and post-fixed with $1 \%$ osmium tetroxide in the same buffer, dehydrated in a graded alcohol series, embedded in epoxy resin Epon 812, and sectioned at $650 \mathrm{~nm}$ with an Ultracut. The sections were stained with 1\% Uranyl Acetate Replacement Stain "UAR" (EMS Science LTD) and lead citrate, and examined under TEM operating at $100 \mathrm{kV}$.

In addition, we took advantage of a new Phenom ProX desktop SEM (ThermoFisher Scientific, Waltham, MA, USA) to obtain high-resolution images of both species along with elemental analyses. This microscope permits, alongside acquiring high-resolution images, identifying the different chemical elements present on a specimen and we used it to with an EID (identification software package specifically designed and fully integrated with an energy dispersive spectrophotometer) to detect any difference in the elemental composition between the two species.

\subsection{Molecular Identification}

Individual cell cultures of both strands were collected and concentrated by centrifugation for $20 \mathrm{~min}$ at $4500 \mathrm{rpm}$ (revolution per minute) at $4{ }^{\circ} \mathrm{C}$, and then frozen at $-20^{\circ} \mathrm{C}$ until use. About one gram of DNA has been used for DNA extraction according a method reported in Ruocco et al. [29] for H. metazoicum, and previously described by Singh et al. [56]. Further, the genomic DNA concentration was quantified by NanoDrop spectrophotometer (ND-1000 UV-vis Spectrophotometer; NanoDrop Technologies, Wilmington, DE, USA) and its integrity was evaluated by electrophoresis on $0.8 \%$ agarose gel. The gene coding for a $16 \mathrm{~S}$ rRNA subunit was amplified by polymerase chain reaction (PCR) using five cyanobacteria-specific universal primer pairs: 1) forward primer CYA106F with an equimolar mixture of reverse primers CYA781R(a) and CYA781R(b) [57], amplifying a fragment of $600 \mathrm{bp}$; 2) forward primer CYA783F with reverse primer S17 [58], amplifying a 600-bp fragment; 3) forward primer P1 with reverse primer P2 [59], amplifying a 1200-bp fragment; 4) forward primer pA with reverse primer B23S [60], amplifying a 1300-bp fragment; and 5) forward primer CYA359F with an equimolar mixture of reverse primers CYA781R(a) and CYA781R(b) [57], amplifying a fragment of $600 \mathrm{bp}$. PCR products were subjected to the DNA sequencing of both strands. The total $16 \mathrm{~S}$ region was aligned to Gene Bank using the Basic Local Alignment Search Tool (BLAST [61]) and then aligned with highly similar sequence using MultiAlin (http://multalin.toulouse.inra.fr/multalin/). For phylogenetic analysis, 14 16S rRNA gene sequences of cyanobacteria (including Cyano_Pos and Halomicronema sp.) have been considered (see Table S1 for species' names and accession numbers). Multiple sequence alignments were conducted using the CLUSTALW program (http:/ / www.genome. $\mathrm{jp} /$ tools-bin/clustalw). Multiple sequence alignments were performed using the service named FASMA, which is available at http:/ / bioinformatica.isa.cnr.it/FASMA/ ([62]; Table S2).

\subsection{Toxicity Tests on Media}

Both strains of cyanobacteria were subjected to standard toxicity tests [63] in order to compare the toxigenic activity of their spent media using an established model: the embryos of the sea urchin Paracentrotus lividus. To this end, cyanobacteria were cultivated in the above-mentioned conditions for one month, in order to facilitate the accumulation of secondary metabolites in the medium. The spent media were collected at the end of the production period, filtered over a 0.22- $\mu \mathrm{m}$ Millipore filter, stored in glass vessels, and kept at $-20^{\circ} \mathrm{C}$ up to the start of bioassays. Prior to performing the tests, the contents of two replicate samples produced by each species were pooled. The medium was sampled and diluted at various concentrations in filtered seawater for both tested species. Basically, we took into account the following dilutions of the culture medium in filtered seawater: 1:10, 1:100, 
1:1000, 1:10,000, and 1:100,000 in volume. Bioassays were prepared starting from two mature females and two males of P. lividus collected in the Bay of Napoli. They were injected with $1 \mathrm{~mL}$ of $0.5 \mathrm{M} \mathrm{KCl}$ into the coelom through the soft derma around the mouthparts, in order to stimulate the contraction of gonads. The sea urchins were vigorously shaken, and females were placed with their mouths up, over a $50 \mathrm{~mL}$ beaker, until the gametes were released into filtered $(0.22 \mu \mathrm{m}$ Millipore, Billerica, MA, USA) seawater to facilitate the collection of oocytes, which were rinsed three times with clean seawater to remove possible organic residuals [64]. Sperms were collected "dry", after the injection of $1 \mathrm{~mL}$ of $0.5 \mathrm{M} \mathrm{KCl}$ into the coelom of males, using a Pasteur pipette and sucking over the surface of gonopores, to avoid premature activation. The gametes obtained from each individual were conserved in plastic vessels up to fertilization. Sub-samples of oocytes were collected and added with a drop of sperm suspension. Normal egg activation was revealed by the elevation of the fertilization membrane within 40-80 s, appearing as a clear circle. Pools of embryos exhibiting percentages of fertilization lower than 95\% were discarded. Pools exhibiting viable embryos were used for bioassays. To this end, embryos produced by the two females were pooled, and 400 embryos were collected in triplicate and transferred into multi-well dishes filled with four $\mathrm{mL}$ of the appropriate dilutions of cyanobacteria culture media, as above specified. Controls were prepared using only seawater added with corresponding proportions of freshly prepared culture medium. The results were recorded at various time intervals and according to each concentration. In particular, after one hour, the multi-wells were observed under a Leica Z6Apo macroscope to record the percentage of individuals showing normal cell division and, eventually, hallmarks of apoptosis (detected by recording nuclear and cellular condensation and fragmentation under optical microscopy), some of which were interesting. After $48 \mathrm{~h}$, the contents of the wells were fixed with the addition of a drop of $4 \%$ buffered formalin and examined to record the percentage of normal plutei, abnormal plutei, or apoptotic embryos.

\subsection{Toxicity Tests on Homogenates of Bacterial Cells}

Bacterial cells were collected from live cultures, centrifuged, and weighed. Four replicates (100 mg each) of fresh cyanobacteria were fragmented into a ceramic mortar, and then transferred into a chilled tube and sonicated twice for one minute, up to a complete homogenization of citoplasmatic contents. The resulting suspension was centrifuged for $10 \mathrm{~min}(1062 \mathrm{G})$, and the supernatant was collected, filtered over a $0.22 \mu \mathrm{m}$ Millipore membrane, brought to a volume of $5 \mathrm{~mL}$ with the addition of filtered and sterilized seawater, and then frozen up to the dilutions for bioassays. The supernatant was melted and further diluted in sterilized seawater at concentrations of 1:5, 1:10, 1:100, 1:1000, and 1:10,000 to test the toxicity of cyanobacterial cell contents as compared to their spent media, as above indicated.

\subsection{Statistical Analyses}

Data were organized as means and their standard deviations from various replicates, for each set of measurements. The results of toxicity tests at one hour (rates of first division and percentage of normal plutei produced) were normalized over the effects on controls, in order to facilitate comparisons, according to the relationship:

$$
\% \text { normal }=\frac{\text { nr.normal larvae in test replicates }}{\text { nr.normal larvae in controls }} \times 100
$$

where \% normal is the rate of first division observed in each replicate and their controls, or the percentage of normal plutei observed in replicates and their controls.

All of the datasets on the toxigenic effects, i.e., the percentage of embryos undergoing the first division in test vessels versus controls, the percentage of normal plutei counted one hour after the fertilization, the percentage of apoptotic embryos recorded one hour and $48 \mathrm{~h}$ after fertilization, as well as percentage of not-divided embryos recorded (one hour and $48 \mathrm{~h}$ after fertilization) were analyzed using one-way and two-way ANOVA, after checking the homogeneity of variance, and Sidak post-hoc tests were applied to check the contribution of each factor to the differences that were observed. 
Data were tested for normality and homogeneity of variances by the D'Agostino-Pearson and Levene's tests, respectively. Graphs and statistical analyses were computed using the software GraphPad Prism version 7.00 for Macintosh (GraphPad Software, La Jolla, CA, USA, www.graphpad.com) and Statistica version 10 (StatSoft Inc., Tulsa, OK, USA).

Supplementary Materials: The following are available online at http://www.mdpi.com/2072-6651/11/2/99/s1. Table S1: Specie names (including Cyano_Pos and Halomicronema sp., analyzed in the present work), acronyms (used in the phylogenetic tree of Figure 3) and accession numbers of cyanobacteria used for phylogenetic analysis of 16S rRNA gene sequences. Table S2: Sequence identity percentage of the fourteen cyanobacteria species used for phylogenetic tree.

Author Contributions: V.Z. conceived the research, designed the experiments, isolated the marine cyanobacteria, and wrote the manuscript. M.M. cultured the marine cyanobacteria, performed the toxicology experiments, contributed to writing the manuscript and run the statistical tests. N.R. performed the molecular analyses and aided in the manuscript preparation. F.G. cultured the marine cyanobacteria and cured the SEM analyses. A.P. performed the morphological analyses, supervised the taxonomical investigations, and contributed to writing the manuscript. A.L.L. isolated the thermal water cyanobacteria and cultured them, also contributing critical editing of the manuscript. G.R. supervised the toxicology experiments. M.C. supervised the molecular tests, shared the conceiving of the experiments and contributed in writing the manuscript.

Funding: This research received no external funding.

Acknowledgments: Samples for electron microscopy were prepared and SEM images were prepared by F. Iamunno, R. Graziano and G. Lanzotti of the Imaging Unit AMOBIO of Stazione Zoologica Anton Dohrn. We thank the unit MEDA for the collection of sea urchins and A. Macina and D. Caramiello of the unit MaRe for the preparation of sea urchin gametes. Cpt. Rando, on board the SZN vessel Phoenicia, collected the seagrass leaves used for isolation of Cyanobacteria. M. Mutalipassi performed these investigations while funded by a SZN-Open University PhD fellowship. Francesca Glaviano was funded by the Flagship project ModRes under the supervision of V. Zupo. We are grateful and indebted with F. De Simone (ThermoFisher Scientific and Alfatest, Rome, Italy) for providing and operating High performance desktop SEM used to obtain high-resolution SEM images and for the detection of the analytical composition of cyanobacteria.

Conflicts of Interest: The authors declare no conflict of interest. The funding sponsors and institutions had no role in the design of the study, in the collection, analyses or interpretation of the data as well as in the writing of the manuscript and in the decision to publish results.

\section{References}

1. Whitton, B.A.; Potts, M. The Ecology of Cyanobacteria: Their Diversity in Time and Space; Kluwer: Dordrecht, The Netherlands, 2000.

2. Hoffman, L. Marine cyanobacteria in tropical regions: Diversity and ecology. Eur. J. Phycol. 1999, 34, 371-379. [CrossRef]

3. Komárek, J.; Kastovsky, J.; Mares, J.; Johansen, J.R. Taxonomic classification of cyanoprokaryotes (cyanobacterial genera) 2014, using a polyphasic approach. Preslia 2014, 86, 295-335.

4. Wilmotte, A. Molecular evolution and taxonomy of the cyanobacteria. In The Molecular Biology of Cyanobacteria; Bryant, D.A., Ed.; Kluwer: Dordrecht, The Netherlands, 1994; pp. 1-25.

5. Mur, L.R.; Skulberg, O.M.; Utkilen, H. Cyanobacteria in the environment. In Toxic Cyanobacteria in Water. A Guide to Their Public Health Consequences and Management; Chorus, I., Bartram, J., Eds.; E\&FN Spon: London, UK, 1999.

6. Finsinger, K.; Scholz, I.; Serrano, A.; Morales, S.; Uribe-Lorio, L.; Mora, M.; Sittenfeld, A.; Weckesser, J.; Hess, W.R. Characterization of truebranching cyanobacteria from geothermal sites and hot springs of Costa Rica. Environ. Microbiol. 2008, 10, 460-473. [CrossRef]

7. Blanco, Y.; Rivas, L.A.; Gonzalez-Toril, E.; Ruiz-Bermejo, M.; Moreno-Paz, M.; Parro, V.; Palacin, A.; Aguilera, A.; Puente-Sanchez, F. Environmental parameters, and not phylogeny, determine the composition of extracellular polymeric substances in microbial mats from extreme environments. Sci. Total. Environ. 2018, 650, 384-393. [CrossRef]

8. Žegura, B.; Štraser, A.; Filipič, M. Genotoxicity and potential carcinogenicity of cyanobacterial toxins-A review. Mutat. Res. 2011, 727, 16-41. [CrossRef]

9. Dias, F.; Antunes, J.T.; Ribeiro, T.; Azevedo, J.; Vasconcelos, V.; Leão, P.N. Cyanobacterial allelochemicals but not cyanobacterial cells markedly reduce microbial community diversity. Front. Microbiol. 2017, 8, 1495. [CrossRef] 
10. Garcia-Pichel, F.; Prufert-Bebout, L.; Muyzer, G. Phenotypic and phylogenetic analyses show Microcoleus chthonoplastes to be a cosmopolitan cyanobacterium. Appl. Environ. Microbiol. 1996, 62, 3284-3291.

11. Garcia-Pichel, F.; Núbel, U.; Muyzer, G. The phylogeny of unicellular, extremely halotolerant cyanobacteria. Arch. Microbiol. 1998, 169, 469-482. [CrossRef]

12. Sivonen, K.; Jones, G. Cyanobacterial toxins. In Toxic Cyanobacteria in Water. A Guide to Their Public Health Consequences and Management; Chorus, I., Bartram, J., Eds.; E\&FN Spon: London, UK, 1999.

13. Lehman, R.M.; O'Connell, S.P. Comparison of extracellular enzyme activities and community composition of attached and free-living bacteria in porous medium columns. Appl. Environ. Microbiol. 2002, 68, 1569-1575. [CrossRef]

14. Bláha, L.; Babica, P.; Maršálek, B. Toxins produced in cyanobacterial water blooms-toxicity and risks. Interdiscip. Toxicol. 2009, 2, 36-41. [CrossRef]

15. Gugger, M.; Lenoir, S.; Berger, C.; Ledreux, A.; Druart, J.C.; Humbert, J.F.; Guette, C.; Bernard, C. First report in a river in France of the benthic cyanobacterium Phormidium favosum producing anatoxin-a associated with dog neurotoxicosis. Toxicon 2005, 45, 919-928. [CrossRef]

16. Teneva, I.; Mladenov, R.; Popov, N.; Dzhambazov, B. Cytotoxicity and apoptotic effects of microcystin-LR and anatoxin-a in mouse lymphocytes. Folia Biol. 2005, 51, 62-67.

17. Wood, S.A.; Selwood, A.I.; Rueckert, A.; Holland, P.T.; Milne, J.R.; Smith, K.F.; Smits, B.; Watts, L.F.; Cary, C.S. First report of homoanatoxin-a and associated dog neurotoxicosis in New Zealand. Toxicon 2007, 50, 292-301. [CrossRef]

18. Borges, H.; Branco, L.; Martins, M.; Lima, C.; Barbosa, P.; Lira, G.; Bittencourt-Oliveira, M.; Molica, R. Cyanotoxin production and phylogeny of benthic cyanobacterial strains isolated from the northeast of Brazil. Harm. Algae 2015, 43, 46-57. [CrossRef]

19. Kuiper-Goodman, T.; Falconer, I.; Fitz-Gerald, J. Human Health Aspects. In Toxic Cyanobacteria in Water. A Guide to Their Public Health Consequences and Management; Chorus, I., Bartram, J., Eds.; E\&FN Spon: London, UK, 1999 .

20. Vasconcelos, V. Cyanobacteria toxins: Diversity and ecological effects. Limnetica 2001, 20, 45-58.

21. Azevedo, S.M.F.O.; Carmichael, W.W.; Jochimsen, E.M.; Rinehart, K.L.; Lau, S.; Shaw, G.R.; Eaglesham, G.K. Human intoxication by microcystins during renal dialysis treatment in Caruaru-Brazil. Toxicology 2002, 181, 441-446. [CrossRef]

22. Hawkins, P.R.; Runnegar, M.T.C.; Jackson, A.R.B.; FALCONER, I.R. Severe hepatotoxicity by the tropical cyanobacterium (bluegreen algae) Cilindrospermopsis racihorskii (Woloszynska) Seenaya and Subba Raju isolated from a domestic water supply reservoir. Appl. Environ. Microbiol. 1985, 50, 1292-1295.

23. Hawkins, P.R.; Chandrasena, N.R.; Jones, G.J.; Humpage, A.R.; Falconer, I.R. Isolation and toxicity of Cylindrospermopsis raciborskii from an ornamental lake. Toxicon 1997, 35, 341-346. [CrossRef]

24. Swain, S.S.; Paidesetty, S.K.; Padhy, R.N. Antibacterial, antifungal and antimycobacterial compounds from cyanobacteria. Biomed. Pharmacother. 2017, 90, 760-776.

25. Shurin, J.B.; Dodson, S.I. Sublethal toxic effects of cyanobacteria and nonyphenol on environmental sex determination and development in Daphnia. Environ. Toxicol. Chem. 1997, 16, 1269-1276. [CrossRef]

26. Quiblier, C.; Wood, S.; Echenique-Subiabre, I.; Heath, M.; Villeneuve, A.; Humbert, J.F. A review of current knowledge on toxic bentic freshwater cyanobacteria-Ecology, toxin production and risk management. Water Res. 2013, 47, 5464-5479.

27. Echenique-Subiabre, I.; Dalle, C.; Duval, C.; Heath, M.W.; Couté, A.; Wood, S.A.; Humbert, J.F.; Quiblier, C. Application of a spectrofluorimetric tool (bbe BenthoTorch) for monitoring potentially toxic benthic cyanobacteria in rivers. Water Res. 2016, 101, 341-350. [CrossRef]

28. Steffen, M.M.; Li, Z.; Effler, T.C.; Hauser, L.J.; Boyer, G.L.; Wilhelm, S.W. Comparative metagenomics of toxic freshwater cyanobacteria bloom communities on two continents. PLoS ONE 2012, 7, e44002. [CrossRef]

29. Watson, S.B. Cyanobacterial and eukaryotic algal odour compounds: Signals or by-products? A review of their biological activity. Phycologia 2003, 42, 332-350. [CrossRef]

30. Holland, A.; Kinnear, S. Interpreting the possible ecological role (s) of cyanotoxins: Compounds for competitive advantage and/or physiological aide? Mar. Drugs 2013, 11, 2239-2258. [CrossRef]

31. Yang, H.; Ye, W.J.; Tan, J.; Liu, X.L.; Lin, S.Q.; Pan, J.L.; Li, D.T. Temporal variability of cyanobacterial populations in the water and sediment samples of Lake Taihu as determined by DGGE and real-time PCR. Harm. Algae 2011, 10, 472-479. 
32. Paerl, H.W.; Xu, H.; McCarthy, M.J.; Zhu, G.W.; Qin, B.Q.; Li, Y.; Gardner, W.S. Controlling harmful cyanobacterial blooms in a hyper-eutrophic lake (Lake Taihu, China): The need for a dual nutrient (N\&P) management strategy. Water Res. 2011, 45, 1973-1983.

33. Wilhelm, S.W.; Farnsley, S.E.; LeCleir, G.R.; Layton, A.C.; Satchwell, M.F.; DeBruyn, J.M.; Boyer, G.L.; Zhu, G.; Paerl, H.W. The relationships between nutrients, cyanobacterial toxins and the microbial community in Taihu (Lake Tai), China. Harm. Algae 2011, 10, 207-215. [CrossRef]

34. Hader, D.P.; Kumar, H.D.; Smith, R.C.; Worrest, R.C. Effects of solar UV radiation on aquatic ecosystems and interactions with climate change. Photochem. Photobiol. Sci. 2007, 6, 267-285. [CrossRef]

35. Paerl, H.W.; Huisman, J. Climate change: A catalyst for global expansion of harmful cyanobacterial blooms. Environ. Microbiol. Rep. 2009, 1, 27-37. [CrossRef]

36. Beardall, J.; Raven, J.A. The potential effects of global climate change on microalgal photosynthesis, growth and ecology. Phycologia 2004, 43, 26-40. [CrossRef]

37. Codd, G.A.; Morrison, L.F.; Metcalf, J.S. Cyanobacteria toxins: Risk management for health protection. Toxicol. Appl. Pharmacol. 2005, 203, 264-272. [CrossRef]

38. Bláhová, L.; Babica, P.; Adamovský, O.; Kohoutek, J.; Maršálek, B.; Bláha, L. Analyses of cyanobacterial toxins (microcystins, cylindrospermopsin) in the reservoirs of the Czech Republic and evaluation of health risks. Environ. Chem. Lett. 2008, 6, 223-227. [CrossRef]

39. Li, N.; Zhang, L.; Li, F.; Wang, Y.; Zhu, Y.; Kang, H.; Wang, S.; Qin, S. Metagenome of microorganisms associated with the toxic cyanobacteria Microcystis aeruginosa analyzed using the 454 sequencing platform. Chin. J. Oceanol. Limnol. 2011, 29, 505-513. [CrossRef]

40. Castenholz, R.W. Endemism and biodiversity of thermophilic cyanobacteria. Nova Hedwigia 1996, $112,33-47$.

41. Zhu, P.; Li, Q.; Wang, G. Unique microbial signatures of the alien Hawaiian marine sponge Suberites zeteki. Microb. Ecol. 2008, 55, 406-414. [CrossRef]

42. Caroppo, C.; Albertano, P.; Bruno, L.; Montinari, M.; Rizzi, M.; Vigliotta, G.; Pagliara, P. Identification and characterization of a new Halomicronema species (Cyanobacteria) isolated from the Mediterranean marine sponge Petrosia ficiformis (Porifera). Fottea 2012, 12, 315-326. [CrossRef]

43. Abed, R.M.; Garcia-Pichel, F.; Hernández-Mariné, M. Polyphasic characterization of benthic, moderately halophilic, moderately thermophilic cyanobacteria with very thin trichomes and the proposal of Halomicronema excentricum gen. nov., sp. nov. Arch. Microbiol. 2002, 177, 361-370. [CrossRef]

44. Ruocco, N.; Mutalipassi, M.; Pollio, A.; Costantini, S.; Costantini, M.; Zupo, V. First evidence of Halomicronema metazoicum (Cyanobacteria) free-living on Posidonia oceanica leaves. PLoS ONE 2018, 13, e0204954. [CrossRef]

45. Zupo, V.; Buia, M.C.; Gambi, M.C.; Lorenti, M.; Procaccini, G. Temporal variations in the spatial structure of a Posidonia oceanica (L.) Delile meadow and its relationships with the patterns of genetic diversity. Mar. Ecol. 2006, 27, 328-338. [CrossRef]

46. Rippka, R.; Deruelles, J.; Waterbury, J.B.; Herdman, M.; Stanier, R.Y. Generic assignments, strain histories and properties of pure cultures of cyanobacteria. J. Gen. Microbiol. 1979, 111, 1-61. [CrossRef]

47. Margaux, C.; Bernard, O.; Steyer, J.P. Modelling an Artificial Microalgae-Cyanobacteria Ecosystem. IFAC-PapersOnLine 2017, 51, 655-660.

48. Rzymski, P.; Poniedziałek, B.; Kokociński, M.; Jurczak, T.; Lipski, D.; Wiktorowicz, K. Interspecific allelopathy in cyanobacteria: Cylindrospermopsin and Cylindrospermopsis raciborskii effect on the growth and metabolism of Microcystis aeruginosa. Harm. Algae 2014, 35, 1-8. [CrossRef]

49. D'Amelio, E.; Cohen, Y.; Des Marais, D.J. Comparative functional ultrastructure of two hypersaline submerged cyanobacterial mats: Guerrero Negro, Baja California Sur, Mexico and Solar Lake, Sinai, Egypt. In Microbial Mats: Physiological Ecology of Benthic Microbial Communities; Cohen, Y., Roseberg, E., Eds.; American Society for Microbiology: Washington, DC, USA, 1989; pp. 97-113.

50. Maibam, C.; Fink, P.; Romano, G.; Buia, M.C.; Gambi, M.C.; Scipione, M.B.; Patti, F.P.; Lorenti, M.; Butera, E.; Zupo, V. Relevance of wound-activated compounds produced by diatoms as toxins and infochemicals for benthic invertebrates. Mar. Biol. 2014, 161, 1639-1652. [CrossRef]

51. Eybe, T.; Audinot, J.N.; Bohn, T.; Guignard, C.; Migeon, H.N.; Hoffmann, L. NanoSIMS 50 elucidation of the natural element composition in structures of cyanobacteria and their exposure to halogen compounds. J. Appl. Microbiol. 2008, 105, 1502-1510. [CrossRef] 
52. Ju, J.J.; Lieke, T.; Saul, N.; Pu, Y.P.; Yin, L.H.; Kochan, C.; Putschew, A.; Baberschke, N.; Steinberg, C.E.W. Neurotoxic evaluation of two organobromine model compounds and natural AO Br-containing surface water samples by a Caenorhabditis elegans test. Ecotoxicol. Environ. Saf. 2014, 104, 194-201. [CrossRef]

53. Zhang, N.; Liu, C.; Qi, F.; Xu, B.B. The formation of haloacetamides, as an emerging class of N-DBPs, from chlor(am)ination of algal organic matter extracted from Microcystis aeruginosa, Scenedesmus quadricauda and Nitzschia palea. RSC Adv. 2017, 7, 7679-7687. [CrossRef]

54. Andrews, J.E.; Nichols, H.P.; Schmid, J.E.; Mole, L.M.; Hunter, E.S.; Klinefelter, G.R. Developmental toxicity of mixtures: The water disinfection by-products dichloro-, dibromo- and bromochloro acetic acid in rat embryo culture. Reprod. Toxicol. 2004, 19, 111-116. [CrossRef]

55. Carmichael, W.W.; Brittain, S.M.; Wang, J.; Babcock-Jackson, L.; Rinehart, K.L.; Culver, D.A. Isolation and characterization of microcystins, cyclic heptapeptide hepatotoxins from a Lake Erie strain of Microcystis aeruginosa. J. Great Lakes Res. 2000, 26, 241-249.

56. Singh, S.P.; Rastogi, R.P.; Häder, D.P.; Sinha, R.P. An improved method for genomic DNA extraction from cyanobacteria. World J. Microbiol. Biotechnol. 2011, 27, 1225-1230. [CrossRef]

57. Nübel, U.; Garcia-Pichel, F.; Muyzer, G. PCR primers to amplify $16 S$ rRNA genes from cyanobacteria. Appl. Environ. Microbiol. 1997, 63, 3327-3332.

58. Altschul, S.F.; Gish, W.; Miller, W.; Myers, E.W.; Lipman, D.J. Basic local alignment search tool. J. Mol. Biol. 1990, 215, 403-410. [CrossRef]

59. Strunecký, O.; Elster, J.; Komárek, J. Phylogenetic relationships between geographically separate Phormidium cyanobacteria: Is there a link between north and south polar regions? Polar Biol. 2010, 33, 1419-1428. [CrossRef]

60. Urbach, E.; Robertson, D.L.; Chisholm, S.W. Multiple evolutionary origins of prochlorophytes within the cyanobacterial radiation. Nature 1992, 355, 267-270. [CrossRef]

61. Stoyanov, P.; Moten, D.; Mladenov, R.; Dzhambazov, B.; Teneva, I. Phylogenetic relationships of some filamentous cyanoprokaryotic species. Evol. Bioinform. 2014, 10, 39-49. [CrossRef]

62. Costantini, S.; Colonna, G.; Facchiano, A.M. FASMA: A service to format and analyse sequences in multiple alignments. Genom. Proteom. Bioinf. 2007, 5, 253-255. [CrossRef]

63. Romano, G.; Costantini, M.; Buttino, I.; Ianora, A.; Palumbo, A. Nitric oxide mediates the stress response induced by diatom aldehydes in the sea urchin Paracentrotus lividus. PLoS ONE 2011, 6, e25980. [CrossRef] [PubMed]

64. Chapman, G.A. Sea urchin sperm cell test. In Fundamentals of Aquatic Toxicology: Effects, Environmental Fate and Risk Assessment, 2nd ed.; Rand, G.M., Ed.; Taylor \& Francis: Washington, DC, USA, 1995; pp. 189-205.

(C) 2019 by the authors. Licensee MDPI, Basel, Switzerland. This article is an open access article distributed under the terms and conditions of the Creative Commons Attribution (CC BY) license (http:/ / creativecommons.org/licenses/by/4.0/). 
Article

\title{
A Novel ShK-Like Toxic Peptide from the Transcriptome of the Cnidarian Palythoa caribaeorum Displays Neuroprotection and Cardioprotection in Zebrafish
}

\author{
Qiwen Liao ${ }^{1,+}$, Guiyi Gong ${ }^{1,+}{ }^{+}$, Shirley Weng In Siu ${ }^{2}$, Clarence Tsun Ting Wong ${ }^{3}$, Huidong Yu ${ }^{4}$, \\ Yu Chung Tse ${ }^{5}$, Gandhi Rádis-Baptista ${ }^{6, *}$ and Simon Ming-Yuen Lee ${ }^{1, *}$ \\ 1 State Key Laboratory of Quality Research in Chinese Medicine and Institute of Chinese Medical Sciences, \\ University of Macau, Macau, China; liaoqw2007@126.com (Q.L.); yb67530@connect.umac.mo (G.G.) \\ 2 Department of Computer and Information Science, Faculty of Science and Technology, University of Macau, \\ Macau, China; shirleysiu@umac.mo \\ 3 Department of Chemistry, The Chinese University of Hong Kong, Shatin, Hong Kong, China; \\ ClarenceTTW@cuhk.edu.hk \\ 4 Shenzhen Rongxin Biotechnology Co., Ltd., Shenzhen 518054, China; huidong.yu@rongene.com \\ 5 Department of Biology, South University of Science and Technology of China, Shenzhen 518055, China; \\ tseyc@sustc.edu.cn \\ 6 Laboratory of Biochemistry and Biotechnology, Institute for Marine Sciences, Federal University of Ceará, \\ Fortaleza 60165-081, Brazil \\ * Correspondence: gandhi.radis@ufc.br (G.R.-B.); simonlee@umac.mo (S.M.-Y.L.); \\ Tel.: +55-85-3366-7007 (G.R.-B.); +853-8822-4695 (S.M.-Y.L.) \\ + These authors contributed equally to this work.
}

Received: 17 May 2018; Accepted: 8 June 2018; Published: 12 June 2018

\begin{abstract}
Palythoa caribaeorum (class Anthozoa) is a zoantharian which, together with other cnidarians, like jellyfishes, hydra, and sea anemones, possesses specialized structures in its tissues, the cnidocytes, which deliver an array of toxins in order to capture prey and deter predators. The whole transcriptome of $P$. caribaeroum was deep sequenced, and a diversity of toxin-related peptide sequences were identified, and some retrieved for functional analysis. In this work, a peptide precursor containing a ShK domain, named PcShK3, was analyzed by means of computational processing, comprising structural phylogenetic analysis, model prediction, and dynamics simulation of peptide-receptor interaction. The combined data indicated that PcShK3 is a distinct peptide which is homologous to a cluster of peptides belonging to the ShK toxin family. In vivo, PcShK3 distributed across the vitelline membrane and accumulated in the yolk sac stripe of zebrafish larvae. Notably, it displayed a significant cardio-protective effect in zebrafish in concentrations inferior to the $\mathrm{IC}_{50}(<43.53 \pm 6.45 \mu \mathrm{M})$, while in high concentrations $\left(>\mathrm{IC}_{50}\right)$, it accumulated in the blood and caused pericardial edema, being cardiotoxic to zebrafish larvae. Remarkably, PcShK3 suppressed the 6-OHDA-induced neurotoxicity on the locomotive behavior of zebrafish. The present results indicated that PcShK3 is a novel member of ShK toxin family, and has the intrinsic ability to induce neuro- and cardio-protective effects or cause cardiac toxicity, according to its effective concentration.
\end{abstract}

Keywords: zoantharian; ShK-like peptide; dynamics simulation; voltage-gated $\mathrm{K}^{+}$ion channel; calcium-activated $\mathrm{K}^{+}$ion channel; animal toxins

Key Contribution: This study discovered a novel peptide, PcShK3, contains the canonical ShK domain in its structure, from zoantharian, displayed cardio-protective and neuroprotective activity. PcShK3 may expand the number of ShK analogs, and will hopefully provide a valuable variant to serve as a new template to be developed as a therapeutic candidate. 


\section{Introduction}

The phylum Cnidaria comprises some of the most venomous known marine animals. Species in this phylum possess unique stinging cells known as cnidocytes, which deliver potent venomous cocktails that immobilize prey for predation or deter them for self-defense [1]. The cnidarian venoms contain disulfide-rich peptides that are cysteine-stabilized toxins which exert their effects by modifying the properties of the ion channels involved in action potential generation in nerve, heart, and skeletal muscle. Collectively, these peptides are typically 10-60 amino acids long, and folded into well-defined secondary structures that are stabilized by multiple, highly-conserved disulfide bonds, which are validated as inhibitors or modulators of different ion channels and neurotransmitter receptors with high potency and selectivity [2]. Based on the number of amino acid residues and disulfide bonds, these toxins can be grouped into four major structural classes: type 1, having 35 to 37 residues with three disulfide bridges; type 2, having 58 to 59 residues and three disulfide bridges; type 3, having 41 to 42 residues and three disulfide bridges; and type 4, having 28 residues and two disulfide bridges. Examples from the first class are BgK from the sea anemone Bunodosoma granulifera and ShK from the sea "sun" anemone Stichodactyla helianthus.

$\mathrm{ShK}$ toxin is a potent blocker of potassium channels. It is a 35-residue peptide originally isolated from sea anemone Stichodactyla helianthus. ShK can block not only $\mathrm{K}_{\mathrm{v}} 1.3$, but also other homologous $\mathrm{K}_{\mathrm{v}}$ subtypes, such as the $\mathrm{K}_{\mathrm{v}} 1.1$, and $\mathrm{K}_{\mathrm{v}} 3.2$ channels [3-5]. Owing to the lack of selectivity, ShK is not suitable for use as a therapeutic agent. Instead, by incorporation of non-natural amino acids or organic labels, analogs of ShK have been designed to be selective for $\mathrm{K}_{\mathrm{v}} 1.3$ over $\mathrm{K}_{\mathrm{v}} 1.1$ and other potassium channels. For example, ShK-Dap22 was generated by replacing its Lys-22 into the positively-charged non-natural residue 1,3-diaminopropionic acid (Dap) [4]. ShK-F6CA was a fluorescein-labeled analog of ShK [6]. Both ShK-186 [3] and ShK-192 [7] were created by attaching the phosphor-Tyr and phosphonic-Phe moieties respectively via a hydrophilic linker to Arg-1. Another ShK analog, ShK-K-amide, was generated by adding a Lys residue and an amide at the C-terminus, and was shown to be a potent and selective blocker of $K_{v} 1.3$ [8]. A recent study by Peng and colleagues [9] demonstrated that $\mathrm{ShK}-170$, which acted as a $\mathrm{K}_{\mathrm{v}} 1.3$ blocker, could protect mice from radiation-induced brain injury. This result suggested that $\mathrm{K}_{\mathrm{v}}$ blockers may have neuroprotective effects.

Changes in the intracellular calcium concentration are coupled with changes in membrane potentials. The changes of membrane potentials are integrated by the activation of calcium-activated $\mathrm{K}^{+}$ channels $\left(\mathrm{K}_{\mathrm{Ca}}\right)$, whose opening probability is increased as a result of membrane hyperpolarization for cytosolic calcium elevation. Many physiological processes, including neurosecretion, smooth muscle tone, action potential shape, and spike frequency adaptation, are regulated by $\mathrm{K}_{\mathrm{Ca}}$ channels activity. The $\mathrm{K}_{\mathrm{Ca}}$ channels can be generally categorized into three subfamilies: BK, SK, and IK channels [10]. Indeed, $\mathrm{K}^{+}$channels play an important role in calcium signaling. Wong $\mathrm{K}$. and collaborators found that the opening of $\mathrm{K}^{+}$channels can be considered as one of the mechanisms responsible for the reduction of intracellular calcium concentration in cultured aortic smooth muscle cells [11]. Jow F. and colleagues proposed a coupling between calcium influx and inactivation of voltage-gated A-type $\mathrm{K}^{+}$channels, resulting in membrane depolarization that contributes to after-hyperpolarization [12]. A number of studies have reported that $\mathrm{Ca}^{2+}$ influx could be regulated by the voltage-gated $\mathrm{K}^{+}$-channel $\mathrm{K}_{\mathrm{v}} 1.3$ and $\mathrm{Ca}^{2+}$-activated $\mathrm{K}^{+}$channel $\mathrm{K}_{\mathrm{Ca}} 3.1$, through the calcium-release activated $\mathrm{Ca}^{2+}$ channel [13-19].

Therefore, taking these facts into consideration, sea anemone ShK peptide highlighted the potential of cnidarians to produce valuable drug candidates. Current genomic, transcriptomic, and proteomic studies provided tools to identify novel peptide families [20]. As a zoantharian, a subclass of Hexacorallia, P. caribaeorum is a sister species of the sea anemone [21]; herein, we studied a peptide precursor, PcShK3, that contains the canonical ShK domain in its structure. Thus, PcShK3 from P. caribaeorum expands the number of ShK analogs, and will hopefully provide a valuable variant to serve as a new template to be developed as a therapeutic candidate. From a functional analysis based on experimental evidence, we found that PcShK3 displayed cardio-protective and neuroprotective activity that, in combination with structurally-guided dissection of peptides which restrained the 
structure to the central ShK core, confirms our findings on the elucidation of its intrinsic biological and pharmacological activities.

\section{Results}

\subsection{PcShK3 Is Identified as a Novel ShK-Like Peptide through Molecular Phylogenetic Analysis}

The ShK-like peptide, PcShK3, is structurally similar to other members of the ShK toxin family. It originates from one of our previous studies on the Palythoa caribaeorum transcriptome [22], whose sequence was deposited at DDBJ/EMBL/GenBank under the accession number GESO00000000. In this study, the contig was selected for further computational and biological analysis, including primary sequence analysis, structure modeling, and chemical peptide synthesis for in vivo assays and functional studies using zebrafish larvae. Both the cDNA and amino acid sequences of PcShK3 are shown in Figure 1A.

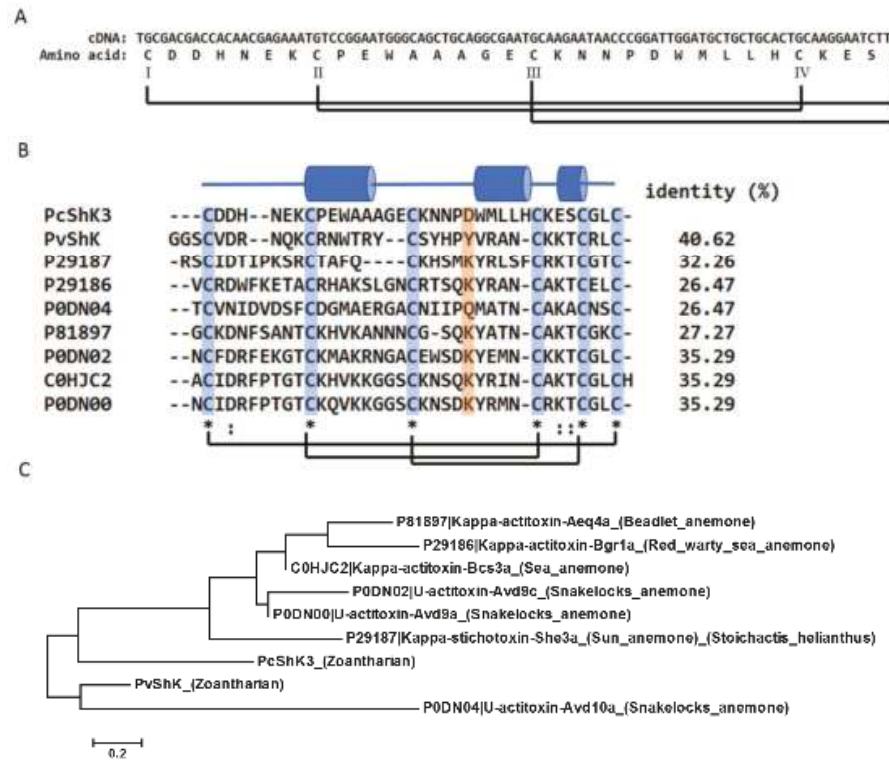

Figure 1. Multiple sequence alignment and phylogenetic analysis of PcShK3 from P. caribaeorum. (A) cDNA and amino sequence of PcShK3; (B) Multiple sequences alignment of P. caribaeorum ShK toxin-like peptides and toxins originated from different ShK species of cnidarians (sea anemones). The PcShK3 peptide maintains the cysteine framework, but is distinct in sequence from these sea anemone toxins. Residues highlighted in blue are cysteine. Regions highlighted in orange are residues to block active sites of ion-channels. Cylinders represent $\alpha$-helices; (C) Maximum-likelihood tree from phylogenetic analysis of PcShK3. Notably, except PvShK, the ShK toxin (P29187) originated from Stichodactyla helianthus is most similar to PcShK3.

PcShK3 and its homologs from other species of marine organisms were selected for multiple sequence alignment and phylogenetic analysis. From the Maximum-likelihood tree (Figure 1C), it is seen that PcShK3 clusters well with the ShK toxin of Protopalythoa variabilis, which was predicted from other zoantharian transcriptomes from our previous study [23]. Also, PcShK3 is phylogenetically related to Kappa-stichotoxin-She3a (UniProt ID: P21987). PcShK3 can be grouped with members of the type 1 sea anemone toxins, each of which contains a cysteine framework similar to that of the ShK toxin from the Stichodactyla helianthus sea anemone. They are canonical peptides with 35 to 37 
amino acids, containing six highly conserved cysteine residues. Structures of these peptides are thus stabilized by means of three characteristic disulfide-disulfide bonds, namely, C1-C6, C2-C4, C3-C5. The comparison of PcShK3 with other ShK domain-containing toxins in multiple sequence alignment analysis is shown in Figure 1B. As observed, except for the highly conserved cysteine residues and disulfide-disulfide framework, the amino acid sequences are divergent. Close to the $N$-terminal of PcShK3, two amino acids were deleted, as compared to the ShK sequence.

Based on the crystal structure of ShK, the homology model of PcShK3 was obtained. It is a highly stable structure, as shown in the 10-ns molecular dynamics (MD) simulation of the PcShK3 model at solvent. As shown in Figure 2A, the root-mean-squared deviation (rmsd) of the peptide structure reaches a plateau of $0.15 \AA$ after $3 \mathrm{~ns}$, and only light fluctuations were seen in the terminals. Superpositions of the equilibrated PcShK3 structure to BgK (non-template) and ShK (template) exhibit similar characteristics folds, giving rmsd values of $5.15 \AA$ and $2.42 \AA$, respectively. The first helical segment of PcShK3 highly resembles that of $\mathrm{BgK}$, while the middle, a slightly distorted helix, and the last helical folds, resemble those of ShK (see Figure 2B).
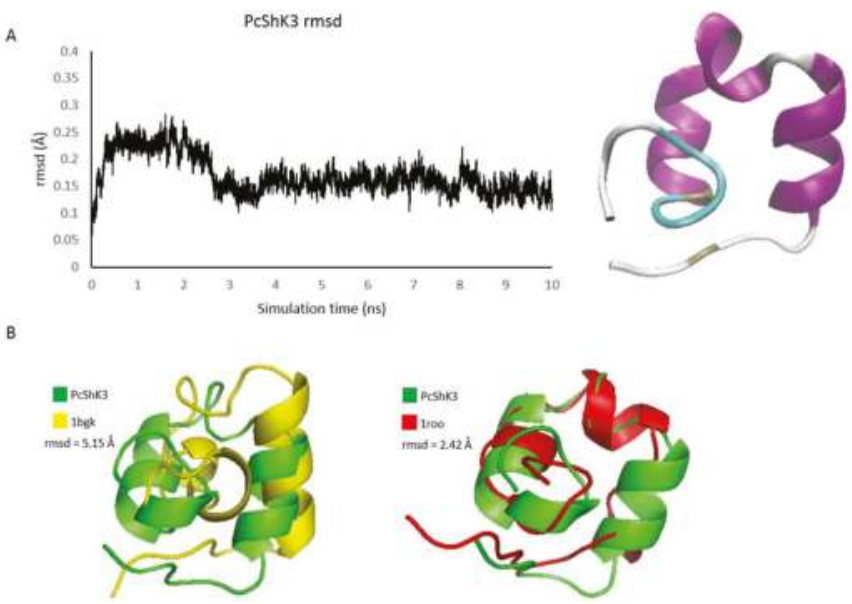

Figure 2. Structure modeling of PcShK3 and structural comparison with ShK and BgK toxins. (A) The homology model of PcShK3 was refined by $10 \mathrm{~ns}$ simulation after minimization and equilibration steps using GROMACS 5.1; (B) Superposition of PcShK3 against crystal structures of ShK toxins, BgK and ShK. The latter was used as template in the homology modeling.

\subsection{PcShK3 Has the Potential to Block to $K_{v} 1.3$ and $K_{C a} 3.1$ through Docking Analysis}

The well-studied ShK peptide is known to block the activities of both $\mathrm{K}_{\mathrm{V}} 1.3$ and $\mathrm{K}_{\mathrm{Ca}} 3.1$ subtypes of voltage-gated $\mathrm{K}^{+}$-ion channels. Electrophysiological studies demonstrated that ShK has a greater affinity for $\mathrm{K}_{\mathrm{v}} 1.3\left(\mathrm{IC}_{50}\right.$ of $\left.133 \mathrm{pM}[6,24]\right)$ than $\mathrm{K}_{\mathrm{Ca}} 3.1$ (IC50 of $\left.30 \mathrm{nM}[5,25]\right)$. Since PcShK3 is phylogenetically related to ShK, it is tempting to speculate that PcShK3 may also block these two channels. MD simulation has confirmed the structural stability of the homology model of PcShK3. To gain further insight into potential interactions between this peptide and the channels, protein-protein docking by the ZDOCK server was performed. ZDOCK [26] is an accurate and widely used tool to solve protein-protein docking problems, also for toxin studies [27-29]. It has a success rate of $70 \%$, and is ranked among the top 10 methods in the CAPRI benchmark test [30]. After docking was complete, the predicted complexes were then fed into PDBe PISA for interfacial residues analysis. As shown in Figure 3A,B, both PcShK3 and ShK interact with the chain D of $\mathrm{K}_{\mathrm{V}} 1.3$ via one hydrogen bond, namely Asn-19 of PcShK3 to the backbone carbonyl oxygen of the channel residue Val- and Tyr-23 of ShK to the backbone carbonyl oxygen of the channel residue Leu-368. Their computed Gibbs 
free energy values are also similar. PcShK3 binding yields $-30.7 \mathrm{kcal} / \mathrm{mol}$, while ShK binding yields $-28.2 \mathrm{kcal} / \mathrm{mol}$. For complexation with $\mathrm{K}_{\mathrm{Ca}} 3.1$, both peptides exploit two residues to interact with the channel, namely Asn-20 and Asp-22, of PcShK3 to the sidechain of the channel residue Trp-262, and Gln-16 and Tyr-23 of ShK to the backbone carbonyl oxygens of the channel residues Ile-251 and Gly-252. The Gibbs free energies of binding in both cases were slightly reduced to $-29.7 \mathrm{kcal} / \mathrm{mol}$ for PcShK3 and $-23.5 \mathrm{kcal} / \mathrm{mol}$ for ShK.

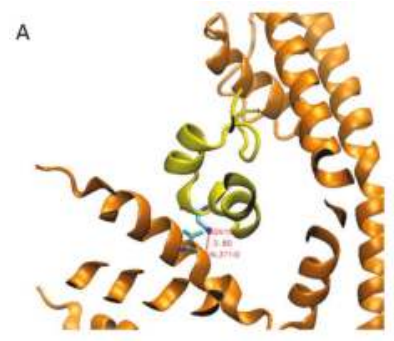

C

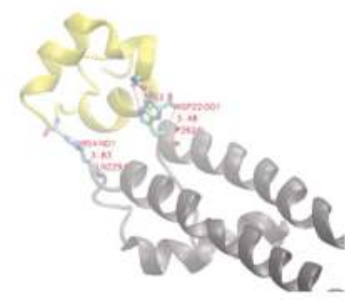

B

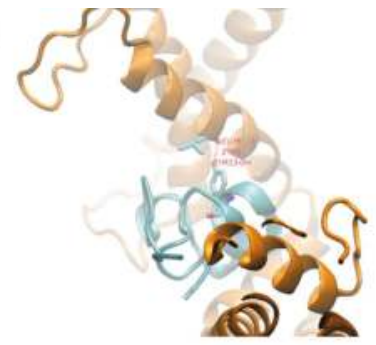

D

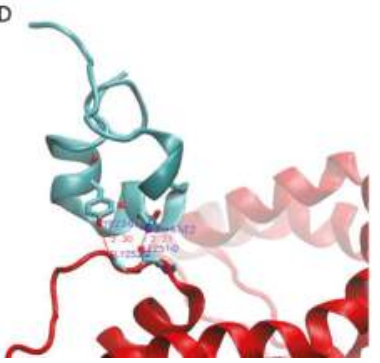

Figure 3. Predicted binding modes of PcShK3 and ShK at the $\mathrm{K}^{+}$-channels. (A) Interface residues between PcShK3 and $\mathrm{K}_{\mathrm{v}} 1.3$, PcShK3 are shown in yellow; chain D of $\mathrm{K}_{\mathrm{V}} 1.3$ is shown in orange. The binding sites are shown in gray; (B) Interface residues between $\mathrm{ShK}$ and $\mathrm{K}_{\mathrm{v}} 1.3$, ShK are shown in cyan; chain D of $\mathrm{K}_{\mathrm{v}} 1.3$ is shown in orange; (C) Interface residues between PcShK3 and $\mathrm{K}_{\mathrm{Ca}} 3.1$, PcShK3 are shown in yellow; chain $\mathrm{C}$ of $\mathrm{K}_{\mathrm{Ca}} 3.1$ is shown in grey; (D) Interface residues between ShK and $\mathrm{K}_{\mathrm{Ca}} 3.1$, ShK are shown in cyan, and chain B of $\mathrm{K}_{\mathrm{Ca}} 3.1$ is shown in red.

\subsection{PcShK3 Distributed across Vitelline Membrane and Accumulated in the Yolk Sac Stripe of Zebrafish Larvae}

To evaluate the biodistribution of the PcShK3, rhodamine B-conjugated PcShK3 was also synthesized to track in vivo how PcShK3 was absorbed and distributed in zebrafish.

In Figure 4A, the biodistribution of PcShK3 is shown, and there is an overlap pattern of peptide distribution and EGFP expression in zebrafish. It showed that the peptide translocated across vitelline membrane and was accumulated in the yolk sac stripe. The assessment of PcShK3's biological activity (Figure 4B) demonstrated that zebrafish larvae that were exposed to $40 \mu \mathrm{M}$ of the peptide for $1 \mathrm{~h}$ displayed a mortality rate of about $60 \%$. When the peptide concentration reached $75 \mu \mathrm{M}$ or higher, the lethality was $100 \%$ after $48 \mathrm{~h}$ of exposure. Therefore, PcShK3, as ShK-like peptide, did not exhibit a high lethal toxicity to zebrafish larvae, with a $\mathrm{LD}_{50}$ value fitting in the range of 30 to $40 \mu \mathrm{M}$.

\subsection{PcShK3 Hold the Potential to Improve or Restore the Cardiovascular Function at Lower Concentration}

From the docking analysis, we could infer that PcShK3 has the potential to block $\mathrm{K}_{\mathrm{Ca}} 3.1$, a $\mathrm{K}^{+}$-dependent calcium ion channel subtype that is widely distributed in cardiovascular system. Then, $\operatorname{Tg}(C M L C 2: G F P)$ zebrafish were utilized to evaluate the pharmacological activity and the protective effect of PcShK3 act on cardiovascular system. The cardiovascular protective effect of the peptide at concentrations lower than $30 \mu \mathrm{M}$ was evaluated using a set of physiological parameters 
including heart rate, stroke volume (SV), cardiac output (CO), and fractional shortening (\% FS) by means of analyzing the videos and images of the recorded fish hearts. When analyzing the cardiac function parameters of zebrafish larvae exposed to $30 \mu \mathrm{M}$, heart rate, SV, \% FS, and CO were all decreased. However, these parameters increased overall in a dose-dependent manner at concentrations lower than $20 \mu \mathrm{M}$. These findings indicated that our ShK toxin-like peptide derivative, PcShK3, can improve or restore the cardiovascular function at concentrations lower than $20 \mu \mathrm{M}$.

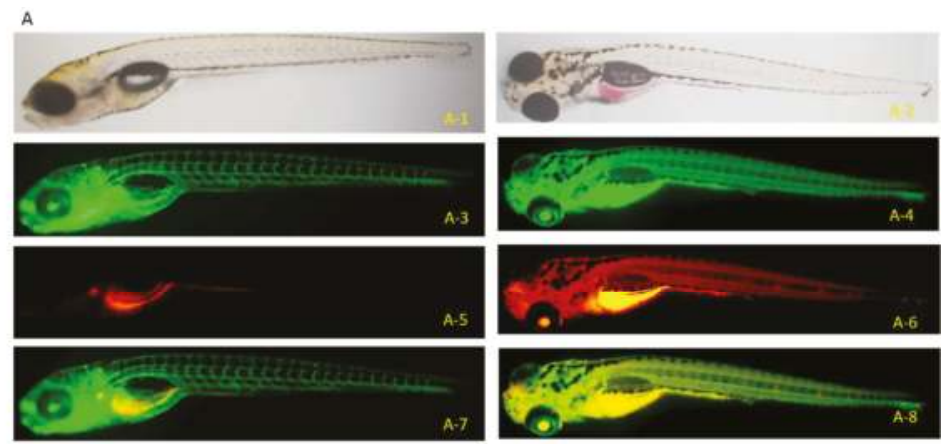

B

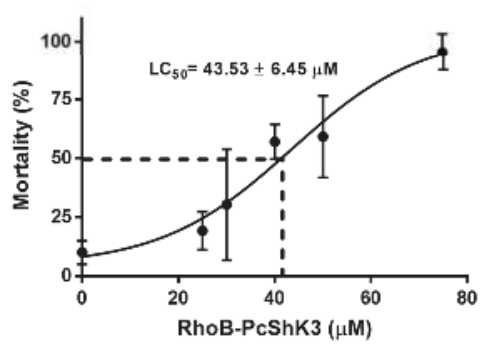

Figure 4. Mortality rate and distribution of P. caribaeorum ShK toxin-like peptide. (A) Fluorescent images of in vivo distribution of rhodamine B-conjugated peptide in $T g(f l i 1: E G F P) y 1$ zebrafish. Bright field pattern of zebrafish (6 dpf) treated with $20 \mu \mathrm{M}$ of RhoB-PcShK3 (A-1) and free rhodamine $\mathrm{B}$ as negative control (A-2) for $24 \mathrm{~h}$. Green fluorescence pattern of EGFP expression in transgenic $\mathrm{Tg}$ (fli1:EGFP)y1 zebrafish (B-3,B-4). Fluorescent images (A-5,A-6) from zebrafish (6 dpf) after incubation with rhodamine B-conjugated PcShK3 $(20 \mu \mathrm{M})$ and free rhodamine B $(20 \mu \mathrm{M})$ for $24 \mathrm{~h}$. Merged images (A-7) of blood vessels (green) and rhodamine B conjugated PcShK3 (red). Merged fluorescent images (A-8) of blood vessels (green) and free rhodamine B (red); (B) Mortality rate of zebrafish larvae after exposure to peptide. The mortality rate reached $50 \%$ when zebrafish larvae was exposed to peptide $(40 \mu \mathrm{M})$ for $8 \mathrm{~h}$. The mortality rate reached $100 \%$ of zebrafish larvae exposed to peptide $(75 \mu \mathrm{M})$ for $48 \mathrm{~h}$. The $\mathrm{LD}_{50}$ is estimated to $43.53 \pm 6.45 \mu \mathrm{M}$.

As seen in Figure 5, the cardiac function parameters were all decreased when zebrafish larvae were exposed to $30 \mu \mathrm{M}$ of the peptide. Cardiac malformation, which included pericardial edema and blood accumulation, occurred at concentrations higher than $30 \mu \mathrm{M}$ (Figure 6A). To zebrafish larvae that survived the peptide, i.e., those that were exposed to $30 \mu \mathrm{M}$ for 4,24 and $48 \mathrm{~h}$, the phenomena of blood accumulation (ba) and pericardial edema (pe) were observed under fluorescence microscope. The phenotypes of cardiac abnormalities induced by a high dosage of the peptide were evident (Figure 6A). The blood accumulation appeared after $4 \mathrm{~h}$ of peptide treatment and decreased after $24 \mathrm{~h}$. The rate of pericardial edema increased from $24 \mathrm{~h}$ post-treatment (hpt) in a dose-dependent manner. The cardiac malformation phenotype and graphical plot are shown in Figure 6B. 

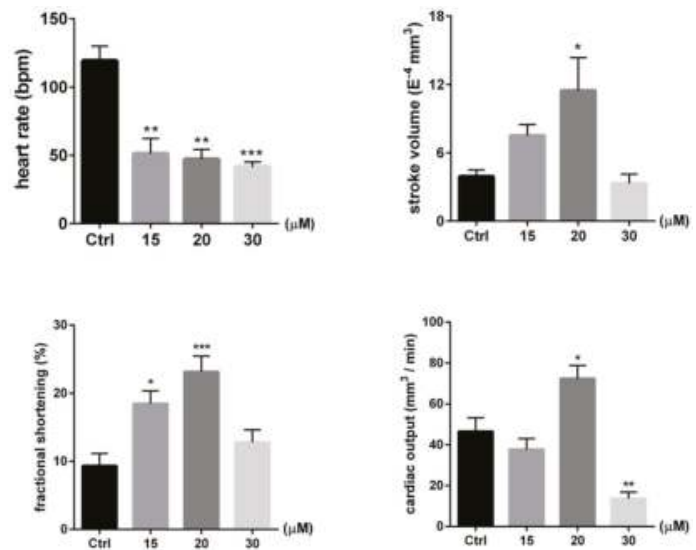

Figure 5. Cardiac functions of zebrafish larvae exposed to various concentrations of PcShK3 peptide for $48 \mathrm{~h}$. Stroke volume (SV), heart rate, cardiac output (CO) and fractional shortening (\% FS) of zebrafish were shown. Data are presented as mean $\pm \operatorname{SEM}(\mathrm{n}=10) .{ }^{*} p<0.05,{ }^{* *} p<0.01,{ }^{* * *} p<0.001$ significantly different compared with the control group.

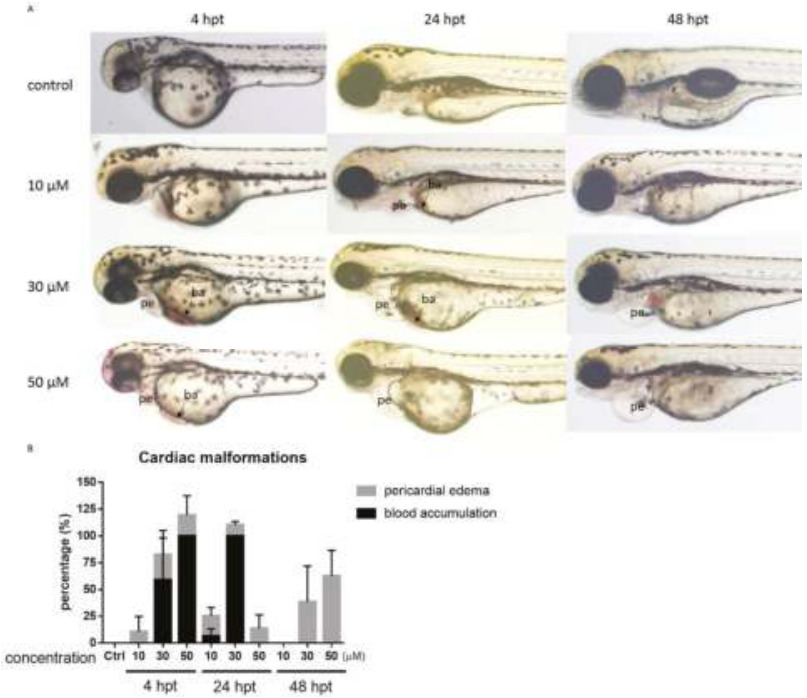

Figure 6. Evaluation of cardiac malformations of zebrafish larvae upon PcShK3 peptide exposure. (A) Time and dose-dependent change in developmental cardiac malformations in larvae after exposure to peptide $(30 \mu \mathrm{M})$ from 4 to $48 \mathrm{hpt}$. The blood accumulation (ba) appeared after $4 \mathrm{~h}$ of drug treatment and decreased after $24 \mathrm{~h}$. The rate of pericardial edema (pe) increased from $24 \mathrm{hpt}$ in a dose-dependent fashion. Values are shown as the mean \pm S.D. of three replicates each with 15 larvae; (B) Phenotype plot of cardiac abnormalities induced by the peptide.

2.5. PcShK3 Could Prevent the In Vivo Dopaminergic (DA) Neuron Loss Induced by 6-Hydroxydopamine (6-OHDA) in Zebrafish

To investigate the neuroprotective effect of the peptide, anti-TH whole-mount immunofluorescent staining was used to examine DA neurons in zebrafish larvae. The development of DA neurons in zebrafish is similar to that seen in other vertebrates [31]. As shown in Figure 7, TH-positive neurons 
in diencephalic area were decreased by about $40 \%$ after exposure to 6-OHDA for $48 \mathrm{~h}$ (indicated by yellow brackets in Figure 7A and fluorescence of $\mathrm{TH}^{+}$in Figure 7B). Co-treatment with the peptide was able to attenuate DA neuron loss induced by 6-OHDA when the peptide concentration was $30 \mu \mathrm{M}$. These results suggested that the peptide provides a protective effect against 6-OHDA-induced dopaminergic neuron death in zebrafish larvae.

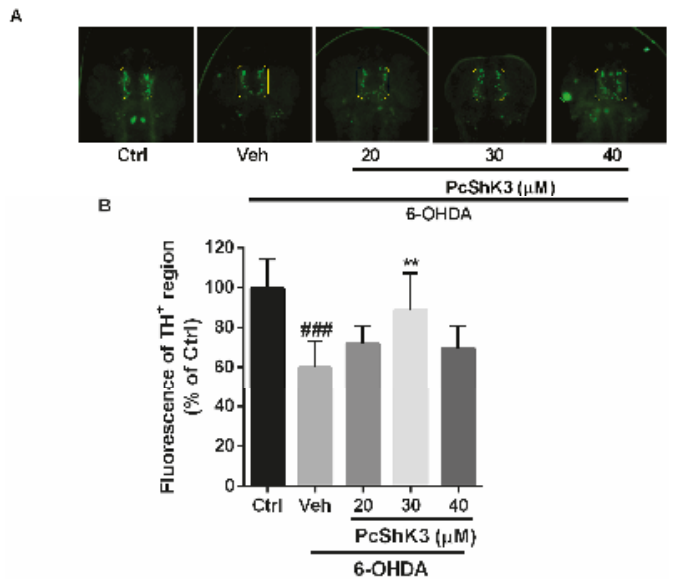

Figure 7. PcShK3 protects against 6-OHDA-induced dopaminergic neuron loss in zebrafish. (A) Representative morphology of DA neurons in zebrafish brain indicated by $\mathrm{TH}$ staining. $\mathrm{TH}^{+}$neurons in diencephalic region are indicated by yellow brackets; (B) quantitative analysis of the area of $\mathrm{TH}^{+}$neurons of each group, \#\#\# $p<0.001$ versus control group, ${ }^{* *} p<0.01$ versus 6-OHDA group.

In a locomotion test, injury of dopaminergic (DA) neurons by 6-OHDA markedly altered the swimming behavior of zebrafish. As shown in Figure 8, 6-OHDA significantly reduced the swimming distance of the larvae after treatment with 6-OHDA. The 6-OHDA-induced lesion was attenuated in a concentration-dependent manner after co-treatment with PcShK3. These data suggested that PcShK3 can suppress 6-OHDA-induced deficits in the locomotive behavior of zebrafish.

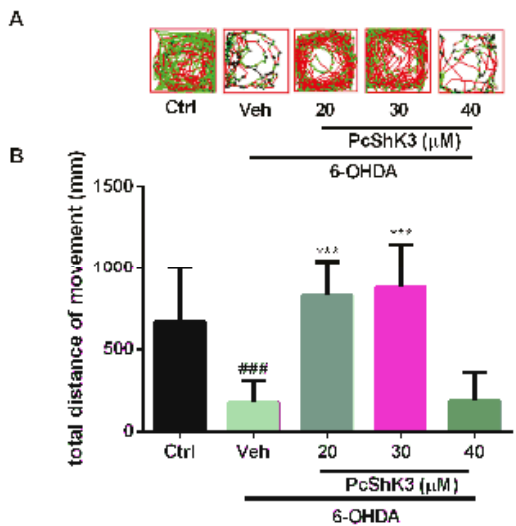

Figure 8. PcShK3 attenuated 6-OHDA-induced lesion in zebrafish. (A) Representative patterns of zebrafish swimming track; (B) Statistics analysis of total distance moved of different treatment groups, eight fish larvae per group from three independent experiments. \#\#\# $p<0.005$ versus control group, *** $p<0.005$ versus 6-OHDA group. 


\section{Discussions}

In this study, from the P. caribaeorum transcriptome (DDBJ/EMBL/GenBank under the accession GESO00000000), the peptide sequence predicted from the Unigene34015, named PcShK3, was found to have a canonical ShK domain, typical of $\mathrm{K}_{\mathrm{v}} 1$ toxin from sea anemones. From molecular phylogenetic analysis, the homology of PcShK3 was confirmed to share structural similarity with known ShK toxins from many venomous animals, particularly the prototype ShK, and the similar BgK, both originating from distinct species of sea anemone. Moreover, from data of structural modeling and alignments, it was determined that PcShK3 clustered much better with ShK (1roo), rather than with BgK (1 bgk). These sea anemones neurotoxic peptides are known selective inhibitors of $\mathrm{K}^{+}$-channel subtypes. In our docking analysis, the Gibbs free energy of complex of ShK and $K_{\mathrm{v}} 1.3$ is $-28.2 \mathrm{kcal} / \mathrm{mol}$. This value is indicative that the peptide interacts with $\mathrm{K}_{\mathrm{v}} 1.3$ through hydrogen bonds between Tyr-23 of ShK and Leu-368 of $\mathrm{K}_{\mathrm{v}} 1.3$, and the distance was calculated to be $2.46 \AA$. The active site Tyr-23 in this computational output was near Lys-22, like that observed in other experimental studies [32]. Similarly, from the present data, the ShK toxin-like peptide from P. caribaeorum, PcShK3, could also bind to $K_{V} 1.3$, according to the docking prediction-Asn-19 of PcShK3, part of the binding site, appears to interact to Val-371 of $\mathrm{K}_{\mathrm{v}} 1.3$ through hydrogen bond within $3.80 \AA$ distance, with a Gibbs free energy of $-30.7 \mathrm{kcal} / \mathrm{mol}$. The presence of Lys-22 of ShK was believed to protrude into the channel selectivity

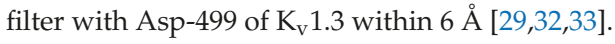

Previous studies showed that ShK toxin displays activity similar to that of cholinesterase inhibitors when injected intraperitoneally in mice [34]. Also, ShK could reduce $\mathrm{K}^{+}$currents in neurons from rat dorsal root ganglia [35]. ShK toxin could induce contractile responses in guinea pig ileum [36]. Interestingly, ShK was able to induce anti-obesity activity and reduction of insulin resistance through the blockade to $\mathrm{K}_{\mathrm{v}} 1.3[37,38]$. Interestingly, blockers of $\mathrm{K}_{\mathrm{v}} 1.3$ channel in lymphocytes preferentially inhibit the activation of these cells, and therefore show considerable potential as therapeutics for autoimmune diseases such as multiple sclerosis, type 1 diabetes mellitus, and rheumatoid arthritis [39]. It is worthy of note that most studies on the development of ShK toxin analogs as therapeutic agents focus on targeting $\mathrm{K}_{\mathrm{v}} 1.3$ ion channel in autoimmune processes and diseases.

We have tested the $\mathrm{Tg}$ (mpo:GFP) zebrafish line treated with PcShK3 for immunomodulation response, and found, at a first glance, that PcShK3 was not capable of affecting neutrophil migration (as shown in Figure S1). An important tool for investigating the biodistribution and site of action of a given peptide is the use of fluorescent dyes, which can be covalently linked to the $N$-termini of the peptide sequence. In the survival test, the $\mathrm{LD}_{50}$ of the peptide is $43.53 \pm 6.45 \mu \mathrm{M}$ after $48 \mathrm{~h}$ of exposure, indicating that the toxicity of PcShK3 derivative in zebrafish is relatively low. However, an evident cardiac malformation was observed in zebrafish larvae upon PcShK3 exposure. In contrast, in $24 \mathrm{~h}$ post-treatment (hpt) with the peptide, as seen in Figure 6, blood accumulation and pericardial edema occurred and blood accumulation disappeared at $48 \mathrm{hpt}$. In other investigative studies with the novel zoanthid ShK-like toxin peptide, identified in the Anthozoa Protopalyhtoa variabilis, we have demonstrated a toxic mortality to zebrafish only when peptide concentration was higher than $20 \mu \mathrm{M}$ [23]. Calcium signaling plays a key role in cardiovascular excitability and function. Excitation-contraction (E-C) coupling in the adult mammalian heart is governed by the $\mathrm{Ca}^{2+}$-induced $\mathrm{Ca}^{2+}$ release (CICR) mechanism [40]. Our results showed that survival rate of zebrafish larvae is significantly dependent on calcium levels, indicating that the peptide RhoB-PcShK3 probably interacts with the cardiovascular system through $\mathrm{K}^{+}$-channel blockade, thus modulating the calcium influx. In fact, the PcShK3 homologous ShK toxin from the Stichodactyla sea anemone could also bind to $\mathrm{K}_{\mathrm{Ca}} 3.1$, although the affinity is much less than for other $\mathrm{K}_{\mathrm{v}} 1$ members [3-5,25]. The residues Asn-20 and Asp-22 of PcShK3 were docked into Trp-262 of $\mathrm{K}_{\mathrm{Ca}} 3.1$ chain $\mathrm{C}$, respectively. The Gibbs free energy was found to be $-29.7 \mathrm{kcal} / \mathrm{mol}$. Therefore, PcShK3 could presumably block $\mathrm{K}_{\mathrm{Ca}} 3.1$ in a similar fashion to ShK. 
It is well known that intracellular calcium release from the sarcoplasmic reticulum (SR), through ryanodine receptor, is required for cardiac muscle contraction. The calcium concentration in the cytosol of cardiac myocytes is elevated by approximately 10-fold from a resting level of $\sim 100 \mathrm{nM}$ to $\sim 1 \mu \mathrm{M}$ with each heart beat [41]. In the cardiomyocyte action potential shape, $\mathrm{K}^{+}$-channels open and cause $\mathrm{K}^{+}$ion outflux during phase 3 [42]. Phase 2 is responsible for the large duration of the action potential, and is important in preventing cardiac arrhythmia [42,43]. Therefore, a defect in the removal of calcium from the cytosol during diastole would impair cardiac relaxation.

Some peptide toxins isolated from the animal venom were found to interact with specific targets, and were then have converted into therapeutics. Successful examples of drugs developed from venom peptides include Captopril ${ }^{\circledR}$, a peptidemimetic which was designed based on pentapeptide toxins from the Brazilian viper and which is now used for hypertension treatment [44]; Byetta ${ }^{\circledR}$, an syncretin peptide from the saliva of Gila monster venom, and used as an anti-diabetic agent to treat type 2 diabetes [45]; and Prialt ${ }^{\circledR}$, derived from the MVIIa omega conotoxin specific to block the subtype $\mathrm{Ca}_{\mathrm{v}} 2.1$ of the calcium ion channel, from the predatory cone snail Conus magus, and used to treat chronic pain $[46,47]$. Despite the high potential for drug development, toxicity is a constant concern regarding to the conversion of venom peptides into drug leads and therapeutics.

Interestingly, our findings demonstrate that the novel ShK-like peptide from P. caribaeorum, potentially has am intrinsic ability to induce cardiovascular protection and neuroprotection, supposedly through $\mathrm{K}^{+}$channels blockade, since calcium signal modulation was also involved. Evaluation of the cardiac function after exposure of zebrafish to the peptide, at a concentration lower than $20 \mu \mathrm{M}$, demonstrated that the heart rate was significantly decreased. Meanwhile, the SV, the \% FS, and the CO were increased almost $100 \%$ compared to the control group. The hypothesis is that, indeed, PcShK3 targets $K_{v}$ and $K_{\mathrm{Ca}}$ channels, and regulates the calcium influx through the membrane of cardiomyocytes, resulting in a specific cardiac protective activity. In addition, some evidence showed that $\mathrm{K}_{\mathrm{v}}$ blockers can exert a neuroprotective effect. It was found that ShK-170, a $\mathrm{K}_{\mathrm{v}} 1.3$ blocker, could in vivo protect against radiation-induced brain injury [9]. Another $\mathrm{K}^{+}$-channel blocker, 4-aminopyridine (4AP), could inhibit neuronal cell death through activation of NMDA receptors after blockade to $\mathrm{K}^{+}$-channel in the murine hippocampus [48]. Furthermore, it was reported that 4AP could decrease MPTP-induced behavioral lesions. [49] reported that 4-aminopyridine decreases MPTP-induced behavioral lesion. In our study, we found that PcShK3 could suppress 6-OHDA-induced deficits in the locomotive behavior of zebrafish, indicating that PcShK3 has a potential ability to induce neuroprotection, an effect that is useful to ameliorate neurodegenerative disorders. This remarkable finding has provided us with insights to develop novel ShK analogs for prospective application in the research and development of an adjuvant therapy to control cardiovascular dysfunctions and neurodegenerative diseases.

In conclusion, the novel ShK-like peptide PcShK3 from P. caribaeorum (a zoantharian species belonging to the subclass Hexacorallia, Cnidaria) has the ability to confer cardiovascular and neurological protective effects in a zebrafish model of drug screening. To further confirm that P. caribaeorum ShK-like peptides act as potent ion-channel blockers of the ShK family of toxins, electrophysiological measurements with subtypes of $\mathrm{K}_{\mathrm{v}} 1$ and $\mathrm{K}_{\mathrm{Ca}}$ channels upon PcShK3 peptide action will be necessary. Moreover, by combining electrophysiology of specific potassium channel subtypes with quantification of intracellular calcium levels, more informative data will give support to hypotheses describing the underlying molecular mechanism of and PcShK3 activity on $\mathrm{K}_{\mathrm{v}} 1$ or $\mathrm{K}_{\mathrm{Ca}}$. Altogether, the present study reported structural and functional data that provide an insightful perspective to characterize novel ShK-like peptide sequences and their derivatives from zoantharians. Particularly, the peptide displayed an interesting cardio-protective and neuroprotective activity that, in combination with structurally-guided dissection of peptides, can be useful for developing peptide-drug candidates for the investigation and prospective adjuvant treatment of cardiovascular and neurodegenerative diseases. 


\section{Materials and Methods}

\subsection{Primary Sequence Analysis, Structure Modeling and Molecular Dynamics Simulation}

The peptide sequences contained ShK domain were downloaded from UniProtKB database. After sequences alignment and editing using the MUSCLE algorithm [50,51], phylogenetic tree was constructed based on the maximum-likelihood method, using the program MEGA version 6 [52]. Reliability of the tree was assessed using 500 bootstrap replicates.

Structures of PcShK3 were modeled using SWISS-MODEL server [53,54], taking the ShK crystal structure as the template [55]. The modeled peptide structure was subjected to energy minimization and molecular dynamics (MD) simulations with CHARMM27 all-atom force field using the GROMACS 5.1 simulation software [56,57]. The equilibrated structure was compared to the known structures of ShK (PDB: 1ROO) and BgK (PDB: 1BGK) toxins. Molecular visualization and structure alignment were achieved using the PyMOL program (version 1.8, Schrödinger, LLC, New York, NY, USA, 2015).

\subsection{Molecular Docking Analysis}

The atomic coordinates of the voltage-gated $\mathrm{K}^{+}$-channel subfamily A channels including member 3 (UniProt ID: P22001, $\mathrm{K}_{\mathrm{v}} 1.3$ ), and intermediate conductance $\mathrm{Ca}^{2+}$-activated $\mathrm{K}^{+}$-channel protein 4 (UniProt ID: O15554, $\mathrm{K}_{\mathrm{Ca}} 3$.1) were modeled by homology in the SWISS-MODEL server, taking the $\mathrm{K}_{\mathrm{v}} 1.2$ crystal structure (PDB ID: 2R9R) as the template. According to the annotations from UniProt database, ion transport region of $\mathrm{K}_{\mathrm{V}} 1.3$ and $\mathrm{K}_{\mathrm{Ca}} 3.1$ were retained for docking prediction. The Fast Fourier Transform (FFT)-based, initial-stage rigid-body molecular docking algorithm ZDOCK [26] was applied to model the interactions between PcShK3 and the interested channels. PDBe PISA v1.52 $[58,59]$ was utilized for interface residues analysis. The all-structure visualization was achieved using the VMD program v1.9.2 [60].

\subsection{Peptide Synthesis}

Sequences of the PcShK3 peptide were retrieved from the P. caribaeorum transcriptome, and synthesized by solid phase chemistry. The presence of a single peak in analytical reverse-phase HPLC (RP-HPLC) and mass spectrometry (MS) analysis was used to confirm a purity grade over $90 \%$ (Cellmano Biotech Limited, Hefei, China). Complete deprotection and cleavage were carried out with trifluoroacetic acid in water. The crude peptides were precipitated out by the addition of chilled ether. Finally, the crude peptide was purified by HPLC, freeze-dried for storage, and retested by HPLC to make sure that it qualified (Figure S2A). To track the biodistribution of the peptides, a rhodamine B conjugated PcShK3 was synthesized (Figure S2B). The peptides were solubilized in dimethyl sulfoxide (DMSO) to make a $1 \mathrm{mM}$ stock solution, and diluted in an assay buffer (see composition below) when required. Peptide stock solutions were stored in DMSO at $-20{ }^{\circ} \mathrm{C}$.

\subsection{Zebrafish Maintenance}

Transgenic fish lines $\operatorname{Tg}(f l i 1: E G F P) y 1$ and $\operatorname{Tg}(C M L C 2: G F P)$, the wild-type AB strain of zebrafish, were manipulated as described in the Zebrafish Handbook [61]. Briefly, the zebrafish embryos were generated by natural pairwise mating (3-12 months old), and were raised at $28.5^{\circ} \mathrm{C}$ in embryo medium at $28.5^{\circ} \mathrm{C}$. The ethical approval for the animal experiments was granted by the Animal Research Ethics Committee in University of Macau, China.

\subsection{Assessment of Survival Rate and Biodistribution of Peptides in Zebrafish Larvae}

Zebrafish larvae ( $\operatorname{Tg}(f l i 1: E G F P) y 1)$ at six-day post-fertilization (6-dpf) were exposed to 2-logs (from 5 to $100 \mu \mathrm{M}$ ) of the peptide. The mortality of zebrafish exposed to peptides was determined by observing the presence of heartbeat absence under a light microscope. Zebrafish larvae were separately exposed to a fixed concentration $(20 \mu \mathrm{M})$ of the peptide for $3 \mathrm{~h}$, then collected and mounted 
on microscope glass slides. An IX81 motorized inverted fluorescent microscope (Olympus Co., Tokyo, Japan) was used to monitor the biodistribution of the peptide in zebrafish.

\subsection{Measurement of Morphology and Functions of Zebrafish Heart}

The Cell^R imaging system of an IX71 microscope (Olympus) was utilized to evaluate the morphology of the heart and cardiac functions of $\mathrm{Tg}(\mathrm{CMLC2:GFP)}$ zebrafish after exposure to increasing concentration of peptides $(10 \mu \mathrm{M}, 30 \mu \mathrm{M}$, and $50 \mu \mathrm{M})$ for $4 \mathrm{~h}, 24 \mathrm{~h}$, and $48 \mathrm{~h}$. The zebrafish larvae were placed in 1\% agarose to fix in a dorsal orientation. A video segment of each larva was recorded for $10 \mathrm{~s}$ (13-15 frames per second) for heart morphology examination. The parameters and morphology of ventricular function of zebrafish were measured, as previously described [62,63]. Briefly, the formula $\mathrm{V}=4 / 3 \pi \mathrm{ab}^{2}$ was used to calculate the volume of ventricles. The longitudinal axis was represented by "a", while the lateral axis was represented by " $b$ ". Stroke volume (SV) was calculated by end-diastolic volume (EDV) and end-systolic volume (ESV). Cardiac output (CO) was determined by heart rate $\times$ stroke volume. Percentage of fractional shortening ( $\%$ FS) was calculated by the formula $\mathrm{FS} \%=($ diastolic diameter - dystolic diameter $) /$ dystolic diameter $\times 100 \%$.

\subsection{Anti-Tyrosine Hydroxylase (TH) Whole-Mount Immunostaining}

Anti-tyrosine hydroxylase (TH) whole-mount immunostaining of zebrafish was carried out as previously described [64,65]. Briefly, zebrafish embryos at $1 \mathrm{dpf}$ were exposed to $250 \mu \mathrm{M}$ 6-hydroxydopamine (6-OHDA) with or without the peptides for 2 days. Then the larvae were fixed with $4 \%$ paraformaldehyde in PBS for $30 \mathrm{~min}$, rinsed, and stored at $-20^{\circ} \mathrm{C}$ in absolute methanol. Semi-quantification of $\mathrm{TH}^{+}$cells was assessed by an investigator blinded to the drug treatment history of zebrafish, using ImageJ software [66]. Results were expressed as percentage of area of $\mathrm{TH}^{+}$cells in control group.

\subsection{Locomotion Behavioral Test}

The locomotion test was carried out as described in previous studies $[64,65]$. Briefly, AB strain zebrafish larvae at $3 \mathrm{dpf}$ were under co-treatment of $250 \mu \mathrm{M}$ 6-OHDA with various concentrations of the peptides for 4 days; then, zebrafish at $7 \mathrm{dpf}$ were transferred into 96-well plates (1 fish/well). The 96-well plates were put into a Zebrabox and the swimming behavior was monitored by an automated video tracking system (Viewpoint, ZebraLab, LifeSciences, Lyon, France). Before the start of data acquisition, the larvae were settled to allow them to accommodate themselves to the environment in the Zebrabox. The swimming pattern of each fish was recorded in five sessions of 10 min each. The total distance traveled was recorded as the distance that a given zebrafish larva was capable of swimming during the $10 \mathrm{~min}$ long session. A statistical analysis of the total distance traveled by each zebrafish larva in the different treatment groups was performed using the ANOVA and Dunnett's test.

Supplementary Materials: The following are available online at http:/ /www.mdpi.com/2072-6651/10/6/238/s1. Figure S1: Immunomodulation response assessment of $T g(m p o: G F P)$ zebrafish larvae after PcShK3 treatment, Figure S2: Purification and characterization of the peptides.

Author Contributions: Q.L. designed the research, performed computational work, analyzed data, and wrote the paper; G.G. designed the research, performed zebrafish experiment, and analyzed data; S.W.I.S. performed computational work; H.Y., C.T.T.W. and Y.C.T. analyzed data; G.R.-B. and S.M.-Y.L. designed the research and wrote the paper.

Funding: Research at University of Macau was supported by grants from the Science and Technology Development Fund (FDCT) of Macao SAR (Ref. No. 069/2015/A2 and No. 134/2014/A3), Research Committee, University of Macau (MYRG2016-00133-ICMS-QRCM, MYRG2015-00182-ICMS-QRCM, and MYRG2016-00129-ICMS-QRCM), and Shenzhen City Science \& Technology Innovation Program (CYZZ20160525094052606). At Federal University of $\mathrm{CE}$, research was financially supported by the Brazilian National Council for Scientific and Technological Development, CNPq (Marine Biotechnology Network-Proc. 408835/2013-3), the Ministry of Science, Technology and Innovation (MCTI), Brasília, DF, Brazil. 
Acknowledgments: This work was performed in part at the high-performance computing cluster (HPCC) which is supported by Information and Communication Technology Office (ICTO) of the University of Macau.

Conflicts of Interest: The authors declare no conflict of interest.

\section{References}

1. Jouiaei, M.; Sunagar, K.; Federman Gross, A.; Scheib, H.; Alewood, P.F.; Moran, Y.; Fry, B.G. Evolution of an ancient venom: Recognition of a novel family of cnidarian toxins and the common evolutionary origin of sodium and potassium neurotoxins in sea anemone. Mol. Biol. Evol. 2015, 32, 1598-1610. [CrossRef] [PubMed]

2. King, G. Venoms to Drugs: Venom as a Source for the Development of Human Therapeutics; Royal Society of Chemistry: London, UK, 2015.

3. Beeton, C.; Pennington, M.W.; Wulff, H.; Singh, S.; Nugent, D.; Crossley, G.; Khaytin, I.; Calabresi, P.A.; Chen, C.Y.; Gutman, G.A.; et al. Targeting effector memory T cells with a selective peptide inhibitor of $\mathrm{K}_{\mathrm{v}} 1.3$ channels for therapy of autoimmune diseases. Mol. Pharmacol. 2005, 67, 1369-1381. [CrossRef] [PubMed]

4. Kalman, K.; Pennington, M.W.; Lanigan, M.D.; Nguyen, A.; Rauer, H.; Mahnir, V.; Paschetto, K.; Kem, W.R.; Grissmer, S.; Gutman, G.A. ShK-Dap22, a potent $\mathrm{K}_{\mathrm{v}} 1.3$-specific immunosuppressive polypeptide. J. Biol. Chem. 1998, 273, 32697-32707. [CrossRef] [PubMed]

5. Yan, L.; Herrington, J.; Goldberg, E.; Dulski, P.M.; Bugianesi, R.M.; Slaughter, R.S.; Banerjee, P.; Brochu, R.M.; Priest, B.T.; Kaczorowski, G.J.; et al. Stichodactyla helianthus peptide, a pharmacological tool for studying $\mathrm{K}_{\mathrm{v}} 3.2$ channels. Mol. Pharmacol. 2005, 67, 1513-1521. [CrossRef] [PubMed]

6. Beeton, C.; Wulff, H.; Singh, S.; Botsko, S.; Crossley, G.; Gutman, G.A.; Cahalan, M.D.; Pennington, M.; Chandy, K.G. A novel fluorescent toxin to detect and investigate $\mathrm{K}_{\mathrm{v}} 1.3$ channel up-regulation in chronically activated T lymphocytes. J. Biol. Chem. 2003, 278, 9928-9937. [CrossRef] [PubMed]

7. Pennington, M.W.; Beeton, C.; Galea, C.A.; Smith, B.J.; Chi, V.; Monaghan, K.P.; Garcia, A.; Rangaraju, S.; Giuffrida, A.; Plank, D.; et al. Engineering a stable and selective peptide blocker of the $K_{\mathrm{v}} 1.3$ channel in T lymphocytes. Mol. Pharmacol. 2009, 75, 762-773. [CrossRef] [PubMed]

8. Pennington, M.W.; Harunur Rashid, M.; Tajhya, R.B.; Beeton, C.; Kuyucak, S.; Norton, R.S. AC-terminally amidated analogue of $\mathrm{ShK}$ is a potent and selective blocker of the voltage-gated potassium channel $\mathrm{K}_{\mathrm{v}} 1.3$. FEBS Lett. 2012, 586, 3996-4001. [CrossRef] [PubMed]

9. Peng, Y.; Lu, K.; Li, Z.; Zhao, Y.; Wang, Y.; Hu, B.; Xu, P.; Shi, X.; Zhou, B.; Pennington, M.; et al. Blockade of $K_{v} 1.3$ channels ameliorates radiation-induced brain injury. Neuro Oncol. 2014, 16, 528-539. [CrossRef] [PubMed]

10. Vergara, C.; Latorre, R.; Marrion, N.V.; Adelman, J.P. Calcium-activated potassium channels. Curr. Opin. Neurobiol. 1998, 8, 321-329. [CrossRef]

11. Wong, K.L.; Yang, H.Y.; Chan, P.; Cheng, T.H.; Liu, J.C.; Hsu, F.L.; Liu, I.M.; Cheng, Y.W.; Cheng, J.T. Isosteviol as a potassium channel opener to lower intracellular calcium concentrations in cultured aortic smooth muscle cells. Planta Med. 2004, 70, 108-112. [PubMed]

12. Jow, F.; Zhang, Z.H.; Kopsco, D.C.; Carroll, K.C.; Wang, K. Functional coupling of intracellular calcium and inactivation of voltage-gated $\mathrm{K}_{\mathrm{v}} 1.1 / \mathrm{K}_{\mathrm{v}}$ beta1.1 A-type $\mathrm{K}^{+}$channels. Proc. Natl. Acad. Sci. USA 2004, 101, 15535-15540. [CrossRef] [PubMed]

13. Feske, S.; Gwack, Y.; Prakriya, M.; Srikanth, S.; Puppel, S.H.; Tanasa, B.; Hogan, P.G.; Lewis, R.S.; Daly, M.; Rao, A. A mutation in Orail causes immune deficiency by abrogating CRAC channel function. Nature 2006, 441, 179-185. [CrossRef] [PubMed]

14. Feske, S.; Prakriya, M.; Rao, A.; Lewis, R.S. A severe defect in CRAC Ca ${ }^{2+}$ channel activation and altered $\mathrm{K}^{+}$channel gating in T cells from immunodeficient patients. J. Exp. Med. 2005, 202, 651-662. [CrossRef] [PubMed]

15. Zhang, S.L.; Yu, Y.; Roos, J.; Kozak, J.A.; Deerinck, T.J.; Ellisman, M.H.; Stauderman, K.A.; Cahalan, M.D. STIM1 is a $\mathrm{Ca}^{2+}$ sensor that activates CRAC channels and migrates from the $\mathrm{Ca}^{2+}$ store to the plasma membrane. Nature 2005, 437, 902-905. [CrossRef] [PubMed]

16. Prakriya, M.; Feske, S.; Gwack, Y.; Srikanth, S.; Rao, A.; Hogan, P.G. Orai1 is an essential pore subunit of the CRAC channel. Nature 2006, 443, 230-233. [CrossRef] [PubMed] 
17. Vig, M.; Peinelt, C.; Beck, A.; Koomoa, D.L.; Rabah, D.; Koblan-Huberson, M.; Kraft, S.; Turner, H.; Fleig, A.; Penner, R.; et al. CRACM1 is a plasma membrane protein essential for store-operated $\mathrm{Ca}^{2+}$ entry. Science 2006, 312, 1220-1223. [CrossRef] [PubMed]

18. Yeromin, A.V.; Zhang, S.L.; Jiang, W.; Yu, Y.; Safrina, O.; Cahalan, M.D. Molecular identification of the CRAC channel by altered ion selectivity in a mutant of Orai. Nature 2006, 443, 226-229. [CrossRef] [PubMed]

19. Lis, A.; Peinelt, C.; Beck, A.; Parvez, S.; Monteilh-Zoller, M.; Fleig, A.; Penner, R. CRACM1, CRACM2, and CRACM3 are store-operated $\mathrm{Ca}^{2+}$ channels with distinct functional properties. Curr. Biol. 2007, 17, 794-800. [CrossRef] [PubMed]

20. Prentis, P.J.; Pavasovic, A.; Norton, R.S. Sea Anemones: Quiet Achievers in the Field of Peptide Toxins. Toxins (Basel) 2018, 10, 36. [CrossRef] [PubMed]

21. Kayal, E.; Bastian, B.; Pankey, M.S.; Ohdera, A.; Medina, M.; Plachetzki, D.C.; Collins, A.; Ryan, J.F. Comprehensive phylogenomic analyses resolve cnidarian relationships and the origins of key organismal traits. Peer] Preprints 2017, 5. [CrossRef]

22. Liao, Q.; Li, S.; Siu, S.W.I.; Yang, B.; Huang, C.; Chan, J.Y.-W.; Morlighem, J.-É.; Wong, C.T.T.; Rádis-Baptista, G.; Lee, S.M.-Y. Novel Kunitz-like peptides discovered in the zoanthid Palythoa caribaeorum through transcriptome sequencing. J. Proteome Res. 2018, 17, 891-902. [CrossRef] [PubMed]

23. Huang, C.; Morlighem, J.-É.R.; Zhou, H.; Lima, É.P.; Gomes, P.B.; Cai, J.; Lou, I.; Pérez, C.D.; Lee, S.M.; Rádis-Baptista, G. The Transcriptome of the Zoanthid Protopalythoa variabilis (Cnidaria, Anthozoa) Predicts a Basal Repertoire of Toxin-like and Venom-Auxiliary Polypeptides. Genome Biol. Evol. 2016, 8, 3045-3064. [CrossRef] [PubMed]

24. Pennington, M.W.; Byrnes, M.E.; Zaydenberg, I.; Khaytin, I.; de Chastonay, J.; Krafte, D.S.; Hill, R.; Mahnir, V.M.; Volberg, W.A.; Gorczyca, W.; et al. Chemical synthesis and characterization of ShK toxin: A potent potassium channel inhibitor from a sea anemone. Int. J. Pept. Protein Res. 1995, 46, 354-358. [CrossRef] [PubMed]

25. Rauer, H.; Pennington, M.; Cahalan, M.; Chandy, K.G. Structural conservation of the pores of calcium-activated and voltage-gated potassium channels determined by a sea anemone toxin. J. Biol. Chem. 1999, 274, 21885-21892. [CrossRef] [PubMed]

26. Pierce, B.G.; Hourai, Y.; Weng, Z. Accelerating protein docking in ZDOCK using an advanced 3D convolution library. PLOS ONE 2011, 6, e24657. [CrossRef] [PubMed]

27. Chen, R.; Chung, S.H. Engineering a potent and specific blocker of voltage-gated potassium channel $\mathrm{K}_{\mathrm{v}} 1.3$, a target for autoimmune diseases. Biochemistry 2012, 51, 1976-1982. [CrossRef] [PubMed]

28. Chen, R.; Chung, S.H. Molecular dynamics simulations of scorpion toxin recognition by the $\mathrm{Ca}^{2+}$-activated potassium channel $\mathrm{K}_{\mathrm{Ca}} 3.1$. Biophys. J. 2013, 105, 1829-1837. [CrossRef] [PubMed]

29. Chen, R.; Robinson, A.; Gordon, D.; Chung, S.H. Modeling the binding of three toxins to the voltage-gated potassium channel $\left(\mathrm{K}_{\mathrm{v}} 1.3\right)$. Biophys. J. 2011, 101, 2652-2660. [CrossRef] [PubMed]

30. Chen, R.; Tong, W.; Mintseris, J.; Li, L.; Weng, Z. ZDOCK predictions for the CAPRI challenge. Proteins 2003, 52, 68-73. [CrossRef] [PubMed]

31. Rink, E.; Wullimann, M.F. The teleostean (zebrafish) dopaminergic system ascending to the subpallium (striatum) is located in the basal diencephalon (posterior tuberculum). Brain Res. 2001, 889, 316-330. [CrossRef]

32. Lanigan, M.D.; Kalman, K.; Lefievre, Y.; Pennington, M.W.; Chandy, K.G.; Norton, R.S. Mutating a critical lysine in ShK toxin alters its binding configuration in the pore-vestibule region of the voltage-gated potassium channel, $\mathrm{K}_{v}$ 1.3. Biochemistry 2002, 41, 11963-11971. [CrossRef] [PubMed]

33. Lange, A.; Giller, K.; Hornig, S.; Martin-Eauclaire, M.F.; Pongs, O.; Becker, S.; Baldus, M. Toxin-induced conformational changes in a potassium channel revealed by solid-state NMR. Nature 2006, 440, 959-962. [CrossRef] [PubMed]

34. Chi, V.; Pennington, M.W.; Norton, R.S.; Tarcha, E.J.; Londono, L.M.; Sims-Fahey, B.; Upadhyay, S.K.; Lakey, J.T.; Iadonato, S.; Wulff, H.; et al. Development of a sea anemone toxin as an immunomodulator for therapy of autoimmune diseases. Toxicon 2012, 59, 529-546. [CrossRef] [PubMed]

35. Beeton, C.; Pennington, M.W.; Norton, R.S. Analogs of the sea anemone potassium channel blocker ShK for the treatment of autoimmune diseases. Inflamm. Allergy Drug Targets 2011, 10, 313-321. [CrossRef] [PubMed] 
36. Suarez-Kurtz, G.; Vianna-Jorge, R.; Pereira, B.F.; Garcia, M.L.; Kaczorowski, G.J. Peptidyl inhibitors of shaker-type $\mathrm{K}_{\mathrm{v}} 1$ channels elicit twitches in guinea pig ileum by blocking $\mathrm{K}_{\mathrm{v}} 1.1$ at enteric nervous system and enhancing acetylcholine release. J. Pharmacol. Exp. Ther. 1999, 289, 1517-1522. [PubMed]

37. Tucker, K.; Overton, J.M.; Fadool, D.A. $\mathrm{K}_{\mathrm{v}} 1.3$ gene-targeted deletion alters longevity and reduces adiposity by increasing locomotion and metabolism in melanocortin-4 receptor-null mice. Int. J. Obes. (Lond.) 2008, 32, 1222-1232. [CrossRef] [PubMed]

38. Xu, J.; Koni, P.A.; Wang, P.; Li, G.; Kaczmarek, L.; Wu, Y.; Li, Y.; Flavell, R.A.; Desir, G.V. The voltage-gated potassium channel $\mathrm{K}_{\mathrm{v}} 1.3$ regulates energy homeostasis and body weight. Hum. Mol. Genet. 2003, 12, 551-559. [CrossRef] [PubMed]

39. Norton, R.S.; Pennington, M.W.; Beeton, C. Case study 2: Transforming a toxin into a therapeutic: The sea anemone potassium channel blocker ShK toxin for treatment of autoimmune diseases. In Venoms to Drugs; IMB: Wollongong, Austraia, 2015; pp. 255-274.

40. Zhang, G.Q.; Wei, H.; Lu, J.; Wong, P.; Shim, W. Identification and characterization of calcium sparks in cardiomyocytes derived from human induced pluripotent stem cells. PLoS ONE 2013, 8, e55266.

41. Marks, A.R. Calcium and the heart: A question of life and death. J. Clin. Investig. 2003, 111, 597-600. [CrossRef] [PubMed]

42. Morad, M.; Tung, L. Ionic events responsible for the cardiac resting and action potential. Am. J. Cardiol. 1982, 49, 584-594. [CrossRef]

43. Tse, G. Mechanisms of cardiac arrhythmias. J. Arrhythm. 2016, 32, 75-81. [CrossRef] [PubMed]

44. Koh, C.Y.; Kini, R.M. From snake venom toxins to therapeutics—Cardiovascular examples. Toxicon 2012, 59, 497-506. [CrossRef] [PubMed]

45. Furman, B.L. The development of Byetta (exenatide) from the venom of the Gila monster as an anti-diabetic agent. Toxicon 2012, 59, 464-471. [CrossRef] [PubMed]

46. Miljanich, G.P. Ziconotide: Neuronal calcium channel blocker for treating severe chronic pain. Curr. Med. Chem. 2004, 11, 3029-3040. [CrossRef] [PubMed]

47. Schmidtko, A.; Lotsch, J.; Freynhagen, R.; Geisslinger, G. Ziconotide for treatment of severe chronic pain. Lancet 2010, 375, 1569-1577. [CrossRef]

48. Ogita, K.; Okuda, H.; Watanabe, M.; Nagashima, R.; Sugiyama, C.; Yoneda, Y. In vivo treatment with the $\mathrm{K}^{+}$ channel blocker 4-aminopyridine protects against kainate-induced neuronal cell death through activation of NMDA receptors in murine hippocampus. Neuropharmacology 2005, 48, 810-821. [CrossRef] [PubMed]

49. Taherian, R.; Ahmadi, M.A. 4-aminopyridine decreases MPTP-induced behavioral disturbances in animal model of Parkinson's disease. Int. Clin. Neurosci. J. 2016, 2, 142-146.

50. Edgar, R.C. MUSCLE: Multiple sequence alignment with high accuracy and high throughput. Nucleic Acids Res. 2004, 32, 1792-1797. [CrossRef] [PubMed]

51. Edgar, R.C. MUSCLE: A multiple sequence alignment method with reduced time and space complexity. BMC Bioinform. 2004, 5, 113. [CrossRef] [PubMed]

52. Tamura, K.; Stecher, G.; Peterson, D.; Filipski, A.; Kumar, S. MEGA6: Molecular Evolutionary Genetics Analysis version 6.0. Mol. Biol. Evol. 2013, 30, 2725-2729. [CrossRef] [PubMed]

53. Biasini, M.; Bienert, S.; Waterhouse, A.; Arnold, K.; Studer, G.; Schmidt, T.; Kiefer, F.; Gallo Cassarino, T.; Bertoni, M.; Bordoli, L.; et al. SWISS-MODEL: Modelling protein tertiary and quaternary structure using evolutionary information. Nucleic Acids Res. 2014, 42, W252-W258. [CrossRef] [PubMed]

54. Kopp, J.; Schwede, T. The SWISS-MODEL Repository: New features and functionalities. Nucleic Acids Res. 2006, 34, D315-D318. [CrossRef] [PubMed]

55. Tudor, J.E.; Pallaghy, P.K.; Pennington, M.W.; Norton, R.S. Solution structure of ShK toxin, a novel potassium channel inhibitor from a sea anemone. Nat. Struct. Biol. 1996, 3, 317-320. [CrossRef] [PubMed]

56. Pronk, S.; Pall, S.; Schulz, R.; Larsson, P.; Bjelkmar, P.; Apostolov, R.; Shirts, M.R.; Smith, J.C.; Kasson, P.M.; van der Spoel, D; ; et al. GROMACS 4.5: A high-throughput and highly parallel open source molecular simulation toolkit. Bioinformatics 2013, 29, 845-854. [CrossRef] [PubMed]

57. Van Der Spoel, D.; Lindahl, E.; Hess, B.; Groenhof, G.; Mark, A.E.; Berendsen, H.J. GROMACS: Fast, flexible, and free. J. Comput. Chem. 2005, 26, 1701-1718. [CrossRef] [PubMed]

58. Krissinel, E. Crystal contacts as nature's docking solutions. J. Comput. Chem. 2010, 31, 133-143. [CrossRef] [PubMed] 
59. Krissinel, E.; Henrick, K. Inference of macromolecular assemblies from crystalline state. J. Mol. Biol. 2007, 372, 774-797. [CrossRef] [PubMed]

60. Humphrey, W.; Dalke, A.; Schulten, K. VMD: Visual molecular dynamics. J. Mol. Graph. 1996, 14, 33-38. [CrossRef]

61. Westerfield, M. A Guide for the Laboratory Use of Zebrafish (Danio rerio) Eugene, 4th ed.; University of Oregon Press: Eugene, OR, USA, 2000; pp. 1.1, 9.7, 10.16.

62. Chan, J.Y.; Zhou, H.; Kwan, Y.W.; Chan, S.W.; Radis-Baptista, G.; Lee, S.M. Evaluation in zebrafish model of the toxicity of rhodamine B-conjugated crotamine, a peptide potentially useful for diagnostics and therapeutics. J. Biochem. Mol. Toxicol. 2017, 31. [CrossRef] [PubMed]

63. Wang, L.; Zhang, X.; Chan, J.Y.; Shan, L.; Cui, G.; Cui, Q.; Wang, Y.; Li, J.; Chen, H.; Zhang, Q.; et al. A Novel Danshensu Derivative Prevents Cardiac Dysfunction and Improves the Chemotherapeutic Efficacy of Doxorubicin in Breast Cancer Cells. J. Cell. Biochem. 2016, 117, 94-105. [CrossRef] [PubMed]

64. Zhang, L.Q.; Sa, F.; Chong, C.M.; Wang, Y.; Zhou, Z.Y.; Chang, R.C.; Chan, S.W.; Hoi, P.M.; Yuen Lee, S.M. Schisantherin A protects against 6-OHDA-induced dopaminergic neuron damage in zebrafish and cytotoxicity in SH-SY5Y cells through the ROS/NO and AKT/GSK3beta pathways. J. Ethnopharmacol. 2015, 170, 8-15. [CrossRef] [PubMed]

65. Zhang, Z.J.; Cheang, L.C.; Wang, M.W.; Li, G.H.; Chu, I.K.; Lin, Z.X.; Lee, S.M. Ethanolic extract of fructus Alpinia oxyphylla protects against 6-hydroxydopamine-induced damage of PC12 cells in vitro and dopaminergic neurons in zebrafish. Cell. Mol. Neurobiol. 2012, 32, 27-40. [CrossRef] [PubMed]

66. Schneider, C.A.; Rasband, W.S.; Eliceiri, K.W. NIH Image to ImageJ: 25 years of image analysis. Nat. Methods 2012, 9, 671-675. [CrossRef] [PubMed]

(C) 2018 by the authors. Licensee MDPI, Basel, Switzerland. This article is an open access article distributed under the terms and conditions of the Creative Commons Attribution (CC BY) license (http:/ / creativecommons.org/licenses/by/4.0/). 
Article

\title{
Nuclear Magnetic Resonance seq (NMRseq): A New Approach to Peptide Sequence Tags
}

\author{
David Wilson and Norelle L. Daly * \\ Centre for Biodiscovery and Molecular Development of Therapeutics, AITHM, James Cook University, \\ Cairns, QLD 4870, Australia; david.wilson4@jcu.edu.au \\ * Correspondence: norelle.daly@jcu.edu.au; Tel.: +61-7-4232-1815
}

Received: 14 October 2018; Accepted: 25 October 2018; Published: 28 October 2018

\begin{abstract}
Structural analysis of peptides with nuclear magnetic resonance (NMR) spectroscopy generally relies on knowledge of the primary sequence to enable assignment of the resonances prior to determination of the three-dimensional structure. Resonance assignment without knowledge of the sequence is complicated by redundancy in amino acid type, making complete de novo sequencing using NMR spectroscopy unlikely to be feasible. Despite this redundancy, we show here that NMR spectroscopy can be used to identify short sequence tags that can be used to elucidate full-length peptide sequences via database searching. In the current study, we have used this approach to identify conotoxins from the venom of the cone snail Conus geographus and determined the three-dimensional structure of a member of the I 3 superfamily. This approach is most likely to be useful for the characterization of disulfide-rich peptides, such as those that were chosen for this study, as they generally have well-defined structures, which enhances the quality of the NMR spectra. In contrast to other sequencing methods, the lack of sample manipulation, such as protease digestion, allows for subsequent bioassays to be carried out using the native sample used for sequence identification.
\end{abstract}

Keywords: NMR spectroscopy; disulfide-rich peptide; conotoxin

Key Contribution: We highlight the potential of NMR for identifying sequence tags for peptide sequence elucidation.

\section{Introduction}

Peptides are highly prevalent in nature and they are of particular interest as therapeutic and bioinsecticide leads due to their typically improved stability, ease of production, and reduced antigenicity over proteins [1-4]. Characterization of the structures and functions of peptides is required to assess the therapeutic or insecticidal potential of a peptide, but before these studies can be carried out it is essential to determine the amino acid sequence. Historically, the sequence has been obtained through chemical sequencing technologies, such as Edman degradation. More recently, advances in omics technologies, such as genomics, transcriptomics, and proteomics have allowed for relatively rapid elucidation of vast numbers of peptide sequences through an integrated bioinformatic approach [5]. However, none of these technologies allow for non-destructive determination of the sequence of the peptide in its native form.

Here, we introduce NMRseq, a complementary proteomics workflow, which allows for the non-destructive determination of sequence tags of a peptide in the native form, while simultaneously providing data on the three-dimensional structure of the molecule. This approach involves the analysis of standard two-dimensional nuclear magnetic resonance (NMR) spectra, including COSY, TOCSY, HSQC, and NOESY, and it is highly suited to the analysis of small peptides with well-resolved cross-peaks in the NMR spectra, such as venom peptides. Venoms from organisms, such as cone snails and spiders, are rich sources of disulfide-rich peptides, many of which have well-defined structures 
and are selective and potent modulators of ion channels or receptors [6,7]. In the current study, we have exemplified the NMRseq approach through the analysis of two peptides from the cone snail venom from the venomous marine mollusc Conus geographus. Furthermore, we have determined the three-dimensional structure of a member of the I3 superfamily of conotoxins.

\section{Results}

\subsection{Venom Isolation and Purification}

Defense-evoked venom was milked from C. geographus and fractionated using semi-preparative reversed-phase high performance liquid chromatography (RP-HPLC) (Figure 1A). The profile is complex, as consistent with previous analyses of venom from this species [8]. Two peaks, each corresponding to the purified peptides characterised in this study, are highlighted. The masses of these two peptides correspond to 1033.4459 Da and 3202.0503 Da, respectively. These peptides were chosen because they were collected in relatively homogeneous fractions from the RP-HPLC and they were purified in sufficient quantities for subsequent analyses.

\subsection{Elucidation of the NMR Sequence Tag for Conopressin $G$}

The peptide corresponding to a mass of $1033.4459 \mathrm{Da}$ was dissolved in aqueous solution at a concentration of approximately $0.5 \mathrm{mM}$ and two-dimensional NMR spectra, including TOCSY, NOESY, COSY, and ${ }^{13} \mathrm{C}$ HSQC experiments, were recorded at $290 \mathrm{~K}$ on a $600 \mathrm{MHz}$ NMR spectrometer. The NMR analysis was done using a "blinded" approach whereby the mass or sequence of the peptide was not known by the researcher doing the analysis until after the sequence tag was identified.

Individual spin systems were identified based on the TOCSY and COSY spectra. This process relied on the differences in the amino acid side chains resulting in different patterns in the spectra, and knowledge of the characteristic chemical shifts for particular residues [9]. For example, residues, such as Val, Ile, Leu, Pro, Arg, and Lys, can often be identified based on the cross-peaks and chemical shifts observed in the TOCSY and COSY spectra. By contrast, residues corresponding to an AMX spin system (i.e., Cys, Asp, Phe, His, Asn, Ser, Trp, Tyr) can be ambiguous. However, for the aromatic residues, the NOESY spectra can often assist in assignment of the residue type. Furthermore, serine residues often have the $\beta$-protons shifted downfield as compared to the other AMX spin systems. Following the identification of the individual spin systems, sequential connections were determined based on the NOESY spectra, and a sequence tag corresponding to AMX_AMX_ILE_ARG_AMX_AMX_PRO_LYS_GLY was identified.

The sequence tag was used in the "Sequence Stretches Search" in ConoServer, a database that collates the sequences of cone snail derived peptides and currently has sequence information on more than 2200 peptides [10]. This analysis indicated that the only match in the ConoServer database was conopressin $\mathrm{G}$, which has the same mass as the isolated peptide and a sequence corresponding to CFIRNCPKG [11]. Therefore, in this example, the sequence tag represents the entire sequence, but it has ambiguous residues in four positions.

Following elucidation of this sequence, the NMR spectra could be fully assigned. Comparison of the $\alpha$-proton secondary shifts with conopressin $\mathrm{T}$, a related conopressin that differs in sequence by Y2-F2, Q3-R3, L7-P7, R8-K8, and V9-G9 (Figure 2), indicates that the structure of these peptides is similar [12]. Conopressin $\mathrm{T}$ has been shown to be a selective antagonist of the human $\mathrm{V}_{1 \mathrm{a}}$ vasopressin receptor, with partial agonist activity at the oxytocin receptor and no detectable activity at the $\mathrm{V}_{1 \mathrm{~b}}$ and $\mathrm{V}_{2}$ vasopressin receptors. Additionally, the mutation of Leu7 to a Pro (L7P), which is conserved in all other conopressins that are listed in ConoServer, increased the affinity of conopressin $\mathrm{T}$ for the $\mathrm{V}_{1 \mathrm{a}}$ receptor, but had negligible effect on the selectivity across all human receptors [12]. 

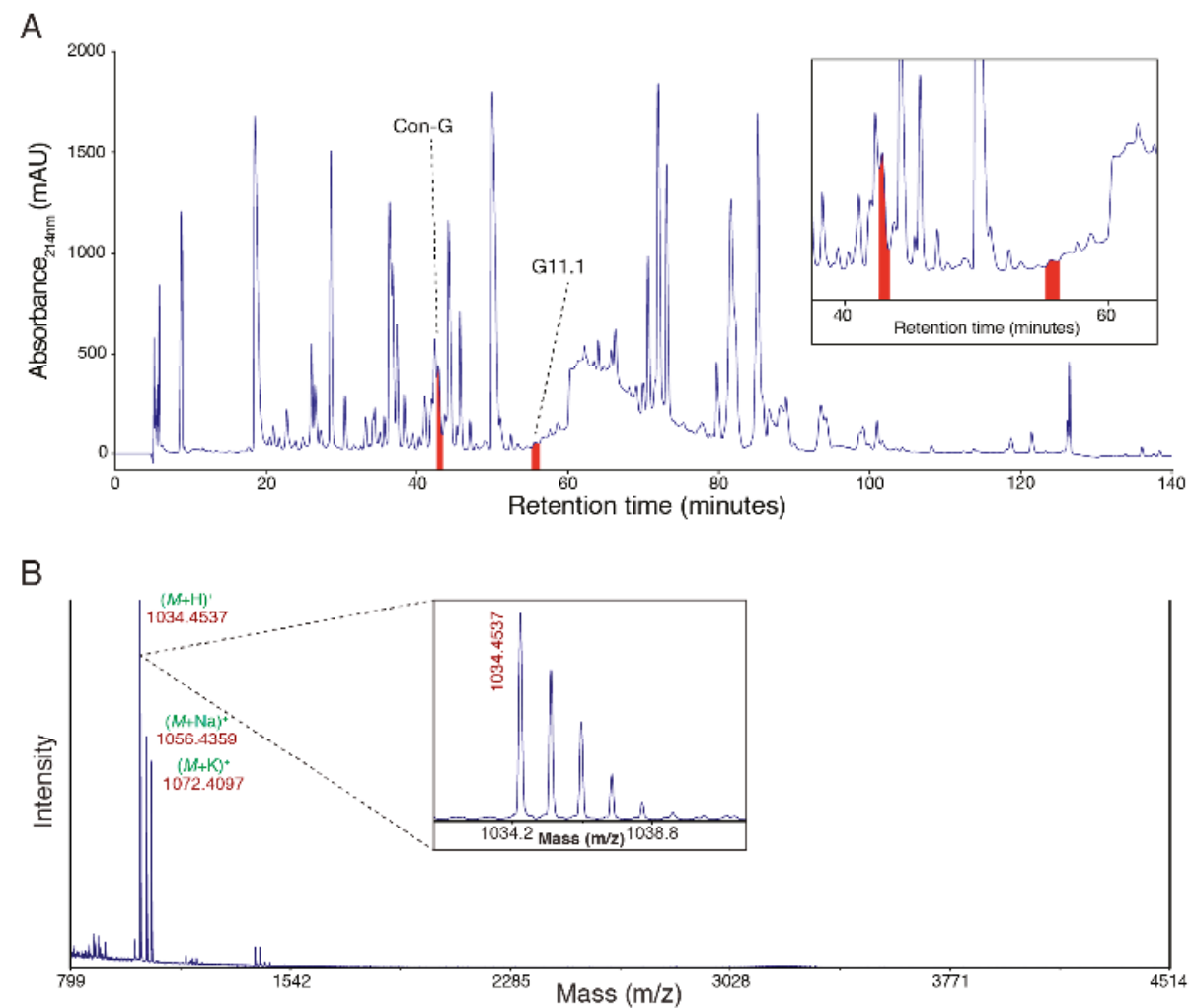

C

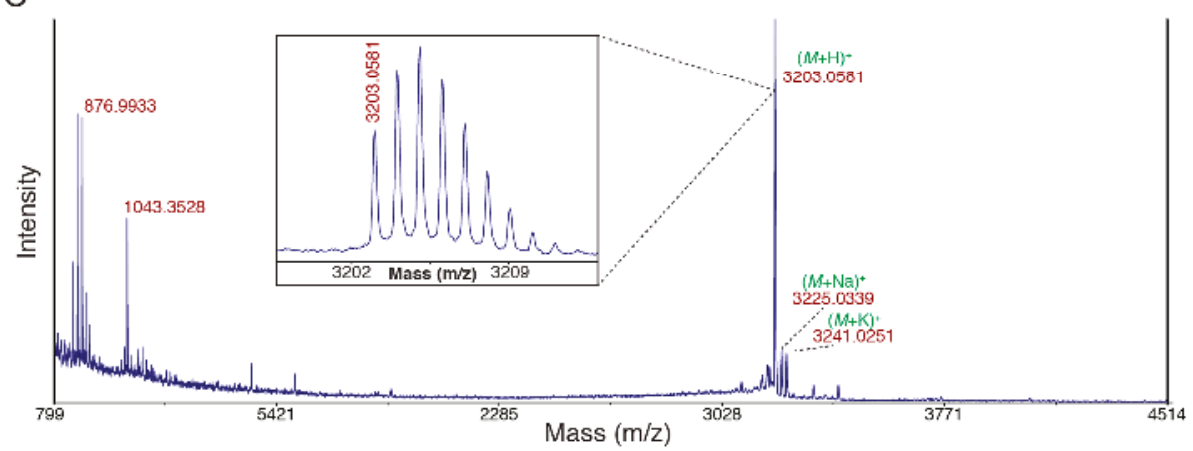

Figure 1. Characterisation of Conus geographus venom peptides. (A) Semi-preparative reversed-phase high performance liquid chromatography (RP-HPLC) chromatogram of crude Conus geographus venom with the peaks corresponding to the two peptides conopressin G (Con-G; mass 1033.4459 Da) and G11.1 (mass 3202.0503 Da), respectively, highlighted in red $\left(\mathrm{C}_{18}\right.$ Phenomenex Jupiter $250 \times 10 \mathrm{~mm}, 10 \mu \mathrm{m}$, $300 \AA ; 3 \mathrm{~mL} / \mathrm{min}$ flow rate; 0-60\% Solvent B in $120 \mathrm{~min}$ (Solvent A: 0.05\% trifluoroacetic acid (TFA); Solvent B: $90 \%$ acetonitrile, $0.045 \%$ TFA), $60-90 \%$ Solvent B in $5 \mathrm{~min}, 90 \%$ Solvent B for $10 \mathrm{~min}, 90-0 \%$ Solvent B in $5 \mathrm{~min}$; UV absorbance at $214 \mathrm{~nm}$ and $280 \mathrm{~nm}$ ); (B) SCIEX TOF/TOFTM 5800 matrix-assisted laser desorption ionization (MALDI) MS spectrum of the conopressin G fraction (mass 1033.4459 Da) using $\alpha$-cyano-4-hydroxycinnamic acid (CHCA) matrix with the isotope distribution shown expanded inset; (C) SCIEX TOF/TOFTM 5800 MALDI MS spectrum of the G11.1 fraction (mass 3202.0503 Da) using CHCA matrix with the isotope distribution shown expanded inset. 


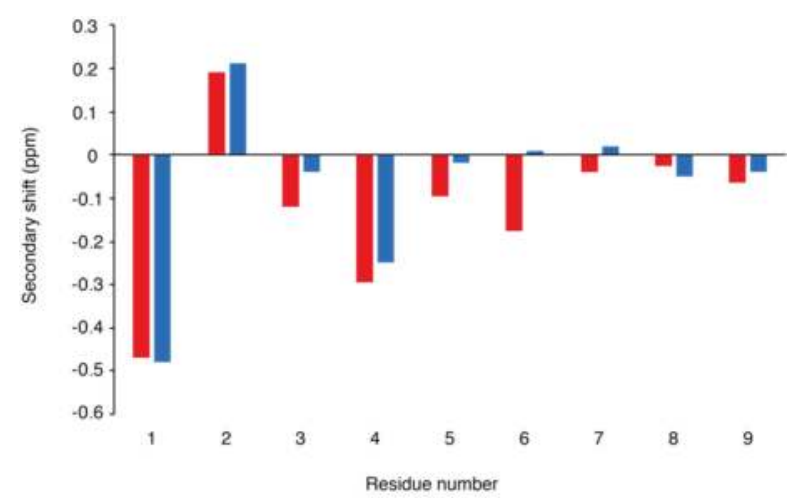

Figure 2. Secondary shift comparison of conopressin $T$ (red) [12] and conopressin G (blue). The secondary shifts were calculated by subtracting random coil shifts [9] from the $\alpha$-proton shift.

\subsection{Mass Spectrometry Sequencing of Conopressin G}

Although the NMR data was fully consistent with the conopressin G sequence, to validate the NMRseq prediction method, the sequence was also confirmed using MS/MS sequencing. The purified peptide with the mass of 1033.4459 Da was spotted with $10 \mathrm{mg} / \mathrm{mL}$ 1,5-diaminonaphthalene (1,5-DAN) and was analysed using MALDI tandem mass spectrometry (MS/MS). The use of 1,5-DAN allows for the reduction of disulfide bonds in the MALDI laser plume and it enhances the in-source decay (ISD) fragmentation of peptides, which can theoretically maintain post-translational modifications $[13,14]$. 1,5-DAN has been successfully used to sequence venom peptides from a number of species of scorpion and the cone snail Conus textile $[15,16]$. The MS/MS spectrum obtained is shown in Figure 3 and it shows evidence of all $y$ and $b$ ions for the conopressin $G$ sequence with the exception of the $y_{1}$ and $\mathrm{b}_{1}$ ions. There is potential ambiguity at residue 3 because the amino acids Ile and Leu have identical masses, however they have unique NMR cross-peak patterns and residue 3 was confirmed as Ile.

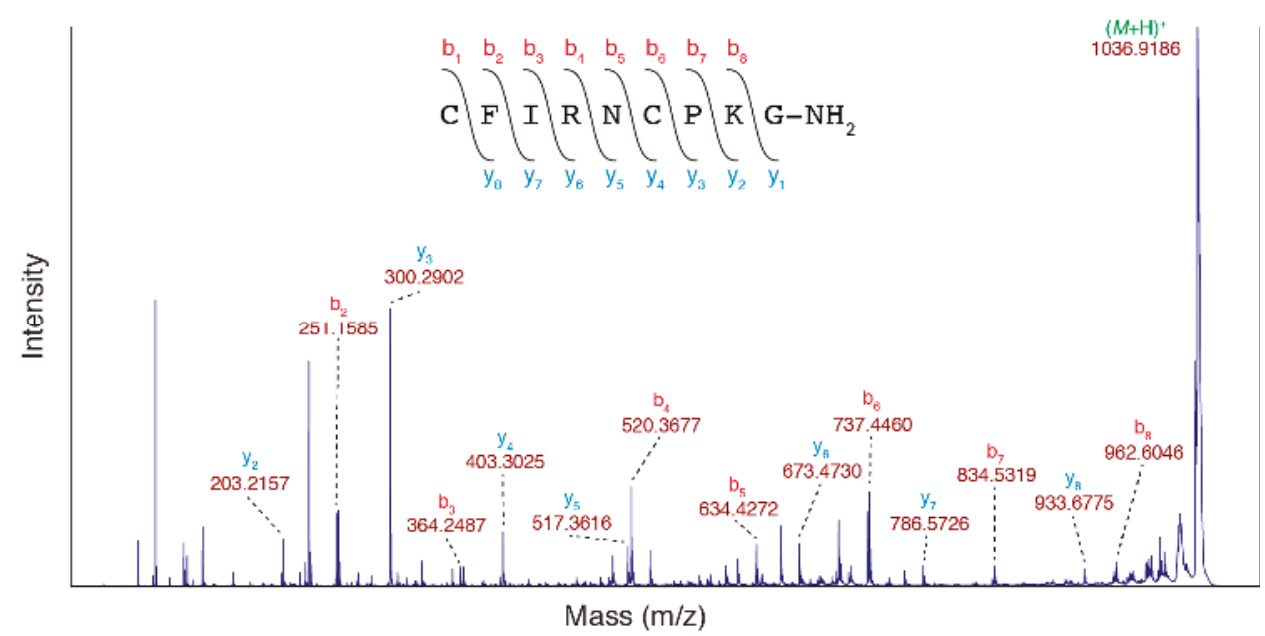

Figure 3. MS/MS sequencing of conopressin G. SCIEX TOF/TOFTM 5800 MALDI MS/MS spectrum of the conopressin G fraction (mass $1033.4459 \mathrm{Da}$ ) using 1,5-DAN matrix with the evident $\mathrm{y}$ and $\mathrm{b}$ ions highlighted. 


\subsection{Elucidation of the NMR Sequence Tag for G11.1}

The same approach applied to conopressin $G$ was applied to the peptide corresponding to the mass of $3202.0503 \mathrm{Da}$, and the following sequence tag was elucidated: VAL_THR_HIS_GLU_LYS_AMX_SER_AMX_AMX_TYR_AMX_AMX. Although the sequence tag consisted of 12 residues/residue types, the VTHEK sequence was unique in ConoServer (accessed on 27 July 2018) and allowed for the identification of the peptide as G11.1 [17]. The complete sequence of G11.1 is shown in Figure 4, and it is consistent with the whole sequence tag obtained. The AMX spin systems were either cysteine or aspartic acid residues.

\subsection{Three-Dimensional Structure of G11.1}

The NMR spectra for G11.1 were fully assigned based on the sequence elucidated in Section 2.3, and the structures were calculated using an automated NOE assignment protocol in CYANA [18]. Dihedral angle restraints were predicted using TALOS-N and hydrogen bond restraints were inferred from the analysis of the temperature coefficients and preliminary structures. Eighteen residues were found to have temperature coefficients more positive than $-4.6 \mathrm{ppb} / \mathrm{K}$, indicating that they are involved in hydrogen bonds [19], and restraints for seven hydrogen bonds were included in the structure calculations based on analysis of the preliminary structures.

Structures that were calculated without the disulfide connectivity indicated that Cys 1 is likely bonded to Cys 15, and Cys 14 bonded to Cys 24 based on the distances between the sulfur atoms. The disulfide bond involving Cys 8 was ambiguous and the C-terminal region of the structure was relatively disordered preventing a prediction for the disulfide bond involving Cys 31 . To resolve this issue, structures were calculated with the three alternative connectivities involving Cys 8, Cys 19, Cys 20, and Cys 31. The Cys 1-Cys 15 and Cys 14-Cys 24 bonds were also included in the calculations. The CYANA target functions and the disulfide connectivities are shown in Table 1. The CYANA target function was significantly lower for the Cys1-Cys15, Cys14-Cys24, Cys8-Cys20, and Cys19-Cys31, than the two alternative connectivities indicating that this is the most likely disulfide connectivity. Structures were calculated using this disulfide connectivity and the overlay of the ensemble of structures is shown in Figure 4. The main element of secondary structure is a $\beta$-hairpin between residues 19 and 25. Four hydrogen bonds were inferred from the temperature coefficients across this $\beta$-hairpin.

Table 1. CYANA target function for possible disulfide connectivities for G11.1.

\begin{tabular}{cc}
\hline Disulfide Connectivity & CYANA Target Function \\
\hline Cys1-Cys15, Cys14-Cys24, Cys8-Cys20, Cys19-31 & $0.076^{1}$ \\
Cys1-Cys15, Cys14-Cys24, Cys8-Cys19, Cys20-31 & 6.00 \\
Cys1-Cys15, Cys14-Cys24, Cys8-Cys31, Cys19-20 & 8.47 \\
\hline
\end{tabular}

G11.1 is classified as a member of the I3 superfamily and it contains the XI disulfide framework. RXIA is the only other conotoxin containing this disulfide framework that has been structurally characterized, but it is a member of the I1 superfamily and has a vastly different amino acid sequence with very limited homology with G11.1 (see Figure 4) [20]. RXIA has the same disulfide connectivity as that predicted for G11.1 in the current study. A comparison of G11.1 and RXIA NMR structures is shown in Figure 4. 
A
Con-G CFIRNCPKG-NH
G11.1 CAVTHEKCSDDYDCCGSLCCVGICAKTIAPC
RXIA GOSFCKADEKOCEYHADCCNCCLSGICAOSTNWILPGCSTSSFFII

B
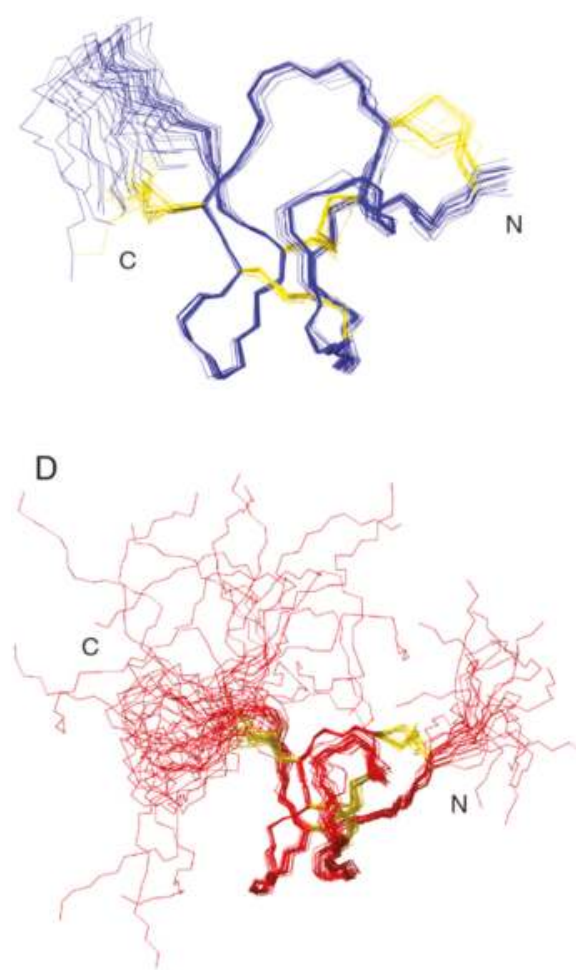

C

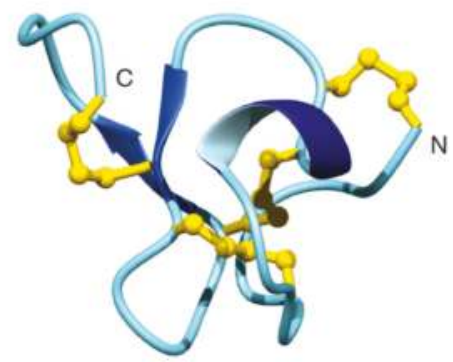

E

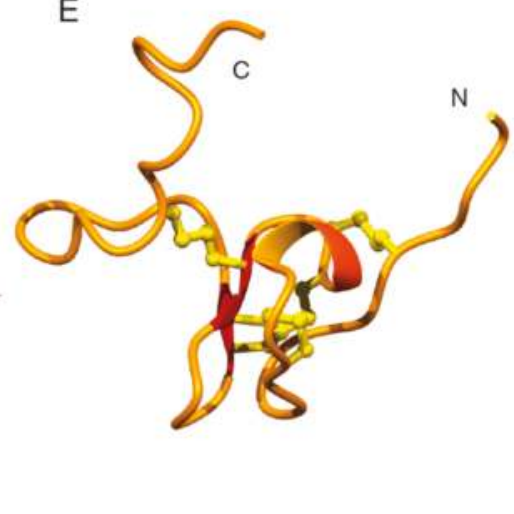

Figure 4. Characterisation of Conus geographus venom peptides. (A) Amino acid sequences of the two peptides conopressin G (mass 1033.4459 Da) and G11.1 (mass 3202.0503 Da), respectively, and RXIA (theoretical mass $4972.02 \mathrm{Da}$; $\mathrm{O}=4$-hydroxyproline, $\mathrm{f}=\mathrm{D}$-phenylalanine) with the disulfide bond connectivities illustrated; (B) Overlay of the 20 lowest energy three-dimensional NMR structures of G11.1 with the amino acid backbone shown in blue and the disulfide bonds in gold; (C) Ribbon representation of the three-dimensional NMR structure of G11.1 showing the presence of the $\alpha$-helix (navy blue and light blue) and $\beta$-sheet (royal blue arrows) secondary structure. Disulfide bonds are shown in gold; (D) Overlay of the 20 lowest energy three-dimensional NMR structures of RXIA (PDB 2P4L) with the amino acid backbone shown in red and the disulfide bonds in gold; (E) Ribbon representation of the three-dimensional NMR structure of RXIA (PDB 2P4L) showing the presence of the $\alpha$-helix (orange red and orange) and $\beta$-sheet (red arrows) secondary structure. Disulfide bonds are shown in gold. Three-dimensional structure figures generated in MOLMOL [21]. 


\section{Discussion}

Venoms from organisms, such as cone snails and spiders, are rich sources of disulfide-rich peptides, many of which are selective and potent modulators of ion channels or receptors $[3,6]$. Consequently, there is significant interest in analyzing the complex mixtures of peptides that are present in the venoms for a range of applications. These analyses are routinely carried out with mass spectrometry, a technique that has had a significant impact on peptide characterization. However, the mass of a peptide alone does not provide the sequence, and peptides with different sequences can have very similar masses. For instance, the conotoxins SrIA and Qc1.17 differ by only 0.12 of a mass unit, but have no sequence homology (ConoServer [10]). To elucidate sequence information, MS/MS approaches can be used, but for disulfide-rich peptides, this generally requires the reduction of the disulfide bonds and proteolytic digestion. This process can sometimes result in elucidation of the complete sequence, but it is often used to identify sequence tags, which are subsequently searched against transcriptomic or genomic databases to identify the presence of particular peptide sequences. Here, we show that NMR spectroscopy is a complementary approach for the identification of these sequence tags that can subsequently be used for database searching.

Advances in NMR spectroscopy, and in particular, the use of cryoprobes has improved sensitivity [22] to the extent that it is possible to record data on small amounts of native peptide that was directly isolated from venoms. NMR spectroscopy has been used for the analysis of three-dimensional structures of peptides, such as those that were derived from venoms, for decades but generally requires knowledge of the amino acid sequence to interpret the data. However, several types of amino acids have unique characteristics in 2D NMR spectra and for relatively small peptides, with well-resolved spectra it is possible to identify "sequence tags" by connecting specific amino acid spin systems through analysis of NOESY connections.

In the current study, we have exemplified the approach of using NMR to identify sequence tags for two conotoxin peptides, conopressin G and G11.1. The peptides were purified from the complex mixture of peptides present in the C. geographus defense-evoked venom and then directly analyzed using 2D NMR experiments. The success of this approach clearly relies on the quality of the NMR spectra. Peptides with multiple conformations and aggregation will likely complicate the process and prevent the assignment of meaningful sequence tags. However, venom peptides are often well structured and soluble in aqueous solution, making this approach highly applicable to this class of compound.

The main advantage of NMRseq is that sequence data is obtained on native sample that can be subsequently used in further analyses, such as calculation of the three-dimensional structure (as the NMR spectra have already been collected) or biological target identification in bioassays. However, it is envisaged that additional applications could include the identification of post-translational modifications, as although transcriptomic and genomic approaches provide a wealth of sequence information, they are limited when it comes to post-translational modifications, which are often present in venom peptides. More comprehensive searches incorporating alternative residues at particular sites could also expand the scope of this approach beyond that which was used with the simple searching used within ConoServer.

Following on from the elucidation of the sequence of G11.1, we determined the three-dimensional structure based on the NMR data, which represents the only structurally characterised member of the I3 superfamily. The structure is similar to that of RXIA, a peptide with the same disulfide framework but a vastly different sequence to G11.1. RXIA targets several sodium channel subtypes [23], but further study is required to determine whether G11.1 also has bioactivity on these channels.

\section{Conclusions}

We have shown here that NMR spectroscopy can be used to identify short sequence tags from native peptide samples that can be subsequently used to elucidate full-length peptide sequences via database searching. We used this NMRseq approach to identify conotoxins from the defensive venom 
of the cone snail C. geographus and determined the three-dimensional structure of a member of the I3 conotoxin superfamily. This approach can be useful for the characterization of disulfide-rich peptides, as they generally have well-defined structures that provide high quality NMR spectra. The primary advantage of NMRseq over other sequencing methods is the provision of native sequence data and the absence of sample degradation in the sequencing process, allowing for subsequent analyses (e.g., bioassays) to be performed with the same sample. NMRseq integrates with, and complements, the proteomic workflow in the venomics pipeline with the distinct advantage of working with intact native sample and maintaining sample integrity.

\section{Materials and Methods}

Commercially available specimens of Conus geographus (Cairns Marine, Cairns North, Queensland, Australia) were maintained in an aquarium at a temperature between $24-28^{\circ} \mathrm{C}$. Defense-evoked venom was collected by following the procedure that was outlined in Dutertre et al. [8]. Briefly, the specimen was removed from the tank and pressure applied to the shell until the proboscis extended. A micro-centrifuge tube covered with parafilm was presented to the proboscis until venom was injected through the parafilm. Samples were stored at $-30{ }^{\circ} \mathrm{C}$ until use.

Crude venom was centrifuged at $\sim 15000 \times \mathrm{rpm}$ for $10 \mathrm{~min}$ in a benchtop centrifuge and the supernatant removed. RP-HPLC was performed and used for purification on a $\mathrm{C}_{18}$ semi-preparative column (Phenomenex Jupiter $250 \times 10$ mm, $10 \mu \mathrm{m}, 300 \AA$; Phenomenex, Torrance, CA, USA) with a flow rate of $3 \mathrm{~mL} / \mathrm{min}$ using a linear gradient of $0-60 \%$ solvent B (solvent A: $0.05 \%$ TFA; solvent B: 90\% acetonitrile, $0.045 \%$ TFA) over $120 \mathrm{~min}$ on an Agilent 1260 series instrument (Agilent, Hanover, Germany). UV absorbance was monitored at $214 \mathrm{~nm}$ and $280 \mathrm{~nm}$, and $30 \mathrm{~s}$ fractions collected in $2 \mathrm{~mL}$ Axygen deep well 96-well plates (Corning, New York City, NY, USA).

Mass spectrometry (MS) was performed using a SCIEX TOF/TOF ${ }^{\mathrm{TM}} 5800$ MALDI mass spectrometer (SCIEX, Framingham, MA, USA). Samples were spotted on 384-well stainless steel target plates using $0.5 \mu \mathrm{L}$ of sample and $0.5 \mu \mathrm{L}$ of either $\alpha$-cyano-4-hydroxycinnamic acid (CHCA; Sigma-Aldrich, St. Louis, MO, USA) matrix at $7.5 \mathrm{mg} / \mathrm{mL}$ in $50 \%$ ACN/0.1\% TFA, or 1,5-diaminonaphthalene (1,5-DAN; Sigma-Aldrich, St. Louis, MO, USA) matrix at $10 \mathrm{mg} / \mathrm{mL}$ in $60 \% \mathrm{ACN} / 0.04 \%$ TFA. Calibration was performed before spectra collection for each sample using Calibration Mix solution 2 (SCIEX, Framingham, MA, USA). Spectra were acquired in reflector positive ion mode from $\mathrm{m} / \mathrm{z} 800$ to $4500 \mathrm{Da}$, and averaged over 2000 laser shots. MS/MS spectra were acquired with a collision energy of $2 \mathrm{kV}$ and were averaged over 2500 laser shots.

Lyophilized peptides were resuspended in $90 \% \mathrm{H}_{2} \mathrm{O}: 10 \% \mathrm{D}_{2} \mathrm{O} .2 \mathrm{D}^{1} \mathrm{H}-{ }^{1} \mathrm{H}$ TOCSY, ${ }^{1} \mathrm{H}-{ }^{1} \mathrm{H}$ NOESY, ${ }^{1} \mathrm{H}-{ }^{1} \mathrm{H}$ DQF-COSY, ${ }^{1} \mathrm{H}-{ }^{15} \mathrm{~N}$ HSQC, and ${ }^{1} \mathrm{H}_{-}{ }^{13} \mathrm{C}$ HSQC spectra were acquired at $290 \mathrm{~K}$ and $305 \mathrm{~K}$ using a $600 \mathrm{MHz}$ AVANCE III NMR spectrometer (Bruker, Karlsruhe, Germany) equipped with a cryogenically cooled probe. All spectra were recorded with an interscan delay of $1 \mathrm{~s}$. NOESY spectra were acquired with mixing times of 200-250 ms, and TOCSY spectra were acquired with isotropic mixing periods of $80 \mathrm{~ms}$. Two-dimensional spectra were collected over 4096 data points in the $\mathrm{f} 2$ dimension and 512 increments in the $\mathrm{f} 1$ dimension over a spectral width of $12 \mathrm{ppm}$. Standard Bruker pulse sequences were used with an excitation sculpting scheme for solvent suppression. NMR assignments were made while using established protocols [24], and the secondary shifts derived by subtracting the random coil $\alpha \mathrm{H}$ shift from the experimental $\alpha \mathrm{H}$ shifts [9]. The two-dimensional NOESY spectra were automatically assigned and an ensemble of structures were calculated using the program CYANA [18]. Torsion-angle restraints from TALOS+ were used in the structure calculations. The final structures were visualized using MOLMOL [21].

Author Contributions: D.W. and N.L.D. designed the study, carried out experiments and wrote the manuscript. Both authors analysed the results and approved the final version of the manuscript.

Funding: This research was funded by James Cook University (Capacity Building Grant). The James Cook University NMR facility was partially funded by the Australian Research Council (LE120100015, LE160100218). 
Acknowledgments: The authors are grateful to Associate Professor Jamie Seymour for access to the Conus geographus specimens.

Conflicts of Interest: The authors declare no conflict of interest.

\section{References}

1. McGregor, D.P. Discovering and improving novel peptide therapeutics. Curr. Opin. Pharmacol. 2008, 8, 616-619. [CrossRef] [PubMed]

2. Norton, R.S. Enhancing the therapeutic potential of peptide toxins. Expert Opin. Drug Discov. 2017, 12, 611-623. [CrossRef] [PubMed]

3. King, G.F.; Hardy, M.C. Spider-venom peptides: Structure, pharmacology, and potential for control of insect pests. Annu. Rev. Entomol. 2013, 58, 475-496. [CrossRef] [PubMed]

4. Windley, M.J.; Herzig, V.; Dziemborowicz, S.A.; Hardy, M.C.; King, G.F.; Nicholson, G.M. Spider-venom peptides as bioinsecticides. Toxins 2012, 4, 191-227. [CrossRef] [PubMed]

5. Wilson, D.; Daly, N.L. Venomics: A Mini-Review. High Throughput 2018, 7, 19. [CrossRef] [PubMed]

6. Muttenthaler, M.; Akondi, K.B.; Alewood, P.F. Structure-activity studies on alpha-conotoxins. Curr. Pharm. Des. 2011, 17, 4226-4241. [CrossRef] [PubMed]

7. Pineda, S.S.; Undheim, E.A.; Rupasinghe, D.B.; Ikonomopoulou, M.P.; King, G.F. Spider venomics: Implications for drug discovery. Future Med. Chem. 2014, 6, 1699-1714. [CrossRef] [PubMed]

8. Dutertre, S.; Jin, A.H.; Vetter, I.; Hamilton, B.; Sunagar, K.; Lavergne, V.; Dutertre, V.; Fry, B.G.; Antunes, A.; Venter, D.J.; et al. Evolution of separate predation- and defence-evoked venoms in carnivorous cone snails. Nat. Commun. 2014, 5, 3521. [CrossRef] [PubMed]

9. Wishart, D.S.; Bigam, C.G.; Holm, A.; Hodges, R.S.; Sykes, B.D. ${ }^{1} \mathrm{H},{ }^{13} \mathrm{C}$ and ${ }^{15} \mathrm{~N}$ random coil NMR chemical shifts of the common amino acids. I. Investigations of nearest-neighbor effects. J. Biomol. NMR 1995, 5, 67-81. [CrossRef] [PubMed]

10. Kaas, Q.; Yu, R.; Jin, A.H.; Dutertre, S.; Craik, D.J. ConoServer: Updated content, knowledge, and discovery tools in the conopeptide database. Nucleic Acids Res. 2012, 40, D325-D330. [CrossRef] [PubMed]

11. Cruz, L.J.; de Santos, V.; Zafaralla, G.C.; Ramilo, C.A.; Zeikus, R.; Gray, W.R.; Olivera, B.M. Invertebrate vasopressin/oxytocin homologs. Characterization of peptides from Conus geographus and Conus straitus venoms. J. Biol. Chem. 1987, 262, 15821-15824. [PubMed]

12. Dutertre, S.; Croker, D.; Daly, N.L.; Andersson, A.; Muttenthaler, M.; Lumsden, N.G.; Craik, D.J.; Alewood, P.F.; Guillon, G.; Lewis, R.J. Conopressin-T from Conus tulipa reveals an antagonist switch in vasopressin-like peptides. J. Biol. Chem. 2008, 283, 7100-7108. [CrossRef] [PubMed]

13. Asakawa, D.; Takayama, M. Mass spectrometric characterization of phosphorylated peptides using MALDI in-source decay via redox reactions. J. Mass Spectrom. 2012, 47, 180-187. [CrossRef] [PubMed]

14. Fukuyama, Y.; Iwamoto, S.; Tanaka, K. Rapid sequencing and disulfide mapping of peptides containing disulfide bonds by using 1,5-diaminonaphthalene as a reductive matrix. J. Mass Spectrom. 2006, 41, 191-201. [CrossRef] [PubMed]

15. Quinton, L.; Demeure, K.; Dobson, R.; Gilles, N.; Gabelica, V.; De Pauw, E. New method for characterizing highly disulfide-bridged peptides in complex mixtures: Application to toxin identification from crude venoms. J. Proteome Res. 2007, 6, 3216-3223. [CrossRef] [PubMed]

16. Smith, J.J.; Jones, A.; Alewood, P.F. Mass landscapes of seven scorpion species: The first analyses of Australian species with 1,5-DAN matrix. J. Venom Res. 2012, 3, 7-14. [PubMed]

17. Hu, H.; Bandyopadhyay, P.K.; Olivera, B.M.; Yandell, M. Elucidation of the molecular envenomation strategy of the cone snail Conus geographus through transcriptome sequencing of its venom duct. BMC Genom. 2012, 13, 284. [CrossRef] [PubMed]

18. Güntert, P. Automated NMR structure calculation with CYANA. Methods Mol. Biol. 2004, 278, 353-378. [PubMed]

19. Cierpicki, T.; Otlewski, J. Amide proton temperature coefficients as hydrogen bond indicators in proteins. J. Biomol. NMR 2001, 21, 249-261. [CrossRef] [PubMed]

20. Buczek, O.; Wei, D.; Babon, J.J.; Yang, X.; Fiedler, B.; Chen, P.; Yoshikami, D.; Olivera, B.M.; Bulaj, G.; Norton, R.S. Structure and sodium channel activity of an excitatory I1-superfamily conotoxin. Biochemistry 2007, 46, 9929-9940. [CrossRef] [PubMed] 
21. Koradi, R.; Billeter, M.; Wüthrich, K. MOLMOL: A program for display and analysis of macromolecular structures. J. Mol. Graph. 1996, 14, 51-55. [CrossRef]

22. Molinski, T.F. Nanomole-scale natural products discovery. Curr. Opin. Drug Discov. Dev. 2009, 12, $197-206$.

23. Fiedler, B.; Zhang, M.M.; Buczek, O.; Azam, L.; Bulaj, G.; Norton, R.S.; Olivera, B.M.; Yoshikami, D. Specificity, affinity and efficacy of iota-conotoxin RXIA, an agonist of voltage-gated sodium channels $\mathrm{Na}(\mathrm{V}) 1.2,1.6$ and 1.7. Biochem. Pharmacol. 2008, 75, 2334-2344. [CrossRef] [PubMed]

24. Wüthrich, K. Sequential individual resonance assignments in the ${ }^{1} \mathrm{H}-\mathrm{NMR}$ spectra of polypeptides and proteins. Biopolymers 1983, 22, 131-138. [CrossRef] [PubMed]

(C) 2018 by the authors. Licensee MDPI, Basel, Switzerland. This article is an open access article distributed under the terms and conditions of the Creative Commons Attribution (CC BY) license (http:/ / creativecommons.org/licenses/by/4.0/). 
Article

\title{
Whole-Genome Sequencing of Chinese Yellow Catfish Provides a Valuable Genetic Resource for High-Throughput Identification of Toxin Genes
}

\author{
Shiyong Zhang ${ }^{1,2,+}$, Jia Li ${ }^{3,+}$, Qin Qin ${ }^{1,+}$, Wei Liu ${ }^{4,+}$, Chao Bian ${ }^{3,+}$, Yunhai $\mathrm{Yi}^{2,3}$, \\ Minghua Wang ${ }^{1}$, Liqiang Zhong ${ }^{1}$, Xinxin You ${ }^{3}$, Shengkai Tang ${ }^{1}$, Yanshan Liu ${ }^{1}$, Yu Huang ${ }^{2,3}$, \\ Ruobo Gu ${ }^{5}$, Junmin $\mathrm{Xu}^{5,6}$, Wenji Bian ${ }^{1, *}$, Qiong Shi ${ }^{2,3,5, *}$ and Xiaohui Chen ${ }^{1, *}$ \\ 1 Freshwater Fisheries Research Institute of Jiangsu Province, Nanjing 210017, China; \\ shiyongzhang@hotmail.com (S.Z.); qinqinapple1980@163.com (Q.Q.); wangminghua18@sina.com (M.W.); \\ lqzhongffri@hotmail.com (L.Z.); tangshengkai1981@sohu.com (S.T.); liuyanshan613@sina.com (Y.L.) \\ 2 BGI Education Center, University of Chinese Academy of Sciences, Shenzhen 518083, China; \\ yiyunhai@genomics.cn (Y.Y.); huangyu@genomics.cn (Y.H.) \\ 3 Shenzhen Key Laboratory of Marine Genomics, Guangdong Provincial Key Lab of Molecular Breeding in \\ Marine Economic Animals, Shenzhen 518083, China; lijia1@genomics.cn (J.L.); bianchao@genomics.cn (C.B.); \\ youxinxin@genomics.cn (X.Y.) \\ 4 Nanjing Institute of Fisheries Science, Nanjing 210029, China; biowliu@163.com \\ 5 BGI Zhenjiang Institute of Hydrobiology, Zhenjiang 212000, China; guruobo@genomics.cn (R.G.); \\ xujunmin@genomics.cn (J.X.) \\ 6 School of Veterinary Medicine, Rakuno Gakuen University, Ebetsu 069-8501, Japan \\ * Correspondence: wenji.bian@aliyun.com (W.B.); shiqiong@genomics.cn (Q.S.); \\ xiaohui.chen@aliyun.com (X.C.); \\ Tel.: +86-25-8658-1557 (W.B.); +86-185-6627-9826 (Q.S.); +86-25-8658-1569 (X.C.) \\ + These authors contributed equally to this work.
}

Received: 11 October 2018; Accepted: 19 November 2018; Published: 23 November 2018

\begin{abstract}
Naturally derived toxins from animals are good raw materials for drug development. As a representative venomous teleost, Chinese yellow catfish (Pelteobagrus fulvidraco) can provide valuable resources for studies on toxin genes. Its venom glands are located in the pectoral and dorsal fins. Although with such interesting biologic traits and great value in economy, Chinese yellow catfish is still lacking a sequenced genome. Here, we report a high-quality genome assembly of Chinese yellow catfish using a combination of next-generation Illumina and third-generation PacBio sequencing platforms. The final assembly reached $714 \mathrm{Mb}$, with a contig N50 of $970 \mathrm{~kb}$ and a scaffold $\mathrm{N} 50$ of $3.65 \mathrm{Mb}$, respectively. We also annotated 21,562 protein-coding genes, in which $97.59 \%$ were assigned at least one functional annotation. Based on the genome sequence, we analyzed toxin genes in Chinese yellow catfish. Finally, we identified 207 toxin genes and classified them into three major groups. Interestingly, we also expanded a previously reported sex-related region (to $\approx 6 \mathrm{Mb}$ ) in the achieved genome assembly, and localized two important toxin genes within this region. In summary, we assembled a high-quality genome of Chinese yellow catfish and performed high-throughput identification of toxin genes from a genomic view. Therefore, the limited number of toxin sequences in public databases will be remarkably improved once we integrate multi-omics data from more and more sequenced species.
\end{abstract}

Keywords: Chinese yellow catfish; whole genome sequencing; toxin genes; identification

Key Contribution: A high-quality genome of the Chinese yellow catfish was assembled; and a high-throughput genome-wide identification of 207 toxin genes was realized. 


\section{Introduction}

As one venomous bony fish in the order of Siluriformes, Chinese yellow catfish (Pelteobagrus fulvidraco) has been an economically important freshwater species in China because of its good meat quality [1]. In 2016, the Chinese yellow catfish production in China was over 300,000 tons with an elevation of $20 \%$ from the previous year [2]. In our previous study [3], we reported a novel multi-omics pipeline to predict toxin genes from the venom glands of Chinese yellow catfish based on transcriptomic and proteomic sequencing. Here, we performed whole genome sequencing of this venomous teleost to provide another valuable genetic resource for high-throughput identification of toxin genes.

As we discussed before [3], aquatic venoms have been largely ignored as a resource for potential pharmaceuticals, although there are more aquatic venomous species than the total of venomous terrestrial animals [3]. The limited number of toxin sequences [3,4] has been an obstacle for development of novel marine drugs.

Whole genome resources provide excellent templates and genetic bases for further exploration of toxin genes. Over the past decades, toxin genes have attracted much attention due to their functionality and evolutionary genesis in various species [5]. Recent studies have discovered the accelerated evolution in snake venom toxin genes, which was indicated by the exonization and intronization of disintegrin or metalloprotease genes [6]. Prey-specific toxin genes, sulditoxin and sulmotoxin 1, also exhibit neofunctionalization and rapidly adaptive evolution [7]. Adaptive evolution of animal toxin multigene families at the intraspecies and interspecies levels had also been investigated [8]. Thus, it is worth investigating the complex venom systems, especially in this "omics" era [9]. As only a few venomous fish genomes are available, while teleost comprises a large part of the world vertebrates, we have been anxious to systematically enrich findings of toxin genes and expedite our understanding of venoms in teleost.

In our present study, we not only generated a high-quality genome assembly of the Chinese yellow catfish, but also established an integrated strategy to identify toxin genes from a genomic view. It seems to be an effective way to increase the number of toxin sequences, which will be very useful for rapid development of novel marine drugs. On the other hand, the whole genome sequence will also be beneficial to further molecular breeding of this economically important fish.

\section{Results}

\subsection{Summary of Sequencing Data and Genome-size Estimation}

A total of 314.37 gigabases $(\mathrm{Gb})$ of raw reads were generated in a next-generation Illumina (San Diego, CA, USA) sequencing platform (Table S1; see more details in Section 5.1). After employing SOAPfilter v2.2 (http:/ / soap.genomics.org.cn/index.html) to remove low-quality reads as well as PCR-replicates and adapter sequences, we obtained $231.60 \mathrm{~Gb}$ of clean data for subsequent assembling. Meanwhile, in order to improve the assembly quality with third-generation sequencing, we also acquired 25.47 Gb of sequencing data in a PacBio (Pacific Biosciences, Menlo Park, CA, USA) sequencing platform, with an average length of $7.10 \mathrm{~kb}$ (Table S2).

Based on our achieved 17-mer distribution (Figure 1), we determined that the total k-mer number and k-mer depth was 410,049,532,138 and 57 respectively. Therefore, we estimated that the genome size of Chinese yellow catfish is $720 \mathrm{Mb}$ (Table S3 and Figure 1; see more details about the calculation in Section 5.2). 


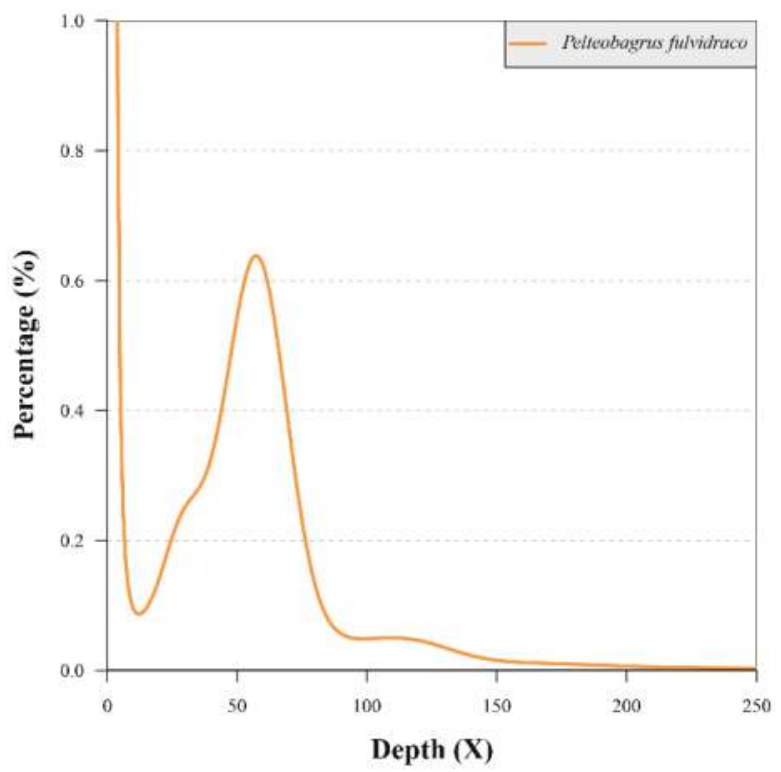

Figure 1. The 17-mer distribution of Chinese yellow catfish. Sequencing data from the Illumina short-insert libraries $(200,500$, and $800 \mathrm{bp}$ ) were used for this analysis. The $x$-axis is the sequencing depth of each unique 17-mer, and the y-axis is the percentage of unique 17-mers. The peak depth was 57 , and the percentage for peak $(0.638 \%)$ was based on the total k-mer number $(410,049,532,138)$.

\subsection{Generation of a High-quality Whole-genome Assembly}

\subsubsection{Primary De Novo Genome Assembly}

We performed a hybrid strategy to generate a primary de novo genome assembly. First, Platanus v1.2.4 (Tokyo Institute of Technology, Tokyo, Japan) [10] with an optimized parameter "-k 35" was employed to obtain a De Bruijin graph assembly by using Illumina short-insert reads. We generated a total of 2,880,541 contigs, with the length of contig N50 at $1054 \mathrm{bp}$. Subsequently, we employed the DBG2OLC [11] program to align these contigs upon the PacBio reads for construction of consensus contigs. Finally, we used Pilon v1.22 (Broad Institute of MIT and Harvard, Cambridge, MA, USA) [12] to polish the assembly. As a result, we assembled a genome with the total size of $703 \mathrm{Mb}$ and the length of contig N50 at $705 \mathrm{~kb}$.

\subsubsection{Genome Scaffolding}

Based on the primary assembly of contigs, we collected PacBio reads to construct scaffolds by using SSPACE-LongRead (Genome Analysis and Technology Department, Leiden University, Leiden, The Netherlands) [13]. After that, we employed Illumina long-insert libraries (2, 5, 10, and $20 \mathrm{~kb})$ to operate scaffolding again by performing SSPACE_Standard [14]. We then used GapCloser (BGI, Shenzhen, China) [15], GapFiller [16] and PBjelly (Baylor College of Medicine, Houston, TX, USA) [17] to fill the gaps of each scaffold. We subsequently applied Pilon v1.22 again to finish the last round of polishing. Finally, we generated a 714-Mb genome (99.17\% of the estimated genome size), with 663 scaffolds, a scaffold N50 of $3.65 \mathrm{Mb}$ and a contig N50 of $970 \mathrm{~Kb}$ (see more details in Table 1). 
Table 1. Summary of the assembled genome in each procedure.

\begin{tabular}{|c|c|c|c|c|c|c|c|c|}
\hline Step & Software & $\begin{array}{l}\text { Contig } \\
\text { N50 (bp) }\end{array}$ & $\begin{array}{l}\text { Maximum } \\
\text { Contig (bp) }\end{array}$ & $\begin{array}{c}\text { Minimum } \\
\text { Contig (bp) }\end{array}$ & $\begin{array}{l}\text { Scaffold } \\
\text { N50 (bp) }\end{array}$ & $\begin{array}{l}\text { Maximum } \\
\text { Scaffold (bp) }\end{array}$ & $\begin{array}{l}\text { Minimum } \\
\text { Scaffold (bp) }\end{array}$ & Total Size (bp \\
\hline \multirow{2}{*}{ Contig assembling } & Platanus & 1054 & 49,678 & 109 & - & - & - & $1,010,987,672$ \\
\hline & DBG2OLC & 707,335 & $6,076,047$ & 268 & - & - & - & $706,928,086$ \\
\hline \multirow{2}{*}{ Scaffolding } & SSPACELongRead & 982,636 & $6,050,085$ & 270 & $1,109,190$ & $7,365,535$ & 270 & $706,306,982$ \\
\hline & SSPACE_Standard & 705,180 & $6,050,085$ & 270 & $3,655,204$ & $19,552,289$ & 270 & $712,893,760$ \\
\hline Gap filling & Gapcloser & 813,785 & $11,966,130$ & 270 & $3,655,204$ & $19,552,617$ & 270 & $712,834,712$ \\
\hline Polishing round 2 & Pilon & 970,098 & $15,455,883$ & 277 & $3,653,474$ & $19,544,699$ & 277 & $713,824,612$ \\
\hline
\end{tabular}

\subsubsection{Evaluation of the Achieved Genome Assembly}

After the polishing procedures, we employed BUSCO (University of Geneva Medical School and Swiss Institute of Bioinformatics, Geneva, Switzerland) [18] to evaluate the completeness of our assembly. The actinopterygii_odb9 [19] orthologues gene set was used as the BUSCO reference. Our results demonstrated that the genome-level benchmarking value was $94.8 \%$, containing S: $90.9 \%$, D: 3.9\%, F: 1.7\%, M: 3.5\%, n: 4584 (S: complete and single-copy, D: complete and duplicated, F: fragmental, M: missed, $n$ : total BUSCO groups for searching). The comparative BUSCO data indicate high-quality of our assembled coverage (Figure 2).

Meanwhile, we employed the available transcriptomic data (see more details in Section 5.3.2) to validate the genome coverage. The de novo assembled transcripts were re-aligned to the genome assembly, and the results demonstrated that our genome assembly covered over $98 \%$ of gene regions (the middle column in Table 2). These data also confirmed the high level of completeness and accuracy of our genome assembly.

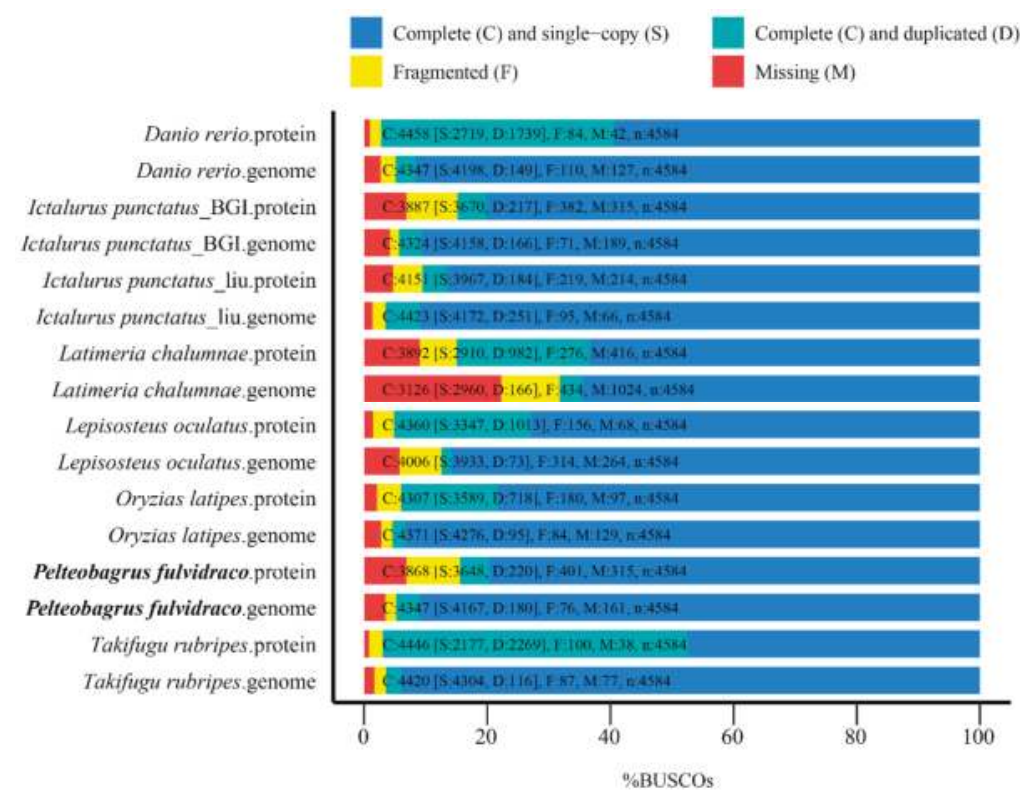

Figure 2. The BUSCO assessment of genomes from Chinese yellow catfish and other fish species. The genome-level benchmarking value of Chinese yellow catfish was C: $94.8 \%$ (containing S: $90.9 \%$, D: 3.9\%, F: 1.7\%, M: 3.5\%, $n: 4584)$, and the corresponding protein-level benchmarking value was C: $84.4 \%$ (including S: 79.6\%, D: 4.8\%, F: 8.7\%, M: 6.9\%, n: 4584). Abbreviations: C, complete; S, Complete and single-copy; D, duplicated; F, fragmental; M, missed; n: total BUSCO groups for searching. 
Additionally, the variation of GC content in Chinese yellow catfish was calculated with 50-kb non-overlapping sliding windows. Our result depicted that the observed GC content showed no sequencing-based GC preference (Figures S1 and S2), suggesting a good purity of our generated assembly (without contamination of prokaryotes).

Table 2. Evaluation the completeness of gene regions in our genome assembly by assembled transcripts.

\begin{tabular}{|c|c|c|c|c|c|c|c|}
\hline \multirow{2}{*}{ Dataset } & \multirow{2}{*}{$\begin{array}{l}\text { Number of } \\
\text { EST Clusters }\end{array}$} & \multirow{2}{*}{ Total Length (bp) } & \multirow{2}{*}{$\begin{array}{l}\text { Coverage Rate by } \\
\text { the Assembly (\%) }\end{array}$} & \multicolumn{2}{|c|}{$\begin{array}{l}\text { with }>90 \% \text { Sequence in One } \\
\text { Scaffold }\end{array}$} & \multicolumn{2}{|c|}{$\begin{array}{c}\text { with }>50 \% \text { Sequence in One } \\
\text { Scaffold }\end{array}$} \\
\hline & & & & Number & Percentage (\%) & Number & Percentage $(\%)$ \\
\hline$>0 \mathrm{bp}$ & 78,225 & $57,694,186$ & 98.1907917 & 73,167 & 93.53404 & 77,222 & 98.7178 \\
\hline$>200 \mathrm{bp}$ & 60,258 & $54,613,314$ & 98.2312921 & 56,311 & 93.44983 & 59,575 & 98.86654 \\
\hline$>500 \mathrm{bp}$ & 30,229 & $45,487,954$ & 98.32383756 & 28,117 & 93.01333 & 29,963 & 99.12005 \\
\hline$>1000 \mathrm{bp}$ & 17,675 & $36,547,853$ & 98.41627906 & 16,434 & 92.97878 & 17,543 & 99.25318 \\
\hline
\end{tabular}

\subsection{Genome Annotation}

Repetitive sequences accounted for $33.99 \%$ of the whole genome assembly. A detailed proportion of the predominant families of repetitive sequences is summarized in Table S4.

A total of 21,562 genes with an average of 9.46 exons and 1698-bp coding-region of each gene were predicted (see more details in Table S5). After the routine functional annotation, we predicted that $97.59 \%$ genes were with at least one related functional assignment (Table S6). Similarly, BUSCO was also used to assess the completeness of Chinese yellow catfish gene set, and a protein-level benchmarking value of $84.4 \%$ (Figure 2) was achieved.

\subsection{Phylogenetic Analysis and Divergence-Time Estimation of Chinese Yellow Catfish}

In the present study, we obtained 1156 one-to-one orthologous genes among Chinese yellow catfish and other 14 examined teleost species (find more details of species names in Figure 3, Table S7 and Section 5.2). Our final phylogenetic analysis indicates that the divergence time of the Chinese yellow catfish and the nearest channel catfish (Ictalurus punctatus) was 63.4 million years ago (mya), with a confidence interval of 38.3-94.3 mya (the numbers at top of Figure 3).

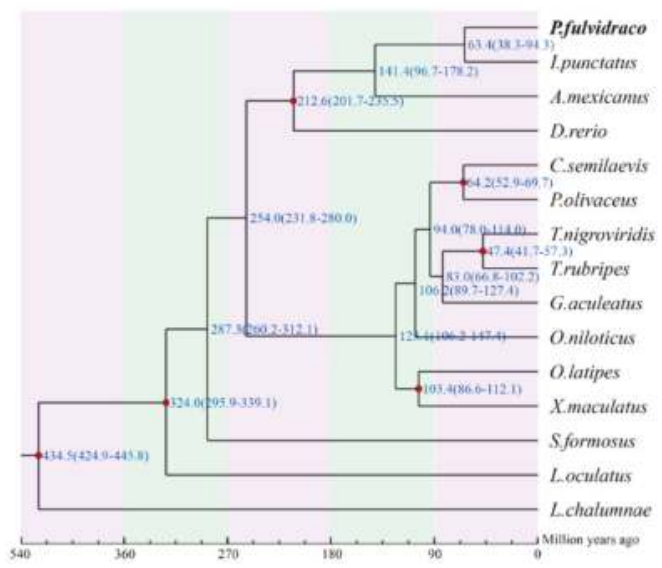

Figure 3. The phylogenetic tree of yellow catfish and other 14 related fish species. The red dot nodes have been validated based on the TimeTree (http://www.timetree.org/). Numbers represent the estimated divergence times.

\subsection{High-Throughput Identification of Toxin Genes}

Based on our previous report of toxin genes from Chinese yellow catfish transcriptomes [4], we identified 37 toxin genes in the yellow catfish. However, based on the 6665 reference toxin 
genes that were collected from NCBI [3,4], we obtained 202 toxin genes from our genome assembly. After removal of low-quality sequences, we finally constructed a local non-redundant database with 207 toxin genes for the Chinese yellow catfish.

On the basis of translated amino acids ( $\mathrm{aa}$ ) of each gene, we manually divided these toxin genes into three groups, including the short-length group (less than $100 \mathrm{aa}$ ), the medium-length group (between 100 and 300 aa), and the long-length group (over 300 aa). Finally, we determined that these three groups included 125, 61, and 21 toxins genes, respectively. Related protein sequences are provided in Data S1-S3.

\subsubsection{The Short-Length Toxin Genes}

The 125 genes with an entire length less than 100 aa (Data S1) accounted for the vast majority of Chinese yellow catfish toxin genes. After alignment searching of public databases, we found that these genes were annotated as "fragmental," which means these genes do not have full structures. However, the typical motif of venom proteins, "Gly-X-Cys (X means any other amino acids)," existed in most of these genes (80/125). Meanwhile, $90.4 \%$ (113/125) of these genes contained at least one cysteine. Usually, the number of cysteine in one single toxin gene varied from 1 to 15.

\subsubsection{The Medium-Length Toxin Genes}

Each gene within this group contained at least one copy of cysteine, and the maximal number of cysteine in Zinc metalloproteinase-disintegrin-like gene reached 26. In the 61 medium-length toxin genes (Data S2), 59 had been attributed into nine subgroups (Figure 4) on the basis of differences in sequences and secondary structures. The detailed information of each subgroup was summarized as follows.

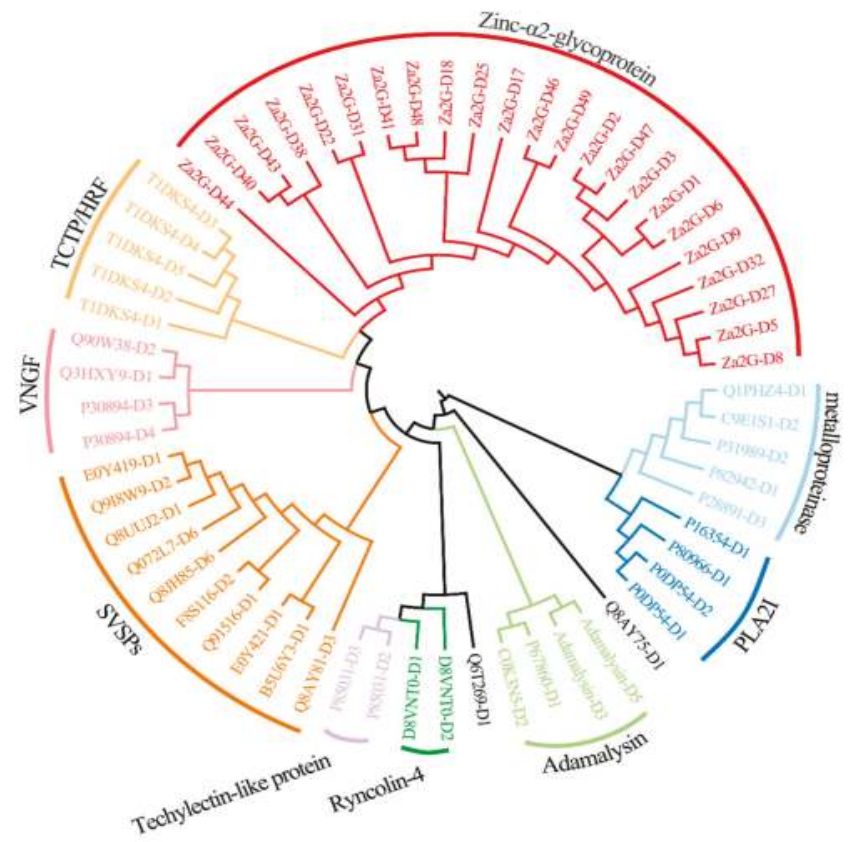

Figure 4. A phylogenetic classification of the nine subgroups of medium-length toxin genes. Two other genes "Q6T269-D1" and "Q8AY75-D1," however, do not belong to any subgroup.

(1) Twenty-three toxin genes (37.70\%) can code Zinc- $\alpha 2$-glycoprotein (Za2G), which may play significant roles in prohibiting growth and proliferation of tumors [20]. 
(2) Ten toxin genes are identified as snake venom serine proteinase (SVSPs) [21]. It was reported that cascade SVSPs disturb hemostasis by acting on related proteins in blood coagulation [22].

(3) Four toxin genes are adamalysin, which were firstly reported in Eastern diamond back rattlesnake [23], although their functions are still unknown.

(4) Five genes are classified as venom metalloproteinases, which belong to the metzincin family and typically show extracellular hemorrhagic activity [24]. Venom metalloproteinases are vastly involved in the local and systemic hemorrhage, such as reducing blood supply, leading to ischemia and causing damage to microvasculature [25].

(5) Five genes decode translationally controlled tumor proteins (TCTP/HRF), which are recognized as venom toxins in different genera of spiders and snakes [26].

(6) Four genes are categorized into the phospholipase A2 family. The most important Phospholipase A2 I (PLA2I) plays a myotoxic role in a venomous pitviper (Porthidium lansbergii lansbergii) [27].

(7) Four genes are annotated as venom nerve growth factor (VNGF). VNGF belongs to the neutrotrophin family, which plays an important role in the survival of neuronal cells [28].

(8) Two genes encode a techylectin-like protein. The basic information of the techylectin-like protein was previously reported in a spider (Phoneutria nigriventer) [29].

(9) Two genes encode ryncolin-4, which was primarily predicted in the reef-building coral (Acropora digitifera) through a venom proteomic expression profiling analysis [30].

The remainder two toxin genes, "Q6T269-D1" and "Q8AY75-D1," did not belong to the above-mentioned subgroups. After searching public databases, we annotated Q6T269-D1 as a Kunitztype serine protease inhibitor and Q8AY75-D1 as a Calglandulin protein.

\subsubsection{The Long-Length Toxin Genes}

In this group, the maximal number of cysteine in one gene is up to 69. Among the 21 toxin genes (Data S3), 18 are assigned into six families (Figure 5). More specifically, two genes are annotated as the venom metalloproteinases. Two genes belong to glutaminyl-peptide cyclotransferase family, which has been identified from the venoms of the Taiwanese snake [31] and bumblebee [32]. Three genes are in the cysteine-rich secretory protein (CRISP) family. Recent studies had uncovered that CRISPs are widely distributing in snake venoms. The main functions of CRISPs include prohibition of smooth muscle contraction and closure of nucleotide-gated ion channels leading to lethargy, hypothermia, and paralysis [33]. Three genes belong to the lipase family. This family had been previously isolated from anguimorph lizard venoms [34]. However, by far the functional study about lipase family is scarce. Two genes are thought to be in the ink toxin family, which had been firstly extracted from purple ink secretions of sea hares. They had been proven to have positive effects in antimicrobial and antitumor studies [35]. Five toxin genes belong to the veficolin family. The main feature of veficolin is the G-X-Y repeats (Glycine plus two other amino acids). By far, veficolins had been predicted to be involved in constriction of platelet aggregation [36]. 


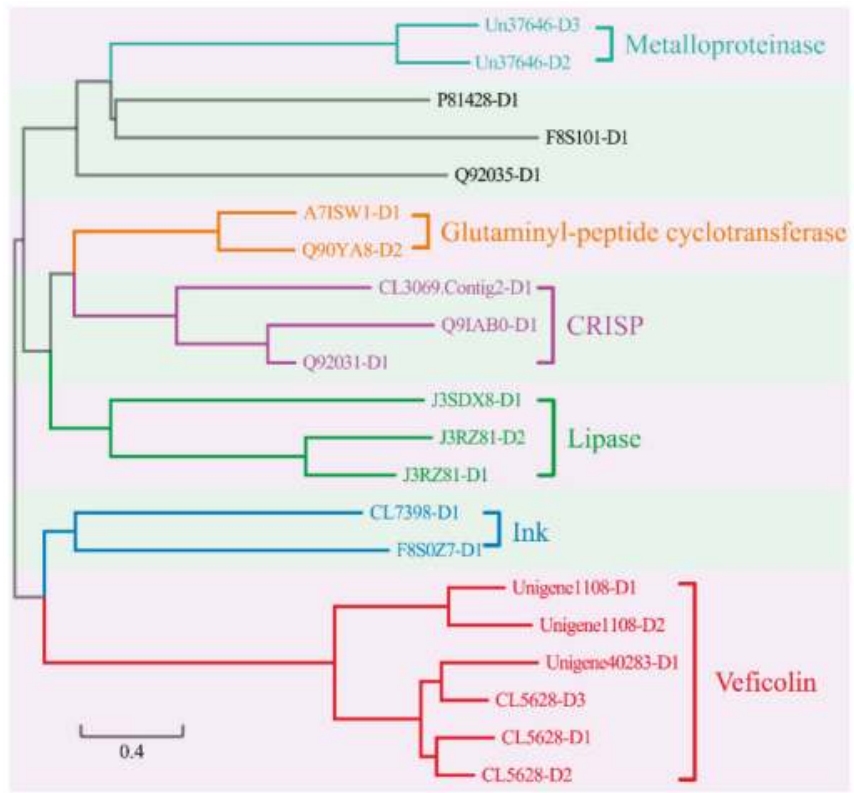

Figure 5. A phylogenetic classification of the 21 long-length toxin genes. Three other genes "P81428-D1," "F8S101-D1," and "Q92035-D1," do not belong to the classified six families.

\subsection{Identification of Toxin Genes in a Special Sex-Related Region}

In the present study, two previously published sex-specific sequences and eleven markers (see more details in Section 5.6) were searched against our achieved genome assembly. Only one female-specific marker mapped one time with 100\% alignment rate in a 6-Mb region (Contig326_pilon; Figure 6). More specifically, this marker located in the intronic region of inad (inaD-like protein) gene. The main function of inad is to mediate protein-protein interactions, which had been validated in previous studies [37].

Interestingly, we also identified two toxin genes in this special sex-related region. They are snaclec coagulation factor IX/factor X-binding protein subunit B (Q9PS06-D1) and thrombin-like enzyme (Q8AY81-D3), respectively. The former, localized at $\approx 2.95 \mathrm{Mb}$ of the Contig326_pilon and previously reported in a venomous viper (Echiscarinatus carinatus) [38], can combine with anticoagulant factor IX and factor X to form an anticoagulant protein [39]; the latter, belonging to the SVSP family (Figure 4) and localized at $\approx 3.6 \mathrm{Mb}$ of the Contig326_pilon, may cause various pathological effects, such as disturbance in the hemostatic system, platelet aggregation, neurologic disorders, thrombosis, and activation of coagulation factors [40].

\section{Discussion}

\subsection{A Good Strategy to Generate the High-Quality Genome Assembly}

With the rapid development of next-generation sequencing (NGS) technology, the output of sequencing platforms has risen vastly, whilst the price per $\mathrm{Gb}$ of data are dropping quickly. These advances allow researchers to easily decode the whole genome sequences. With the help of NGS, many fish genomes have been reported, such as Atlantic herring [41], channel catfish [42], mudskippers [43], half-smooth tongue sole [44], large yellow croaker [45], and so on.

In recent years, third-generation sequencing technology, also recognized as long-read sequencing, has been soaring. In comparison with NGS and first-generation sequencing technologies, 
third-generation sequencing has the distinct advantage of the length of sequencing reads, i.e., production of much longer reads than NGS. However, the sequencing errors happen at random in third-generation sequencing, which means we can dramatically reduce the sequencing errors through increasing the sequencing depth. The sequencing errors of NGS in Illumina sequencing platforms [46], by contrast, possibly increase because of either sequence-specific alterations in enzyme preference or single-strand DNA folding. Third-generation sequencing with longer read length will effectively alleviate tremendous computing workload for genome assembly. Nowadays, more and more fish genomes have been sequenced by using third-generation sequencing, such as Asian seabass [47] and Chinese sillago [48]. Collectively, these fish genome sequences will promote the biological research and molecular breeding of these interesting fishes.

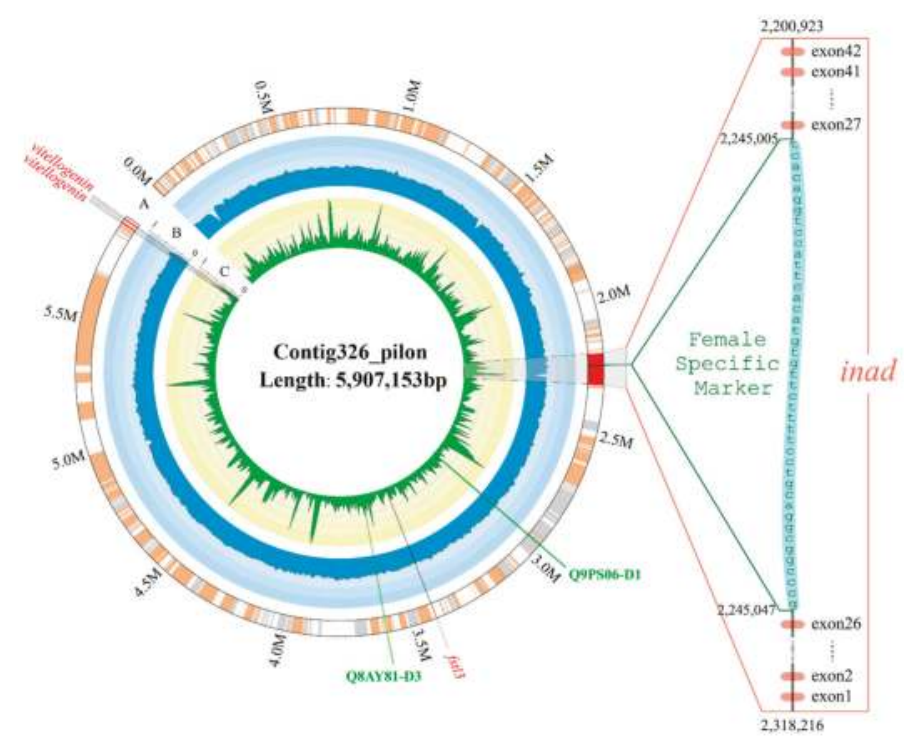

Figure 6. Distribution of a female specific marker and other sex-related/toxin genes in the Contig326_pilon. Two toxin gens, "Q9PS06-D1" and "Q8AY81-D3," were presented in dark green. The female specific marker, located in the intron 26 of inad gene, was $42 \mathrm{bp}$ in length. The left circos atlas represents the entire Contig326_pilon. Its rings from outside to inside include: (A) nucleotide sequence of the Contig326_pilon, (B) percentage of GC content in 10-kb non-overlapping windows, and $(\mathrm{C})$ percentage of repeat elements in 10-kb non-overlapping windows. In the Contig326_pilon, faint yellow ribbons represent " + " orientating genes, while grey ribbons represent " -" orientating genes; sex-related genes and inad were drawn with a red ribbon.

As a representative venomous freshwater fish with high economic value, Chinese yellow catfish is extensively available in river basins of China, such as the Yangtze River and Huaihe River. Since the nutrient-rich flesh of Chinese yellow catfish have a high elasticity and pleasant firmness [49], the artificial culture of Chinese yellow catfish has been highly recognized. Although the scale of its aquaculture industry has been expanding, the wild germplasm resources of Chinese yellow catfish have degenerated continually because of overfishing and habitat contamination. Traditional breeding methods are too time-consuming to support the rapid development of its industry. However, genome-based marker-assisted breeding will become a more efficient and holistic approach after realization of whole genome sequencing [50,51]. In this study, we also employed a PacBio sequencing platform to yield long sequencing reads for a high-quality assembly. The PacBio SMAT (Single-Molecular Real-Time sequencing) is a typical third-generation sequencing platform and has been widely used for whole genome sequencing. At the same time, we also adopt the Illumina NGS 
sequencing platform to create the short sequencing reads. With the hybrid assembling of these two different types of reads, we decoded the Chinese yellow catfish genome with a high quality based on the BUSCO assessments.

The availability of Chinese yellow catfish whole genome can narrow down the gaps between genotypes and phenotypes. We here provided a good reference genome for further biological studies and molecular breeding of this economically important teleost.

\subsection{High Efficiency to Identify Toxin Sequences}

Acquisition of toxin genes through sequencing technology had been proven to be efficient and practicable. Based on transcriptomes, we have identified conotoxins from cone snails in a high-throughput way. In the Chinese tubular cone snail (Conus betulinus) [52,53], we identified a total of 215 distinct conotoxins, in which 183 are novel.

Chinese yellow catfish, sometimes called stringing catfish in South China, has venom glands in the sharp spines of the dorsal and pectoral fins. Venom is produced by glandular cells in the epidermal tissue of the spines [3,4]. The symptoms of yellow catfish venom intoxication include local pain, edema, bleeding, and even serious and painful injuries to human $[3,54]$. However, the previous studies of Chinese yellow catfish venom were generally based on molecular markers or transcriptomic analyses [4]. Although more than two dozen toxin genes had been reported in Chinese yellow catfish, we still lack comprehensive understanding about the venom. The deciphering of Chinese yellow catfish genome can provide a fundamental genetic resource for venom studies.

In our present research, based on the whole genome sequences, we constructed a local venom database of Chinese yellow catfish. With one shot, we obtained 207 toxin sequences. The outcome also depicted that a complex structural differentiation of venoms may exist in Chinese yellow catfish, which was supported by our previous transcriptome study [3,4].

There is no denying that the fragmental toxin genes occupy a considerable proportion in the annotated toxin genes. We assumed two possible reasons to explain the results. The first is limitation of the reference databases of toxin genes. There are limited species that have been reported with toxins, and the main study objects focused on snakes, spiders, and a few invertebrates. Only few researches on fish toxin genes have been published by far. The lacking reference information of toxins constricts the deep research of toxin genes in many fishes including the Chinese yellow catfish. The second reason is the constraints of currently available technologies. Nowadays, molecular and pharmacological methods are still the traditional ways to investigate functions of toxins. However, they are time-consuming and inefficient. Fortunately, with the advance of genome and transcriptome sequencing techniques, more and more genomic sequences will be available for toxin discovery and drug development.

\section{Conclusions}

We performed whole-genome sequencing, using a combination of traditional next-generation and new third-generation sequencing strategies, to generate a high-quality genome reference for Chinese yellow catfish. Based on the achieved genome assembly, we identified 207 toxin genes in a high-throughput way. We also preliminarily classified these toxin genes into three main groups on the basis of their protein sequence length. In summary, we provide a valuable genetic resource for high-throughput identification of toxin genes in the venomous yellow catfish. These toxin genes will be useful for further development of drugs and pesticides.

\section{Materials and Methods}

\subsection{Sampling and Genome Sequencing}

To generate genome sequencing data of Chinese yellow catfish, we adopted two different strategies. The first one was the traditional Illumina whole-genome sequencing strategy. The detailed 
procedures were provided in the followed sections. Genomic DNAs were isolated from muscle tissue of a female Chinese yellow catfish, which was collected from a fish farm in Jiangsu province, China. Seven paired-end sequencing libraries, including three short-insert libraries (200, 500, and $800 \mathrm{bp}$ ) and four long-insert libraries $(2,5,10$, and $20 \mathrm{~kb})$, were constructed using the standard operating protocol provided by Illumina (San Diego, CA, USA). Finally, paired-end sequencing was performed using the Illumina HiSeq X-Ten platform. The second way was the PacBio single-molecule real-time sequencing strategy. Kidney genomic DNA was extracted for the construction of a 20-kb insert-size library, which was sequenced in a PacBio Bioscience Sequel platform.

All the animal experiments were approved by the Institutional Review Board on Bioethics and Biosafety of BGI (No. FT1510).

\subsection{Estimation of Genome Size}

Generally speaking, the distribution of k-mers is subjected to a Poisson distribution [55]. In this study, we estimated the genome size of Chinese yellow catfish using the k-mer method and the following equation (Equation (1)):

$$
\text { G = k-mer_number/k-mer_depth }
$$

where the $\mathrm{G}$ is the genome size, the k-mer_number is the total number of k-mers, and k-mer_depth means the peak frequency of k-mer analysis.

\subsection{Genome Annotation}

\subsubsection{Repeat Annotation}

We applied two different methods to annotate the repeat elements of Chinese yellow catfish genome. The first method was de novo prediction. Software including RepeatModeller v1.08 (http: / / www.repeatmasker.org/RepeatModeler/) and LTR_FINDER v1.0.6 (Fudan University, Shanghai, China) [56] was employed to generate the local repeat reference. Subsequently, the achieved genome sequences were aligned against this reference to produce the de novo predicted repeat elements. The second method was the homology-based prediction. Our assembly was aligned to the RepBase v21.01 (Genetic Information Research Institute, Sunnyvale, CA, USA) [57] by using RepeatMasker v4.06 and RepeatProteinMask v4.06 (Institute for Systems Biology, Seattle, WA, USA) [58]. Finally, the data from two methods were integrated to generate the non-redundant results.

\subsubsection{Annotation of Gene Set}

We utilized three different strategies to annotate the whole gene set. The first strategy was $\mathrm{ab}$ initio annotation. After masking the genomic repetitive elements, AUGUSTUS v2.5 (Institute of Microbiology and Genetics, University of Göttingen, Göttingen, Germany) [59] and GENSCAN v1.0 (Stanford University, Stanford, CA, USA) [60] were employed to ab initio predict genes. The second method was homologous-gene-based annotation. We firstly downloaded the protein sequences of zebrafish (Danio rerio), Atlantic cod (Gadus morhua), coelacanth (Latimeria chalumnae), medaka (Oryzias latipes), Japanese puffer (Takifugu rubripes), pufferfish (Tetraodon nigroviridis), Nile tilapia (Oreochromis niloticus), platyfish (Xiphophorus maculatus), and three-spined stickleback (Gasterosteus aculeatus) from the Ensembl database (release version 87). These protein sequences were used to search for best-hit alignments in the generated yellow catfish genome using the Tblastn (National Center for Biotechnology Information, Bethesda, MD, USA) [61] program, with the channel catfish proteins [42] as the reference. Subsequently, GeneWise v2.2.0 (The European Bioinformatics Institute, Cambridge, UK) [62] was employed to identify the potential gene structure of each best-hit alignment. The third method was the transcriptome-based prediction. We used two different transcriptomic data, including our previously reported data [4] and the muscle transcriptomic data sequenced 
by an Illumina platform. Tophat v2.1.1 (Johns Hopkins University, Baltimore, MD, USA) [63] and Cufflinks v2.2.1 (http:/ / cufflinks.cbcb.umd.edu/) were performed to generate the whole gene set. Finally, GLEAN (Texas A \& M University, College Station, TX, USA) [64] was utilized to produce the consensus results by integration of the data from above-mentioned three methods.

The predicted genes of Chinese yellow catfish were used to search several public functional databases, including NCBI-Nr (non-redundant protein sequences), Swiss-Prot [65], Interpro [66], TrEMBL, and KEGG [67], for identification of functional motifs and domains by using BLAST (National Center for Biotechnology Information, Bethesda, MD, USA).

\subsection{Phylogenetic Analysis}

We downloaded the proteomes of 14 species from public databases (Table S7). These proteomes contained a total of 316,447 proteins. The one-to-one orthologous proteins were generated by using Blastp [61] and Hcluster_sg [68]. First, Blastp was performed to generate the best-hit for each protein. Then, Hcluster_sg with parameter setting of "-w 10 -s 0.34 " was used to identify the one-to-one orthologous proteins among these species.

Subsequently, MrMTgui program was employed to obtain the best nucleotide substitution model ("GTR + I + G"). Based on the best substitution model, MrBayes v3.1.2 (Swedish Museum of Natural History, Stockholm, Sweden) [69] with generation setting to 1,000,000 was performed to construct the phylogenetic trees. Mcmctree (PAML package) [70] was operated to estimate divergence times.

\subsection{Prediction of Toxin Genes}

Fifteen putative toxin genes had been consolidated based on transcriptomic and proteomic data in our previous study [4]. In the present study, the following two ways were combined to predict toxin genes in the yellow catfish. First, we searched the 15 putative toxin genes in the yellow catfish genome using the Blastp program. Second, a reference database including 6665 toxin genes was used to search against the Chinese yellow catfish genome. The reference database was generated by the following methods: (1) toxin sequences were downloaded from NCBI by using keywords "Toxin" and "Venom," and (2) these sequences were realigned with the NCBI-Nr database for validation. Finally, we merged the results from the two ways and filtered those genes with premature termination or low alignment rates (lower than $50 \%$ ).

\subsection{Localization of Potential Toxin Genes in the Sex-Related Region}

In previous studies [51,71], the sex-determination of Chinese yellow catfish was reported as the $\mathrm{XY}$ system. Two fragmental sequences had been proven to be associated with sex-specificity, including one 8102-bp male-specific sequence and another 5362-bp female-specific sequence. Meanwhile, three male-specific markers and eight female-specific makers have been identified before [72]. In our current study, these sequences were downloaded from NCBI, and they were aligned against the yellow catfish genome assembly by using the Blastn program. We filtered the results with a threshed of $100 \%$ match and one hit.

Supplementary Materials: The following materials are available online at http:/ / www.mdpi.com/2072-6651/ 10/12/488/s1. Figure S1: GC content and sequencing depth of the yellow catfish genome. Figure S2: Comparisons of GC content between the yellow catfish and other seven fish species. Table S1: Summary of the next-generation sequencing data from an Illumina X-Ten platform. Table S2: Summary of the third-generation sequencing data from a PacBio Bioscience Sequel platform. Table S3: Genome-size estimation based on the 17-mer frequencies. Table S4: The detailed repetitive elements in the yellow catfish genome. Table S5: Statistics of gene annotation from the genome assembly of Chinese yellow catfish. Table S6: Functional assignments from the genome assembly of Chinese yellow catfish. Table S7: Information of the fish species used for phylogenetic analyses. Data S1: The short-length toxin proteins in the yellow catfish. Data S2: The medium-length toxin proteins in the yellow catfish. Data S3: The long-length toxin proteins in the yellow catfish. Data Availability: The genome assembly of Chinese yellow catfish has been deposited at the NCBI Genbank under the project ID of PRJNA494039.

Author Contributions: S.Z., Q.S., W.B., and X.C. conceived and designed the project; M.W., L.Z., S.T. and Y.L.; performed the experiments; J.L., Y.Y., C.B., X.Y., and Y.H. performed the bioinformatics analysis; S.Z., J.Q., W.L., 
and Y.Y. wrote the manuscript; R.G. and J.X. contributed to the planning of the whole project. J.L., S.Z., and Q.S. revised the manuscript.

Funding: This research was funded by Major Project for New Cultivar Breeding of Jiangsu Province (No. PZCZ201742), China Agriculture Research System (No. CARS-46), Major Project of Hydrobios Resources in Jiangsu Province (No. ZYHB16-3), Shenzhen Dapeng Special Program for Industrial Development (PT20170302), and Yunnan Innovation and Enhancement Program of Provincial Science and Technology Department (No. 2016AB024).

Acknowledgments: We are grateful for the instructive comments of two anonymous reviewers. The genome assembly of Chinese yellow catfish has been deposited at the NCBI GenBank under the project ID of PRJNA494039.

Conflicts of Interest: The authors declare no conflict of interest.

\section{References}

1. Kim, L.O.; Lee, S.-M. Effects of the dietary protein and lipid levels on growth and body composition of bagrid catfish, Pseudobagrus fulvidraco. Aquaculture 2005, 243, 323-329. [CrossRef]

2. Wang, Q.; Cheng, L.; Liu, J.; Li, Z.; Xie, S.; De Silva, S.S. Freshwater aquaculture in PR China: Trends and prospects. Rev. Aquac. 2016, 7, 283-302. [CrossRef]

3. Xie, B.; Huang, Y.; Baumann, K.; Fry, B.; Shi, Q. From Marine Venoms to Drugs: Efficiently Supported by a Combination of Transcriptomics and Proteomics. Mar. Drugs 2017, 15, 103. [CrossRef] [PubMed]

4. Xie, B.; Li, X.; Lin, Z.; Ruan, Z.; Wang, M.; Liu, J.; Tong, T.; Li, J.; Huang, Y.; Wen, B.; et al. Prediction of Toxin Genes from Chinese Yellow Catfish Based on Transcriptomic and Proteomic Sequencing. Int. J. Mol. Sci. 2016, 17, 556. [CrossRef] [PubMed]

5. Duda, T.F.; Palumbi, S.R. Molecular genetics of ecological diversification: Duplication and rapid evolution of toxin genes of the venomous gastropod Conus. Proc. Natl. Acad. Sci. USA 1999, 96, 6820-6823. [CrossRef] [PubMed]

6. Kini, R.M. Accelerated evolution of toxin genes: Exonization and intronization in snake venom disintegrin/metalloprotease genes. Toxicon 2018, 148, 16-25. [CrossRef] [PubMed]

7. Modahl, C.M.; Mrinalini; Frietze, S.; Mackessy, S.P. Adaptive evolution of distinct prey-specific toxin genes in rear-fanged snake venom. Proc. R. Soc. B Biol. Sci. 2018, 285. [CrossRef]

8. Kordiš, D.; Gubenšek, F. Adaptive evolution of animal toxin multigene families. Gene 2000, 261, 43-52. [CrossRef]

9. Casewell, N.R.; Wüster, W.; Vonk, F.J; Harrison, R.A.; Fry, B.G. Complex cocktails: The evolutionary novelty of venoms. Trends Ecol. Evol. 2013, 28, 219-229. [CrossRef] [PubMed]

10. Kajitani, R.; Toshimoto, K.; Noguchi, H.; Toyoda, A.; Ogura, Y.; Okuno, M.; Yabana, M.; Harada, M.; Nagayasu, E.; Maruyama, H.; et al. Efficient de novo assembly of highly heterozygous genomes from whole-genome shotgun short reads. Genome Res. 2014, 24, 1384-1395. [CrossRef] [PubMed]

11. Ye, C.; Hill, C.M.; Wu, S.; Ruan, J.; Ma, Z. DBG2OLC: Efficient Assembly of Large Genomes Using Long Erroneous Reads of the Third Generation Sequencing Technologies. Sci. Rep. 2016, 6, 31900. [CrossRef] [PubMed]

12. Walker, B.J.; Abeel, T.; Shea, T.; Priest, M.; Abouelliel, A.; Sakthikumar, S.; Cuomo, C.A.; Zeng, Q.; Wortman, J.; Young, S.K.; et al. Pilon: An Integrated Tool for Comprehensive Microbial Variant Detection and Genome Assembly Improvement. PLoS ONE 2014, 9, e112963. [CrossRef] [PubMed]

13. Boetzer, M.; Pirovano, W. SSPACE-LongRead: Scaffolding bacterial draft genomes using long read sequence information. BMC Bioinform. 2014, 15, 211. [CrossRef] [PubMed]

14. Boetzer, M.; Henkel, C.V.; Jansen, H.J.; Butler, D.; Pirovano, W. Scaffolding pre-assembled contigs using SSPACE. Bioinformatics 2011, 27, 578-579. [CrossRef] [PubMed]

15. Li, R.; Yu, C.; Li, Y.; Lam, T.W.; Yiu, S.M.; Kristiansen, K.; Wang, J. SOAP2: An improved ultrafast tool for short read alignment. Bioinformatics 2009, 25, 1966-1967. [CrossRef] [PubMed]

16. Nadalin, F.; Vezzi, F.; Policriti, A. GapFiller: A de novo assembly approach to fill the gap within paired reads. BMC Bioinform. 2012, 13 (Suppl. 14), S8. [CrossRef] [PubMed]

17. English, A.C.; Richards, S.; Han, Y.; Wang, M.; Vee, V.; Qu, J.; Qin, X.; Muzny, D.M.; Reid, J.G.; Worley, K.C.; et al. Mind the gap: Upgrading genomes with Pacific Biosciences RS long-read sequencing technology. PLoS ONE 2012, 7, e47768. [CrossRef] [PubMed] 
18. Sim, A.F.O.; Waterhouse, M.R.; Ioannidis, P.; Kriventseva, V.E.; Zdobnov, M.E. BUSCO: Assessing genome assembly and annotation completeness with single-copy orthologs. Bioinformatics 2015, 31, 3210-3212. [CrossRef] [PubMed]

19. Zdobnov, E.M.; Tegenfeldt, F.; Kuznetsov, D.; Waterhouse, R.M. OrthoDB v9.1: Cataloging evolutionary and functional annotations for animal, fungal, plant, archaeal, bacterial and viral orthologs. Nucleic Acids Res. 2017, 45, D744-D749. [CrossRef] [PubMed]

20. Albertus, D.L.; Seder, C.W.; Chen, G.; Wang, X.; Hartojo, W.; Lin, L.; Silvers, A.; Thomas, D.G.; Giordano, T.J.; Chang, A.C.; et al. AZGP1 autoantibody predicts survival and histone deacetylase inhibitors increase expression in lung adenocarcinoma. J. Thorac. Oncol. 2008, 3, 1236-1244. [CrossRef] [PubMed]

21. Zelanis, A.; Huesgen, P.F.; Oliveira, A.K.; Tashima, A.K.; Serrano, S.M.T.; Overall, C.M. Snake venom serine proteinases specificity mapping by proteomic identification of cleavage sites. J. Proteom. 2015, 113, 260-267. [CrossRef] [PubMed]

22. Madrigal, M.; Alape-Girón, A.; Barboza-Arguedas, E.; Aguilar-Ulloa, W.; Flores-Díaz, M. Identification of B cell recognized linear epitopes in a snake venom serine proteinase from the central American bushmaster Lachesis stenophrys. Toxicon 2017, 140, 72-82. [CrossRef] [PubMed]

23. Stocker, W.; Grams, F.; Baumann, U.; Reinemer, P.; Gomis-Ruth, F.X.; McKay, D.B.; Bode, W. The metzincinstopological and sequential relations between the astacins, adamalysins, serralysins, and matrixins (collagenases) define a superfamily of zinc-peptidases. Protein Sci. 1995, 4, 823-840. [CrossRef] [PubMed]

24. Moura-da-Silva, A.M.; Butera, D.; Tanjoni, I. Importance of Snake Venom Metalloproteinases in Cell Biology: Effects on Platelets, Inflammatory and Endothelial Cells. Curr. Pharm. Des. 2007, 13, 2893-2905. [CrossRef] [PubMed]

25. Gutiérrez, J.M.; Rucavado, A.; Escalante, T.; Díaz, C. Hemorrhage induced by snake venom metalloproteinases: Biochemical and biophysical mechanisms involved in microvessel damage. Toxicon 2005, 45, 997-1011. [CrossRef] [PubMed]

26. Senff-Ribeiro, A. Translationally Controlled Tumor Protein (TCTP/HRF) in Animal Venoms. In TCTP/tpt1 Remodeling Signaling from Stem Cell to Disease; Telerman, A., Amson, R., Eds.; Springer International Publishing: Cham, Switzerland, 2017; pp. 193-200. [CrossRef]

27. Jimenez-Charris, E.; Montealegre-Sanchez, L.; Solano-Redondo, L.; Castro-Herrera, F.; Fierro-Perez, L.; Lomonte, B. Divergent functional profiles of acidic and basic phospholipases A2 in the venom of the snake Porthidium lansbergii lansbergii. Toxicon 2016, 119, 289-298. [CrossRef] [PubMed]

28. Lu, Z.; Lei, D.; Jiang, T.; Yang, L.; Zheng, L.; Zhao, J. Nerve growth factor from Chinese cobra venom stimulates chondrogenic differentiation of mesenchymal stem cells. Cell Death Dis. 2017, 8, e2801. [CrossRef] [PubMed]

29. Liberato, T.; Troncone, L.R.P.; Yamashiro, E.T.; Serrano, S.M.T.; Zelanis, A. High-resolution proteomic profiling of spider venom: Expanding the toxin diversity of Phoneutria nigriventer venom. Amino Acids 2016, 48, 901-906. [CrossRef] [PubMed]

30. Gacesa, R.; Chung, R.; Dunn, S.R.; Weston, A.J.; Jaimes-Becerra, A.; Marques, A.C.; Morandini, A.C.; Hranueli, D.; Starcevic, A.; Ward, M.; et al. Gene duplications are extensive and contribute significantly to the toxic proteome of nematocysts isolated from Acropora digitifera (Cnidaria: Anthozoa: Scleractinia). BMC Genom. 2015, 16, 774. [CrossRef] [PubMed]

31. Liu, C.-C.; Lin, C.-C.; Hsiao, Y.-C.; Wang, P.-J.; Yu, J.-S. Proteomic characterization of six Taiwanese snake venoms: Identification of species-specific proteins and development of a SISCAPA-MRM assay for cobra venom factors. J. Proteom. 2018, 187, 59-68. [CrossRef] [PubMed]

32. Van Vaerenbergh, M.; Debyser, G.; Smagghe, G.; Devreese, B.; de Graaf, D.C. Unraveling the venom proteome of the bumblebee (Bombus terrestris) by integrating a combinatorial peptide ligand library approach with FT-ICR MS. Toxicon 2015, 102, 81-88. [CrossRef] [PubMed]

33. Adade, C.M.; Carvalho, A.L.O.; Tomaz, M.A.; Costa, T.F.R.; Godinho, J.L.; Melo, P.A.; Lima, A.P.C.A.; Rodrigues, J.C.F.; Zingali, R.B.; Souto-Padrón, T. Crovirin, a Snake Venom Cysteine-Rich Secretory Protein (CRISP) with Promising Activity against Trypanosomes and Leishmania. PLoS Negl. Trop. Dis. 2014, 8, e3252. [CrossRef] [PubMed]

34. Koludarov, I.; Jackson, T.N.; Brouw, B.O.D.; Dobson, J.; Dashevsky, D.; Arbuckle, K.; Clemente, C.J.; Stockdale, E.J.; Cochran, C.; Debono, J.; et al. Enter the Dragon: The Dynamic and Multifunctional Evolution of Anguimorpha Lizard Venoms. Toxins 2017, 9, 242. [CrossRef] [PubMed] 
35. Butzke, D.; Machuy, N.; Thiede, B.; Hurwitz, R.; Goedert, S.; Rudel, T. Hydrogen peroxide produced by Aplysia ink toxin kills tumor cells independent of apoptosis via peroxiredoxin I sensitive pathways. Cell Death Differ. 2004, 11, 608-617. [CrossRef] [PubMed]

36. OmPraba, G.; Chapeaurouge, A.; Doley, R.; Devi, K.R.; Padmanaban, P.; Venkatraman, C.; Velmurugan, D.; Lin, Q.; Kini, R.M. Identification of a novel family of snake venom proteins Veficolins from Cerberus rynchops using a venom gland transcriptomics and proteomics approach. J. Proteome Res. 2010, 9, 1882-1893. [CrossRef] [PubMed]

37. Philipp, S.; Flockerzi, V. Molecular characterization of a novel human PDZ domain protein with homology to INAD from Drosophila melanogaster. FEBS Lett. 1997, 413, 243-248. [CrossRef]

38. Patra, A.; Kalita, B.; Chanda, A.; Mukherjee, A.K. Proteomics and antivenomics of Echis carinatus carinatus venom: Correlation with pharmacological properties and pathophysiology of envenomation. Sci. Rep. 2017, 7, 17119. [CrossRef] [PubMed]

39. Atoda, H.; Hyuga, M.; Morita, T. The primary structure of coagulation factor IX/factor X-binding protein isolated from the venom of Trimeresurus flavoviridis. Homology with asialoglycoprotein receptors, proteoglycan core protein, tetranectin, and lymphocyte Fc epsilon receptor for immunoglobulin E. J. Biol. Chem. 1991, 266, 14903-14911. [PubMed]

40. Ullah, A.; Masood, R.; Ali, I.; Ullah, K.; Ali, H.; Akbar, H.; Betzel, C. Thrombin-like enzymes from snake venom: Structural characterization and mechanism of action. Int. J. Biol. Macromol. 2018, 114, 788-811. [CrossRef] [PubMed]

41. Martinez Barrio, A.; Lamichhaney, S.; Fan, G.; Rafati, N.; Pettersson, M.; Zhang, H.; Dainat, J.; Ekman, D.; Höppner, M.; Jern, P.; et al. The genetic basis for ecological adaptation of the Atlantic herring revealed by genome sequencing. eLife 2016, 5, e12081. [CrossRef] [PubMed]

42. Chen, X.; Zhong, L.; Bian, C.; Xu, P.; Qiu, Y.; You, X.; Zhang, S.; Huang, Y.; Li, J.; Wang, M.; et al. High-quality genome assembly of channel catfish, Ictalurus punctatus. GigaScience 2016, 5, 39. [CrossRef] [PubMed]

43. You, X.; Bian, C.; Zan, Q.; Xu, X.; Liu, X.; Chen, J.; Wang, J.; Qiu, Y.; Li, W.; Zhang, X.; et al. Mudskipper genomes provide insights into the terrestrial adaptation of amphibious fishes. Nat. Commun. 2014, 5, 5594. [CrossRef] [PubMed]

44. Chen, S.; Zhang, G.; Shao, C.; Huang, Q.; Liu, G.; Zhang, P.; Song, W.; An, N.; Chalopin, D.; Volff, J.-N.; et al. Whole-genome sequence of a flatfish provides insights into ZW sex chromosome evolution and adaptation to a benthic lifestyle. Nat. Genet. 2014, 46, 253-260. [CrossRef] [PubMed]

45. Wu, C.; Zhang, D.; Kan, M.; Lv, Z.; Zhu, A.; Su, Y.; Zhou, D.; Zhang, J.; Zhang, Z.; Xu, M.; et al. The draft genome of the large yellow croaker reveals well-developed innate immunity. Nat. Commun. 2014, 5, 5227. [CrossRef] [PubMed]

46. Nakamura, K.; Oshima, T.; Morimoto, T.; Ikeda, S.; Yoshikawa, H.; Shiwa, Y.; Ishikawa, S.; Linak, M.C.; Hirai, A.; Takahashi, H.; et al. Sequence-specific error profile of Illumina sequencers. Nucleic Acids Res. 2011, 39, e90. [CrossRef] [PubMed]

47. Vij, S.; Kuhl, H.; Kuznetsova, I.S.; Komissarov, A.; Yurchenko, A.A.; Van Heusden, P.; Singh, S.; Thevasagayam, N.M.; Prakki, S.R.S.; Purushothaman, K.; et al. Chromosomal-Level Assembly of the Asian Seabass Genome Using Long Sequence Reads and Multi-layered Scaffolding. PLoS Genet. 2016, 12, e1005954. [CrossRef]

48. Xu, S.; Xiao, S.; Zhu, S.; Zeng, X.; Luo, J.; Liu, J.; Gao, T.; Chen, N. A draft genome assembly of the Chinese sillago (Sillago sinica), the first reference genome for Sillaginidae fishes. GigaScience 2018, 7, 9. [CrossRef] [PubMed]

49. Ma, L.-Q.; Xing, T.; Rong, T. The muscular nutritional components and flesh quality of farmed Pelteobagrus fulvidraco yearlings. Acta Hydrobiol. Sin. 2015, 39, 193-196.

50. Tong, J.; Sun, X. Genetic and genomic analyses for economically important traits and their applications in molecular breeding of cultured fish. Sci. China Life Sci. 2015, 58, 178-186. [CrossRef] [PubMed]

51. Gui, J.; Zhu, Z. Molecular basis and genetic improvement of economically important traits in aquaculture animals. Chin. Sci. Bull. 2012, 57, 1751-1760. [CrossRef]

52. Peng, C.; Yao, G.; Gao, B.-M.; Fan, C.-X.; Bian, C.; Wang, J.; Cao, Y.; Wen, B.; Zhu, Y.; Ruan, Z.; et al. High-throughput identification of novel conotoxins from the Chinese tubular cone snail (Conus betulinus) by multi-transcriptome sequencing. GigaScience 2016, 5, 17. [CrossRef] [PubMed] 
53. Lluisma, A.O.; Milash, B.A.; Moore, B.; Olivera, B.M.; Bandyopadhyay, P.K. Novel venom peptides from the cone snail Conus pulicarius discovered through next-generation sequencing of its venom duct transcriptome. Mar. Genom. 2012, 5, 43-51. [CrossRef] [PubMed]

54. Nelson, J.S. Fishes of the World, 3rd ed.; John Wiley \& Sons: New York, NY, USA, 1994.

55. Liu, B.; Shi, Y.; Yuan, J.; Hu, X.; Zhang, H.; Li, N.; Li, Z.; Chen, Y.; Mu, D.; Fan, W. Estimation of genomic characteristics by analyzing k-mer frequency in de novo genome projects. Quant. Boil. 2013, 35, 62-67.

56. Xu, Z.; Wang, H. LTR_FINDER: An efficient tool for the prediction of full-length LTR retrotransposons. Nucleic Acids Res. 2007, 35, W265-W268. [CrossRef] [PubMed]

57. Jurka, J.; Kapitonov, V.V.; Pavlicek, A.; Klonowski, P.; Kohany, O.; Walichiewicz, J. Repbase Update, a database of eukaryotic repetitive elements. Cytogenet. Genome Res. 2005, 110, 462-467. [CrossRef] [PubMed]

58. Chen, N. Using RepeatMasker to Identify Repetitive Elements in Genomic Sequences; John Wiley \& Sons, Inc.: Hoboken, NY, USA, 2004; pp. 4.10.11-14.10.14.

59. Stanke, M.; Keller, O.; Gunduz, I.; Hayes, A.; Waack, S.; Morgenstern, B. AUGUSTUS: Ab initio prediction of alternative transcripts. Nucleic Acids Res. 2006, 34, W435-W439. [CrossRef] [PubMed]

60. Burge, C.; Karlin, S. Prediction of complete gene structures in human genomic DNA. J. Mol. Biol. 1997, 268, 78-94. [CrossRef] [PubMed]

61. Pevsner, J. Basic Local Alignment Search Tool (BLAST); John Wiley \& Sons, Inc.: Hoboken, NY, USA, 2005; pp. 87-125.

62. Birney, E.; Clamp, M.; Durbin, R. GeneWise and Genomewise. Genome Res. 2004, 14, 988-995. [CrossRef] [PubMed]

63. Trapnell, C.; Pachter, L.; Salzberg, S.L. TopHat: Discovering splice junctions with RNA-Seq. Bioinformatics 2009, 25, 1105-1111. [CrossRef] [PubMed]

64. Elsik, C.G.; Mackey, A.J.; Reese, J.T.; Milshina, N.V.; Roos, D.S.; Weinstock, G.M. Creating a honey bee consensus gene set. Genome Biol. 2007, 8, R13. [CrossRef] [PubMed]

65. Bairoch, A.; Apweiler, R. The SWISS-PROT protein sequence database and its supplement TrEMBL in 2000. Nucleic Acids Res. 2000, 28, 45-48. [CrossRef] [PubMed]

66. Hunter, S.; Apweiler, R.; Attwood, T.K.; Bairoch, A.; Bateman, A.; Binns, D.; Bork, P.; Das, U.; Daugherty, L.; Duquenne, L. InterPro: The integrative protein signature database. Nucleic Acids Res. 2009, 37, D211-D215. [CrossRef] [PubMed]

67. Kanehisa, M.; Goto, S. KEGG: Kyoto encyclopedia of genes and genomes. Nucleic Acids Res. 2000, 27, $29-34$. [CrossRef]

68. Li, H.; Coghlan, A.; Ruan, J.; Coin, L.J.; Hériché, J.-K.; Osmotherly, L.; Li, R.; Liu, T.; Zhang, Z.; Bolund, L.; et al. TreeFam: A curated database of phylogenetic trees of animal gene families. Nucleic Acids Res. 2006, 34, D572-D580. [CrossRef] [PubMed]

69. Ronquist, F.; Teslenko, M.; van der Mark, P.; Ayres, D.L.; Darling, A.; Höhna, S.; Larget, B.; Liu, L.; Suchard, M.A.; Huelsenbeck, J.P. MrBayes 3.2: Efficient Bayesian Phylogenetic Inference and Model Choice Across a Large Model Space. Syst. Biol. 2012, 61, 539-542. [CrossRef] [PubMed]

70. Yang, Z.; Rannala, B. Bayesian estimation of species divergence times under a molecular clock using multiple fossil calibrations with soft bounds. Mol. Biol. Evol. 2006, 23, 212-226. [CrossRef] [PubMed]

71. Jing, J.; Wu, J.; Liu, W.; Xiong, S.; Ma, W.; Zhang, J.; Wang, W.; Gui, J.F.; Mei, J. Sex-Biased miRNAs in Gonad and Their Potential Roles for Testis Development in Yellow Catfish. PLoS ONE 2014, 9, e107946. [CrossRef] [PubMed]

72. Dan, C.; Mei, J.; Wang, D.; Gui, J.F. Genetic differentiation and efficient sex-specific marker development of a pair of Y- and X-linked markers in yellow catfish. Int. J. Biol. Sci. 2013, 9, 1043-1049. [CrossRef] [PubMed] 

MDPI

St. Alban-Anlage 66

4052 Basel

Switzerland

Tel. +41 616837734

Fax +41 613028918

www.mdpi.com

Toxins Editorial Office

E-mail: toxins@mdpi.com www.mdpi.com/journal/toxins

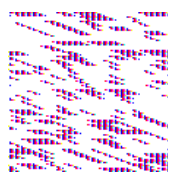



MDPI

St. Alban-Anlage 66

4052 Basel

Switzerland

Tel: +41 616837734

Fax: +41 613028918

www.mdpi.com 